\title{
SAVING ELECTRICITY FOR A GREEN ENERGY SYSTEM IN CHINA
}

THE PIVOTAL ROLE OF INDUSTRIAL ENERGY EFFICIENCY TO PHASE

OUT COAL, IMPROVE AIR QUALITY AND MITIGATE CLIMATE CHANGE

HUI YUE

㺯

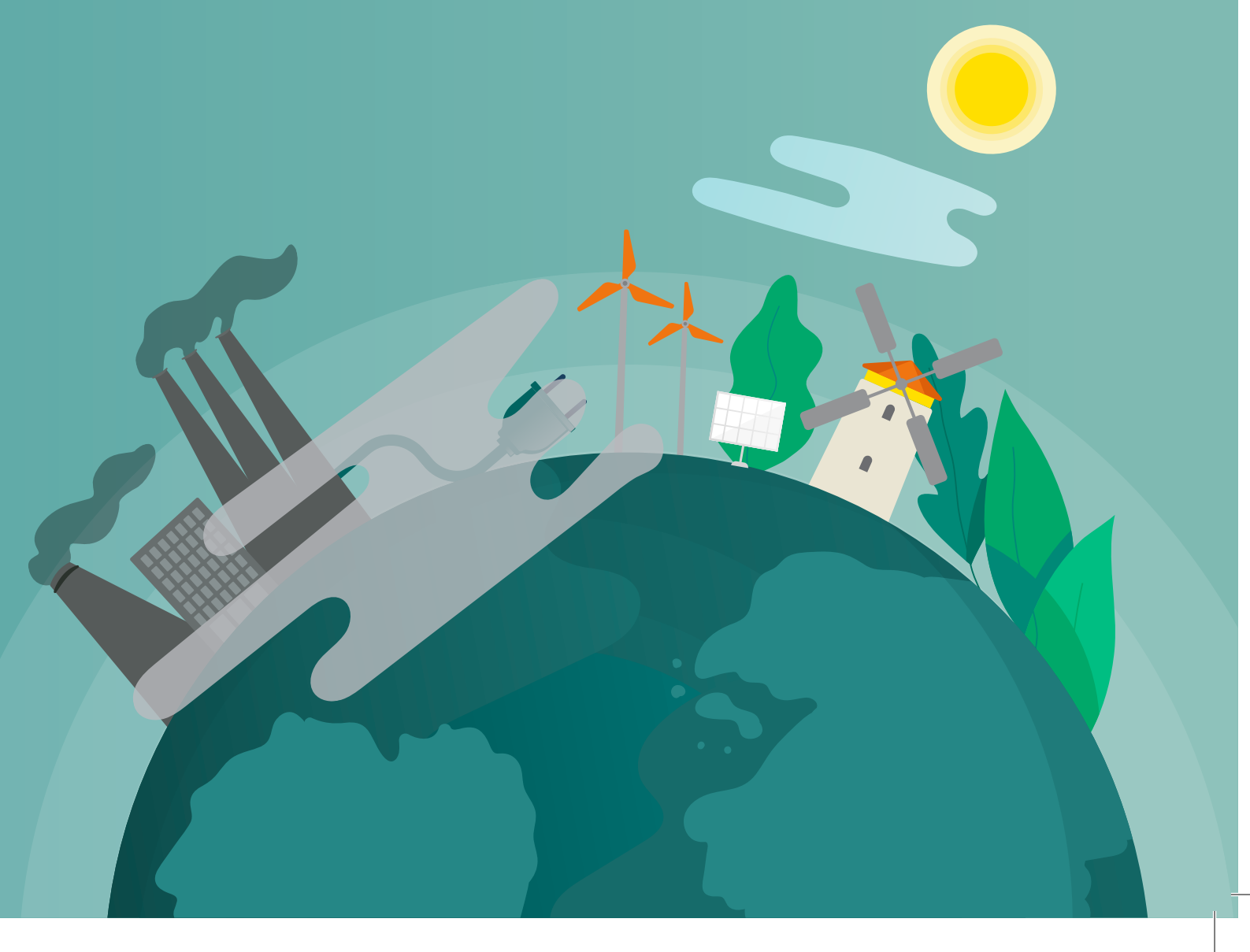




\section{Saving Electricity for a Green Energy System in China}

The Pivotal Role of Industrial Energy Efficiency to Phase Out Coal, Improve Air Quality and Mitigate Climate Change

Hui Yue 


\section{Saving Electricity for a Green Energy System in China}

The Pivotal Role of Industrial Energy Efficiency to Phase Out Coal, Improve Air Quality and Mitigate Climate Change

The research reported in this dissertation has been carried out at the Copernicus Institute of Sustainable Development, Faculty of Geosciences, Utrecht University, The Netherlands. The research leading to the results has received funding from the China Scholarship Council - Utrecht University (CSC-UU) Programme.

(C) copyright Hui Yue, 2020

Printing: ProefschriftMaken || www.proefschriftmaken.nl ISBN 978-94-6423-082-6

All rights reserved. No part of this publication may be reproduced, stored in a retrieval system or transmitted, in any form or by any means, electronic, mechanical, photocopying, recording or otherwise, without prior permission of the author or the copyright-owning journals for previous published chapters. 


\section{Saving Electricity for a \\ Green Energy System in China}

\section{The Pivotal Role of Industrial Energy Efficiency to Phase Out Coal, Improve Air Quality and Mitigate Climate Change}

Elektriciteit besparen voor een groen energiesysteem in China

De cruciale rol van industriële energie-efficiëntie om steenkool geleidelijk uit te faseren, de luchtkwaliteit te verbeteren en klimaatverandering te beperken

(met een samenvatting in het Nederlands)

\section{Proefschrift}

ter verkrijging van de graad van doctor aan de Universiteit Utrecht op gezag van de rector magnificus, prof.dr. H.R.B.M. Kummeling, ingevolge het besluit van het college voor promoties in het openbaar te verdedigen op vrijdag 4 december 2020 des middags te 2.30 uur

door

\section{Hui Yue}

geboren op 6 december 1992

Peking, China 


\section{Promotor:}

Prof. dr. E. Worrell

\section{Copromotor:}

Dr. W.H.J. Crijns-Graus

\section{Examination Committee:}

Prof. dr. W. Eichhammer, Utrecht University \& Fraunhofer Institute for Systems and Innovation Research ISI

Prof. dr. D.P. van Vuuren, Utrecht University \& PBL Netherlands Environmental Assessment Agency

Prof. dr. E. Masanet, University of California, Santa Barbara \& Northwestern University Prof. dr. Y. Fan, Beihang University \& Chinese Academy of Sciences

Prof. dr. F. Wagner, International Institute for Applied Systems Analysis IIASA 
"What I needed was an equation that would help me understand how we might get our $\mathrm{CO}_{2}$ down to zero. Here's what I came up with: None of the first three-population, services, and energy - are getting close to zero. But to stop climate change and make energy affordable for everyone, we're also going to need some new inventions."

- Bill Gates

"You never change things by fighting the existing reality. To change something, build a new model that makes the existing model obsolete."

- R. Buckminster Fuller

"The last leg of a journey marks the halfway point."

- in 'Strategies of Qin - Strategies of the Warring States' 


\section{Table of contents}

Abbreviations and units $\quad 11$

$\begin{array}{lll}\text { Chapter } 1 & \text { Introduction } & 15\end{array}$

1.1. Development and challenges of global electricity demand and supply 17

$\begin{array}{ll}\text { 1.1.1. Development of electricity demand and supply } & 17\end{array}$

1.1.2. Challenges for electricity demand and supply 20

1.2. Global largest industry and energy infrastructure: China 24

$\begin{array}{ll}\text { 1.2.1. China's industry } & 24\end{array}$

$\begin{array}{ll}\text { 1.2.2. China's power sector } & 27\end{array}$

1.3. Environmental concerns 31

1.3.1. Climate change in China 31

1.3.2. Air pollution in China $\quad 32$

1.4. Energy efficiency and electricity savings 35

1.5. Framework of research objective 38

1.6. Thesis outline $\quad 39$

$\begin{array}{ll}\text { References } & 42\end{array}$

Chapter 2 Saving energy in China's industry with a focus on electricity: A review of opportunities, potentials, and environmental benefits $\mathbf{5 3}$

ABSTRACT $\quad 54$

2.1. Introduction $\quad 55$

2.2. Methodology 58

2.2.1. Review method 58

2.2.2. Literature selection $\quad 58$

2.3. Modeling factor identification 65

2.4. Results and discussion $\quad 67$

$\begin{array}{ll}\text { 2.4.1. China's industry } & 67\end{array}$

2.4.2. China's industrial subsectors 69

2.4.3. Summary of electricity savings and associated emissions reduction $\quad 76$

2.4.4. Discussion of impact modeling factors on results 80

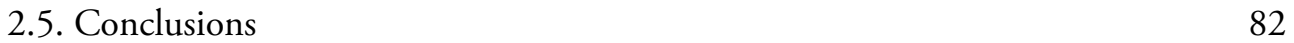

2.6. Policy implications and directions for research 83

$\begin{array}{ll}\text { Acknowledgements } & 85\end{array}$

Supplementary Information $\quad 86$

2.S1. Overview of China's industry 86

2.S2. Energy consumption in baseline scenario and energy intensity trends $\quad 87$

$\begin{array}{ll}\text { 2.S2.1. China’s industry } & 87\end{array}$

2.S2.2. China’s industrial subsector 88

2.S3. Methodology for accounting the multiple benefits of electricity savings 99

$\begin{array}{ll}\text { References } & 113\end{array}$ 
Chapter 3 Modeling the multiple benefits of electricity savings for emissions reduction on power grid level: A case study of China's chemical industry

ABSTRACT

3.1. Introduction

3.2. Overview of China's chemical industry 132

3.3. Methodology and data sources 137

3.3.1. Electricity conservation supply curves 137

3.3.2. Emission factors of GHG and air pollutants for different grids $\quad 139$

3.3.3. Multiple benefits on emissions reduction per grid 141

3.3.4. Data sources 141

3.4. Results and discussion $\quad 147$

3.4.1. Electricity saving potential by grid in China's chemical industry 147

3.4.2. Multiple benefits on climate change and air quality 152

3.5. Sensitivity analysis 158

3.5.1. Chemicals output 158

3.5.2. Energy prices 159

3.5.3. Discount rate 163

3.6. Conclusions and policy implications $\quad 164$

3.6.1. Conclusions 164

3.6.2. Policy implications and future research direction $\quad 166$

$\begin{array}{ll}\text { Acknowledgments } & 167\end{array}$

$\begin{array}{ll}\text { Appendix 3.A } & 167\end{array}$

$\begin{array}{ll}\text { Appendix 3.B } & 167\end{array}$

Appendix 3.C 167

Supplementary Information $\quad 185$

3.S1. Additional information on the analysis of China's chemical sub-sectors 185

3.S1.1. China's ammonia production, electricity use and related emissions 185

3.S1.2. China's caustic soda and PVC production, electricity use and related emissions

3.S1.3. China’s calcium carbide production, electricity use and related emissions

3.S2. Methodology for $\mathrm{CO}_{2}$ emission accounting in China's chemical industry 187

3.S3. Emission factors of GHG and air pollutants per grid 188

References 189 
Chapter 4 Air emissions and energy efficiency: realizing multiple benefits for power sector by saving industrial electricity use in China ABSTRACT

4.1. Introduction

4.2. Methods

4.2.1. Modeling the deployment of power plant fleet 205

4.2.2. Electricity saving technologies 206

4.2.3. Estimation of emissions levels of air pollutants and $\mathrm{CO}_{2}$

4.2.4. Investment budgets for achieving air pollutants reductions 208

4.2.5. Emission scenarios design. 209

4.3. Results

210

4.3.1. Electricity savings in industry 210

4.3.2. High-value benefits of industrial EE in the electricity supply sector 213

4.3.3. Comparing the portfolio cost of EE and EoP 216

4.4. Discussion 218

4.5. Conclusions 220

CRediT authorship contribution statement 221

Declaration of Competing Interest 221

Acknowledgements 221

Appendix 4.A. Dataset of commercially available energy efficiency technologies

Appendix 4.B. Electricity saving potentials and associated capital expenditure for each industrial process 222

Supplementary Discussion $\quad 236$

4.S1. The impacts of joint measures on air pollutant emissions from coal fleet 236

Supplementary Tables $\quad 239$

References 243

Chapter 5 Impacts of regional industrial electricity savings on the development of future coal capacity per electricity grid and related air pollution emissions - A case study for China 255

ABSTRACT 256

5.1. Introduction 257

5.2. Methods and materials $\quad 260$

5.2.1. Scenario design 260

5.2.2. Electricity conservation supply curve modeling 261

5.2.3. GAINS model 262

5.2.4. Emissions from coal generation fleet 263

5.2.5. Data sources 264

5.3. Results 266

5.3.1. Commissioning coal power fleet in 2016

5.3.2. Electricity savings by industrial sectors at power grid level 270 
5.3.3. Displaced coal power capacity and synergies of emission reductions 273

5.3.4. Portfolio costs of air pollutant reductions 278

$\begin{array}{ll}\text { 5.4. Discussion } & 279\end{array}$

5.5. Conclusions and policy implications 282

5.5.1. Conclusions 282

5.5.2. Policy implications 284

CRediT authorship contribution statement $\quad 284$

Declaration of Competing Interest 284

Acknowledgements 284

Appendix 5.A 285

References 286

$\begin{array}{lll}\text { Chapter } 6 \text { Summary and conclusions } & 297\end{array}$

6.1. Research context 299

6.2. Research goals $\quad 300$

6.3. Main findings of the thesis 302

6.4. General conclusions and policy implications 307

6.5. Future research direction 309

References 311

$\begin{array}{lll}\text { Chapter } 7 \text { Samenvatting en conclusies } & 315\end{array}$

$\begin{array}{ll}\text { 7.1. Onderzoekscontext } & 317\end{array}$

7.2. Onderzoeksdoelen $\quad 318$

7.3. Belangrijkste bevindingen van het proefschrift $\quad 320$

7.4. Algemene conclusies en beleidsimplicaties 326

7.5. Toekomstige onderzoeksrichting $\quad 329$

$\begin{array}{ll}\text { Referenties } & 331\end{array}$

$\begin{array}{ll}\text { Acknowledgements } & 333\end{array}$

$\begin{array}{ll}\text { Curriculum vitae } & 337\end{array}$

Research output $\quad 341$

Publications during the $\mathrm{PhD}$ journey 343 


\section{Abbreviations and units}

\begin{tabular}{|c|c|}
\hline AIM & Asian-Pacific Integrated Model \\
\hline APC & Air pollution control \\
\hline BAU & Business-as-usual \\
\hline $\mathrm{BOF}$ & Basic oxygen furnace \\
\hline CCE & Cost of conserved energy \\
\hline CCGT & Combined cycle gas turbine \\
\hline CCS & Carbon capture and storage \\
\hline CEC & China Electricity Council \\
\hline CERSC & Conservation and Emission Reduction Supply Curve \\
\hline $\mathrm{CH}_{4}$ & Methane \\
\hline CNREC & China National Renewable Energy Centre \\
\hline $\mathrm{CO}_{2}$ & Carbon dioxide \\
\hline $\mathrm{CO}_{2 \mathrm{eq}}$ & Carbon dioxide equivalent \\
\hline CPol & Current Policies \\
\hline CSC & Conservation Supply Curve \\
\hline CSP & Concentrating solar power \\
\hline CSPs & Cumulative saving potentials \\
\hline DEA & Data Envelopment Analysis \\
\hline DSM & Demand-side management \\
\hline EAF & Electric arc furnace \\
\hline $\mathrm{EE}$ & Energy efficiency \\
\hline $\mathrm{EF}$ & Emission factor \\
\hline EIA & U.S. Energy Information Administration \\
\hline EJ & Exajoule ( $10^{18}$ Joules) \\
\hline EoP & End-of-pipe \\
\hline EPA & U.S. Environmental Protection Agency \\
\hline ERI & Energy Research Institute of China \\
\hline ESP & Electrostatic precipitator \\
\hline ETSAP & Energy Technology Systems Analysis Program \\
\hline EU & European Union \\
\hline EUM & Electricity use management \\
\hline $\mathrm{FAO}$ & Food and Agriculture Organization of the United Nations \\
\hline $\mathrm{g}$ & gram \\
\hline GAINS & Greenhouse gas - Air pollution Interactions and Synergies \\
\hline GBD MAPS & Global Burden of Disease - Major Air Pollution Sources \\
\hline GDP & Gross domestic product \\
\hline GEM & Global Energy Monitor \\
\hline GHG & Greenhouse gas \\
\hline GJ & Gigajoule ( $10^{9}$ Joules) \\
\hline
\end{tabular}




$\begin{array}{ll}\text { Gt } & \text { Gigaton (10 } 0^{9} \text { tons) } \\ \text { GW } & \text { Gigawatt }\left(10^{9} \text { Watts) }\right. \\ \text { GWh } & \text { Gigawatt-hour } \\ \text { HELE } & \text { High efficiency low emissions } \\ \text { IAI } & \text { International Aluminium Institute } \\ \text { IEA } & \text { International Energy Agency } \\ \text { IGCC } & \text { Integrated gasification combined cycle } \\ \text { IIASA } & \text { International Institute for Applied Systems Analysis } \\ \text { INDC } & \text { Intended nationally determined contribution } \\ \text { IPCC } & \text { Intergovernmental Panel on Climate Change } \\ \text { IRENA } & \text { International Renewable Energy Agency } \\ \text { IRP } & \text { Integrated resource planning } \\ \text { ISEEM } & \text { Industry Sector Energy Efficiency Modeling } \\ \text { IVA } & \text { Industrial value added } \\ \text { IWPCTP } & \text { Industrial Water Pollutant Control and Technology Policy } \\ \text { kg } & \text { kilogram (10 } 0^{3} \text { grams) } \\ \text { kgce } & \text { kilogram of coal equivalent } \\ \text { kt } & \text { kiloton (10 } 10^{3} \text { tons) } \\ \text { kWh } & \text { kiloWatt-hour } \\ \text { LBNL } & \text { Lawrence Berkeley National Laboratory } \\ \text { LCA } & \text { Life Cycle Assessment } \\ \text { LEAP } & \text { Long-range Energy Alternatives Planning system } \\ \text { LMDI } & \text { Logarithmic Mean Divisia Index } \\ \text { LNB } & \text { Low nitrogen burning } \\ \text { LSB } & \text { Liquid and solid biomass } \\ \mathrm{m}^{3} & \text { cubic metre } \\ \text { MACC } & \text { Marginal Abatement Cost Curve } \\ \text { MEP } & \text { Ministry of Environmental Protection of China } \\ \text { MFA } & \text { Material Flow Analysis } \\ \text { MIIT } & \text { Ministry of Industry and Information Technology of China } \\ \text { MJ } & \text { Megajoule (10 } \text { Joules) } \\ \text { MSW } & \text { Municipal solid waste } \\ \text { Mt } & \text { Megaton (106 tons) } \\ \text { Mtoe } & \text { Million tons of oil equivalent } \\ \text { MW } & \text { Megawatt (10 } 6 \text { Watts) } \\ \text { MWh } & \text { Megawatt-hour } \\ \text { NBS } & \text { National Bureau of Statistics of China } \\ \text { NDRC } & \text { National Development and Reform Commission of China } \\ \text { NEA } & \text { Nuclear Energy Agency } \\ \text { Nm }{ }^{3} & \text { Normal cubic meter } \\ \text { NO } & \text { Nitrogen oxides } \\ & \end{array}$




$\begin{array}{ll}\mathrm{N}_{2} \mathrm{O} & \text { Nitrous oxide } \\ \text { OCGT } & \text { Open cycle gas turbine } \\ \text { OECD } & \text { Organisation for Economic Co-operation and Development } \\ \mathrm{PJ} & \text { Petajoule }\left(10^{15} \text { Joules }\right) \\ \mathrm{PV} & \text { Photovoltaic } \\ \mathrm{PM} & \text { Particulate matter } \\ \mathrm{PM}_{2.5} & \text { Particulate matter (aerodynamic diameters less than } 2.5 \mu \mathrm{m}) \\ \mathrm{PM}_{10} & \text { Particulate matter (aerodynamic diameters less than } 10 \mu \mathrm{m}) \\ \mathrm{PVC} & \text { Polyvinyl chloride } \\ \text { SDG } & \text { Sustainable Development Goal } \\ \text { SFA } & \text { Stochastic Frontier Analysis } \\ \text { SO } & \text { Sulfur dioxide } \\ \text { ST } & \text { Steam turbine } \\ \text { t } & \text { ton } \\ \text { TES } & \text { Total energy saving } \\ \text { TIMES } & \text { The Integrated MARKAL-EFOM System } \\ \text { TWh } & \text { Terawatt-hour } \\ \text { USC } & \text { Ultra-supercritical } \\ \mu \mathrm{g} & \text { Microgram }\left(10^{-6} \text { gram) }\right. \\ \text { WEO } & \text { World Energy Outlook } \\ \text { WHO } & \text { World Health Organization } \\ \text { WRI } & \text { World Resources Institute } \\ \text { WEPP } & \text { World Electric Power Plants } \\ \text { WSA } & \text { World Steel Association }\end{array}$




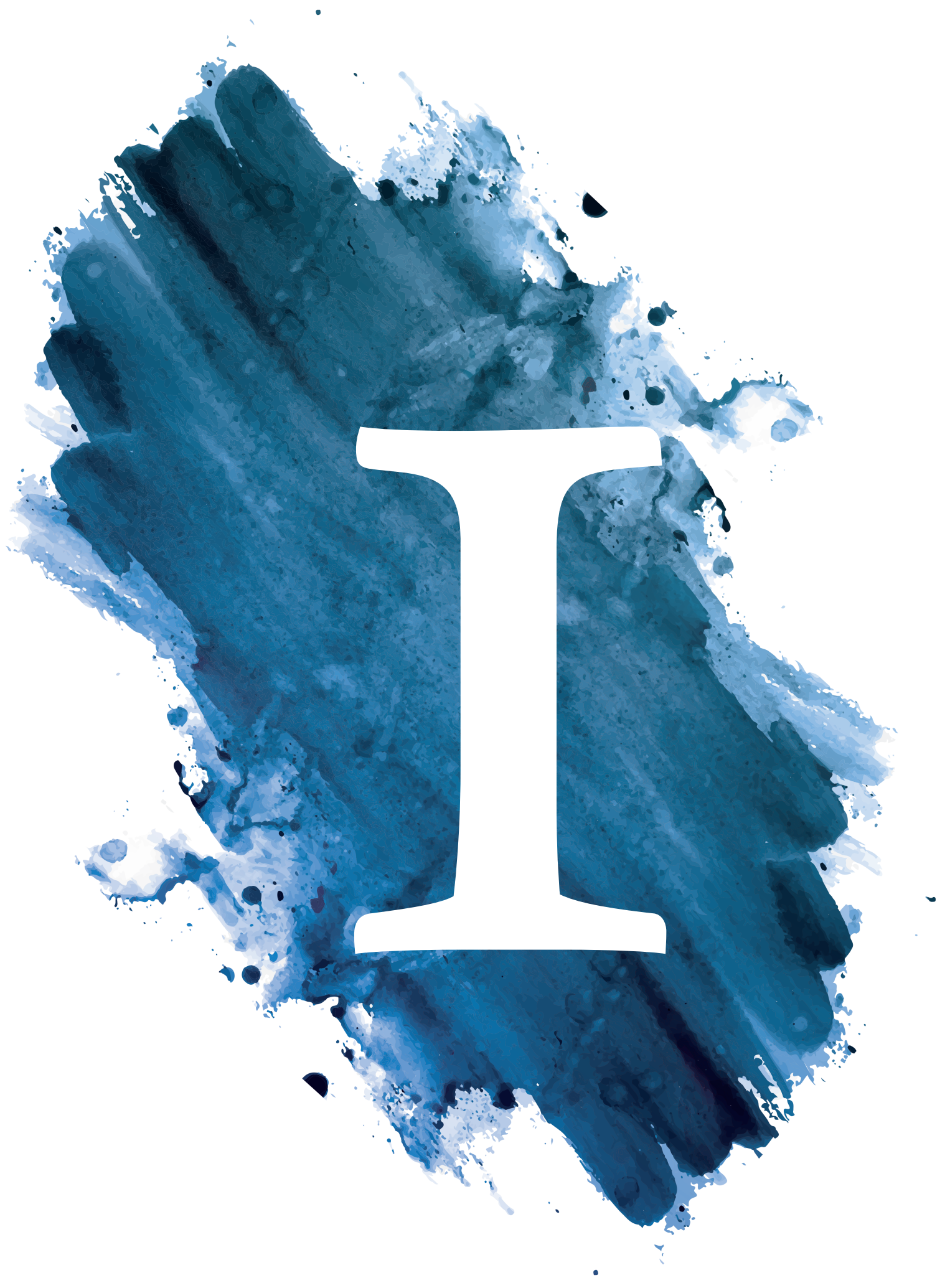




\section{Chapter I}

\section{Introduction}




\section{I.I. Development and challenges of global electricity demand and supply}

\section{I.I.I. Development of electricity demand and supply}

Electricity is indispensable to human wellbeing and economic activities. Providing a reliable and affordable electricity system can be seen as a prerequisite for ending poverty and offering economic opportunities. Thanks to the development of electricity infrastructure (i.e. power stations and grid expansion) around the world, the number of people lacking access to electricity has declined by half since 2000, from 1.66 billion to 840 million in 2017 (IEA et al., 2019). Developing Asia and sub-Saharan Africa account for around $97 \%$ of the population that has no access to this essential service. However, the current electrification pace will fall short of achieving the Sustainable Development Goals of universal access to modern energy by 2030 (IEA, 2018b; IEA et al., 2019). Along with urbanization advancement in developing countries, the world's population living in urban areas has grown drastically from 1.35 billion in 1970 to 4.22 billion in 2018, accounting for $55 \%$ of the total population (United Nations, 2019a). The urbanization level in Asia (50\%) is lower than the global average level, but it grows at a fast pace and now represents $54 \%$ of the world's urban population in 2018. At the same time, increasingly electricity is becoming the alternative to fossil fuels for meeting the energy demand of households and industries, which results in rapidly rising electricity consumption. Meanwhile, the growth rate of fossil fuel consumption is slowing down, and in particular coal demand. Electricity demand is growing at an average annual rate of $3.5 \%$ since 1971, far exceeding the annual growth rate of $1.5 \%$ of fossil fuel use (IEA, 2019c). Furthermore, electricity demand is closely linked to economic development. The global real GDP has grown at a similar rate as electricity demand during the period 1971-2017 (with 3.1\% per year) (World Bank, 2020b). The total final energy consumption and electricity demand per capita by country (or region) in 2016 are plotted in Figure 1.1. The final electricity consumption per capita in 2016 reached $2.8 \mathrm{MWh}$, which was more than double that in 1971 (1.2 MWh per capita) (IEA, 2018a). The share of electricity in total final energy consumption has increased from $9 \%$ in 1971 to $19 \%$ in 2017, of which more than $50 \%$ of the increase occurred after 2000 (IEA, 2019c). Developing economies account for around 86\% of this increase (from 2000 to 2017) in the past twenty years. China is now the largest electricity market among the developing countries, and is responsible for nearly $50 \%$ of the electricity demand by developing countries $(5,600 \mathrm{TWh})$ in 2017 , doubling that of the European Union (2,800 TWh). 

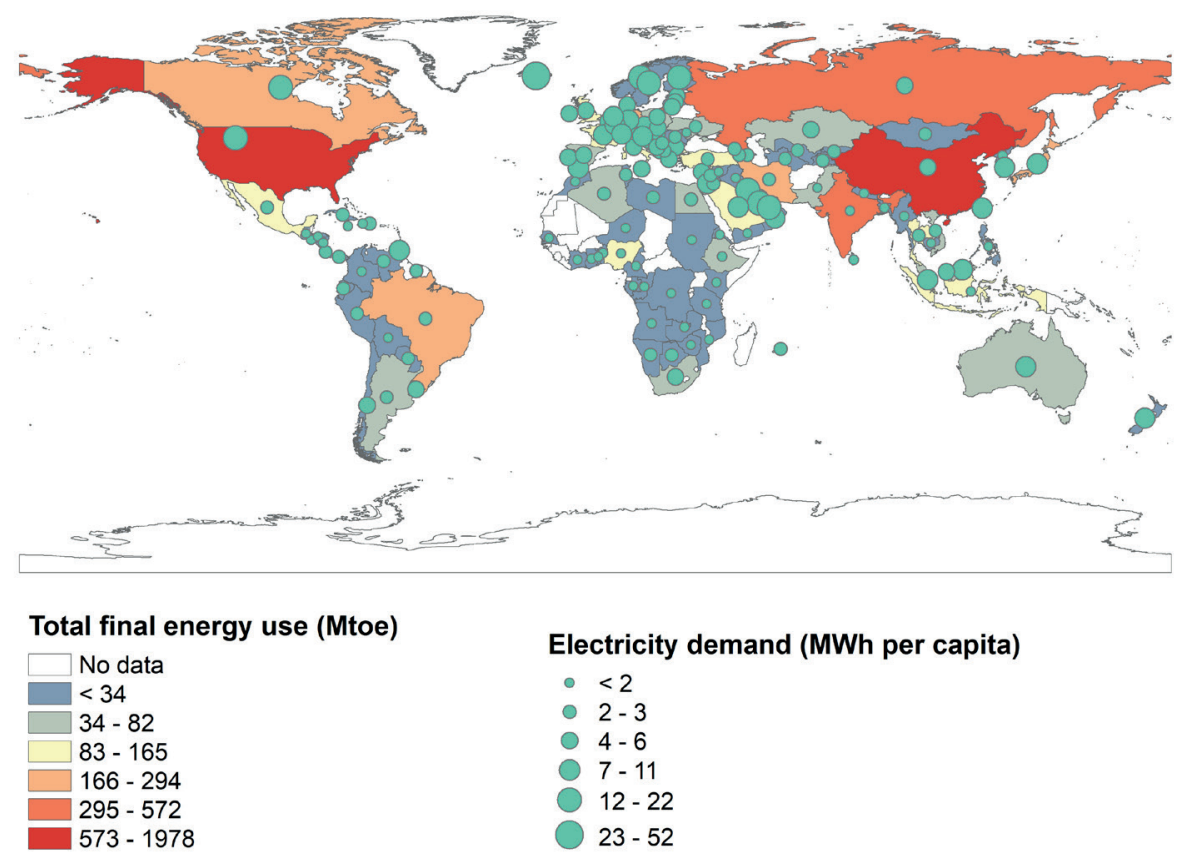

Figure 1.1. Total final energy use and electricity demand per capita by country or region in 2016.

Source: Calculated from the World Energy Balances (IEA, 2018a) and the World Population Prospects (United Nations, 2019b).

As the ever-growing role of electricity in meeting the human required energy, the power sector is crucial to meet global electricity demand. The power sector has been the largest consumer of primary energy, consuming $63 \%, 40 \%, 5 \%$ and $39 \%$ of global coal, natural gas, oil, and renewable energy use, respectively. Renewable energy (i.e. hydro, bioenergy, wind, geothermal, solar and marine) in the generation fuel mix has remained steady at a low level since 1980 , producing around $20 \%$ of the global electricity supply. This is partly because most renewable electricity generators are influenced by the ambient environment (e.g. wind speeds, solar radiation and rain patterns), and can have trouble to contribute to a stable or flexible supply of electricity (Staffell and Pfenninger, 2018; $\mathrm{Hu}$ et al., 2019). Although the role of the renewables has slightly risen after 2010 (from $20 \%$ to $24 \%$ in 2017), the largest source of electricity is derived from combusting fossil fuel, which generates $65 \%$ of the global electricity production in 2017 (see Figure 1.2). However, fossil fuels and especially coal has caused high amounts of GHG emissions (Tong et al., 2019), serious local air pollution (Oberschelp et al., 2019; Li et al., 2017) and health concerns (Koplitz et al., 2017). European countries, e.g. France and Denmark, have planned to shut down coal-fired power stations by 2030 to move towards cleaner 
electricity production and keep global temperatures from rising to near-catastrophic levels (Europe Beyond Coal, 2020; Kanellopoulos, 2018). From 2010 to 2017, the installed coal power capacity declined by $16 \%$ in the European Union, while renewable power deployment increased by 66\% (see Figure 1.3c). The United States is gradually abandoning the use of coal and replacing it with natural gas (U.S. EIA, 2019). In 2017, natural gas fueled around $40 \%$ of installed power capacity in the United States and generated more than one-third of the total electricity production (see Figure 1.3b). In contrast, a substantial number of coal-fired power plants (39 GW) came online in 2016 in China, while the rest of the world collectively removed coal capacity of $18 \mathrm{GW}$ (S\&P Global Platts, 2018). The coal power additions in China led the expansion of the coalfired generation fleet worldwide (which grows at an annual rate of $1.3 \%$ since 2010) and confounded the movement against the most polluting fossil fuel (see Figure 1.3).

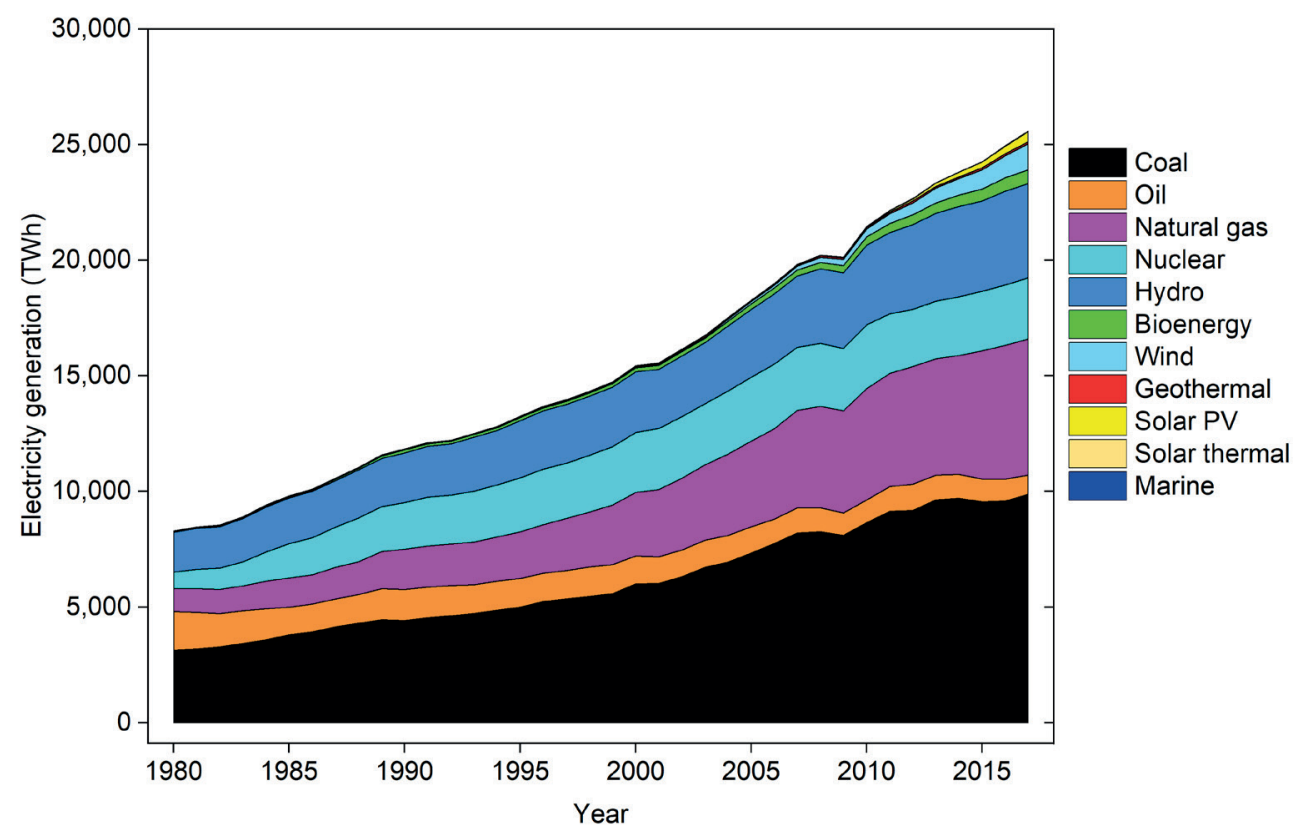

Figure 1.2. Global electricity generation by energy source during the period 1980 to 2017.

Source: The World Energy Balances (IEA, 2018a) and the World Energy Outlook (IEA, 2019c). 

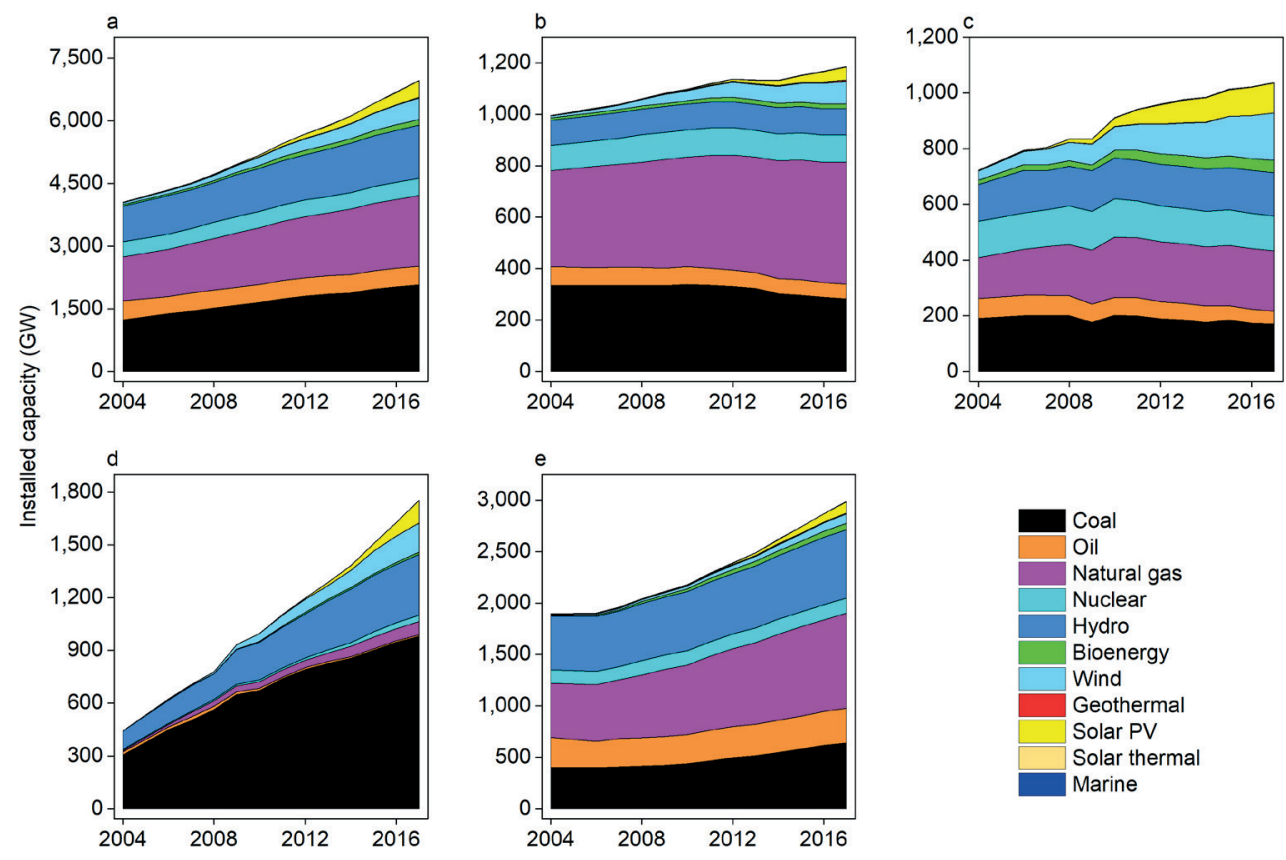

Figure 1.3. Power installed capacity by energy source in the World (a), the United States (b), the European Union (c), China (d) and the Rest of the World (e) from 2004 to 2017.

Source: Calculated from the World Energy Outlook series.

\section{I.I.2. Challenges for electricity demand and supply}

In 2015, an aspirational plan of action to transform our world by 2030 was agreed unanimously by all the United Nations Member States, which placed sustainable development as the core principle (United Nations, 2015). The 2030 Agenda for Sustainable Development succeeds the Millennium Development Goals, and features 17 ambitious Sustainable Development Goals consisting of 169 associated targets. These targets balance multiple dimensions that are closely related: economic, social, energy and environmental concerns. Sustainable modern energy systems are a core component of the 2030 Agenda for Sustainable Development (Nerini et al., 2018; Rao and Pachauri, 2017). The current surging electricity demand and the carbon-intensive supply have important environmental and human health impacts, challenging a sustainable future.

Developing economics has deployed over $70 \%$ of global coal power capacity in 2017, of which $82 \%$ is located in China and India, to meet their fast-growing electricity demand. Since 2010, the coal power fleet in developing countries has expanded by 589 GW, almost equivalent to the total existing coal generation capacity in advanced economies. The increased coal capacity offsets the efforts of countries that plan to shift away from 
coal-fired electricity generation, causing a rise of anthropogenic global greenhouse gas (GHG) emissions. Total $\mathrm{CO}_{2}$ emissions and the share of emissions from coal-fired power generation by country in 2017 are shown in Figure 1.4. Globally, the power sector emits $41 \%$ of total energy-related $\mathrm{CO}_{2}$ emissions, while around $73 \%$ of these emissions are due to coal burning. The $\mathrm{CO}_{2}$ emissions in 31 countries (representing 50\% of global $\mathrm{CO}_{2}$ emissions) are dominated by a coal-fired power fleet, which accounts for more than $30 \%$ of the total $\mathrm{CO}_{2}$ emissions in these countries. Most of these countries are located in Europe (e.g. Germany, Ukraine, and the Czech Republic) and Developing Asia (e.g. China, India, Indonesia, and the Philippines). The $\mathrm{CO}_{2}$ emissions in the coal power fleet have grown by $3.3 \mathrm{Gt}$ since 2000 , which accounts for around $80 \%$ of the total increase in $\mathrm{CO}_{2}$ emissions in the global power sector. The continuing growth of $\mathrm{CO}_{2}$ emissions from coal-fired power plants is inconsistent with long-term climate goals of keeping global warming within $2^{\circ} \mathrm{C}$ and pursuing efforts to limit warming to $1.5^{\circ} \mathrm{C}$ above pre-industrial levels (IPCC, 2018).

Around $90 \%$ of people around the world are exposed to air pollutants at concentrations exceeding the World Health Organization limits (WHO, 2020). Air pollution is particularly severe in developing and densely populated areas (e.g. Delhi, Shijiazhuang, and Anyang) (WHO, 2016), where energy-intensive economic activities cause high pollution levels. Coal-intensive electricity supply systems are a major source of air pollution, contributing to $35 \%, 15 \%$ and $6 \%$ of $\mathrm{SO}_{2}, \mathrm{NO}_{\mathrm{x}}$ and fine particulate matter $\left(\mathrm{PM}_{2.5}\right)$ emissions worldwide in 2017 (see Figure 1.5), respectively. The most dangerous consequence of poor air quality is a significant increase in the death rate that contributes to $9 \%$ of annual mortality globally, varying by country from $2 \%$ to $15 \%$ (Institute for Health Metrics and Evaluation, 2019; Burnett et al., 2018). Electricity generation accounts globally for an average of $14 \%$ in the air pollution-related mortality (Lelieveld et al., 2015). Meanwhile, the growing health risks due to air pollution are expected to significantly increase the healthcare burden and lead to welfare losses (OECD, 2016; World Bank, 2016). Several countries have adopted mandatory measures to combat local air pollution and reduce negative effects on the economy and human health (Bollen and Brink, 2014; Balakrishnan et al., 2019; U.S. EPA, 2013; State Council of China, 2013a). The power sector is one of the key areas for this policy actions focusing for example on shutting down super-polluting power units, retrofitting power plants with flue gas controls and substituting renewable energy for fossil fuels. However, around 6,000 small coal-fired power units or $475 \mathrm{GW}$ (units below $300 \mathrm{MW}$ ), with poor environmental performance, are still in operation across the world (S\&P Global Platts, 2018). 

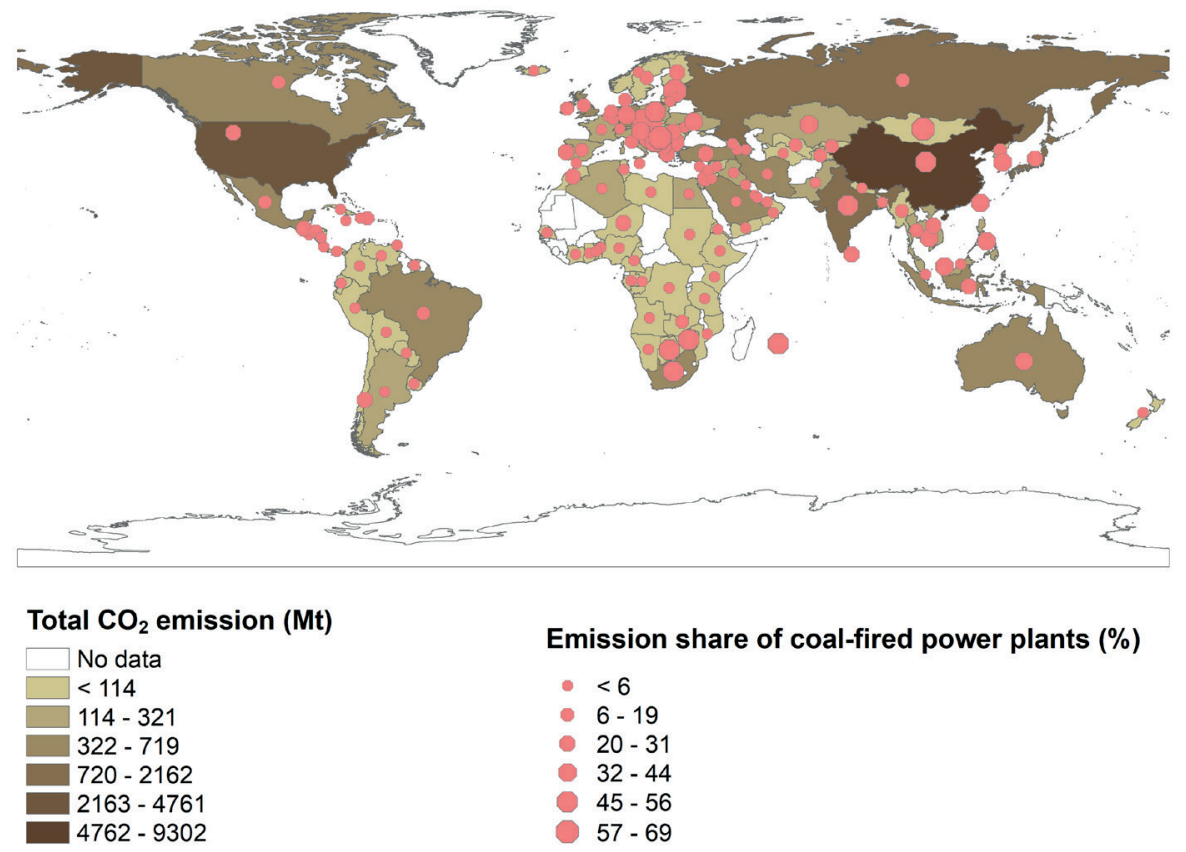

Emission share of coal-fired power plants (\%)
- $<6$
- $6-19$
$20-31$
$32-44$
$45-56$
$57-69$

Figure 1.4. Total energy-related $\mathrm{CO}_{2}$ emission and the $\mathrm{CO}_{2}$ emission share of coal-fired power plants by country or region in 2017.

Source: IEA - Data and statistics (IEA, 2020).

Options that optimize the electricity supply system have been considered by countries around the world to meet these multiple challenges. Five popular strategies to realize deep emission reductions in the power sector are listed as follows: first, efficient use of electricity in the demand-side (e.g. industry and building sector) to reduce coal power load; secondly, installing post-combustion control measures for coal power plants (e.g. carbon capture and storage (CCS), desulfurization and denitrification technologies); thirdly, deploying renewable energy to displace emissions from conventional coal-fired power plants; fourthly, replacing coal generation capacity by low-carbon fuel (e.g. natural gas); fifthly, improving the thermal efficiency of coal power plants. 


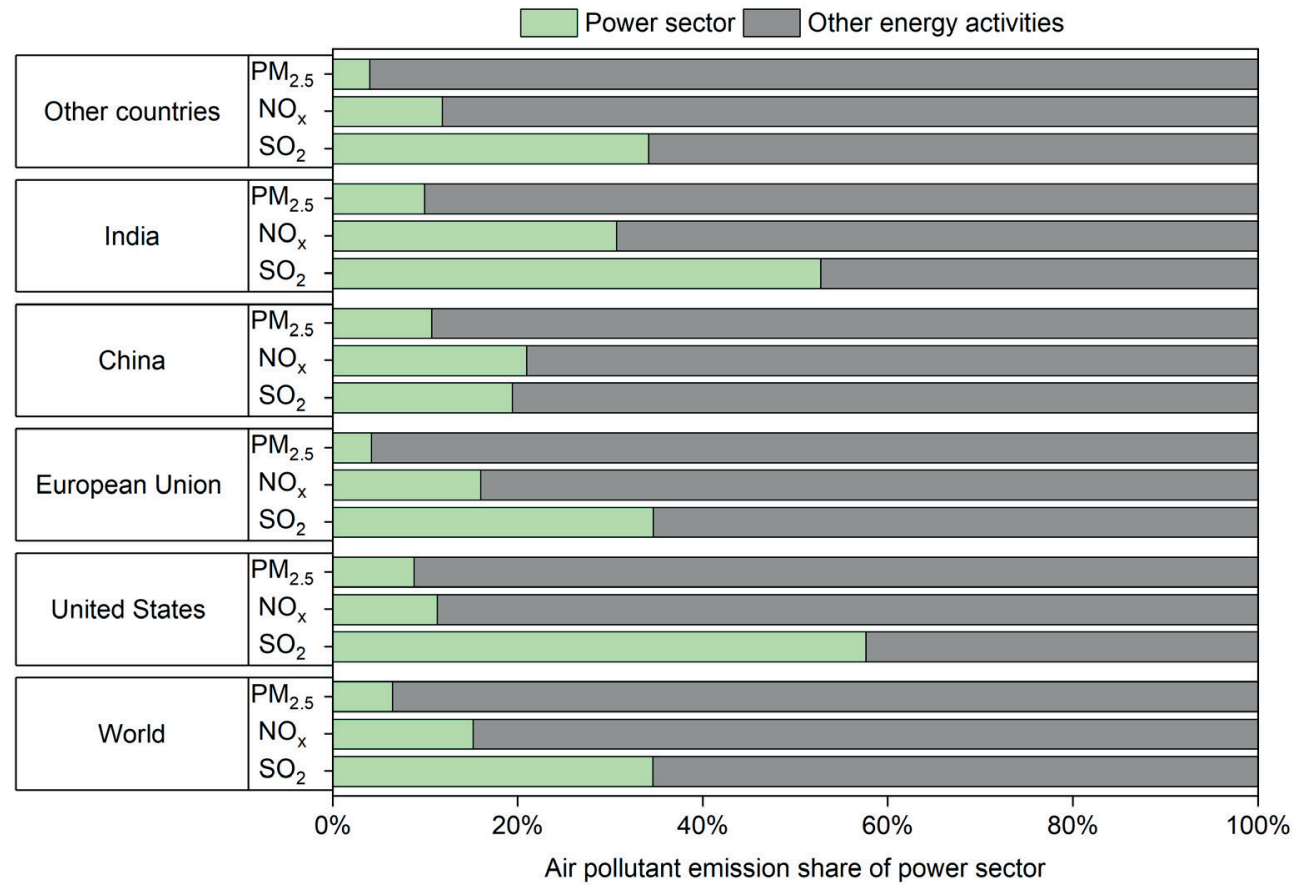

Figure 1.5. Share air pollutant emissions $\left(\mathrm{SO}_{2}, \mathrm{NO}_{\mathrm{x}}\right.$ and $\left.\mathrm{PM}_{2.5}\right)$ from the power sector by region in 2017.

Source: Calculated from the World Energy Outlook series.

End-of-pipe treatment measures are widely used in large-size coal-fired power units, which can effectively reduce air pollutants from electricity generation. Air pollution control retrofits are rarely applied to small polluting units because of the high investment and operation cost (Yang et al., 2018; Tong et al., 2018a). Installing CCS technology is a potential way to reach a carbon-free power sector in the future, but at very expensive mitigation costs (Wang et al., 2020). Currently, this carbon mitigation system is still in the demonstration stage for the power sector and is only deployed in two large-size power units (Global CCS Institute, 2019). Moreover, those post-combustion control technologies (i.e. end-of-pipe and CCS) increase the auxiliary electricity use and cause an energy penalty in power plants, thus resulting in secondary environmental impacts (Jacobson, 2019; Graus and Worrell, 2007).

Substituting renewables or natural gas for coal in producing electricity heavily depends on the resource availability and ambient environmental factors. Russia, the United States, Iran and Qatar together account for around 55\% of the global natural gas proven reserves, while the European Union only accounts for $0.3 \%$. Frequency fluctuations in a power system with high penetration of intermittent electricity (e.g. solar and wind) 
can threaten the grid's overall stability. High-efficiency low-emission (HELE) coal-fired power units play a pivotal role in improving the mean generation efficiency of the overall fleet by a major coal-using country (IEA, 2012). HELE units are characterized by large capacities and have relatively low air pollutant emission, but contribute less to avoiding $\mathrm{CO}_{2}$ emissions. However, massive expansion of the HELE coal power capacity, without CCS technology, would still work against climate goals.

Due to the absence of emission controls in super-polluting units, various restrictions of alternative energy, and the avoidance of new coal projects as much as possible around the world, efficient use of electricity in the demand-side is a preferable alternative in helping to rapidly escape from a coal-intensive electricity supply and responding the environmental concerns, simultaneously (Grubler et al., 2018; Abel et al., 2019; IEA, 2019b). In this thesis, we focus on the critical role of industrial electricity savings in reshaping the power sector and achieving a low carbon future.

\section{I.2. Global largest industry and energy infrastructure: China}

\section{I.2.I. China's industry}

Industry is a pillar economic activity to support human development from poverty to prosperity, which generates nearly $30 \%$ of the global gross domestic product (GDP) and provides $23 \%$ of total employment in 2017 (see Figure 1.6). China's industrial value-added, with an average annual growth rate of $11 \%$ from 1980 to 2017 , reached 4.7 trillion US\$2010 in 2017, accounting for $21 \%$ of the global total industrial valueadded. Different from other developed countries, China's national economic structure heavily depends on industry (contributing to $46 \%$ of the country's GDP), particularly the energy-intensive industrial subsectors. China has been the world's leading producer and consumer of primary materials, such as crude steel (WSA, 2019), cement (U.S. Geological Survey, 2020a), chemical fertilizers (U.S. Geological Survey, 2020b) and aluminium (IAI, 2020). Massive amounts of energy are consumed in these industrial production processes, accounting for 50\% of China's total final energy demand in 2017 (amounting to 35\% of the global final energy use). The energy consumption of China's industry shows explosive growth after 2000, with an annual increase of $7.5 \%$, which is nearly triple the annual growth rate during the period 1980 to 2000 (2.8\%). More than $70 \%$ of the energy consumption is occurring in four energy-intensive subsectors, i.e. iron \& steel, chemical, non-ferrous metals (mainly consisting by aluminium, copper and lead) and non-metallic minerals (e.g. cement and clay building materials) (see Figure 1.7). Energy consumption growth in some energy-intensive subsectors has slowed down significantly since 2011, because the Chinese government is closing inefficient capacity in the iron \& steel, cement and chemicals industries (State Council of China, 2010; State Council of China, 2012). Intensive research indicated that the demand of crude steel (Wen et al., 2018; Zhang et al., 2018), cement (Liu et al., 2017; Zhou et al., 2016) 
and ammonia (Yue et al., 2018; Zhou et al., 2013) will be saturated around 2020, and then steadily decline, which would substantially decrease the growth rate of total energy consumption in China's industry.
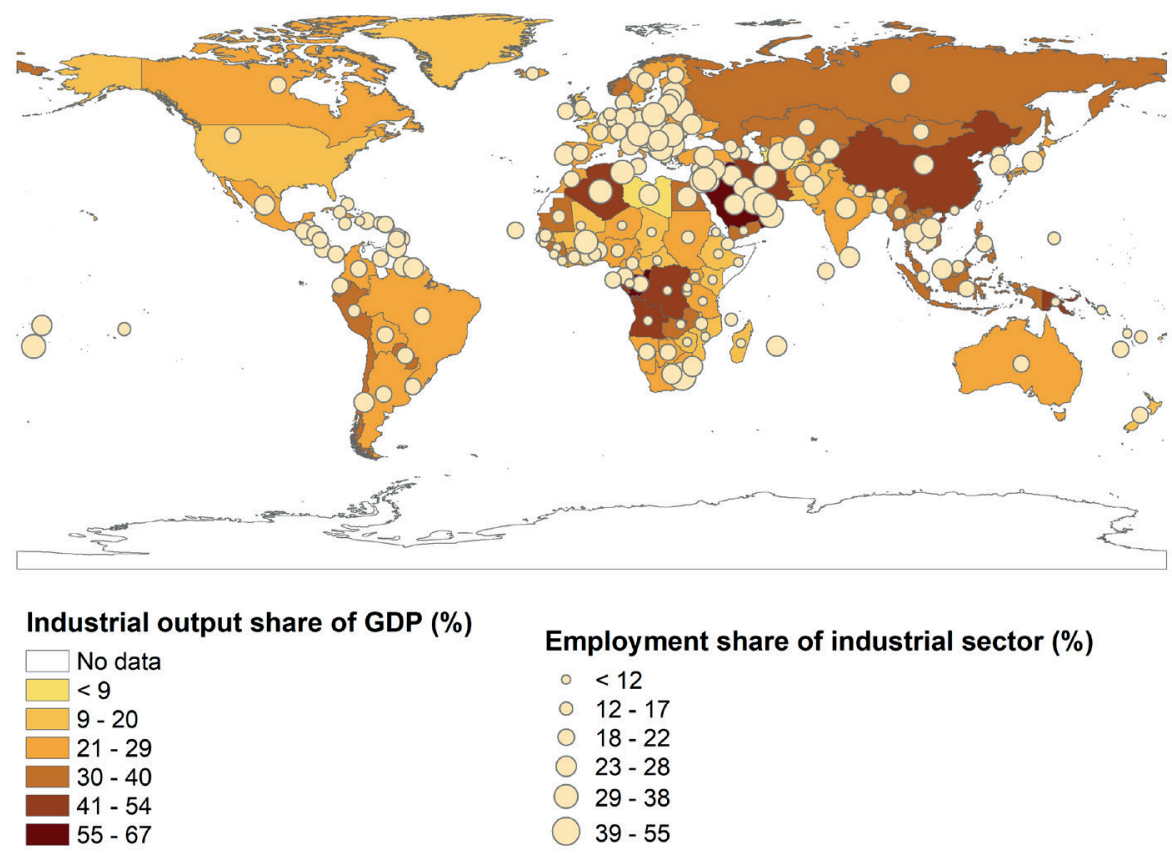

Figure 1.6. Industrial value-added share of GDP and Employment in industry by country or region in 2017.

Source: Calculated from the World Bank (2020a) and the International Labour Organization (2020).

Coal and electricity, together accounting for $82 \%$ of final energy consumption in Chinese industry, are the main energy carriers fueling the sector (see Figure 1.8). Coal consumption has increased by 3.5 times over the past four decades, reaching 519 Mtoe in 2017, thereby dominating the industrial energy consumption mix. Directly combusting coal in China's industry has resulted in serious environmental concerns, for example, increasing GHG emissions, air pollution, and surface water pollution. Action to co-control coal consumption and intensity (ton/\$) for industries has been incorporated in the National Five-Year Plan since 2011 (State Council of China, 2013b; National Energy Administration of China, 2016). The growth rate of coal consumption in industries shows a significant decline after 2011, with an average annual growth rate of $-2.9 \%$. The government is ambitiously promoting the substitution of electricity for coal, to improve the energy efficiency in end-user sectors and reduce damage to the environment (National Development and Reform Commission of China, 2016). The 
electricity demand in industry grows rapidly since 1971, from 91 TWh to $3452 \mathrm{TWh}$ in 2017. Moreover, this positive growth is expected to continue in the future because the share of electricity in final energy consumption mix of China's industry (30\%) is still lower than the average level in advanced economics (32\%). Electricity instead of coal has been the fastest growing energy carrier, holding an average annual $10 \%$ growth rate in industries since 2000. Additional electricity generation capacity is required to meet the future growth of industrial electricity demand. If the electrification is powered by a coal-intensive electricity system, the increase in GHG and air pollutant emissions to produce the additional electricity largely or more then offsets the emission reductions from displacing direct combustion of fossil fuels with electricity in the industry (Khanna et al., 2019).

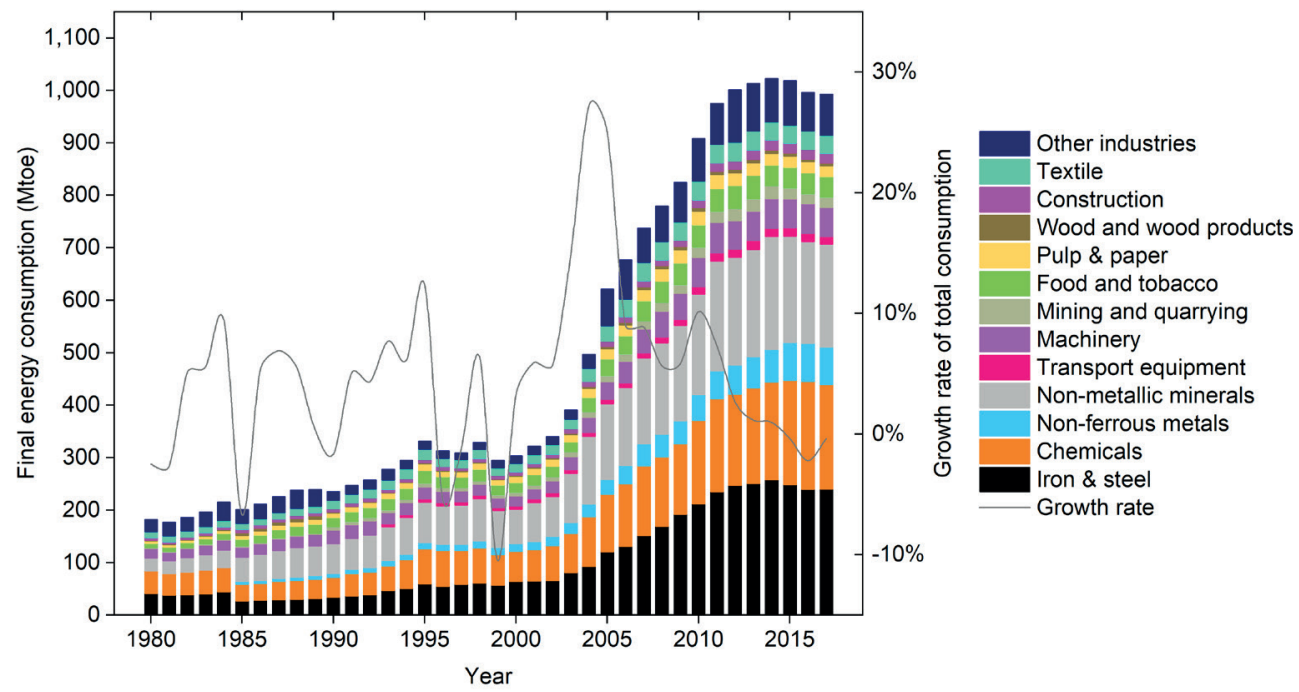

Figure 1.7. Final energy consumption by industrial subsector and annual growth rate of total industrial energy demand during 1980-2017. The color bars indicate the historical energy use by sector. The gray curve represents the growth rate of total energy use in industries.

Source: Calculated from the World Energy Outlook (IEA, 2019c), the World Energy Balances (IEA, 2018a) and China Energy Statistical Yearbook (National Bureau of Statistics of China, 2019a). 


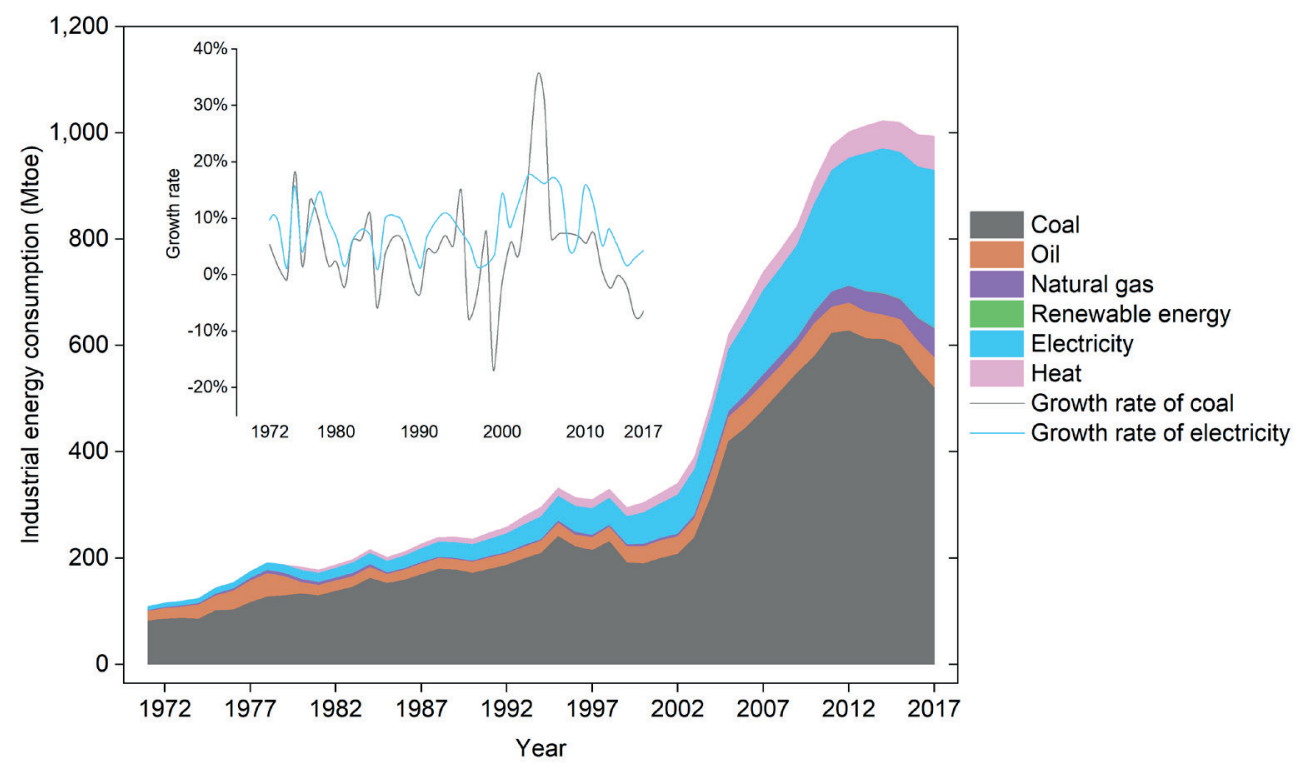

Figure 1.8. Energy consumption by fuel, and the growth rate of coal and electricity use in China's industry during 1971-2017. The stacked areas represent the historical energy demand by fuel in Chinese industry. The gray and blue curves represent the growth rate of coal and electricity consumption in industries, respectively.

Source: Calculated from the World Energy Outlook (IEA, 2019c) and the World Energy Balances (IEA, 2018a).

\section{I.2.2. China's power sector}

China's power sector is the world's largest energy infrastructure (Tong et al., 2019), which has more than 10,000 commissioned generation units of a total capacity of $1,754 \mathrm{GW}$ in 2017 (see Figure 1.3). Electricity access in China has reached 100\% in 2016, powering around 1.4 billion people (IEA, 2017). The dominating source that supplies China's electrical energy is the most polluting fossil fuel, coal, which annually provides around $70 \%$ of power generation over the past third decades (see Figure 1.9). The Chinese power sector is a veritable coal \& carbon-intensive electricity supply system. In the 2009 Copenhagen climate change conference, China announced goals to reduce the national carbon intensity by $40-45 \%$ below 2005 levels by 2020 (National Development and Reform Commission of China, 2010). Six years later, new ambitious targets post-2020, known as, intended nationally determined contribution (INDC), built on the Copenhagen climate goal, are proposed by the Chinese government to deliver the long-term efforts to combat environmental deterioration. The post-2020 climate actions in China include peaking $\mathrm{CO}_{2}$ emissions by around 2030 and increasing the share of non-fossil fuels in primary energy consumption to approximately $20 \%$ by the same year (National Development and Reform Commission of China, 2015). These climate targets decrease Chinass appetite for coal-fired power plants, but the net 
changes of coal installed capacity are still positive in recent years (see Figure 1.10). The newly-built coal power plants would lock-in the energy infrastructure in a carbonintensive pathway for at least the next 40 years (Cui et al., 2019; Farfan and Breyer, 2017), thus has detrimental implications for not only climate change but also air quality. The trend of installed coal power capacity in the world is highly similar to that in China, this indicates China's power sector plays a pivotal role in moving the global energy system on a course towards sustainable development. China is turning to develop the potentials of renewable energy sources, aiming to displace the role of fossil fuels in the power generation mix (China National Renewable Energy Centre, 2019). The installed renewable energy capacity increased by 1.5 times from 2010 to 2017, with an average annual growth rate of $14 \%$, which is faster than the expansion of coal power capacity $(5 \%)$ in the same period. However, renewable-based power, particularly intermittent power, still accounts for a limited share in total electricity production (see Figure 1.9).

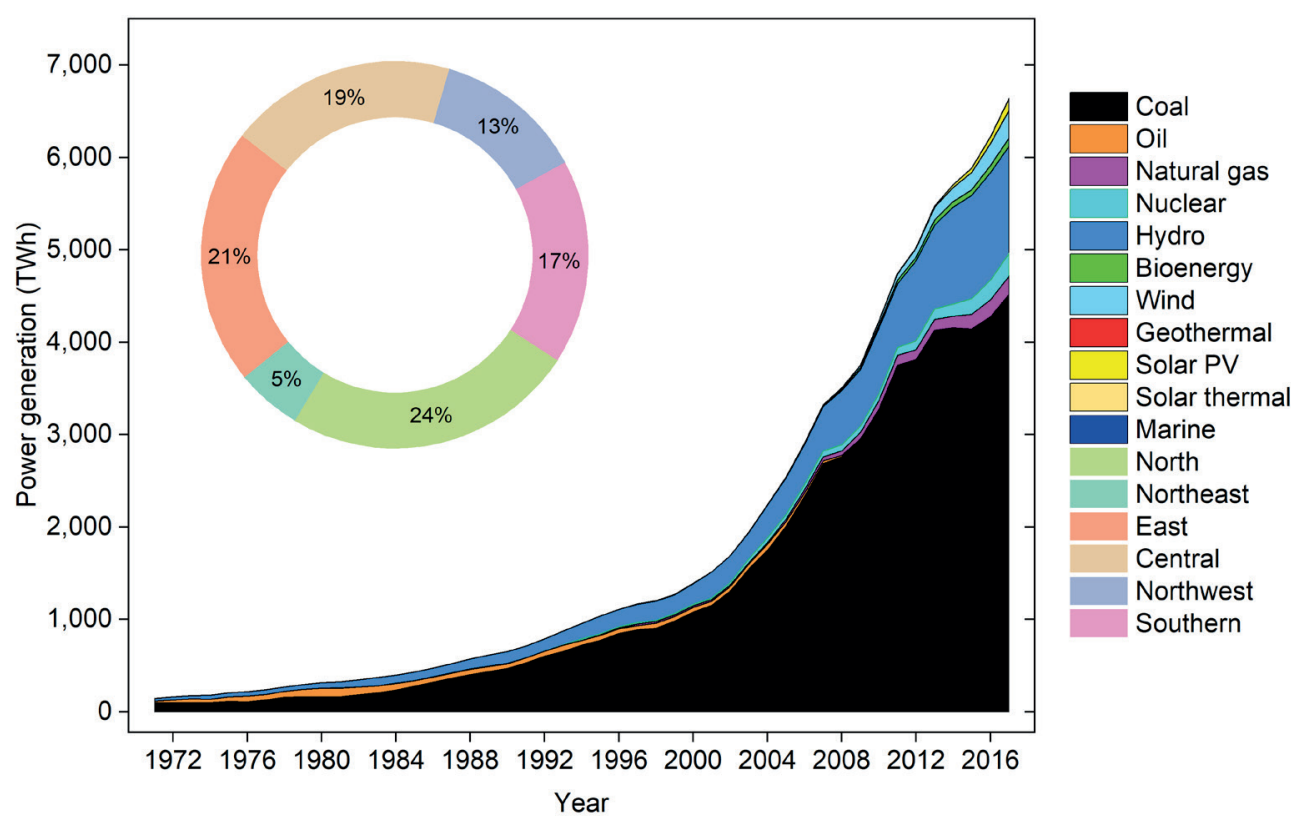

Figure 1.9. Electricity generation by fuel and power grid, respectively, in China from 1971 to 2017.

Source: Calculated from the World Energy Outlook (IEA, 2019c), the World Energy Balances (IEA, 2018a) and China Electric Power Yearbook (2018). 


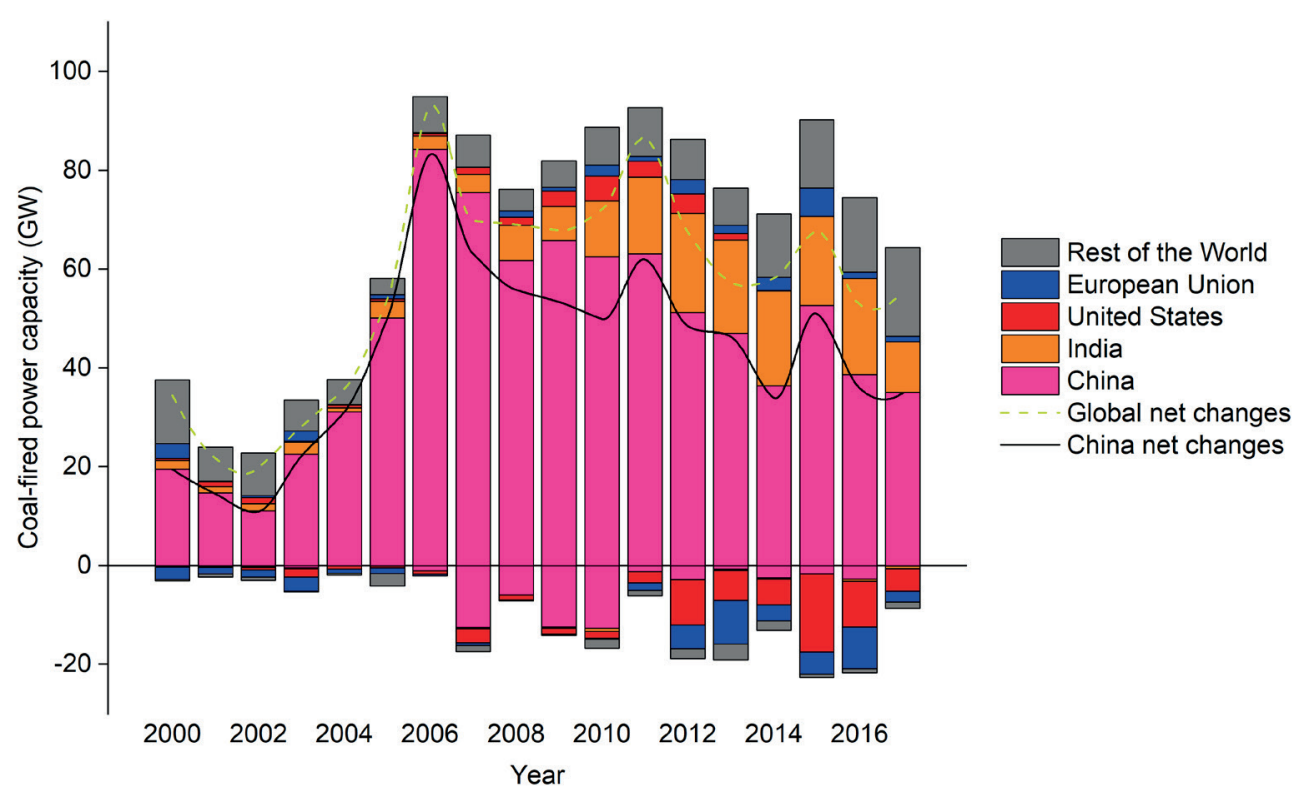

Figure 1.10. The bars represent additional and retired coal-fired power capacity by country or region from 2000 to 2017. The curves represent the net changes of coal-fired capacity Globally and in China.

Source: Calculated from the World Electric Power Plants database (S\&P Global Platts, 2018), the Worldwide Coal-Fired Power Stations database (Global Energy Monitor, 2019) and China Electric Power Yearbook (2018).

China's electricity system consists of six power grids, i.e. the North, Northeast, East, Central, Northwest and Southern grid. The North grid includes six provinces and has the largest power plant fleet, contributing to $24 \%$ of total electricity generation. More than $90 \%$ of electricity generation is provided by coal-fired power plants in this grid. Furthermore, less-efficient coal generation technology (i.e. subcritical units) accounts for $73 \%$ of total coal power capacity in the North grid (see Figure 1.11). Therefore, the North grid is a highly polluting power grid, that urgently needs to be improved. The Northeast grid has the lowest contribution to total electricity generation, while 95\% of electricity production in the grid is supplied by combusting coal. In the Southern and Central grids, coal power provides less than $50 \%$ of electricity generation. This is because a higher penetration of renewable energy is integrated into these two grids. For example, the power plant fleet in the Southern grid consists of $43 \%$ coal capacity, $5 \%$ of nuclear, $48 \%$ renewables, and $4 \%$ of oil and gas capacity. Driven by the booming demand of the energy-intensive industries, the scale of power infrastructures has been rapidly expanded in the western regions since 2010 (e.g. Shaanxi, Gansu, Ningxia, Qinghai and Xinjiang). Coal power plants in the Northwest grid have a high utilization rate and supply $71 \%$ of the grid electricity generation. 


\section{Chapter I}
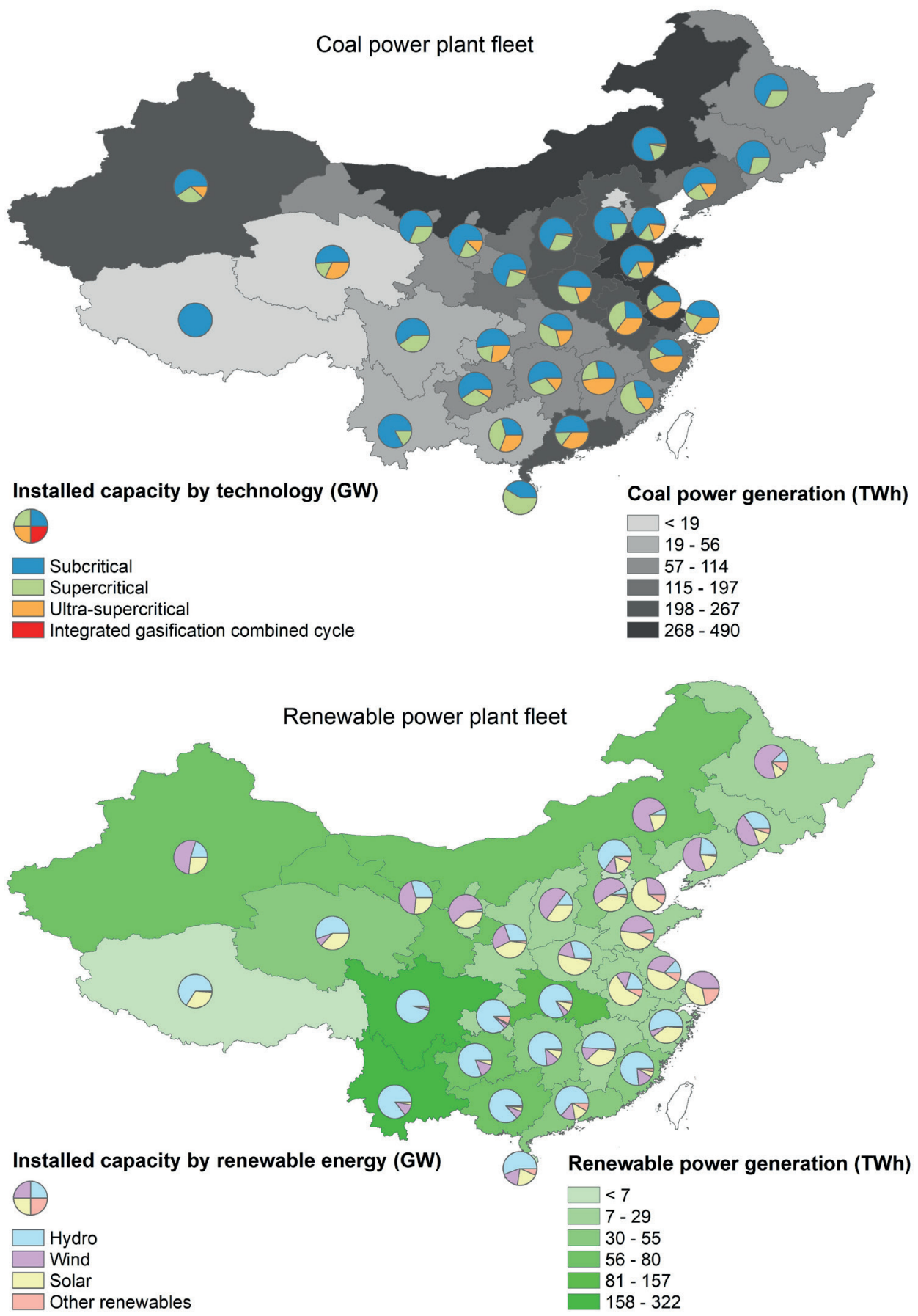

Figure 1.11. Installed capacity and power generation by energy source in 2017 per province.

Source: Calculated from the World Electric Power Plants database (S\&P Global Platts, 2018), the World Energy Outlook (IEA, 2019c) and China Electric Power Yearbook (2018). 


\section{I.3. Environmental concerns}

\section{I.3.I. Climate change in China}

The coal-based electricity system and fast-increasing energy demand in industry led China to fall into the trade-off between economic growth and environmental burdens. Fossil fuel combustion in China, resulting in $92 \%$ of total $\mathrm{CO}_{2}$ emissions in 2017, dominates the anthropogenic carbon emissions (see Figure 1.12). China's energy-related $\mathrm{CO}_{2}$ emissions increased dramatically, with an average annual growth of $5.4 \%$, from $1.4 \mathrm{Gt}$ in 1980 to a historic high of $9.3 \mathrm{Gt}$ in 2017 , accounting for $28 \%$ of global $\mathrm{CO}_{2}$ emissions. Coal combustion is the biggest contributor, representing $81 \%$ of energyrelated $\mathrm{CO}_{2}$ emissions, followed by oil use (accounting for $14 \%$ of the emissions). The greenhouse gas emissions from natural gas combustion are lower than those from coal or oil. Natural gas emits an average $43 \%$ less $\mathrm{CO}_{2}$ when combusted in a natural gas power plant compared with emissions from a conventional coal-fired power plant. China is trying to decouple the energy-related carbon emissions from economic expansion by implementing various measures (e.g. piloting circular economy industrial parks and deploying renewable energy (National Development and Reform Commission of China, 2014)). The $\mathrm{CO}_{2}$ emission per unit GDP is below $1 \mathrm{~kg}-\mathrm{CO}_{2} / \$$ in 2017 , which shows a steep decline of $73 \%$ compared to the level in 1980. If China can achieve its INDC pledges, the $\mathrm{CO}_{2}$ emission intensity would drop to $0.5-0.6 \mathrm{~kg}-\mathrm{CO}_{2} / \$$ by 2030 . The INDC targets would result in peaking $\mathrm{CO}_{2}$ emission levels of 9-15 Gt before 2030, and 3-8 Gt in 2050 (Climate Action Tracker, 2019; IEA, 2019c; China National Renewable Energy Centre, 2019).

The $\mathrm{CO}_{2}$ emissions vary among the 31 provinces, depending on the fossil fuel use and in particular coal combustion (see Figure 1.13). The North and East grids have deployed nearly $50 \%$ of total coal power installed capacity and contribute to $47 \%$ of national $\mathrm{CO}_{2}$ emissions. The Central grid contributes to $18 \%$ of China's $\mathrm{CO}_{2}$ emissions, though the industry is the largest emitter (representing $45 \%$ of the grid's $\mathrm{CO}_{2}$ emissions). The power sector in the Central grid generates a lower share of the grid's $\mathrm{CO}_{2}$ emissions, relative to industrial sectors, because hydropower power plants are the major electricity provider. The Northeast grid only covers three provinces, but contributes to a share of $\mathrm{CO}_{2}$ emissions similar to the Southern grid (which has an electricity system that relies less on coal). The Northwest grid with the rapid expansion of coal-fired power plants has become the fastest growing $\mathrm{CO}_{2}$ producer in China (Ministry of Ecology and Environment of China, 2018). Moreover, $\mathrm{CO}_{2}$ emissions from the residential sector in the densely populated provinces (e.g. Guangdong, Shandong, Hebei and Henan) should not be neglected. 


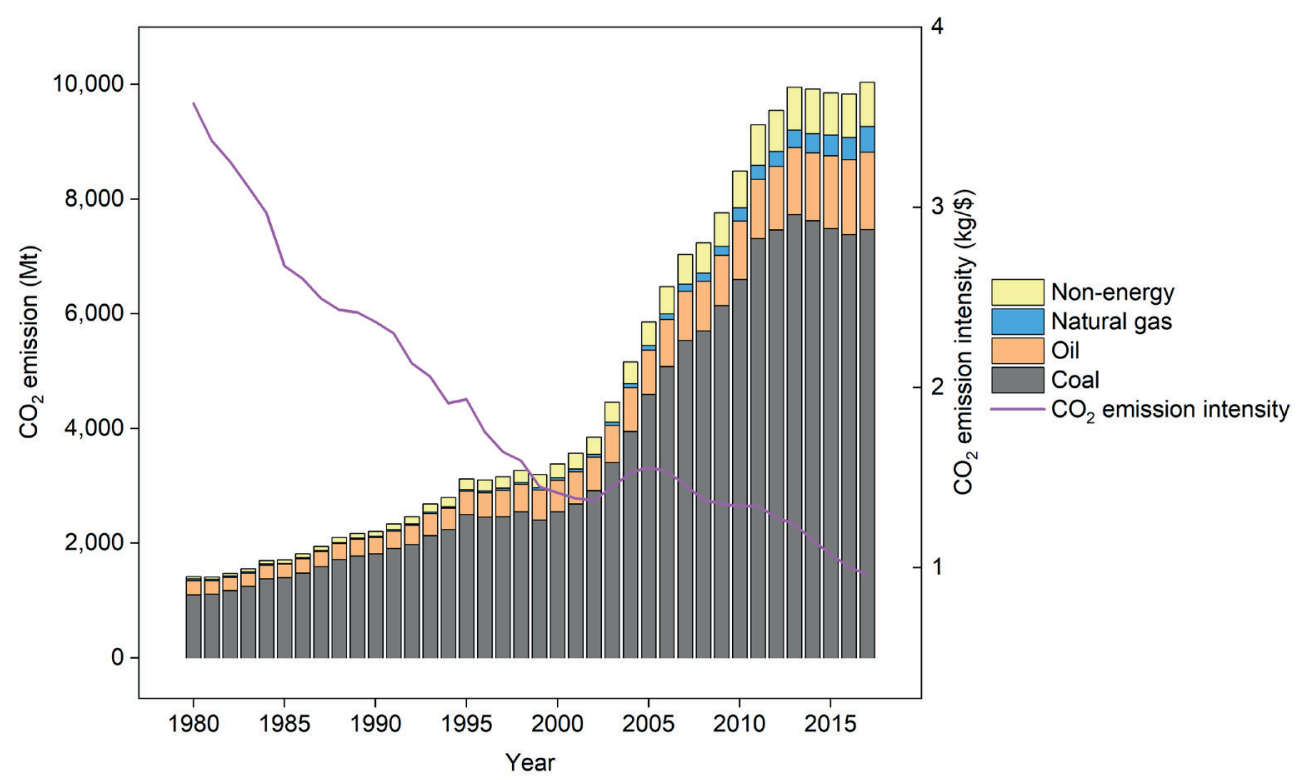

Figure 1.12. $\mathrm{CO}_{2}$ emissions by fuel and $\mathrm{CO}_{2}$ emissions per GDP (constant \$2010) in China during 1980-2017.

Source: IEA (2019a) and Global Carbon Project (2019).

\section{I.3.2. Air pollution in China}

Detrimental smog, composed of various anthropogenic air pollutants, frequently appears across China over the past decade, and are most pronounced in the northern regions (e.g. Beijing, Shijiazhuang and Tangshan) in winter. Air pollution, causing about 1.2 million premature deaths per year in China, has been the fourth biggest risk factor threatening local health (see Figure 1.14). The impact on public health, endangering the pace of China's economic growth, is estimated to result in a loss of $0.7 \%$ of the country's GDP per year (Gu et al., 2018). The unhealthy air quality has wakened up China's government to adopt stricter environmental regulations. During 2012-2017, a total of $\$ 48$ billion is spend on deploying high-efficiency flue gas control systems to tackle urban air pollution (National Bureau of Statistics of China, 2019b). These measures have been showing effect. In 2019, the average concentrations of $\mathrm{SO}_{2}, \mathrm{NO}_{\mathrm{x}}$ and $\mathrm{PM}_{2.5}$ are $11 \mathrm{ug} / \mathrm{m}^{3}, 27 \mathrm{ug} / \mathrm{um}^{3}$ and $36 \mathrm{ug} / \mathrm{m}^{3}$, respectively, showing a decline of $73 \%, 39 \%$ and 50\% since 2013 (Ministry of Ecology and Environment of China, 2020). However, the $\mathrm{PM}_{2.5}$ concentration in China is as much as $31 \%$ higher than the global average level of $25 \mathrm{ug} / \mathrm{m}^{3}$, and $72 \%$ higher than the WHO guideline value of $10 \mathrm{ug} / \mathrm{m}^{3}$. 

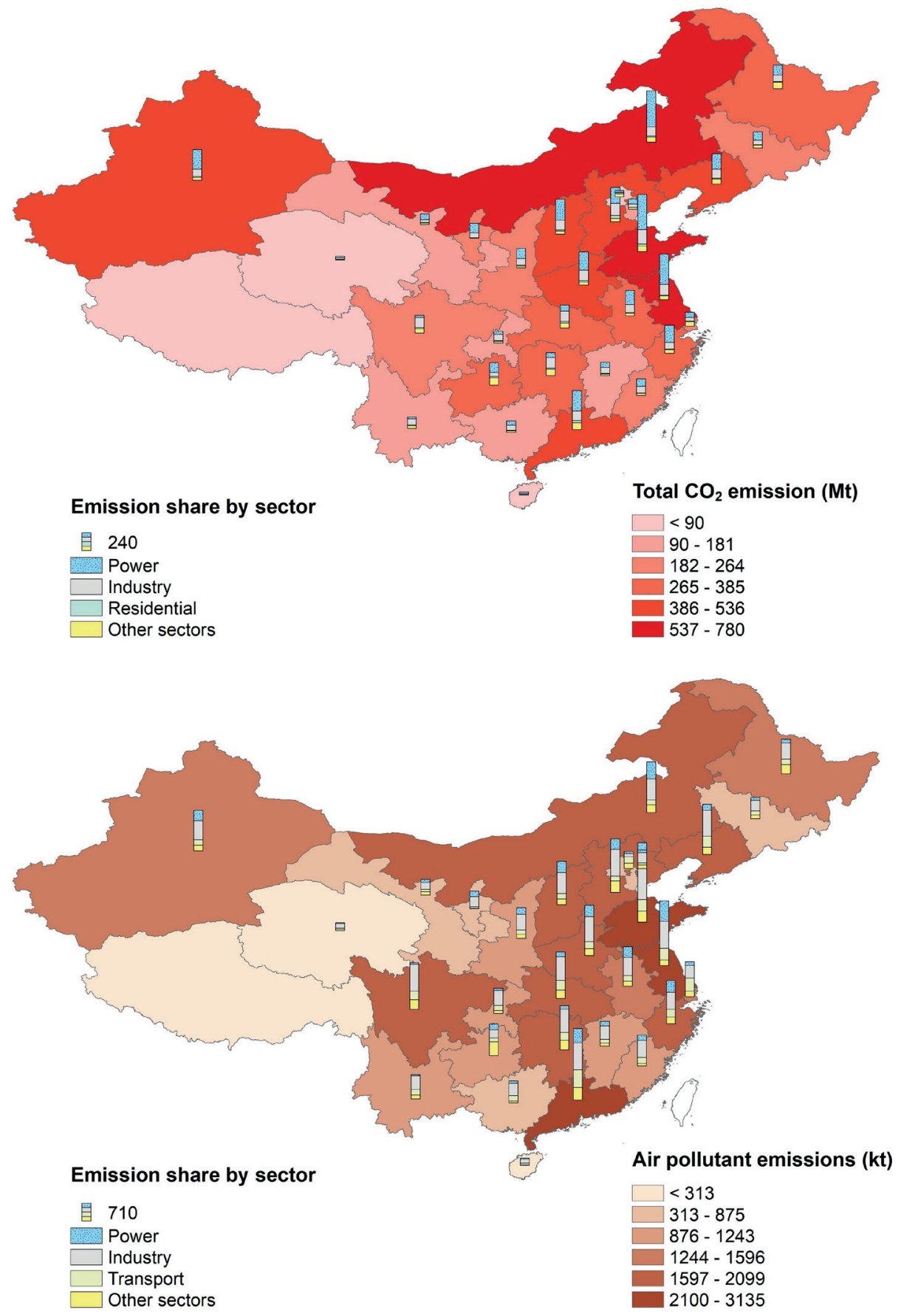

Figure 1.13. $\mathrm{CO}_{2}$ and air pollutant emissions by sector across China's regions in 2017.

Source: Calculated from China Energy Statistical Yearbook (National Bureau of Statistics of China, 2019a), China Electric Power Yearbook (2018) and IEA's reports (IEA, 2019c; IEA, 2019a). 


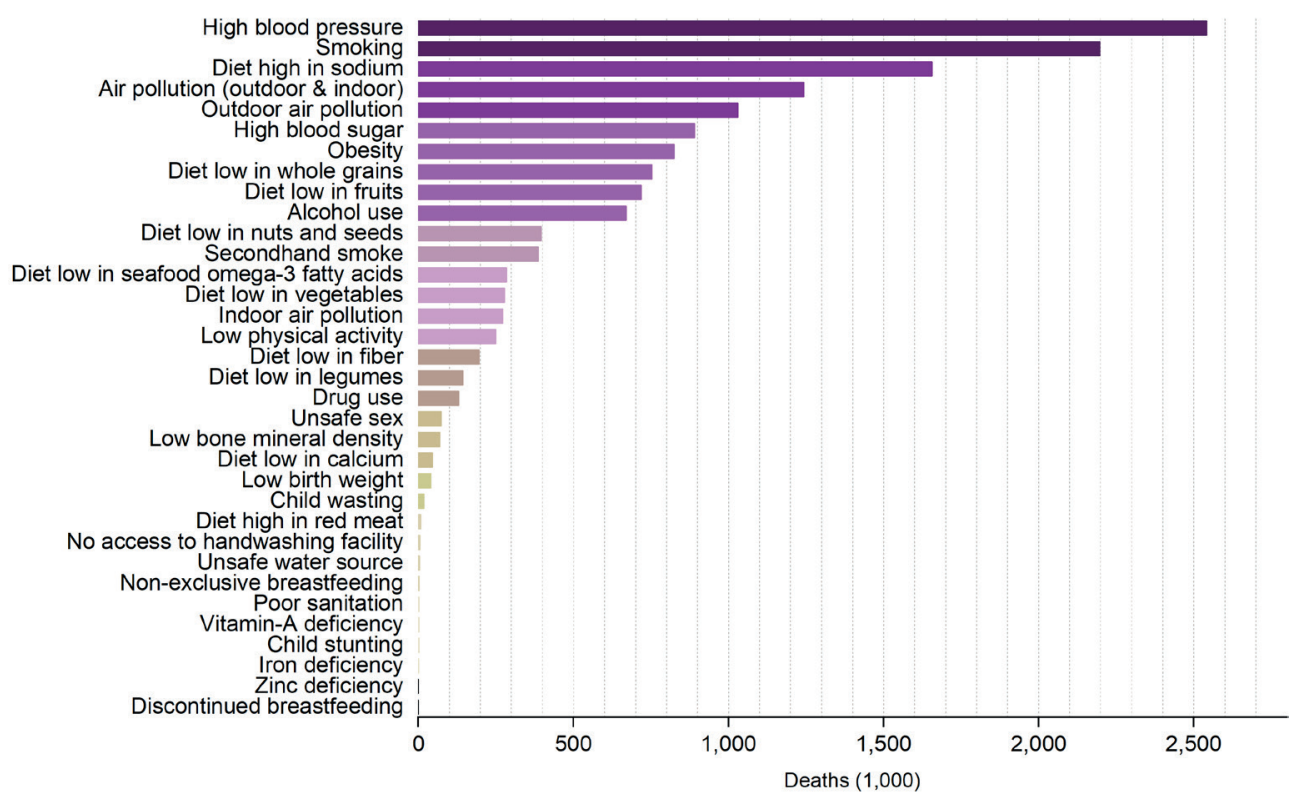

Figure 1.14. Number of deaths by risk factor for China in 2017.

Source: Institute for Health Metrics and Evaluation (2019)

Coal combustion is responsible for $86 \%, 47 \%$ and $52 \%$ of $\mathrm{SO}_{2}, \mathrm{NO}_{\mathrm{x}}$ and $\mathrm{PM}_{2.5}$ emissions in China (IEA, 2019c), respectively, and contributes to $40 \%$ of air pollution-related mortality (GBD MAPS Working Group, 2016). Although the power sector is the largest coal consumer, the air pollutant emissions from electricity generation are much lower than those from industrial activities across China. This is because most large-size power plants are equipped with end-of-pipe treatment measures (China Electricity Council, 2019; GBD MAPS Working Group, 2016). The regions that are dominated by industry and rely on coal-intensive electricity supply systems have high emission levels of air pollutants (see Figure 1.15). The North grid is the largest contributor to air pollutant emissions, representing 25\%,23\% and $24 \%$ of $\mathrm{SO}_{2}, \mathrm{NO}_{x}$ and PM2.5 emissions, respectively. The East grid consumes a greater amount of coal compared to the Central grid, but the air pollutant emissions in the East grid are lower than those in the Central grid. This is because around $76 \%$ of coal demand in the East grid is consumed by the power sector, which has installed effective pollution control technologies. Similarly, the power sector accounts for a higher share of coal consumption in the Northwest grid, thereby resulting in lower air pollutant emissions, compared to the Southern grid. Many scenario-based studies (Cui et al., 2019; Tong et al., 2018b; Yue et al., 2018) indicate that China's environmental burdens are expected to mount in the future if industrial energy demand continues to grow and new coal power projects are scheduled to come online. Minimizing industrial energy demand by efficiency improvements to accelerate 
coal power plant phase-out is perhaps the single most important strategy for the world, as well as China to address climate change and air pollution simultaneously.

\section{I.4. Energy efficiency and electricity savings}

Energy efficiency means getting more output or service per unit of energy input. For example, a light-emitting diode bulb consumes up to $90 \%$ less electricity than a traditional incandescent bulb when producing a similar brightness (U.S. Department of Energy, 2008). The International Energy Agency believes that energy efficiency is the "first fuel" for reshaping energy systems across the world (IEA, 2019b). This is largely because energy efficiency can provide potential capacity at a much lower cost than expanding energy supply. The change of energy intensity, which means the amount of energy needed per unit of product output or economic output (e.g. GDP), can reflect the improvement levels of energy efficiency by production process or aggregated economic activities.

China has integrated the energy intensity targets into the national development framework (State Council of China, 2016) and made great efforts to improve energy efficiency across economic activities (National Development and Reform Commission of China, 2017). The primary energy intensity fell by 63\% between 1990 and 2017, mainly driven by energy efficiency policies focused on industries, e.g. iron \& steel, chemicals, aluminium, pulp \& paper and cement sector (see Figure 1.15a). The annual improvement rates of primary energy intensity varied among industrial products during 1990-2017, with a range of $1.5 \%$ to $4.0 \%$. After 2010 , the pace of improvements in primary energy intensity is slowing, particularly because of the increased share of energyintensive industrial production and insufficient policy strength (IEA, 2019b). Compared to the national primary energy intensity, the country's electricity use efficiency improved much lower, only dropped by $15 \%$ in the past three decades. The annual improvement rates of electricity use efficiency are $0.9 \%$ at the national level and $3.7 \%$ for industry from 1990 to 2017. Although electricity use efficiency in China's industry has been greatly improved, the industrial electricity intensity $(0.98 \mathrm{kWh} / \$)$ is much higher than that of the United States $(0.24 \mathrm{kWh} / \$)$ and the European Union $(0.28 \mathrm{kWh} / \$)$ in 2017. This demonstrates that China's industry still has enormous opportunities for efficient use of electricity, which potentially can reduce the coal-intensive electricity supply capacity. 


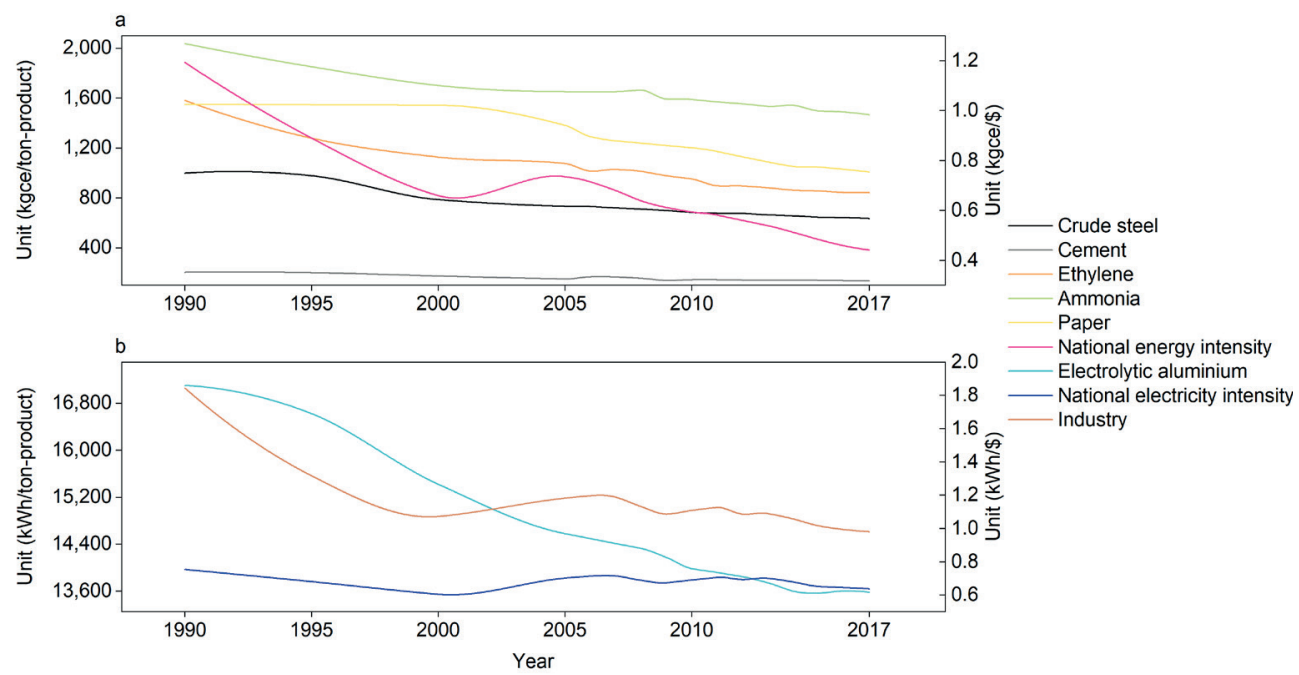

Figure 1.15. Primary energy intensity (a) and electricity intensity (b) by process and economy in China during 19902017.

Source: Calculated from China Energy Statistical Yearbook (National Bureau of Statistics of China, 2019a) and the World Bank (2020a).

As energy efficiency continues to gain attention as a key resource for economic and social development across all economies, understanding its real value is increasingly important. This is becoming more urgent for emerging economies and developing countries (Nemet et al., 2010) as they seek to optimize their resource base to reduce poverty and support sustainable growth. Previous studies, adopting aggregated exogenous parameters (e.g. production elasticity coefficient and labor index), made useful attempts to identify the potentials of energy efficiency improvement in China, with a focus on the industry. For example, Shi et al. (2010) assessed the maximum room for industrial efficiency improvements across China's regions by applying a popular top-down model, i.e. data envelopment analysis. Xiao et al. (2017) examined the electricity consumption performance by industrial subsector across all China's regions via employing inputoutput framework, and the results point out that chemical and metal smelting industries have great efficiency improvement potentials. Furthermore, the logarithmic mean Divisia index method is widely used by energy scholars to investigate the driving factors impacting the growth of energy consumption and provide valuable insights in understanding the energy savings of various sectors (Wang et al., 2014; Liu et al., 2018; $\mathrm{Ma}$ et al., 2017). However, most of these studies are limited to macro-economic analysis on a country or sector level and fail to capture the available potentials of energy savings at technology level.

Actions to improve energy efficiency are frequently portrayed as the lowest-cost strategies available because the reduced energy bills can recover capital investments (National 
Action Plan for Energy Efficiency, 2008). A growing body of evidence (U.S. EPA, 2015; Summerbell et al., 2017) shows that energy efficiency improvements can deliver substantial value through a broad range of economic and social impacts beyond the traditional focus on energy demand reduction. These impacts are also called co-benefits or multiple benefits, such as enhancing the sustainability of the energy system, avoiding multiple detrimental air emissions, reducing air pollution-related health impacts, and raising living standards. These high-value benefits have attracted much attention from both researchers and policymakers. (Zhang et al., 2015; Zhang et al., 2016) analyzed the potentials of energy savings in China's cement sector and associated benefits of reducing air pollutant emissions, further quantifying the avoided early deaths due to the improved air quality. The results showed that a total of 37 commercially available efficiency technologies can decrease around $25 \%, 20 \%$ and $4 \%$ of $\mathrm{SO}_{2}, \mathrm{NO}_{\mathrm{x}}$ and $\mathrm{PM}_{2.5}$ emissions by 2030 , thereby avoided annual 10,000 premature deaths. Hasanbeigi et al. (2013) quantified the relationship between efficiency improvements and $\mathrm{CO}_{2}$ emissions, taking China's iron $\&$ steel sector as a case. These studies, using a bottom-up or integrated model, outlined a cost-effective path for mining energy saving potentials and promoting environmental goals in a single-element industry (e.g. cement, steel and aluminium). Several studies extended the scope to the sectors with complex production systems such as the chemical industry (Talaei et al., 2019). Current research is confined to a specific industrial consumer and concerned on a single benefit (e.g. $\mathrm{CO}_{2}$ or air pollutant emission reductions). Nevertheless, there is a lack of comprehensive studies assessing the technology-driven potentials of electricity savings across China's industries and its impacts on taking coal power plants off the grid network, thereby generating benefits on cleaning the air and mitigating climate change.

China promoted proactively the implementation of energy efficiency measures across industrial processes (National Development and Reform Commission of China, 2019), but the synergies due to demand-side electricity savings have rarely been incorporated into the assessment of national sustainable development policies, nor in power system planning or air pollutant emissions management. A major barrier to the integration of electricity and air quality planning is the difficulty in fully quantifying the potential mutual benefits existing for both end-users and electricity generators. This thesis models the connections between the largest electricity user (industry) and the largest energy infrastructure (power sector) in terms of electricity savings, air emission changes (i.e. GHGs and air pollutants), and associating abatement costs. It provides a comprehensive understanding of the pivotal role of industrial energy efficiency improvements, which is critical for China to achieve a more sustainable industry and moving towards a coalfree electricity supply system. Quantifying the multiple benefits also promotes the penetration of high-efficiency technologies and allows investors to adopt the most costeffective technologies. 


\section{I.5. Framework of research objective}

Three key knowledge gaps are relevant in this thesis: 1) How much electricity can saved in China's industries and what is the role that electricity plays in the total final energy use; 2) what is the potential impact of industrial electricity savings on the evolution of electricity supply systems among different power grids; and 3) what is the relationship between electricity use, energy efficiency investments, GHG and air pollution emissions, on various spatial scales.

Given the identified knowledge gaps, the objective of this thesis is to conduct an indepth analysis of electricity saving potentials and cost-benefits of emission mitigation due to scaling up energy efficiency in industries. Our research targets industrial electric efficiency improvements in China, where electricity supply heavily depends on a coalfired power plant fleet and faces multiple challenges to a sustainable future. To meet the research purpose, the following five sub-goals are established:

1. Comparing electricity use projections and electricity saving potentials for China's industry in different studies to provide an overview of efficiency improvement opportunities and identify sectors with the highest potential for electricity savings.

2. Understanding the modeling parameters and approaches that affect the studied results across different scenarios.

3. Measuring the multiple benefits of electricity savings in industrial sub sectors, in terms of GHG and air pollution emission reductions at a power grid level.

4. Quantifying the potential impacts of reduced electricity load from industry on the phaseout of high-polluting coal power units, air emission changes from the power sector, and air pollutant control costs.

5. A comprehensive assessment of the mutual benefits of industrial electricity savings, coal power removal, emission reductions and related investment optimization across provincial and grid level.

These research to meet the sub-goals are described in Chapters 2 to 5 (see Table 1.1). In Chapter 2, a review of selected studies on industrial electricity savings potentials is carried out to provide insights in the most contributing subsectors and important energy efficiency measures. This section describes the characteristics of the modeling method, scenario indicators and system boundaries that affect the studied results, thereby guiding the modeling framework and research scope of the following chapters. Subsequently, Chapter 3 develops electricity conservation supply curves per power grid to evaluate the multiple benefits of electricity savings and emission reductions of GHGs (i.e. $\mathrm{CO}_{2}$, 
$\mathrm{CH}_{4}$ and $\mathrm{N}_{2} \mathrm{O}$ ) and air pollutants (i.e. $\mathrm{SO}_{2}, \mathrm{NO}_{\mathrm{x}}$ and $\mathrm{PM}_{2.5}$ ) in China's chemical sector. This is a complex production industry, covering upstream and downstream products (e.g. ammonia, caustic soda and polyvinyl chloride). Chapter 3 identifies key electricity saving opportunities for the chemical industry and contributes to building an exhaustive compilation of industrial energy efficiency measures that are further applied in Chapter 4 and Chapter 5. A comprehensive power plant database for China that includes all commissioned units and those under construction in 2016 (a total of 10,159 generation units) is developed in Chapters 4-5. Chapter 4 conducts a unit-by-unit assessment of the most polluting power plant phaseout due to the reduced electricity load from China's industry. It further evaluates air pollutant reductions benefiting from the displaced power generation units, and compares the air pollution control costs of demand-side efficiency improvements and end-of-pipe treatment measures. Finally, a multi-sectoral and multiregional framework is developed in Chapter 5, aiming to provide a more comprehensive understanding of the pivotal role of industrial energy efficiency improvements in comanaging electricity savings and emission mitigation.

Table 1.1. Overview of the thesis chapters and their corresponding research sub-goals.

\begin{tabular}{|c|c|c|c|c|c|c|}
\hline Chapter & Topic & \multicolumn{5}{|c|}{ Research sub-goal } \\
\hline & & 1 & 2 & 3 & 4 & 5 \\
\hline 2 & $\begin{array}{l}\text { Saving electricity in China's industry: A review of opportunities, potentials, } \\
\text { and environmental benefits }\end{array}$ & $\mathrm{X}$ & $\mathrm{X}$ & & & \\
\hline 3 & $\begin{array}{l}\text { Modeling the multiple benefits of electricity savings for emissions } \\
\text { reduction on power grid level: A case study of China's chemical industry }\end{array}$ & & & $\mathrm{X}$ & & \\
\hline 4 & $\begin{array}{l}\text { Air emissions and energy efficiency: realizing multiple benefits for power } \\
\text { sector by saving industrial electricity use in China }\end{array}$ & & & & $\mathrm{X}$ & \\
\hline 5 & $\begin{array}{l}\text { Modeling linkages between the industry and power sector to co-manage } \\
\text { regional electricity savings and air pollution - A case study of China }\end{array}$ & & & & $\mathrm{X}$ & $\mathrm{X}$ \\
\hline
\end{tabular}

\section{I.6. Thesis outline}

Chapter 2 addresses the sub-goals 1 and 2 by a thorough and comprehensive reviewbased analysis of electricity saving potentials in China's industry with details for six electricity-intensive subsectors, i.e. iron \& steel, cement, non-ferrous metals, pulp \& paper, textile and chemicals. China's industry is the world's largest electricity consumer, representing $16 \%$ of the world's electricity use. While the six electricity-intensive subsectors together account for more than $50 \%$ of China's industrial consumption. The available studies that include electricity performance information are further classified into six industrial subsectors to facilitate the evaluation of electricity savings and emission reductions per subsector. This systematic review reveals that a substantial room of electricity savings still lies in China's industry, and identifies the sectors with top electricity savings within the industry. Furthermore, the opportunities to improve 
electricity use efficiency and reduce electricity-derived emissions for each subsector are discussed. However, electricity consumption and savings per sector vary quite strongly in the modeling results among reviewed studies. The modeling factors that affect the results are explored from five aspects, i.e. system boundary, modeling approach, social and economic indicators, technology representation and data sources. Coupling the reviewed analysis and discussion, policy recommendations and future research directions are drawn in the chapter.

Chapter 3 addresses goal 3 by quantifying the multiple benefits of actions to improve electricity use efficiency in China's chemical industry via a bottom-up model. China represents around $1 / 3$ of the global demand for chemicals, being the largest chemical market worldwide. Meanwhile, the enormous output of chemicals causes surging electricity consumption and mounting emissions of GHGs and air pollutants over the past two decades. A comprehensive overview of China's chemical industry in terms of historical output of products and electricity consumption is provided at first. This allows determining the research boundary and provides insights into key energy efficiency choices in the next step. Electricity conservation supply curves are constructed to capture electricity savings and emission reductions from a total of 60 energy efficiency technologies across six power grids in the period up to 2035. Furthermore, a cost analysis of efficiency improvements at power grid level is conducted to present how the share of co-benefits that can be obtained cost-effectively. Policy suggestions on energy efficiency integration and emission burden allocation are proposed for national and local decisionmakers, respectively.

Chapter 4 addresses sub-goals 4 by providing unit-level information of China's power plant fleets and assessing the impacts of industrial energy efficiency improvements on the evolution of electricity supply system, particularly in regards to scaling down coal-fired generation fleet and associated changes of multiple air emissions $\left(\mathrm{CO}_{2}, \mathrm{SO}_{2}, \mathrm{NO}_{\mathrm{x}}\right.$ and $\mathrm{PM})$. First, two comprehensive databases, i.e. industrial energy efficiency technologies and power plants, are developed. The energy efficiency database covers hundreds of commercially available technologies with detailed technical characterization, that reflect the current knowledge of performance in terms of electricity savings and costs. Detailed information (e.g. geocoordinate, fuel type, capacity size, thermal efficiency, environmental performance) for each power generation unit in service of 2016 is compiled in the power plant database. Next, the two databases, electricity conservation supply curves, combined with the GAINS model (Greenhouse Gas - Air Pollution Interactions and Synergies) are applied to measure the industrial electricity savings and associated impacts on the deployment of power installed capacity and air emission levels from power sector up to 2040 among four scenarios. The resulting air pollutant emission reductions are compared to the alternative of installing flue gas control technologies in terms of investment costs to achieve the same impact. 
Chapter 5 models the linkages between industrial demand-side and electricity supplyside to co-manage the electricity savings and air pollution on various spatial scales, thereby addressing sub-goals 4 and 5. A multi-sectoral and multi-regional framework considering regional characteristics is developed in this chapter to quantify the offset coal-fired power units (prioritizing super-polluting and less-efficient units) by load reduction, and assesses the contributions to air pollutant reductions $\left(\mathrm{SO}_{2}, \mathrm{NO}_{\mathrm{x}}, \mathrm{PM}\right)$ for six electricity grids (covering 31 provinces) across China. The geographic information system (ArcGIS) is incorporated into the modeling framework to map the geographic location of coal-fired power units, emission levels, and potential electricity savings at a provincial and grid level for a better understanding of the regional variation. Cost analyses for different abatement portfolios are conducted per grid to identify the most cost-effective way to tackle air pollution. Besides contributing to air quality, the carbon emission reductions delivered by the closed coal power capacity due to the industrial electricity savings are discussed in Chapter 5.

Chapter 6 provides a summary of the main findings of Chapters 2-5 to answer the research questions of this thesis, and recommendations for future research are given. 


\section{References}

Abel, D.W., Holloway, T., Martínez-Santos, J., Harkey, M., Tao, M., Kubes, C., Hayes, S., 2019. Air quality-related health benefits of energy efficiency in the United States. Environmental science \& technology, 53, 3987-3998.

Balakrishnan, K., Dey, S., Gupta, T., Dhaliwal, R.S., Brauer, M., Cohen, A.J., et al., 2019. The impact of air pollution on deaths, disease burden, and life expectancy across the states of India: the Global Burden of Disease Study 2017. The Lancet Planetary Health, 3, e26-e39.

Bollen, J., Brink, C., 2014. Air pollution policy in Europe: Quantifying the interaction with greenhouse gases and climate change policies. Energy Economics, 46, 202-215.

Burnett, R., Chen, H., Szyszkowicz, M., Fann, N., Hubbell, B., Pope, C.A., et al., 2018. Global estimates of mortality associated with long-term exposure to outdoor fine particulate matter. Proceedings of the National Academy of Sciences, 115, 9592-9597.

China Electric Power Yearbook, 2018. China electric power yearbook. China Electric Power Press, Beijing (China).

China Electricity Council, 2019. Annual development report of China's power sector 2019. China Market Press, Beijing (China).

China National Renewable Energy Centre, 2019. China renewable energy outlook 2019. Energy Research Institute of China, Beijing (China). URL: http://boostre.cnrec.org.cn/index. php/2019/12/12/creo2019/?lang=en (accessed 01 August 2020).

Climate Action Tracker, 2019. GHG emission assessments by country. URL: https:// climateactiontracker.org/countries/china/ (accessed 01 August 2020).

Cui, R.Y., Hultman, N., Edwards, M.R., He, L., Sen, A., Surana, K., McJeon, H., Iyer, G., Patel, P., Yu, S., Nace, T., Shearer, C., 2019. Quantifying operational lifetimes for coal power plants under the Paris goals. Nature Communications. 10, 1-9.

Europe Beyond Coal, 2020. Overview: National coal phase-out announcements in Europe. Berlin (Germany). URL: https://beyond-coal.eu/wp-content/ uploads/2020/07/Overview_of_national_coal_phase-out_announcements.pdf (accessed 01 August 2020).

Farfan, J., Breyer, C., 2017. Structural changes of global power generation capacity towards sustainability and the risk of stranded investments supported by a sustainability indicator. Journal of Cleaner Production, 141, 370-384. 
GBD MAPS Working Group, 2016. Burden of disease attributable to coal-burning and other major sources of air pollution in China. Health Effects Institute, Boston (USA). URL: https://www.healtheffects.org/publication/burden-disease-attributable-coal-burning-andother-air-pollution-sources-china (accessed 01 August 2020).

Global Carbon Project, 2019. Supplemental data of Global Carbon Budget 2019 (Version 1.0). Integrated Carbon Observation System, Helsinki (Finland). URL: https://doi.org/10.18160/ gcp-2018 (accessed 01 August 2020).

Global CCS Institute, 2019. The global status of CCS 2019. Global Carbon Capture and Storage Institute, Melbourne (Australia). URL: https://www.globalccsinstitute.com/wpcontent/uploads/2019/12/GCC_GLOBAL_STATUS_REPORT_2019.pdf (accessed 01 August 2020).

Global Energy Monitor, 2019. Database of worldwide coal-fired power stations. URL: https:// globalenergymonitor.org/coal/ (accessed 01 August 2020).

Graus, W., Worrell, E., 2007. Effects of $\mathrm{SO}_{2}$ and $\mathrm{NO}_{x}$ control on energy-efficiency power generation. Energy Policy, 35, 3898-3908.

Grubler, A., Wilson, C., Bento, N., Boza-Kiss, B., Krey, V., McCollum, D.L., Rao, N.D., Riahi, K., Rogelj, J., De Stercke, S., Cullen, J., Frank, S., Fricko, O., Guo, F., Gidden, M., Havlík, P., Huppmann, D., Kiesewetter, G., Rafaj, P., Schoepp, W., Valin, H., 2018. A low energy demand scenario for meeting the $1.5^{\circ} \mathrm{C}$ target and sustainable development goals without negative emission technologies. Nature Energy, 3, 515-527.

Gu, Y., Wong, T.W., Law, C.K., Dong, G.H., Ho, K.F., Yang, Y., Yim, S.H.L., 2018. Impacts of sectoral emissions in China and the implications: air quality, public health, crop production, and economic costs. Environmental Research Letters, 13, 084008.

Hasanbeigi, A., Morrow, W., Sathaye, J., Masanet, E., Xu, T., 2013. A bottom-up model to estimate the energy efficiency improvement and $\mathrm{CO} 2$ emission reduction potentials in the Chinese iron and steel industry. Energy, 50, 315-325.

Hu, J., Harmsen, R., Crijns-Graus, W., Worrell, E., 2019. Geographical optimization of variable renewable energy capacity in China using modern portfolio theory. Applied Energy, 253, 113614.

IAI, 2020. Primary aluminium production 2020. International Aluminium Institute (IAI), London (UK). URL: http://www.world-aluminium.org/statistics/ (accessed 01 August 2020). 
IEA,2020.CO2emissionsstatistics.InternationalEnergyAgency(IEA), Paris(France).URL:https://www. iea.org/data-and-statistics? country=WORLD\&fuel=CO2\%20emissions\&indicator=CO2\%20 emissions\%20by\%20energy\%20source (accessed 01 August 2020).

IEA, 2019a. CO2 emissions from fuel combustion 2019. International Energy Agency (IEA), Paris (France).

IEA, 2019b. Energy efficiency 2019. International Energy Agency (IEA), Paris (France). URL: https://webstore.iea.org/download/direct/2891 (accessed 01 August 2020).

IEA, 2019c. World energy outlook 2019. International Energy Agency (IEA), Paris (France).

IEA, 2018a. World energy balances (2018 edition). International Energy Agency (IEA), Paris (France).

IEA, 2018b. World energy outlook 2018. International Energy Agency (IEA), Paris (France).

IEA, 2017. Energy access outlook 2017. International Energy Agency (IEA), Paris (France). URL: https://webstore.iea.org/download/direct/274 (accessed 01 August 2020).

IEA, 2012. Technology roadmap: High-Efficiency, low-emissions coal-fired power generation. International Energy Agency (IEA), Paris (France). URL: https:/www.iea.org/reports/ technology-roadmap-high-efficiency-low-emissions-coal-fired-power-generation (accessed 01 August 2020).

IEA (International Energy Agency), IRENA (International Renewable Energy Agency), UNSD (United Nations Statistics Division), WB (World Bank), WHO (World Health Organization), 2019. Tracking SDG 7: The energy progress report 2019. Washington (USA). URL: https:// www.irena.org/publications/2019/May/Tracking-SDG7-The-Energy-Progress-Report-2019 (accessed 01 August 2020).

Institute for Health Metrics and Evaluation, 2019. Global health data exchange. Seattle (USA). URL: http://ghdx.healthdata.org/gbd-results-tool (accessed 01 August 2020).

International Labour Organization, 2020. Employment distribution by economic activity. URL: https://ilostat.ilo.org/data/ (accessed 01 August 2020).

IPCC, 2018. Global warming of $1.5^{\circ} \mathrm{C}$ : An IPCC Special Report on the impacts of global warming of $1.5^{\circ} \mathrm{C}$ above pre-industrial levels and related global greenhouse gas emission pathways, in the context of strengthening the global response to the threat of climate change, sustainable development, and efforts to eradicate poverty. Intergovernmental Panel on Climate Change (IPCC), Geneva. URL: https://www.ipcc.ch/sr15/ (accessed 01 August 2020). 
Jacobson, M.Z., 2019. The health and climate impacts of carbon capture and direct air capture. Energy \& Environmental Science, 12, 3567-3574.

Kanellopoulos, K., 2018. Scenario analysis of accelerated coal phase-out by 2030: A study on the European power system based on the EUCO27 scenario using the METIS model.

Khanna, N., Fridley, D., Zhou, N., Karali, N., Zhang, J., Feng, W., 2019. Energy and $\mathrm{CO}_{2}$ implications of decarbonization strategies for China beyond efficiency: Modeling 2050 maximum renewable resources and accelerated electrification impacts. Applied Energy, 242, 12-26.

Koplitz, S.N., Jacob, D.J., Sulprizio, M.P., Myllyvirta, L., Reid, C., 2017. Burden of disease from rising coal-fired power plant emissions in Southeast Asia. Environmental science \& technology, 51, 1467-1476.

Lelieveld, J., Evans, J.S., Fnais, M., Giannadaki, D., Pozzer, A., 2015. The contribution of outdoor air pollution sources to premature mortality on a global scale. Nature, 525, 367.

Li, M., Zhang, Q., Kurokawa, J., Woo, J., He, K., Lu, Z., Ohara, T., Song, Y., Streets, D.G., Carmichael, G.R., Cheng, Y., Hong, C., Huo, H., Jiang, X., Kang, S., Liu, F., Su, H., Zheng, B., 2017. MIX: a mosaic Asian anthropogenic emission inventory under the international collaboration framework of the MICS-Asia and HTAP. Atmospheric Chemistry and Physics (Online), 17.

Liu, J., Zhang, S., Wagner, F., 2018. Exploring the driving forces of energy consumption and environmental pollution in China's cement industry at the provincial level. Journal of Cleaner Production, 184, 274-285.

Liu, X., Yuan, Z., Xu, Y., Jiang, S., 2017. Greening cement in China: A cost-effective roadmap. Applied Energy, 189, 233-244.

Ma, M., Yan, R., Du, Y., Ma, X., Cai, W., Xu, P., 2017. A methodology to assess China's building energy savings at the national level: an IPAT-LMDI model approach. Journal of Cleaner Production, 143, 784-793.

Ministry of Ecology and Environment of China, 2020. Report on the State of the Ecology and Environment in China 2019. URL: http://english.mee.gov.cn/Resources/Reports/ (accessed 01 August 2020).

Ministry of Ecology and Environment of China, 2018. Baseline emission factors of China's regional power grids 2017. URL: http://www.mee.gov.cn/ywgz/ydqhbh/wsqtkz/201812/ P020181220579925103092.pdf (accessed 01 August 2020). 
National Action Plan for Energy Efficiency, 2008. Understanding cost-effectiveness of energy efficiency programs: Best practices, technical methods, and emerging issues for policymakers. Energy and Environmental Economics, Inc. and Regulatory Assistance Project, Washington (USA). URL: https:/www.epa.gov/sites/production/files/2015-08/documents/ cost-effectiveness.pdf (accessed 01 August 2020).

National Bureau of Statistics of China, 2019a. China energy statistical yearbook 2018. China Statistics Press, Beijing (China).

National Bureau of Statistics of China, 2019b. China statistical yearbook on environment 2018. China Statistics Press, Beijing (China).

National Development and Reform Commission of China, 2019. National key energy conservation and low carbon technologies promotion catalogue. URL: http://www.mee.gov. cn/ywgz/ydqhbh/wsqtkz/201904/t20190419_700394.shtml (accessed 01 August 2020).

National Development and Reform Commission of China, 2017. National action plan for energy efficiency in 13th Five-Year Plan period. URL: http://www.gov.cn/ xinwen/2017-01/05/5156903/files/ac60f02ad50c403b97146b80ebeab5e6.pdf (accessed 01 August 2020).

National Development and Reform Commission of China, 2016. Guidelines on promoting the use of electricity to replace other energy sources. URL: https:/www.scio.gov.cn/xwfbh/ xwbfbh/wqfbh/39595/41802/xgzc41808/Document/1664893/1664893.htm (accessed 01 August 2020).

National Development and Reform Commission of China, 2015. China’s intended nationally determined contribution: Enhanced actions on climate change. URL: https://www4.unfccc. $\mathrm{int} /$ sites/ndcstaging/PublishedDocuments/China\%20First/China $\% 27 \mathrm{~s} \% 20$ First $\% 20$ NDC\%20Submission.pdf (accessed 01 August 2020).

National Development and Reform Commission of China, 2014. China's national plan on addressing climate change (2014-2020). URL: http://www.scio.gov.cn/xwfbh/xwbfbh/ wqfbh/33978/35364/xgzc35370/Document/1514527/1514527_1.htm (accessed 01 August 2020).

National Development and Reform Commission of China, 2010. China additional information relating to Copenhagen Accord. URL: https://unfccc.int/files/meetings/cop_15/copenhagen_ accord/application/pdf/chinacphaccord.pdf (accessed 01 August 2020). 
National Energy Administration ofChina, 2016. China: 13th Five-Year Plan of energy development (2016-2020). URL: http://www.gov.cn/xinwen/2017-01/05/content_5156795.htm\#1 (accessed 01 August 2020).

Nemet, G.F., Holloway, T., Meier, P., 2010. Implications of incorporating air-quality co-benefits into climate change policymaking. Environmental Research Letters, 5, 014007.

Nerini, F.F., Tomei, J., To, L.S., Bisaga, I., Parikh, P., Black, M., Borrion, A., Spataru, C., Broto, V.C., Anandarajah, G., Milligan, B., Mulugetta, Y., 2018. Mapping synergies and trade-offs between energy and the Sustainable Development Goals. Nature Energy, 3, 10-15.

Oberschelp, C., Pfister, S., Raptis, C.E., Hellweg, S., 2019. Global emission hotspots of coal power generation. Nature Sustainability, 2, 113-121.

OECD, 2016. The economic consequences of outdoor air pollution. Organisation for Economic Co-operation and Development (OECD), Paris (France). URL: https://www.oecd.org/ environment/indicators-modelling-outlooks/Policy-Highlights-Economic-consequences-ofoutdoor-air-pollution-web.pdf (accessed 01 August 2020).

Rao, N.D., Pachauri, S., 2017. Energy access and living standards: some observations on recent trends. Environmental Research Letters, 12, 025011.

S\&P Global Platts, 2018. World electric power plants (WEPP) database v. September 2017. Washington (USA).

Shi, G., Bi, J., Wang, J., 2010. Chinese regional industrial energy efficiency evaluation based on a DEA model of fixing non-energy inputs. Energy Policy, 38, 6172-6179.

Staffell, I., Pfenninger, S., 2018. The increasing impact of weather on electricity supply and demand. Energy, 145, 65-78.

State Council of China, 2016. China: 13th Five-Year Plan of the comprehensive working schemes on energy conservation and emission reduction. URL: http://www.gov.cn/zhengce/ content/2017-01/05/content_5156789.htm (accessed 01 August 2020).

State Council of China, 2013a. Air pollution prevention and control action plan (English version). Clean Air Alliance of China, Beijing (China). URL: http://en.cleanairchina.org/ product/6346.html (accessed 01 August 2020).

State Council of China, 2013b. China: 12th Five-Year Plan of energy development (2011-2015). URL: http://www.gov.cn/zwgk/2013-01/23/content_2318554.htm (accessed 01 August 2020). 
State Council of China, 2012. China: 12th Five-Year Plan of energy conservation and emission reduction (2011-2015). URL: http://www.gov.cn/zwgk/2012-08/21/content_2207867.htm (accessed 01 August 2020).

State Council of China, 2010. Notice of the State Council on further strengthening the elimination of backward production capacities. URL: http://www.gov.cn/zwgk/2010-04/06/ content_1573880.htm (accessed 01 August 2020).

Summerbell, D.L., Khripko, D., Barlow, C., Hesselbach, J., 2017. Cost and carbon reductions from industrial demand-side management: Study of potential savings at a cement plant. Applied Energy, 197, 100-113.

Talaei, A., Pier, D., Iyer, A.V., Ahiduzzaman, M., Kumar, A., 2019. Assessment of long-term energy efficiency improvement and greenhouse gas emissions mitigation options for the cement industry. Energy, 170, 1051-1066.

Tong, D., Zhang, Q., Davis, S.J., Liu, F., Zheng, B., Geng, G., Xue, T., Li, M., Hong, C., Lu, Z., Streets, D.G., Guan, D., He, K., 2018a. Targeted emission reductions from global superpolluting power plant units. Nature Sustainability, 1, 59-68.

Tong, D., Zhang, Q., Liu, F., Geng, G., Zheng, Y., Xue, T., Hong, C., Wu, R., Qin, Y., Zhao, H., Yan, L., He, K., 2018b. Current Emissions and Future Mitigation Pathways of CoalFired Power Plants in China from 2010 to 2030. Environmental science \& technology, 52, $12905-12914$.

Tong, D., Zhang, Q., Zheng, Y., Caldeira, K., Shearer, C., Hong, C., Qin, Y., Davis, S.J., 2019. Committed emissions from existing energy infrastructure jeopardize $1.5 \mathrm{C}$ climate target. Nature, 572, 373-377.

U.S. Department of Energy, 2008. Energy savings estimates of light emitting diodes in niche lighting applications. Washington (USA). URL: https://www.energy.gov/sites/prod/ files/maprod/documents/Energy_Savings_Light_Emitting_Diodes_Niche_Lighting_Apps. pdf (accessed 01 August 2020).

U.S. EIA, 2019. More U.S. coal-fired power plants are decommissioning as retirements continue. Energy Information Administration (EIA), Washington (USA). URL: https://www.eia.gov/ todayinenergy/detail.php?id=40212 (accessed 01 August 2020).

U.S. EPA, 2015. Demand-side energy efficiency technical support document. Environmental Protection Agency (EPA), Washington (USA). URL: https://19january2017snapshot.epa. gov/sites/production/files/2015-11/documents/tsd-cpp-demand-side-ee.pdf (accessed 01 August 2020). 
U.S. EPA, 2013. Clean air act text. Environmental Protection Agency (EPA), Washington (USA). URL: https://www.epa.gov/clean-air-act-overview/clean-air-act-text (accessed 01 August 2020).

U.S. Geological Survey, 2020a. Cement statistics and information 2020. Reston (USA). URL: https://pubs.usgs.gov/periodicals/mcs2020/mcs2020-cement.pdf (accessed 01 August 2020).

U.S. Geological Survey, 2020b. Nitrogen statistics and information 2020. Reston (USA). URL: https://pubs.usgs.gov/periodicals/mcs2020/mcs2020-nitrogen.pdf (accessed 01 August 2020).

United Nations, 2019a. World urbanization prospects: The 2018 revision. New York. URL: https://population.un.org/wup/ (accessed 01 August 2020).

United Nations, 2019b. World population prospects 2019: Highlights. New York. URL: https:// population.un.org/wpp/Publications/Files/WPP2019_Highlights.pdf (accessed 01 August 2020).

United Nations, 2015. Transforming our world: The 2030 Agenda for Sustainable Development. New York. URL: https://sustainabledevelopment.un.org/post2015/ transformingourworld/publication (accessed 01 August 2020).

Wang, P., Wei, Y., Yang, B., Li, J., Kang, J., Liu, L., Yu, B., Hou, Y., Zhang, X., 2020. Carbon capture and storage in China's power sector: Optimal planning under the $2{ }^{\circ} \mathrm{C}$ constraint. Applied Energy, 263, 114694.

Wang, W., Liu, X., Zhang, M., Song, X., 2014. Using a new generalized LMDI (logarithmic mean Divisia index) method to analyze China’s energy consumption. Energy, 67, 617-622.

Wen, Z., Wang, Y., Zhang, C., Zhang, X., 2018. Uncertainty analysis of industrial energy conservation management in China's iron and steel industry. Journal of environmental management, 225, 205-214.

WHO, 2020. World health statistics 2020: monitoring health for the SDGs, sustainable development goals. World Health Organization (WHO), Geneva. URL: https://apps.who. int/iris/bitstream/handle/10665/332070/9789240005105-eng.pdf (accessed 01 August 2020).

WHO, 2016. Ambient air pollution database. World Health Organization (WHO), Geneva. URL: https://www.who.int/gho/phe/outdoor_air_pollution/exposure/en/ (accessed 01 August 2020). 
World Bank, 2020a. Industry value added (constant 2010 US\$). URL: https://data.worldbank. org/indicator/NV.IND.TOTL.KD (accessed 01 August 2020).

World Bank, 2020b. Real GDP. URL: https://data.worldbank.org/indicator/NY.GDP.MKTP. KD (accessed 01 August 2020).

World Bank, 2016. The cost of air pollution: Strengthening the economic case for action. World Bank Group, Washington (USA). URL: https://openknowledge.worldbank.org/bitstream/ handle/10986/25013/108141.pdf?sequence=4\&isAllowed=y (accessed 01 August 2020).

WSA, 2019. Steel statistical yearbook 2019. World Steel Association (WSA), Brussels (Belgium). URL: https://www.worldsteel.org/steel-by-topic/statistics/steel-statistical-yearbook.html (accessed 01 August 2020).

Xiao, H., Li, S., Chevallier, J., Zhu, B., 2017. Electricity-savings pressure and electricity-savings potential among China’s inter-provincial manufacturing sectors. Energy Systems, 8, 581600 .

Yang, H., Zhang, Y., Zheng, C., Wu, X., Chen, L., Fu, J.S., Gao, X., 2018. Cost estimate of the multi-pollutant abatement in coal-fired power sector in China. Energy, 161, 523-535.

Yue, H., Worrell, E., Crijns-Graus, W., 2018. Modeling the multiple benefits of electricity savings for emissions reduction on power grid level: A case study of China's chemical industry. Applied Energy, 230, 1603-1632.

Zhang, Q., Xu, J., Wang, Y., Hasanbeigi, A., Zhang, W., Lu, H., Arens, M., 2018. Comprehensive assessment of energy conservation and CO 2 emissions mitigation in China's iron and steel industry based on dynamic material flows. Applied Energy, 209, 251-265.

Zhang, S., Worrell, E., Crijns-Graus, W., 2015. Evaluating co-benefits of energy efficiency and air pollution abatement in China’s cement industry. Applied Energy, 147, 192-213.

Zhang, S., Worrell, E., Crijns-Graus, W., Krol, M., de Bruine, M., Geng, G., Wagner, F., Cofala, J., 2016. Modeling energy efficiency to improve air quality and health effects of China's cement industry. Applied Energy, 184, 574-593.

Zhou, N., Fridley, D., Khanna, N.Z., Ke, J., McNeil, M., Levine, M., 2013. China’s energy and emissions outlook to 2050: Perspectives from bottom-up energy end-use model. Energy Policy, 53, 51-62.

Zhou, W., Jiang, D., Chen, D., Griffy-Brown, C., Jin, Y., Zhu, B., 2016. Capturing $\mathrm{CO}_{2}$ from cement plants: A priority for reducing CO2 emissions in China. Energy, 106, 464-474. 
General introduction 


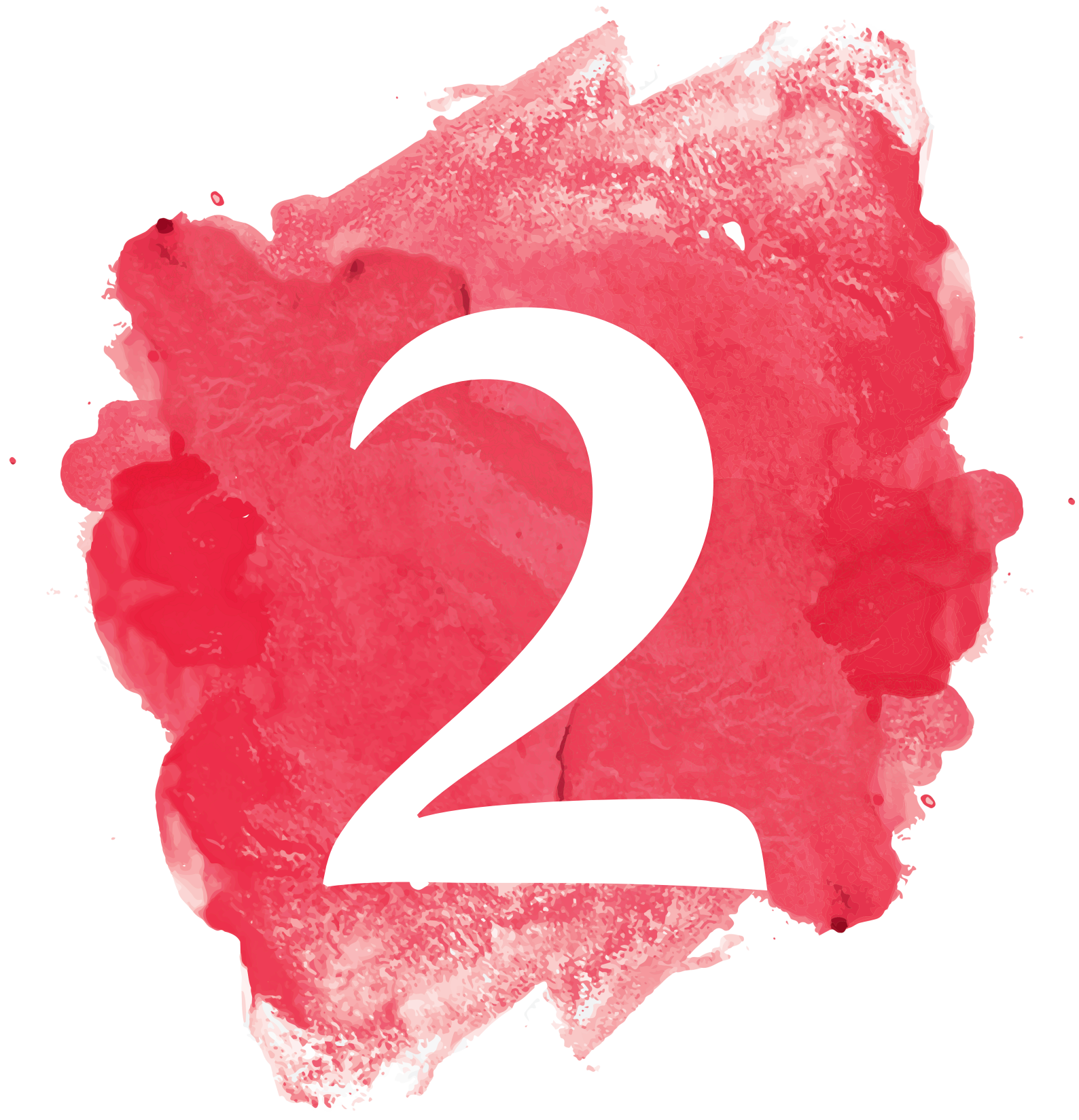




\section{Chapter 2}

\section{Saving energy in China's industry}

with a focus on electricity: A review of opportunities, potentials, and environmental benefits

Hui Yue, Ernst Worrell, Wina Crijns-Graus, Wen Liu, Shaohui Zhang 


\begin{abstract}
Industry is the largest electricity consuming sector in the world. China consumes about $25 \%$ of global electricity demand and $69 \%$ of this is used in industries. The high electricity demand in industry is responsible for $45 \%$ of $\mathrm{CO}_{2}, 25 \%$ of $\mathrm{SO}_{2}, 34 \%$ of $\mathrm{NO}_{x}$ and $14 \%$ of PM-emissions in China. This study aims to fill the knowledge gap on the potential for electricity savings in China's industries, thereby providing important implications for the potential of reducing emissions in electricity-intensive industrial subsectors in general. Available studies are reviewed and compared to identify electricity-saving potentials. The findings show that China's industrial energy system is shifting to higher electricity and relatively lower fossil fuel use due to accelerated enduse electrification. China's industry can reduce total electricity use by $7-24 \%$ in 2040 , and generate emission reductions of 192-1118 $\mathrm{Mt}_{-} \mathrm{CO}_{2}, 385-2241 \mathrm{kt}-\mathrm{SO}_{2}, 406-2362$ $\mathrm{kt}-\mathrm{NO}_{\mathrm{x}}$ and $92-534 \mathrm{kt}-\mathrm{PM}_{2.5}$. The iron \& steel subsector has the largest contribution to the industrial electricity savings, followed by non-ferrous metals, chemicals, cement and pulp \& paper. Policies that combine environmental targets, demand-side efficiency and supply-side retrofits in the power sector should be adopted. Given the different performance of policies in terms of energy savings and emissions reduction, sector- and region-specific policies would be preferred.
\end{abstract}




\section{I. Introduction}

Since 1990, global electricity demand has more than doubled (from 9,700 TWh in 1990 to $20,900 \mathrm{TWh}$ in 2016 ), with a growth rate of $3.4 \%$ per year (IEA, 2018). In 2016 , $38 \%$ of global electricity use was generated by coal, $23 \%$ by natural gas, $17 \%$ by hydro, $10 \%$ by nuclear, $8 \%$ by renewables and the remaining $4 \%$ by oil (IEA, 2018). The high share of fossil fuels makes the power sector one of the largest sources of greenhouse gases (GHGs) and air pollutants. In 2016, $41 \%$ of $\mathrm{CO}_{2}$ emissions, and $36 \%$ of $\mathrm{SO}_{2}$ emissions, $15 \%$ of $\mathrm{NO}_{\mathrm{x}}$ emissions, $6 \%$ of $\mathrm{PM}_{2.5}$ emissions around the world are produced by electricity generation (IEA, 2016b). It is expected that global power consumption will keep growing over the next decades due to the acceleration of industrialization and electrification in developing economies. As a major source of GHG emissions, many countries are making great efforts to decarbonize their power supply. Besides climate change, health impacts of air pollution are of great attention. An estimate by the World Health Organization shows that 4.2 million premature deaths globally are attributable to air pollution in 2016 (WHO, 2018). Improving energy efficiency in end-use sectors would therefore generate multiple benefits, by reducing both types of emissions, as well as limiting the needs for investments in new power capacities and grid extensions.

Industrial processes are responsible for $42 \%$ of global electricity demand in 2016 (IEA, 2018). This makes the industry sector an attractive target for reducing emissions through the efficient use of electricity. This study focuses on electricity conservation in industrial sectors by performing an in-depth review of available literature on the most consuming subsectors and key energy-saving technologies, taking the largest electricity consumer, China, as case. China consumes $25 \%$ of global electricity demand, which is double the total consumption of the European Union, and 69\% of the national electricity consumption is used by the industrial sector, in 2016 (see Figure 2.1) (IEA, 2018; NBS, 2017). As a large manufacturing country of energy-intensive products, China also leads the electricity consumption at subsector level (followed by the U.S., Russia, India, respectively), accounting for around $50 \%$ of global electricity consumption per industrial subsector (see Figure 2.1). The high electricity demand increases air pollutants from the power sector in China, for example, around $27.2 \%$ of $\mathrm{SO}_{2}$ emission, $26.9 \%$ of $\mathrm{NO}_{\mathrm{x}}$ emission and $14.8 \%$ of PM are caused by power generation (NBS and MEP, 2018). Annually more than 1 million people die prematurely in China as a result of exposure to high concentrations of PM, of which power generation is estimated to contribute to $39 \%$ of mortality (Gao et al., 2018). While the annual concentration of $\mathrm{PM}_{2.5}$ and $\mathrm{PM}_{10}$ decreased by $5.4 \%$ and $1.9 \%$ in 2017 (Huang et al., 2018), respectively, compared to 2016 levels, concentrations are still higher than the Chinese national level II targets $\left(\mathrm{PM}_{2.5}\right.$ of $35 \mu \mathrm{g} / \mathrm{m}^{3}$ and $\mathrm{PM}_{10}$ of $70 \mu \mathrm{g} / \mathrm{m}^{3}$ ) (MEP and AQSIQ, 2016), stressing the need for future emission reductions. The high electricity demand delivered by a coaldominated power generation sector, and its contribution to poor air quality require integrated approaches to help improve air quality. The Chinese government is taking 
serious efforts to control emissions of air pollutants by requiring more strict emissions standards for energy-intensive sectors (e.g. cement, chemical, and iron \& steel) (MEP and AQSIQ, 2019), retiring small coal-fired power units (NDRC, 2019), and limiting energy consumption per unit product (e.g. primary aluminium and crude steel) (MIIT, 2017a). Furthermore, China is also under huge pressure to reduce GHG emissions, and has committed to cutting its carbon intensity by 60 to $65 \%$ by 2030 from a 2005 baseline, peaking GHG emissions by 2030 . About $45 \%$ of $\mathrm{CO}_{2}$ emissions from China's industrial sector can be attributed to electricity consumption, reaching $2690 \mathrm{Mt}-\mathrm{CO}_{2 \mathrm{eq}}$ in 2015 (CEADs, 2017). Promoting electricity conservation is an effective way to both reduce overall emissions of GHG and air pollutants from coal-fired power generation, offering synergies for electricity intensity, air quality (Yue et al., 2018), climate change (IRENA, 2017) and health effects from ambient air pollution (Abel et al., 2019), as well as economic benefits (U.S. EPA, 2015).

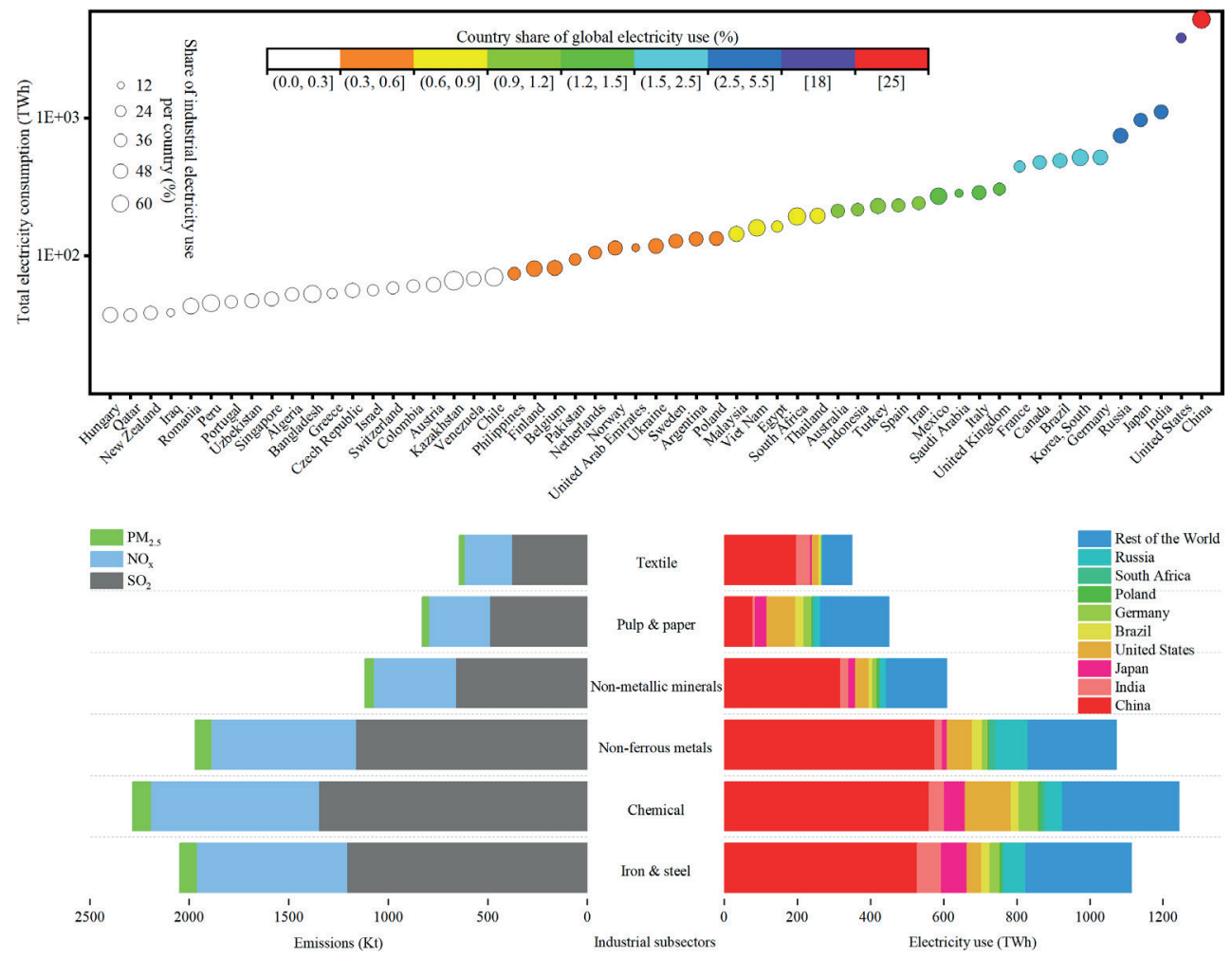

Figure 2.1. Electricity consumption levels, and sectoral emission levels due to electricity use.

Source: World Energy Balances (IEA, 2018) and China energy statistical yearbook (NBS, 2017). Calculated by authors. Note: the $y$-axis in Bubble plot represents the logarithmic scale. 
Although studies have looked previously at energy efficiency (Karali et al., 2020; Zhang et al., 2021) and emission reduction in China (Khanna et al., 2019; Zhou et al., 2018a), a comprehensive understanding of electricity use and conservation in China's industry perspective is still lacking. Most studies have focused on direct fuel use in end-use sectors, as fuel demand is still larger and contributes to direct emissions of the end-use sectors. Moreover, the studies on electricity often take a top-down view on electricity demand, without sufficient detail on the electricity end-uses and subsectors. To fill this gap, this study provides an industry-wide overview of electricity savings potentials in China, based on available studies, and estimates associated benefits on emission reduction potentials. China can be a great case bringing guidance for countries dominated with industry and coal-power (e.g. Australia, India, Mongolia, South Africa and Poland) in saving energy, cleaning up air and mitigating climate change. Within industry, five energyintensive subsectors (i.e. iron $\&$ steel, cement, non-ferrous metals, pulp \& paper and chemical) together account for $65 \%$ of China's industrial energy consumption ${ }^{1}$ and are analyzed in-depth in this study. These industries are also highlighted by the IEA (IEA, 2016a; IEA, 2017), EIA (U.S. EIA, 2018), and China's development plan for energy conservation and emission reduction (State Council of China, 2017). The five energyintensive subsectors are complemented by the textile industry, which is a non-energyintensive industry, but a large electricity consumer. This review-based research provides important insights in the way forward for reducing electricity-derived emissions in the industry for the most polluting countries, with an in-depth focus on the big contributing subsectors and key manufacturing processes.

Specifically, the main contribution of this study is answering the following four questions. (1) How much electricity can China's industry save? (2) Which industrial subsectors have the highest potentials of electricity savings and associated emission reduction? (3) Which research fields should be given more attention? (4) How to design and implement (industrial energy) policies to jointly achieve electricity, climate and clean-air goals (at national, regional and sectoral levels)? The study presents the available literature and classified these studies by industrial subsectors in Section 2.2. Section 2.3 discusses the methodological differences between the studies. The main results, in terms of electricitysaving potentials and associated environmental benefits in China's industrial sectors are presented in Section 2.4. Finally, conclusions and policy implications are given in Sections 2.5 and 2.6, respectively.

1 The five subsectors are electricity-intensive end-use sectors, which together accounted for around $50 \%$ of China's industrial electricity consumption. 


\subsection{Methodology}

\subsection{Review method}

A systematic review method is carried out to address the questions in this study, consisting of seven steps (see Figure 2.2). In the first step, four questions are proposed related to the knowledge gap on understanding the role and potential of electricity savings for reducing air emissions in industry. In the second step, targeted keywords are used, combined with the snowballing technique to identify relevant publications from various databases (e.g. Google Scholar, Web of Science and Scopus). Keywords reflecting the study purpose include "electricity saving", "energy saving", "efficiency" and "China's industry". Snowballing was used to check for additional publications in the reference list of the identified papers and for studies that cited the identified papers. During the third step, the available publications are analyzed to discuss their main characteristics (in Section 2.2). The selected studies allowed obtaining relevant data to be analyzed. In the fourth step, the methodological differences between the studies are discussed to be able to interpret the modeling results (Section 2.3). In the fifth and sixth step, the collected data on energy consumption and intensity from the studies are systematically processed to estimate the electricity saving potentials (Section 2.4). The framework is completed in the seventh step, highlighting the role of electricity as a key energy carrier and identifying the highest potential subsectors (Section 2.5). Furthermore, suggestions on joint policy design and further research are provided in the seventh step (Section 2.6).

\subsubsection{Literature selection}

Table 2.1 gives an overview of studies that focused on energy savings potentials in China's industrial subsectors (i.e. iron \& steel, cement, non-ferrous, pulp \& paper and chemical sectors), including some of their key characteristics (such as studied period, model used and research scope). A discussion on the literature review of energy savings potentials in China's industry is given below and is structured by subsector ${ }^{2}$, starting with studies that focus on industry as a whole.

2 Five key energy-intensive industrial subsectors with detailed information on energy savings are included in Section 2.2. Studies on CTI, a light industry, focus more on $\mathrm{CO}_{2}$ emissions and less on energy savings. Therefore, we include electricity-saving opportunities for CTI in the section of Results and discussion (Section 2.4.2.6). 


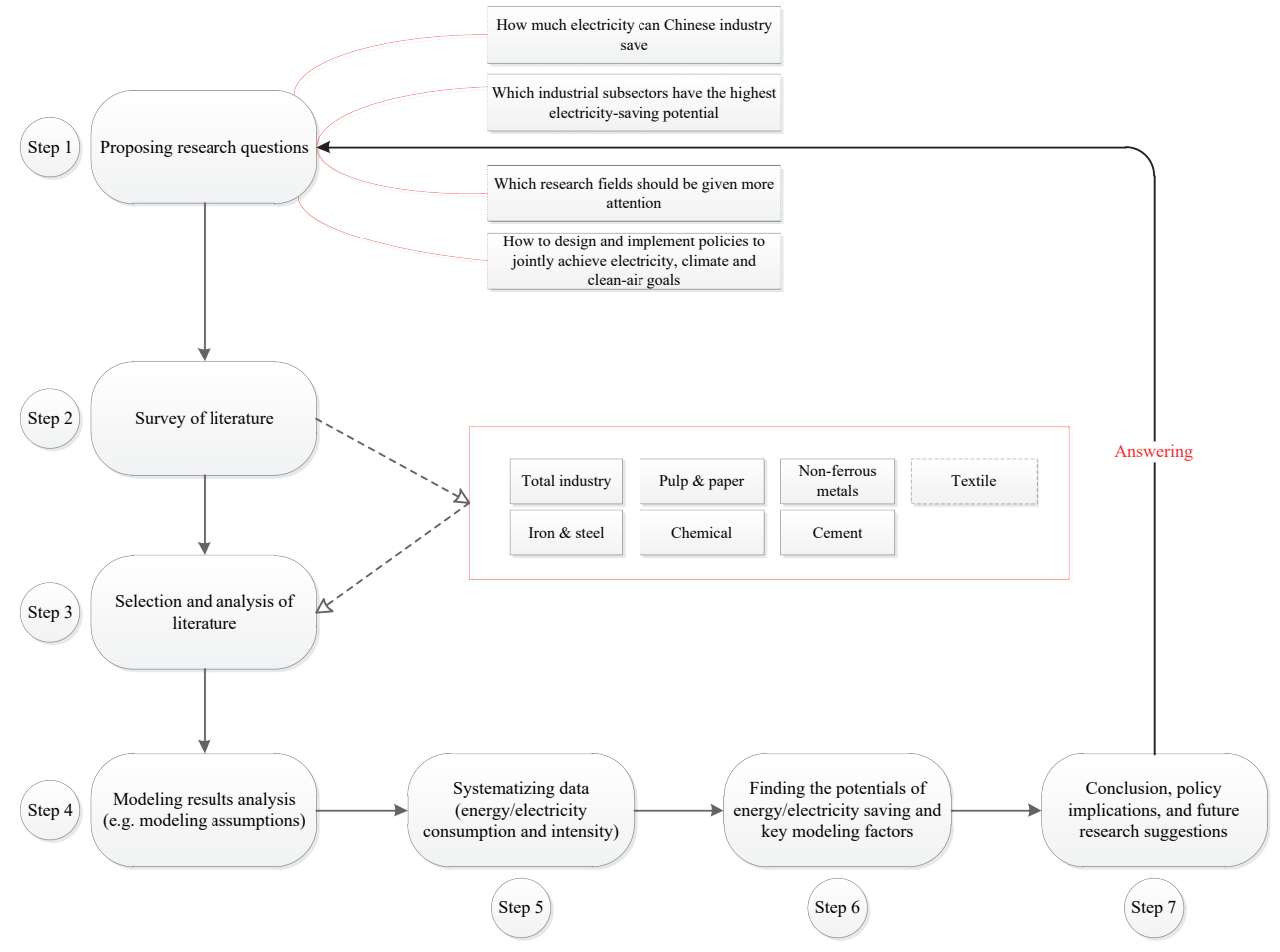

Figure 2.2. Methodological steps.

China's industry: Limited studies were found that evaluate the future potentials of China's entire industry with detailed subsector information. The study of Ouyang and Lin (2015) analyzed the driving forces of energy-related $\mathrm{CO}_{2}$ emissions in China's industry, and suggested that energy efficiency improvement through efficient technologies promotion and phasing out of inefficient production capacities was a major cause of $\mathrm{CO}_{2}$ emissions reduction in the period 1991-2010. Another study of Meng et al. (2014) analyzed the electricity-saving potentials of 20 economic sectors in China, and show that the chemical sector and mechanical sector have large potentials for electricity efficiency improvement. These studies emphasize the considerable energysaving potentials in China's industry and indicate energy efficiency improvement is key to achieving sustainable development. However, they did not quantify future energy (and electricity) demand and emissions. IEA (2016a) and EIA (2018) give an overview of energy efficiency improvement in China's industry but provide limited information on industrial electricity use. ERI (Dai et al., 2013), LBNL (Zhou et al., 2011) and THU (Zhou et al., 2018b) disaggregate China's industrial sector into key energy-intensive subsectors, such as iron $\&$ steel, cement, non-ferrous metals, pulp $\&$ paper and chemical. However, there is little information available on sectoral energy/electricity use and their contributions to electricity savings. 


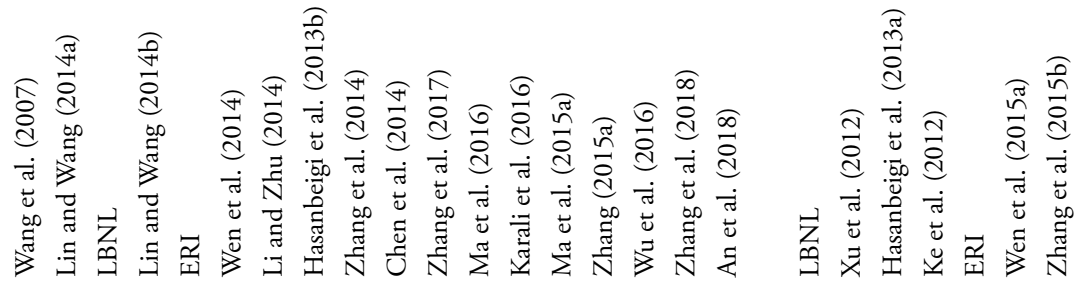
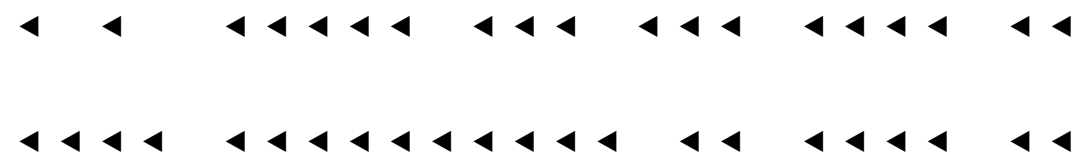

44444

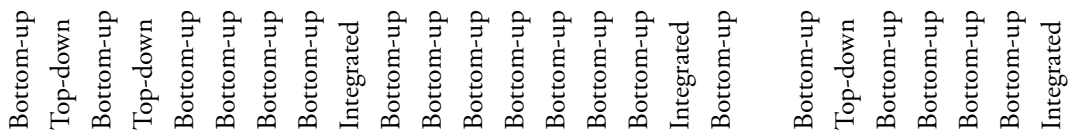

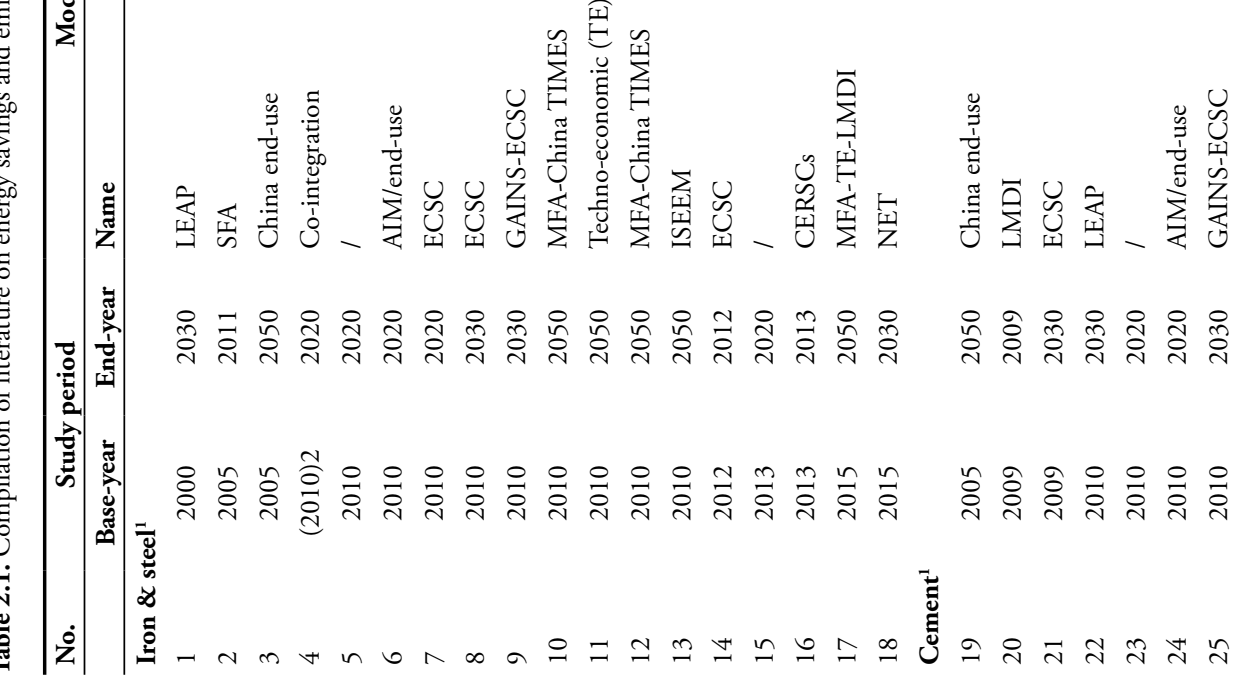


Saving energy in China's industry with a focus on electricity

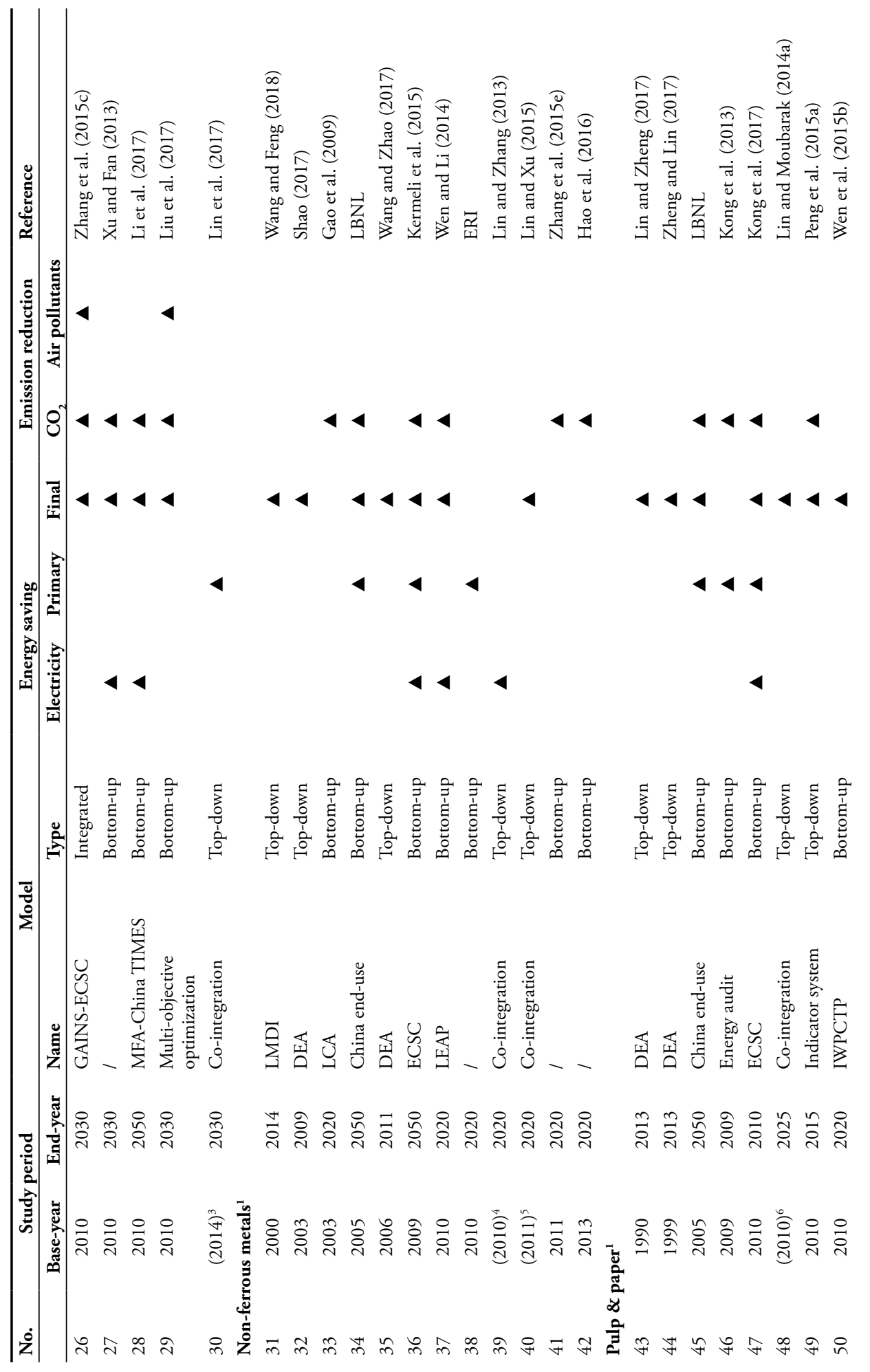




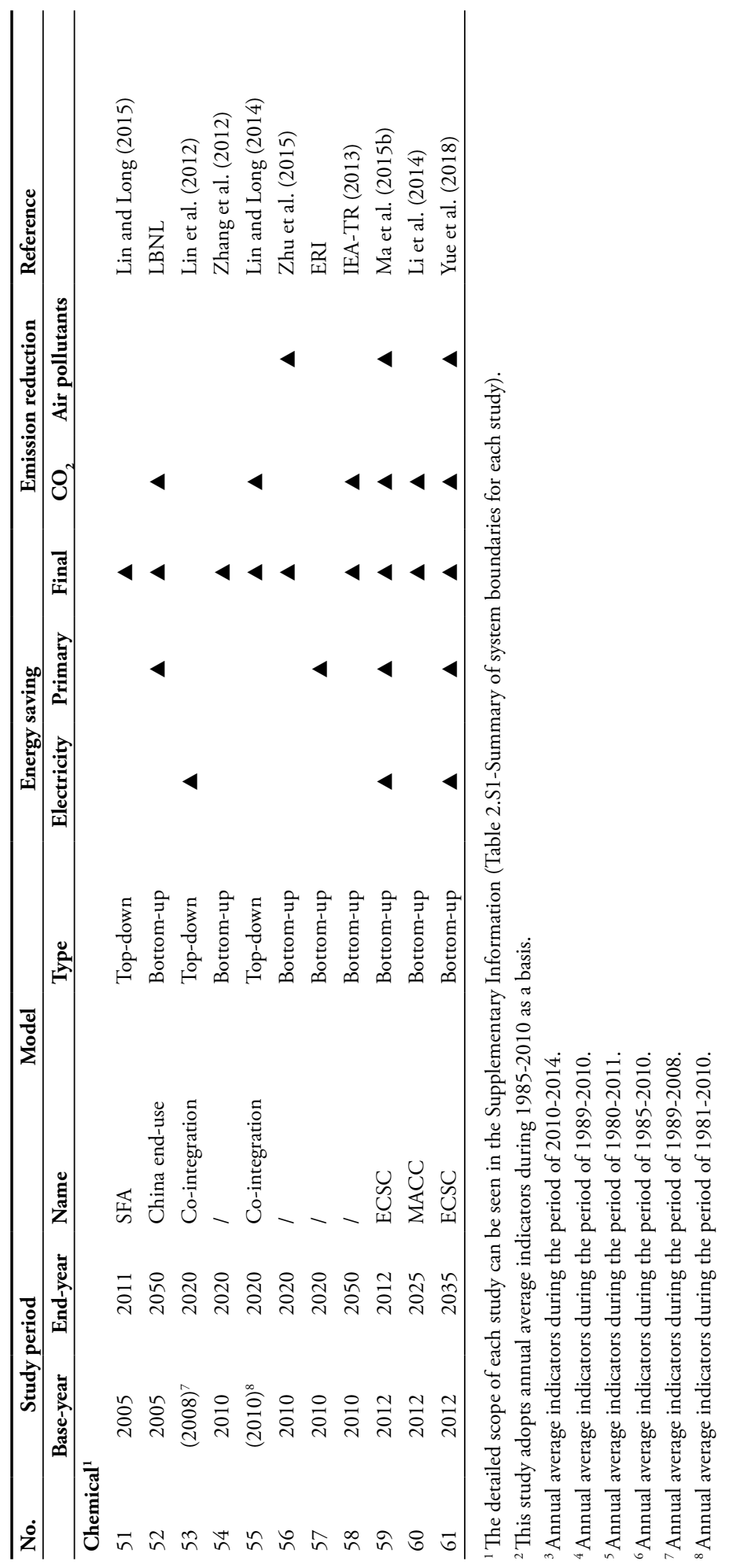


Iron \& steel industry: Table 2.1 indicates 18 studies that focus on energy savings and emissions reduction in China's iron \& steel industry (CISI). Most notably He and Wang (2017) summarized detailed parameters of 158 available energy efficiency technologies (EETs) used in iron \& steel plants around the world. Chen et al. (2014) and Ma et al. (2016) employed the China-TIMES (MARKAL-EFOM System) model to simulate the future energy-saving potentials of 10 and 28 EETs in CISI, respectively. Based on energy conservation supply curves (ECSC), Li and Zhu (2014), Hasanbeigi et al. (2013b), Zhang et al. (2014), Ma et al. (2015a), Zhang (2015a), Zhang et al. (2017, 2018) identified optimum EET options from an economic perspective. In summary, these studies indicate production structure adjustment (i.e. shift from Basic Oxygen Furnace (BOF) to Electric Arc Furnace (EAF)) and technological progress as the main forces to reduce future energy use and emissions in CISI. In addition, actions to improve energy efficiency by EETs can bring synergies for climate change, air quality and public health to be achieved cost-effectively (Wu et al., 2016).

Cement industry: 12 studies focus on energy efficiency improvement and emissions mitigation in China's cement industry (CCI, Table 2.1). Xu et al. (2012) showed that $25 \%$ of energy use (2009) could be saved if best available technologies were implemented. Hasanbeigi et al. (2013a) evaluated the cumulative saving potentials (CSPs) and associated $\mathrm{CO}_{2}$ emission reduction of 23 technologies in the period 2010 to 2030. However, CSPs provide limited transparency for policy-makers for understanding energy-savings and emission reductions by year, when designing policies. To fill this gap, Wen et al. (2015a) and Li et al. (2017) simulated the future trends of energy consumption and $\mathrm{CO}_{2}$ emissions using single-objective optimization models. Zhang et al. (2015b,c, 2016) modeled the multiple benefits of 37 EETs in energy-savings and emissions reduction ( $\mathrm{CO}_{2}$ and air pollutants) as well as health effects contributed by $\mathrm{PM}_{2.5}$ from CCI for the period 2010-2030 at various regional levels. Yang et al. $(2013 \mathrm{a}, \mathrm{b})$ estimated the benefits of 18 mitigation measures, monetized in $\$ / \mathrm{t}-\mathrm{CO}_{2}$ by MACCs (marginal abatement cost curves), at national and provincial level. In summary, the studies indicate that improving energy efficiency, switching to low-carbon fuels, reducing the clinker to cement ratio and integrating carbon capture into cement production are the main energy-saving and carbon mitigation measures which support a transition to sustainability in the cement sector. The integration of carbon capture technologies and reducing of the clinker content in cement are identified to provide the largest cumulative $\mathrm{CO}_{2}$ emissions reductions in a long-term perspective.

Non-ferrous metals industry: Table 2.1 includes 12 studies that investigate energy efficiency and carbon emission reduction in China's non-ferrous metals industry (CNFMI). Based on a top-down approach, Wang and Feng (2018), Shao (2017) and Wang and Zhao (2017) examined the energy efficiency performance of CNFMI, and found that an energy efficiency improvement potential of more than $20 \%$ remains in CNFMI. Because the CNFMI sector consists of multiple products, it is difficult for 
bottom-up models to cover all production processes. Thus, bottom-up models are used to analyze specific subsectors. For example, Gao et al. (2009), Zhang et al. (2015e) and Hao et al. (2016) predicted the GHG emissions in 2020 for China's primary aluminum industry by assuming different levels of electricity intensity $(\mathrm{kWh} / \mathrm{t}-\mathrm{Al})$ based on national plans. Wen and Li (2014) evaluated the energy-saving potentials of 67 EETs for five main non-ferrous metals (aluminum, copper, lead, zinc and magnesium) during 20102020. Kermeli et al. (2015) assessed the technical and economic potentials of 22 EETs for aluminum industry at global level (including China) up to 2050. In summary, both technological progress and rising electricity prices have greatly promoted the decline in energy consumption and GHG emissions. In addition, promoting non-ferrous metals recycling through the implementation of circular economy is also of great importance to reduce energy consumption in the future. As the transition to clean power generation cannot be achieved short-term, decision-makers can prioritize the use of EETs to achieve energy-saving and emission reduction targets in CNFMI (Wen and Li, 2014; Zhang et al., 2015e).

Pulp \& paper industry: As shown in Table 2.1 and Table 2.S2 (Supplementary Information), several approaches have been adopted to analyze energy efficiency and intensity, yet few have evaluated the energy-saving potential in China's pulp \& paper industry (CPPI). Lin and Zheng (2017) and Zheng and Lin (2017) studied energy efficiency using a total factor energy index, implying that CPPI could save at least $40 \%$ of its energy use. Kong et al. (2017) estimated the energy-saving potentials of 23 available EETs in 2010. Research on future energy savings at the national level is limited (Lin and Moubarak, 2014a; Wen et al., 2015b; Zhou et al., 2011). Lin and Moubarak (2014a) established relationships between economic variables to forecast the energysaving potentials up to 2025. Wen et al. (2015b) evaluated the co-benefits of 14 EETs on energy-savings and water-pollution reduction from 2010-2020 by industrial water pollutant control and technology policy (IWPCTP) model. These studies indicate that efforts to improve energy efficiency will benefit both the economy and the environment by reducing energy costs and emissions of water pollutants and GHG. Closing small capacity and updating production technology have been identified as effective ways to improve energy efficiency in the CPPI. China's NDRC (2018) and MIIT (2012) also pointed out that dry-wet stock preparation, high-efficiency pulp washing, and efficient double-disc refiner are efficient technologies that both conserve energy and mitigate emissions. In addition, 36 emerging technologies to substantially reduce energy use and GHG emissions compiled by Kong et al. (2012) should be promoted.

Chemical industry: Research on China's chemical industry (CCMI) is mainly limited to energy efficiency evaluation (Han et al., 2015; Lin et al., 2012; Lin and Long, 2014, 2015) and carbon emissions (Kahrl et al., 2010; Lin and Long, 2016; Liu et al., 2011; Zhou et al., 2010; Zhu et al., 2010). Only a few studies focus on future efficiency improvement potentials in CCMI and its subsectors, especially for electricity demand 
(Table 2.1). The chemical industry is a multi-products sector. Top-down approaches (Lin et al., 2012; Lin and Long, 2014, 2015) used aggregated economic indicators to describe the industry as a whole. Lin and Long (2015) explored the performance of energy efficiency in CCMI during 2005-2011, and showed that energy efficiency could be further improved by 31\%. IEA (2013) identified that radical improvement of energy efficiency in the global chemical industry can save 5.3 EJ by 2050 . Ma et al. (2015b) estimated fuel and electricity savings for 26 EETs, applicable to China's ammonia industry in 2012. Li et al. (2014) studied the energy efficiency improvement for the chlor-alkali industry in Shandong Province. Technological progress has proven an efficient way to improve energy efficiency. Studies on how to achieve the potentials by specific technologies are rare. Zhu et al. (2015) and Zhang et al. (2012) identified technological opportunities for energy-savings and water-pollution reduction for ammonia production in the short-term. Yue et al. (2018) estimated the electricitysaving potentials and associated emissions reduction (GHG and air pollutants) of 60 electricity-saving measures in CCMI, covering 4 electricity-intensive chemicals. These studies reveal that efficient technology promotion and switching feedstocks (ammonia: coal-based to natural gas-based; PVC: calcium carbide-based to ethylene-based) are the main factors to reduce energy use and emissions of water and air pollutants. Increasing energy prices can drive the diffusion of EETs.

\subsection{Modeling factor identification}

Model-based scenario analysis nowadays plays a key role in informing decision makers about future trends in the energy system. However, a slightly different hypothesis or scenario storyline can result in large differences in projected energy consumption. Therefore, it is necessary to understand studies in terms of their system boundaries, data sources, modeling approaches, key driver assumptions, assumed policy instruments, and explicit technologies modeled.

Firstly, as shown in Table 2.S2, the base-year final energy and electricity use varies in the included studies as a result of different input data and system boundaries. For example, China's iron and steel sector as identified in Zhang et al., (2014) shows a lower final energy use in base-year 2010, of 16 EJ, compared to Hasanbeigi et al. (2013b) (from China's Statistics Bureau-CSB (NBS, 2017)) and ERI (Dai et al., 2013), which is around $17 \mathrm{EJ}$. The processes of steel production and its specific energy consumption differ between various studies (Chen et al., 2014; Karali et al., 2016; Ma et al., 2016; Wen et al., 2014), and conflict with statistics for 2010 (ERI and CSB). The studies (Li and Zhu, 2014; Zhang et al., 2017) are based on the same energy consumption per unit product $(17.72 \mathrm{GJ} / \mathrm{t}$-steel) to explore future energy efficiency improvement. Different statistical methods and system boundaries (e.g. the major process energy intensity of iron \& steel in the GAINS model is lower than official data in 2010) are responsible 
for the divergences of base-year energy consumption among the listed studies (Zhang et al., 2014).

Secondly, modeling approaches and included drivers are key factors that affect projections. Various modeling approaches are used to analyze energy-saving potentials (Table 2.1). These can be classified into three general types: (1) top-down models, (2) bottom-up models, and (3) integrated models (Karali et al., 2012). The drivers used typically vary per modeling approach (Table $2 . S 3$ for an overview of the key drivers used in the included studies). Top-down models (e.g. SFA, Co-integration and LMDI) have a macro-economic perspective and use socio-economic variables to predict energy use developments. Sectoral economic activities are represented through aggregated production functions. For example, the studies (Lin et al., 2012; Lin and Zhang, 2013) evaluated the electricity-saving potentials in CNFMI and CCMI by 2020 based on topdown approaches. However, top-down approaches (characterized by implicit technology representation like R\&D progress) fail to capture technological details of energy conservation, and are unable to incorporate different assumptions about how discrete EETs and costs will evolve in the future (see Table 2.S4) (Karali et al., 2012). In the list of Table 2.1, bottom-up models with specific technology representation are widely used to explore future energy demand and emissions in different sectors. However, some studies using bottom-up models (e.g. ECSC, ISEEM, NET and IWPCTP) include very limited interactions with the macro-economic system (see Table 2.S3). Integrated models (e.g. GAINS-ECSC and MFA-TE-LMDI) combine top-down and bottomup modeling approaches through hard or soft linking. However, integrated models are typically limited in the amount and details of key drivers compared to top-down or bottom-up models alone (see Table 2.S3). Detailed strengths and weaknesses of various models used in China were assessed by Zhang et al., and Mischke et al (Mischke and Karlsson, 2014; Zhang et al., 2015d). Additionally, power pinch method based on the concept of thermodynamics is widely used to analysis energy efficiency gap (Klemeš et al., 2018), but the applied coverages are mostly on optimizing hybrid power systems from supply-side (Rozali et al., 2014; Rozali et al., 2019), rarely on quantitatively estimating the electricity savings in demand-side (Hackl and Harvey, 2013) for China, like industry and building. Therefore, the power pinch analysis related studies are out of this research scope focusing on industrial efficiency improvements in terms of electricity. While the pinch method should be given more attention to extend the application in annual strategic deployment of energy conservation, or to explore more efficient energy systems in combination with demand-side.

Thirdly, although some studies use the same model, the policy instruments or type and specific EETs modeled in alternative scenarios can result in different results for energy savings. Tables $2 . S 4$ and 2.S5 give an overview policy instruments and specific technologies modeled in the different studies, respectively. Technology selection and diffusion are the main factors that affect energy savings in the studies using bottom-up 
approaches. For example, study (Li and Zhu, 2014) collected 41 EETs for CISI, while 25 technologies are cost-effective. The results show that the technical and cost-effective energy savings are $4.63 \mathrm{GJ} / \mathrm{t}$ and $3.89 \mathrm{GJ} / \mathrm{t}$, respectively, which is higher than the results from study (Zhang et al., 2017) (also on the basis of an ECSC model), i.e. $3.08 \mathrm{GJ} / \mathrm{t}$ and $1.93 \mathrm{GJ} / \mathrm{t}$. The main reasons are the inclusion of more EETs for EAF-steelmaking, casting, rolling and finishing processes in study (Li and Zhu, 2014) than study (Zhang et al., 2017) (see Table 2.S5).

\subsection{Results and discussion}

Based on the literature collection in Table 2.1, a comparative analysis of electricity savings for China's five key industrial subsectors is conducted. Moreover, the share of electricity savings in total final energy savings is assessed for each sector to understand the role of electricity savings can play in reducing industrial energy use and providing an intuitive understanding of the relationship between electricity savings and total energy savings. Opportunities to improve electricity efficiency in China's textile sector are also discussed. A detailed description on final energy consumption is presented in the Supplementary Information. Finally, the synergies of electricity saving in relation to climate change and air quality are quantified (Tables 2.2 and 2.3).

\subsection{China's industry}

Figure 2.3 shows the future electricity consumption and saving potentials in China's industry. Industrial electricity consumption grows steadily in all IEA scenarios (IEA, 2016a), with an average annual rate of $1.8 \%$ (with a range of $1.2-2.3 \%$ ), which is higher than the annual growth rate of industrial final energy use of $0.5 \%(-0.2-1.1 \%)$. Interestingly, the projected electricity use in 2020 for IEA's 450 and THU's Reference scenarios (Zhou et al., 2018b) are similar with a consumption of around $3500 \mathrm{TWh}$. THU predicts that electricity use will peak at 2025, with an average annual growth rate of $0.8 \%$ during 2015-2025 (range 0.5-1.2\%), and then declining with $0.5 \%$ after 2025 (range 0.5-0.6\%). In comparison to the baseline scenarios, industrial electricity consumption is expected to lower by $4 \%$ in 2020 (range 2-5\%), 10\% in 2030 (range 6-15\%), 14\% in 2040 (range 7-24\%) and 3\% in 2050. 


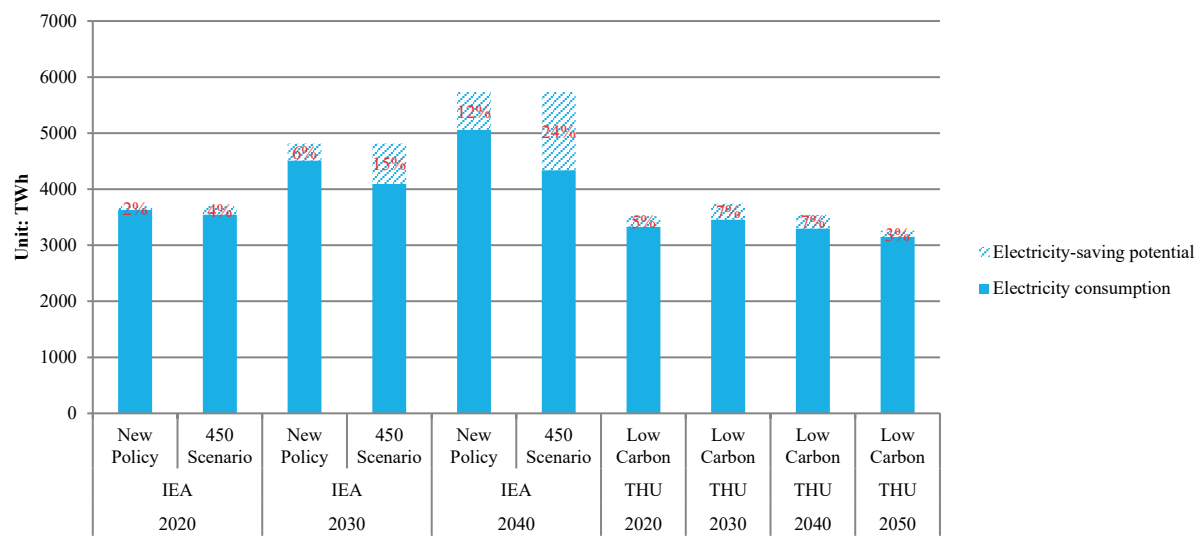

Figure 2.3. Electricity consumption and saving potentials in China's industry.

China's industrial energy system is expected to shift to higher electricity and lower fossil fuels in the future due to accelerated end-use electrification. As shown in Figure 2.4, the share of electricity consumption in industrial final energy use is expected to increase from an average of $24 \%$ in 2015 (range 20-28\%) to 33\% in 2040 (range $21-39 \%$ ). Meanwhile, electricity savings are estimated to be $31 \%$ (with a range of $23-39 \%$ ), 26\% (20-29\%), and 25\% (11-33\%) of total industrial final energy saving in 2020, 2030 and 2040, respectively. Promoting electricity conservation therefore is an effective way to reduce overall consumption in China's industry.

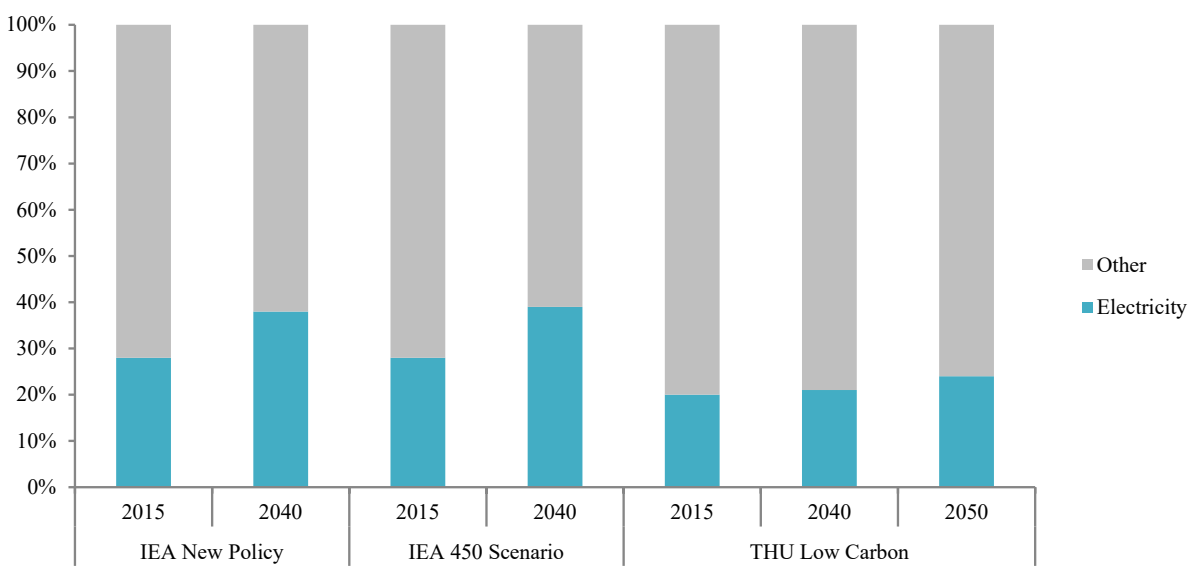

Figure 2.4. Share of electricity in China's industrial final energy use. 


\subsubsection{China's industrial subsectors}

\subsubsection{Iron \& steel industry}

As shown in Table 2.1, six studies focus on the electricity saving potentials in CISI. Some of these studies (Hasanbeigi et al., 2013b; Li and Zhu, 2014; Ma et al., 2015a) show that with proven EETs a considerable amount of electricity can be avoided. Only two studies (Wang et al., 2007; Zhang et al., 2014) present the evolution of electricity use and efficiency improvements in the future (see Figure 2.5). Electricity use in CISI is expected to peak around 2020 , and then decline slightly (by $0.1-0.4 \%$ per year) till to 2030. With the diffusion of advanced technologies, electricity intensity would be able to decrease, with $10 \%$ in 2020 (range 8-12\%) and 23\% in 2030 (range 18-27\%). The electricity savings potential is estimated to be $16 \%$ in 2020 (range 13-17\%) and $23 \%$ in 2030 (range 13-31\%), compared to the baseline.

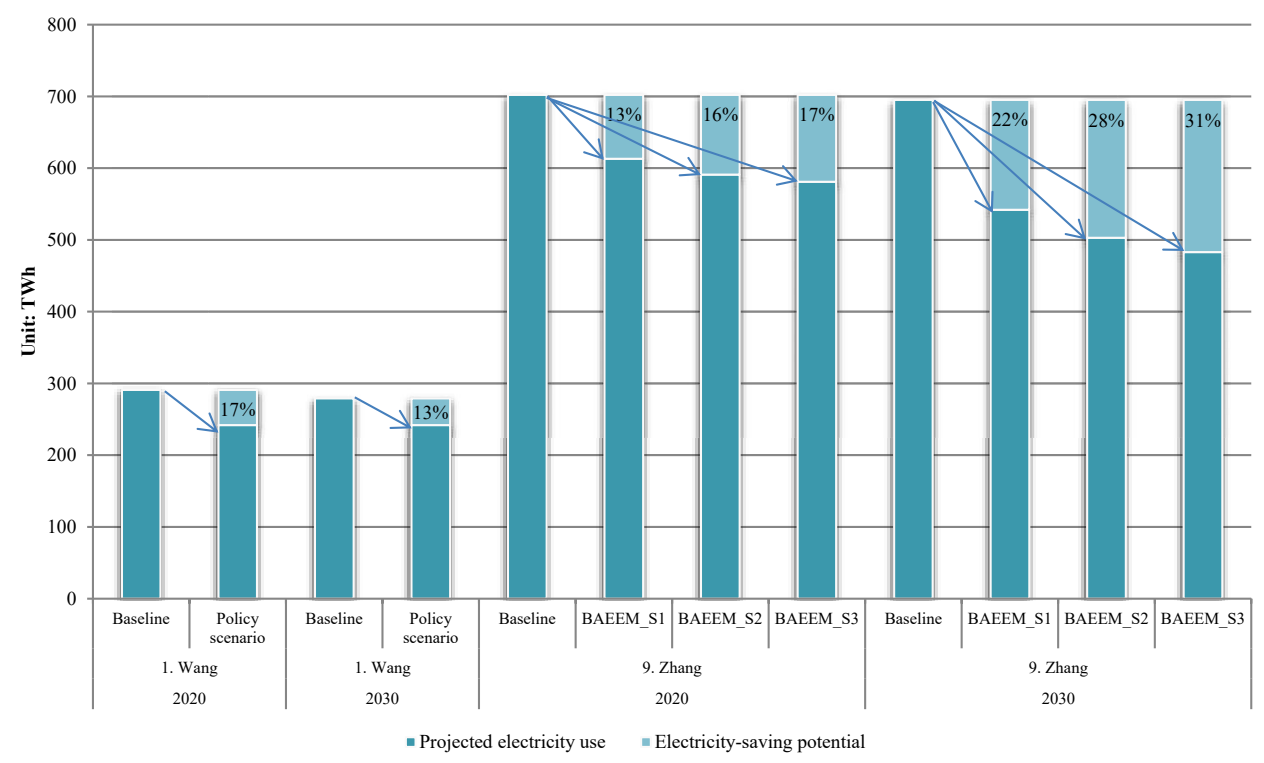

Figure 2.5. Electricity saving potentials in CISI compared to the baseline.

Driven by the increasing proportion of EAF, electricity consumption is expected to increase from $10 \%$ of final energy use of CISI in 2010 to $13-14 \%$ in 2020 and 14$16 \%$ in 2030 . There are not many long-term studies but Chen et al. (2014) projects in a baseline scenario, a share of $22 \%$ in 2050 . Generally, the proportion of coal keeps declining in the final energy mix of CISI, and electricity will increasingly become a more dominant energy carrier. Efficient use of electricity can save $2-3 \%$ and $2-5 \%$ of final energy use of CISI in 2020 and 2030, which accounts for $11-12 \%$ and $10-12 \%$ of energy savings in 2020 and 2030, respectively. Five major processes (coke making, 
sintering, iron making, steel making, and casting, rolling \& finishing) are involved in steel production (see Table 2.S1). The largest potential of electricity savings is found in the process of casting, rolling and finishing, which contributes to around $52 \%$ of the electricity savings in the steel industry. Direct rolling technology is one of the key costeffective measures to reduce electricity demand in the finishing mills. Besides improving the casting and rolling process, considerable potentials of electricity savings are expected by promoting the penetration of new EAF systems such as direct current arc furnaces and twin shell furnaces.

\subsubsection{Cement industry}

Figure 2.6 and Table 2.2 show the electricity saving potential in China's cement sector. The included studies mainly focus on the short-term (i.e. 2010-2030). Baseline scenarios show that electricity use in CCI will approach a peak of 211 TWh in 2020 (range 180$259 \mathrm{TWh}$ ), and then decline to $90 \mathrm{TWh}$ by 2050. Compared to the baseline, electricity use can be reduced by $8 \%$ in 2020 (range 4-21\%), 15\% in 2030 (range 10-33\%) and $15 \%$ in 2050 (range $9-18 \%$ ). Compared to 2010 , the electricity intensity is expected to be able to decrease by $27 \%$ in 2030 (range of 20-33\%) and thereafter reach world best practice level (i.e. 54-60 kWh/t-cement) in 2050 (Worrell et al., 2008).

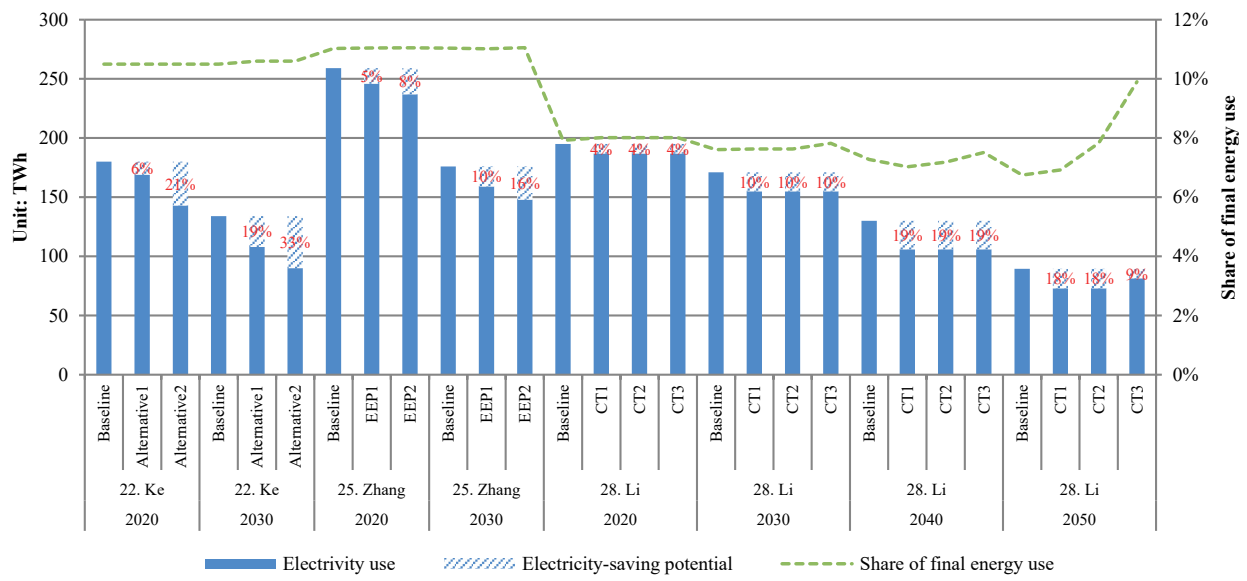

Figure 2.6. Electricity saving potentials in CCI compared to the baseline.

Electricity accounts for around 10\% (range 8-11\%) of final energy use, and changes not significantly during the period 2010 to 2030 . Around $10 \%$ (range 6-16\%) and $10 \%$ (range 6-14\%) of final energy savings are contributed to electricity savings in 2020 and 2030 , respectively, which account for $1 \%$ and $2 \%$ of final energy use. There are not many long-term studies, but Li et al. (2017) projects that the share of electricity use would grow if a carbon tax increased from $50 \$ / \mathrm{t}-\mathrm{CO}_{2}$ in 2020 to $215 \$ / \mathrm{t}-\mathrm{CO}_{2}$ in 
2050. The main reason is that the tax will promote energy system changes towards lower coal and higher electricity. Around $1.5 \%$ of final energy use can be saved by improving electricity efficiency in 2050. Cement manufacturing consists of four major production processes, i.e. fuel preparation, raw material preparation, clinker making, grinding and finishing. Around $50 \%$ of the electricity saving potential can be released through improving the electricity use efficiency in the processes of raw material preparation and cement grinding. It is worth noting that general measures, such as high-efficiency motors and energy management systems, have huge potentials to reduce electricity demand. These measures represent around $20 \%$ of total electricity savings in the cement sector. Meanwhile, most of the general measures are economically feasible for investors.

\subsubsection{Non-ferrous metals industry}

Research for the CNFMI is mainly concentrated on two aspects, i.e. GHG emissions (Gao et al., 2009; Hao et al., 2016; Zhang et al., 2015e) and historical energy efficiency investigations (Shao, 2017; Wang and Zhao, 2017; Wang and Feng, 2018). Studies on predicting the energy conservation trajectory in the whole non-ferrous metals industry are rare. As shown in Table 2.1, most of these studies focus on aluminum production because it accounts for $74 \%$ and $75 \%$ of total energy consumption and electricity consumption in the whole non-ferrous metals industry, respectively (CNMIA, 2017).

Future electricity demand in CNFMI will keep growing with the expected increasing demand for nonferrous metals. The increasing electricity demand would result in large indirect emissions of GHG and air pollutants. Figure 2.7 shows that future electricity savings in the non-ferrous metals sector are considerable in 2020. For the overall nonferrous metals industry, projected electricity use could be reduced by $41 \%$ in 2020 (with a range of 31-52\%), corresponding to around $132 \mathrm{TWh}$ (range 99-164 TWh). For aluminum production, electricity use is expected to be reduced by $8 \%$ in 2020 (range 6-10\%). Both technological progress and increasing use of secondary metals greatly promote the decline in electricity consumption and GHG emissions. However, increases in the share of secondary production of non-ferrous metals are limited by the availability of scrap (IEA, 2017). Thus, the adoption of cost-effective technologies should be prioritized to improve electricity efficiency and reduce emissions by CNFMI. 


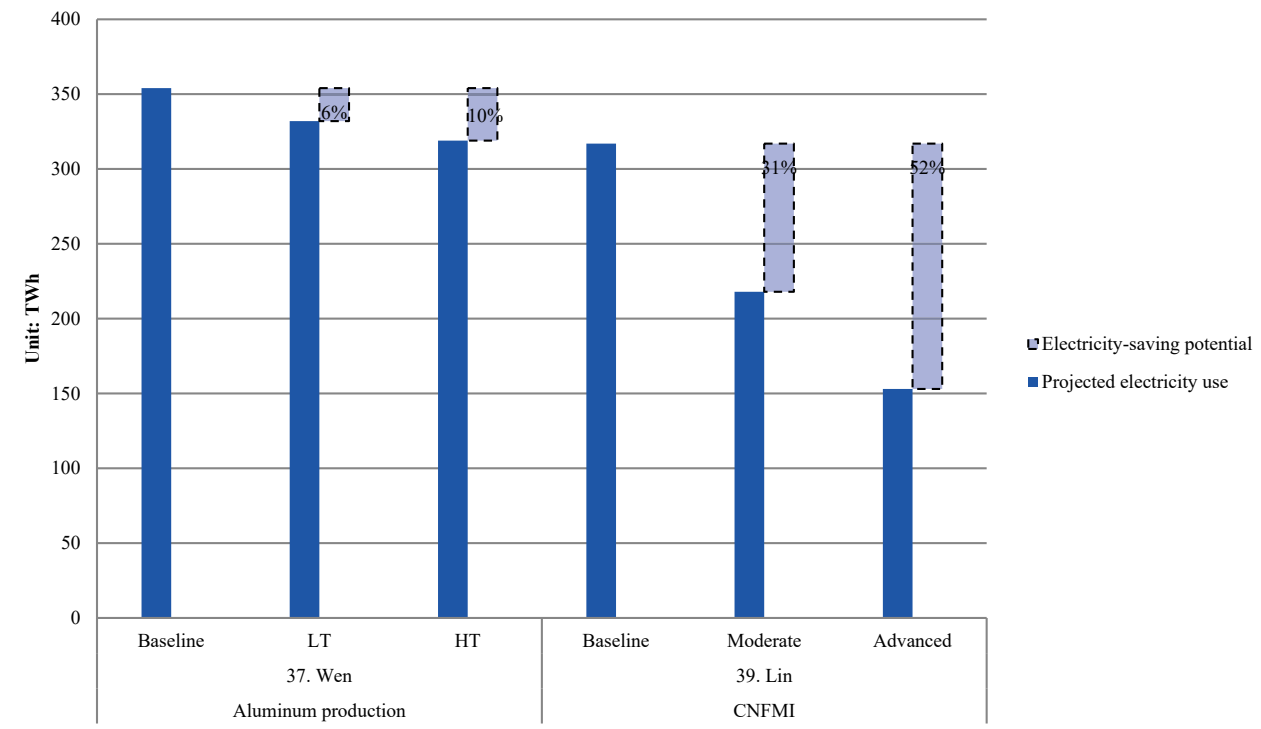

Figure 2.7. Electricity-saving potentials in China's non-ferrous metals sector in 2020.

As the dominant energy carrier, the share of electricity in final energy use of CNFMI increased from 38\% in 2000 to 66\% in 2016 (NBS, 2017). The increased electricity use comes mainly from aluminum production. Electricity consumed by aluminum production accounts for $49 \%$ of total final energy use of CNFMI. In 2020, around 4\% (range 3-5\%) of final energy use in CNFMI can be avoided by improving electricity efficiency in aluminum production. Electricity savings in aluminum production can contribute to 58\% (range 56-60\%) of energy savings of CNFMI in 2020. Saving electricity in aluminum production thus can effectively reduce overall energy consumption in CNFMI. Actions to improve the alumina refining process are expected to unleash around $10 \%$ of total electricity saving potentials in China's aluminium sector. The most cost-effective way to reduce the electricity intensity of primary aluminium is to retrofit and upgrade outdated electrolytic cells, which can contribute more than $80 \%$ of the total electricity savings in the aluminium sector. Therefore, the government should prioritize the penetration of high-efficiency electrolyzers, such as new reduction cells with low-temperature and low-voltage, and TiB2/C composite cathodes with highwettability and impermeability.

\subsubsection{Pulp \& paper industry}

Figure 2.8 shows the electricity-saving potentials in CPPI in $2010.4 \%$ of the electricity use in CPPI can be avoided though implementing 3 process electricity-saving technologies (i.e. vacuum system optimization, high-efficiency double-disc refiners, refiner improvements) and 2 general measures (i.e. adjustable-speed drivers and energy- 
efficient lighting). It is worth noting that Germany as one of the most efficient paper producers still has $16 \%$ electricity-saving potentials though promoting 11 electricitysaving technologies (Fleiter et al., 2012). As the world's largest paper producer, the electricity savings (4\%) in China's paper sector thus may be underestimated due to the few technologies included in the study (Kong et al., 2017). The shortcoming makes it difficult for policy-makers to fully understand the electricity savings and emission reduction potentials, and to make reasonable and cost-effective choices.

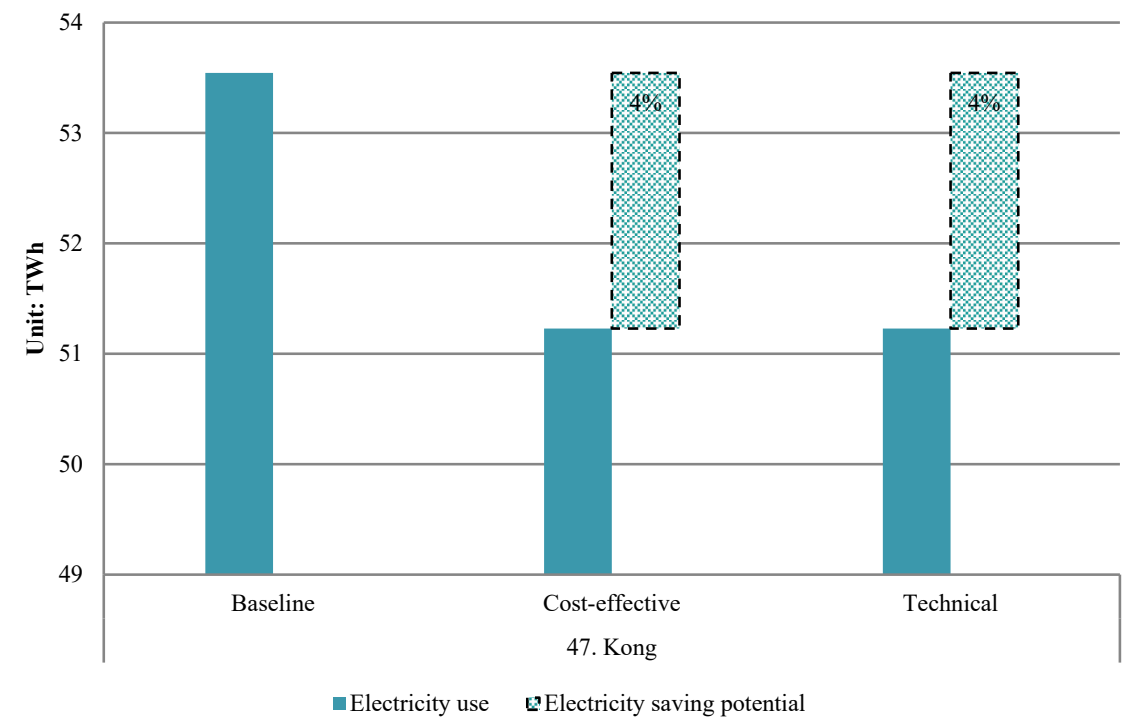

Figure 2.8. Electricity-saving potentials for CPPI in 2010 .

Similar to other sectors, the energy system of CPPI is shifting towards higher electricity and lower coal use. Final energy consumption has peaked in 2009, and then declined with an average annual rate of 2\% during 2009-2016 (Supplementary Information). However, electricity use continued to grow, with an average annual rate of $5 \%$ in the period 2009 to 2016. The share of electricity demand thereby increased from $18 \%$ in 2000 to $29 \%$ in 2016. According to Kong et al. (2017), electricity savings (2 TWh) of CPPI can contribute to $3-4 \%$ of energy savings, representing around $1 \%$ of final energy use in 2010 by this sector. However due to the limited studies and especially scope of included electricity conservation measures, these results are expected to be an underestimation. Two major production processes (i.e. pulping and papermaking) are included in paper manufacturing. Electricity savings in the pulping process account for around $20 \%$ of total electricity savings in CPPI. The papermaking process has the highest potential for reducing electricity use (accounting for nearly 60\% of total electricity savings). Besides these two major processes, approximately $20 \%$ of the electricity saving 
potentials can be accessed by cross-cutting measures (e.g. adjustable-speed drives, and anti-scaling technology for cooling water systems). With the increasing share of wood-based pulping (10\% in 2010 to 13\% in 2017 (CTAPI 2018)), more advanced electricity-saving technologies can be introduced to CPPI, like high-efficiency grinding, enzymatic pre-treatment and chemical modification of fibers (Fleiter et al. 2012). It is necessary to build a cost-effective technology roadmap to facilitate the electricity saving potentials and investments for CPPI in the future.

\subsubsection{Chemical industry}

As shown in Figure 2.9, only two studies (Lin et al., 2012; Yue et al., 2018) focus on future electricity saving potentials in the CCMI. Top-down approaches (Lin et al., 2012) show a large electricity saving potential for the overall chemical industry in 2020 , of around 40\% (ranging from 29 to 50\%). Bottom-up approaches (Yue et al., 2018) on the other hand, estimate a lower possible reduction of electricity use by $16 \%$ in 2025 (range 15-18\%), 25\% in 2030 (range 22-28\%) and 35\% in 2035 (range 31-39\%), compared to business as usual.

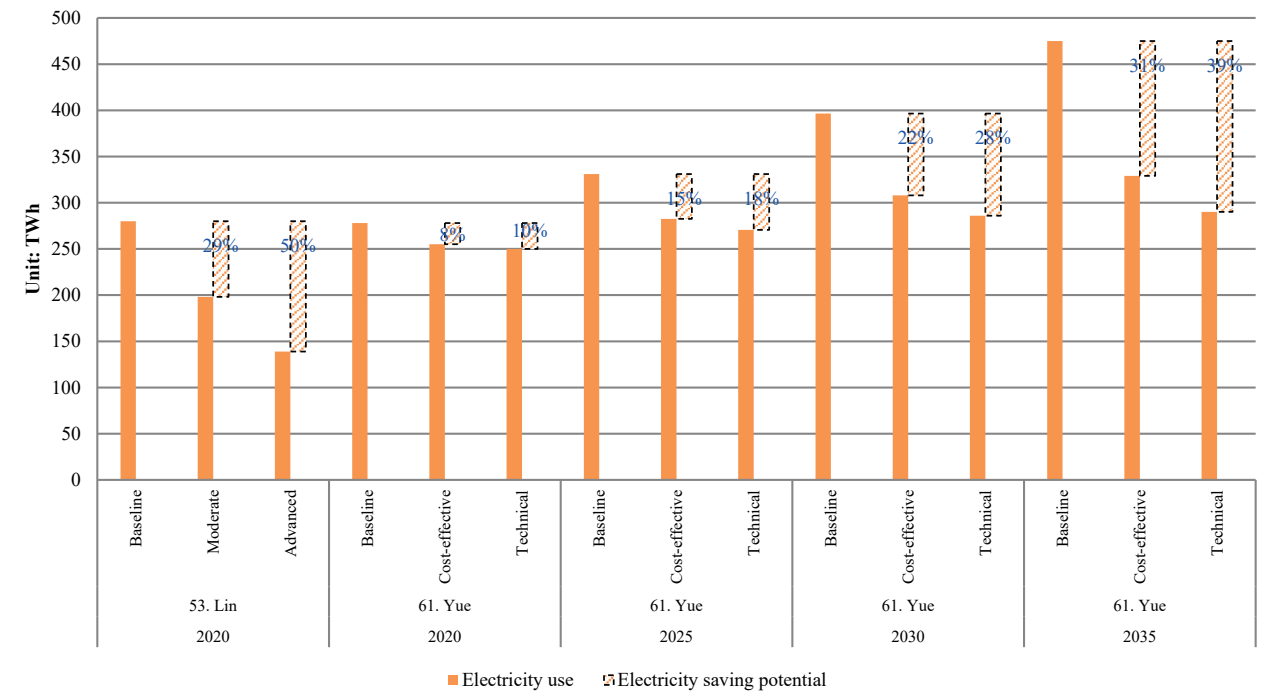

Figure 2.9. Electricity saving potentials in CCMI compared to the baseline.

Note: the study 53. Lin studied the electricity use in the whole chemical industry; the study 61. Yue projected the electricity savings in three chemical subsectors (ammonia, chlor-alkali and calcium carbide).

As one of main energy carriers in CCMI, electricity consumption in 2016 doubled in comparison to 2005 , with an average annual growth rate of $8 \%$, which is higher than the growth rate of final energy use (5\%). The share of electricity in the final energy mix increased from $12 \%$ in 2005 to $15 \%$ in 2016 . With accelerating electrification in CCMI, 
electricity consumption is expected to further increase (IEA, 2013; Yue et al., 2018). Efficient use of electricity by adopting 60 EETs can save 6\% in 2030 (range 5-7\%) and $9 \%$ in 2035 (range $8-10 \%$ ) of final energy use of CCMI. Investments in energy efficiency in the chemical industry should focus especially on calcium carbide manufacturing (in particular the calcium carbide furnace), which is expected to deliver around $50 \%$ of the electricity savings among three key chemical subsectors (i.e. ammonia, chlor-alkali and calcium carbide). The chlor-alkali sector produces two major electricity-intensive chemicals, i.e. caustic soda and PVC. Efficient ion-exchange membrane electrolyzer (e.g. oxygen depolarized cathodes membrane electrolyzer, and zero electrode-distance membrane electrolyzer) and dry-process acetylene are key to reducing electricity costs in caustic soda and PVC production, respectively. Ammonia manufacturing includes four major processes, i.e. gas generation, shift conversion, gas purification, and ammonia synthesis. China's ammonia production is dominated by coal feedstocks, which account for $86 \%$ of total ammonia capacity. The process of gas purification thus has the highest potential for conserving electricity (representing around $30 \%$ of total electricity savings in China's ammonia sector), which can be achieved by implementing high-efficiency desulfurization and decarbonization technologies (e.g. pressure swing adsorption for removing $\mathrm{CO}_{2}$ ). Replacing and upgrading low efficiency ammonia synthesis towers can further release around $27 \%$ of the electricity saving potential. Considering the electricity performance of each process, policy-makers and managers are suggested to scale up efficiency by targeting key areas within an industrial sector. This presents an option to access significant reductions in a rapid way with high cost performance.

\subsubsection{Textile industry}

The textile industry in China is not considered an energy-intensive sector. However, CTI consists of a large number of factories which together consume significant amounts of energy. CTI consumes $2 \%$ and $4 \%$ of China's industrial final energy and electricity consumption, respectively. Final energy use of CTI increased dramatically in the period 2000-2016, with an average annual growth rate of 5\%. Within the energy consumption in CTI, electricity is one of the dominant energy sources, with an increasing share from $23 \%$ in 2000 to $45 \%$ in 2016 (NBS, 2017).

However, existing studies mainly focus on carbon emissions (Huang et al., 2017; Lin and Moubarak, 2013, 2014b) and have limited information on energy savings in CTI. An international comparison of energy efficiency shows the large gap between China $(31 \mathrm{MJ} / \$)$ and US $(11 \mathrm{MJ} / \$)$ in the textile industry (Peng et al., 2015b). Lin and Zhao (2016b) found the CTI sector has a $20-33 \%$ available potential to improve energy efficiency. Various energy efficiency opportunities (including available and emerging EETs) in the textile industry have been summarized by LBNL, many of which are costeffective (Hasanbeigi and Price, 2012, 2015). As a dominant energy carrier, efficient use of electricity can effectively reduce the overall energy consumption and indirect emissions in the sector. Electricity-saving potentials of available technologies for major 
textile processes (i.e. spinning, weaving and wetting processing) are shown in Figure 2.10 (Hasanbeigi and Price, 2012; Huang et al., 2017). Most of the technologies are applied to the electric motor-driven systems (i.e. pumps, fans and compressed air). Thus, promoting efficient motor systems is key to realizing electricity efficiency improvement in CTI (Lin and Zhao, 2016a,b).

Energy consumption in China's textile industry will continue to increase, while the growth rate is expected to slow down due to energy efficiency improvements. Various measures (e.g. industrial scale adjustment and technology upgrading) reduce energy use in CTI, of which technology upgrading is the most effective way (Lin and Zhao, 2016a; Wang et al., 2017). It is worth noting that the energy efficiency of the entire motordriven systems in the textile industry leaves much room for improvement.

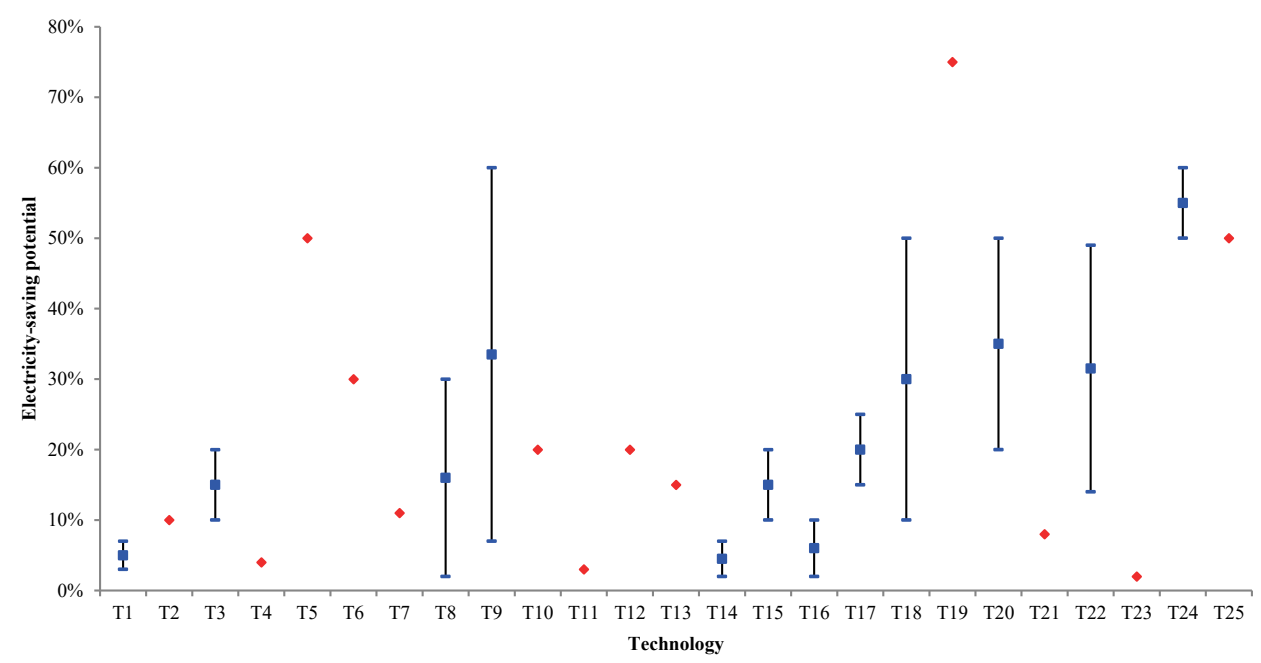

Figure 2.10. Electricity-saving potential per technology applied in major textile processes.

Note: T1-T25 refer to the technology summarized by Hasanbeigi and Price (2012): No. 3, 7, 12, 16, 34, 58, 97, 117, 121, $127,132,133,134,135,138,139,140,141,142,143,146,153,154,157$ and 158, respectively; the black vertical lines represent ranged potential value from low to high; the blue and red markers mean average value and non-ranged value, respectively.

\subsubsection{Summary of electricity savings and associated emissions reduction}

In this study we aim to include total industrial electricity demand, including purchased power from the grid as well as self-generated power (e.g. by combined heat and power (CHP) plants). For most literatures we found that the energy demand data is consistent with this definition, however not all studies are clear in this regard. In terms of savings potential as share, there is little impact to be expected since this is based on the 
percentual savings potentials of measures that are applied to total electricity demand. The total development of industrial electricity demand may however be underestimated to a certain extent because of this.

Tables 2.2 and 2.3 summarize the saving potentials for final energy and electricity use in China's industry and for the five industrial subsectors. The electricity saving potentials in China's industry show an increasing trend in the period 2020 and 2040, from 4\% to $14 \%$. Within total industry, electricity savings in the CISI sector have the largest contribution, followed by CNFMI, CCMI, CCI and $\mathrm{CPPI}^{3}$ in 2020. The non-ferrous metals sector has the largest electricity saving potential with $25 \%$, followed by chemicals (24\%), iron \& steel (16\%), cement (8\%) and pulp \& paper (4\%) in 2020. In 2030, the electricity-saving potentials of CISI and CCI increase to $23 \%$ and $15 \%$, respectively. By 2030 , the chemical sector $(25 \%)$ still has greater potentials than the iron \& steel and cement sector. In generally, CNFMI and CCMI have more opportunities to improve electricity efficiency, while the saving contribution to the whole industry is less than that of the iron $\&$ steel sector.

Based on the data collected in Table 2.2, co-benefits of electricity-savings in terms of emission reduction of GHGs $\left(\mathrm{CO}_{2}, \mathrm{CH}_{4}\right.$ and $\left.\mathrm{N}_{2} \mathrm{O}\right)$ and air pollutants $\left(\mathrm{SO}_{2}, \mathrm{NO}_{\mathrm{x}}\right.$ and $\mathrm{PM}_{2.5}$ ) in China's industry are calculated (see Figure 2.11). The emissions of GHGs and air pollutants can potentially reduce by $153 \mathrm{Mt}-\mathrm{CO}_{2 \mathrm{eq}}$ and $699 \mathrm{kt}$ in 2020 , and by 1123 $\mathrm{Mt}-\mathrm{CO}_{2 \mathrm{eq}}$ and $5137 \mathrm{kt}$ in 2040, respectively. The maximum reduction of $\mathrm{CO}_{2}, \mathrm{SO}_{2}$ and $\mathrm{NO}_{\mathrm{x}}$ in 2040 equals $42 \%, 63 \%$ and $68 \%$ in comparison to 2015 industrial indirect emissions, respectively. The emission benefits from electricity savings are important to China for achieving climate and clean-air goals (e.g. reducing $60-65 \%$ of $\mathrm{CO}_{2}$ intensity by 2030 compared that of 2005).

3 CPPI can reduce electricity use at least $2 \mathrm{TWh}$, while future trajectories of electricity savings are unavailable. 

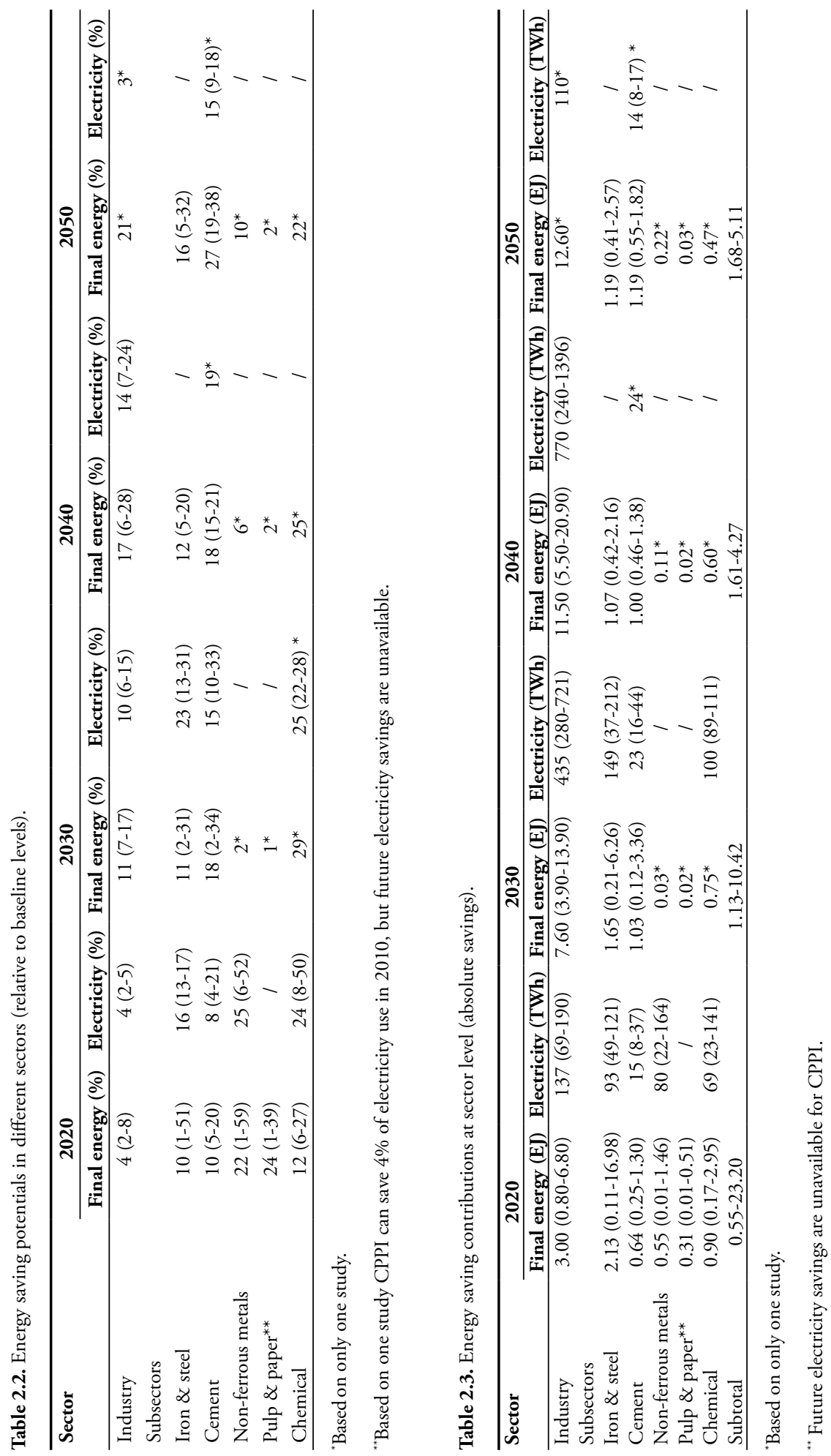


\section{Saving energy in China's industry with a focus on electricity}
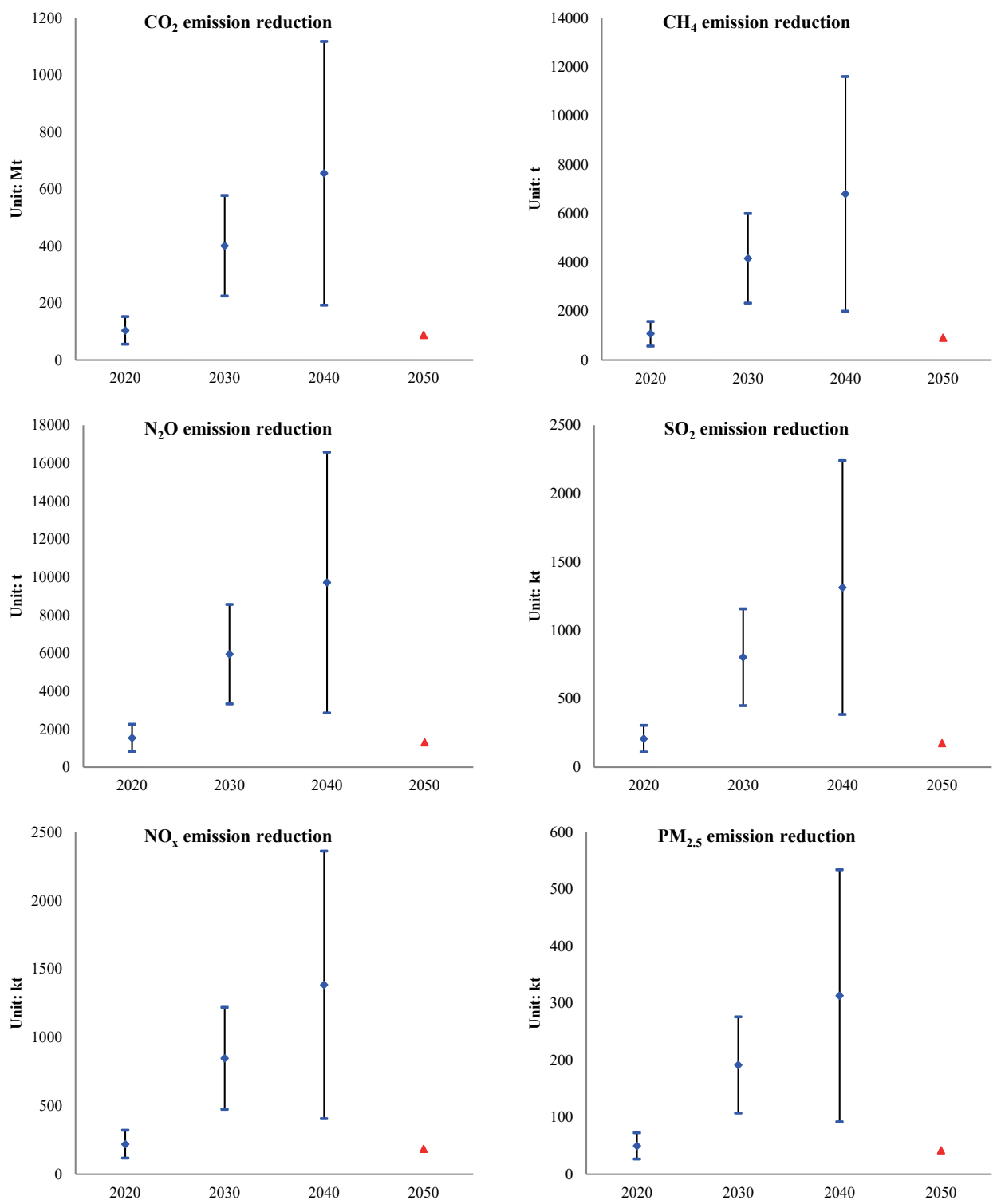

Figure 2.11. Emissions reduction of GHGs and air pollutants.

Note: only THU projected the electricity savings in 2050 for China's industry; the black vertical lines represent ranged emission value from low to high; the blue and red markers mean average value and non-ranged value, respectively. 
Table 2.4. Co-benefits of electricity savings in terms of emissions reduction in China's industry.

\begin{tabular}{lcccc}
\hline Emission & $\mathbf{2 0 2 0}$ & $\mathbf{2 0 3 0}$ & $\mathbf{2 0 4 0}$ & $\mathbf{2 0 5 0}$ \\
\hline GHGs & & & & \\
$\mathrm{CO}_{2}(\mathrm{Mt})$ & $55-152$ & $224-577$ & $192-1118$ & 88 \\
$\mathrm{CH}_{4}(\mathrm{t})$ & $574-1579$ & $2327-5993$ & $1995-11603$ & 914 \\
$\mathrm{~N}_{2} \mathrm{O}(\mathrm{t})$ & $820-2257$ & $3326-8565$ & $2851-16584$ & 1307 \\
Air pollutants & & & & \\
$\mathrm{SO}_{2}(\mathrm{kt})$ & $111-305$ & $449-1157$ & $385-2241$ & 177 \\
$\mathrm{NO}_{x}(\mathrm{kt})$ & $117-321$ & $474-1220$ & $406-2362$ & 186 \\
$\mathrm{PM}_{2.5}(\mathrm{kt})$ & $26-73$ & $107-276$ & $92-534$ & 42 \\
\hline
\end{tabular}

Calculated by authors (Supplementary Information).

\subsubsection{Discussion of impact modeling factors on results}

Sectoral energy/electricity consumption and savings vary quite strongly in the included studies. In order to understand these differences, key factors that impact results are summarized below. These factors are partly based on the results from Section 2.3, that analyzes model approaches and assumptions, recorded in Tables 2.S1, 2.S3, 2.S4 and 2.S5. In addition, a comparison of energy demand levels in baseline scenarios and energy intensity trends, which is included in the Supplementary Information, is used.

- System boundary is identified as an important factor that especially has great influence on projections in sectors with multiple products, like non-ferrous metals and the chemical industry. As shown in Figure 2.S6, final baseline energy use of CNFMI projected by bottom-up approaches developed by Wen and Li (2014) (2.6 EJ) is double that of LBNL (1.3 EJ) in 2020, due to differences in the scope of included products ( the study of Wen and Li (2014) includes other materials besides aluminum production (e.g. lead, copper and zinc)). Another example is the chemical industry, where a wide range in potentials occurs, from $6 \%$ to $20 \%$ in 2020, as shown in Table 2.2. A main difference in sector coverage concerns which products are included and should therefore always be taken into account when comparing energy saving potentials. Detailed system boundaries for each study are shown in Table 2.S1.

- The modeling approach is another key factor resulting in significant divergences among projections. Most included top-down approaches focus on modeling shortterm horizons (up to 2020), while bottom-up and integrated approaches focus more on the medium- and long-term (see Table 2.1). Modeling projections by top-down approaches often give bigger energy demand result than other modeling approaches. For example, the studies (Lin and Wang, 2014b; Lin et al., 2017) using a co-integration model shows a much higher energy demand in 2020 for CISI (33 EJ) and CCI (9 EJ) than average levels projected by bottom-up modeling (14 EJ for CISI and 6 EJ for CCI, Supplementary Information). This could be related to the higher level of technology detail in bottom-up approaches and assumed lower 
energy intensity developments. Moreover, there is a larger range in alternative scenario results in terms of energy savings. A key difference among model structures is the drivers used for energy modeling as shown in Table 2.S3 (detailed discussion in Section 2.3), and is related to the next point on socio-economic indicators.

- The assumed development of Social and economic indicators (e.g. GDP, population and urbanization) strongly impact production functions (Edelenbosch et al., 2017; Wen et al., 2014; Zhang et al., 2018; Zhou et al., 2011). The modeled output of industrial products in turn directly affects the development of energy demand and thus energy savings for a given sector (Figure 2.S12). A large level of assumed production (e.g. the found range is 364 to $881 \mathrm{Mt}$-steel by 2020) usually results in a high energy use in the baseline (ranging from 8 to $17 \mathrm{EJ}$ by 2020). This also impacts the alternative scenarios, together with varying assumptions regarding implemented energy efficiency technologies and policy measures, as indicated in the next point.

- Assumed efficiency improvement room and technology characterization largely determine the modeling potentials of energy savings. Differing collected levels of energy saving technology impact bottom-up approaches with rich technology representations (as described in Section 2.3 and Table 2.S5). Technology cost is a main barrier for measures when considering necessary investment. High levels of assumed policy instruments (e.g. carbon tax, technology subsidies) can reduce the relative cost of technologies and thus increase the technology implementation level (Li et al., 2017; Zhang et al., 2018). This level is also referred to as the technology diffusion rate and has a direct impact on the savings potential. For example, scenarios modeled by Liu et al. (2017), who included 23 technologies with all nearly 100\% implementation rates in 2030 for CCI, show a higher potential energy savings (relative savings of 20\%) than other studies (e.g. 9-16\% projected by Zhang et al. (2015b)), which included more technologies, but with a lower diffusion rate. Key differences in included policy measures found are the technology representation and the level of economy regulatory incentives.

- Data sources also affect the modeling results to a certain extent. For example, the energy demand for CISI projected by Wang et al. (2007) and LBNL are lower than for other studies, probably because the energy service demands are based on historical data up to 2005. Different data sources and statistical methods used have different qualities and timeliness. The impact of data sources is difficult to quantify, but for long-term trends the impact on sectoral energy use and intensity seems to be limited (Supplementary Information).

The absolute development of energy or electricity use in the scenarios and therefore absolute savings are difficult to compare amongst studies, e.g. due to different activity 
levels assumed (e.g. more or less iron and steel production). Therefore, the focus was on percentual changes of the alternative scenario compared to the baseline scenario, with the only difference being the implementation of energy efficiency measures, while activity data in the scenarios remain the same. There may however already be some energy efficiency improvement included in the baseline scenario, such as is to be expected in real life (e.g. the energy intensity in GJ/t-steel in most included studies is lower in the end year compared to the base year, see Supplementary material). The potentials are then an underestimation of the energy efficiency improvement compared to base year energy efficiency levels. On the other hand, for quite some studies the base year is 2010 or before and it is to be expected that the energy intensity has improved in the current situation. However, the actual decrease in intensity, since the base year, may be higher or lower than assumed in the baseline scenario. As another factor, in most studies new and emerging technologies are not included in the energy efficiency potentials, meaning that more potential would be available in the future when these technologies become commercial. Therefore, the potentials should be seen as broad indications and would likely be expanded by new and emerging technologies.

\subsection{Conclusions}

Industry is the largest energy using sector in China, resulting in high emissions of GHGs and air pollutants, while large potentials for improving energy efficiency exist. With accelerating end-use electrification, coal-intensive electricity has become a dominant energy source in China's industry. This systematic review evaluates energy saving potentials in China's industry, while especially focusing on electricity savings in five industrial electricity users (representing more than $50 \%$ of total industrial electricity consumption) that are generally targeted by the IEA and the Chinese government. Results show varying levels of electricity saving potentials, depending on sector, modeling approach (e.g. top-down, bottom-up) and scope (included products). Based on the results, synergies of electricity-saving and climate change and air quality are quantified. Countries (e.g. India, Poland, Czechia and Australia) structured with heavy industry and coal-based power would get large benefits through saving electricity in end-use sectors. Main conclusions are as follows:

1. As a key energy carrier, electricity accounts for $\mathbf{2 4} \%$ of final energy use in China's industry. Electricity consumed by industry increased more than fourfold from 907 TWh in 2000 (16\% of final energy use) to 4003 TWh in 2016 (24\% of final energy use). Coal-intensive electricity results in serious environmental problems, i.e. $45 \%$ of $\mathrm{CO}_{2}, 25 \%$ of $\mathrm{SO}_{2}, 34 \%$ of $\mathrm{NO}_{\mathrm{x}}$ and $14 \%$ of PM-emissions of the industry can be attributed to electricity consumption. 
2. China's industrial energy system is shifting to higher power and lower fossil fuels. The share of electricity in final energy use is expected to further increase to $33 \%(21-39 \%)$ by 2040 . Electricity saving potentials, in China's industry, are expected to reduce 4\% (2-5\%), 10\% (6-15\%) and 14\% (7-24\%) of electricity use in 2020, 2030 and 2040, respectively. The electricity savings contribute to $31 \%$ (23$39 \%$ ), 26\% (20-29\%), and 25\% (11-33\%) of total industrial final energy saving in 2020, 2030 and 2040, respectively.

3. Electricity-saving potentials (\%) and contributions (TWh) vary for different industrial subsectors. The iron $\&$ steel sector $(93 \mathrm{TWh})$ contributes to the largest electricity savings, followed by non-ferrous metals, chemical, cement and pulp \& paper sector. The non-ferrous (25\%) and chemical sector (24\%) have the largest potentials to save electricity in 2020. In addition, motor-driven systems in the textile industry leave much room for improving energy efficiency.

4. Increasing energy efficiency in industry can generate synergies to mitigate climate change and improve air quality by reducing emissions of GHGs and air pollutants. In 2040, the potential co-benefits achieved with saving electricity in industry can be reduced emissions of 192-1118 $\mathrm{Mt}_{-} \mathrm{CO}_{2}, 1995-11603 \mathrm{t}-\mathrm{CH}_{4}$, 2851-16584 t- $\mathrm{N}_{2} \mathrm{O}, 385-2241 \mathrm{kt}-\mathrm{SO}_{2}, 406-2362 \mathrm{kt}-\mathrm{NO}_{\mathrm{x}}$ and 92-534 kt-PM ${ }_{2.5}$. Many options exist to reduce emissions from power generation (e.g. more efficient technology, fuel substitution and end-of-pipe measures), but end-use energy efficiency promotion is often cost-effective and can achieve multiple national energy and environmental goals.

\subsection{Policy implications and directions for research}

A trend towards higher electricity and lower fossil fuels is observed in China's industrial energy system. The efficient use of electricity can contribute to around $30 \%$ of total industrial final energy savings in China. This study shows that promoting electricity savings in specific end-use sectors is a win-win strategy for demand-side management and supply-side structural reform. The decrease of electricity demand could reduce emissions of GHGs and air pollutants while limiting the need for construction of new capacity (Peng et al., 2018). Based on the reviewed analysis and discussion, this study highlights the following policy implications (from national, sectoral and regional levels, respectively) and directions for future research.

1. As for national government, it is strongly suggested to further implement energy conservation and emission reduction through a joint policy of enhancing environment quality and energy efficiency on both demand- and supply-side. Electricity savings provide a large potential reduction of air pollutant and GHG 
emission, and need to be included in air quality and climate policy. In addition, policies integrating demand-side savings into power sector planning would help to design a pathway to phase out small and old coal-fired units (e.g. $<300 \mathrm{MWh}$ and $>20$ years) with super-polluting (Tong et al., 2018). To economically achieve the sustainable development goals, a cost-effective technology roadmap for industry should be designed, including details on the energy-intensive subsectors, to maximize benefits of electricity savings, emissions reduction and improving public health. These benefits outweigh investments. The findings suggest that energy efficiency technology will help policies for climate and air quality to be more cost-effective.

2. Promoting electricity conservation in different end-use sectors is an important policy measure. Within industry, policies should prioritize the iron \& steel industry with the largest electricity saving contribution (around $93 \mathrm{TWh}$ in 2020), followed by non-ferrous metals (80 TWh), chemicals (69 TWh) and cement (15 TWh). When implementing sectoral efficiency policies, it would be more effective and economical if decision-makers are able to allocate limited resources to key areas. For example, the efforts for the non-ferrous metals should focus on e.g. aluminum electrolysis (which consume more than 70\% of electricity use in CNFMI) and motor-driven systems for textiles. It is worth noting that increasing waste materials recovery and recycling for non-ferrous metals and pulp \& paper also helps to reduce electricity use but is limited by the available resources. Learning from experiences in the European Union, standardized recycling systems of waste resources (for example, managing the waste material classification and investing in new recycling capacity) should be established to increase the recycling rates of waste materials. Furthermore, new policy of value-added-tax rebates should be formulated to incentive the enthusiasm of enterprises to participate in waste resource recovering and recycling.

3. The impacts of regional grid distribution to address air pollution (Yang et al., 2013a; Yue et al., 2018) and climate change (Peng et al., 2018; Wang and Zhao 2017) should not be ignored. This study suggests that regional decision-makers need to not only understand the co-benefits of emissions reduction and public health, but also different levels of power supply (and consumption) and air quality related to the possible relocation of electricity-intensive industry. Strict regional standards for large electricity consumers (e.g. aluminum and chlor-alkali sectors) should be carried out to restrict new capacity and phase out inefficient capacity in regions with higher emissions of power generation (e.g. Northeast and North grids). Meanwhile, regions in grids with lower emissions of power generation (e.g. Northwest grids) may consider expanding industrial capacity. Regional development policies should include these priorities to effectively address air quality improvements.

4. Regional governments should understand grid-specific synergies related to the regional allocation of abatement targets. Synergies between electricity savings and 
emissions reduction vary per region due to the different levels of power use and specific emission intensities. To achieve national reduction goals effectively, this study suggests that different responsibilities should be assumed by different regions. Therefore, specific policies should be designed to set regional targets. Regions in grids with high potentials of electricity savings and emission reduction should bear the largest responsibility; the minimum burden should be allocated to regions in grids with lower multiple benefits.

5. Future research should focus on studying electricity saving trajectories in the nonferrous metals, textile and pulp \& paper sectors, for which few studies are available. Furthermore, expanding the analysis to other electricity consuming sectors and to provincial/regional level will help to fully understand the contribution of electricity saving to environment and public health, as well as the impacts on grid distribution. Moreover, determining savings helps to identify options to reduce and optimize investments in new power plants and grid expansion, resulting in additional economic benefits. Quantifying the linkages between the supply and demand sides would warrant further research to optimally assess the impacts on power system.

6. Model-based scenario analysis is expected to continue to play a key role in assessing energy systems. A spread in modeling results for different policy scenarios (e.g. energy efficiency, pollutant control and tax measures) is unavoidable due to differing assumptions for urbanization and industrial electrification (especially in developing countries like China and India). Therefore, it is necessary to further improve modeling structures, upgrade key drivers (e.g. GDP, population and urbanization) and technology representations (e.g. specific technology) to design more effective policies.

\section{Acknowledgements}

This study was supported by the China Scholarship Council (Grant No. 201607040082) and the Natural Science Foundation of China (71904007). We would like to thank Prof. Sheng Zhou (Institute of Energy, Environment and Economy at Tsinghua University) and Prof. Qi Zhang (SEPA Key Lab on Eco-industry at Northeastern University) for the valuable comments and input data. The authors gratefully acknowledge Kangyin Dong (School of Business Administration at China University of Petroleum-Beijing), Nan Li (Institute of Nuclear and New Technology at Tsinghua University), Runying An (Center for Energy and Environmental Policy Research at Beijing Institute of Technology), Xuewei Liu (State Key Laboratory of Pollution Control and Resource Reuse at Nanjing University) for the data input in various sectors to this study. 


\section{Supplementary Information}

The supplementary material begins with an overview of China's industry in Section 2.S1. This overview describes the status quo of China's industry in terms of historical electricity consumption, air emissions from purchased electricity, and implemented policy measures targeting energy savings and emission reductions. Thus, this section further emphasized that managing coal-intensive electricity use in China's industry is essential to improve air quality and mitigate climate change. Section $2 . S 2$ provides information on energy consumption trends and energy intensity improvement potentials by industries. This section is a complement of Section 2.4 in the main text, aiming to help decision-makers and researchers to fully understand the relationship between electricity and energy savings in China's industrial energy systems. Section 2.S3 presents the method applied to evaluate the co-benefits of electricity savings in terms of air emission reductions. Supplementary tables include modeling results in absolute value and modeling characteristics (e.g. system boundaries, modeling approaches and scenario parameters) amongst available studies.

\section{SI. Overview of China's industry}

With accelerating industrialization and urbanization, China's industrial value added (IVA) increased nearly five-fold, from $\$ 826$ billion in 2000 to $\$ 3774$ billion in 2016 (at constant 2010 prices (OECD, 2019)), contributing to 33\% of GDP (NBS, 2018). China has been the world's top producer and consumer in key industrial products such as steel, cement, aluminum, paper and chemicals, which are primarily driven by the demand of downstream industries (e.g. construction, automotive and packaging sectors) (Liu et al., 2016). The industrial sector has been a major driver of China's economic boom, and is thus responsible for the vast majority of total energy demand. In 2016, China's industry consumed around $46 \mathrm{EJ}$ of fuel and $4003 \mathrm{TWh}$ of electricity, accounting for $64 \%$ and $69 \%$ of fuel and electricity use, respectively (NBS, 2017). Electricity is the rising force in China's industrial energy use, making up $47 \%$ of the growth in final energy consumption from 2000 to 2016. Due to accelerating end-use electrification, the share of electricity in final energy consumption increased from $12 \%$ in 1996 to $24 \%$ in 2016 . Correspondingly the share of direct coal use decreased from $48 \%$ to $26 \%$. Electricity consumed by China's industry increased dramatically with $9.7 \%$ per year between 2000 and 2016, similar to the average annual growth rate of IVA, which was $9.9 \%$ in the same period. Driven by economic growth and electrification (NDRC and NEA, 2017), the demand for electricity in China's industrial sector is expected to increase further in the future (IEA, 2016a).

The power generation mix in China consists for $72 \%$ of thermal power plants, in 2016 (NBS, 2017). However, the growing use of coal-fired electricity generation to meet the 
fast development of the industrial sector has resulted in large emissions of air pollutants and GHGs. China has doubled its energy-related $\mathrm{CO}_{2}$ emissions from industry since 2005, reaching $5941 \mathrm{Mt}$ in 2015, which is responsible for $69 \%$ of national $\mathrm{CO}_{2}$ emissions (CEADs, 2017). The largest source of $\mathrm{CO}_{2}$ emission from industry is from electricity use with approximately $45 \%$; while coal contributes to approximately $23 \%$, coke $20 \%$, coal gas and natural gas together contribute about $9 \%$, and finally oil $3 \%$. Besides $\mathrm{CO}_{2}$ emissions, industry is the largest contributor to air pollutant emissions in China. In 2015, China's industry is responsible for $76 \%$ of $\mathrm{SO}_{2}, 56 \%$ of $\mathrm{NO}_{\mathrm{x}}$ and $76 \%$ of PM-emissions of total emissions. While $3556 \mathrm{kt}-\mathrm{SO}_{2}, 3494 \mathrm{kt}-\mathrm{NO}_{\mathrm{x}}$ and $1599 \mathrm{kt}-$ $\mathrm{PM}$ are indirect emissions due to the consumption of purchased electricity by industry (MEP, 2018; NBS and MEP, 2018).

In recent years, China took a series of measures (MIIT, 2017b) and policies ((McCollum et al., 2018) to reduce energy consumption and emissions in the industrial sectors. Measures can be classified into 4 types: (1) structural adjustment (e.g. phasing out inefficient production capacities); (2) technology diffusion; (3) constraint control (e.g. capping energy consumption and emissions of GHG and air pollutants); (4) economic incentives (e.g. implementing differential electricity prices and a carbon trading scheme). As a result of these initiatives, the energy intensity (final energy use-to-IVA ratios) reduced at an average rate of 5.0\% per year, from $29 \mathrm{MJ} / \$$ in 2005 to $17 \mathrm{MJ} / \$$ in 2015 . The $\mathrm{CO}_{2}$ emission intensity (emission-to-IVA ratios) dropped at an average rate of $4.5 \%$ per year, declining from $2.6 \mathrm{~kg}-\mathrm{CO}_{2} / \$$ in 2005 to $1.6 \mathrm{~kg}-\mathrm{CO}_{2} / \$$ in 2015 . The emission intensity of air pollutants (emission-to-IVA ratios) reduced dramatically at an average annual rate of $12.1 \%, 10.6 \%$ and $12.8 \%$ for $\mathrm{SO}_{2}, \mathrm{NO}_{\mathrm{x}}$ and $\mathrm{PM}$, respectively. However, the electricity intensity (electricity use-to-IVA ratios) only improved by $12 \%$ in total (equivalent to $1.1 \%$ per year). Therefore, electricity savings and associated synergies in China's industrial sector should be given more attention.

\section{S2. Energy consumption in baseline scenario and energy intensity trends}

\section{S2.I. China's industry}

Final energy consumption in baseline scenario

A comparison of final energy use under different scenarios from 2015 to 2050 is shown in Figure 2.S1. Although energy consumption estimates differ, the characteristics of final energy consumption are reasonably similar in the baseline scenarios (IEA (2016a), EIA (2018) and THU (Zhou et al., 2018b)). All results indicate China's industry is responsible for around 30\% of global industrial energy use, while energy-intensive industrial subsectors account for about half of China's total industrial energy use. China's industrial final energy use will increase steadily from 2015-2030 with $1.1 \%$ of annual average rate (range: $0.9-1.4 \%$ ) in the baseline. However, there are clear differences in 
the projected trends after 2030. The IEA and EIA project a continuous low growth of energy demand until 2040, THU shows a declining trend after 2030. Generally, the final energy use will increase by 19\% (7-31\%) on average in 2040, compared with 2015 levels.

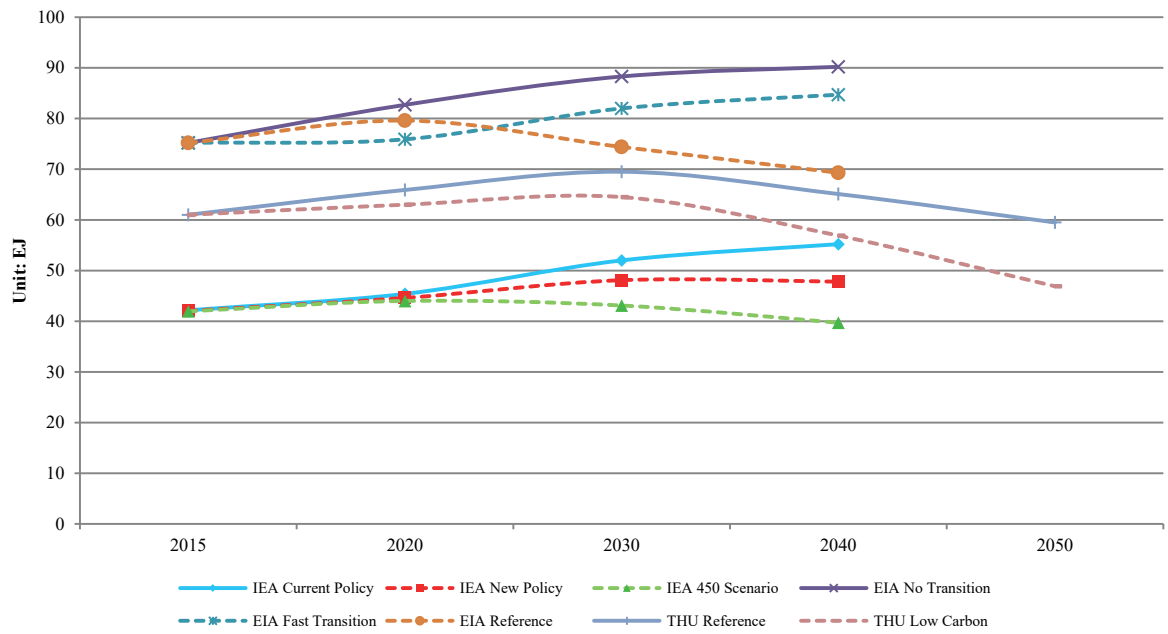

Figure 2.S1. Comparison of final energy use from 2015 to 2050 in different scenarios.

Note: industrial final energy use in IEA (2016a) excluded the coke ovens and blast furnaces.

\section{S2.2. China's industrial subsector}

\section{S2.2.1. Iron \& steel industry}

China's iron \& steel industry (CISI) is defined as the manufacture of ferrous metals smelting and pressing based on China's industrial classification for national economic activities (ICNEA_GB/T 4754-2017), i.e. classification code 31, which comprises of 4 sub-categories (including iron making (311), steel making (312), steel rolling (313), and ferroalloy smelting (314) (AQSIQ and SAC, 2017; NDRC, 2013a).

\section{Final energy consumption in baseline scenario}

As shown in Table 2.1 and Table 2.S2, the estimations of final energy consumption vary in different studies due to the heterogeneity of modeling method, basic assumptions and base-year energy use. Lin and Wang (2014b) using a top-down approach, shows a higher energy demand in CISI, reaching 33 EJ in 2020, compared to other studies that used a bottom-up approach. The energy demand projected by Wang et al. (2007) and LBNL (Zhou et al., 2011) are lower than other studies before 2020, because the energy service demands are based on historical data up to 2005. However, these differences do not have a significant impact on the long-term final energy demand trends (see Figure 2.S2). The 
final energy demand of CISI is expected to approach a plateau at around 2020, and then decline steadily, due to an increased share of EAF production. Generally, the energy demand of CISI is expected to peak around $17 \mathrm{EJ}$ and then decline to $8 \mathrm{EJ}$ (6-10 EJ) in 2050 under baseline scenarios.

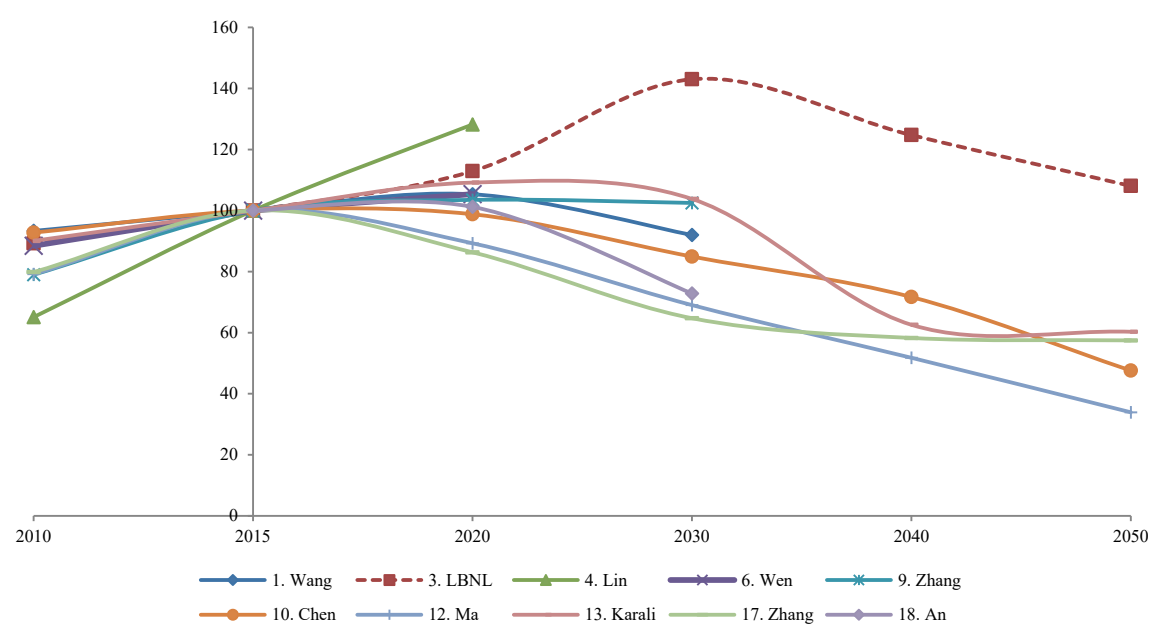

Figure 2.S2. Final energy demand trends in CISI under baseline scenarios (2015=100).

Source: Primary data are from the references compiled in Table 2.1.

\section{Energy intensity trends}

Figure 2.S3 shows the projections of physical energy intensity (GJ/t) for CISI under various scenarios. All scenarios show that the energy intensity of CISI will improve year by year in the future. Changes in CISI's energy intensity can be the result of production structure adjustment (BOF shifts to EAF) and advanced technology promotion. During 2010-2050, the annual average decrease of the energy intensity ranges from 0.3 to $2.1 \%$ (studies focus on the period of 2010-2050). Compared to 2010 level, the energy intensity of CISI is expected to drop by $8 \%$ (4-18\%) in 2020, i.e. from $18-21 \mathrm{GJ} / \mathrm{t}$-steel to $16-20 \mathrm{GJ} / \mathrm{t}$-steel. In the long-term, the energy intensity continues to decline to 12 $\mathrm{GJ} / \mathrm{t}$-steel on average level in 2050, less than the best practice technology level (BPT) (Worrell et al., 2008). Under strong $\mathrm{CO}_{2}$ emission control scenario, Karali et al. (2016) found the energy intensity could be reduced by max- $56 \%$ in 2050 compared to the level of 2010 (from 18 to $8 \mathrm{GJ} / \mathrm{t}$-steel) via implementing more EETs (see Table 2.S5). 


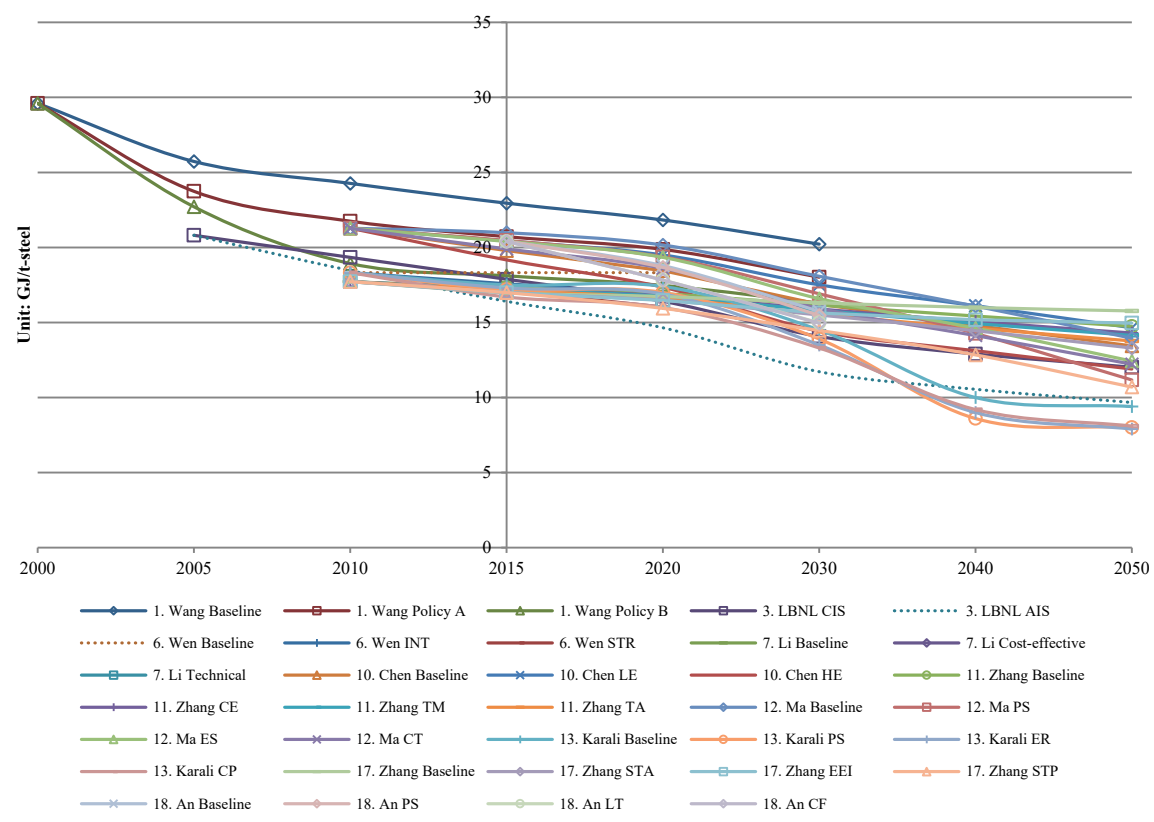

Figure 2.S3. Trends of energy intensity of CISI under various scenarios.

Source: Primary data are from the references compiled in Table 2.1.

\section{S2.2.2. Cement industry}

China's cement industry (CCI) is defined as a sub-category of the manufacture of non-metallic mineral products, i.e. ICNEA classification code 301 (AQSIQ and SAC, 2017). The processes involved in cement manufacturing include fuel and raw material preparation, clinker making and cooling, and cement grinding) (NDRC, 2013b).

\section{Final energy consumption in baseline scenario}

Figure 2.S4 shows the future trends of energy demand for CCI from 2010 to 2050 under baseline scenarios. Different with CISI, the study period of final energy use in CCI is mainly concentrated in the short-term (i.e. 2010-2030). Only two studies (Zhou et al., 2011; Li et al., 2017) project the long-term energy consumption until 2050. The energy demand in China's cement sector peaked at around 2015 in accordance with the projected peak cement output, and peak final energy use reached around 6 EJ. Energy demand then shows a declining trend during 2015-2030, by an annual average rate of $3 \%(1-5 \%)$. By 2030, energy demand is expected to drop to less than 2010. In the longterm, the final energy use optimistically declines by around $27 \%(23-31 \%)$ in 2050 , compared to 2010 . 


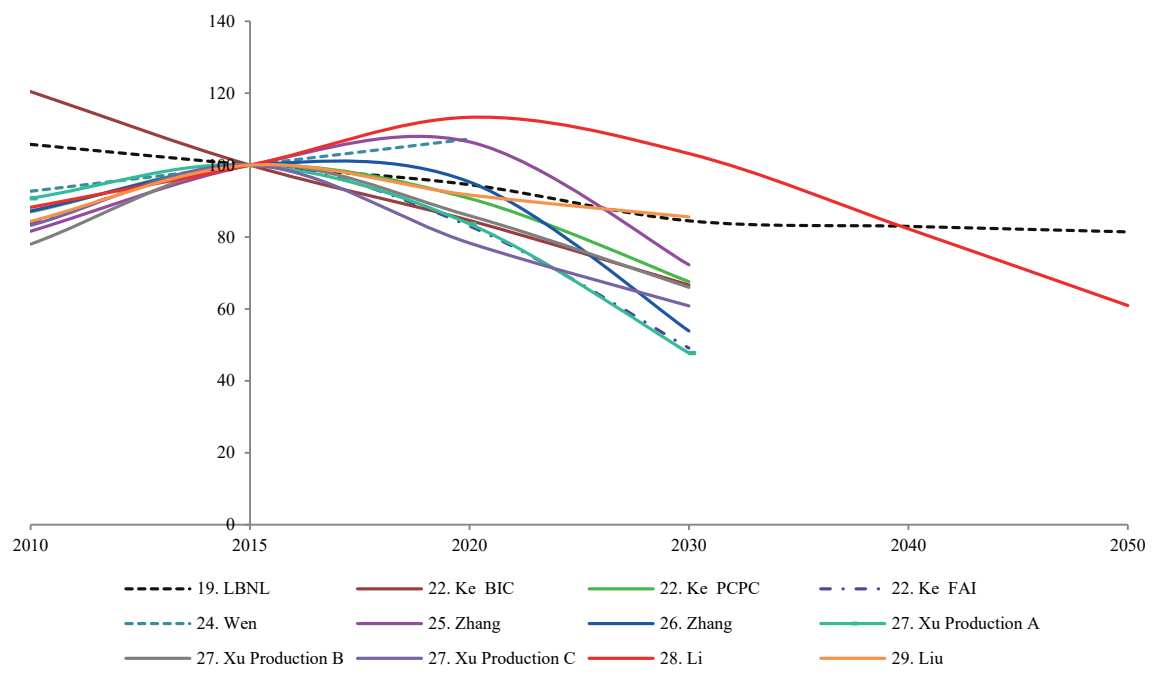

Figure 2.S4. Final energy demand trends in CCI under baseline scenarios $(2015=100)$.

Source: Primary data are from the references compiled in Table 2.1.

\section{Energy intensity trends}

Figure 2.S5 shows the decreasing energy intensity for all scenarios (with the exception of Liu et al. (2017)) in CCI. The shape of energy intensity trends is not smooth during 2010-2030, showing that energy efficiency would improve greatly in the short-term. One study (Ke et al., 2012) assumed that the overall energy intensity would reach the BPT level for 425 fly ash cement (FAC) in 2030 (Worrell et al., 2008), i.e. $2.1 \mathrm{GJ} / \mathrm{t}$ cement, with a maximum reduction of $34 \%$ compared to 2010. If a high carbon tax $\left(215 \$ / \mathrm{t}-\mathrm{CO}_{2}\right.$ ) was implemented to promote EETs (Li et al., 2017), the energy intensity of CCI would be further reduced to the BPT level of 425 blast furnace slag cement (BFSC) by 2050 (i.e. $1.6 \mathrm{GJ} / \mathrm{t}$-cement). The annual reduction of the energy intensity is within the range of $0.2-2.0 \%$ and $0.3-2.1 \%$ for $2010-2030$ and $2030-2050$, respectively. 


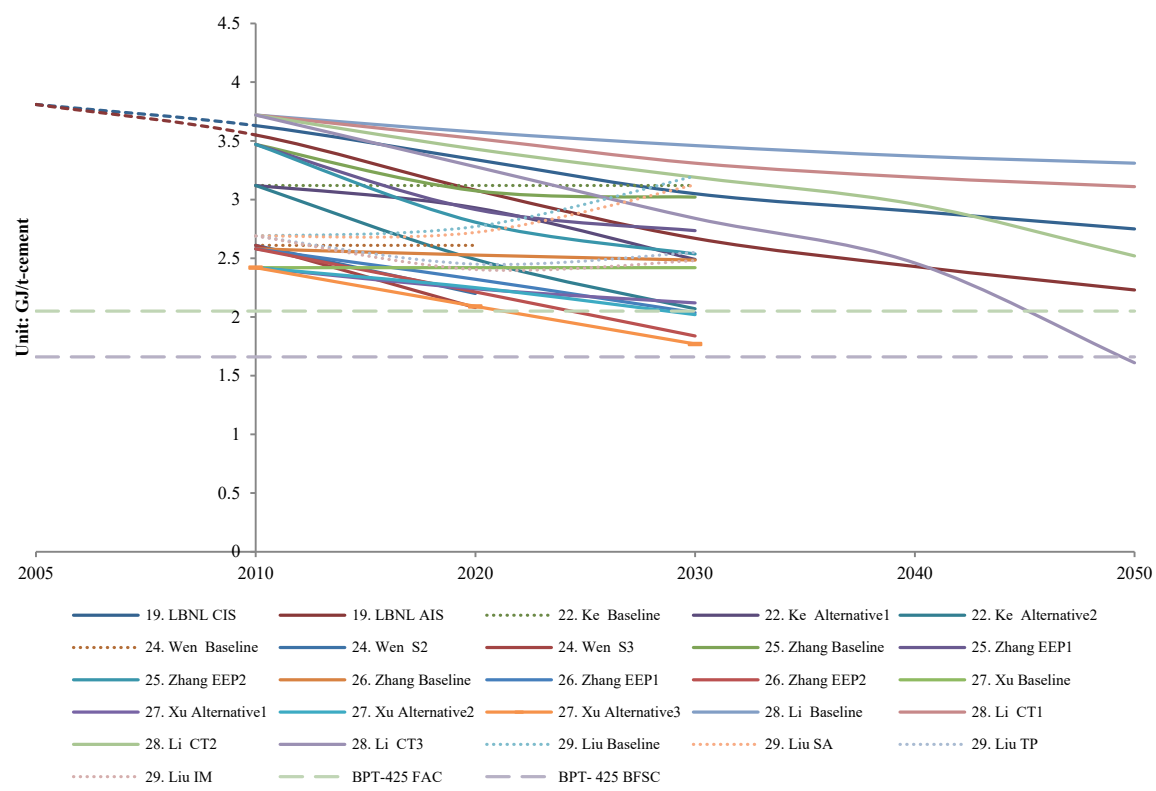

Figure 2.S5. Energy intensity of CCI under all scenarios.

Source: Primary data are from the references compiled in Table 2.1.

\section{S2.2.3. Non-ferrous metals industry}

China's non-ferrous metals industry (CNFMI) is a multi-products industry producing more than ten non-ferrous metals (e.g. aluminum, copper, lead, magnesium, zinc). CNFMI is defined as the manufacture of non-ferrous metals smelting and pressing based on ICNEA, i.e. classification code 32, which consists of 5 sub-categories (including common non-ferrous metals smelting (321), noble metals smelting (322), rare and rare earth metals smelting (323), non-ferrous metal alloy making (324), and non-ferrous metal rolling (325)) (AQSIQ and SAC, 2017; NDRC, 2013c, d).

\section{Final energy consumption in baseline scenario}

As shown in Figure 2.S6, all studies indicate the final energy use in CNFMI is expected to keep growing in the future. The future energy consumption in CNFMI was explored from 2 aspects. (1) For the aluminum production, the energy demand will increase by 9-76\% in the coming year 2020 compared to 2015 level, reaching $1.9 \mathrm{EJ}$ (range: 1.3-2.5 EJ) (Zhou et al., 2011; Lin and Xu, 2015). In the long-term, LBNL projected the energy consumption will continue increase during 2020-2050, with an annual growth rate of $2 \%$. (2) For five non-ferrous metals (i.e. aluminum, copper, lead, zinc and magnesium), the total final energy use is expected to grow by $15 \%$ in 2020 compared to 2015 , reaching 2.6 EJ (Wen and Li, 2014). Final energy use in the whole non-ferrous metals sector will grow both in absolute terms and the relative share of China's industrial total 
energy consumption, attributing to the increasing vehicle ownership and upgrading of rural power grids (MIIT, 2016).

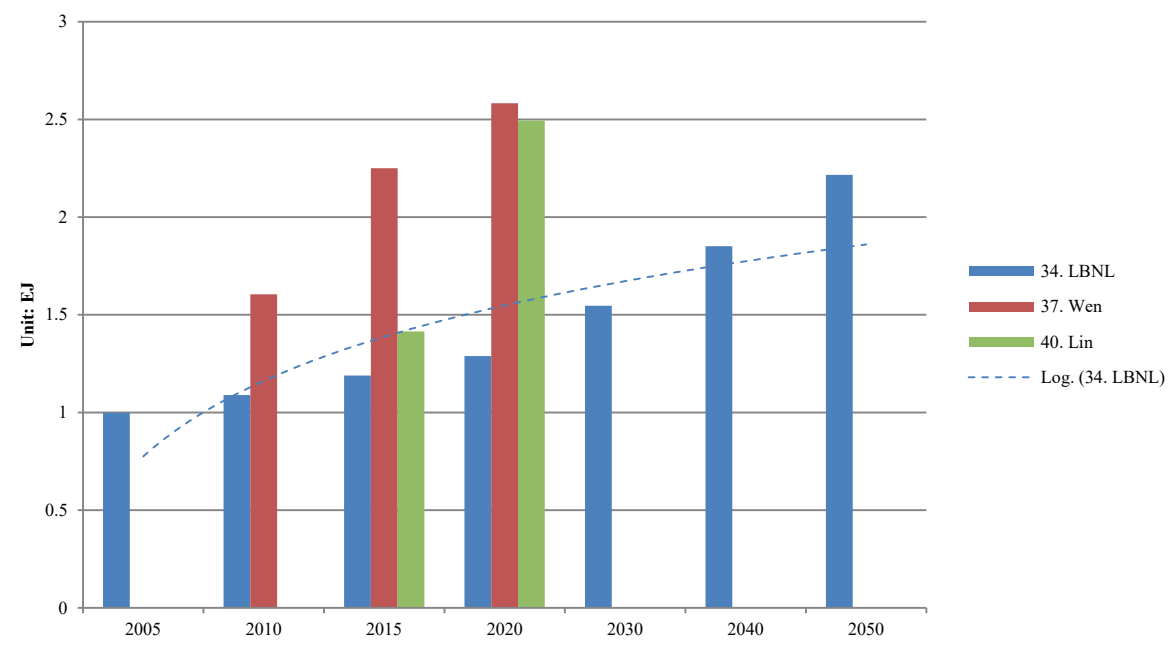

Figure 2.S6. Final energy demand trends in CNFMI.

Source: Primary data are from the references compiled in Table 2.1. Note: the studies 34. LBNL and 40. Lin focus on the final energy use of aluminum production; the study 37. Wen projected the final energy use of five non-ferrous metals.

\section{Electricity intensity trends}

The downward trend of projected electricity intensity (alternating current-AC) for aluminum smelting is shown in Figure 2.S7. IAI (2020) indicates Chinese producers have overtaken most primary smelters to become the world's most efficient (world average value of 14.2 MWh in 2015). MIIT (2016) shows the electricity intensity has dropped by $4.5 \%$ in 2015 compared to 2010 , and set a target efficiency of $13.2 \mathrm{MWh} / \mathrm{t}$ $\mathrm{Al}$ for 2020. However, the target efficiency in 2020 still has a gap with the international advanced level, i.e. 12.9 MWh/t-Al (NBS, 2017). If more investments were allocated to promote advanced technologies (e.g. anode current distribution on-line measuring, and new cathode structure of aluminum reduction cell) and phase out inefficient capacity (i.e. prebaked anode aluminum electrolysis cell below $400 \mathrm{kA}$ ), the electricity intensity would expect to drop by 7\% (5-10\%) in 2020 compared to 2015 level, lower than the world advanced level (Wen and Li, 2014; Zhang et al., 2015e). 


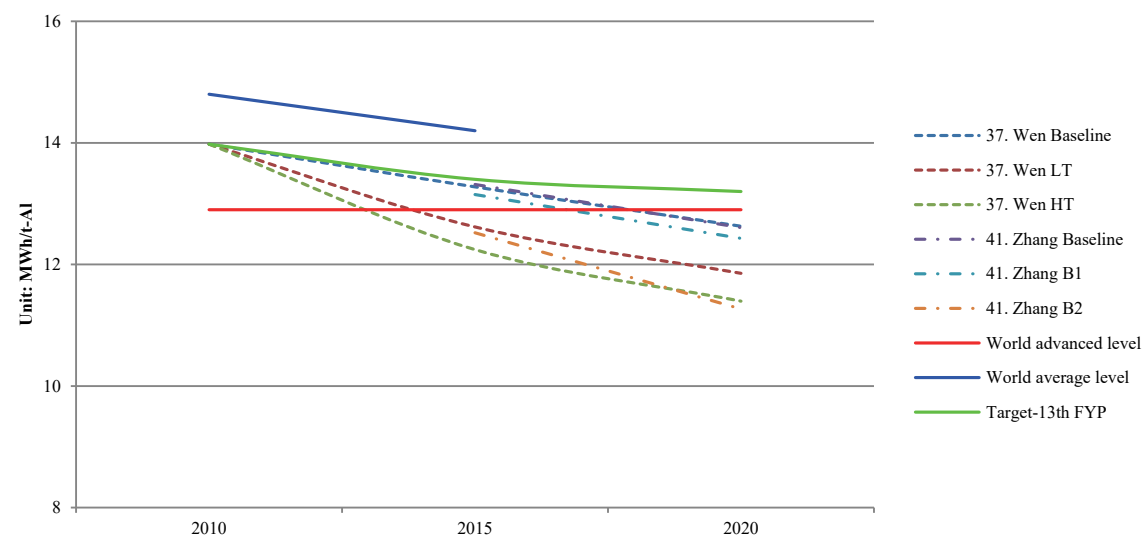

Figure 2.S7. AC-electricity intensity of aluminum smelting under various scenarios.

Source: Primary data are from the references compiled in Table 2.1.

\section{S2.2.4. Pulp \& paper industry}

China's pulp \& paper industry (CCI) refers to the manufacture of paper and paper products based on the ICNEA, i.e. classification code 22 . Three sub-categories are included in the classification of CCI (i.e. pulp making (221), paper making (222), and paper products making (223)) (AQSIQ and SAC, 2017; NDRC, 2013e).

\section{Final energy consumption in baseline scenario}

Research on the future energy consumption in China's pulp \& paper industry (CPPI) is limited (see Table 1). Only two studies project the energy consumption in China's pulp \& paper sector after 2020, as shown in Figure 2.S8. LBNL predicted the final energy consumption will peak at $1.3 \mathrm{EJ}$ around 2030. However, China's official data show the energy consumption has peaked in 2009, and then declined with an annual rate of $2 \%$ during 2009-2016 (NBS, 2017). Interestingly, the official peak value is similar with the predicted value, around $1.3 \mathrm{EJ}$. 


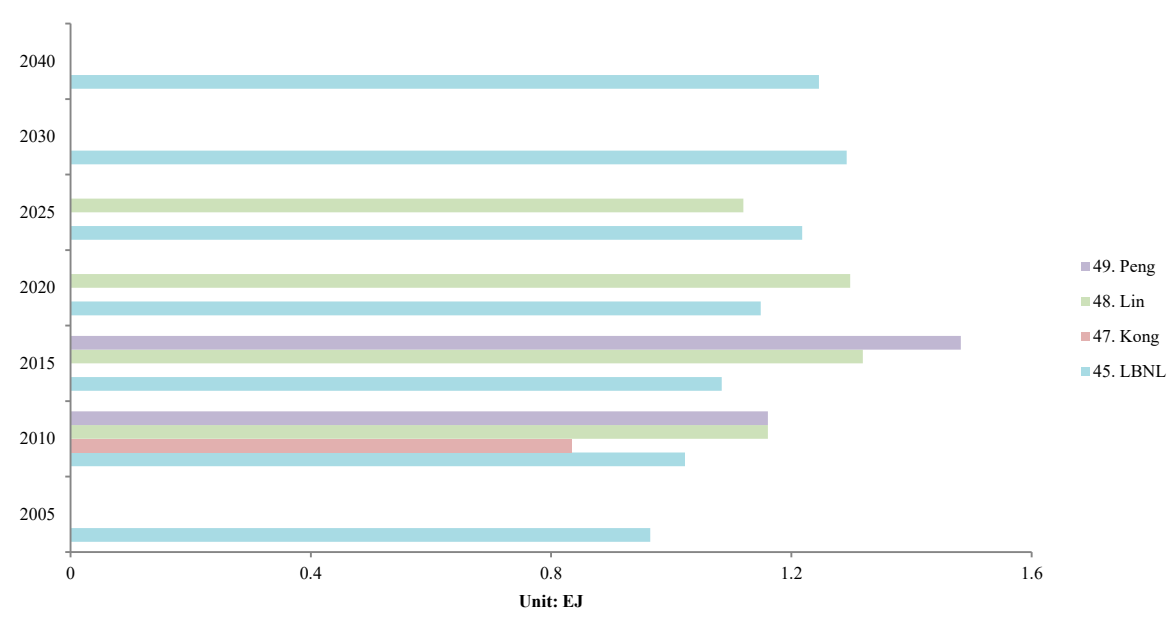

Figure 2.S8. Final energy demand in CPPI under baseline scenarios.

Source: Primary data are from the references compiled in Table 2.1.

\section{Energy intensity trends}

Figure 2.S9 shows the reducing trends in projected energy intensity both from an economic $\left(\mathrm{GJ} / 10^{3} \mathrm{RMB}\right)$ and physical perspective $(\mathrm{GJ} / \mathrm{t}$-paper) in CPPI. From an economic view, the energy intensity changes dramatically during 2010-2025, dropping from 11.7 to $1.1-2.1 \mathrm{GJ} / 10^{3} \mathrm{RMB}$. The physical intensity is our focus because it can better reflect how the energy efficiency evolves (Liu et al., 2013; Peng et al., 2015a). The physical energy intensity projected by LBNL will decline from 15.5 in 2005 to $9.7 \mathrm{GJ} / \mathrm{t}$ paper in 2050, with an annual average decline rate of $1 \%$. Interestingly, the projected value by LBNL in 2050 (9.7 GJ/t-paper) is similar to the norm of energy consumption per unit product of CPPI, and it would be achieved in recent years (AQSIQ and SAC, 2016; MIIT, 2014). Although the physical energy intensity improved noticeably in China, there still are large gaps with best available technology (BAT) level, i.e. 5.0 GJ/tpaper (Peng et al., 2015a; Kong et al., 2013). In addition, the available official data indicate that the current energy intensity of CPPI (average level of enterprises which made pulp by oneself) doubled that of Japan (NBS, 2017). The sector should continue to focus on improving energy efficiency, moving towards BAT-level performance. 


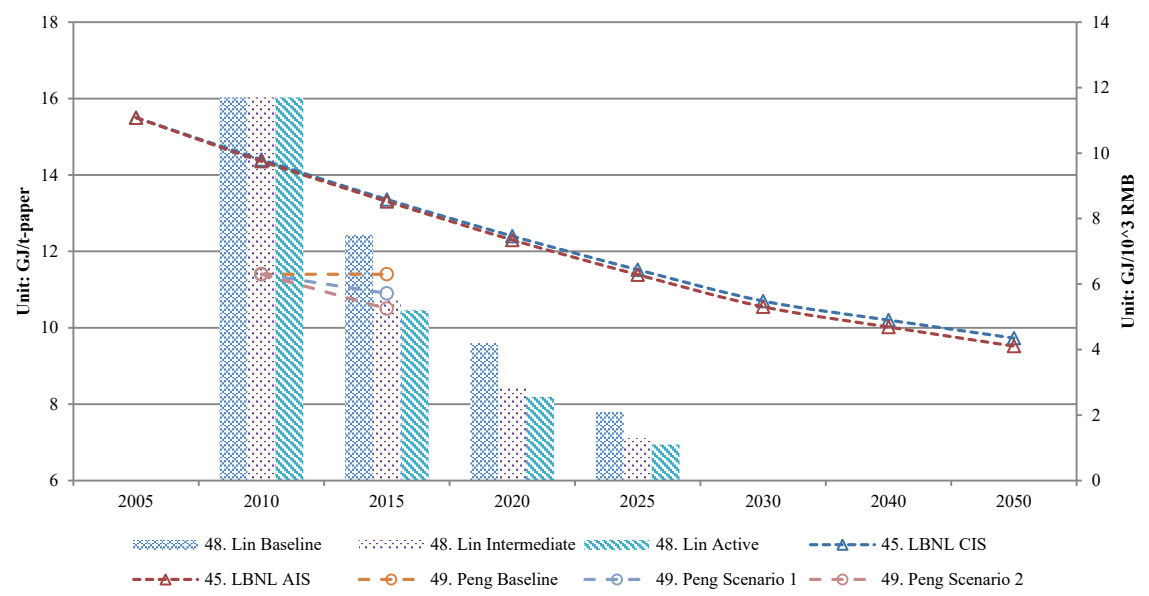

Figure 2.S9. Energy intensity for CPPI under various scenarios.

Source: Primary data are from the references compiled in Table 2.1.

\section{S2.2.5. Chemical industry}

China's chemical industry (CCMI), producing thousands of chemical products, refers to the manufacture of raw chemical materials and chemical products (ICNEA classification code 26) (AQSIQ and SAC, 2017). Eight sub-categories are included in CCMI (i.e. basic chemicals making (261), fertilizers making (262), pesticides making (263), coatings, inks, paints and similar products making (264), synthetic materials making (265), special chemical products making (266), explosives, pyrotechnics and fireworks making (267), and daily chemical products making (268)) (Yue et al., 2018; NDRC, 2013f).

\section{Final energy consumption in baseline scenario}

Figure 2.S10 shows the final energy consumption in CCMI will increase until 2030 under baseline scenarios. However, two different trajectories are projected by LBNL and IEA-technology roadmap (IEA, 2013) after 2030. LBNL, including 2 chemical sectors (ammonia and ethylene), shows a declining trend, while IEA-TR including 18 chemical sectors indicates a steady growth for the chemical industry during 2030-2050. Different boundaries of the chemical industry are responsible for the differences in energy consumption. Chemical products are widely applied in various industries and show a large market demand (Kearney and CPCIF, 2017; CPCIF, 2017). In addition, "The Belt and Road Initiative" (Ascensão et al., 2018) and "Made in China 2025" (Li, 2018) will drive future demand for chemical products in the long-term. However, ammonia (one of energy-intensive chemicals) is an exception because $90 \%$ of ammonia production is used to produce fertilizers in China (CPCIF, 2017; Kermeli et al., 2017). Driven by fertilizer demand, ammonia production is likely to show slower growth in the future and will peak by 2030 (Zhou et al., 2011; Zhang et al. 2013; MAC, 2015). 
After 2030, ammonia production is expected to show a declining trend due to demand saturation and overcapacity (Yue et al., 2018). For the whole chemical industry, the final energy consumption is expected to continue rising in the long-term (IEA, 2013; Yue et al., 2018).

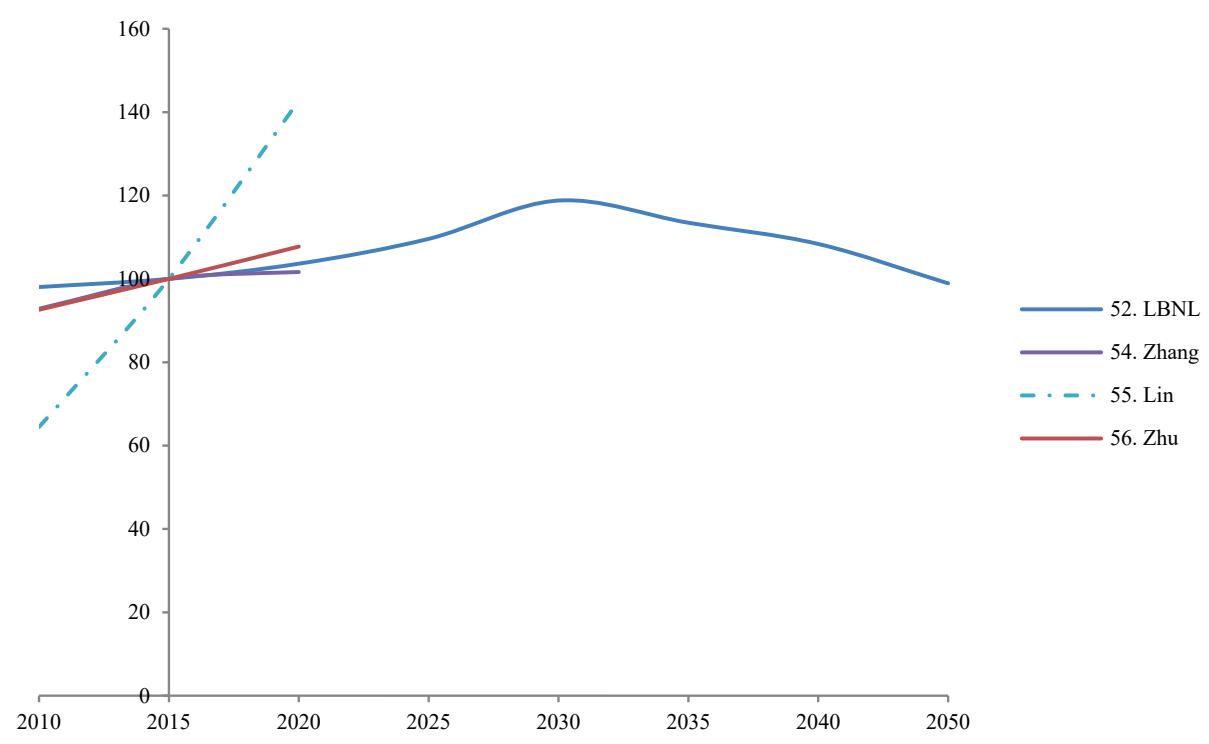

Figure 2.S10. Final energy demand trends in CCMI $(2015=100)$.

Source: Primary data are from the references compiled in Table 1. Note: the study 55. Lin focus on fossil fuel consumption in the entire chemical industry; the study 52. LBNL projected the total final energy use of ammonia and ethylene; the studies 54. Zhang and 56. Zhu focus on the final energy consumption of ammonia.

\section{Electricity intensity trends}

The economic electricity intensity for the whole chemical sector had a downward electricity tendency, and declined by a large margin (as shown in Figure 2.S11). Due to the diversity of chemical products, the bottom-up approach cannot cover all production processes in the chemical industry. Yue et al. (2018) covers three electricity-intensive chemical subsectors, and shows continuous improvement of electricity efficiency for each subsector. The results indicate that the physical intensity with promoting the electricity conservation technologies is expected to reduce by $60-65 \%, 20-30 \%$ and 31 $39 \%$ for ammonia, chlor-alkali and calcium carbide sectors in 2035 compared to 2012 level, respectively. 


\section{Chapter 2}

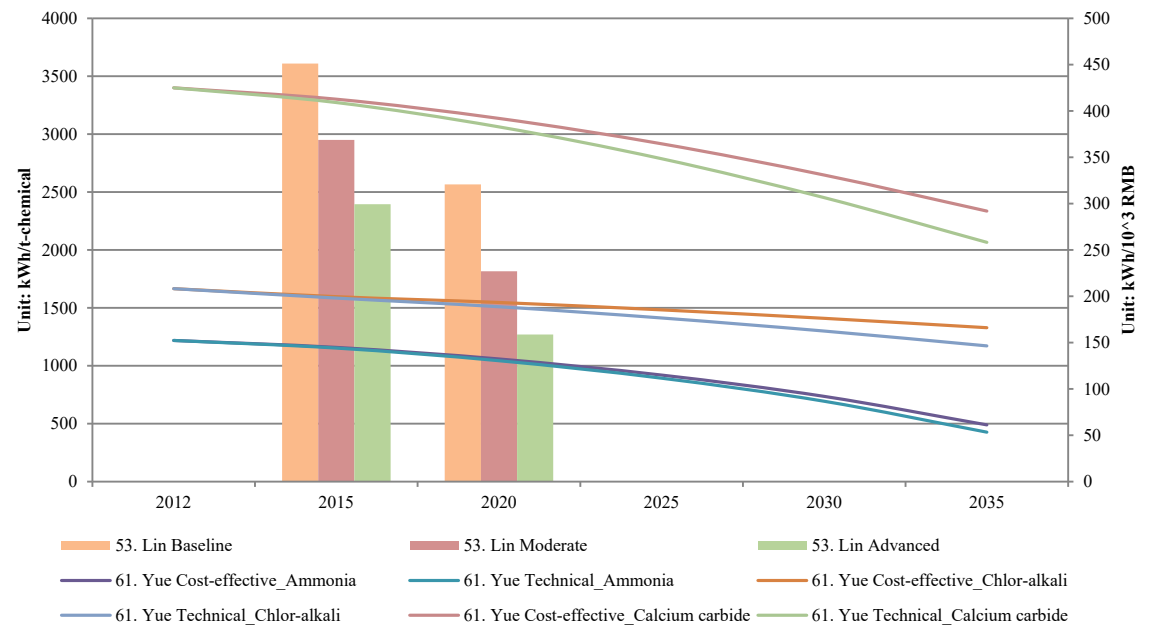

Figure 2.S11. Electricity intensity for CCMI under various scenarios.

Source: Primary data are from the references compiled in Table 1. Note: the study 53. Lin studied the electricity use in the whole chemical industry; the study 61. Yue projected the electricity savings in three chemical subsectors (ammonia, chlor-alkali and calcium carbide).

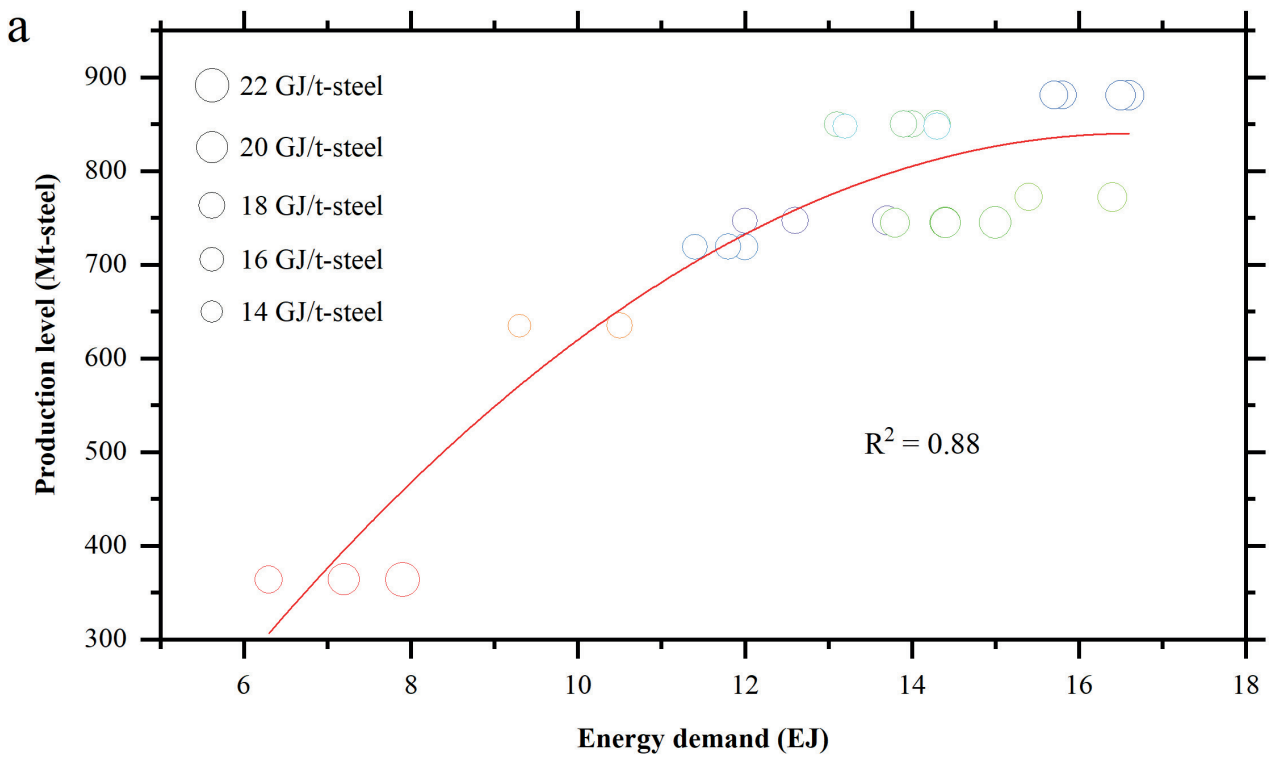

Figure 2.S12. 


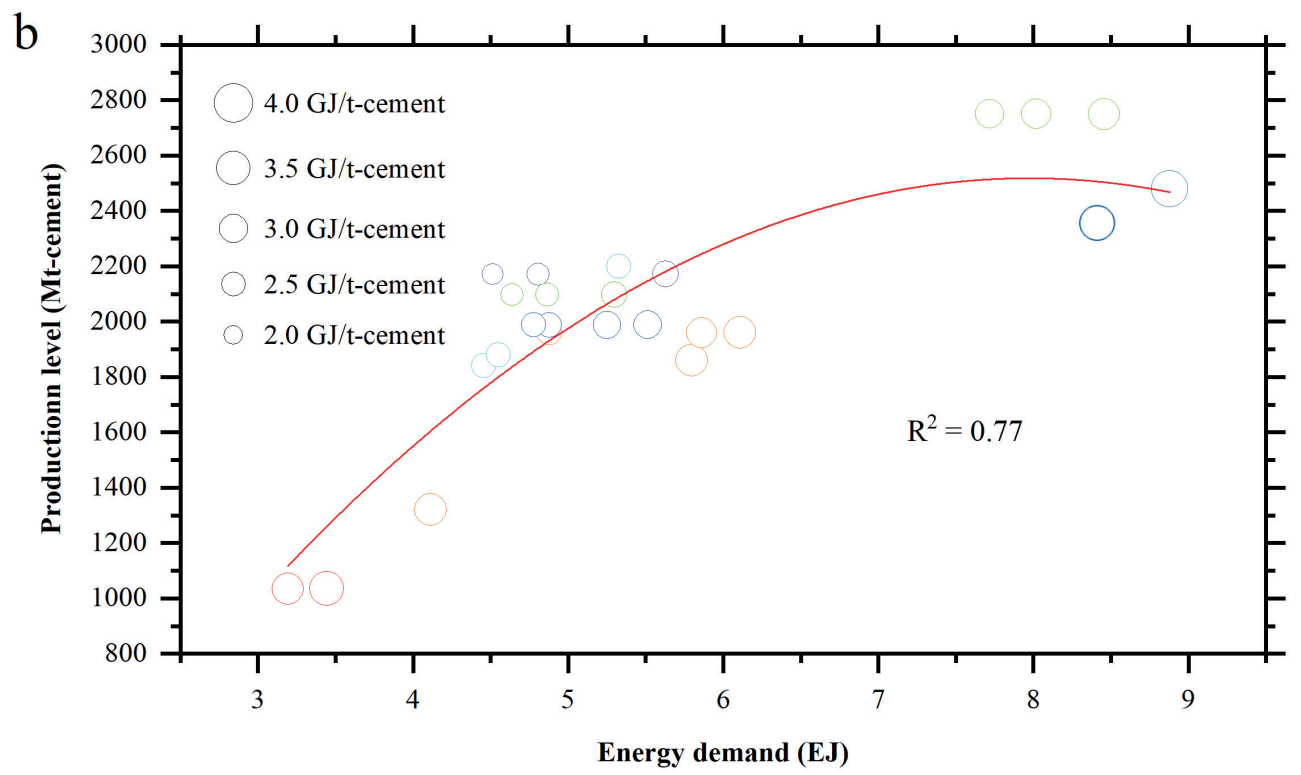

Figure 2.S12 (continued). Comparison of modeling projections in terms of energy demand and intensity for CISI (a) and CMI (b) in various scenarios among studies. Source: Primary data are from (a) Wang et al. (2007), Zhou et al. (2011), Wen et al. (2014), Chen et al. (2014), Ma et al. (2016), Karali et al. (2016), Zhang (2015a), Zhang et al. (2018) and An et al. (2018); (b) Zhou et al. (2011), Ke et al. (2012), Wen et al. (2015a), Zhang et al. (2015b,c), Xu and Fan (2013), Li et al. (2017) and Liu et al. (2017).

\section{S3. Methodology for accounting the multiple benefits of electricity savings}

Improving electricity efficiency in China's industry can bring multiple benefits for climate change and air quality, by reducing both types of emissions. Based on the emission factors of $\mathrm{GHG}$ (e.g. $\mathrm{CO}_{2}, \mathrm{CH}_{4}$ and $\mathrm{N}_{2} \mathrm{O}$ ) and air pollutants (e.g. $\mathrm{SO}_{2}, \mathrm{NO}_{x}$ and $\left.\mathrm{PM}_{2.5}\right)$ and the amount of electricity savings, the synergies of electricity saving on emissions reduction in China's industry can be calculated by Equation (2.S1) (Yue et al., 2018).

$E R B_{i}=E S \times E F_{i}$

Where $E R B_{i}$ represents the reduction benefits of emission $i$ (i.e. $\mathrm{CO}_{2}, \mathrm{CH}_{4}, \mathrm{~N}_{2} \mathrm{O}, \mathrm{SO}_{2}$, $\mathrm{NO}_{\mathrm{x}}$ and $\mathrm{PM}_{2.5}$ ) from electricity savings; $E S$ is the electricity savings in China's industry; $E F_{i}$ is the emission factor for $i$.

The emission factors are the average level of China's six power grids (North, Northeast, East, Central, Northwest and Southern) from Yue et al. (2018). The amounts of electricity savings in Chinass industry are from IEA (2016a) and THU (Zhou et al., 2018b). 


\section{Chapter 2}

Table 2.S1. Summary of system boundaries for each study.

\begin{tabular}{|c|c|c|}
\hline No. & Reference & Major system boundary \\
\hline \multicolumn{3}{|c|}{ Iron \& steel } \\
\hline 1 & Wang et al. (2007) & $\begin{array}{l}\text { Coke making, sintering, iron making (blast furnace), steel making (BOF and EAF), } \\
\text { casting and rolling }\end{array}$ \\
\hline 2 & Lin and Wang (2014a) & Iron $\&$ steel industry as a whole (economic activity drivers) \\
\hline 3 & LBNL & $\begin{array}{l}\text { Iron } \& \text { steel industry as a whole (physical activity drivers for different production } \\
\text { routes, i.e. EAF and BOF) }\end{array}$ \\
\hline 4 & Lin and Wang (2014b) & Iron $\&$ steel industry as a whole (economic activity drivers) \\
\hline 5 & ERI & $\begin{array}{l}\text { Coke making, sintering, iron making (blast furnace), steel making (BOF and EAF), } \\
\text { casting, and rolling }\end{array}$ \\
\hline 6 & Wen et al. (2014) & $\begin{array}{l}\text { Coke making, sintering, iron making (blast furnace), steel making (BOF and EAF), } \\
\text { casting, and rolling }\end{array}$ \\
\hline 7 & $\mathrm{Li}$ and $\mathrm{Zhu}(2014)$ & $\begin{array}{l}\text { Coke making, sintering, iron making (blast furnace), steel making (BOF and EAF), } \\
\text { casting, and rolling }\end{array}$ \\
\hline 8 & $\begin{array}{l}\text { Hasanbeigi et al. } \\
(2013 b)\end{array}$ & $\begin{array}{l}\text { Coke making, sintering, iron making (blast furnace), steel making (BOF and EAF), } \\
\text { casting, and rolling }\end{array}$ \\
\hline 9 & Zhang et al. (2014) & $\begin{array}{l}\text { Coke making, sintering, iron making (blast furnace), steel making (BOF and EAF), } \\
\text { casting and rolling }\end{array}$ \\
\hline 10 & Chen et al. (2014) & $\begin{array}{l}\text { Coke making, sintering, iron making (blast furnace), steel making (BOF and EAF), } \\
\text { casting, and rolling }\end{array}$ \\
\hline 11 & Zhang et al. (2017) & $\begin{array}{l}\text { Coke making, sintering, iron making (blast furnace), steel making (BOF and EAF), } \\
\text { casting and rolling }\end{array}$ \\
\hline 12 & Ma et al. (2016) & $\begin{array}{l}\text { Coke making, sintering, iron making (blast furnace), steel making (BOF and EAF), } \\
\text { casting, and rolling }\end{array}$ \\
\hline 13 & Karali et al. (2016) & $\begin{array}{l}\text { Coke making, sintering, iron making, steel making (BOF and EAF), casting, and } \\
\text { rolling }\end{array}$ \\
\hline 14 & Ma et al. (2015a) & $\begin{array}{l}\text { Coke making, sintering, iron making (blast furnace), steel making (BOF and EAF), } \\
\text { casting, and rolling }\end{array}$ \\
\hline 15 & Zhang (2015a) & $\begin{array}{l}\text { Coke making, sintering, iron making (blast furnace), steel making (BOF and EAF), } \\
\text { casting, and rolling }\end{array}$ \\
\hline 16 & Wu et al. (2016) & $\begin{array}{l}\text { Coke making, sintering, iron making (blast furnace), steel making (BOF and EAF), } \\
\text { casting, and rolling }\end{array}$ \\
\hline 17 & Zhang et al. (2018) & $\begin{array}{l}\text { Coke making, sintering, iron making (blast furnace), steel making (BOF and EAF), } \\
\text { casting, and rolling }\end{array}$ \\
\hline 18 & An et al. (2018) & $\begin{array}{l}\text { Coke making, sintering, iron making (non-blast and blast furnace), steel making } \\
\text { (BOF and EAF), casting, and rolling }\end{array}$ \\
\hline
\end{tabular}

\section{Cement}

19 LBNL

20 Xu et al. (2012)

21 Hasanbeigi et al. (2013a)

$22 \quad$ Ke et al. (2012)

23 ERI

24 Wen et al. (2015a)

25 Zhang et al. (2015b)

26 Zhang et al. (2015c)

$27 \quad \mathrm{Xu}$ and Fan (2013)

$28 \quad$ Li et al. (2017)

Cement industry as a whole (physical activity drivers for different production routes, i.e. rotary and shaft kilns)

Cement industry as a whole (physical activity drivers for different production routes, i.e. rotary and shaft kilns)

Raw materials and fuel preparation, clinker making, and cement grinding

Cement industry as a whole (physical activity drivers for different production routes, i.e. rotary and shaft kilns)

Raw materials and fuel preparation, clinker making, and cement grinding

Raw materials and fuel preparation, clinker making, and cement grinding

Raw materials and fuel preparation, clinker making, and cement grinding

Raw materials and fuel preparation, clinker making, and cement grinding

Cement industry as a whole (physical activity drivers)

Raw materials and fuel preparation, clinker making, and cement grinding 


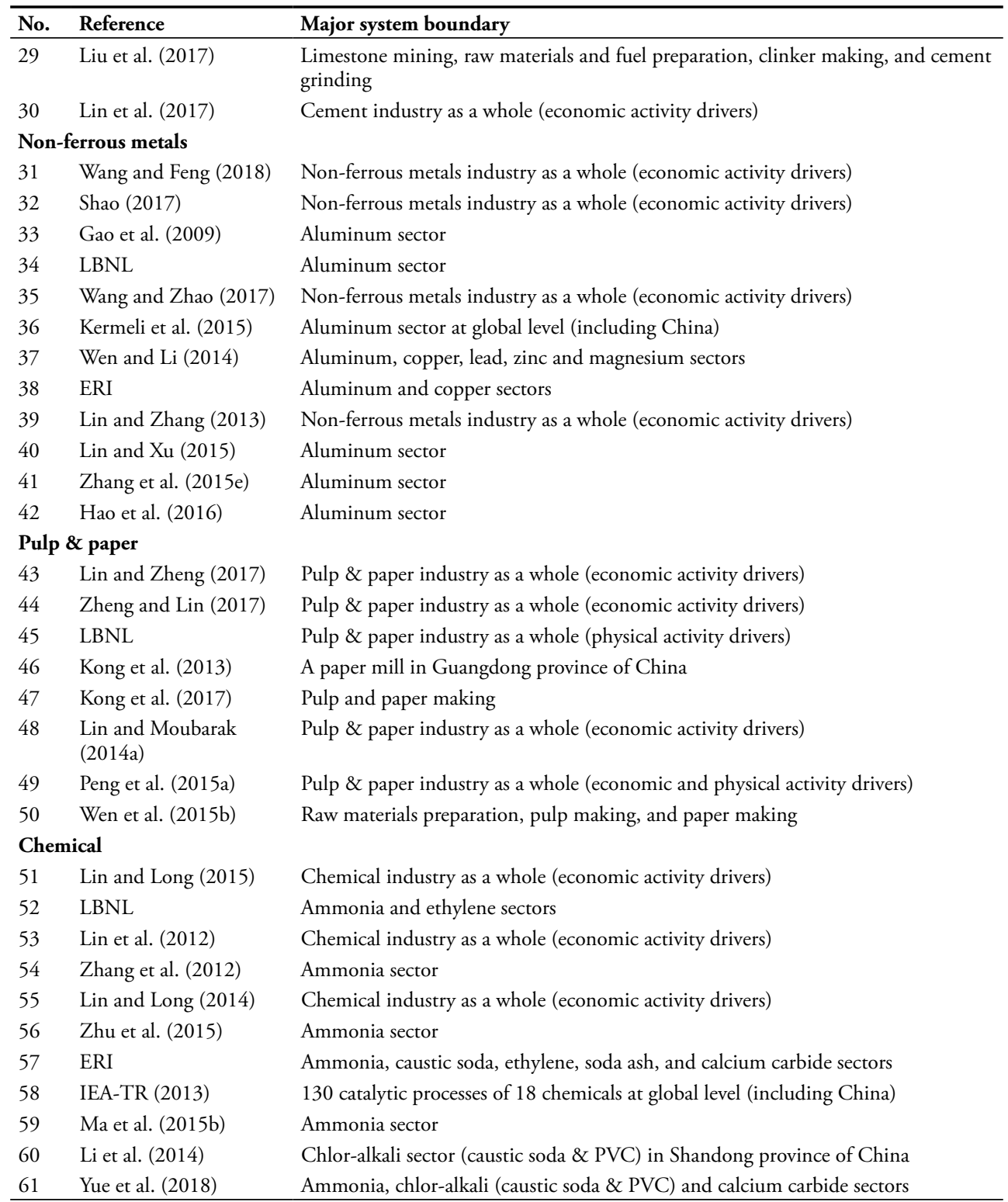

Note: the references in Table S1 correspond to the paper (one by one) instead of the Supplementary material. 


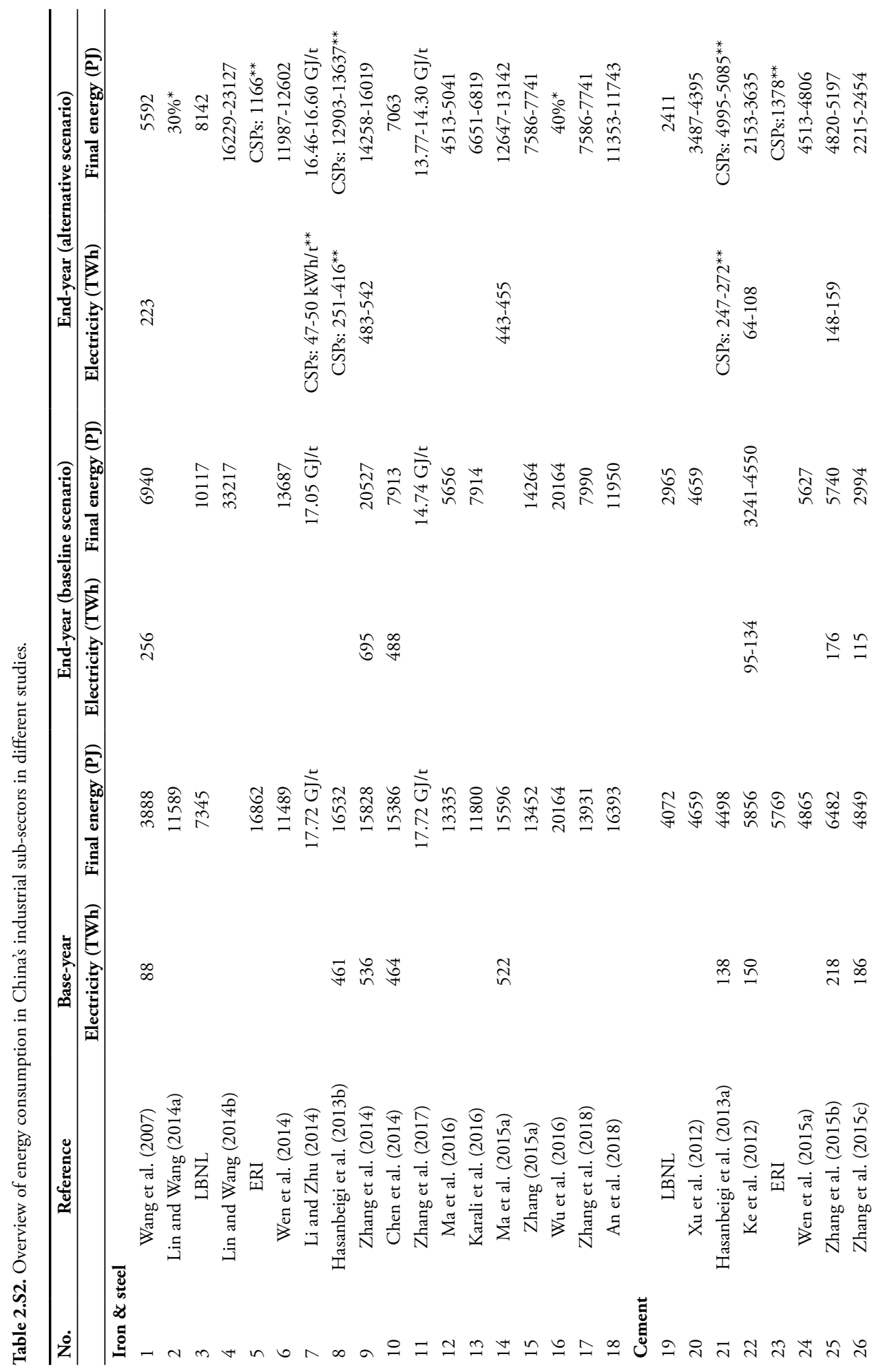


Saving energy in China's industry with a focus on electricity

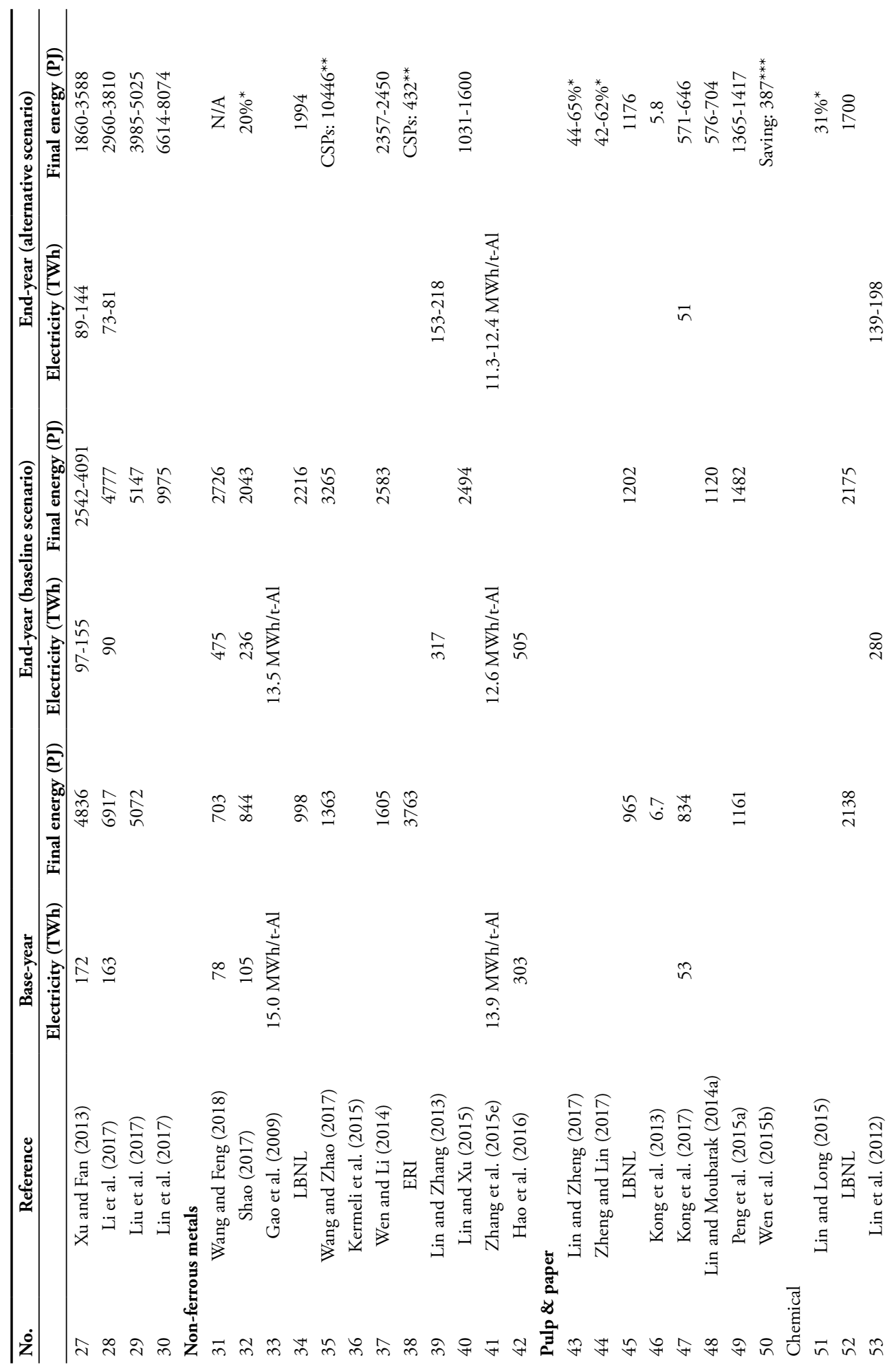


Chapter 2

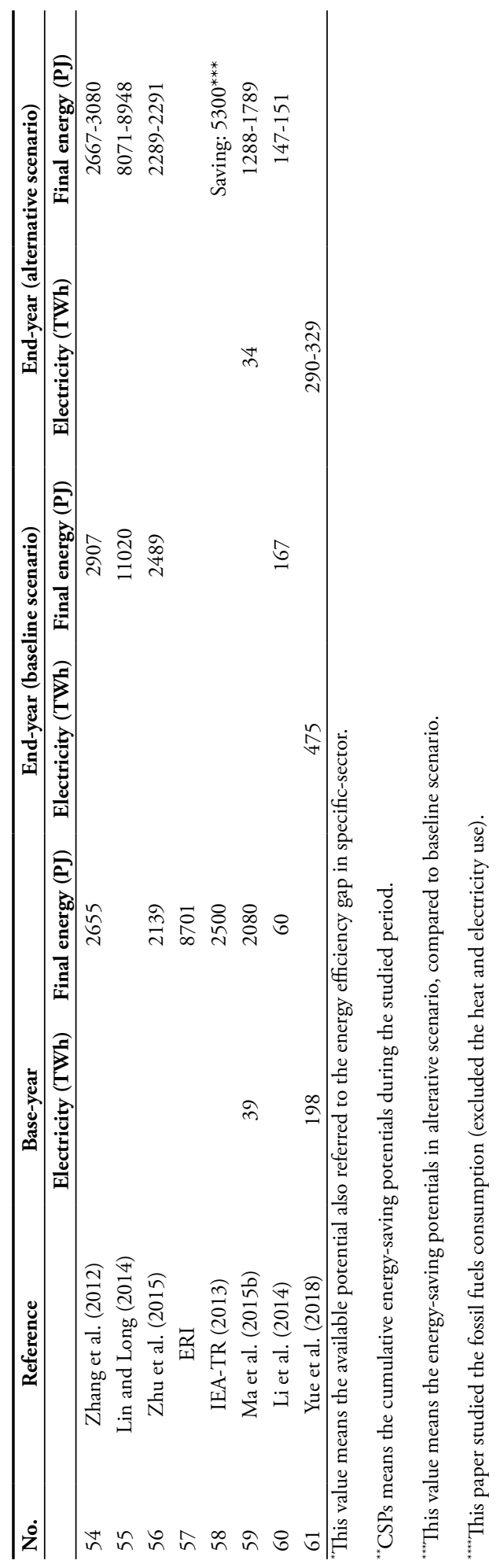


Saving energy in China's industry with a focus on electricity

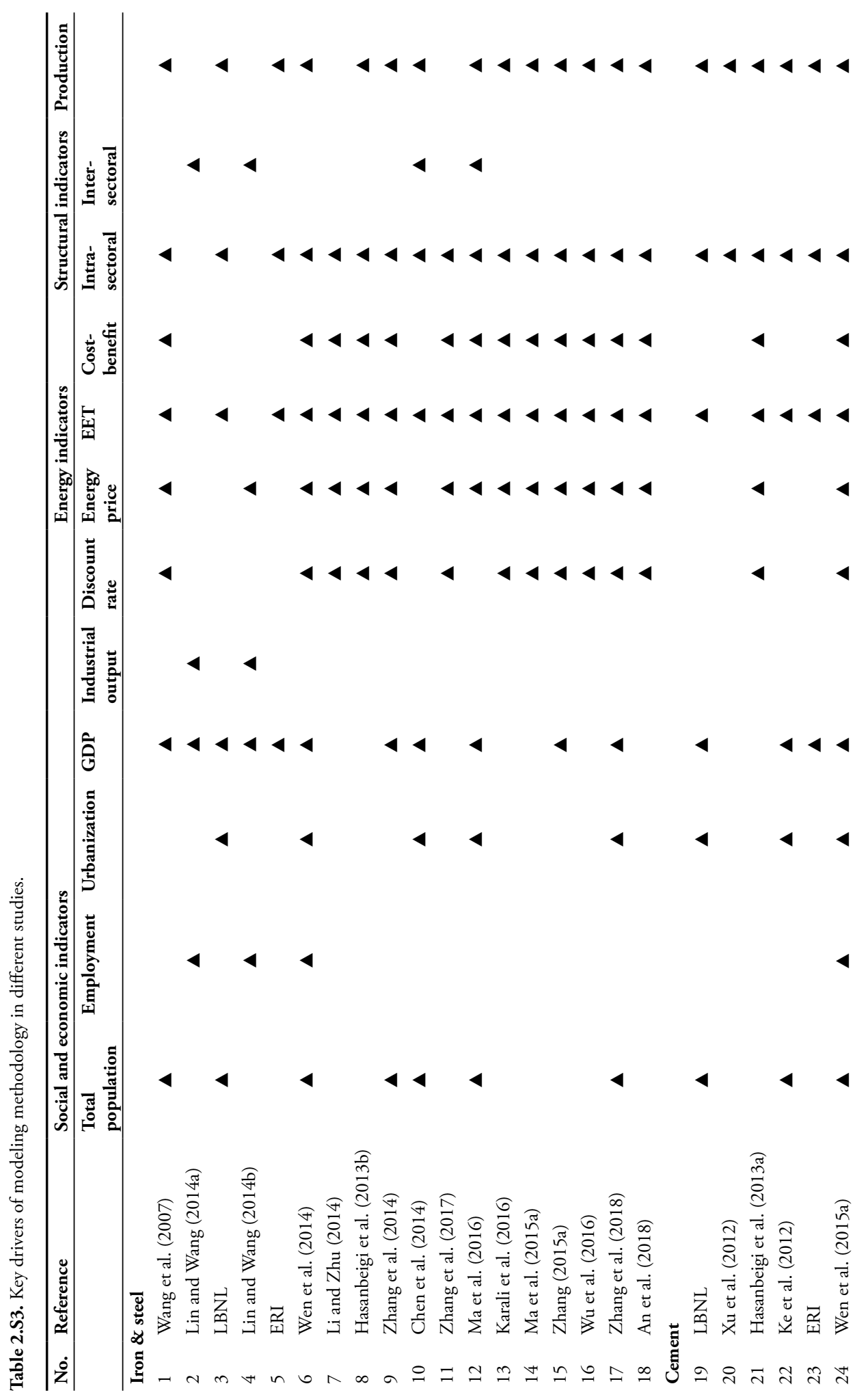


Chapter 2

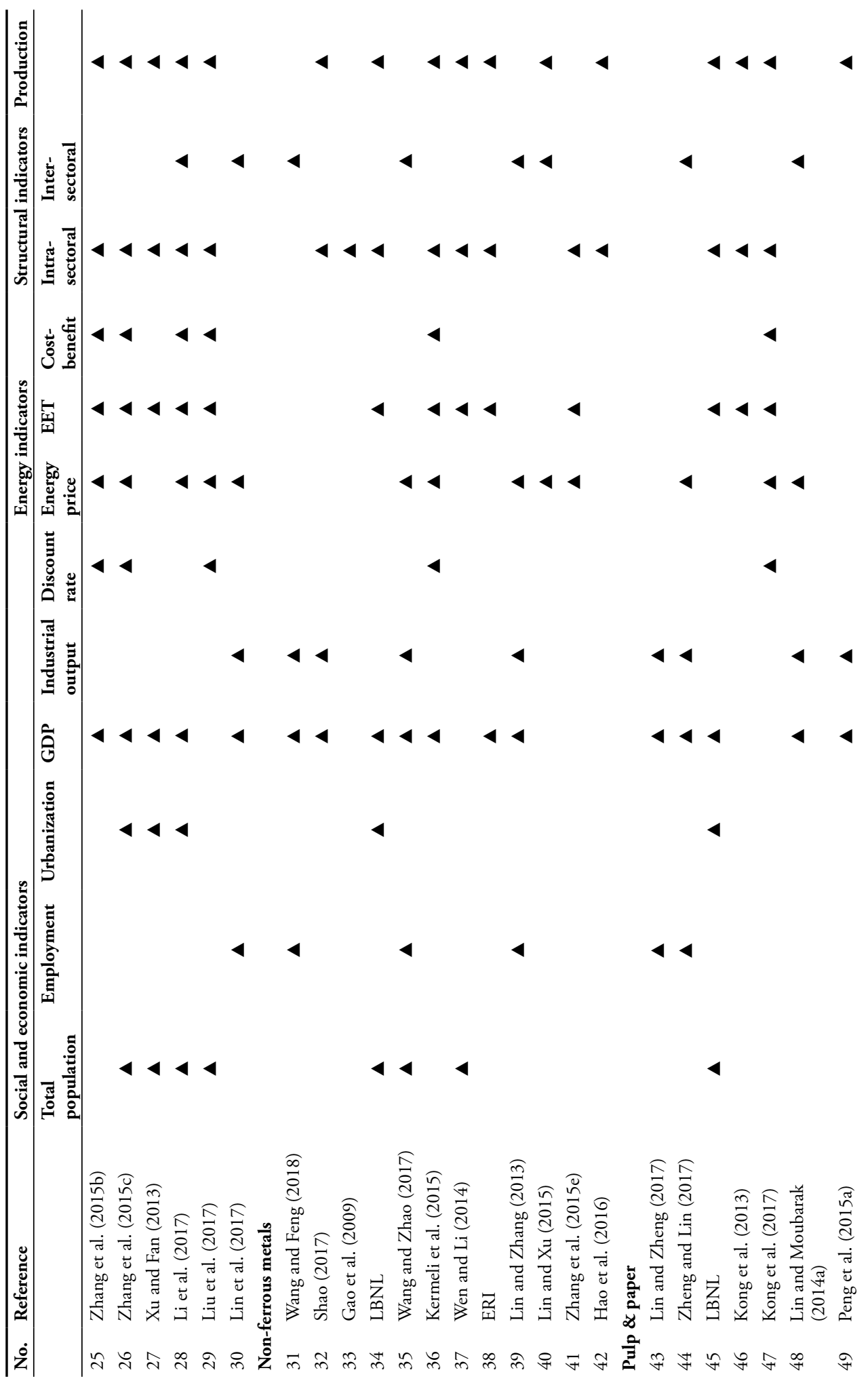


Saving energy in China's industry with a focus on electricity

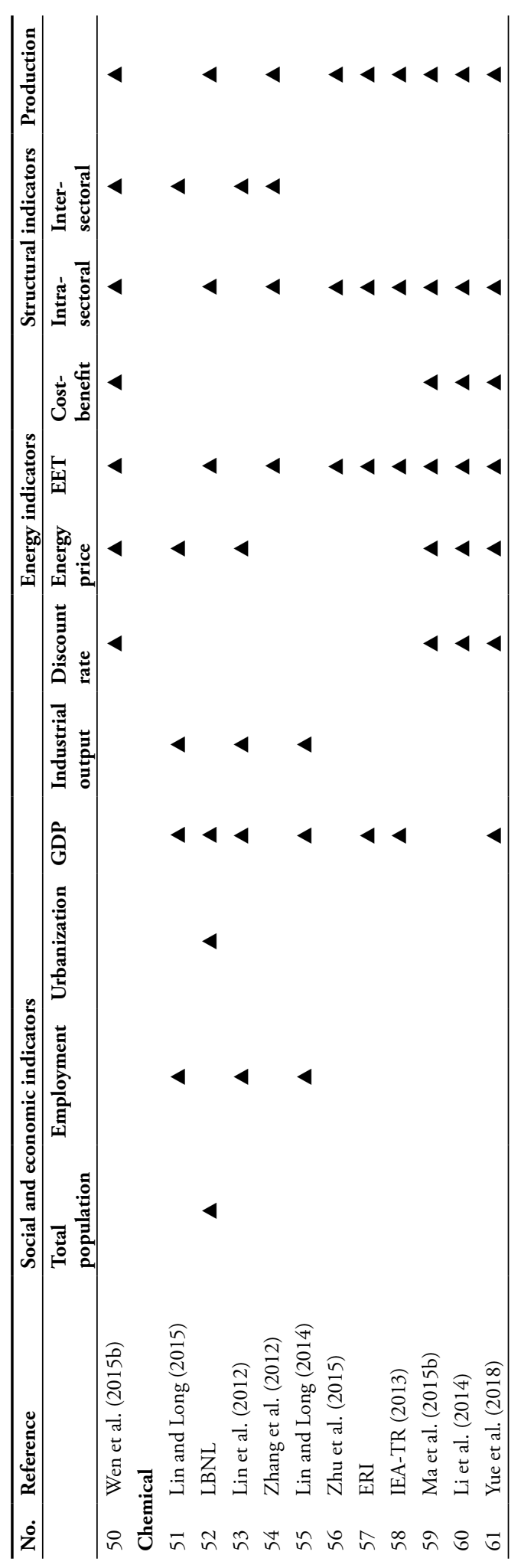




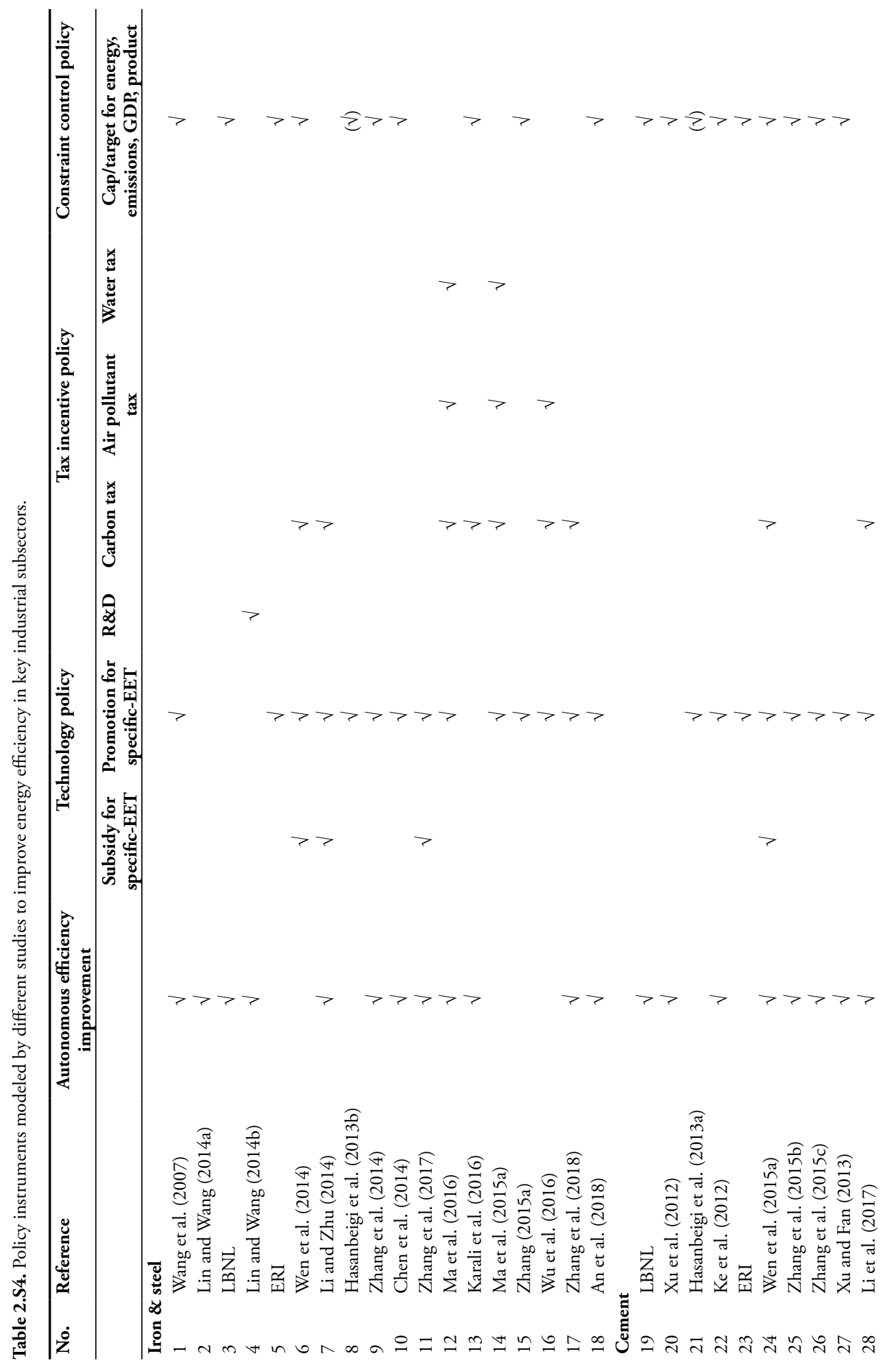


Saving energy in China's industry with a focus on electricity

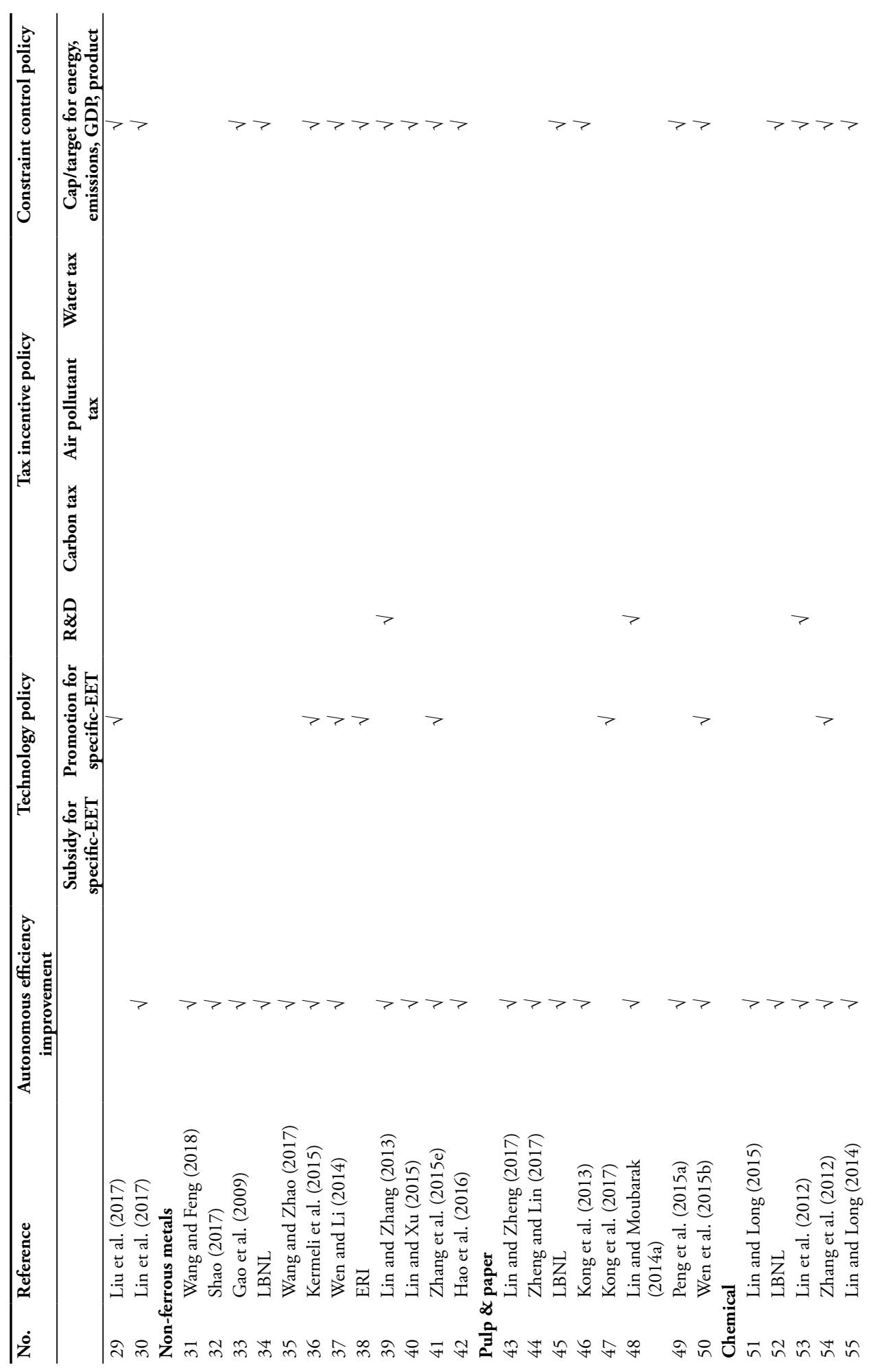


Chapter 2

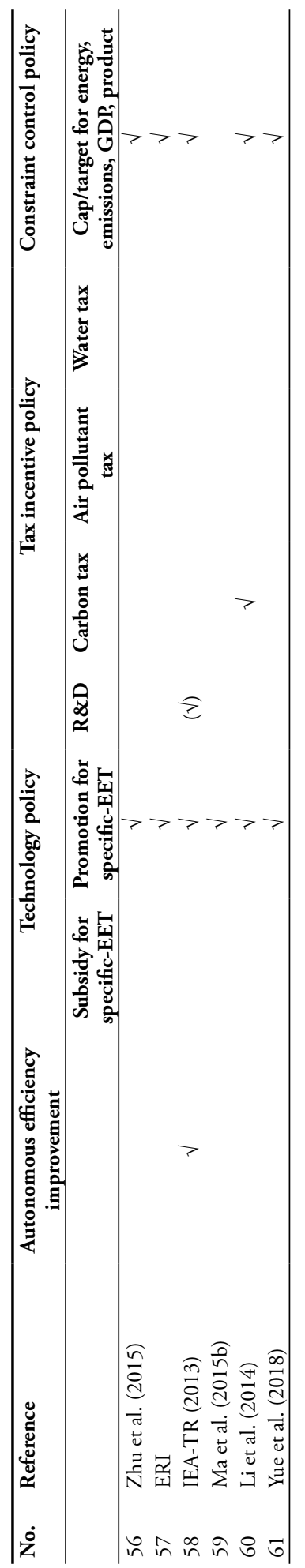


Saving energy in China's industry with a focus on electricity

Table 2.S5. Specific technologies modeled by different studies to improve energy efficiency in key industrial subsectors.

\begin{tabular}{|c|c|c|c|c|c|c|}
\hline \multirow[t]{2}{*}{ No. } & \multirow[t]{2}{*}{ Reference } & \multirow{2}{*}{$\begin{array}{c}\text { Total number of } \\
\text { technologies }\end{array}$} & \multicolumn{2}{|l|}{ EET } & \multicolumn{2}{|l|}{ End-of-pipe } \\
\hline & & & Process & $\begin{array}{c}\text { Resource and } \\
\text { energy recycling }\end{array}$ & Air pollutants & CCS \\
\hline \multicolumn{7}{|c|}{ Iron \& steel } \\
\hline 1 & Wang et al. (2007) & 12 & $\sqrt{ }$ & $\sqrt{ }$ & - & - \\
\hline 2 & Lin and Wang (2014a) & - & - & - & - & - \\
\hline 3 & LBNL & N/A & N/A & N/A & - & $\sqrt{ }$ \\
\hline 4 & Lin and Wang (2014b) & - & - & - & - & - \\
\hline 5 & ERI & 32 & $\sqrt{ }$ & $\sqrt{ }$ & - & - \\
\hline 6 & Wen et al. (2014) & 21 & $\sqrt{ }$ & $\sqrt{ }$ & $\sqrt{ }$ & - \\
\hline 7 & Li and Zhu (2014) & 41 & $\sqrt{ }$ & $\sqrt{ }$ & - & - \\
\hline 8 & Hasanbeigi et al. (2013b) & 23 & $\sqrt{ }$ & $\sqrt{ }$ & - & - \\
\hline 9 & Zhang et al. (2014) & 56 & $\sqrt{ }$ & $\sqrt{ }$ & $\sqrt{ }$ & - \\
\hline 10 & Chen et al. (2014) & 10 & $\sqrt{ }$ & $\sqrt{ }$ & - & - \\
\hline 11 & Zhang et al. (2017) & 35 & $\sqrt{ }$ & $\sqrt{ }$ & - & - \\
\hline 12 & Ma et al. (2016) & 29 & $\sqrt{ }$ & $\sqrt{ }$ & - & $\sqrt{ }$ \\
\hline 13 & Karali et al. (2016) & 129 & $\sqrt{ }$ & $\sqrt{ }$ & - & - \\
\hline 14 & Ma et al. (2015a) & 36 & $\sqrt{ }$ & $\sqrt{ }$ & - & - \\
\hline 15 & Zhang (2015a) & 19 & $\sqrt{ }$ & $\sqrt{ }$ & $\sqrt{ }$ & - \\
\hline 16 & Wu et al. (2016) & 24 & $\sqrt{ }$ & $\sqrt{ }$ & $\sqrt{ }$ & - \\
\hline 17 & Zhang et al. (2018) & 35 & $\sqrt{ }$ & $\sqrt{ }$ & - & - \\
\hline 18 & An et al. (2018) & 64 & $\sqrt{ }$ & $\sqrt{ }$ & - & - \\
\hline \multicolumn{7}{|c|}{ Cement } \\
\hline 19 & LBNL & N/A & N/A & N/A & - & $\sqrt{ }$ \\
\hline 20 & Xu et al. (2012) & - & - & - & - & - \\
\hline 21 & Hasanbeigi et al. (2013a) & 23 & $\sqrt{ }$ & $\sqrt{ }$ & - & - \\
\hline 22 & Ke et al. (2012) & 3 & $\sqrt{ }$ & $\sqrt{ }$ & - & - \\
\hline 23 & ERI & 13 & $\sqrt{ }$ & $\sqrt{ }$ & - & - \\
\hline 24 & Wen et al. (2015a) & 8 & $\sqrt{ }$ & $\sqrt{ }$ & - & - \\
\hline 25 & Zhang et al. (2015b) & 37 & $\sqrt{ }$ & $\sqrt{ }$ & N/A & - \\
\hline 26 & Zhang et al. (2015c) & 37 & $\sqrt{ }$ & $\sqrt{ }$ & N/A & - \\
\hline 27 & $\mathrm{Xu}$ and Fan (2013) & 1 & - & $\sqrt{ }$ & - & - \\
\hline 28 & Li et al. (2017) & 21 & $\sqrt{ }$ & $\sqrt{ }$ & $\sqrt{ }$ & - \\
\hline 29 & Liu et al. (2017) & 23 & $\sqrt{ }$ & $\sqrt{ }$ & $\sqrt{ }$ & - \\
\hline 30 & Lin et al. (2017) & - & - & - & - & - \\
\hline \multicolumn{7}{|c|}{ Non-ferrous metals } \\
\hline 31 & Wang and Feng (2018) & - & - & - & - & - \\
\hline 32 & Shao (2017) & - & - & - & - & - \\
\hline 33 & Gao et al. (2009) & - & - & - & - & - \\
\hline 34 & LBNL & N/A & N/A & N/A & - & $\sqrt{ }$ \\
\hline 35 & Wang and Zhao (2017) & - & - & - & - & - \\
\hline 36 & Kermeli et al. (2015) & 32 & $\sqrt{ }$ & $\sqrt{ }$ & - & - \\
\hline 37 & Wen and Li (2014) & 67 & $\sqrt{ }$ & $\sqrt{ }$ & - & - \\
\hline 38 & ERI & 38 & $\sqrt{ }$ & $\sqrt{ }$ & - & - \\
\hline 39 & Lin and Zhang (2013) & - & - & - & - & - \\
\hline 40 & Lin and $\mathrm{Xu}(2015)$ & - & - & - & - & - \\
\hline 41 & Zhang et al. (2015e) & 5 & $\sqrt{ }$ & - & - & - \\
\hline
\end{tabular}


Chapter 2

\begin{tabular}{|c|c|c|c|c|c|c|}
\hline No. & Reference & Total number of & EET & & End-of-pipe & \\
\hline & & & Process & $\begin{array}{c}\text { Resource and } \\
\text { energy recycling }\end{array}$ & Air pollutants & CCS \\
\hline 42 & Hao et al. (2016) & - & - & - & - & - \\
\hline \multicolumn{7}{|c|}{ Pulp \& paper } \\
\hline 43 & Lin and Zheng (2017) & - & - & - & - & - \\
\hline 44 & Zheng and Lin (2017) & - & - & - & - & - \\
\hline 45 & LBNL & N/A & N/A & N/A & - & $\sqrt{ }$ \\
\hline 46 & Kong et al. (2013) & 9 & $\sqrt{ }$ & $\sqrt{ }$ & - & - \\
\hline 47 & Kong et al. (2017) & 23 & $\sqrt{ }$ & $\sqrt{ }$ & - & - \\
\hline 48 & Lin and Moubarak (2014a) & - & - & - & - & - \\
\hline 49 & Peng et al. (2015a) & - & - & - & - & - \\
\hline 50 & Wen et al. (2015b) & 14 & $\sqrt{ }$ & $\sqrt{ }$ & - & - \\
\hline \multicolumn{7}{|c|}{ Chemical } \\
\hline 51 & Lin and Long (2015) & - & - & - & - & - \\
\hline 52 & LBNL & $\mathrm{N} / \mathrm{A}$ & N/A & N/A & - & $\sqrt{ }$ \\
\hline 53 & Lin et al. (2012) & - & - & - & - & - \\
\hline 54 & Zhang et al. (2012) & 15 & $\sqrt{ }$ & $\sqrt{ }$ & $\sqrt{ }$ & - \\
\hline 55 & Lin and Long (2014) & - & - & - & - & - \\
\hline 56 & Zhu et al. (2015) & 14 & $\sqrt{ }$ & $\sqrt{ }$ & $\sqrt{ }$ & - \\
\hline 57 & ERI & 62 & $\sqrt{ }$ & $\sqrt{ }$ & - & - \\
\hline 58 & IEA-TR (2013) & N/A & N/A & N/A & - & $\sqrt{ }$ \\
\hline 59 & Ma et al. (2015b) & 26 & $\sqrt{ }$ & $\sqrt{ }$ & - & - \\
\hline 60 & Li et al. (2014) & 13 & $\sqrt{ }$ & $\sqrt{ }$ & - & - \\
\hline 61 & Yue et al. (2018) & 76 & $\sqrt{ }$ & $\sqrt{ }$ & $\sqrt{ }$ & - \\
\hline
\end{tabular}




\section{References}

Abel, D.W., Holloway, T., Martínez-Santos, J., Harkey, M., Tao, M., Kubes, C., Hayes, S., 2019. Air quality-related health benefits of energy efficiency in the United States. Environmental Science \& Technology, 53, 3987-3998.

An, R., Yu, B., Li, R., Wei, Y., 2018. Potential of energy savings and $\mathrm{CO}_{2}$ emission reduction in China's iron and steel industry. Applied Energy, 226, 862-880.

AQSIQ (General Administration of Quality Supervision, Inspection and Quarantine of China), SAC (Standardization Administration of China), 2017. Industrial classification for national economic activities (GB/T 4754-2017). URL: http://www.stats.gov.cn/tjsj/tjbz/201709/ P020180124537249410457.pdf (accessed 10 February 2020).

AQSIQ (General Administration of Quality Supervision, Inspection and Quarantine of China), SAC (Standardization Administration of China), 2016. Norm of energy consumption per unit product of pulp and paper (GB 31825-2015). URL: http://www.gb688.cn/bzgk/gb/ newGbInfo?hcno=40D944F0F56CCEA13D95238B9ED46C39 (accessed 10 February 2020).

Ascensão, F., Fahrig, L., Clevenger, A.P., Corlett, R.T., Jaeger, J.A.G., Laurance, W.F., Pereira, H.M., 2018. Environmental challenges for the Belt and Road Initiative. Nature Sustainability, 1, 206-209.

A. T. Kearney, CPCIF (China Petroleum and Chemical Industry Federation), 2017. Global opportunities for the Chinese chemical industry.

CEADs (China Emission Accounts \& Datasets), 2017. Sectoral $\mathrm{CO}_{2}$ emission inventory at national level. URL: http://www.ceads.net/data/ (accessed 10 February 2020).

Chen, W., Yin, X., Ma, D., 2014. A bottom-up analysis of China's iron and steel industrial energy consumption and $\mathrm{CO}_{2}$ emissions. Applied Energy, 136, 1174-1183.

CNMIA (China Non-Ferrous Metals Industry Association), 2017. The yearbook of nonferrous metals industry of China. China Nonferrous Metals Industry Association Press, Beijing (China).

CPCIF (China Petroleum and Chemical Industry Federation), 2017. China chemical industry yearbook 2016. China National Chemical Information Center, Beijing (China).

CTAPI (China Technical Association of Paper Industry), 2018. Almanac of China paper industry 2018. China Light Industry Press, Beijing (China). 
Dai, Y., Xiong, W., Jiao, J., 2013. Roadmap study on achieving technical energy conservation potential in China's industrial sector by 2020. China Science and Technology Press, Beijing (China).

Edelenbosch, O.Y., Kermeli, K., Crijns-Graus, W., Worrell, E., Bibas, R., Fais, B., Fujimori, S., Kyle, P., Sano, F., van Vuuren, D.P., 2017. Comparing projections of industrial energy demand and greenhouse gas emissions in long-term energy models. Energy, 122, 701-710.

Fleiter, T., Fehrenbach, D., Worrell, E., Eichhammer, W., 2012. Energy efficiency in the German pulp and paper industry - a model-based assessment of saving potentials. Energy, 40, 84-99.

Gao, F., Nie, Z., Wang, Z., Li, H., Gong, X., Zuo, T., 2009. Greenhouse gas emissions and reduction potential of primary aluminum production in China. Science in China Series E: Technological Sciences, 52, 2161-2166.

Gao, M., Beig, G., Song, S., Zhang, H., Hu, J., Ying, Q., Liang, F., Liu, Y., Wang, H., Lu, X., 2018. The impact of power generation emissions on ambient $\mathrm{PM}_{2.5}$ pollution and human health in China and India. Environment International, 121, 250-259.

Hackl, R., Harvey, S., 2013. Applying exergy and total site analysis for targeting refrigeration shaft power in industrial clusters. Energy, 55, 5-14.

Han, Y., Geng, Z., Zhu, Q., Qu, Y., 2015. Energy efficiency analysis method based on fuzzy DEA cross-model for ethylene production systems in chemical industry. Energy, 83, 685695.

Hao, H., Geng, Y., Hang, W., 2016. GHG emissions from primary aluminum production in China: regional disparity and policy implications. Applied Energy, 166, 264-272.

Hasanbeigi, A., Morrow, W., Masanet, E., Sathaye, J., Xu, T., 2013a. Energy efficiency improvement and $\mathrm{CO}_{2}$ emission reduction opportunities in the cement industry in China. Energy Policy, 57, 287-297.

Hasanbeigi, A., Morrow, W., Sathaye, J., Masanet, E., Xu, T., 2013b. A bottom-up model to estimate the energy efficiency improvement and $\mathrm{CO}_{2}$ emission reduction potentials in the Chinese iron and steel industry. Energy, 50, 315-325.

Hasanbeigi, A., Price, L., 2015. A technical review of emerging technologies for energy and water efficiency and pollution reduction in the textile industry. Journal of Cleaner Production, 95, $30-44$. 
Hasanbeigi, A., Price, L., 2012. A review of energy use and energy efficiency technologies for the textile industry. Renewable and Sustainable Energy Reviews, 16, 3648-3665.

Hasanbeigi, A., Price, L., Lin, E., 2012. Emerging energy-efficiency and $\mathrm{CO}_{2}$ emission-reduction technologies for cement and concrete production: A technical review. Renewable and Sustainable Energy Reviews, 16, 6220-6238.

He, K., Wang, L., 2017. A review of energy use and energy-efficient technologies for the iron and steel industry. Renewable and Sustainable Energy Reviews, 70, 1022-1039.

Huang, B., Zhao, J., Geng, Y., Tian, Y., Jiang, P., 2017. Energy-related GHG emissions of the textile industry in China. Resources, Conservation \& Recycling, 119, 69-77.

Huang, J., Pan, X., Guo, X., Li, G., 2018. Health impact of China's Air Pollution Prevention and Control Action Plan: an analysis of national air quality monitoring and mortality data. The Lancet Planetary Health, 2, e313-e323.

IAI, 2020. IAI Statistics. International Aluminium Institute (IAI), London (UK). URL: http:// www.world-aluminium.org/statistics (accessed 10 February 2020).

IEA, 2018. World energy balances (2018 edition). International Energy Agency (IEA), Paris (France).

IEA, 2017. Energy technology perspectives 2017: Catalysing energy technology transformation. International Energy Agency (IEA), Paris (France).

IEA, 2016a. World energy outlook 2016. International Energy Agency (IEA), Paris (France).

IEA, 2016b. World energy outlook special report 2016: Energy and air pollution. International Energy Agency (IEA), Paris (France).

IEA, 2013. Technology roadmap: Energy and GHG reductions in the chemical industry via catalytic processes. International Energy Agency (IEA), Paris (France).

IRENA, 2017. Synergies between renewable energy and energy efficiency, a working paper based on REmap. International Renewable Energy Agency (IRENA), Abu Dhabi (UAE).

Kahrl, F., Li, Y., Su, Y., Tennigkeit, T., Wilkes, A., Xu, J., 2010. Greenhouse gas emissions from nitrogen fertilizer use in China. Environmental Science \& Policy, 13, 688-694. 
Karali, N., Shah, N., Park, W.Y., Khanna, N., Ding, C., Lin, J., Zhou, N., 2020. Improving the energy efficiency of room air conditioners in China: Costs and benefits. Applied Energy, $258,114023$.

Karali, N., Xu, T., Sathaye, J., 2016. Developing long-term strategies to reduce energy use and $\mathrm{CO}_{2}$ emissions -analysis of three mitigation scenarios for iron and steel production in China. Mitigation and Adaptation Strategies for Global Change, 21, 699-719.

Karali, N., Xu, T., Sathaye, J., 2012. Industrial sector energy efficiency modeling (ISEEM) framework Documentation. Lawrence Berkeley National Laboratory, Berkeley (USA).

Ke, J., Zheng, N., Fridley, D., Price, L., Zhou, N., 2012. Potential energy savings and $\mathrm{CO}_{2}$ emissions reduction of China's cement industry. Energy Policy, 45, 739-751.

Kermeli, K., Worrell, E., Crijns-Graus, W., Corsten, M., 2017. Energy efficiency and cost saving opportunities for ammonia and nitrogenous fertilizer production. U.S. Environmental Protection Agency and Utrecht University, Utrecht (The Netherlands).

Kermeli, K., ter Weer, P., Crijns-Graus, W., Worrell, E., 2015. Energy efficiency improvement and GHG abatement in the global production of primary aluminium. Energy Efficiency, 8, 629-666.

Khanna, N., Fridley, D., Zhou, N., Karali, N., Zhang, J., Feng, W., 2019. Energy and $\mathrm{CO}_{2}$ implications of decarbonization strategies for China beyond efficiency: modeling 2050 maximum renewable resources and accelerated electrification impacts. Applied Energy, 242, $12-26$.

Klemeš, J.J., Varbanov, P.S., Walmsley, T.G., Jia, X., 2018. New directions in the implementation of Pinch Methodology (PM). Renewable and Sustainable Energy Reviews, 98, 439-468.

Kong, L., Hasanbeigi, A., Price, L., 2012. Emerging energy-efficiency and greenhouse gas mitigation technologies for the pulp and paper industry. Lawrence Berkeley National Laboratory, Berkeley (USA).

Kong, L., Hasanbeigi, A., Price, L., Liu, H., 2017. Energy conservation and $\mathrm{CO}_{2}$ mitigation potentials in the Chinese pulp and paper industry. Resources, Conservation \& Recycling, $117,74-84$.

Kong, L., Price, L., Hasanbeigi, A., Liu, H., Li, J., 2013. Potential for reducing paper mill energy use and carbon dioxide emissions through plant-wide energy audits: A case study in China. Applied Energy, 102, 1334-1342. 
Li, C., Zhu, L., Fleiter, T., 2014. Energy efficiency potentials in the chlor-alkali sector - A case study of Shandong province in China. Energy \& Environment, 25, 661-686.

Li, L., 2018. China's manufacturing locus in 2025: With a comparison of "Made-in-China 2025" and "Industry 4.0." Technological Forecasting and Social Change, 135, 66-74.

Li, N., Ma, D., Chen, W., 2017. Quantifying the impacts of decarbonisation in China's cement sector: a perspective from an integrated assessment approach. Applied Energy, 185, 18401848 .

Li, Y., Zhu, L., 2014. Cost of energy saving and $\mathrm{CO}_{2}$ emissions reduction in China's iron and steel sector. Applied Energy, 130, 603-616.

Lin, B., Long, H., 2016. Emissions reduction in China’s chemical industry - based on LMDI. Renewable and Sustainable Energy Reviews, 53, 1348-1355.

Lin, B., Long, H., 2015. A stochastic frontier analysis of energy efficiency of China's chemical industry. Journal of Cleaner Production, 87, 235-244.

Lin, B., Long, H., 2014. How to promote energy conservation in China's chemical industry. Energy Policy, 73, 93-102.

Lin, B., Moubarak, M., 2014a. Estimation of energy saving potential in China's paper industry. Energy, 65, 182-189.

Lin, B., Moubarak, M., 2014b. Mitigation potential of carbon dioxide emissions in the Chinese textile industry. Applied Energy, 113, 781-787.

Lin, B., Moubarak, M., 2013. Decomposition analysis: change of carbon dioxide emissions in the Chinese textile industry. Renewable and Sustainable Energy Reviews, 26, 389-396.

Lin, B., Wang, X., 2014a. Exploring energy efficiency in China's iron and steel industry: a stochastic frontier approach. Energy Policy, 72, 87-96.

Lin, B., Wang, X., 2014b. Promoting energy conservation in China's iron \& steel sector. Energy, $73,465-474$.

Lin, B., Wu, Y., Zhang, L., 2011. Estimates of the potential for energy conservation in the Chinese steel industry. Energy Policy, 39, 3680-3689.

Lin, B., Xu, L., 2015. Energy conservation of electrolytic aluminum industry in China. Renewable and Sustainable Energy Reviews, 43, 676-686. 
Lin, B., Zhang, G., 2013. Estimates of electricity saving potential in Chinese nonferrous metals industry. Energy Policy, 60, 558-568.

Lin, B., Zhang, L., Wu, Y., 2012. Evaluation of electricity saving potential in China's chemical industry based on cointegration. Energy Policy, 44, 320-330.

Lin, B., Zhang, Z., Ge, F., 2017. Energy conservation in China’s cement industry. Sustainability, 9,668 .

Lin, B., Zhao, H., 2016a. Technological progress and energy rebound effect in China's textile industry: evidence and policy implications. Renewable and Sustainable Energy Reviews, 60, 173-181.

Lin, B., Zhao, H., 2016b. Technology gap and regional energy efficiency in China's textile industry: a non-parametric meta-frontier approach. Journal of Cleaner Production, 137, 21-28.

Lin, B., Zheng, Q., 2017. Energy efficiency evolution of China’s paper industry. Journal of Cleaner Production, 140, 1105-1117.

Liu, X., Zhu, B., Zhou, W., Hu, S., Chen, D., Griffy-Brown, C., 2011. CO emissions in calcium carbide industry: An analysis of China's mitigation potential. International Journal of Greenhouse Gas Control, 5, 1240-1249.

Liu, X., Yuan, Z., Xu, Y., Jiang, S., 2017. Greening cement in China: a cost-effective roadmap. Applied Energy, 189, 233-244.

Liu, Z., Davis, S.J., Feng, K., Hubacek, K., Liang, S., Anadon, L.D., Chen, B., Liu, J., Yan, J., Guan, D., 2016. Targeted opportunities to address the climate-trade dilemma in China. Nature Climate Change, 6, 201-206.

Liu, Z., Guan, D., Crawford-Brown, D., Zhang, Q., He, K., Liu, J., 2013. Energy policy: a lowcarbon road map for China. Nature. 500, 143-145.

Ma, D., Chen, W., Xu, T., 2015a. Quantify the energy and environmental benefits of implementing energy-efficiency measures in China's iron and steel production. Future Cities and Environment, 1, 7 .

Ma, D., Chen, W., Yin, X., Wang, L., 2016. Quantifying the co-benefits of decarbonisation in China's steel sector: an integrated assessment approach. Applied Energy, 162, 1225-1237. 
Ma, D., Hasanbeigi, A., Chen, W., 2015b. Energy-efficiency and air-pollutant emissionsreduction opportunities for the ammonia industry in China. Lawrence Berkeley National Laboratory, Berkeley (USA).

McCollum, D.L., Zhou, W., Bertram, C., De Boer, H., Bosetti, V., Busch, S., Després, J., Drouet, L., Emmerling, J., Fay, M., 2018. Energy investment needs for fulfilling the Paris Agreement and achieving the Sustainable Development Goals. Nature Energy, 3, 589-599.

Meng, F.Y., Zhou, D.Q., Zhou, P., Bai, Y., 2014. Sectoral comparison of electricity-saving potentials in China: an analysis based on provincial input-output tables. Energy, 72, 772-782.

MEP (Ministry of Environmental Protection of China), 2018. Annual statistic report on environment in China 2017. URL: http://www.mee.gov.cn/hjzl/zghjzkgb/lnzghjzkgb/ (accessed 10 February 2020).

MEP (Ministry of Environmental Protection of China), AQSIQ (General Administration of Quality Supervision, Inspection and Quarantine of China), 2019. Emission standards of air pollutants from stationary sources. URL: http://www.mee.gov.cn/ywgz/fgbz/bz/bzwb/ dqhjbh/dqgdwrywrwpfbz/ (accessed 10 February 2020).

MEP (Ministry of Environmental Protection of China), AQSIQ (General Administration of Quality Supervision, Inspection and Quarantine of China), 2016. Ambient air quality standards (GB 3095-2012). URL: http://www.mee.gov.cn/ywgz/fgbz/bz/bzwb/dqhjbh/ dqhjzlbz/ (accessed 10 February 2020).

MIIT (Ministry of Industry and Information Technology of China), 2012. Advanced technologies guideline for energy conservation and emission reduction in China's light industry. URL: http://www.miit.gov.cn/n1146285/n1146352/n3054355/n3057542/n3057546/c3634361/ content.html (accessed 10 February 2020).

MIIT (Ministry of Industry and Information Technology of China), 2014. Guideline of national industrial energy efficiency. URL: http://www.miit.gov.cn/n1146285/n1146352/n3054355/ n3057542/n3057546/c3634672/content.html (accessed 10 February 2020).

MIIT (Ministry of Industry and Information Technology of China), 2016. The development plan of China's nonferrous metals industry 2016-2020. URL: http://www.miit.gov.cn/n1146295/ n1652858/n1652930/n3757017/c5288739/content.html (accessed 10 February 2020).

MIIT (Ministry of Industry and Information Technology of China), 2017a. Action plan 20172019 for industrial energy conservation and green standardization. URL: http://www.miit. gov.cn/n1146295/n1652858/n1652930/n3757016/c5660058/content.html (accessed 10 February 2020). 
MIIT (Ministry of Industry and Information Technology of China), 2017b. China’s industry green development report 2017. Beijing Normal University Press, Beijing (China).

Mischke, P., Karlsson, K.B., 2014. Modelling tools to evaluate China’s future energy system-a review of the Chinese perspective. Energy, 69, 132-143.

MAC (Ministry of Agriculture of China), 2015. Zero growth programme in fertilizer use by 2020. URL: http://jiuban.moa.gov.cn/zwllm/tzgg/tz/201503/t20150318_4444765.htm (accessed 10 February 2020).

NBS (National Bureau of Statistics of China), 2018. China statistical yearbook 2018. China Statistics Press, Beijing (China).

NBS (National Bureau of Statistics of China), 2017. China energy statistical yearbook 2017. China Statistics Press, Beijing (China).

NBS (National Bureau of Statistics of China), MEP (Ministry of Environmental Protection of China), 2018. China statistical yearbook on environment 2017. China Statistics Press, Beijing (China).

NDRC (National Development and Reform Commission of China), 2019. Notice on 2019 tasks for solving overcapacity in key industries. URL: http://www.gov.cn/xinwen/2019-05/09/ content_5390005.htm (accessed 10 February 2020).

NDRC (National Development and Reform Commission of China), 2018. National key energy conservation and low carbon technologies promotion catalogue. URL: https://www.ndrc. gov.cn/fggz/hjyzy/jnhnx/ (accessed 10 February 2020).

NDRC (National Development and Reform Commission of China), 2017. China: 13th Five-Year Plan of power sector. URL: http://www.gov.cn/xinwen/2016-12/22/5151549/ files/696e98c57ecd49c289968ae2d77ed583.pdf (accessed 10 February 2020).

NDRC (National Development and Reform Commission of China), 2013a. The guideline of GHG accounting method and report for China's iron \& steel enterprise. URL: http://www. gov.cn/zwgk/2013-11/04/content_2520743.htm (accessed 10 February 2020).

NDRC (National Development and Reform Commission of China), 2013b. The guideline of GHG accounting method and report for China's cement enterprise. URL: http://www.gov. cn/zwgk/2013-11/04/content_2520743.htm (accessed 10 February 2020). 
NDRC (National Development and Reform Commission of China), 2013c. The guideline of GHG accounting method and report for China's aluminum electrolysis enterprise. URL: http://www.gov.cn/zwgk/2013-11/04/content_2520743.htm (accessed 10 February 2020).

NDRC (National Development and Reform Commission of China), 2013d. The guideline of GHG accounting method and report for China's magnesium enterprise. URL: http://www. gov.cn/zwgk/2013-11/04/content_2520743.htm (accessed 10 February 2020).

NDRC (National Development and Reform Commission of China), 2013e. The guideline of GHG accounting method and report for China's paper \& paper products enterprise. URL: http://www.gov.cn/zwgk/2013-11/04/content_2520743.htm (accessed 10 February 2020).

NDRC (National Development and Reform Commission of China), 2013f. The guideline of GHG accounting method and report for China's chemical enterprise. URL: http://www.gov. cn/zwgk/2013-11/04/content_2520743.htm (accessed 10 February 2020).

NDRC (National Development and Reform Commission of China), NEA (National Energy Administration of China), 2017. China: 13th Five-Year Plan of energy development. URL: http://www.nea.gov.cn/2017-01/17/c_135989417.htm (accessed 10 February 2020).

OECD, 2019. OECD Statistics. Organization for Economic Co-operation and Development (OECD), Pairs (France). URL: https://stats.oecd.org/ (accessed 10 February 2020).

Ouyang, X., Lin, B., 2015. An analysis of the driving forces of energy-related carbon dioxide emissions in China's industrial sector. Renewable and Sustainable Energy Reviews, 45, 838-849.

Peng, L., Zeng, X., Wang, Y., Hong, G., 2015a. Analysis of energy efficiency and carbon dioxide reduction in the Chinese pulp and paper industry. Energy Policy, 80, 65-75.

Peng, L., Zhang, Y., Wang, Y., Zeng, X., Peng, N., Yu, A., 2015b. Energy efficiency and influencing factor analysis in the overall Chinese textile industry. Energy, 93, 1222-1229.

Peng, W., Wagner, F., Ramana, M.V., Zhai, H., Small, M.J., Dalin, C., Zhang, X., Mauzerall, D.L., 2018. Managing China's coal power plants to address multiple environmental objectives. Nature Sustainability, 1, 693-701.

Rozali, N.E.M., Alwi, S.R.W., Manan, Z.A., Klemeš, J.J., Hassan, M.Y., 2014. Optimal sizing of hybrid power systems using power pinch analysis. Journal of Cleaner Production, 71, 158-167. 
Rozali, N.E.M., Ho, W.S., Alwi, S.R.W., Manan, Z.A., Klemeš, J.J., Cheong, J.S., 2019. Probability-Power Pinch Analysis targeting approach for diesel/biodiesel plant integration into hybrid power systems. Energy, 187, 115913.

Shao, Y., 2017. Analysis of energy savings potential of China's nonferrous metals industry. Resources, Conservation \& Recycling, 117, 25-33.

State Council of China, 2017. China: 13th Five-Year Plan of energy conservation and emission reduction programme. URL: http://www.gov.cn/zhengce/content/2017-01/05/ content_5156789.htm (accessed 10 February 2020).

Tong, D., Zhang, Q., Davis, S.J., Liu, F., Zheng, B., Geng, G., Xue, T., Li, M., Hong, C., Lu, Z., 2018. Targeted emission reductions from global super-polluting power plant units. Nature Sustainability, 1, 59-68.

U.S. EIA, 2018. International energy outlook 2018. Energy Information Administration (EIA), Washington (USA).

U.S. EPA, 2015. Demand-side energy efficiency technical support document. Environmental Protection Agency (EPA), Washington (USA). URL: https://19january2017snapshot.epa. gov/sites/production/files/2015-11/documents/tsd-cpp-demand-side-ee.pdf (accessed 20 September 2020).

Wang, J., Zhao, T., 2017. Regional energy-environmental performance and investment strategy for China's non-ferrous metals industry: a non-radial DEA based analysis. Journal of Cleaner Production, 163, 187-201.

Wang, K., Wang, C., Lu, X., Chen, J., 2007. Scenario analysis on $\mathrm{CO}_{2}$ emissions reduction potential in China's iron and steel industry. Energy Policy, 35, 2320-2335.

Wang, L., Li, Y., He, W., Wang, L., Li, Y., He, W., 2017. The energy footprint of China's textile industry: perspectives from decoupling and decomposition analysis. Energies, 10, 1461.

Wang, M., Feng, C., 2018. Decomposing the change in energy consumption in China's nonferrous metal industry: An empirical analysis based on the LMDI method. Renewable and Sustainable Energy Reviews, 82, 2652-2663.

Wen, Z., Chen, M., Meng, F., 2015a. Evaluation of energy saving potential in China's cement industry using the Asian-Pacific Integrated Model and the technology promotion policy analysis. Energy Policy, 77, 227-237. 
Wen, Z., Li, H., 2014. Analysis of potential energy conservation and $\mathrm{CO}_{2}$ emissions reduction in China's non-ferrous metals industry from a technology perspective. International Journal of Greenhouse Gas Control, 28, 45-56.

Wen, Z., Meng, F., Chen, M., 2014. Estimates of the potential for energy conservation and $\mathrm{CO}_{2}$ emissions mitigation based on Asian-Pacific Integrated Model (AIM): the case of the iron and steel industry in China. Journal of Cleaner Production, 65, 120-130.

Wen, Z., Xu, C., Zhang, X., 2015b. Integrated control of emission reductions, energy-saving, and cost-benefit using a multi-objective optimization technique in the pulp and paper industry. Environmental Science \& Technology, 49, 3636-3643.

WHO, 2018. Ambient air pollution - a major threat to health and climate. World Health Organization (WHO), Geneva (Switzerland).

Worrell, E., Price, L., Neelis, M., Galitsky, C., Zhou, N., 2008. World best practice energy intensity values for selected industrial sectors. Lawrence Berkeley National Laboratory, Berkeley (USA).

Wu, X., Zhao, L., Zhang, Y., Zhao, L., Zheng, C., Gao, X., Cen, K., 2016. Cost and potential of energy conservation and collaborative pollutant reduction in the iron and steel industry in China. Applied Energy, 184, 171-183.

Xi, Yang., Fei, T., Wang, G., 2013a. Incorporating environmental co-benefits into climate policies: a regional study of the cement industry in China. Applied Energy, 112, 1446-1453.

$\mathrm{Xu}$, J., Fan, Y., 2013. Potential energy saving and $\mathrm{CO}_{2}$ emission reduction in China's cement industry. Progressus Inquisitiones DE Mutatione Climatis, 9, 341-349.

Xu, J., Fleiter, T., Eichhammer, W., Fan, Y., 2012. Energy consumption and $\mathrm{CO}_{2}$ emissions in China's cement industry: a perspective from LMDI decomposition analysis. Energy Policy, $50,821-832$.

Yang, X., Teng, F., Wang, G., 2013b. Quantifying co-benefit potentials in the Chinese cement sector during 12th Five Year Plan: an analysis based on marginal abatement cost with monetized environmental effect. Journal of Cleaner Production, 58, 102-111.

Yue, H., Worrell, E., Crijns-Graus, W., 2018. Modeling the multiple benefits of electricity savings for emissions reduction on power grid level: a case study of China's chemical industry. Applied Energy, 230, 1603-1632. 
Zhang, C., Chen, J., Wen, Z., 2012. Assessment of policy alternatives and key technologies for energy conservation and water pollution reduction in China's synthetic ammonia industry. Journal of Cleaner Production, 25, 96-105.

Zhang, C., 2015a. Potential analysis and synergy approaches of energy saving and pollution reduction: case in iron industry. MS thesis. Tsinghua University, Beijing (China).

Zhang, Q., Xu, J., Wang, Y., Hasanbeigi, A., Zhang, W., Lu, H., Arens, M., 2018. Comprehensive assessment of energy conservation and $\mathrm{CO}_{2}$ emissions mitigation in China's iron and steel industry based on dynamic material flows. Applied Energy, 209, 251-265.

Zhang, Q., Zhao, X., Lu, H., Ni, T., Li, Y., 2017. Waste energy recovery and energy efficiency improvement in China's iron and steel industry. Applied Energy, 191, 502-520.

Zhang, S., Worrell, E., Crijns-Graus, W., 2015b. Evaluating co-benefits of energy efficiency and air pollution abatement in China’s cement industry. Applied Energy, 147, 192-213.

Zhang, S., Worrell, E., Crijns-Graus, W., 2015c. Mapping and modeling multiple benefits of energy efficiency and emission mitigation in China's cement industry at the provincial level. Applied Energy, 155, 35-58.

Zhang, S., Worrell, E., Crijns-Graus, W., 2015d. Synergy of air pollutants and greenhouse gas emissions of Chinese industries: A critical assessment of energy models. Energy, 93, 24362450 .

Zhang, S., Worrell, E., Crijns-Graus, W., Krol, M., de Bruine, M., Geng, G., Wagner, F., Cofala, J., 2016. Modeling energy efficiency to improve air quality and health effects of China's cement industry. Applied Energy, 184, 574-593.

Zhang, S., Worrell, E., Crijns-Graus, W., Wagner, F., Cofala, J., 2014. Co-benefits of energy efficiency improvement and air pollution abatement in the Chinese iron and steel industry. Energy, 78, 333-345.

Zhang, S., Xie, Y., Sander, R., Yue, H., Shu, Y., (2021). Potentials of energy efficiency improvement and energy-emission-health nexus in Jing-Jin-Ji's cement industry. Journal of Cleaner Production, 278, 123335.

Zhang, W., Dou, Z., He, P., Ju, X-T., Powlson, D., Chadwick, D., et al., 2013. New technologies reduce greenhouse gas emissions from nitrogenous fertilizer in China. Proceedings of the National Academy of Sciences, 110, 8375-8380. 
Zhang, W., Li, H., Chen, B., Li, Q., Hou, X., Zhang, H., 2015e. $\mathrm{CO}_{2}$ emission and mitigation potential estimations of China's primary aluminum industry. Journal of Cleaner Production, $103,863-872$.

Zheng, Q., Lin, B., 2017. Industrial polices and improved energy efficiency in China's paper industry. Journal of Cleaner Production, 161, 200-210.

Zhou, N., Fridley, D., McNeil, M., Zheng, N., Ke, J., Levine, M., 2011. China's energy and carbon emissions outlook to 2050. Lawrence Berkeley National Laboratory, Berkeley (USA).

Zhou, N., Khanna, N., Feng, W., Ke, J., Levine, M., 2018a. Scenarios of energy efficiency and $\mathrm{CO}_{2}$ emissions reduction potential in the buildings sector in China to year 2050. Nature Energy, 3, 978-984.

Zhou, S., Wang, Y., Yuan, Z., Ou, X., 2018b. Peak energy consumption and $\mathrm{CO}_{2}$ emissions in China's industrial sector. Energy strategy reviews, 20, 113-123.

Zhou, W.J., Zhu, B., Li, Q.A., Ma, T.J., Hu, S.Y., Griffybrown, C., 2010. $\mathrm{CO}_{2}$ emissions and mitigation potential in China’s ammonia industry. Energy Policy, 38, 3701-3709.

Zhu, B., Chen, X., Zhang, W., Hu, S., Jin, Y., 2015. Potential assessment of cleaner production in China's ammonia industry. Journal of Tsinghua University (Science and Technology), 54, 309-313.

Zhu, B., Zhou, W., Hu, S., Li, Q., Griffy-Brown, C., Jin, Y., 2010. $\mathrm{CO}_{2}$ emissions and reduction potential in China's chemical industry. Energy, 35, 4663-4670. 


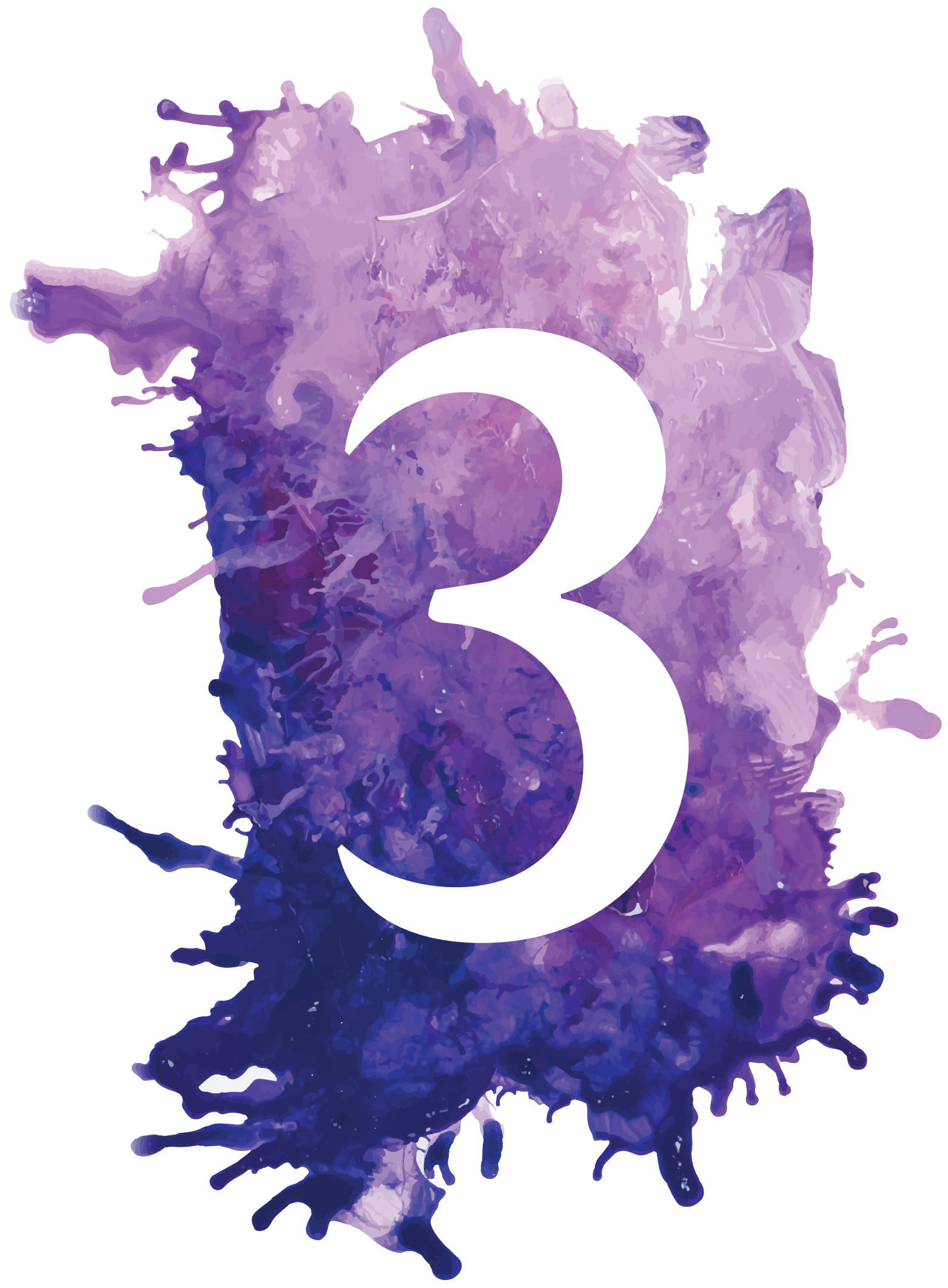




\section{Chapter 3}

\section{Modeling the multiple benefits of electricity savings for emissions reduction on power grid level: A case study of China's chemical industry}

Hui Yue, Ernst Worrell, Wina Crijns-Graus 


\section{ABSTRACT}

Industry is a large electricity user. China's chemical industry (globally the largest based on sales) contributes $7 \%$ to China's GDP, while it consumes $11 \%$ of the total electricity consumption in industry and is responsible for $40 \%$ of total $\mathrm{CO}_{2 \mathrm{eq}}, 40 \%$ of $\mathrm{SO}_{2}, 59 \%$ of $\mathrm{NO}_{x}$ and $18 \%$ of PM-emissions of the chemical industry emissions. The heterogeneity of GHG and air pollutant emissions across electricity grids (within a country) is rarely included in analyses. In this paper, electricity conservation supply curves are developed (distinguishing the grids) to estimate the cost-effective and technical potentials of electricity conservation in China's chemical industry. The emission factors per grid for $\mathrm{GHG}$ (i.e. $\mathrm{CO}_{2}, \mathrm{CH}_{4}$ and $\mathrm{N}_{2} \mathrm{O}$ ) and air pollutants (i.e. $\mathrm{SO}_{2}, \mathrm{NO}_{\mathrm{x}}$ and $\mathrm{PM}_{2.5}$ ) are calculated and used to quantify the emissions mitigation achieved by electricity saving technologies in the chemical industry for the period 2012-2035. Results show that significant multiple benefits can be obtained by implementing electricity efficiency measures. There are large differences among the six grids in terms electricity savings and emissions abatement of GHG and air pollutants. $83 \%$ of the total electricity saving potential is contributed by the North, Northwest and Central grids, equal to $32 \%$ of baseline electricity consumption in 2035. In 2035, $129 \mathrm{Mt} \mathrm{CO}_{2}, 33 \mathrm{kt} \mathrm{CO}_{2 \mathrm{eq}}$ of $\mathrm{CH}_{4}$, $571 \mathrm{kt} \mathrm{CO}_{2 \mathrm{eq}}$ of $\mathrm{N}_{2} \mathrm{O}, 235 \mathrm{kt}$ of $\mathrm{SO}_{2}, 275 \mathrm{kt}$ of $\mathrm{NO}_{\mathrm{x}}$ and $52 \mathrm{kt}$ of $\mathrm{PM}_{2.5}$ in these three grids can be avoided as a result of electricity savings (a reduction of 31-33\% compared to baseline emissions). When decision-makers set targets for energy saving and emission reduction, the multiple benefits and grid heterogeneity should not be ignored. 


\section{I. Introduction}

From 2010 to 2014, global electricity demand increased by 56\% from 13,199 TWh to $20,557 \mathrm{TWh}$, accounting for $18 \%$ of total final energy demand (IEA, 2016a; IEA, 2017). This huge demand for electricity exacerbates emissions of air pollutants and GHGs worldwide. Electricity generation contributes to $42 \%$ of $\mathrm{CO}_{2}$ emissions around the world, as well as 33\% of $\mathrm{SO}_{2}$ emissions, $14 \%$ of $\mathrm{NO}_{\mathrm{x}}$ emissions, $5 \%$ of $\mathrm{PM}_{2.5}$ emissions (IEA, 2016a; IEA, 2016b). As a major emission source of GHGs, the global power sector needs to convert to net zero emissions by 2050 (IPCC, 2014; Audoly et al., 2018). Besides concerns for GHG emissions and climate change, fossil fuel related air pollutant emissions are of high concern for public health (WHO, 2013). The efficient use of electricity in end-user sectors would therefore generate synergies, by reducing both types of emissions, as well as reduce investments in new power plants (Summerbell et al., 2017; Peng et al., 2018; Helin et al., 2017). Electricity savings are hence an integral part of air quality and climate policy. However, these synergies do not get the full attention they deserve and impacts are often not quantified.

The paper describes a method to quantify the synergies of electricity efficiency improvement on emissions reduction of GHG and air pollutants, and is applied to a case study of China's chemical industry. China's chemical industry is the world's largest, contributes to $7 \%$ of China's GDP. China makes a great case because of the poor air quality, massive use of coal-fired power generation, and new policies to clean up the air, coupled to a growing pressure to reduce GHG emissions (State Council of China, 2013a; State Council of China, 2016; Zhang et al., 2012a). Furthermore, China's chemical industry is one of the largest electricity consumers in the country, accounting for $11 \%$ of industrial electricity consumption in 2014 (with about $475 \mathrm{TWh}$ ). The indirect emissions of $\mathrm{SO}_{2}, \mathrm{NO}_{x}$ and $\mathrm{PM}$ caused by electricity use in China's chemical industry account for $40 \%, 59 \%$ and $18 \%$ of total emissions in the chemical industry, respectively in 2014 (Cai et al., 2013; National Bureau of Statistics of China, 20152017; NBS and MEP, 2006-2016). For GHG emissions, this share is 40\%, with 464 $\mathrm{Mt} \mathrm{CO}_{2 \mathrm{eq}}$ in 2014 (National Bureau of Statistics of China, 2015-2017; Song et al., 2013; Zhu et al., 2010). The high level of electricity use and emissions means that China's chemical industry should play a significant role in realizing electricity savings and emission reductions. In addition, considering substantial differences across China's six electricity grids (North, Northeast, Northwest, Central, East, Southern) in terms of electricity prices, fuel use, efficiency, and emissions performance, the potentials of electricity efficiency improvement and emission cuts in the chemical industry vary significantly depending on location. Therefore, it is important to evaluate the synergies for chemical industry in China at the grid level. 


\begin{tabular}{|c|c|c|c|}
\hline \multicolumn{4}{|c|}{ Nomenclature } \\
\hline \multicolumn{2}{|c|}{ Abbreviations } & $P_{\text {fuel }}$ & fuel price \\
\hline GHG & greenhouse gas & $P E S_{\text {grid, } i}$ & annual primary energy saving in a grid $i$ \\
\hline $\mathrm{CO}_{2 \mathrm{eq}}$ & carbon dioxide equivalent & $I$ & investment \\
\hline $\mathrm{CH}_{4}$ & methane & $d$ & discount rate \\
\hline $\mathrm{N}_{2} \mathrm{O}$ & nitrous oxide & $l$ & lifetime of the electricity efficiency measures \\
\hline $\mathrm{SO}_{2}$ & sulfur dioxide & $G E_{g r i d, i}$ & generation efficiency of power grid $i$ \\
\hline $\mathrm{NO}_{\mathrm{x}}$ & nitrogen oxides & $E F_{g r i d, i, G, y}$ & $\begin{array}{l}\text { emission factors of GHG } G \text { (i.e. } \mathrm{CO}_{2}, \mathrm{CH}_{4} \text { and } \\
\mathrm{N}_{2} \mathrm{O} \text { ) for grid } i \text { in year } y\end{array}$ \\
\hline $\mathrm{PM}_{2.5}$ & $\begin{array}{l}\text { particular matter with aerodynamic } \\
\text { diameters less than } 2.5 \mu \mathrm{m}\end{array}$ & $E G_{i m p, j, i, y}$ & net import electricity of grid $i$ from grid $j$ in year $y$ \\
\hline Mt & million tons & $E_{\text {grid, }, G, y}$ & emissions of GHG $G$ of grid $i$ in year $y$ \\
\hline $\mathrm{kt}$ & kiloton & $E G_{\text {grid,i,y }}$ & $\begin{array}{l}\text { power generation from all technologies for grid } i \\
\text { in year } y\end{array}$ \\
\hline Mtce & million tons standard coal equivalent & $E F_{\text {gridj, }, G, y}$ & emission factors of GHG $G$ for grid $i$ in year $y$ \\
\hline LNG & liquefied natural gas & $F C_{r, f, y}$ & amount of fuel $f$ consumed by province $r$ in year $y$ \\
\hline PVC & polyvinyl chloride & $L C V_{f}$ & lower calorific value of fuel $f$ \\
\hline ECSCs & electricity conservation supply curves & $E F_{f, G}$ & GHG $G$ emission factors of fuel $f$ \\
\hline MACCs & marginal abatement cost curves & $C C_{f}$ & carbon content per unit calorific value of fuel $f$ \\
\hline NDRC & $\begin{array}{l}\text { National Development and Reform } \\
\text { Commission of China }\end{array}$ & $O R_{f}$ & oxidation rate of fuel $f$ \\
\hline WRI & World Resources Institute & $E F_{g r i d, i p, y}$ & $\begin{array}{l}\text { emission factors of pollutant } p \text { (i.e. } \mathrm{SO}_{2}, \mathrm{NO}_{\mathrm{x}} \text { and } \\
\mathrm{PM}_{2.5} \text { ) for grid } i \text { in year } y\end{array}$ \\
\hline IPCC & $\begin{array}{l}\text { Intergovernmental Panel on Climate } \\
\text { Change }\end{array}$ & $E_{\text {grid,ip,y }}$ & emissions of pollutant $p$ for grid $i$ in year $y$ \\
\hline LBNL & Lawrence Berkeley National Laboratory & $E F_{\text {gridj,jp,y }}$ & emission factors of pollutant $p$ for grid $j$ in year $y$ \\
\hline $\mathrm{CP}$ & current energy prices & $E F_{r, f, p}$ & $\begin{array}{l}\text { uncontrolled emission factor of pollutant } p \text { of fuel } \\
f \text { in province } r\end{array}$ \\
\hline SP & energy prices of sensitivity analysis & $\gamma_{p, n}$ & $\begin{array}{l}\text { removal efficiency of abatement measure } n \text { for } \\
\text { pollutant } p\end{array}$ \\
\hline LG & lime-gypsum & $S_{p, n, r, y}$ & $\begin{array}{l}\text { share of installed capacity of abatement measure } n \\
\text { for pollutant } p \text { in province } r \text { in year } y\end{array}$ \\
\hline LIF & limestone injection into furnace & $o_{p, n, r y}$ & $\begin{array}{l}\text { operation rate of abatement measure } n \text { for pollutant } \\
p \text { in province } r \text { in year } y\end{array}$ \\
\hline LNB & low nitrogen burning & $S_{f, r}$ & sulfur content of fuel $f$ in province $r$ \\
\hline SCR & selective catalytic reduction & $S C R_{f, r}$ & $\mathrm{SO}_{2}$ conversion rate of fuel $f$ in province $r$ \\
\hline SNCR & selective non-catalytic reduction & $A_{f, r}$ & ash content of fuel $f$ in province $r$ \\
\hline ESP & electrostatic precipitator & $B A_{f, r}$ & ratio of bottom ash of fuel $f$ in province $r$ \\
\hline Symbols & & $\beta_{P M 2.5, f, r}$ & $\mathrm{PM}_{2.5}$ mass fraction of fuel $f$ in province $r$ \\
\hline$C C E_{\text {grid, } i}$ & $\begin{array}{l}\text { costs of conserved electricity for an } \\
\text { electricity efficiency technology in a } \\
\text { grid } i\end{array}$ & $E R S_{\text {gridi,iy }}$ & $\begin{array}{l}\text { emissions reduction synergies for a technology for } \\
\text { grid } i \text { in year } y\end{array}$ \\
\hline$A I$ & annualized investment & Subscripts & \\
\hline$O \& M^{f i x}$ & $\begin{array}{l}\text { annual change in operation and } \\
\text { maintenance fixed cost }\end{array}$ & $i, j$ & power grid type (e.g. Central grid and East grid) \\
\hline$O \& M^{\text {var }}$ & $\begin{array}{l}\text { annual change in operation and } \\
\text { maintenance variable cost }\end{array}$ & fuel & fuel type (e.g. coal, oil, gas) \\
\hline ES & $\begin{array}{l}\text { annual electricity saving for a } \\
\text { technology }\end{array}$ & $G, y$ & GHG and year \\
\hline$P_{g r i d, i}$ & electricity price in a grid $i$ & $\operatorname{imp}$ & net import electricity \\
\hline$F S$ & annual fuel saving for a technology & $r, p, n$ & province, pollutant, abatement measure \\
\hline
\end{tabular}


Multiple benefits of energy efficiency and emission mitigation for different sectors have been discussed by various researchers, especially focusing on the iron $\&$ steel industry and cement industry (e.g. global (Van Ruijven et al., 2016), national (Liu et al., 2017; Zhang et al., 2018a; Zuberi and Patel, 2017; Ma et al., 2016; Karali et al., 2017) and regional (Zhang et al., 2018b; Zhang et al., 2016)). For example, Liu et al. (2017) estimated the synergies of energy efficiency technologies to reduce $\mathrm{CO}_{2}$ and air pollutant emissions in China's cement industry at the national level during the period of 2011 to 2030, and found significant cost-effective potentials of energy-savings and emission mitigation in China's cement sector. Karali et al. (2017) used the industry sector energy efficiency model (ISEEM) to evaluate the impacts of 24 energy efficiency measures on energy-savings and $\mathrm{CO}_{2}$ emission reduction in U.S. iron \& steel industry between 2010 and 2050, and indicated $180 \mathrm{PJ}$ energy use and 14.9 billion tons of $\mathrm{CO}_{2}$ emissions would be saved by 2050 . Unlike the single-product industries (iron \& steel, cement and power (Wang et al., 2016)), few studies have separately estimated the potentials of $\mathrm{CO}_{2}$ emission mitigation and energy conservation in the chemical industry (Zhu et al., 2010; Saygin et al., 2011; Lin and Long, 2015). Zhu et al. (2010) studied the $\mathrm{CO}_{2}$ emissions though emission factor-based methods and two-level method from the whole chemical industry and sub chemical sectors level respectively, and suggested large amounts of $\mathrm{CO}_{2}$ can be saved in China's chemical industry. Saygin et al. (2011) assessed the energy conservation potential by implementing Best Practice Technology in global (petro) chemical industry at a country level, and found approximately $16 \%$ of energy efficiency improvement potential (excluding savings in electricity use) worldwide, varying by country. However, no study has focused on the synergies between electricity use and emissions of GHG and air pollutants characterized by regional grid heterogeneity for the chemical industry with multi-products. To fill this gap, a bottom-up approach is developed based on key characteristics of energy saving technologies and GHG and air pollutants emission factors for the six regional electricity grids. These are used to assess the multiple benefits of electricity efficiency improvement on energy use savings and emission mitigation (i.e. $\mathrm{CO}_{2}, \mathrm{CH}_{4}, \mathrm{~N}_{2} \mathrm{O}, \mathrm{SO}_{2}, \mathrm{NO}_{\mathrm{x}}$ and $\mathrm{PM}_{2.5}$ ) per grid in China's chemical industry for the period 2012-2035.

The paper is organized as follows: an overview of the chemical industry and its subsectors is given in Section 3.2. The methodology and data sources used to estimate the multiple benefits and costs of electricity saving measures are provided in Section 3.3, while the results of electricity savings and emission reductions of $\mathrm{CO}_{2}, \mathrm{CH}_{4}, \mathrm{~N}_{2} \mathrm{O}, \mathrm{SO}_{2}$, $\mathrm{NO}_{\mathrm{x}}$ and $\mathrm{PM}_{2.5}$ in different scenarios and grids are presented in Section 3.4. A sensitivity analysis for important factors that affect the results is given in Section 3.5; and finally, conclusions and policy implications are drawn in Section 3.6. 


\subsection{Overview of China's chemical industry}

China's chemical industry is a complicated system, producing many different chemical products. In this study, China's chemical industry is defined as the manufacture of raw chemical materials and chemical products based on the industrial classification for national economic activities (ICNEA) (AQSIQ and SAC, 2017), i.e. classification code 26, which consists of 8 sub-categories (including basic chemicals manufacturing, fertilizers manufacturing, pesticides manufacturing, coatings, inks, paints and similar products manufacturing, synthetic materials manufacturing, special chemical products manufacturing, explosives, pyrotechnics and fireworks manufacturing, and daily chemical products manufacturing) (AQSIQ and SAC, 2017). China's chemical industry has grown dramatically since 2000 , accounting for $14 \%-35 \%$ of total industrial output value, with an annual growth rate of 23\% (National Bureau of Statistics of China, 2014-2017; National Bureau of Statistics of China, 2006-2017). As the largest chemical market worldwide, China represents around $1 / 3$ of the global chemicals demand. The production of main chemicals grew at an annual rate of $9 \%$ between 2000 and 2014, i.e. from $144 \mathrm{Mt}$ to $484 \mathrm{Mt}$. Strong growth in chemical production has been primarily driven by fast growth of downstream industries such as construction, food and packaging sectors. In particular, China is the largest producer and consumer of ammonia (Zhou et al., 2010), caustic soda (Hong et al., 2014), polyvinyl chloride (PVC) (Li et al., 2014) and calcium carbide (Liu et al., 2011). The total production of ammonia, caustic soda, PVC and calcium carbide accounts for $27 \%$ of main chemicals production, reaching 57 $\mathrm{Mt}, 32 \mathrm{Mt}, 16 \mathrm{Mt}$ and 25Mt, respectively, at the end of 2014 (see Figure 3.1) (National Bureau of Statistics of China, 2006-2017; China Petroleum and Chemical Industry Federation, 2002-2016). 


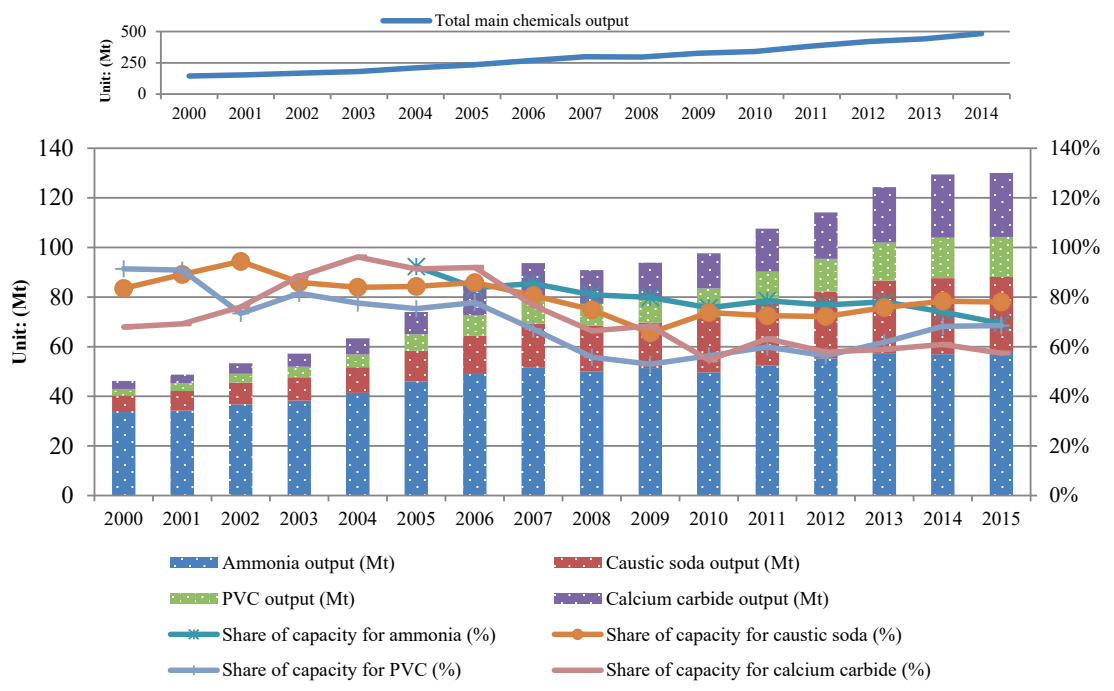

Figure 3.1. Historical output of different chemicals (Mt) and share of capacity (\%).

Source: Primary data from (National Bureau of Statistics of China, 2014-2017; National Bureau of Statistics of China, 2006-2017; China Petroleum and Chemical Industry Federation, 2002-2016; Wen, 2012). Calculated by authors. Note: data for ammonia capacity during 2000-2004 are not available.

Energy consumption of China's chemical industry increased with the growth of chemicals output. At present, China's chemical industry has become the second largest energy consumer after the iron \& steel industry. Energy consumption in the chemical industry increased from $4.1 \mathrm{EJ}$ in 2000 to $14.4 \mathrm{EJ}$ in 2015, accounting for $11 \%$ of China's total energy demand (National Bureau of Statistics of China, 2015-2017). The final energy consumption mix of China's chemical industry shows that electricity has increasingly become the dominant energy source, amounting to 30\% in 2015 (see Figure 3.2). Electricity use of China's chemical industry increased with an annual rate of $10 \%$ during 2000 to 2015 , higher than the annual growth rate of total energy use of China's chemical industry ( $9 \%$ for the same period). With the implementation of a large number of energy efficiency measures and related policies (e.g. phasing out backward production capacities and promoting best practice technologies), the energy and electricity efficiency of the chemical industry has significantly improved. The energy intensity and electricity intensity of the chemical industry dropped by $82 \%$ and $73 \%$ respectively in 2013 compared to 1995 (National Bureau of Statistics of China, 20152017; National Bureau of Statistics of China, 2006-2017). 


\section{Chapter 3}

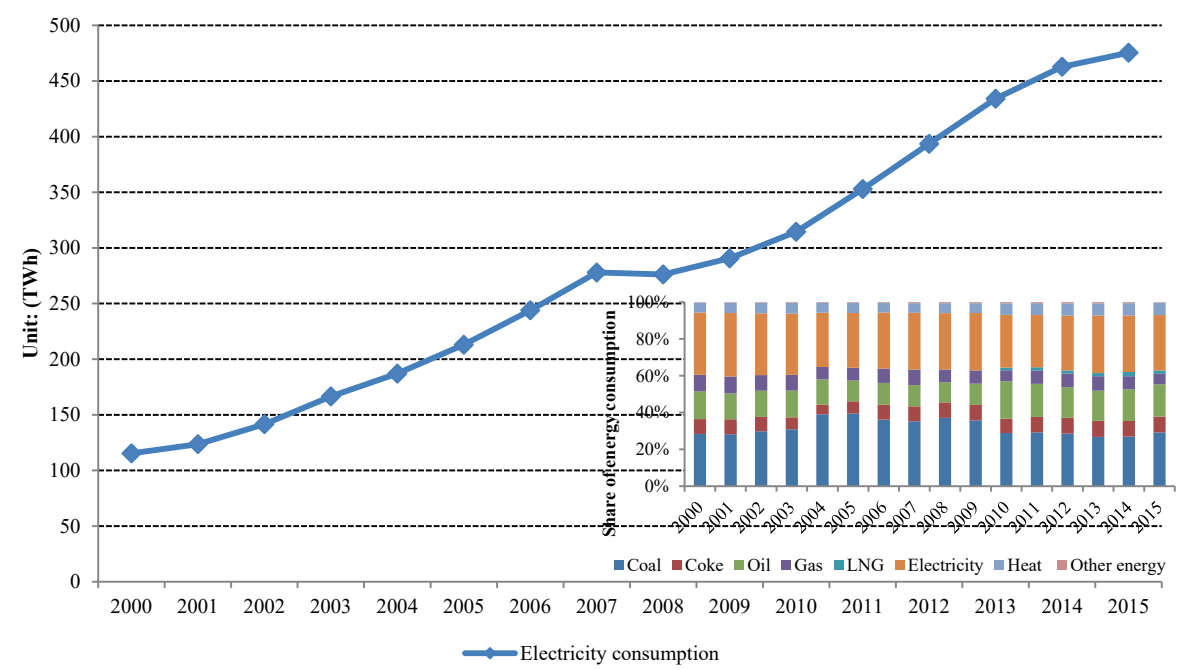

Figure 3.2. Electricity consumption in China's chemical industry during 2000-2015.

Source: Primary data from (National Bureau of Statistics of China, 2015-2017). Calculated by authors.

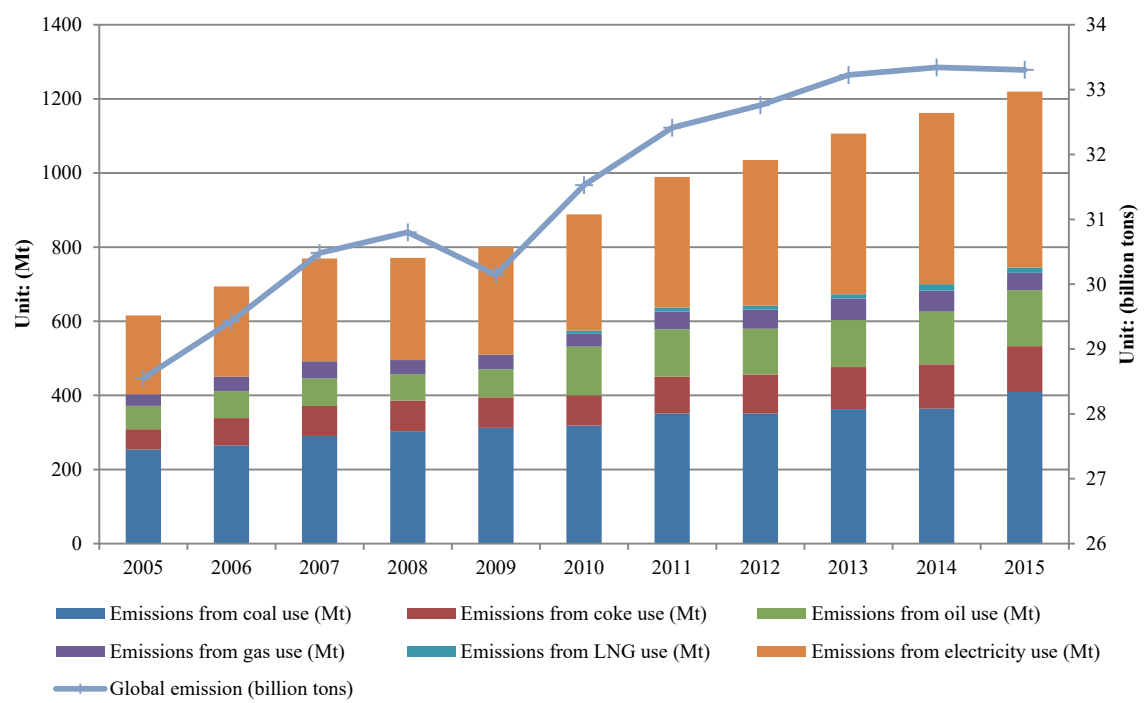

Figure 3.3. $\mathrm{CO}_{2}$ emissions of China's chemical industry (Mt) and global (billion tons) during 2005-2015.

Source: Primary data from (National Bureau of Statistics of China, 2015-2017; Song et al., 2013; Zhu et al., 2010; BP, 2017; Ma and Ge, 2014; National Development and Reform Commission of China, 2006-2017; IPCC, 2006; National Development and Reform Commission of China, 2011; National Development and Reform Commission of China, 2008; National Government Offices Administration of China, 2011). Calculated by authors (see Supplementary Information). 
Despite the improvement in energy efficiency, the growing energy consumption of the chemical industry has resulted in enormous emissions of air pollutants and GHGs. As shown in Figure 3.3, the energy-related $\mathrm{CO}_{2}$ of China's chemical industry accounts for $3.7 \%$ of global total in 2015 , with $1220 \mathrm{Mt} \mathrm{CO}_{2}$, which nearly doubled since 2005 (BP, 2017). The share of electricity-related $\mathrm{CO}_{2}$ emissions is approximately $39 \%$ of total emissions, while coal contributes to approximately $34 \%$, coke to $10 \%$, LNG to $1 \%$, coal gas and nature gas together contribute to about $4 \%$, and oil to $12 \%$. Since 2011 , the share of electricity based emissions has outgrown the direct coal emissions. The $\mathrm{CO}_{2}$ emission intensity of key chemicals dropped at an annual rate of $1 \%$, declining from 2.6 to $2.4 \mathrm{t} \mathrm{CO}_{2} / \mathrm{t}$ chemicals between 2005 and 2014. Despite the decline, it is still higher than that of the cement and iron \& steel industries (Cai et al., 2016). Figure 3.4 shows the historical emissions of air pollutants and the emission intensity. As a key emitter of air pollutants, China's chemical industry emitted $2254 \mathrm{kt}$ of SO $\mathrm{z}_{2}$, $1512 \mathrm{kt}$ of $\mathrm{NO}_{\mathrm{x}}$ and $808 \mathrm{kt}$ of PM in 2015, contributing 12\%, 8\% and 5\% to the national emissions, respectively (Cai et al., 2013; NBS and MEP, 2006-2016). In line with the energy consumption trend, total emissions of air pollutants increased at an average rate of 3.6\% per year between 2005 and 2015, from $3250 \mathrm{kt}$ to $4574 \mathrm{kt}$ (NBS and MEP, 2006-2016; Ministry of Environmental Protection of China, 2009-2017). Declining air quality forced the government to introduce stricter emission standards, and promote desulfurization and denitrification of combustion installations (MEP and AQSIQ, 2015; State Council of China, 2017). As a result of these initiatives, the emission intensities of $\mathrm{SO}_{2}, \mathrm{NO}_{x}$ and $\mathrm{PM}$ declined by $32 \%, 22 \%$ and $50 \%$ respectively by 2015, compared to 2005 (see Figure 3.5). In the 13th Five-Year Plan (2016-2020), more measures will be implemented to reduce $\mathrm{NO}_{x}$ and $\mathrm{SO}_{2}$ emissions by an expected $15 \%$ in 2020 , compared to 2015 levels. 


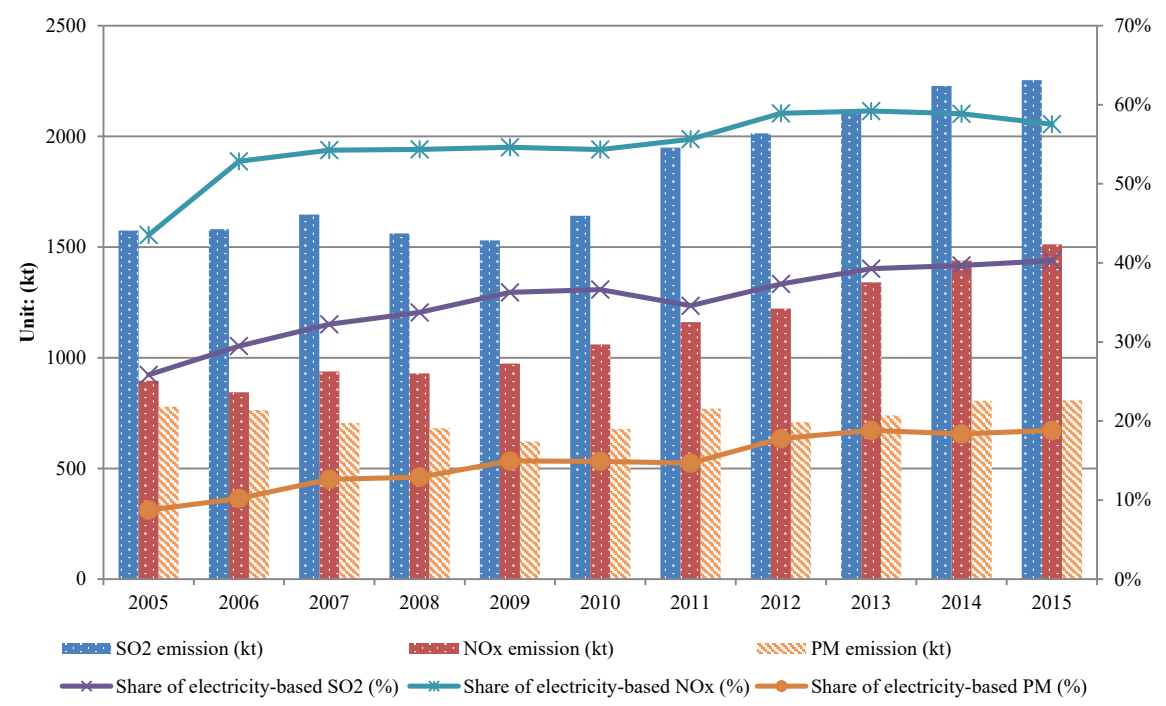

Figure 3.4. Total air pollutants emission (kt) and share of electricity-based air pollutants emission (\%) in China's chemical industry during 2005-2015.

Source: Primary data from (Cai et al., 2013; National Bureau of Statistics of China, 2015-2017; NBS and MEP, 20062016; Ministry of Environmental Protection of China, 2009-2017; China Electric Power Yearbook Editorial Committee, 2013-2017; National Development and Reform Commission of China, 2006-2017; Zhao et al., 2010; Chinese Research Academy of Environmental Sciences, 2010; Zhang, 2008; Shi et al., 2014; China Electricity Council, 2015). Calculated by authors.

While China's chemical industry produces thousands of chemicals, only a few chemicals are relevant for electricity use, GHG and air pollutant emissions (Saygin et al., 2011). The electricity use in three sub-sectors (ammonia, chlor-alkali and calcium carbide) accounts for $54 \%$ of total electricity consumption of China's chemical industry in 2015 , which is equal to $15 \%$ of total energy consumption of the chemical industry (China Electric Power Yearbook Editorial Committee, 2013-2017). Emission reduction in these three sub-sectors plays a crucial role for the chemical industry to achieve the $18 \% \mathrm{CO}_{2}$ emission reduction target and $15 \%$ reduction targets of $\mathrm{SO}_{2}$ and $\mathrm{NO}_{\mathrm{x}}$ in 2020. In addition, energy and environmental policy focus mainly on these three subsectors. Therefore, these three key electricity-intensive sub-sectors were selected to assess the multiple benefits of electricity savings and emissions reduction by implementing electricity efficiency technologies. Detailed description on the levels of production, electricity consumption and emissions of GHG and air pollutants for these sub-sectors is presented in the Supplementary Information. 


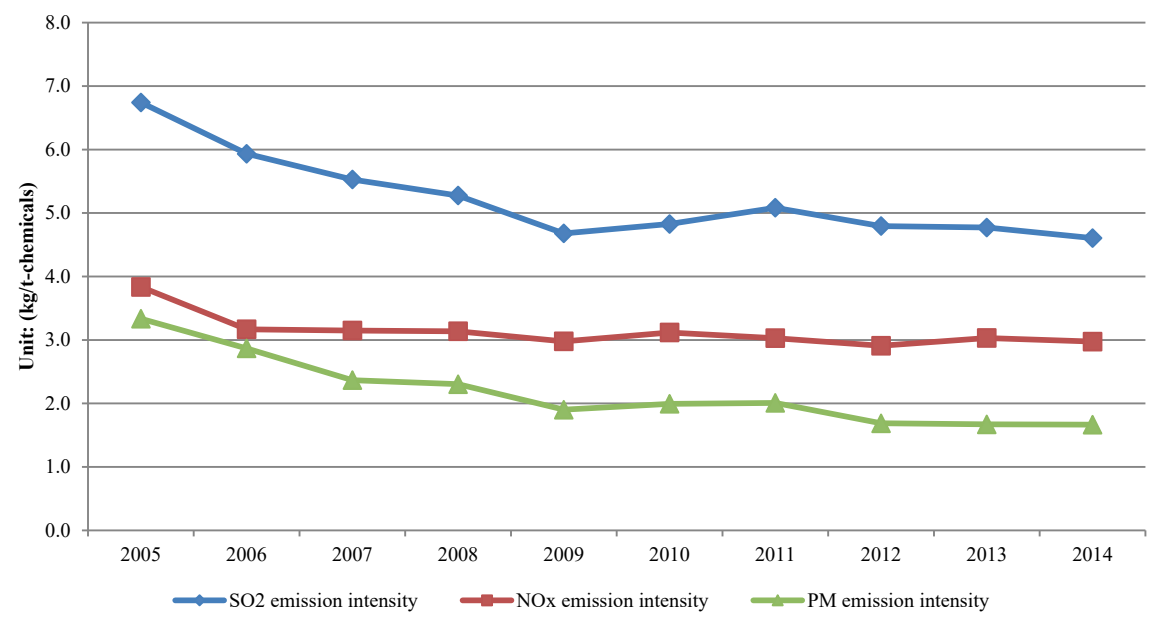

Figure 3.5. Air pollutants emission intensity of China’s chemical industry during 2005-2014.

Source: Primary data from (NBS and MEP, 2006-2016; National Bureau of Statistics of China, 2006-2017; China Petroleum and Chemical Industry Federation, 2002-2016; Ministry of Environmental Protection of China, 2009-2017; Zhang, 2008; Shi et al., 2014). Calculated by authors.

\subsection{Methodology and data sources}

First, electricity conservation supply curves (ECSCs) (or marginal abatement cost curves; MACCs) are developed to analyze the cost associated with each energy efficiency technology and electricity saving potential for the six electricity grids in China (Section 3.3.1). Second, the emission factors of GHG, $\mathrm{SO}_{2}, \mathrm{NO}_{\mathrm{x}}$ and $\mathrm{PM}_{2.5}$ in each grid were calculated accounting for emission abatement measures applied in power generation (Section 3.3.2). Electricity prices, power generation efficiencies and emission factors per grid reflect the spatial variability of power generation. Finally, the results of the ECSC are combined with the emission factors to estimate the co-benefits of electricity conservation for climate change mitigation and air quality improvement at grid level in China's chemical industry (Section 3.3.3). Data sources and electricity efficiency technologies are described in Section 3.3.4.

\subsection{Electricity conservation supply curves}

ECSCs are constructed per grid to quantify the cost effectiveness and technical potential of electricity conservation accumulated for the available technologies in the chemical industry from 2012 to 2035. Cost curves, including ECSCs and MACCs, have been used to evaluate costs and potentials of technologies for various industrial sectors (Zhang et al., 2018a; Zuberi and Patel, 2017; Ma et al., 2016; Zhang et al., 2016; Kong et al., 2015; Zhang et al., 2017; Yang et al., 2013). For example, Kong et al. (2015) employed 
the conservation supply curves to estimate the co-benefits of energy-savings and $\mathrm{CO}_{2}$ emission mitigation by implementing 23 energy efficiency measures in China's pulp and paper industry. The results show that 180-254 PJ and $2316 \mathrm{GWh}$ can be saved in 2010, and the corresponding $\mathrm{CO}_{2}$ emission reduction potential is estimated to be $19-26 \mathrm{Mt}$. Similarly, Yang et al. (2013) evaluated the multiple benefits of 18 mitigation technologies on $\mathrm{CO}_{2}$ and air pollutants in the cement industry though MACCs approach. They found that the monetized co-benefits varied from $0.4 \$ / \mathrm{t} \mathrm{CO}$ to $39 \$ / \mathrm{t} \mathrm{CO}_{2}$ during 2011-2015 on the national level. Previous co-benefits studies have only estimated the impacts on $\mathrm{CO}_{2}$ emissions alone (or on $\mathrm{CO}_{2}$ and air pollutant emissions) in singleproduct industries at national level, like cement (Liu et al., 2017; Zuberi and Patel, 2017; Yang et al., 2013; Zhang et al., 2015), iron \& steel (Zhang et al., 2018a; Ma et al., 2016; Karali et al., 2017) and paper (Kong et al., 2015; Wen et al., 2015). However, a study on the multiple benefits of electricity savings on emissions mitigation of GHG and air pollutants for the chemical industry is still lacking, as are studies that consider the heterogeneity of electricity grids. In this study, three electricity-intensive sectors representing China's chemical industry are selected to evaluate the multiple benefits of 60 electricity efficiency measures on electricity savings and emissions mitigation for six grids. These sectors account for more than $50 \%$ of the electricity consumption in the chemical industry in China.

In this study, electricity prices and power generation efficiencies for the six different grids in China are included in the costs calculations. The costs of each technology is converted to 2010 constant prices in $\$(2010 \$)$ using deflators and currency conversion factors, which are derived from the China statistical yearbook (National Bureau of Statistics of China, 2014-2017) and OECD data (OECD, 2017). The CCE of each electricity efficiency technology at a grid level is calculated by Equations (3.1), (3.2) and (3.3) (Zhang et al., 2015).

$$
C C E_{\text {grid }, i}=\frac{A I+O \& M^{f i x}+O \& M^{v a r}-\left(E S * P_{\text {grid }, i}+F S * P_{f u e l}\right)}{P E S_{\text {grid }, i}}
$$

Where $C C E_{\text {gridi }}$ represents the cost of conserved electricity for an electricity efficiency technology $(\$ / G \mathrm{~J})$ in a grid $i ; A I$ represents the annualized investment $(\$) ; O \& M^{f i x}$ and $O \& M^{v a r}$ represent the annual change in operation and maintenance fixed and variable $\operatorname{cost}(\$)$, respectively; $E S$ is the annual electricity saving for a technology $(\mathrm{kWh}) ; P E S_{\text {grid, } i}$ represents the electricity price in a grid $i(\$ / \mathrm{kWh}) . F S$ is the annual fuel saving for a technology (GJ); $P_{\text {fuel }}$ is the fuel price $(\$ / G \mathrm{~J})$ and $P E S_{\text {grid, } i}$ is the annual primary energy saving in a grid $i(\mathrm{GJ})$.

$A I$ and $P E S_{\text {grid, } i}$ can be obtained from Equations (3.2) and (3.3). A real discount rate of $10 \%$ is used in this research to reflect barriers (Zhang et al., 2016; Zhang et al., 2015; Worrell et al., 2001). The electricity prices per grid are based on the provincial electricity pricing policies released by State Grid Corporation of China (2015). 


$$
\begin{aligned}
& A I=I * \frac{d}{\left(1-(1+d)^{-l}\right)} \\
& P E S_{\text {grid }, i}=E S * G E_{\text {grid }, i}+F S
\end{aligned}
$$

Where $l$ is the investment; $d$ is the discount rate and $l$ represents the lifetime of the electricity efficiency measures. $G E_{\text {grid, } i}$ is the generation efficiency of power grid $i(\mathrm{GJ} /$ $\mathrm{kWh}$ ), including the transmission and distribution losses and auxiliary power use.

\subsubsection{Emission factors of $\mathrm{GHG}$ and air pollutants for different grids}

Power generation (primarily from coal) has resulted in massive emissions of GHG and air pollutants in China (Ma et al., 2017; Zhao et al., 2008). Hence, improving demandside electricity efficiency contributes to emission reductions of GHG and air pollutants through reduced power generation. To quantify the potential of emissions mitigation achieved by electricity savings in China's chemical industry at grid level, $\mathrm{GHG}\left(\mathrm{CO}_{2}, \mathrm{CH}_{4}\right.$ and $\mathrm{N}_{2} \mathrm{O}$ ) intensity (ton/MWh) and air pollutants $\left(\mathrm{SO}_{2}, \mathrm{NO}_{\mathrm{x}}\right.$ and $\left.\mathrm{PM}\right)$ intensity (ton/ $\mathrm{MWh}$ ) of power generation for six grids are calculated in this study. Several approaches are used to measure the $\mathrm{CO}_{2}$ intensity of power generation at different scopes (e.g. national, global and regional level), such as exergy method (Graus and Worrell, 2011) consumer responsibility method ( $\mathrm{Ma}$ and $\mathrm{Ge}$ et al, 2014) and power $\&$ heat method (Harmsen and Graus, 2013). In this study, an approach to determine emission factors of purchased electricity for end-user sectors at the grid level (including 30 provinces) is developed, based on studies of NDRC (National Development and Reform Commission of China, 2006-2017), WRI (Song et al., 2013), and Tsinghua University (Cai et al., 2013; Zhao et al., 2008; Zhao et al., 2010). This approach includes electricity generated per technology, the exchange of electricity between grids and the emission allocation between power and heat from cogeneration plants. ${ }^{4}$

\subsubsection{GHG emission factors per grid}

If electricity exchange between grids is present, emission factors of GHG for grid $i$ in year $y$ can be calculated by Equation (3.4).

$E F_{\text {grid }, i, G, y}=\frac{E_{\text {grid }, i, G, y}+\sum_{j}\left(E F_{\text {grid }, j, G, y} * E G_{i m p, j, i, y}\right)}{E G_{\text {grid }, i, y}+\sum_{j} E G_{i m p, j, i, y}}$

If the net import electricity of grid $i$ from grid $j$ in year $y$ is 0 , the emission factors of GHG for grid $i$ in year $y$ can be obtained by Equation (3.5).

$E F_{\text {grid }, i, G, y}=E_{\text {grid }, i, G, y} / E G_{\text {grid }, i, y}$

4 The fuel of cogeneration plants has been allocated to the emission factor of power generation although also heat is generated. The impacted is however expected to be small since cogeneration plants represent a small share of total power generation (IEA's 2016 World Energy Balances). 
Where $i, j, G, y$ represents the grid $i$, grid $j$, GHG and year $y$; $E F_{\text {grid,i, }, y}$ is the emission factors of $\mathrm{GHG} G$ (e.g. $\mathrm{CO}_{2}, \mathrm{CH}_{4}, \mathrm{~N}_{2} \mathrm{O}$ ) of grid $i$ in year $y$ (ton/MWh); $E F_{\text {grid,i,G,y }}$ is the emissions of GHG $G$ of grid $i$ in year $y$ (ton); $E F_{\text {grid,j, }, y, y}$ is the emission factors of GHG $G$ of grid $j$ in year $y$ (ton/MWh); $E F_{i m p, j, i, y}$ is the net import electricity of grid $i$ from grid $j(\mathrm{MWh}) ; E F_{\text {gridi, } y}$ is the power generation from all technologies for grid $i$ in year $y$ (MWh). The $E F_{g r i d, i, i, y}$ can be calculated from Equation (3.6).

$E_{\text {grid }, i, G, y}=\sum_{r \in i} \sum_{f} \frac{F C_{r, f, y} * L C V_{f} * E F_{f, G}}{10^{6}}$

Where $r \in i$ represents province $r$ belonging to grid $i$; $f$ represents the fuel type (e.g. raw coal, coke, crude oil, gasoline, etc); $F C_{r, f, y}$ represents the amount of fuel $f$ consumed by province $r$ in year $y$ (ton or $\mathrm{m}^{3}$ ), $L C V_{f}$ represents the lower calorific value of fuel $f(\mathrm{MJ} /$ ton or $\left.\mathrm{MJ} / \mathrm{m}^{3}\right) ; \mathrm{E} F_{f, G}$ is the GHG emission factors of fuel $f(\mathrm{~g} / \mathrm{MJ})$. In this study, the emission factors of $\mathrm{CH}_{4}$ and $\mathrm{N}_{2} \mathrm{O}$ of fuel $f$ are derived from the 2006 IPCC Guidelines for National Greenhouse Gas Inventories (g/MJ) (IPCC, 2006). The emission factor of $\mathrm{CO}_{2}$ of fuel $f$ can be obtained by Equation (3.7).

$E F_{f, C O 2}=C C_{f} * O R_{f} * \frac{44}{12}$

Where $C G_{f}$ is carbon content per unit calorific value of fuel $f(\mathrm{~g} / \mathrm{MJ})$; $O R_{f}$ is the oxidation rate of fuel $f(\%)$.

\subsubsection{Air pollutant emission factors per grid}

The grid-based emission factors of air pollutants after application of abatement measures for each grid can be calculated by Equation (3.8).

$E F_{\text {grid }, i, p, y}=\frac{E_{\text {grid }, i, p, y}+\sum_{j}\left(E F_{\text {grid }, j, p, y} * E G_{i m p, j, i, y}\right)}{E G_{g r i d, i, y}+\sum_{j} E G_{i m p, j, i, y}}$

Where $E F_{\text {grid,i,py }}$ represents the abated emission factors of pollutant $p$ (e.g. $\mathrm{SO}_{2}, \mathrm{NO}_{\mathrm{x}}$, $\mathrm{PM}_{2.5}$ ) for grid $i$ in year $y$ (ton/MWh); $E_{\text {grid,i,p,y }}$ is emissions of pollutant $p$ for grid $i$ in year $y$ (ton); $E F_{\text {grid,j,p,y }}$ is the abated emission factors of pollutant $p$ for grid $j$ in year $y$ (ton/MWh). The $E_{g r i d, i, p, y}$ can be calculated from Equation (3.9).

$$
\begin{aligned}
E_{g r i d, i, p, y}= & \sum_{r \in i} \sum_{f} \sum_{n} F C_{r, f, y} * E F_{r, f, p} *\left[\left(1-\gamma_{p, n}\right) * s_{p, n, r, y} * o_{p, n, r, y}+s_{p, n, r, y} *\left(1-o_{p, n, r, y}\right)+(1\right. \\
& \left.\left.-s_{p, n, r, y}\right)\right]
\end{aligned}
$$

Where $n$ is identifies the individual abatement measure; $E F_{r f, p}$ is the uncontrolled emission factors of pollutant $p$ of fuel $f$ in province $r\left(\mathrm{~g} / \mathrm{g}\right.$ or $\left.\mathrm{g} / \mathrm{m}^{3}\right) ; \gamma_{p, n}$ is the removal efficiency of abatement measure $n$ for pollutant $p(\%) ; S_{p, n, r y}$ is the share of installed 
capacity of abatement measure $n$ for pollutant $p$ in province $r$ in year $y(\%) ; O_{p, n, r, y}$ is the operation rate of abatement measure $n$ for pollutant $p$ in province $r$ in year $y(\%)$.

In this study, $E F_{r, f, N O x}$ which is the uncontrolled emission factor of $\mathrm{NO}_{\mathrm{x}}$ of fuel $f$ in province $r$ can be obtained from the manual of pollutants production and emission coefficients for coal-fired power plants (Chinese Research Academy of Environmental Sciences, 2010), and literatures (Cai et al., 2013; Zhang, 2008). The uncontrolled emission factor of $\mathrm{SO}_{2}$ and $\mathrm{PM}_{2.5}$ can be calculated with Equations (3.10) and (3.11), respectively (Cai et al., 2013; Zhao et al., 2010).

$E F_{r, f, S O 2}=S_{f, r} * S C R_{f, r} * \frac{64}{32}$

$E F_{r, f, P M 2.5}=A_{f, r} *\left(1-B A_{f, r}\right) * \beta_{P M 2.5, f, r}$

Where $E F_{r, f, S O 2}$ is the uncontrolled emission factor of $\mathrm{SO}_{2}$ of fuel $f$ in province $r$; $S_{f, \mathrm{r}}$ is sulfur content of fuel $f$ in province $r ; S C R_{f, \mathrm{r}}$ is $\mathrm{SO}_{2}$ conversion rate of fuel $f$ in province $r . E F_{r, f, P M 2.5}$ is the uncontrolled emission factor of $\mathrm{PM}_{2.5}$ of fuel $f$ in province $r ; A_{f, \mathrm{r}}$ is ash content of fuel $f$ in province $r$; $B A_{f, \mathrm{r}}$ is the ratio of bottom ash of fuel $f$ in province $r$; $\beta_{P M 2.5, f, \mathrm{r}}$ is the $\mathrm{PM}_{2.5}$ mass fraction of fuel $f$ in province $r$.

\subsubsection{Multiple benefits on emissions reduction per grid}

Technologies to improve electricity efficiency can generate synergies for climate change and air quality, by reducing both types of emissions. The multiple benefits of electricity saving on emissions reduction for an electricity efficiency technology at a grid level can be calculated by Equation (3.12).

$E R S_{\text {grid }, i, y}=E S * I R_{y} * E F_{\text {grid }, i}$

Where $E R S_{\text {grid,i }}$ represents the synergies of electricity saving in terms of emissions reduction for a technology at grid $i$ in year $y ; I R_{y}$ is the implementation rate for a technology in year y. $E F_{\text {grid, } i}$ is the emission factor (for $\mathrm{CO}_{2}, \mathrm{CH}_{4}, \mathrm{~N}_{2} \mathrm{O}, \mathrm{SO}_{2}, \mathrm{NO}_{\mathrm{x}}$ and $\mathrm{PM}_{2.5}$ ) for grid $i$. The calculation of emission factors for the six grids was presented in Section 3.3.2.

\subsubsection{Data sources}

\subsubsection{Future demand for chemical products}

Future production levels for ammonia, caustic soda, PVC and calcium carbide are required to evaluate the benefits of electricity efficiency measures in the chemical industry. Material flow analysis (MFA) is widely used to predict steel and cement demand at national level via evaluating the product flow in downstream industries (Zhang et al., 2018a; Ma et al., 2016). For example, steel demand can be divided into five steel-intensive industries reflecting the steel flow in construction, vehicle, machinery, appliances and other industries, of which $73 \%$ of total steel demand consumed by the former three in China (Zhang et 
al., 2018a). Chemical industry products are extensively applied in various downstream industries such as agriculture, construction, food and packaging. However, few studies have done systematic analysis of the chemical products flow because of its complexity. Based on the concept of MFA, the correlation between chemical products and downstream industries were firstly analyzed in this study. Based on the correlation analysis, the average annual growth rates of the chemicals during 2015-2035 are obtained from national plans and related studies. Finally, the average proportion of provincial production and future average annual growth rates of chemicals are used to forecast chemicals output at grid level between 2016 and 2035. Table 3.1 shows the share of provincial production of national production during 12th Five-Year Plan (2011-2015), and it is assumed that this remains unchanged during the study period. A sensitivity analysis was conducted to explore the impact of chemicals output (see Section 3.5.1).

Table 3.1. Average share of provincial production of national production during 12th Five-Year Plan (\%).

\begin{tabular}{|c|c|c|c|c|c|}
\hline Grid & Region & Ammonia & Caustic soda & PVC & Calcium carbide \\
\hline \multirow[t]{6}{*}{ North } & Beijing & 0.0 & 0.1 & 0.0 & 0.0 \\
\hline & Hebei & 5.2 & 3.6 & 4.2 & 0.0 \\
\hline & Inner Mongolia & 2.4 & 7.4 & 16.2 & 31.3 \\
\hline & Shanxi & 9.1 & 1.8 & 3.3 & 1.7 \\
\hline & Shandong & 13.3 & 22.2 & 6.9 & 0.2 \\
\hline & Tianjin & 0.3 & 4.0 & 9.5 & 0.0 \\
\hline \multirow[t]{3}{*}{ Northeast } & Heilongjiang & 1.4 & 0.5 & 0.4 & 0.0 \\
\hline & Jilin & 0.9 & 0.6 & 0.8 & 0.0 \\
\hline & Liaoning & 1.7 & 2.1 & 1.0 & 0.5 \\
\hline \multirow[t]{5}{*}{ East } & Anhui & 5.8 & 1.7 & 0.6 & 0.1 \\
\hline & Fujian & 1.6 & 0.9 & 0.1 & 0.1 \\
\hline & Jiangsu & 6.3 & 13.4 & 1.3 & 0.0 \\
\hline & Shanghai & 0.0 & 2.5 & 1.3 & 0.0 \\
\hline & Zhejiang & 1.1 & 5.1 & 2.6 & 0.2 \\
\hline \multirow[t]{6}{*}{ Central } & Chongqing & 3.4 & 1.1 & 0.0 & 0.1 \\
\hline & Henan & 9.1 & 6.0 & 7.4 & 5.2 \\
\hline & Hubei & 8.2 & 3.3 & 3.4 & 3.6 \\
\hline & Hunan & 2.6 & 2.4 & 1.6 & 0.9 \\
\hline & Jiangxi & 0.3 & 1.4 & 0.0 & 0.2 \\
\hline & Sichuan & 6.9 & 4.0 & 6.5 & 3.5 \\
\hline \multirow[t]{5}{*}{ Northwest } & Gansu & 1.2 & 0.8 & 0.6 & 5.7 \\
\hline & Ningxia & 1.7 & 1.4 & 3.1 & 14.4 \\
\hline & Qinghai & 0 & 0.8 & 1.6 & 1.3 \\
\hline & Shannxi & 2.7 & 2.4 & 5.9 & 8.0 \\
\hline & Xinjiang & 3.5 & 6.8 & 18.3 & 18.7 \\
\hline \multirow[t]{5}{*}{ Southern } & Hainan & 1.5 & 0.0 & 0.0 & 0.0 \\
\hline & Guangdong & 0.1 & 1.1 & 0.8 & 0.0 \\
\hline & Guangxi & 1.9 & 1.5 & 0.7 & 0.5 \\
\hline & Guizhou & 3.6 & 0.3 & 0.4 & 1.2 \\
\hline & Yunnan & 4.2 & 0.8 & 1.5 & 2.6 \\
\hline Nation & & 100.0 & 100.0 & 100.0 & 100.0 \\
\hline
\end{tabular}

Sources: primary data from (National Bureau of Statistics of China, 2014-2017; National Bureau of Statistics of China, 2006-2017; China Petroleum and Chemical Industry Federation, 2002-2016). 
Ammonia demand can be divided into two downstream industries: fertilizer and other, of which the former is the key market (Zhou et al., 2010; Zhang et al., 2012b; Kermeli et al., 2013). About $90 \%$ of ammonia production is used as a nitrogen source for the manufacture of fertilizers in China (Ma et al., 2015; Wen, 2012). The remaining 10\% of ammonia production is used for producing various industrial products, such as plastics, acrylonitrile, caprolactam, and other organic nitrogen compounds (Kermeli et al., 2013; $\mathrm{Ma}$ et al., 2015). Driven by fertilizer demand, ammonia production is likely to show slower growth in the future and will peak by 2030 (Zhou et al., 2013; Ren, 2015; Zhang et al., 2013). After 2030, ammonia production is expected to show a declining trend due to demand saturation and overcapacity (see Figure 3.1) (China Petroleum and Chemical Industry Federation, 2002-2016; Ren, 2015). Therefore, the annual growth rate will be set at 1\% during 2015-2020 based on the national plan (Wen, 2012; Ren, 2015; Ministry of Agriculture of China, 2015; Zhu et al., 2015). Between 2020 and 2030, the annual growth rate will slow down to $0.5 \%$ and peak by 2030 (Zhang et al., 2013). After 2030, LBNL indicates that ammonia production will decline by $0.3 \%$ per year (Zhou et al., 2013). Ammonia production at a regional level in China between 2015 and 2035 is presented in Appendix 3.A1. Ammonia production in this study is similar to the new policy scenario of IEA's 2018 Word Energy Outlook (unpublished).

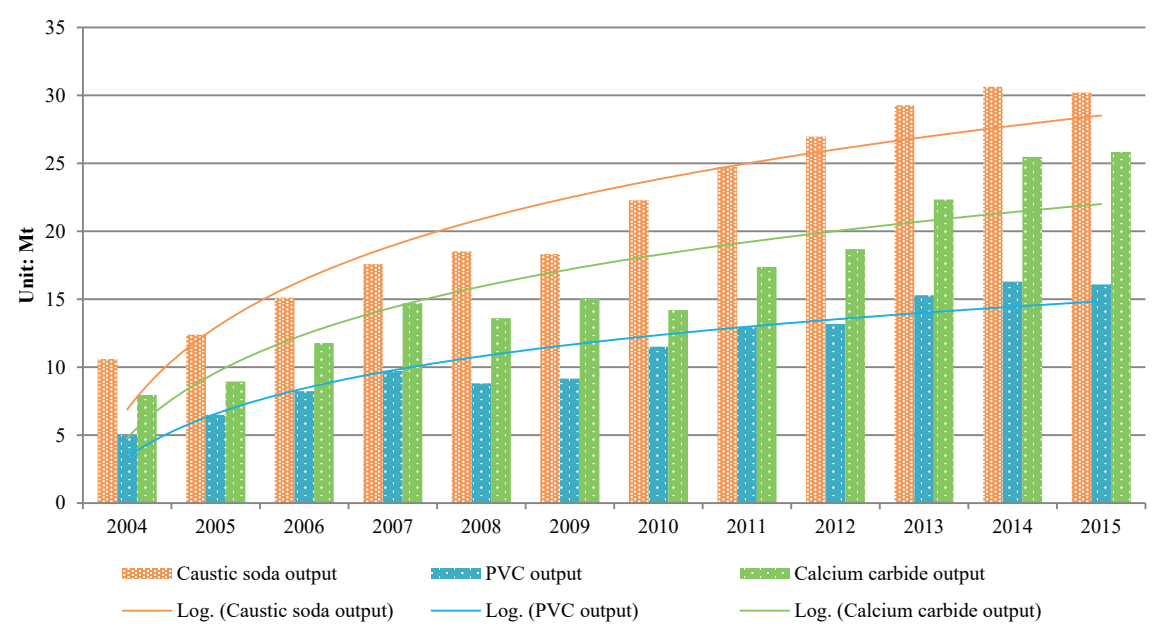

Figure 3.6. Output trend of caustic soda, PVC and calcium carbide in China.

Source: Primary data from (National Bureau of Statistics of China, 2014-2017; National Bureau of Statistics of China, 2006-2017; China Petroleum and Chemical Industry Federation, 2002-2016). Calculated by authors. 
Caustic soda and PVC are the main products in the chlor-alkali industry and widely applied in various industries and have large market demand. Caustic soda demand in China is driven by 9 industries: paper (25\%), chemical (23\%), textile (19\%), alumina (9\%), medicines (5\%), iron \& steel (4\%) and other industries (15\%) (China Petroleum and Chemical Industry Federation, 2002-2016; Zhang, 2017; Zhang, 2018). PVC is mainly used to produce plastic products and applied in building, automobile, electrical parts, packaging and other industries (China Petroleum and Chemical Industry Federation, 2002-2016; Zhang, 2017). As shown in Figure 3.1 and Figure 3.6, the output of caustic soda and PVC increased sharply with a growth rate of $13 \%$ per year during 11th Five-Year Plan (2006-2010). By phasing out inefficient production capacity, the annual growth rate of caustic soda and PVC output slowed and stabilized after 2010 (see Figure 3.6) (China Chlor-Alkali Online, 2016a; Ministry of Industry and Information Technology of China, 2016; State Council of China, 2013b). Industrialization and urbanization will further fuel caustic soda and PVC demand (National Bureau of Statistics of China, 2014-2017; Li et al., 2014; China Chlor-Alkali Online, 2016a). In addition, "The Belt and Road Initiative" and "Made in China 2025" will likely drive future market demand for caustic soda and PVC (A. T. Kearney and CPCIF, 2017; Ascensão et al., 2018; $\mathrm{Li}, 2017)$. As a result of the current low capacity utilization rate, the future annual growth rate of caustic soda and PVC production are assumed to be lower than those of 12th Five-Year Plan (where were 6\% and 7\%, respectively). Annual growth rates of $4.5 \%$ and $4.6 \%$ are used for the total output of caustic soda and PVC, respectively, based on the national plans (China Chlor-Alkali Online, 2016a; Ministry of Industry and Information Technology of China, 2016). The output of caustic soda and PVC at regional level in China between 2015 and 2035 are presented in Appendix 3.A2.

The development of calcium carbide industry in China is highly correlated with that of the chlor-alkali industry, as $80 \%$ of the calcium carbide output is used to produce PVC (Liu et al., 2011; China Chlor-Alkali Online, 2016a). The remaining 20\% of calcium carbide is used to produce acetylene (9\%) and other products (11\%) (China Petroleum and Chemical Industry Federation, 2002-2016). As shown in Figure 3.6, the historical trend of calcium carbide production maintain with that of PVC. The annual growth rate of calcium carbide output shows a gradual decline and tends to stabilize after 2010. Driven by PVC demand, the future trend of calcium carbide output is expected to be in line with the PVC growth rate (Liu et al., 2011; China Petroleum and Chemical Industry Federation, 2002-2016; China Chlor-Alkali Online, 2016b; China Carbide Industry Association, 2013). Specifically, the total output of calcium carbide is assumed to grow at an average rate of 4.6\% per year between 2015 and 2035 (Ministry of Industry and Information Technology of China, 2016). The future calcium carbide output at a regional level in China is presented in Appendix 3.A3. 


\subsubsection{Energy, emission and technical parameters}

The historic production volumes and capacities of ammonia, caustic soda, PVC and calcium carbide in each province used to forecast future output are derived from the China statistical yearbook (National Bureau of Statistics of China, 2014-2017), China industrial statistical yearbook (National Bureau of Statistics of China, 2006-2017), China Petroleum and Chemical Industry Federation (CPCIF), and China chemical industry yearbook (China Petroleum and Chemical Industry Federation, 2002-2016). Final energy consumption and electricity consumption of the chemical industry between 2000-2015 are from China energy statistical yearbook (National Bureau of Statistics of China, 2015-2017), and China electric power yearbook (China Electric Power Yearbook Editorial Committee, 2013-2017). Air pollutants emissions are from the China environmental statistics yearbook (NBS and MEP, 2006-2016), annual statistic report on environment in China (Ministry of Environmental Protection of China, 2009-2017), and studies from Zhang (2008) and Shi et al. (2014).

Sixty electricity efficiency technologies (21 technologies for ammonia production, 17 technologies for calcium carbide production and 22 technologies for caustic soda and PVC production) are included in our study. The technology characteristics (e.g. investment, operation and maintenance cost and electricity saving) are derived from NDRC (National Development and Reform Commission of China, 2015-2017), MIIT (Ministry of Industry and Information Technology of China, 2009-2011, 2010, 2012), LBNL (Ma et al., 2015), Energy Research Institute of China (Dai and Hu, 2013; Dai et al., 2013), China Chemical Energy Efficiency Technology Association (2006, 2011), and other studies (detailed information can be found in Appendix 3.B1) (Li et al., 2014; Liu et al., 2011; Zhang et al., 2012b; Zhu et al., 2015). The transmission and distribution losses and auxiliary power use for the calculation of the generation efficiency for six grids are taken from the power industry statistical compilation (Song et al., 2013; China Electricity Council, 2015). The study period is 2012 to 2035, while 2012 is taken as the base year because that is the latest year for which the implementation rates are available. Based on new capacity and withdrawal of capacity for the selected subsector, potential implementation rates up to 2035 are determined for each technology assuming linear deployment (see Appendix 3.B1) (Song et al., 2013; Hasanbeigi et al., 2013). The diaphragm caustic soda process will be withdrawn from the Chinese market due to its high electricity cost and high pollution (State Council of China, 2013b). Therefore, the implementation rates of electricity efficiency measures (e.g. three-phase flow evaporation technology and modified diaphragm and expanded metal anode technology) used for diaphragm caustic soda are assumed to be 0 after 2025 in this study. Electricity prices $(\$ / \mathrm{kWh})$ of the chemical industry in each grid can be obtained from the provincial electricity pricing policies released by State Grid Corporation of China (State Grid Corporation of China, 2015). In addition, 3.22 \$/GJ is used as the fuel price in this study (Zhang et al., 2016; Zhang et al., 2015). The prices of electricity and fuel 
are assumed to remain unchanged during the study period 2012-2035. Appendix 3.B2 shows the CCE of each energy efficiency technology.

Electricity exchange between grids is derived from power industry statistical compilation (Hasanbeigi et al., 2013), and NDRC (National Development and Reform Commission of China, 2006-2017). Power generation per grid is from China electric power yearbook (China Electric Power Yearbook Editorial Committee, 2013-2017). Fuel consumption for power generation in each province is obtained from the China energy statistical yearbook (National Bureau of Statistics of China, 2015-2017). The lower calorific value, carbon content and oxidation rate for each fuel are from NDRC (National Development and Reform Commission of China, 2006-2017, 2008, 2011), National Government Offices Administration of China (2011), IPCC (2006), and WRI (Song et al., 2013). 16 air pollutant control technologies (including 10 desulfurization technologies, 4 denitrification technologies and $2 \mathrm{PM}_{2.5}$ removal technologies) are selected (see Appendix 3.B3) (Chinese Research Academy of Environmental Sciences, 2010; Ministry of Environmental Protection of China, 2009-2014; Ministry of Environmental Protection of China, 2011-2014). The share of each $\mathrm{SO}_{2} / \mathrm{NO}_{x}$ abatement technology at provincial level is calculated from the list of desulfurization and denitrification facilities for China's coal-fired power units. The share of $\mathrm{PM}_{2.5}$ removal technologies at the provincial level are from Tsinghua University's study (Cai et al., 2013). More than 50 abatement technologies in 4467 generator units in operation for removing $\mathrm{SO}_{2}$ in China's power sector, 10 desulfurization technologies are selected because they have the largest shares in total installed capacity, and together account for more than $95 \%$ (Ministry of Environmental Protection of China, 2009-2014). The remaining desulfurization technologies (e.g. dry process, $\mathrm{NaOH}+$ microbial reduction, and activated coke) are classified as remaining desulfurization technology. The removal efficiencies for each technology are derived from recent studies (including the sulfur content, $\mathrm{SO}_{2}$ conservation rate, $\mathrm{PM}_{2.5}$ emission factors and $\mathrm{NOx}$ emission factors for each fuel) (Cai et al., 2013; Zhao et al., 2010; Chinese Research Academy of Environmental Sciences, 2010; Ministry of Environmental Protection of China, 2005-2015). Additionally, 95\%, $100 \%$ and $100 \%$ operation rate are assumed for desulfurization, denitrification and $\mathrm{PM}_{2.5}$ removal technologies respectively, and remain unchanged for each grid (Cai et al., 2013; National Development and Reform Commission of China, 2007). The emission factors of air pollutants are assumed to remain constant over the studied period. 


\subsection{Results and discussion}

The ECSCs per grid are developed to capture the cost effectiveness and technical potential of 60 electricity efficiency technologies in the chemical industry till 2035. A CCE of $0 \$ / G J$ (at a discount rate of 10\%) is chosen as the threshold to determine the cost-effective potential, representing economically feasible opportunities. Moreover, the environmental benefits of the electricity savings in China's chemical industry are identified at grid level.

\subsection{Electricity saving potential by grid in China's chemical industry}

Figure 3.7 shows the electricity consumption in three chemical sub-sectors between 2012 and 2035 under two scenarios (without and with electricity efficiency measures called frozen scenario and technical scenario, respectively). Total electricity consumption for these sub-sectors under the frozen scenario will increase to $475 \mathrm{TWh}$ in 2035, 1.4 times higher than in 2012. The potential technical electricity efficiency improvement is different for the six grids. North grid and Northwest grid have the greatest electricity saving potentials, together accounting for $60-63 \%$ of total electricity savings during 2015-2035, followed by the Central grid with around 20\%. The East and Southern grids, which are clustered by coastal regions (e.g. Zhejiang, Guangdong and Shanghai) account for $16 \%-15 \%$ of total electricity savings. The chemical industry is mainly concentrated in regions with abundant resources, showing the resource-oriented development pattern (A. T. Kearney and CPCIF, 2017). The Northeast grid, including Liaoning, Shenyang and Heilongjiang, with low shares of chemicals output, only accounts for around $2 \%$ of total electricity consumption and savings. The total cost-effective electricity savings potential $(<0 \$ / G J)$ accounts for more than $79 \%$ of the technical electricity savings potential, equal to $23 \mathrm{TWh}$ in $2020,49 \mathrm{TWh}$ in $2025,88 \mathrm{TWh}$ in 2030 and $146 \mathrm{TWh}$ in 2035, respectively (see Figure 3.8). The cost-effective potential of electricity efficiency improvement for these chemical sectors in the North grid, Northwest grid and Central grid amounts to $121 \mathrm{TWh}$ in 2035 , or $83 \%$ of the total cost-effective electricity savings. Southern grid and Northeast grid have the lowest share of the cost-effective electricity savings, accounting for around 6\% and 2\% respectively in 2035 . 


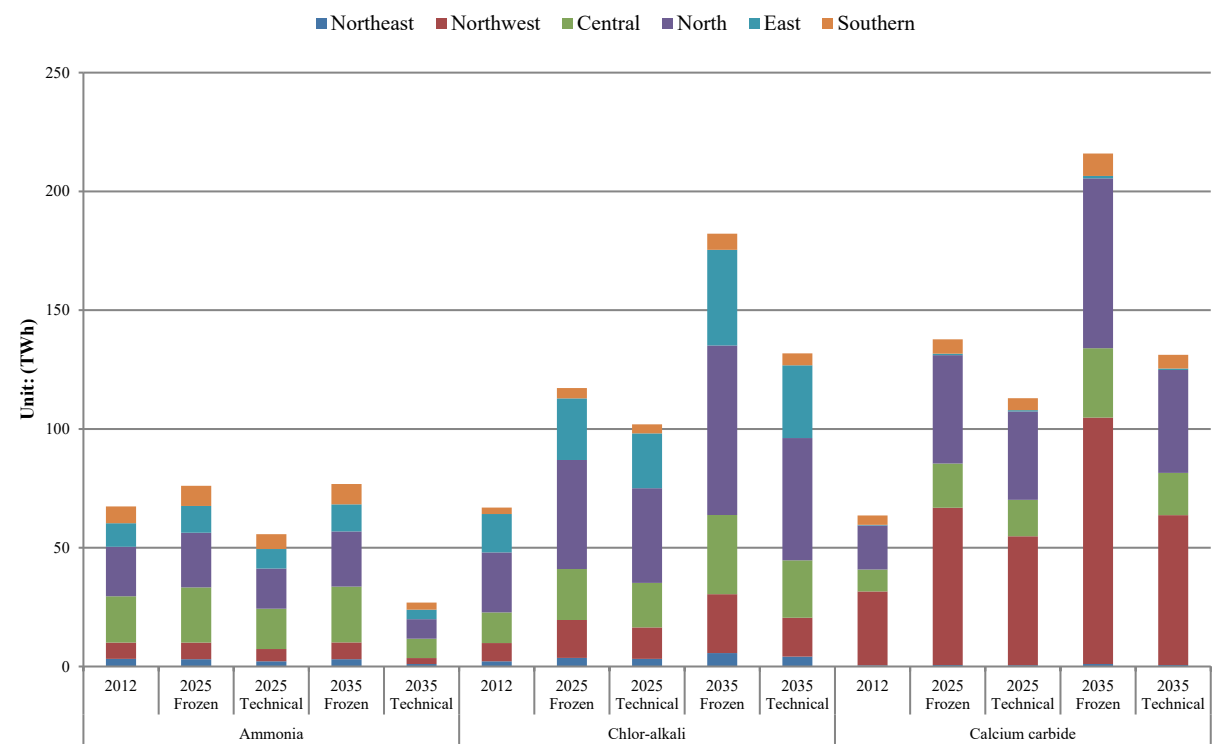

Figure 3.7. Electricity consumption in sub-sectors at grid level during 2012-2035 under two scenarios.

\subsubsection{Electricity saving potential by grid in China's ammonia industry}

The ECSCs of each sub-sector per grid are constructed to identify which sub-sector has the largest contribution. Table 3.2 shows the annual electricity saving potentials in the ammonia industry, which vary from 11 TWh in 2020 to $50 \mathrm{TWh}$ in 2035, equaling $38 \%-27 \%$ of total electricity savings. The cost-effective measures are about $90 \%$ of the total electricity savings in ammonia industry (equal to $10 \mathrm{TWh}$ in 2020,19 TWh in 2025, 31 TWh in 2030 and 46 TWh in 2035; see Appendix 3.C1). Ammonia production capacity is concentrated in grain and cotton producing regions (e.g. Shanxi, Shandong, Henan, Sichuan) (China Petroleum and Chemical Industry Federation, 2002-2016). These regions are mainly located in the Central grid and North grid. Therefore, the North and Central grids show larger electricity saving potential than other grids, accounting for $61 \%$ of the total electricity saving potential in ammonia industry between 2020 and 2035. Liaoning, Jilin, Heilongjiang, Qinghai, Gansu, Ningxia located in Northeast grid and Northwest grid are ammonia importing provinces. Low shares of ammonia production cause lower electricity efficiency improvement potentials in the Northeast grid (0.5-2 TWh) and Northwest grid (1-5 TWh) during 2020-2035. Around $26 \%$ of electricity saving potential is contributed by the East grid and Southern grid in the same period. 

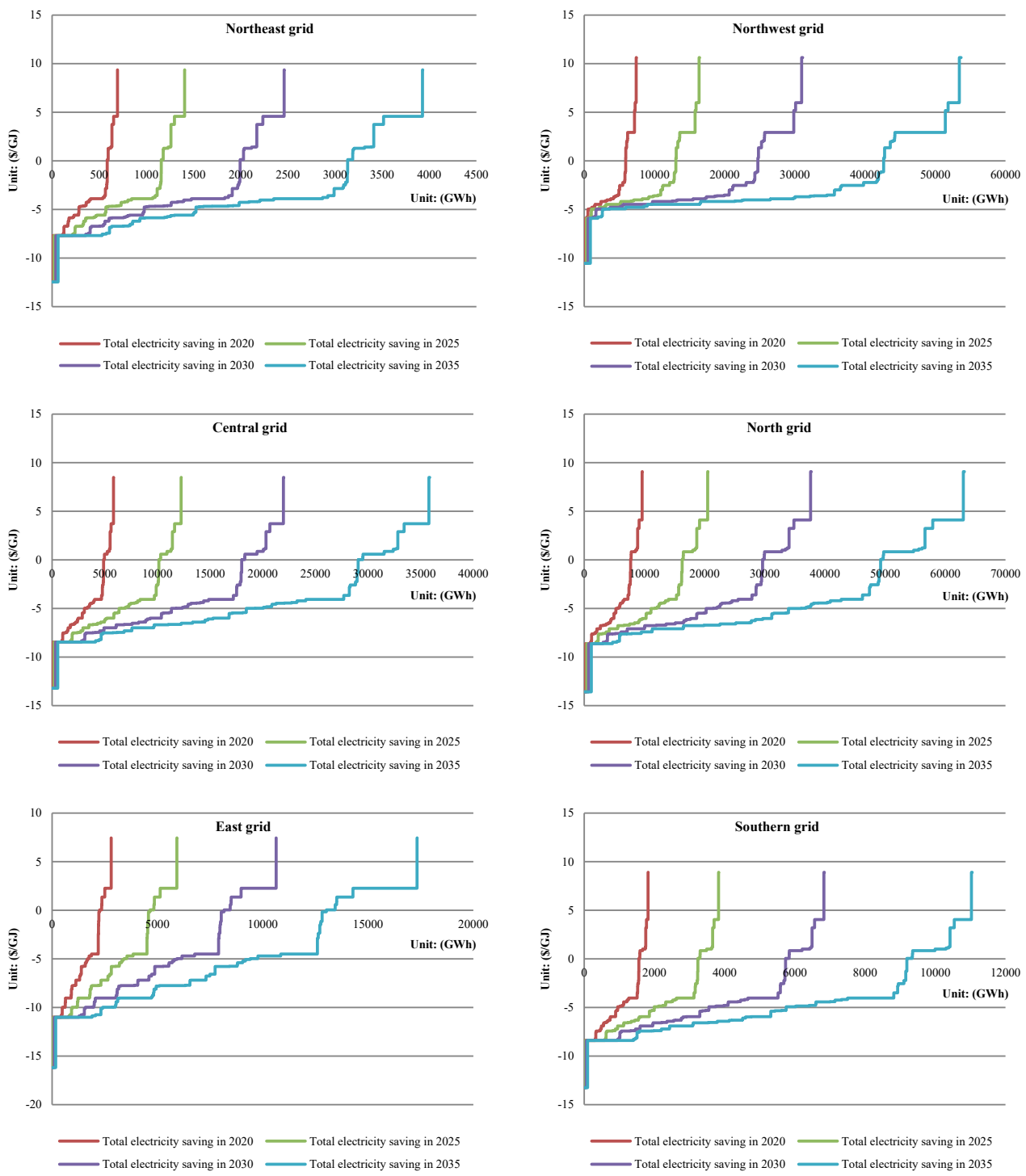

Figure 3.8. Total electricity saving potentials for chemical sectors in each grid during 2020-2035.

\subsubsection{Electricity saving potential by grid in China's chlor-alkali industry}

The total (technical) electricity savings in the chlor-alkali industry increase from $7 \mathrm{TWh}$ in 2020 to $50 \mathrm{TWh}$ in 2035 , and account for $24-27 \%$ of the improvement potential (see Table 3.3). The cost-effective electricity saving potential in the chlor-alkali industry equals $5 \mathrm{TWh}$ in 2020, $10 \mathrm{TWh}$ in 2025, $19 \mathrm{TWh}$ in 2030 and $33 \mathrm{TWh}$ in 2035, which is a bit lower than that of the ammonia industry (see Appendix 3.C2). Shandong, Tianjin, Jiangsu, Zhejiang and Inner Mongolia, with the advantages of salt and power 
resources, have a large share in caustic soda and PVC production (accounted 54\% of total caustic soda output and 39\% of total PVC output in 2015). As a result, North grid and East grid hold the largest potential in electricity efficiency improvement, accounting for $58 \%$ of electricity savings in the chlor-alkali industry. Affected by the circular economy project for integrated coal-electricity-salt production (Ministry of Industry and Information Technology of China, 2016), the Northwest and Central grids also show higher reduction of electricity use, compared to $7 \%$ of improvement potential in the Northeast and Southern grid between 2020 and 2035.

\subsubsection{Electricity saving potential by grid in China's calcium carbide industry}

Calcium carbide production is the largest electricity consumer, and has the greatest impact on electricity efficiency improvement for the chemical industry. As shown in Table 3.4, the electricity saving potential in calcium carbide industry grows from 11 TWh to 85 TWh between 2020 and 2035. 85 TWh electricity savings in 2035 is nearly $43 \%$ electricity use of these chemical sectors in 2012 . Around $79 \%$ of the technical electricity saving potential is contributed by the cost-effective measures in the calcium carbide industry (equaling $9 \mathrm{TWh}$ in 2020, $20 \mathrm{TWh}$ in 2025, $38 \mathrm{TWh}$ in 2030 and $68 \mathrm{TWh}$ in 2035; see Appendix 3.C3). Most of the calcium carbide enterprises are concentrated in the Northwest and North regions (i.e. Inner Mongolia, Shannxi, Gansu, Ningxia and Xinjiang) (China Carbide Industry Association, 2013). Therefore the Northwest grid has the largest electricity saving potential accounting for $48 \%$ of the improvement potential for calcium carbide industry in 2035, followed by the North and Central grid with 33\% and 13\% respectively. Only $4 \%$ of improvement potential is found in the East, Northeast and Southern grid as a result of relatively small calcium carbide production capacity. 
Table 3.2. Electricity saving potentials in the ammonia industry at grid level. Unit: (GWh)

\begin{tabular}{lcccccccc}
\hline Grid & \multicolumn{2}{c}{$\mathbf{2 0 2 0}$} & \multicolumn{2}{c}{2025} & \multicolumn{2}{c}{$\mathbf{2 0 3 0}$} & \multicolumn{2}{c}{$\mathbf{2 0 3 5}$} \\
\cline { 2 - 8 } & $\begin{array}{c}\text { Cost- } \\
\text { effective }\end{array}$ & Technical & $\begin{array}{c}\text { Cost- } \\
\text { effective }\end{array}$ & Technical & $\begin{array}{c}\text { Cost- } \\
\text { effective }\end{array}$ & Technical & $\begin{array}{c}\text { Cost- } \\
\text { effective }\end{array}$ & Technical \\
\hline Northeast & 424 & 460 & 785 & 854 & 1276 & 1390 & 1882 & 2049 \\
Northwest & 886 & 971 & 1704 & 1865 & 2819 & 3081 & 4195 & 4578 \\
Central & 2989 & 3275 & 5711 & 6251 & 9424 & 10299 & 14002 & 15282 \\
North & 2886 & 3162 & 5579 & 6106 & 9252 & 10111 & 13782 & 15040 \\
East & 1465 & 1565 & 2825 & 3007 & 4681 & 4970 & 6970 & 7385 \\
Southern & 1087 & 1191 & 2084 & 2281 & 3443 & 3762 & 5119 & 5586 \\
Total & 9737 & 10624 & 18688 & 20364 & 30895 & 33613 & 45950 & 49920 \\
\hline
\end{tabular}

Table 3.3. Electricity saving potentials in the chlor-alkali industry at grid level. Unit: (GWh)

\begin{tabular}{lcccccccc}
\hline Grid & \multicolumn{2}{c}{$\mathbf{2 0 2 0}$} & \multicolumn{2}{c}{$\mathbf{2 0 2 5}$} & \multicolumn{2}{c}{$\mathbf{2 0 3 0}$} & \multicolumn{2}{c}{$\mathbf{2 0 3 5}$} \\
\cline { 2 - 8 } & $\begin{array}{c}\text { Cost- } \\
\text { effective }\end{array}$ & Technical & $\begin{array}{c}\text { Cost- } \\
\text { effective }\end{array}$ & Technical & $\begin{array}{c}\text { Cost- } \\
\text { effective }\end{array}$ & Technical & $\begin{array}{c}\text { Cost- } \\
\text { effective }\end{array}$ & Technical \\
\hline Northeast & 124 & 188 & 284 & 439 & 539 & 847 & 930 & 1479 \\
Northwest & 928 & 1234 & 1954 & 2651 & 3575 & 4924 & 6045 & 8409 \\
Central & 807 & 1177 & 1840 & 2744 & 3482 & 5282 & 6002 & 9204 \\
North & 1869 & 2714 & 4081 & 6070 & 7597 & 11503 & 12991 & 19901 \\
East & 753 & 1202 & 1727 & 2819 & 3284 & 5461 & 5692 & 9576 \\
Southern & 152 & 227 & 356 & 540 & 681 & 1048 & 1179 & 1834 \\
Total & 4633 & 6742 & 10242 & 15263 & 19158 & 29065 & 32839 & 50403 \\
\hline
\end{tabular}

Table 3.4. Electricity saving potentials in the calcium carbide industry at grid level. Unit: (GWh)

\begin{tabular}{lcccccccc}
\hline Grid & \multicolumn{2}{c}{$\mathbf{2 0 2 0}$} & \multicolumn{2}{c}{$\mathbf{2 0 2 5}$} & \multicolumn{2}{c}{$\mathbf{2 0 3 0}$} & \multicolumn{2}{c}{$\mathbf{2 0 3 5}$} \\
\cline { 2 - 8 } & $\begin{array}{c}\text { Cost- } \\
\text { effective }\end{array}$ & Technical & $\begin{array}{c}\text { Cost- } \\
\text { effective }\end{array}$ & Technical & $\begin{array}{c}\text { Cost- } \\
\text { effective }\end{array}$ & Technical & $\begin{array}{c}\text { Cost- } \\
\text { effective }\end{array}$ & Technical \\
\hline Northeast & 36 & 45 & 89 & 113 & 179 & 226 & 322 & 404 \\
Northwest & 4091 & 5229 & 9394 & 11913 & 18336 & 23110 & 32414 & 40693 \\
Central & 1093 & 1391 & 2590 & 3272 & 5106 & 6423 & 9068 & 11371 \\
North & 2954 & 3778 & 6612 & 8388 & 12778 & 16110 & 22487 & 28236 \\
East & 37 & 38 & 98 & 101 & 200 & 206 & 361 & 370 \\
Southern & 317 & 404 & 799 & 1012 & 1613 & 2031 & 2894 & 3631 \\
Total & 8528 & 10885 & 19582 & 24799 & 38212 & 48106 & 67546 & 84705 \\
\hline
\end{tabular}




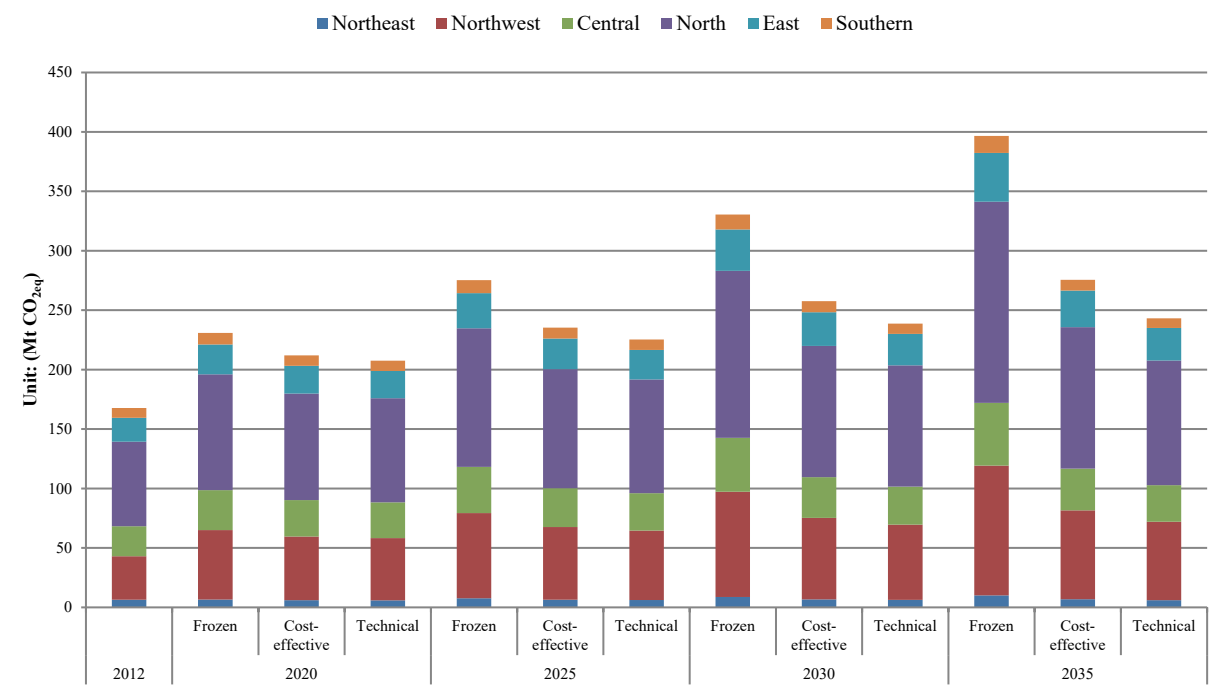

Figure 3.9. GHG emissions in chemical sectors between 2012 and 2035 under different scenarios.

\subsubsection{Multiple benefits on climate change and air quality 3.4.2.1. GHG emissions reduction by grid}

Figure 3.9 shows the GHG emissions caused by electricity use in the chemical sectors by grid between 2012 and 2035 under different scenarios. In the frozen scenario, GHG emissions increase rapidly from $168 \mathrm{Mt} \mathrm{CO}_{2 \mathrm{eq}}$ in 2012 to $397 \mathrm{Mt} \mathrm{CO}_{2 \mathrm{eq}}$ in 2035 with an average rate of $3.8 \%$ per year. Electricity efficiency measures play a key role in reducing $\mathrm{CO}_{2}$ emissions. By adopting all 60 electricity efficiency measures, emissions can be reduced by $23 \mathrm{MtCO}_{2 \mathrm{eq}}$ in 2020, $50 \mathrm{Mt}$ in 2025, $92 \mathrm{Mt}$ in 2030 and $154 \mathrm{Mt}$ in 2035 (equivalent to $39 \%$ reduction compared to the frozen scenario in 2035). More than $79 \%$ of the GHG emissions reduction potential can be achieved cost effectively. The reduction potential varies for the different grids. In 2035, the absolute savings potential is highest in North grid (42\% of total savings), followed by Northwest grid (28\%), Central gird (14\%), East grid (9\%), Southern grid (4\%) and lastly Northeast grid (3\%). 

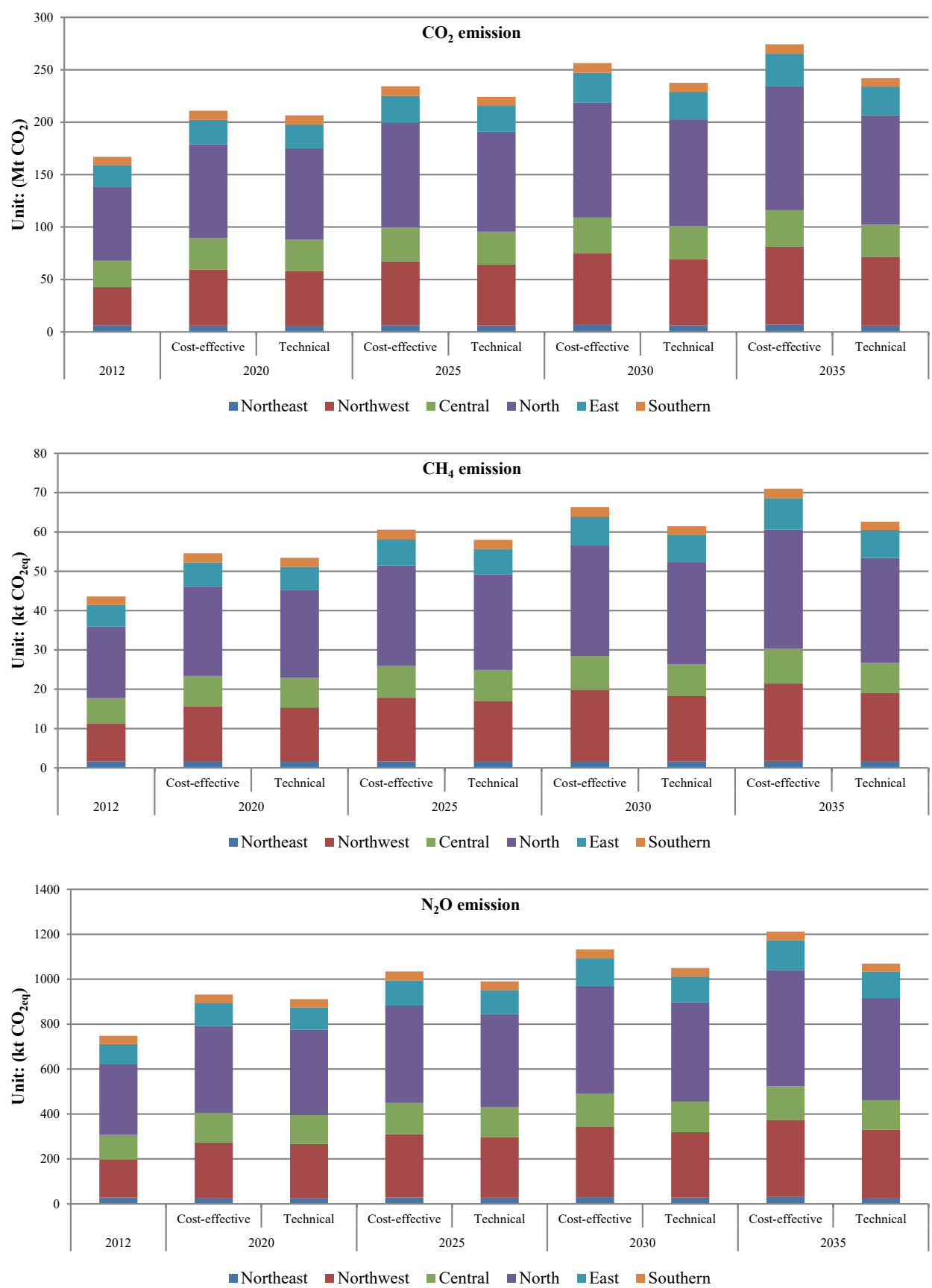

Figure 3.10. Emissions per grid of $\mathrm{CO}_{2}, \mathrm{CH}_{4}$ and $\mathrm{N}_{2} \mathrm{O}$ under two scenarios between 2020 and 2035 . 
Detailed emissions of $\mathrm{CO}_{2}, \mathrm{CH}_{4}$ and $\mathrm{N}_{2} \mathrm{O}$ for two scenarios per grid are shown in Figure 3.10. Between 2020 and 2035, the North grid with the greatest $\mathrm{CO}_{2}$ emissions has the largest potential for $\mathrm{CO}_{2}$ emission reduction though implementing cost-effective measures, which accounted for around $42 \%$ of total reduction potential. In 2020, the Northwest and Central grids together accounted for $40 \%$ of total grid emissions, and show a $41 \% \mathrm{CO}_{2}$ reduction potential under cost-effective scenario. The Northeast grid with the smallest share of chemical production emits $7 \mathrm{Mt} \mathrm{CO}_{2}$ emissions under cost-effective scenario (equal to 3\% of total emissions). Compared with 2012, in the technical scenario total $\mathrm{CH}_{4}$ and $\mathrm{N}_{2} \mathrm{O}$ emissions will increase by $19 \mathrm{kt} \mathrm{CO}_{2 \mathrm{eq}}$ and 321 kt $\mathrm{CO}_{2 \mathrm{eq}}$ in 2035 respectively.

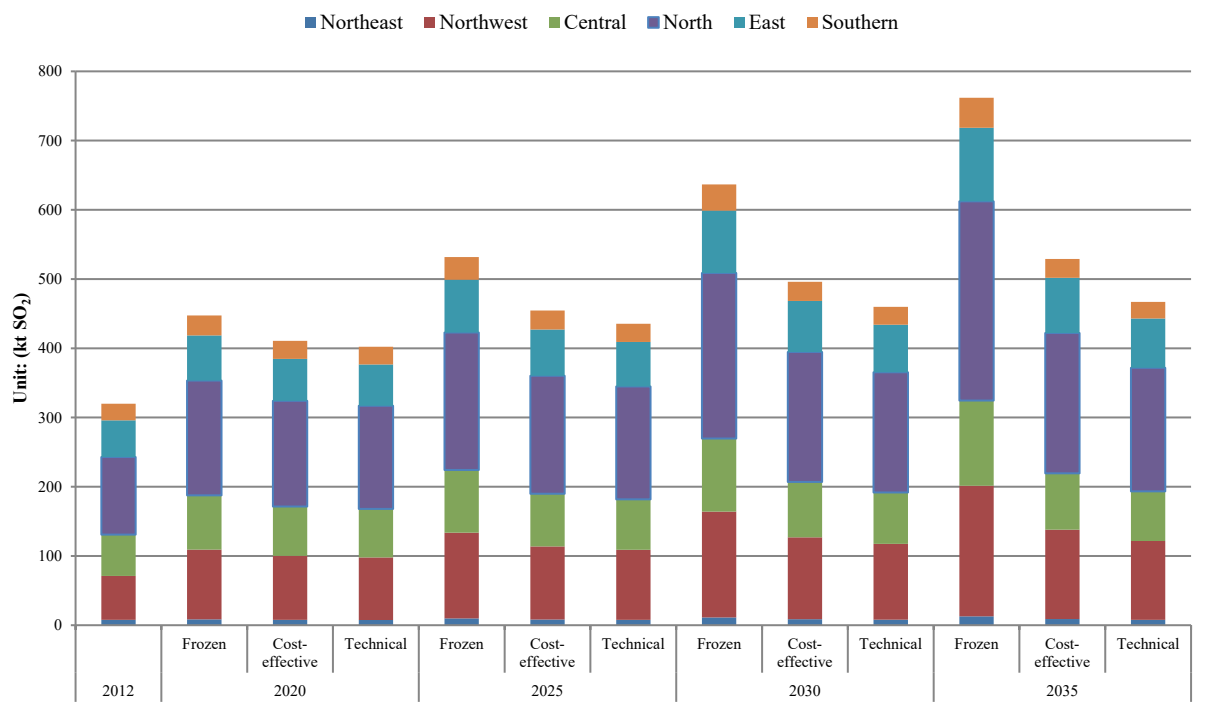

Figure 3.11. $\mathrm{SO}_{2}$ emissions at grid level between 2012 and 2035 under different scenarios.

\subsubsection{Air pollutant emissions reduction by grid}

$\mathrm{SO}_{2}$ emissions caused by electricity consumption in the chemical industry are influenced by the generation efficiency, sulfur content of fuels and degree of flue gas desulfurization. $\mathrm{SO}_{2}$ emissions in different grids under different scenarios between 2012 and 2035 are shown in Figure 3.11. The total $\mathrm{SO}_{2}$ emissions will increase from $320 \mathrm{kt}$ in 2012 to 762 kt in 2035 under frozen scenario. If the cost-effective electricity saving measures were adopted, $8 \%$ and $31 \%$ of $\mathrm{SO}_{2}$ emissions can be avoided in 2020 and 2035 respectively. If all electricity saving measures were implemented (technical scenario), $\mathrm{SO}_{2}$ emissions will drop further by $2 \%$ and $8 \%$ in 2020 and 2035. In the frozen and cost-effective scenarios, $\mathrm{SO}_{2}$ emissions in all grids show steady growth during 2012-2035. In the 
technical scenario, $\mathrm{SO}_{2}$ emissions from the Northeast, Central and Southern grids will peak around 2030, and then decline slightly (see Figure 3.12). As shown in Figure 3.11 and Figure 3.12, in the technical scenario $\mathrm{SO}_{2}$ emissions would still grow at an average rate of $1.2 \%, 1.6 \%$ and $1.2 \%$ per year in the North, Northwest and East grid respectively, from $149 \mathrm{kt}, 90 \mathrm{kt}$ and $60 \mathrm{kt}$ in 2020 to $178 \mathrm{kt}, 114 \mathrm{kt}$ and $71 \mathrm{kt}$ in 2035. The contribution to $\mathrm{SO}_{2}$ emission reductions varies among different grids, dependent on the electrical output and chemical production during 2020-2035. Regions with the largest share of $\mathrm{SO}_{2}$ emissions are mainly located in the North and Northwest grids. North grid and Northwest grid account for $37 \%$ and $22 \%$ of total $\mathrm{SO}_{2}$ emission reductions under cost-effective scenario in 2020, followed by Central grid and East grid with $19 \%$ and $13 \%$, respectively (see Figure 3.11). In cost-effective scenario, the share of reduction potential in Northwest grid will increase by 3\% in 2035 because of the implementation of coal-electricity-salt projects for the chlor-alkali sector (Ministry of Industry and Information Technology of China, 2016).

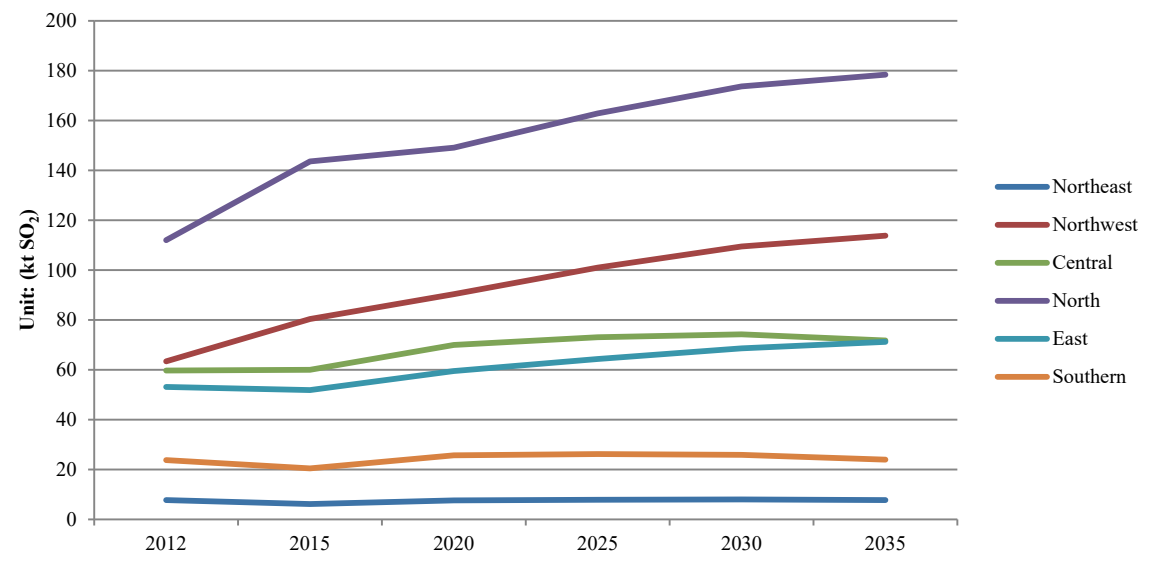

Figure 3.12. Trend of $\mathrm{SO}_{2}$ emissions at grid level in technical scenario during 2012-2035.

Figure 3.13 shows the $\mathrm{NO}_{\mathrm{x}}$ emissions (per grid) in the chemical industry for various scenarios between 2012 and 2035. Compared to the frozen scenario, the cost-effective measures contribute to $105 \mathrm{kt}$ and $322 \mathrm{kt}$ of $\mathrm{NO}_{\mathrm{x}}$ emission reductions in 2025 and 2035, respectively. If all the electricity efficiency measures implemented with expected adoption rates, the $\mathrm{NO}_{\mathrm{x}}$ emissions will further decrease by $21 \mathrm{kt}$ in 2025 and $68 \mathrm{kt}$ in 2035. $\mathrm{NO}_{\mathrm{x}}$ emission reductions in the North and Northwest grids are higher than other grids during the studied period in all scenarios, together accounting for around $70 \%$ of total $\mathrm{NO}_{x}$ emission reductions (see Figure 3.14). This is because more than $60 \%$ of total electricity savings in the chemical industry are from the North and Northwest grids. Additionally, the share of $\mathrm{NO}_{\mathrm{x}}$ emission reductions from the Northwest grid in 
2035 will be $2-3 \%$ higher than in 2020. Central grid and East grid with large share of ammonia, caustic soda and PVC production also have a high potential for $\mathrm{NO}_{\mathrm{x}}$ emission reductions, accounting for $14 \%$ and $8 \%$ of total $\mathrm{NO}_{\mathrm{x}}$ emission reductions in 2035 respectively. This is followed by the Southern grid and Northeast grid with 4\% and $3 \%$.

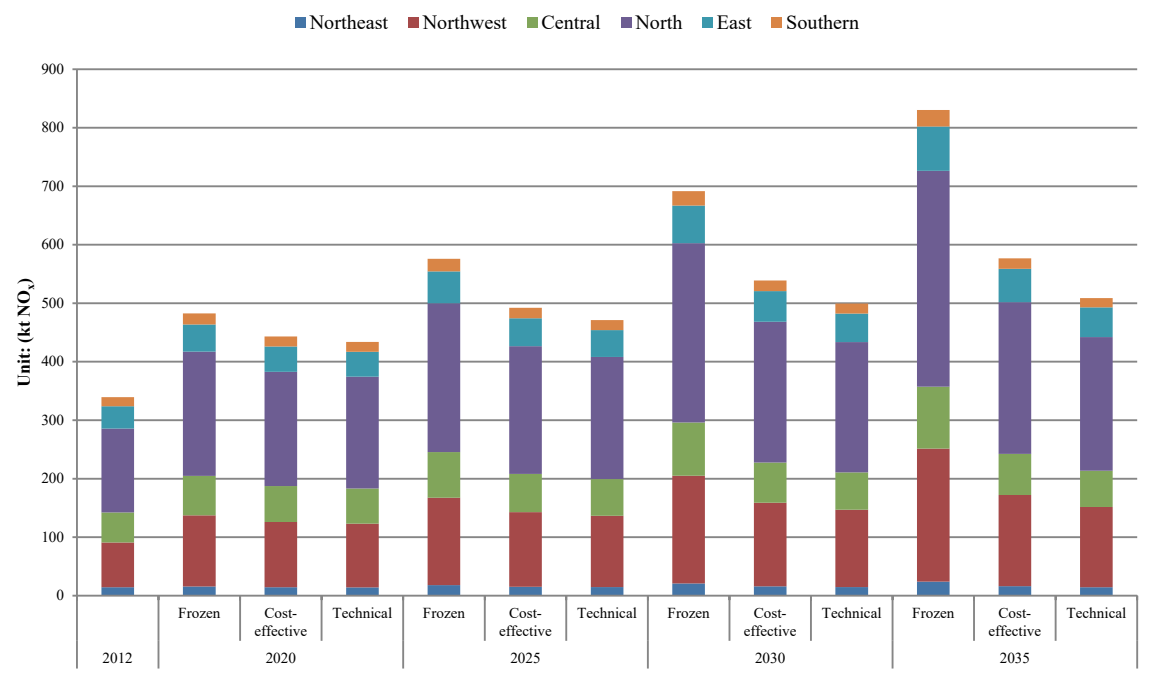

Figure 3.13. $\mathrm{NO}_{\mathrm{x}}$ emissions at grid level between 2012 and 2035 under different scenarios.
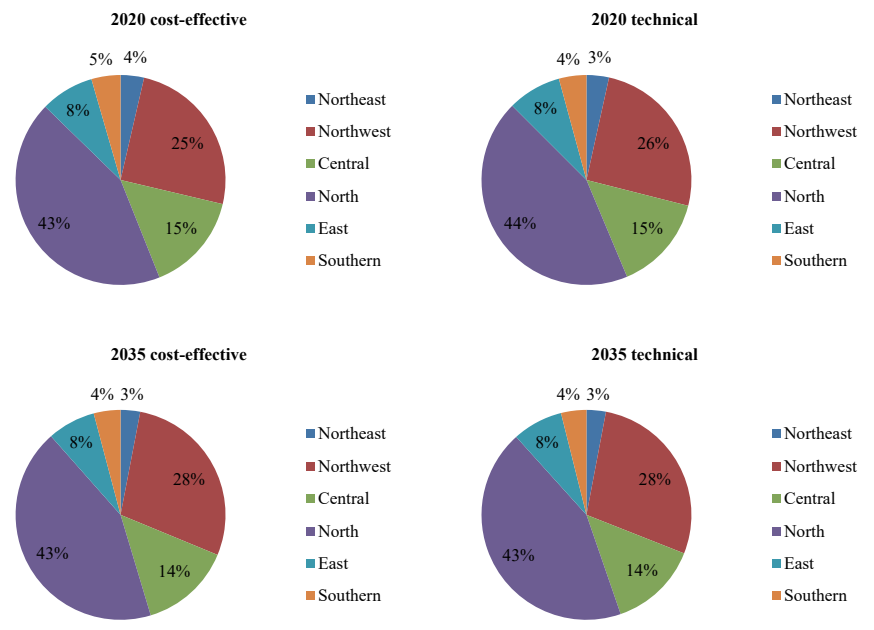

Figure 3.14. Share of $\mathrm{NO}_{\mathrm{x}}$ emission reduction potential per grid under different scenarios in 2020 and 2035. 
The co-benefit of electricity efficiency measures on $\mathrm{PM}_{2.5}$ emission reductions for chemical industry at grid level are shown in Figure 3.15. The total $\mathrm{PM}_{2.5}$ emissions increase to $167 \mathrm{kt}$, or 2.4 times during 2012-2035 equal to an increase of 3.8\%/year. Compared to the frozen scenario, in the cost-effective scenario, the average growth per year will decrease to $2.2 \%$. Reductions of $17 \mathrm{kt}$ and $51 \mathrm{kt} \mathrm{PM}_{2.5}$ emissions are feasible by adopting the cost-effective measures in 2025 and 2035 (equal to $15 \%$ and $31 \%$ of total $\mathrm{PM}_{2.5}$ emissions, respectively). If all the electricity saving measures were applied to the chemical sectors, the total $\mathrm{PM}_{2.5}$ emissions would further reduce by $3-8 \%$ during 2025-2035. Similar to the emissions of $\mathrm{SO}_{2}$ and $\mathrm{NO}_{x}$ under the technical scenario, $\mathrm{PM}_{2.5}$ emissions from the Northeast, Central and Southern grids will reach a peak of 3.6 kt, $1.5 \mathrm{kt}$ and $4.7 \mathrm{kt}$ in 2030 , and then decline to $3.5 \mathrm{kt}, 1.4 \mathrm{kt}$ and $4.3 \mathrm{kt}$ in 2035 (see Figure 3.16). In the North, Northwest and East grids, the trends of $\mathrm{PM}_{2.5}$ emission will continue to grow at an annual rate of $1 \%, 2 \%$ and $1 \%$ during 2020-2035, respectively. Provinces (e.g. Shandong, Inner Mongolia, Hebei, Shannxi and Xinjiang) with a large share of chemicals production and electricity consumption are mainly located in the North and Northwest. Therefore, the North grid and Northwest grid have the greatest $\mathrm{PM}_{2.5}$ emission reduction potential, together accounting for $64 \%$ of total $\mathrm{PM}_{2.5}$ emission reduction, followed by Central grid with $16 \%$, and East grid with $11 \%$. The Northeast and Southern grids with $8 \%$ of total electricity saving in chemical sectors, only account for $9 \%$ of total $\mathrm{PM}_{2.5}$ emission reduction in 2035 .

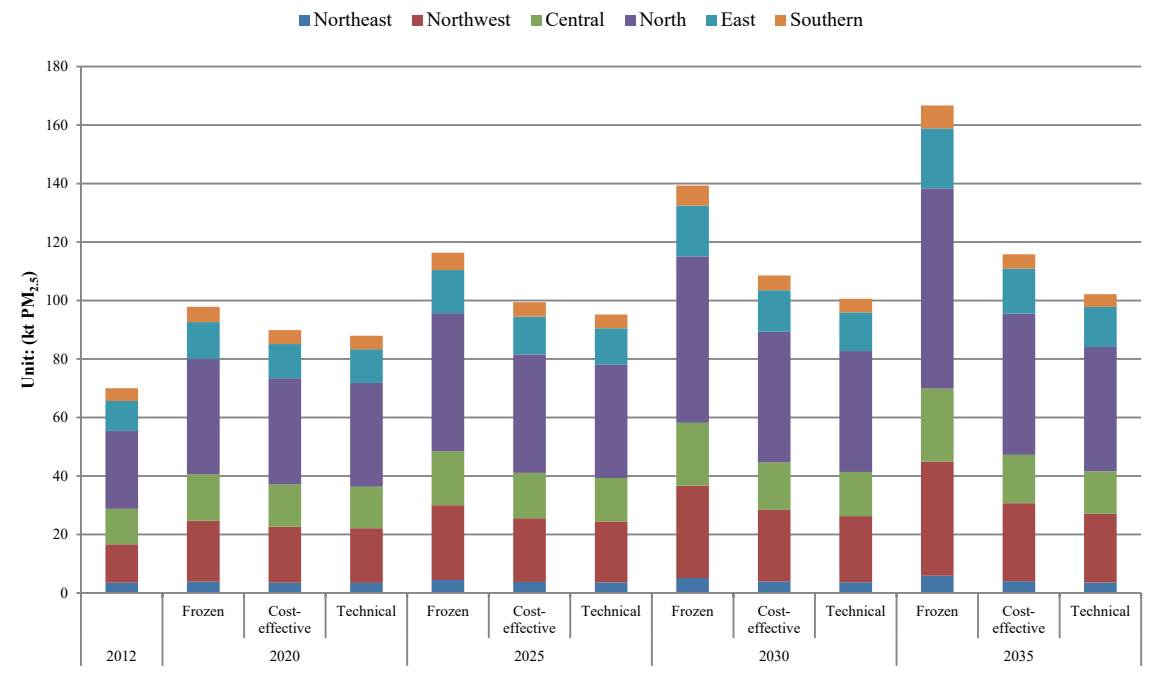

Figure 3.15. $\mathrm{PM}_{2.5}$ emissions at grid level between 2012 and 2035 under different scenarios. 


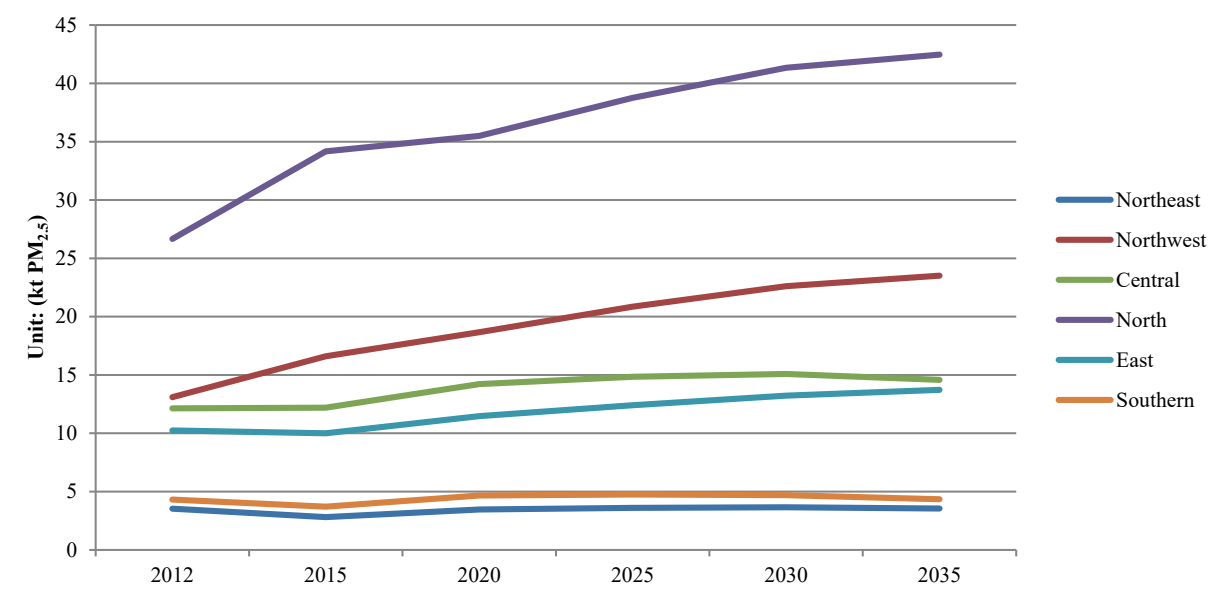

Figure 3.16. Trend of $\mathrm{PM}_{2.5}$ emissions at grid level in technical scenario during 2012-2035.

\subsection{Sensitivity analysis}

The impact of key factors affecting the results of electricity saving potential and related emission reductions, like chemical output, discount rate, and electricity prices in different grids, are analyzed.

\subsection{Chemicals output}

The future output of chemical products plays a crucial role in estimating the benefits of electricity savings and emissions reduction. Few studies have analyzed future chemicals production on a national or regional level due to its diversity and heterogeneity (Saygin et al., 2011; IEA, 2013). Based on the analysis of chemical products flow in downstream industries, the national plans and historical regional output for key chemicals are used to project the future output at grid level in this study (see Section 3.3.4.1 and Supplementary Information). Chemical plants characterized by energy intensive products are mainly located in regions with abundant raw materials and energy (coal and electricity), that are mainly concentrated in the North and Northwest grids (e.g. Inner Mongolia, Xinjiang and Shandong). In general, the growth rate of chemicals output in these grids is higher than the national average rate during 12th Five-Year Plan. For example, the output of caustic soda and calcium carbide in Northwest grid increased form 2.7 Mt and 8.1 Mt in 2011 to $4.1 \mathrm{Mt}$ and $12.4 \mathrm{Mt}$ in 2015, with $10 \%$ and $11 \%$ of annual growth rate higher than $5 \%$ and $10 \%$ of national average rate. However, the annual growth of caustic soda and calcium carbide production in the Southern grid area is lower than the national average, with $-3.6 \%$ and $-14.7 \%$ respectively. Under the guidance of industrial policy, the capacities of calcium carbide and chlor-alkali will be further concentrated in 
regions with large environmental capacity and rich resources (Ministry of Industry and Information Technology of China, 2016; China Carbide Industry Association, 2013). Hence, electricity savings and emissions reduction in the North grid and Northwest grid may be underestimated as a result of the assumed average growth rate used to predict the chemicals output for each region.

\subsubsection{Energy prices}

The cost effectiveness of multiple benefits on electricity savings and emissions reduction is affected by the electricity prices among different grids. The electricity price in China is influenced by the coal price, which is expected to continue to rise in the future $(\mathrm{Ni}$, 2009). Increasing energy prices will increase cost-effective potentials of electricity savings and emissions reductions of GHG and air pollutants. Therefore, changing energy prices will affect the cost-effective potentials on a grid level. Based on the studies by LBNL, the annual price escalation rates of electricity and fuel are used to estimate the economic sensitivity of multiple benefits for each grid between 2020 and 2035 , while the other factors remain constant (see Table 3.5) (Hasanbeigi et al., 2013; Ni, 2009). Table 3.6 and Figure 3.17 show the sensitivity analysis results of energy prices on cost-effective potentials of electricity saving and related emission reduction of GHG and air pollutants in each grid during 2020-2035. Changes in energy prices have a great impact on cost-effective potentials, especially in the long-term. $86 \%$ and $98 \%$ of the total electricity saving potentials can be achieved cost effectively with SP prices in 2020 and 2035 respectively, which increased by $5 \%$ and $19 \%$ compared to that with CP price. The East grid with high electricity prices is more sensitive to price changes than the other grids. Cost-effective electricity savings with SP price in East grid will rise by $33 \%$ in 2035 compared to that with CP price. Total cost-effective emission reductions of $\mathrm{CO}_{2}, \mathrm{CH}_{4}$ and $\mathrm{N}_{2} \mathrm{O}$ with SP prices will future increase by $30 \mathrm{Mt} \mathrm{CO}_{2}, 8 \mathrm{kt} \mathrm{CO}_{2 \mathrm{eq}}$ and $132 \mathrm{kt} \mathrm{CO}_{2 \mathrm{eq}}$ in 2035 respectively. Similar to changes in electricity saving potentials, the cost-effective emission reduction potentials are affected by varying degrees among different grids. In 2035, nearly $100 \%$ of the $\mathrm{CO}_{2}$ emission reduction potential will be cost-effective with SP price in North grid. Figure 3.17 shows the impacts of different prices on the economic potentials of $\mathrm{SO}_{2}, \mathrm{NO}_{\mathrm{x}}$ and $\mathrm{PM}_{2.5}$ in the short-term lower than that in the long-term. The total economic potentials of $\mathrm{SO}_{2}, \mathrm{NO}_{\mathrm{x}}$ and $\mathrm{PM}_{2.5}$ reductions in 2035 will shift from $233 \mathrm{kt}, 254 \mathrm{kt}$ and $51 \mathrm{kt}$ to $291 \mathrm{kt}, 316 \mathrm{kt}$ and $63 \mathrm{kt}$ when using different energy prices. The cost-effective potentials of $\mathrm{SO}_{2}, \mathrm{NO}_{\mathrm{x}}$ and $\mathrm{PM}_{2.5}$ with SP prices in the North and Northwest grids would increase dramatically in the long-term. 


\section{Chapter 3}
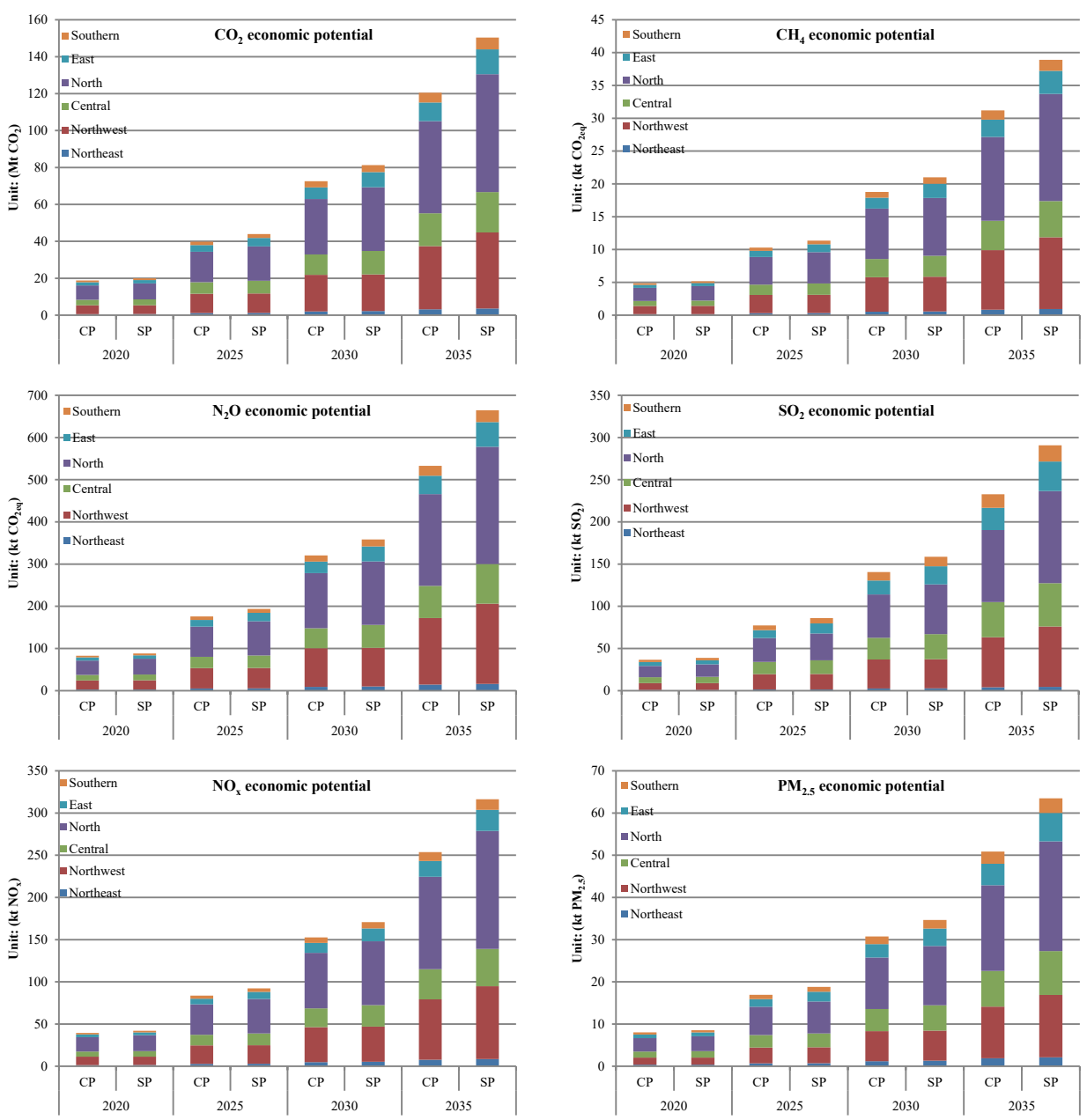

Figure 3.17. Sensitivity analysis of energy prices on emissions mitigation in the chemical industry during 2020-2035. 
Modeling the multiple benefits of electricity savings in China's chemical industry

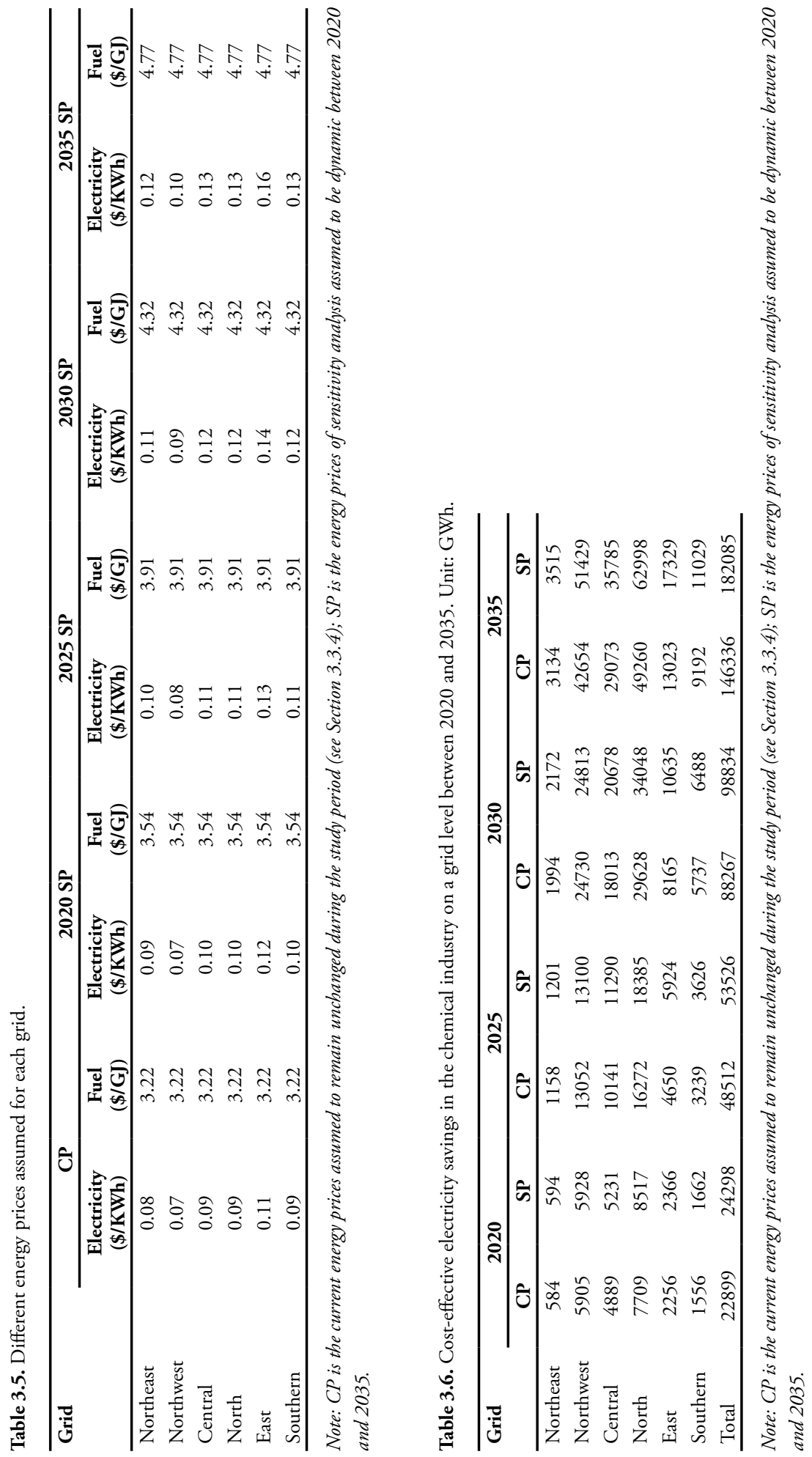


Chapter 3

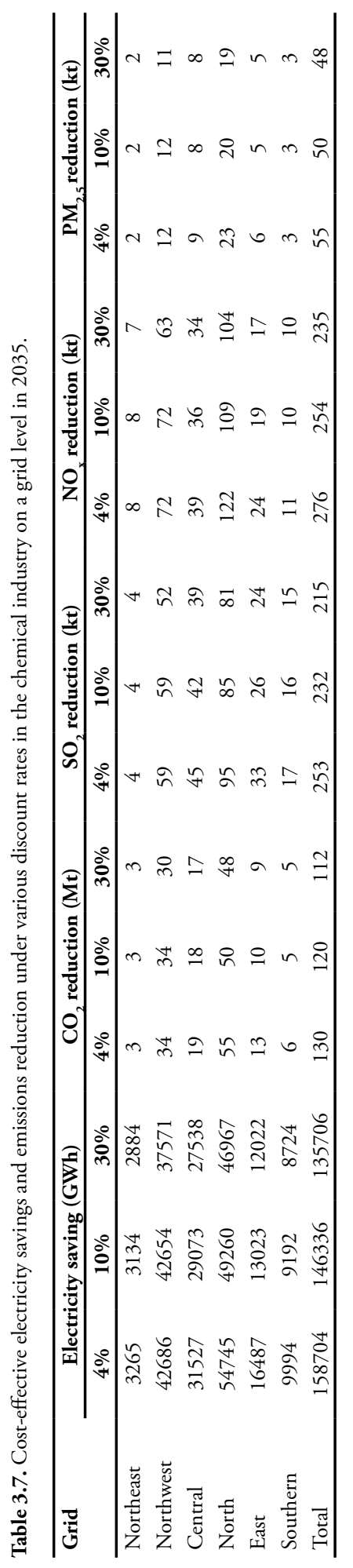




\subsubsection{Discount rate}

A discount rate of $10 \%$ was assumed in this study. Dependent on the perspectives, various discount rates are used to estimate the economic benefits of energy efficiency improvement and emission reduction (Hasanbeigi et al., 2013). From the perspectives of policy making and market investment, discount rates of $4 \%$ to $30 \%$ are used to assess the sensitivity of cost-effective potentials in different grids (Wang et al., 2016). Table 3.7 and Figure 3.18 show the effect of various discount rates on the economic potentials of electricity saving and associated emission reduction at a grid level (while other parameters remain constant). With a discount rate of 4\%, 54 electricity efficiency technologies will be cost-effective in the North grid, corresponding to cost-effective electricity savings reached $87 \%$ of total electricity savings. However, the number of costeffective measures would decrease to 46 when the discount rate is $30 \%$, and the costeffective electricity saving reduced to $74 \%$ of total electricity savings. A lower discount rate would result in more cost-effective potentials of electricity saving and emission reduction in the chemical industry. Compared to the used discount rate of $10 \%$, the total cost-effective electricity saving would increase by $11 \%$ for a $4 \%$ discount rate and decrease by $5 \%$ for $30 \%$ discount rate in 2035 (see Table 3.7). The economic potentials would increase from $112 \mathrm{Mt}, 215 \mathrm{kt}, 235 \mathrm{kt}$ and $48 \mathrm{kt}$ to $130 \mathrm{Mt}, 253 \mathrm{kt}, 276 \mathrm{kt}$ and $55 \mathrm{kt}$ in 2035 when the discount rate decreases from $30 \%$ to $4 \%$. Generally, the effect of the discount rate on the cost-effective potentials is lower than that of energy prices in China's chemical industry. 

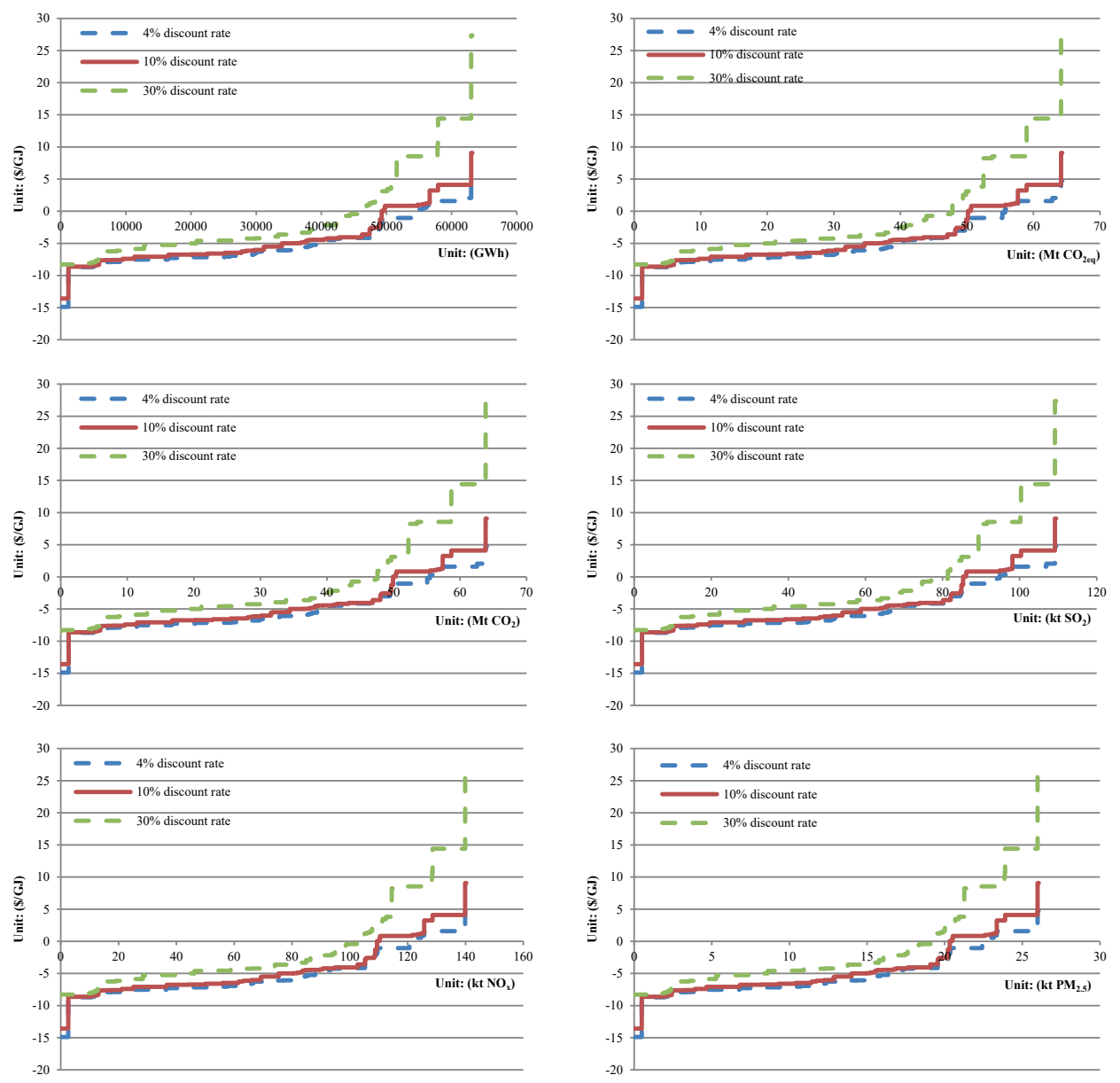

Figure 3.18. Potentials of electricity saving and emission reduction in North grid under various discount rates.

\subsection{Conclusions and policy implications}

\subsection{Conclusions}

The chemical industry is one of the most electricity-intensive sectors, subsequently resulting in high emissions of GHGs and air pollutants. In this study, the multiple benefits of electricity efficiency measures on electricity efficiency improvement, and emissions reduction of GHG $\left(\mathrm{CO}_{2}, \mathrm{CH}_{4}\right.$ and $\left.\mathrm{N}_{2} \mathrm{O}\right)$ and air pollutants $\left(\mathrm{SO}_{2}, \mathrm{NO}_{\mathrm{x}}\right.$ and $\mathrm{PM}_{2.5}$ ) in China's chemical industry up to 2035 are quantified. Due to the spatial distribution of the chemical industry and variety in emission intensities of power generation in the power grids in China, the study discerns six regions. This results in 
large differences among the six grids in terms electricity savings and emissions reduction of GHG and air pollutants due to concentration of power generation/use and specific emissions. The following conclusions are drawn from the study:

a. Electricity has become the dominant energy source equivalent to $30 \%$ of final energy use in China's chemical industry. Electricity use of China's chemical industry increased fourfold from $115 \mathrm{TWh}$ in 2000 to $475 \mathrm{TWh}$ in $2015.54 \%$ of total electricity consumption of China's chemical industry consumed by three sub-sectors (ammonia, chlor-alkali and calcium carbide). These sub-sectors together indirectly emitted $254 \mathrm{Mt}$ of $\mathrm{CO}_{2}, 447 \mathrm{kt}$ of $\mathrm{SO}_{2}, 428 \mathrm{kt}$ of $\mathrm{NO}_{\mathrm{x}}$ and $75 \mathrm{kt}$ of PM in 2015, contributing to $21 \%, 20 \%, 28 \%$ and $9 \%$ of total emissions of the chemical industry respectively.

b. Electricity conservation supply curves are constructed per grid to quantify the cost-effective and technical potentials of electricity savings at the grid level up to 2035. The total cost-effective electricity savings account for more than $80 \%$ of total electricity savings in the chemical industry, reaching $147 \mathrm{TWh}$ in 2035 . Due to the heterogeneity of the regional grids, the contribution to electricity savings among the six grids is different. Most of the chemical plants are located in the regions with abundant resources (e.g. Inner Mongolia, Shandong, Shannxi, Gansu and Xinjiang). Therefore the Northwest grid and North grid have the largest electricity saving potential, accounting for $34 \%$ and $29 \%$ of the total economic potential in 2035 respectively, followed by the Central grid with $20 \%$.

c. The emission factors of GHG and air pollutants in each grid were calculated to quantify the emissions mitigation benefits achieved by electricity savings in China's chemical industry during 2012 to 2035, resulting in an economic emission reduction of $121 \mathrm{Mt} \mathrm{CO}_{2}, 233 \mathrm{kt} \mathrm{SO}_{2}, 254 \mathrm{kt} \mathrm{NO}_{\mathrm{x}}$ and $51 \mathrm{kt} \mathrm{PM}_{2.5} .70 \%$ of the economic potential for $\mathrm{CO}_{2}$ emission reduction is contributed in the North and Northwest grids. Similar to GHG emissions, the North grid and Northwest grid have the high emission reduction potentials of $\mathrm{SO}_{2}, \mathrm{NO}_{\mathrm{x}}$ and $\mathrm{PM}_{2.5}$ due to the large chemicals production and electrical output. In 2035, $184 \mathrm{kt} \mathrm{SO}_{2}$ emissions can be avoided in the North and Northwest grids, while $79 \%$ emission reduction is cost-effective. The economic electricity saving measures can cut $254 \mathrm{kt} \mathrm{NO}_{\mathrm{x}}$ and $51 \mathrm{kt} \mathrm{PM}_{2.5}$ in 2035. Therefore, multiple economic and environmental benefits can be achieved by focusing on improving the efficiency with which electricity is consumed in end-use sectors, warranting to include electricity efficiency in air quality policy.

d. The sensitivity analysis indicates that changes of energy price and discount rate have great influences on the cost-effective potentials in China's chemical industry. Increasing energy prices (or decreasing the discount rate) will increase cost-effective 
potentials of electricity savings and emissions reduction. Grids with a high electricity price are more sensitive to price changes than other grids.

\subsubsection{Policy implications and future research direction}

This study shows that multiple benefits of electricity savings are important for both policy as well as investment in electricity generation and air pollution control options. This study highlights the policy implications for national and regional grid levels, and future research:

a. Nationally, the results suggest that policies integrating end-use electricity efficiency would increase the efficiency and effectiveness of air quality policies and climate. It was shown that up to $80 \%$ of the emission reductions resulting from electricity efficiency can be achieved cost-effectively. Thus, policies promoting cost-effective efficiency technologies should be designed and implemented. To achieve greater benefits, policymakers should consider providing subsidies to specific currently non-economic but highly efficient technologies (e.g. high-temperature and highpressure chlorine liquefying technology and new conductive copper contact shoe for closed furnaces), as the co-benefits may outweigh the investments (when evaluated based on energy cost-reductions alone).

b. The synergies between electricity savings and emissions reduction vary for the regional grids due to the concentration of power generation (and consumption) and specific emission factors. The understanding of grid-specific synergies is crucial for the regional allocation of emission reduction targets. Based on the principle of "common but differentiated responsibilities", the results suggest that different regions should shoulder different abatement goals. In the case of the chemical industry, the largest responsibility should be shouldered by regions in grids with high potentials of electricity savings and emissions reduction, such as North and Northwest grids. The minimum burden should be allocated to regions in Northeast and Southern grids, which have low multiple benefits. Moreover, determining savings on grid level helps to identify options to optimize investments in new power generation capacity and grid capacity, resulting in additional economic benefits. This would warrant further research.

c. For other countries these results are expected to be similar, depending on the energy sources and related emission factors associated with the electricity grids, as is shown in this study. Further research should focus on valuing all benefits to allow a full cost-benefit analysis. Furthermore, expanding the analysis to other sectors will help to fully quantify the contribution of electricity savings to air quality, public health, climate change mitigation, and economics. 


\section{Acknowledgments}

This study was supported by the China Scholarship Council under Grant No. 201607040082. We extend our gratitude to the valuable comments of the anonymous reviewers. We thank Jing $\mathrm{Hu}$ (Copernicus Institute of Sustainable Development) for useful comments to this study.

\section{Appendix 3.A}

See Tables 3.A1 - 3.A3.

\section{Appendix 3.B}

See Tables 3.B1 - 3.B3.

\section{Appendix 3.C}

See Figures 3.C1 - 3.C3. 


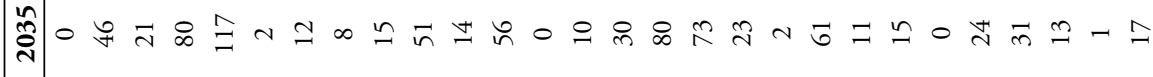

商

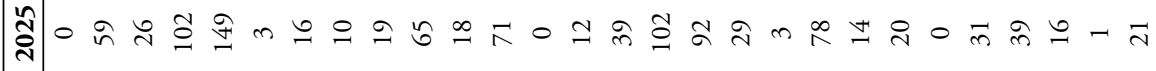

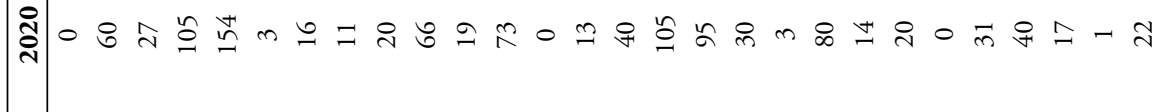

高

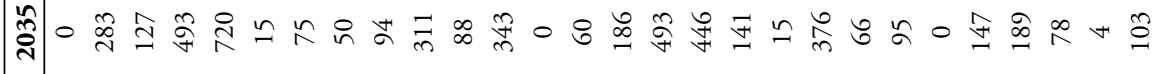

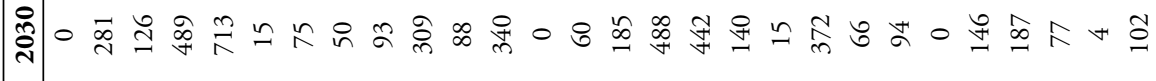

亗

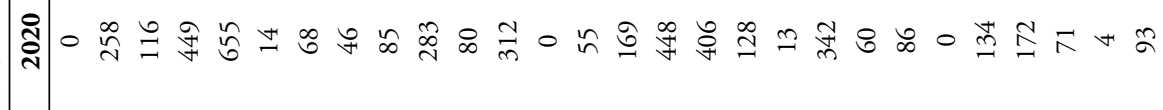

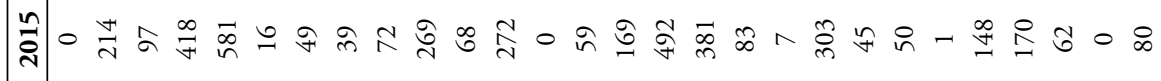

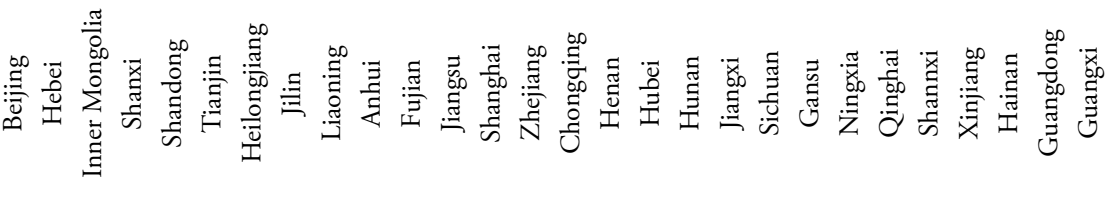

Z

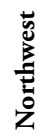

ڤั 
Modeling the multiple benefits of electricity savings in China's chemical industry

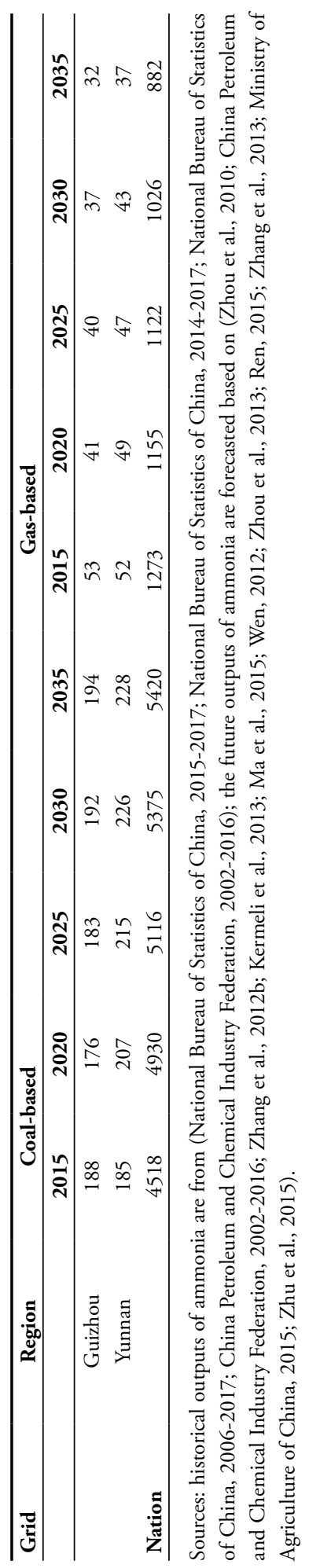




\section{Chapter 3}

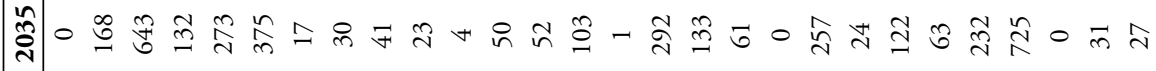

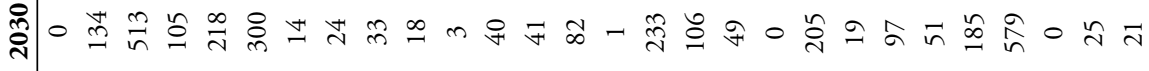

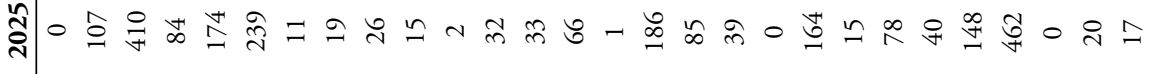

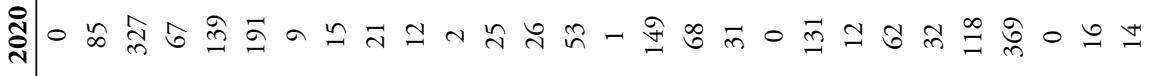
$\sum$

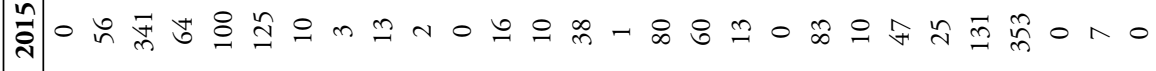

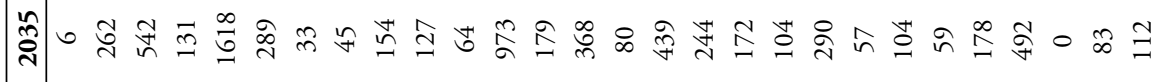

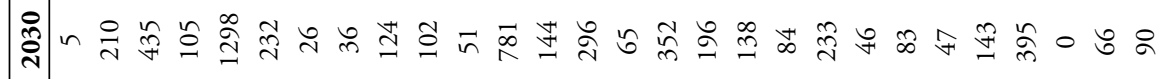

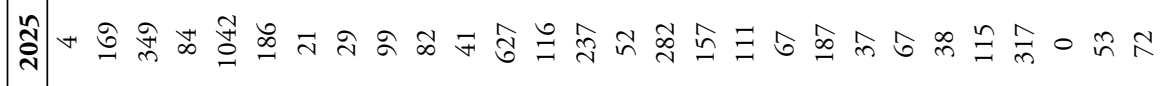

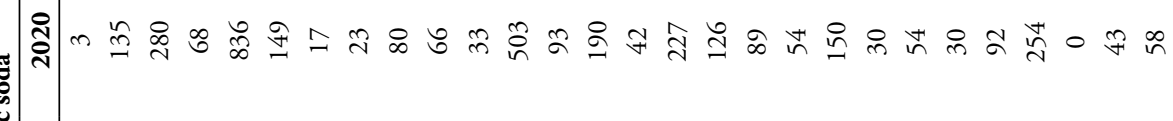

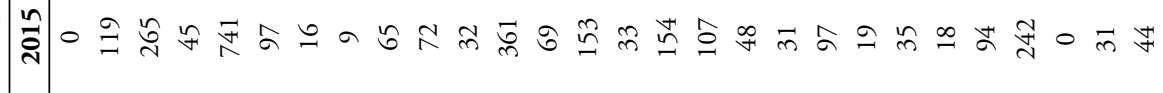


Modeling the multiple benefits of electricity savings in China's chemical industry

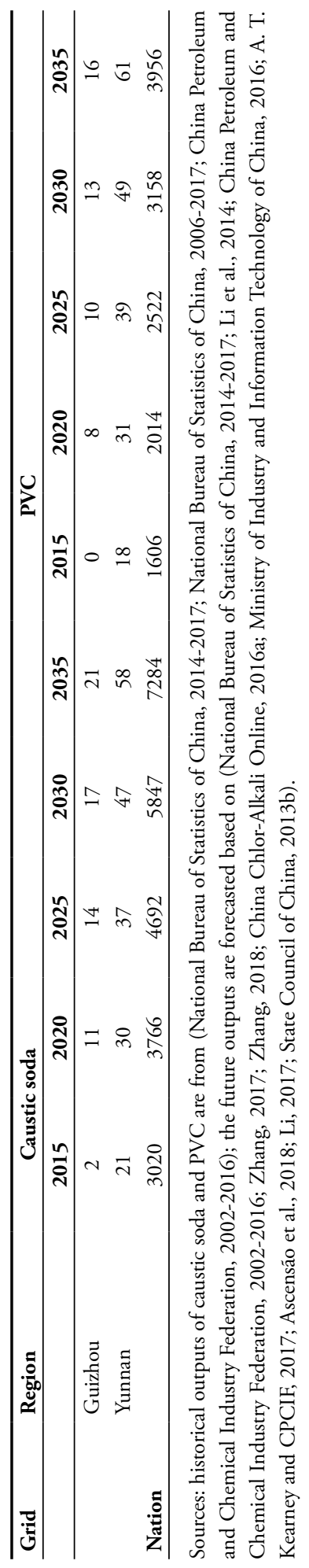


Chapter 3

Table 3.A3. Calcium carbide production by each grid during the period of 2015-2035 (10 $\mathrm{t})$.

\begin{tabular}{|c|c|c|c|c|c|c|}
\hline Grid & Region & 2015 & 2020 & 2025 & 2030 & 2035 \\
\hline \multirow[t]{6}{*}{ North } & Beijing & 0 & 0 & 0 & 0 & 0 \\
\hline & Hebei & 0 & 0 & 0 & 0 & 0 \\
\hline & Inner Mongolia & 957 & 1011 & 1265 & 1584 & 1984 \\
\hline & Shanxi & 34 & 55 & 69 & 87 & 109 \\
\hline & Shandong & 0 & 6 & 7 & 9 & 12 \\
\hline & Tianjin & 0 & 0 & 0 & 0 & 0 \\
\hline \multirow[t]{3}{*}{ Northeast } & Heilongjiang & 0 & 0 & 0 & 0 & 0 \\
\hline & Jilin & 0 & 0 & 1 & 1 & 1 \\
\hline & Liaoning & 7 & 15 & 19 & 24 & 30 \\
\hline \multirow[t]{5}{*}{ East } & Anhui & 0 & 3 & 4 & 5 & 7 \\
\hline & Fujian & 3 & 4 & 5 & 7 & 8 \\
\hline & Jiangsu & 0 & 0 & 0 & 1 & 1 \\
\hline & Shanghai & 0 & 0 & 0 & 0 & 0 \\
\hline & Zhejiang & 0 & 7 & 8 & 10 & 13 \\
\hline \multirow[t]{6}{*}{ Central } & Chongqing & 7 & 4 & 5 & 6 & 8 \\
\hline & Henan & 128 & 168 & 210 & 263 & 329 \\
\hline & Hubei & 59 & 117 & 146 & 183 & 229 \\
\hline & Hunan & 19 & 30 & 38 & 48 & 60 \\
\hline & Jiangxi & 6 & 7 & 8 & 10 & 13 \\
\hline & Sichuan & 67 & 112 & 140 & 175 & 219 \\
\hline \multirow[t]{5}{*}{ Northwest } & Gansu & 114 & 185 & 232 & 290 & 364 \\
\hline & Ningxia & 312 & 464 & 581 & 728 & 911 \\
\hline & Qinghai & 26 & 42 & 53 & 67 & 83 \\
\hline & Shannxi & 252 & 258 & 323 & 405 & 507 \\
\hline & Xinjiang & 537 & 604 & 756 & 947 & 1185 \\
\hline \multirow[t]{5}{*}{ Southern } & Hainan & 0 & 0 & 0 & 0 & 0 \\
\hline & Guangdong & 0 & 0 & 0 & 0 & 0 \\
\hline & Guangxi & 0 & 16 & 20 & 25 & 32 \\
\hline & Guizhou & 6 & 40 & 50 & 63 & 79 \\
\hline & Yunnan & 51 & 85 & 106 & 133 & 167 \\
\hline Nation & & 2585 & 3233 & 4046 & 5071 & 6351 \\
\hline
\end{tabular}

Sources: historical outputs of calcium carbide are from (National Bureau of Statistics of China, 2014-2017; National Bureau of Statistics of China, 2006-2017; China Petroleum and Chemical Industry Federation, 2002-2016); the future outputs of calcium carbide are forecasted based on (Liu et al., 2011; China Petroleum and Chemical Industry Federation, 2002-2016; China Chlor-Alkali Online, 2016a; Ministry of Industry and Information Technology of China, 2016; China Chlor-Alkali Online, 2016b; China Carbide Industry Association, 2013). 
Modeling the multiple benefits of electricity savings in China's chemical industry

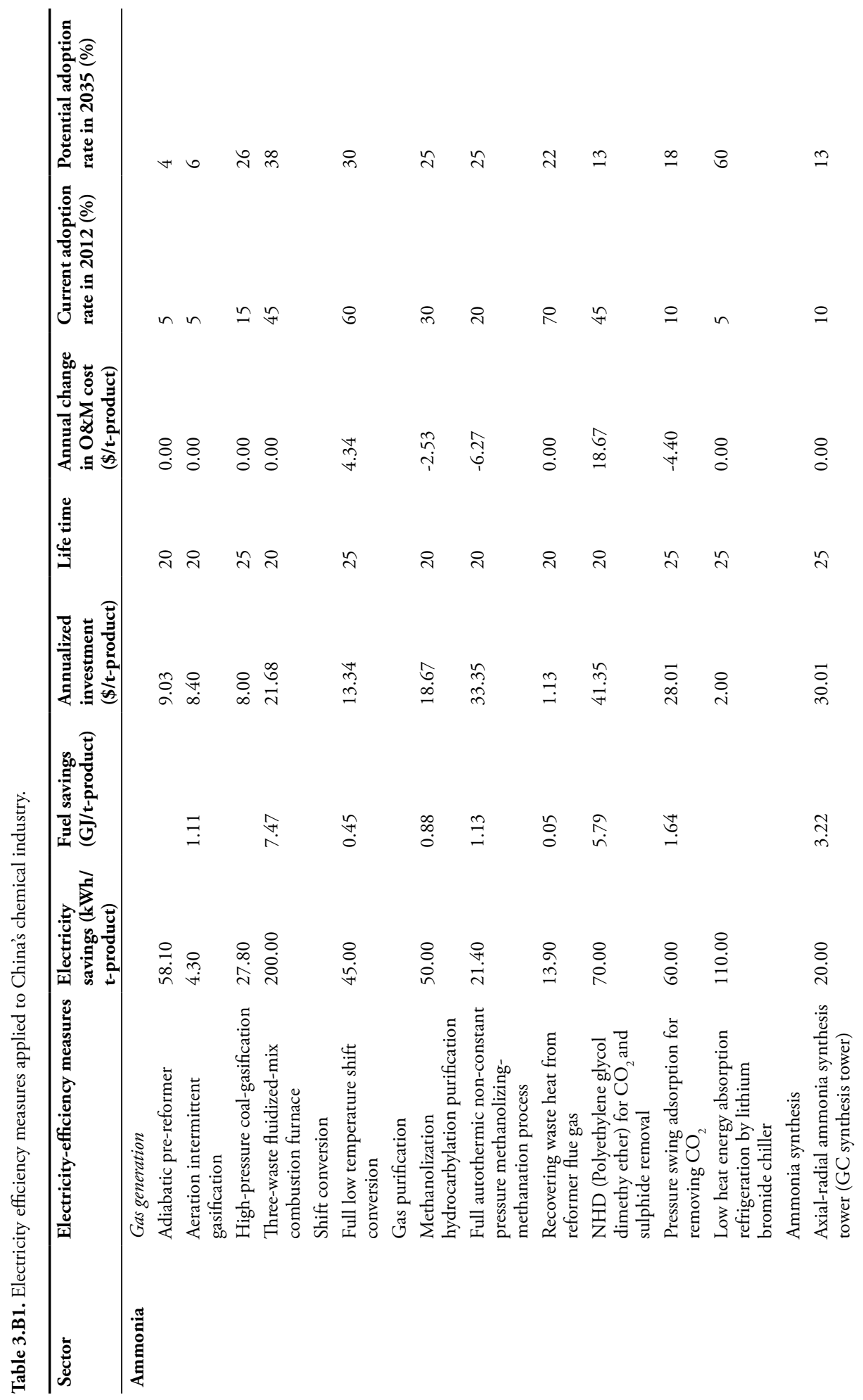




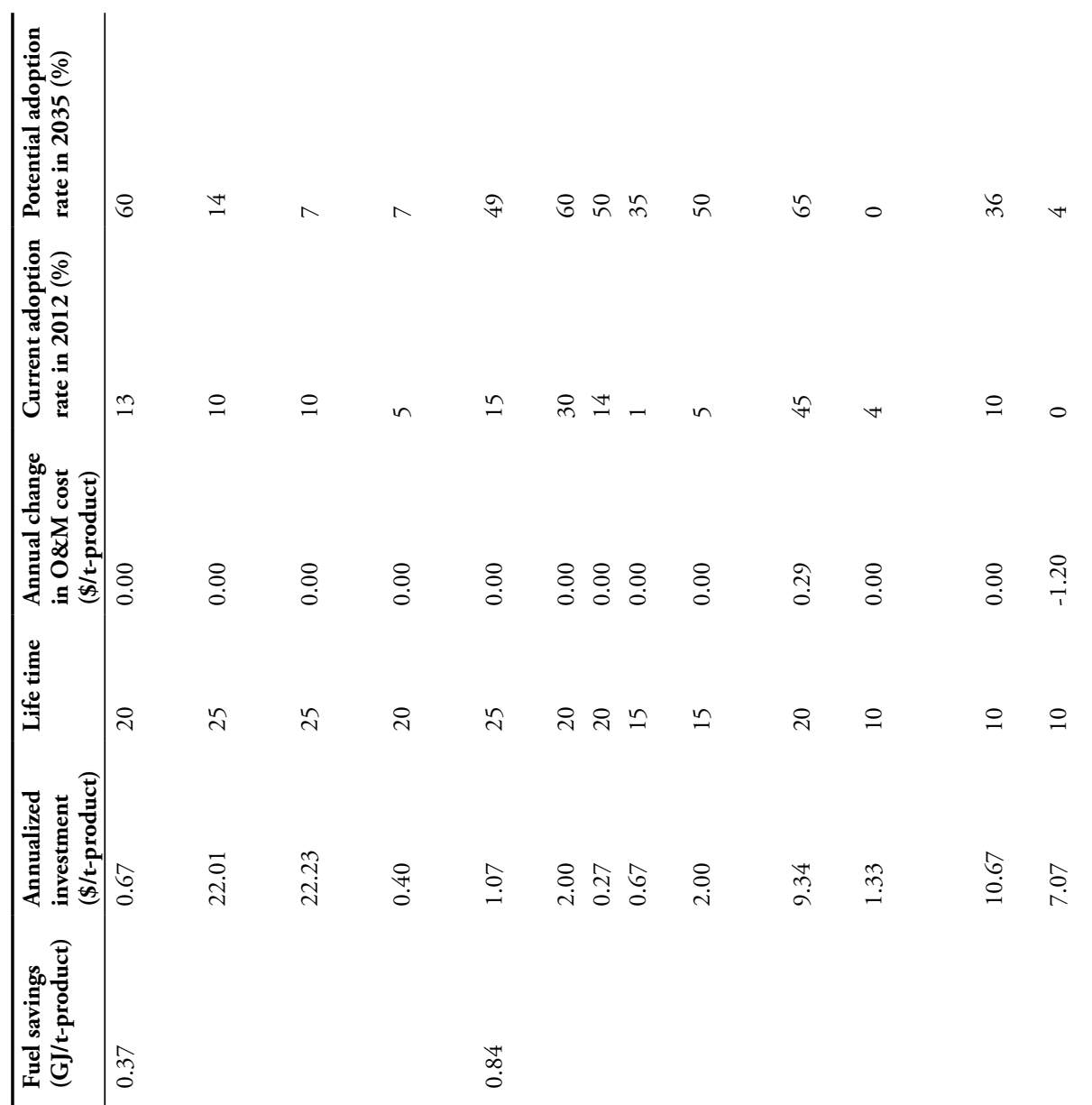


Modeling the multiple benefits of electricity savings in China's chemical industry

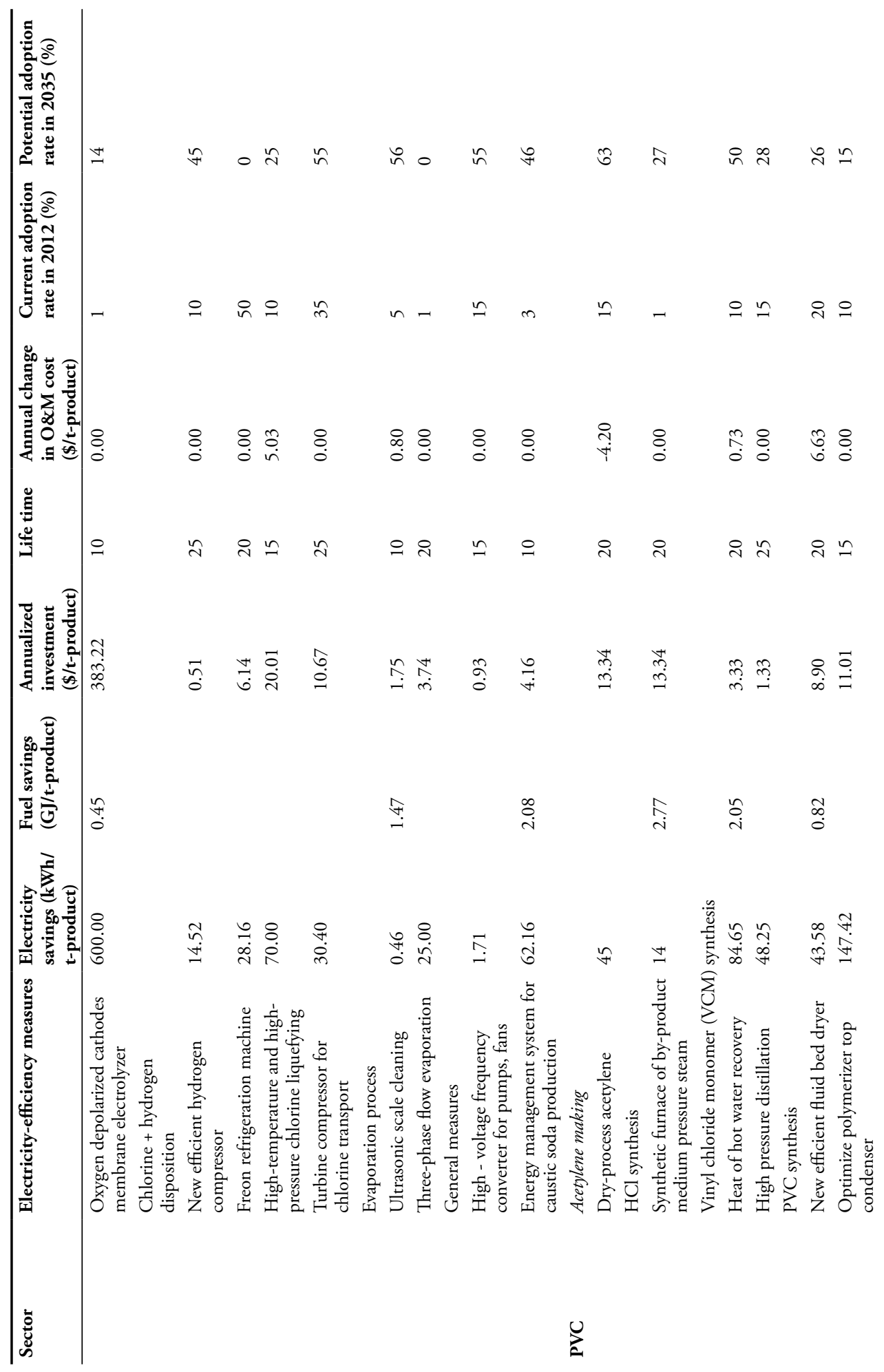




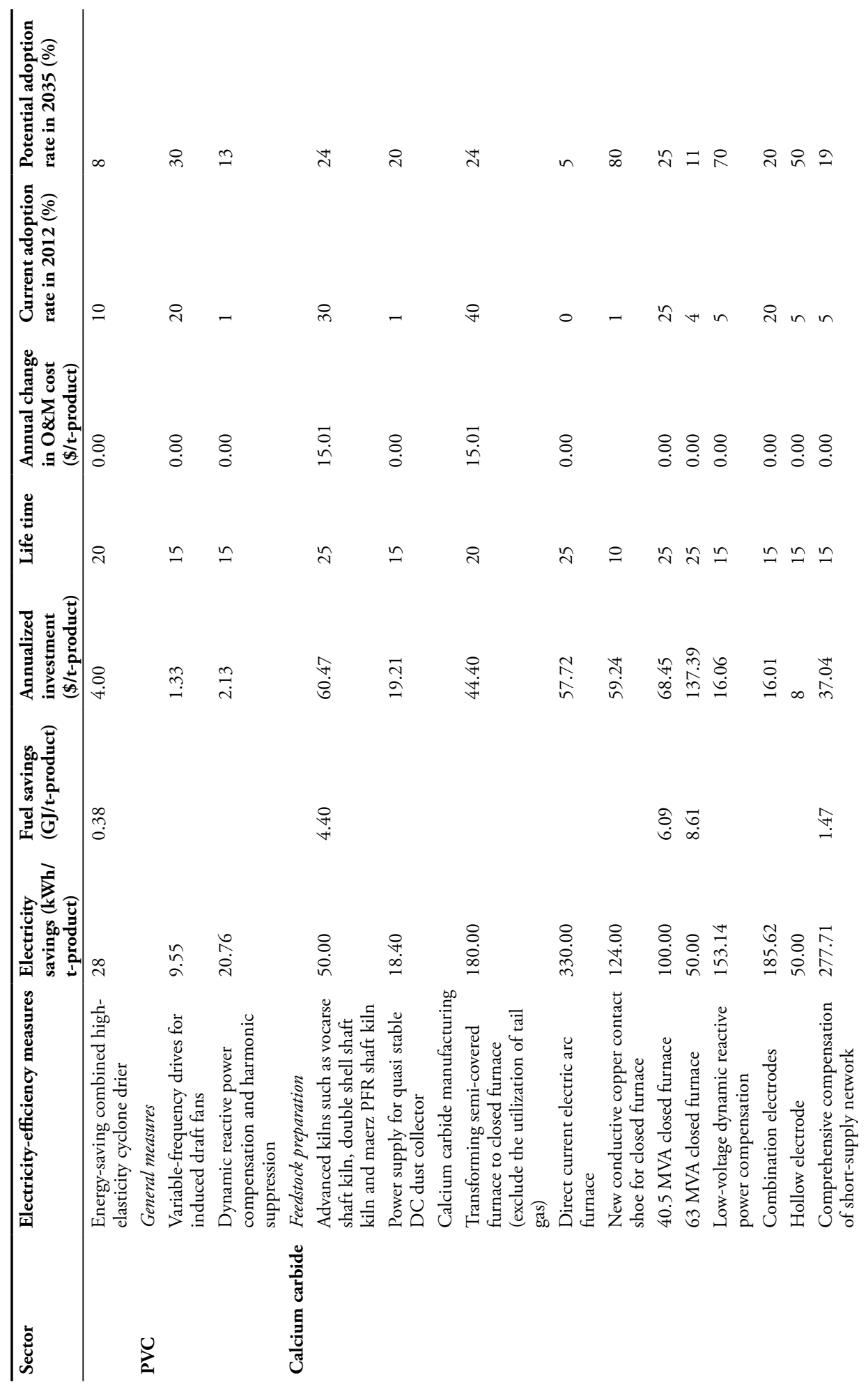


Modeling the multiple benefits of electricity savings in China's chemical industry

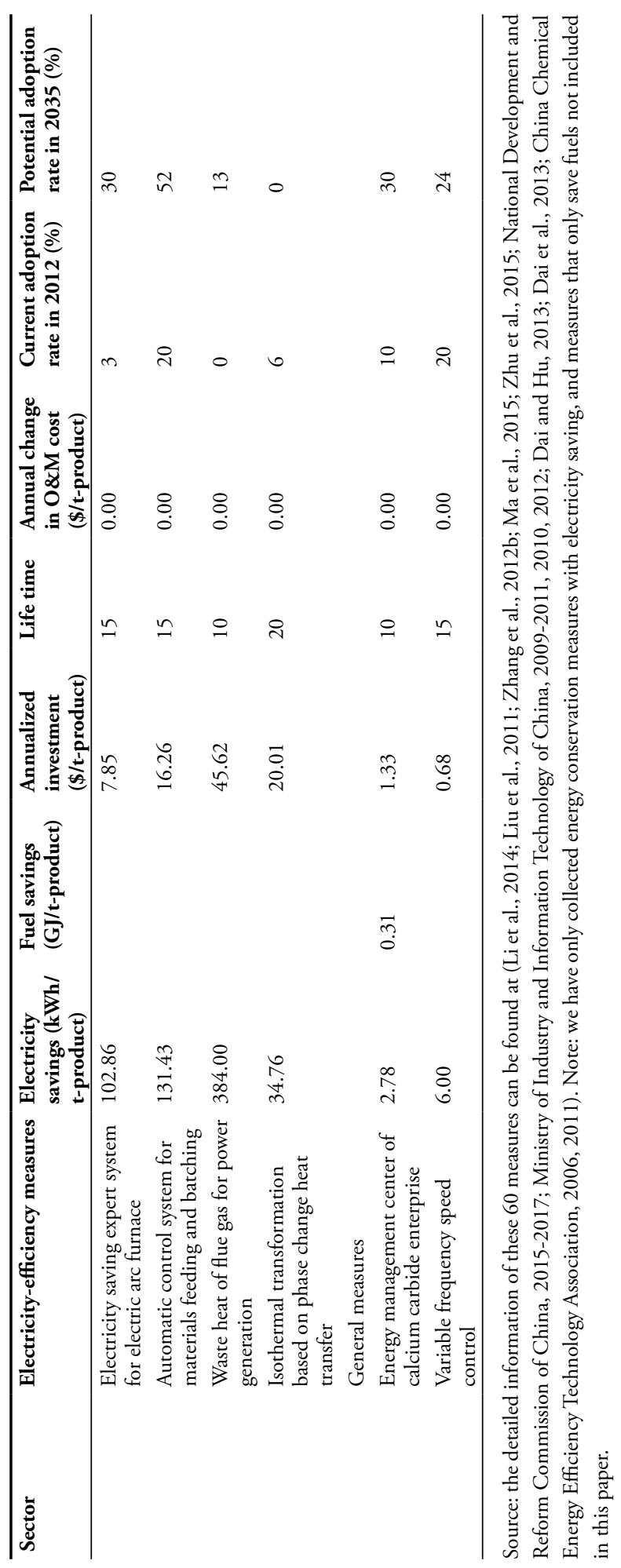




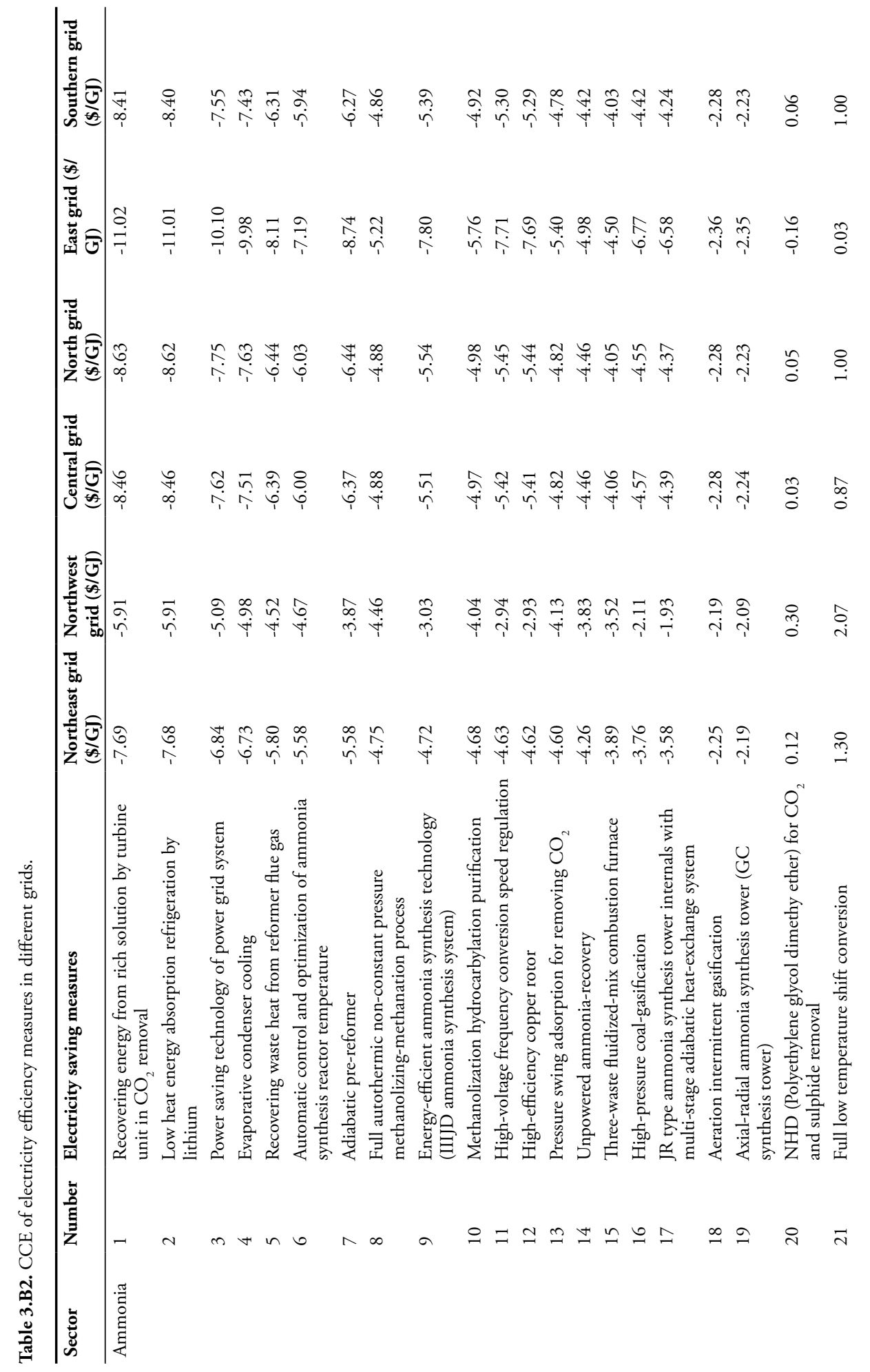




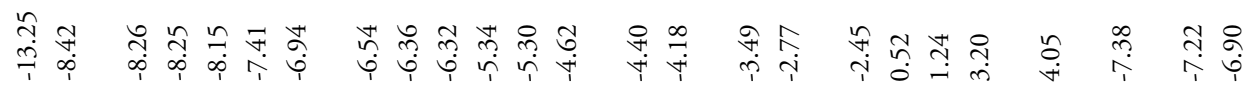

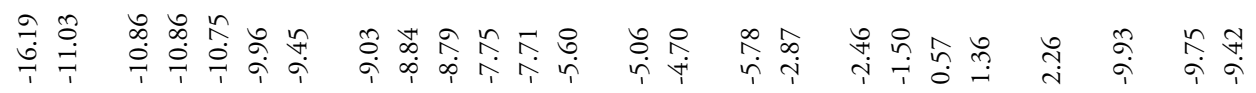

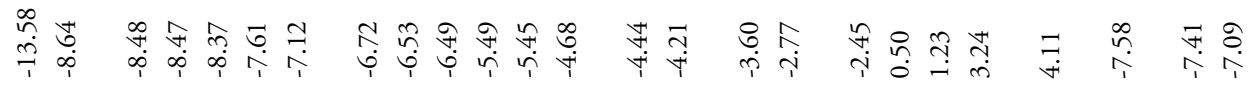

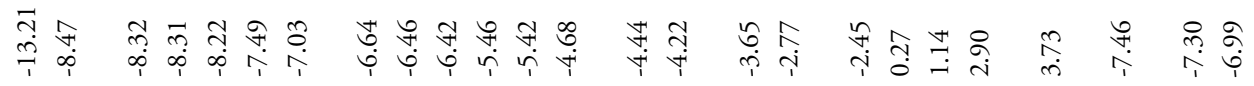

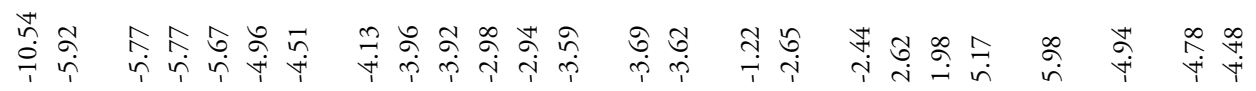

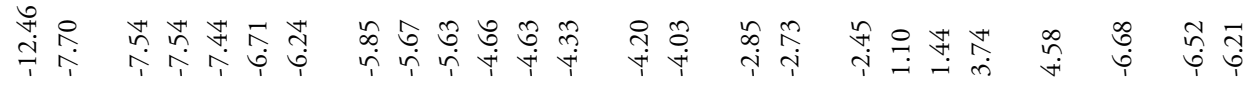

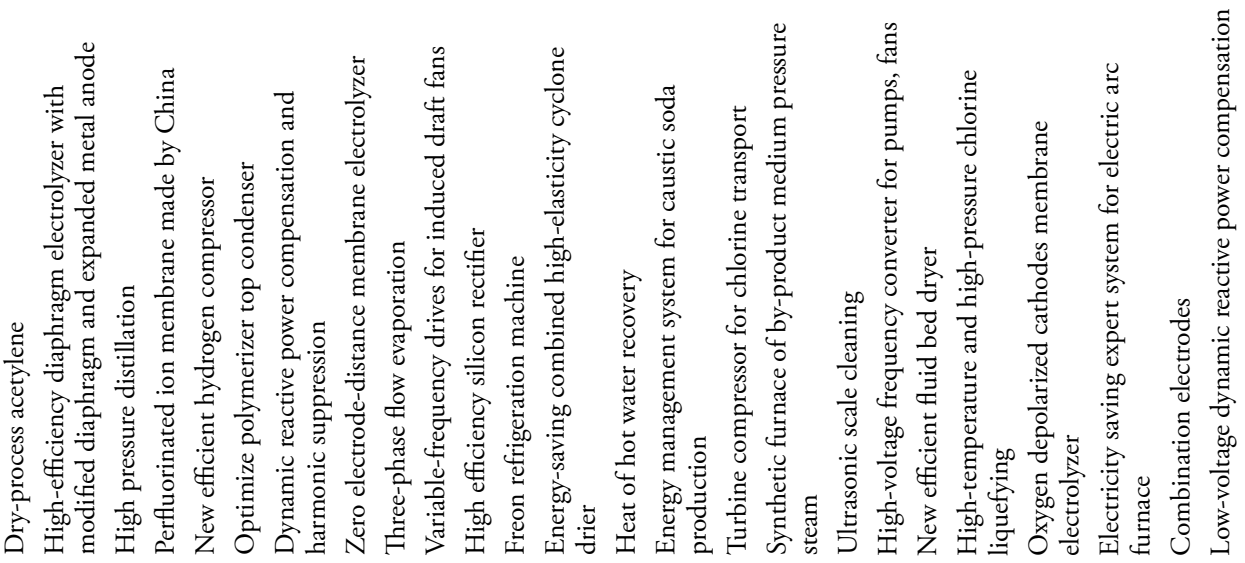

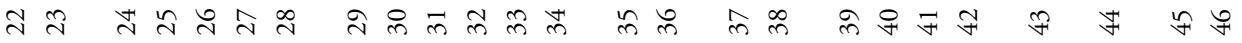

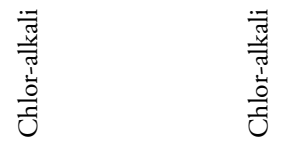




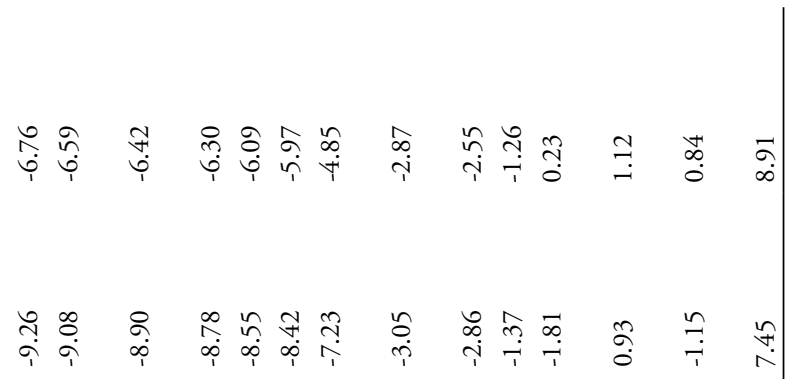

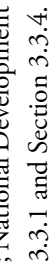

ते

赵离

范资

1

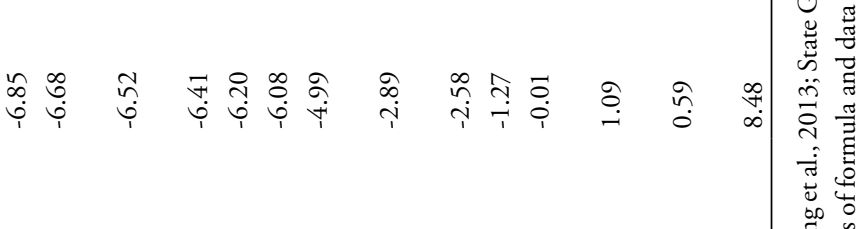

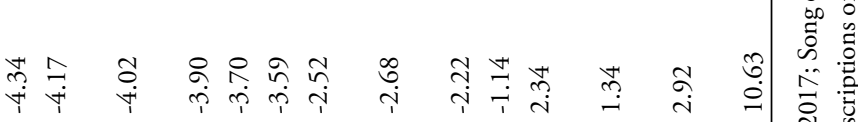

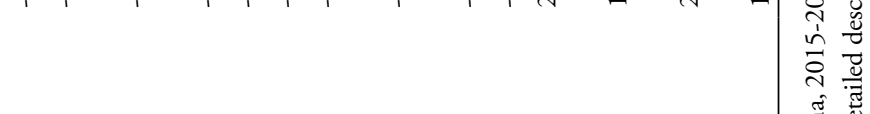

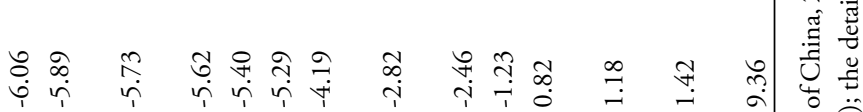

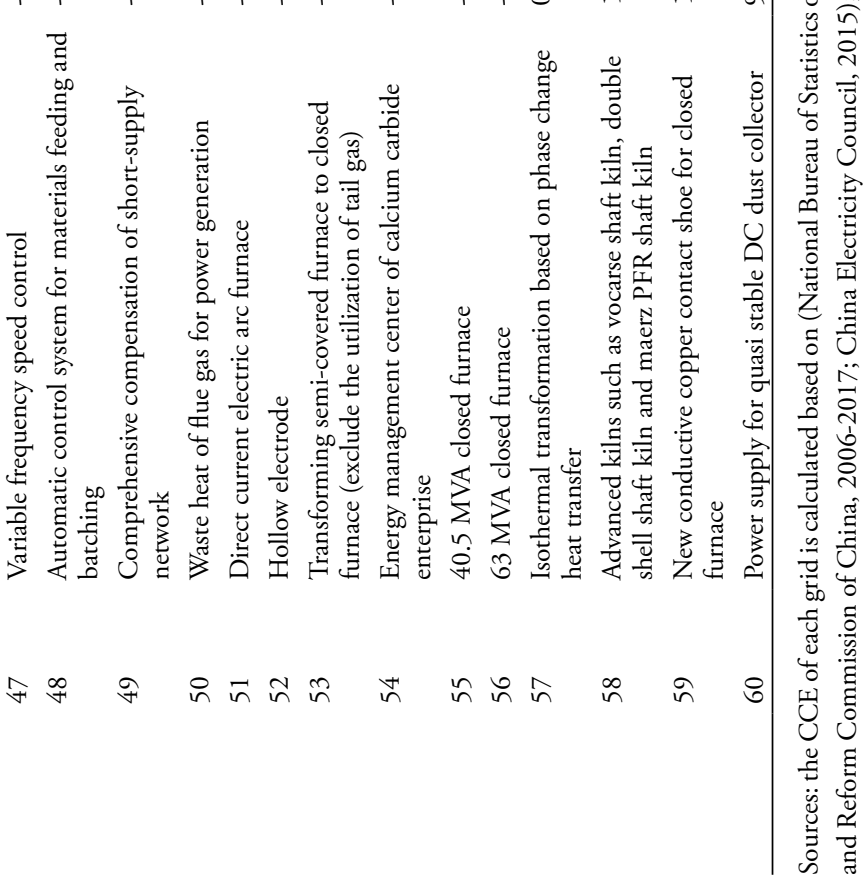


Modeling the multiple benefits of electricity savings in China's chemical industry

Table 3.B3. Air pollutant abatement measures applied to China's power sector.

\begin{tabular}{|c|c|c|c|c|c|}
\hline $\begin{array}{l}\text { Air } \\
\text { pollutants }\end{array}$ & Number & Abatement measures & $\begin{array}{l}\text { Removal } \\
\text { efficiency (\%) }\end{array}$ & $\begin{array}{l}\text { Operation } \\
\text { rate }(\%)\end{array}$ & $\begin{array}{l}\text { Share of total } \\
\text { installation (\%) }\end{array}$ \\
\hline \multirow[t]{11}{*}{$\mathrm{SO}_{2}$} & 1 & Wet limestone/lime-gypsum (LG) & 95 & 95 & 83.1 \\
\hline & 2 & Limestone injection into furnace (LIF) & 70 & 95 & 6.1 \\
\hline & 3 & Seawater & 90 & 95 & 2.9 \\
\hline & 4 & Circulating fluidized bed & 85 & 95 & 2.0 \\
\hline & 5 & Dual alkali process & 95 & 95 & 1.0 \\
\hline & 6 & Ammonia process & 95 & 95 & 0.8 \\
\hline & 7 & Carbide slag slurry/White mud & 95 & 95 & 0.8 \\
\hline & 8 & $\mathrm{LIF}+\mathrm{LG}$ & 90 & 95 & 0.5 \\
\hline & 9 & Semi-dry process & 85 & 95 & 0.5 \\
\hline & 10 & Magnesium oxide & 95 & 95 & 0.5 \\
\hline & 11 & $\begin{array}{l}\text { Remaining desulfurization technology } \\
\text { (including dry process and } \mathrm{NaOH}+ \\
\text { Microbial reduction) }\end{array}$ & 90 & 95 & 1.8 \\
\hline \multirow[t]{4}{*}{$\mathrm{NO}_{\mathrm{x}}$} & 12 & Low nitrogen burning (LNB) & 33 & 100 & 50.3 \\
\hline & 13 & $\begin{array}{l}\text { LNB + Selective catalytic reduction (LNB } \\
+ \text { SCR) }\end{array}$ & 80 & 100 & 47.4 \\
\hline & 14 & $\begin{array}{l}\text { LNB + Selective non-catalytic reduction } \\
(\mathrm{LNB}+\mathrm{SNCR})\end{array}$ & 40 & 100 & 1.6 \\
\hline & 15 & $\mathrm{LNB}+\mathrm{SNCR}+\mathrm{SCR}$ & 80 & 100 & 0.7 \\
\hline \multirow[t]{2}{*}{$\mathrm{PM}_{2.5}$} & 16 & Electrostatic precipitator (ESP) & 93 & 100 & 16 \\
\hline & 17 & $\mathrm{ESP}+\mathrm{LG}$ & 97 & 100 & 79 \\
\hline
\end{tabular}

Sources: the detailed information for 17 abatement measures can be found at (Cai et al., 2013; Chinese Research Academy of Environmental Sciences, 2010; Ministry of Environmental Protection of China, 2005-2015, 2009-2014, 2011-2014; National Development and Reform Commission of China, 2007); the share of total installation is calculated by authors. 


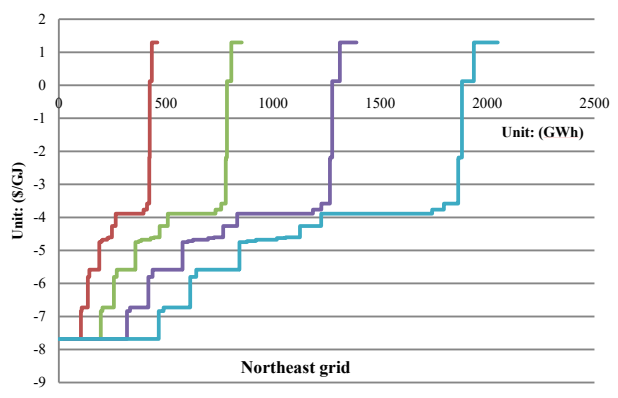

Electricity saving in 2020 Electricity saving in 2025

Electricity saving in 2030 Electricity saving in 2035

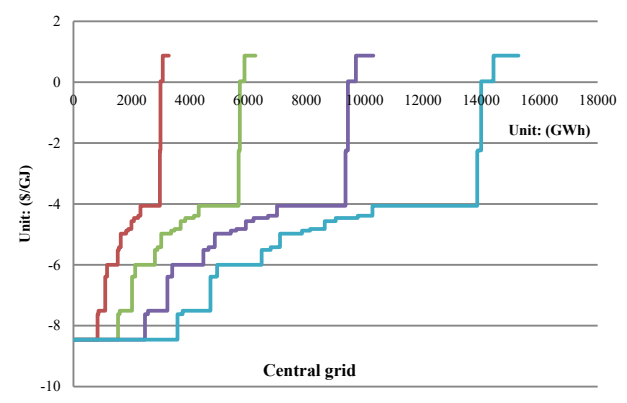

$\begin{array}{rr}- \text { Electricity saving in } 2020 & \text { Electricity saving in } 2025 \\ \text { Electricity saving in } 2030 & \text { Electricity saving in } 2035\end{array}$

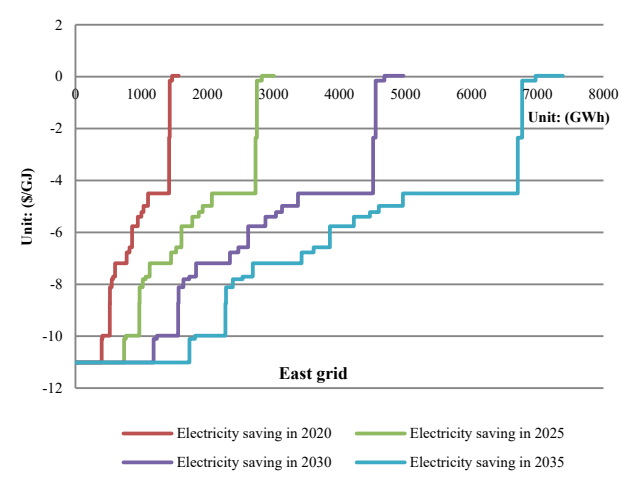

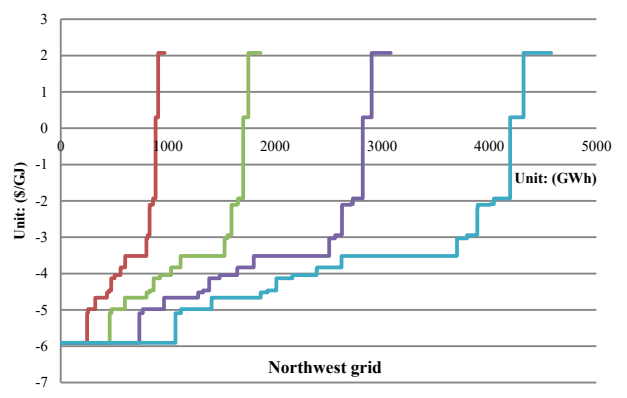

— Electricity saving in $2020 \quad$ Electricity saving in 2025

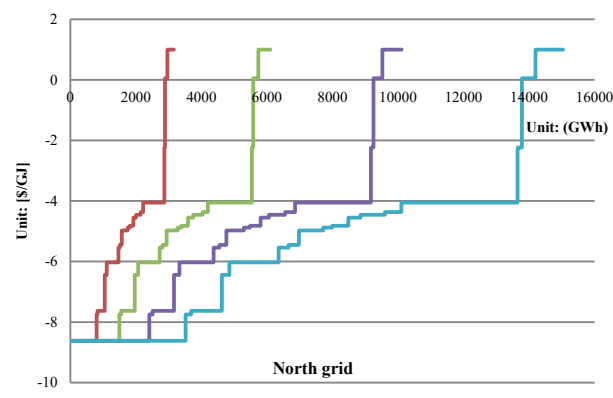

Electricity saving in $2020 \quad$ Electricity saving in 2025

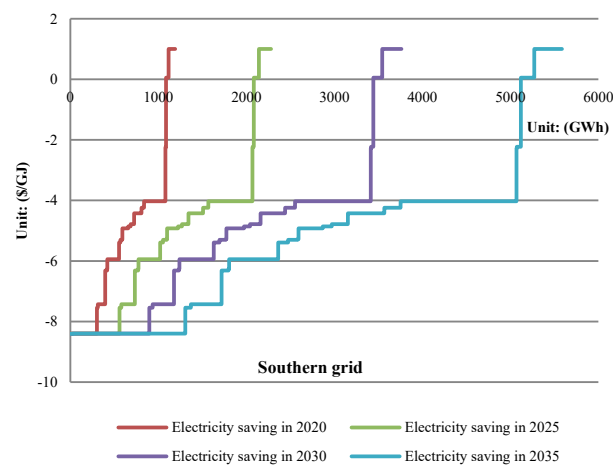

Figure 3.C1. ECSC per grid for ammonia industry between 2020 and 2035. 


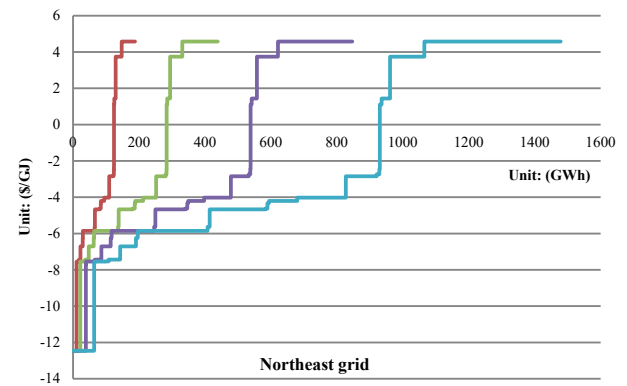

Electricity saving in $2020 \quad$ Electricity saving in 2025

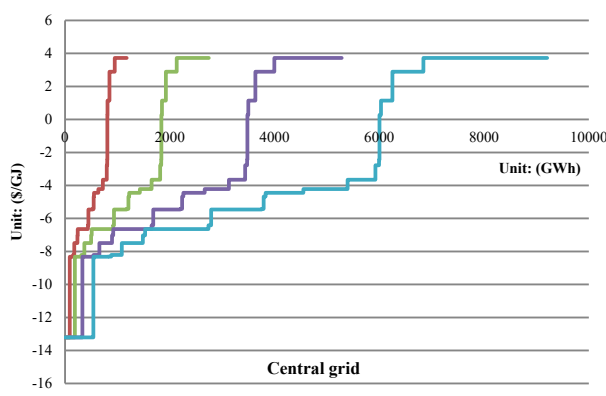

Electricity saving in $2020 \quad$ Electricity saving in 2025

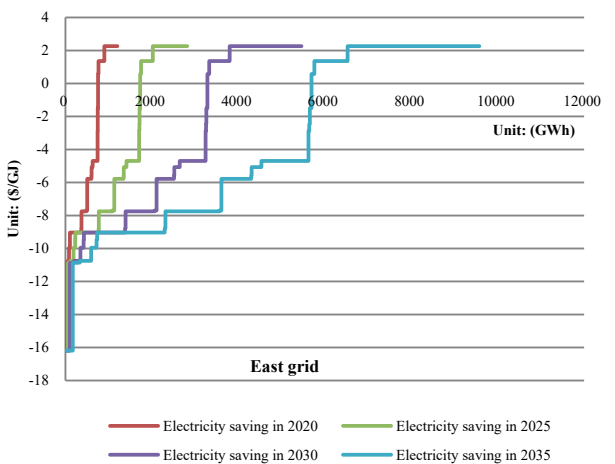

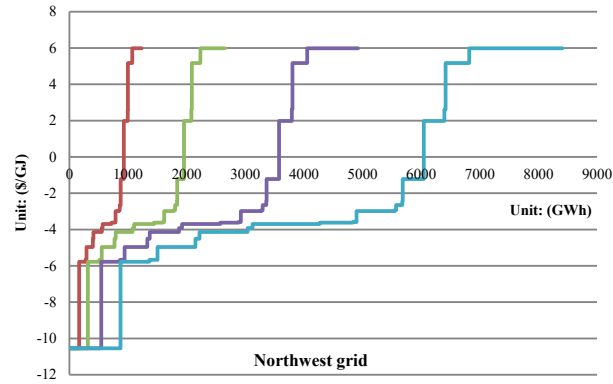
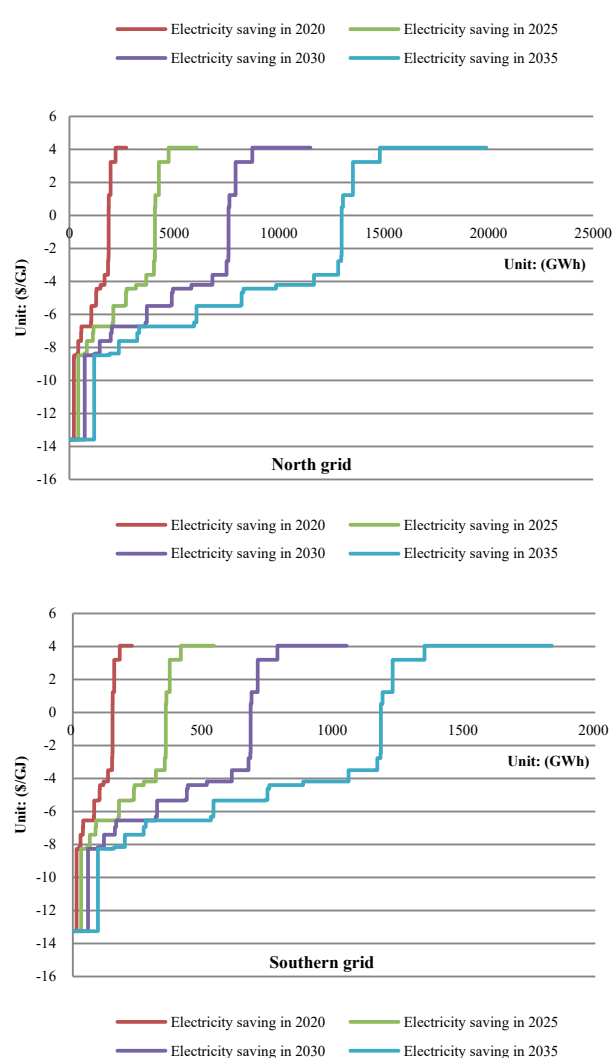

Figure 3.C2. ECSC per grid for chlor-alkali industry between 2020 and 2035. 


\section{Chapter 3}

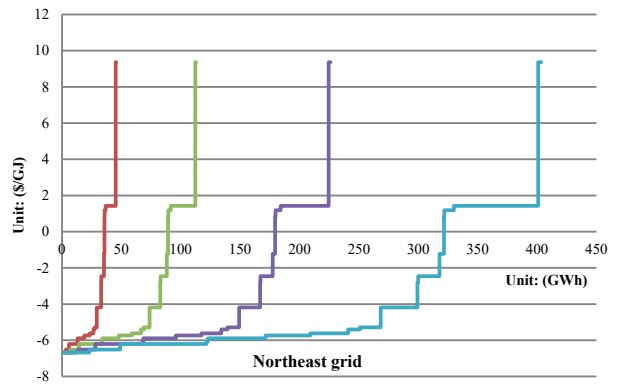

Electricity saving in $2020 \quad$ Electricity saving in 2025

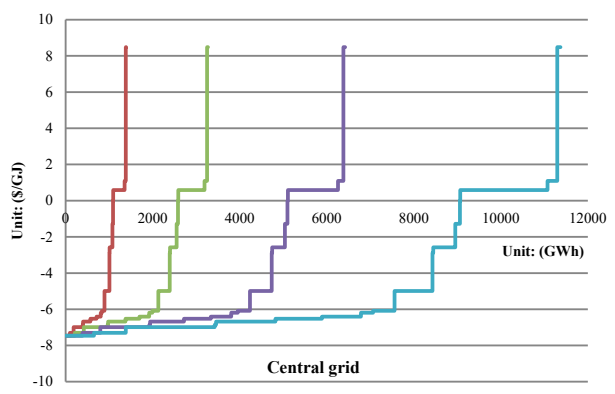

Electricity saving in 2020 Electricity saving in 2025 — Electricity saving in 2030 Electricity saving in 2035

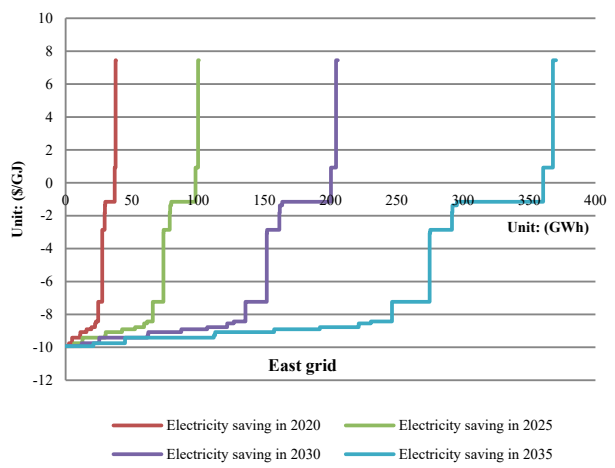

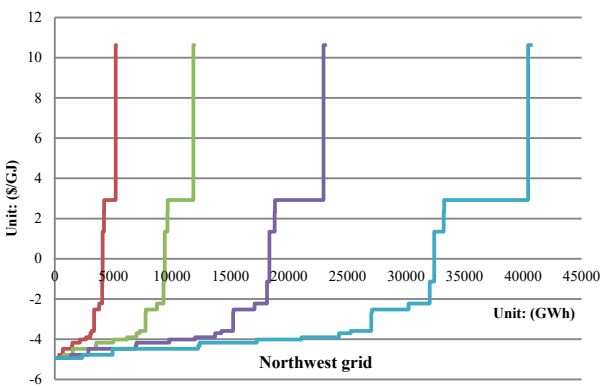

Electricity saving in $2020 \quad$ Electricity saving in 2025

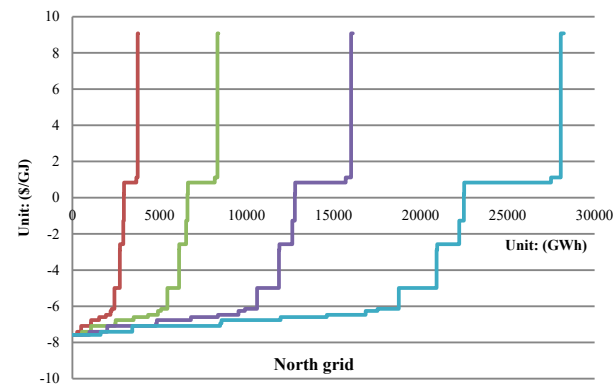

Electricity saving in 2020 Electricity saving in 2025 Electricity saving in $2030 \ldots$ Electricity saving in 203

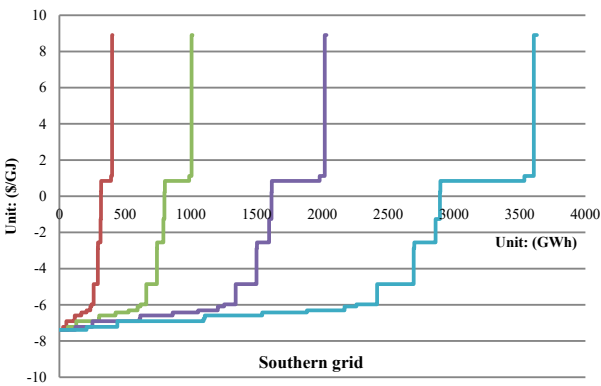

— Electricity saving in 2020 Electricity saving in 2025 Electricity saving in $2030 \quad$ Electricity saving in 2035

Figure 3.C3. ECSC per grid for calcium carbide industry between 2020 and 2035. 


\section{Supplementary Information}

\section{SI. Additional information on the analysis of China's chemical sub-sectors}

\section{SI.I. China's ammonia production, electricity use and related emissions} China's ammonia production capacity and output are ranked first in the world, accounting for about $40 \%$ of global ammonia capacity and output (International Fertilizer Association, 2017). In 2015, China’s ammonia capacity was $84 \mathrm{Mt}$ and its ammonia output was $58 \mathrm{Mt}$, reflecting a low capacity utilization rate. With the continuing expansion of the ammonia capacity, oversupply of ammonia capacity in China will continue. China's ammonia plants are mainly concentrated in East China, Central China and North China, and ammonia produced by them is mainly used for producing nitrogen fertilizers. Coal as the raw material is widely used in China's ammonia plants to synthesize ammonia due to its lower cost and abundant endowment. Coal-based ammonia accounts for $76 \%$ of China's total ammonia output, and natural gas-based ammonia accounts for 23\% (National Bureau of Statistics of China, 20152017; Zhang et al., 2012b). The remaining 1\% share, oil-based, is gradually withdrawn from the Chinese market. China's ammonia industry is facing structural adjustment because of the overcapacity and feedstock prices. The 13th Five-Year Plan of the nitrogen fertilizer industry, the norm of energy consumption per unit product of ammonia and the restriction policy of natural gas used by ammonia industry will lead the future adjustment of the ammonia industry. The share of coal-based ammonia is expected to rise in the foreseeable future as a result of the inadequate reserves and higher prices of nature gas and oil (Wen, 2012). China's ammonia plants are generally characterized by high energy intensities. The average energy intensity for China's ammonia production amounted to $44 \mathrm{GJ} / \mathrm{t}$ ammonia in 2015 . This is a decrease of $27 \%$ compared to the 1990 level $(60 \mathrm{GJ} / \mathrm{t}$ ammonia) due to phasing out inefficient capacity and implementation of energy efficiency measures. However, China is still $18 \%$ less efficient than the 2010 level in Western Europe dominated by natural gas (36 GJ/t ammonia) (National Bureau of Statistics of China, 2014-2017; Kermeli et al., 2013). Energy used in ammonia production accounts for about $20 \%$ of total energy consumption of China's chemical industry (Dai et al., 2013). Moreover, the total electricity consumption of ammonia production increased by $73 \%$ from $41 \mathrm{TWh}$ in 2000 to $71 \mathrm{TWh}$ in 2015, accounting for $1.2 \%$ of national power consumption in 2015 (National Bureau of Statistics of China, 2015-2017; Ministry of Industry and Information Technology of China, 2012). As one of the high electricity consumers, China's ammonia industry indirectly emitted $55 \mathrm{Mt} \mathrm{CO} 2$ emissions accounting for about 5\% of total chemical industry emissions. Electricity consumption in the ammonia industry also resulted in large amounts of air pollutants, $135 \mathrm{kt} \mathrm{SO} 2,129 \mathrm{kt} \mathrm{NOx}$ and $23 \mathrm{kt}$ PM respectively in 2015. Electricity 
consumption and emissions are expected to increase at a lower rate in the future as a result of the slower growth of ammonia production (Zhu et al., 2014).

\section{SI.2. China's caustic soda and PVC production, electricity use and related emissions}

The chlor-alkali industry produces caustic soda and chlorine products, with salt and electricity as raw materials. Between 2000 and 2015, the production capacity and output of caustic soda increased by as much as a factor 4 to $39 \mathrm{Mt}$ and $30 \mathrm{Mt}$, respectively. Caustic soda produced by the diaphragm process is being phased out because of its high energy cost and high pollution (State Council of China, 2013b). In 2015, caustic soda capacity based on the ion-exchange membrane technology was about $38 \mathrm{Mt}$, accounting for $97 \%$ of the total capacity of China's caustic soda (China Chlor-Alkali Online, 2016a). As one of the main chlorine products in the chlor-alkali industry, polyvinyl chloride (PVC) production is mainly dominated by the calcium carbide process in China that accounted for $82 \%$ of total PVC capacity. This deviates from the global more common ethylene-based PVC production route. The annual growth rate of PVC production was $21 \%$ between 2000 and 2007 , and dropped to $-9 \%$ by 2008 affected by the financial crisis (China Petroleum and Chemical Industry Association, 2002-2016). Between 2009 and 2015, PVC production increased from $9 \mathrm{Mt}$ to $16 \mathrm{Mt}$ at an average rate of $10 \%$ per year. Electricity consumption is the main source of energy used in the chlor-alkali industry, and keeps pace with the growth of China's caustic soda and PVC output (China Chemical Energy Efficiency Technology Association, 2014). In 2015, $69 \mathrm{TWh}$ was consumed for caustic soda production and $6 \mathrm{TWh}$ for PVC production, which together account for $1.3 \%$ of national power consumption (in 2010 account for 1.44\%) (Dai et al., 2013; Ministry of Industry and Information Technology of China, 2014b; AQSIQ and SAC, 2014). The emissions of $\mathrm{CO}_{2}, \mathrm{SO}_{2}, \mathrm{NO}_{\mathrm{x}}$ and $\mathrm{PM}$ caused by electricity consumption in the chlor-alkali industry reached $64 \mathrm{Mt}, 144 \mathrm{kt}, 138$ $\mathrm{kt}$ and $24 \mathrm{kt}$, respectively in 2015. Promoting energy efficiency technologies such as oxygen depolarized cathodes membrane electrolyzer and dry-process acetylene to saving electricity in chlor-alkali industry are expected to be more effective than diaphragm electrolyzer and wet-process acetylene in national $\mathrm{CO}_{2}$ and air pollutants reduction.

\section{SI.3. China's calcium carbide production, electricity use and related emissions}

China represented $95 \%$ of global calcium carbide capacity and output. About $80 \%$ of calcium carbide output is used to produce PVC (China Carbide Industry Association, 2013). Spurred by the increased demand of PVC, calcium carbide capacity expanded from $5 \mathrm{Mt}$ in 2000 to $45 \mathrm{Mt}$ in 2015, at an annual growth rate of $17 \%$ (China Petroleum and Chemical Industry Association, 2002-2016; China Chlor-Alkali Online, 2016b). However, output of calcium carbide was $26 \mathrm{Mt}$ in 2015 , only $58 \%$ of the effective capacity due to the disorderly capacity expansion and high energy cost. Phasing out the open furnace and upgrading the internal-combustion furnace to closed 
furnace was implemented by China's government to improve capacity utilization and energy efficiency. China's calcium carbide is characterized by high energy cost and high pollution. In particular, around $3400 \mathrm{kWh}$ is consumed by the electric arc furnace to produce a ton calcium carbide, accounting for the largest share of energy consumption (96\%) (Dai et al., 2013; Ministry of Industry and Information Technology of China, 2014a). With the fast development of China's calcium carbide industry, electricity used in calcium carbide industry jumped from $11 \mathrm{TWh}$ in 2000 to as much as $88 \mathrm{TWh}$ in 2015 (Ministry of Industry and Information Technology of China, 2014a; AQSIQ and SAC, 2008). This led to a significant increase in emissions of $\mathrm{CO}_{2}$ and air pollutants in the same period. China's calcium carbide industry emitted $135 \mathrm{Mt} \mathrm{CO}_{2}$ in 2015 , of which the electricity accounted for $56 \%$. The electricity-based emissions of $\mathrm{SO}_{2}$, $\mathrm{NO}_{\mathrm{x}}$ and PM increased by 7 times, 7 times and 6 times respectively between 2000 and 2015, from $21 \mathrm{kt}, 20 \mathrm{kt}$ and $4 \mathrm{kt}$ to $168 \mathrm{kt}, 161 \mathrm{kt}$ and $28 \mathrm{kt}$. To cut the air pollutants emissions in the calcium carbide industry, cleaner production standards and pollutants discharge standards were proposed by the Chinese government (Ministry of Environmental Protection of China, 2008; Ministry of Environmental Protection of China, 2015). Introducing best available power-saving technologies (e.g. advanced kilns and closed furnaces) will help to achieve these mandatory standards, thereby improving air quality.

\section{S2. Methodology for $\mathrm{CO}_{2}$ emission accounting in China's chemical industry}

Based on the $\mathrm{CO}_{2}$ emission factor of fuel (e.g. coal, coke and oil) and the amount of fuel consumed by China's chemical industry, the historical energy-related $\mathrm{CO}_{2}$ of China's chemical industry can be calculated by Equation (3.S1).

$E_{f, y}=\frac{F C_{f, y} * L C V_{f} * E F_{f, C O 2}}{10^{6}}$

Where $E_{f, y}$ is the $\mathrm{CO}_{2}$ emission of fuel $f$ in year $y$ (ton); $F C_{f, y}$ represents the amount of fuel $f$ consumed by the chemical industry in year $y$ (ton or $\left.\mathrm{m}^{3}\right) ; L C V_{f}$ represents the lower calorific value of fuel $f\left(\mathrm{MJ} /\right.$ ton or $\left.\mathrm{MJ} / \mathrm{m}^{3}\right) ; E F_{f, \mathrm{CO} 2}$ is the $\mathrm{CO}_{2}$ emission factors of fuel $f$, which can be obtained by Equation (3.S2).

$E F_{f, C O 2}=C C_{f} * O R_{f} * \frac{44}{12}$

Where $C C_{f}$ is carbon content per unit calorific value of fuel $f(\mathrm{~g} / \mathrm{MJ}) ; O R_{f}$ is the oxidation rate of fuel $f(\%)$. 
The lower calorific value, carbon content and oxidation rate for each fuel are from National Development and Reform Commission (2006-2017, 2011, 2008), National Government Offices Administration (2011), IPCC (2006), and Word Resources Institute (2013). The amount of each fuel consumed by China's chemical industry during 2005-2015 is from the China Energy Statistical Yearbook (2015-2017).

\section{S3. Emission factors of GHG and air pollutants per grid}

Table 3.S1. Emission factors of GHG and air pollutants at grid level.

\begin{tabular}{llllllll}
\hline Grid & GHG & \multicolumn{5}{c}{ Air pollutant } \\
\cline { 2 - 7 } & $\begin{array}{l}\mathrm{CO}_{2}(\mathrm{t} / \\
\mathrm{MWh})\end{array}$ & $\begin{array}{l}\mathrm{CH}_{4} \\
(\mathrm{~g} / \mathrm{MWh})\end{array}$ & $\begin{array}{l}\mathrm{N}_{2} \mathrm{O} \\
(\mathrm{g} / \mathrm{MWh})\end{array}$ & $\begin{array}{l}\mathrm{GHGs}^{1} \\
\left(\mathrm{tCO}_{2 \mathrm{eq}} / \mathrm{MWh}\right)\end{array}$ & $\begin{array}{l}\mathrm{SO}_{2} \\
(\mathrm{~kg} / \mathrm{MWh})\end{array}$ & $\begin{array}{l}\mathrm{NO}_{\mathrm{x}} \\
(\mathrm{kg} / \mathrm{MWh})\end{array}$ & $\begin{array}{l}\mathrm{PM}_{2.5} \\
(\mathrm{~kg} / \mathrm{MWh})\end{array}$ \\
\hline Northeast & 1.025 & 10.627 & 15.417 & 1.030 & 1.317 & 2.441 & 0.602 \\
Northwest & 0.801 & 8.505 & 12.400 & 0.805 & 1.390 & 1.678 & 0.287 \\
Central & 0.612 & 6.166 & 8.814 & 0.614 & 1.431 & 1.232 & 0.291 \\
North & 1.014 & 10.363 & 14.806 & 1.018 & 1.733 & 2.220 & 0.412 \\
East & 0.776 & 8.108 & 11.280 & 0.780 & 2.021 & 1.442 & 0.389 \\
Southern & 0.577 & 6.102 & 8.561 & 0.579 & 1.738 & 1.137 & 0.315 \\
\hline
\end{tabular}

${ }^{1}$ Based on the emission factors of $\mathrm{CO}_{2}, \mathrm{CH}_{4}$ and $\mathrm{N}_{2} \mathrm{O}$, the emission factor of GHGs is calculated. 


\section{References}

AQSIQ (General Administration of Quality Supervision, Inspection and Quarantine of China), SAC (Standardization Administration of China), 2017. Industrial classification for national economic activities (GB/T 4754-2017). URL: http://www.stats.gov.cn/tjsj/tjbz/201709/ P020180124537249410457.pdf (accessed 06 February 2018).

AQSIQ (General Administration of Quality Supervision, Inspection and Quarantine of China), SAC (Standardization Administration of China), 2014. The norm of energy consumption per unit product of caustic soda (GB 21257-2014). URL: http://std.samr.gov.cn/gb/search/ gbDetailed?id=71F772D7E9F3D3A7E05397BE0A0AB82A (accessed 06 February 2018).

AQSIQ (General Administration of Quality Supervision, Inspection and Quarantine of China), SAC (Standardization Administration of China), 2008. The norm of energy consumption per unit product of calcium carbide (GB 21343-2008). URL: http://std.samr.gov.cn/gb/search/ gbDetailed?id=71F772D80AD9D3A7E05397BE0A0AB82A (accessed 06 February 2018).

Ascensão, F., Fahrig, L., Clevenger, A.P., Corlett, R.T., Jaeger, J.A.G., Laurance, W.F., Pereira, H.M., 2018. Environmental challenges for the Belt and Road Initiative. Nature Sustainability, 1, 206-209.

A. T. Kearney, CPCIF (China Petroleum and Chemical Industry Federation), 2017. Global opportunities for the Chinese chemical industry.

Audoly, R., Vogt-Schilb, A., Guivarch, C., Pfeiffer, A., 2018. Pathways toward zero-carbon electricity required for climate stabilization. Applied Energy, 225, 884-901.

BP, 2017. Statistical Review of World Energy. British Petroleum, London (UK).

Cai, B., Wang, J., He, J., Geng, Y., 2016. Evaluating $\mathrm{CO}_{2}$ emission performance in China's cement industry: An enterprise perspective. Applied Energy, 166, 191-200.

Cai, W., Wang, C., Jin, Z., Chen, J., 2013. Quantifying baseline emission factors of air pollutants in China's regional power grids. Environmental science \& technology, 47, 3590-3597.

China Carbide Industry Association, 2013. 12th Five-Year Plan of China's calcium carbide industry. URL: http://www.cciac.org.cn/view.asp?id=9817 (accessed 06 February 2018).

China Chemical Energy Efficiency Technology Association, 2014. Progress report on energy conservation in petroleum and chemical industry. Beijing (China). 


\section{Chapter 3}

China Chemical Energy Efficiency Technology Association, 2011. 100 energy conservation technologies for China's petroleum and chemical industry. URL: http://www.syhgjn.cn/ news/view/5479-1.html (accessed 06 February 2018).

China Chemical Energy Efficiency Technology Association, 2006. Handbook of energy saving technology in chemical industry. Chemical Industry Press, Beijing (China).

China Chlor-Alkali Online, 2016a. 13th Five-Year Plan of China's chlor-alkali industry. URL: http://www.chemol.net/zt/thirteen/download/003.pdf (accessed 06 February 2018).

China Chlor-Alkali Online, 2016b. Research report on China's calcium carbide industry. URL: http://www.ccaon.com/ (accessed 06 February 2018).

China Electricity Council, 2015. Power Industry Statistical Compilation 2014. Beijing (China).

China Electric Power Yearbook Editorial Committee, 2013-2017. China Electric Power Yearbook (2013-2016). China Electric Power Press, Beijing (China).

China Petroleum and Chemical Industry Federation, 2002-2016. China Chemical Industry Yearbook (2001-2015). China National Chemical Information Center, Beijing (China).

Chinese Research Academy of Environmental Sciences, 2010. First China pollution source census: Manual of industrial pollutants production and discharge coefficients [Chapter 10]. Beijing (China).

Dai, Y., Hu, X., 2013. Potential and cost study on China's carbon mitigation technologies. China Environmental Press, Beijing (China).

Dai, Y., Xiong, W., Jiao, J., 2013. Roadmap study on achieving technical energy conservation potential in China's industrial sector by 2020. China Science and Technology Press, Beijing (China).

Graus, W., Worrell, E., 2011. Methods for calculating $\mathrm{CO}_{2}$ intensity of power generation and consumption: A global perspective. Energy Policy, 39, 613-627.

Harmsen, R., Graus, W., 2013. How much $\mathrm{CO}_{2}$ emissions do we reduce by saving electricity? A focus on methods. Energy Policy, 60, 803-812.

Hasanbeigi, A., Morrow, W., Masanet, E., Sathaye, J., Xu, T., 2013. Energy efficiency improvement and $\mathrm{CO}_{2}$ emission reduction opportunities in the cement industry in China. Energy Policy, 57, 287-297. 
Helin, K., Käki, A., Zakeri, B., Lahdelma, R., Syri, S., 2017. Economic potential of industrial demand side management in pulp and paper industry. Energy, 141, 1681-1694.

Hong, J., Chen, W., Wang, Y., Xu, C., Xu, X., 2014. Life cycle assessment of caustic soda production: A case study in China. Journal of Cleaner Production, 66, 113-120.

IEA, 2017. Energy technology perspectives 2017: Catalysing energy technology transformation. International Energy Agency (IEA), Paris (France).

IEA, 2016a. World energy outlook 2016. International Energy Agency (IEA), Paris (France).

IEA, 2016b. World energy outlook special report 2016: Energy and air pollution. International Energy Agency (IEA), Paris (France).

IEA, 2013. Technology roadmap: Energy and GHG reductions in the chemical industry via catalytic processes. International Energy Agency (IEA), Paris (France).

International Fertilizer Association (IFA), 2017. IFA Statistics Databases 2017. URL: http:// www.fertilizer.org/Statistics (accessed 06 February 2018).

IPCC, 2014. Climate change 2014: Mitigation of climate change. Working Group III Contribution to the Fifth Assessment Report of the Intergovernmental Panel on Climate Change. Cambridge University Press, Cambridge (UK).

IPCC, 2006. IPCC guidelines for national greenhouse gas inventories. Intergovernmental Panel on Climate Change (IPCC). URL: https://www.ipcc-nggip.iges.or.jp/public/2006gl/index. html (accessed 06 February 2018).

Karali, N., Park, W.Y., McNeil, M., 2017. Modeling technological change and its impact on energy savings in the US iron and steel sector. Applied Energy, 202, 447-458.

Kermeli, K., Corsten, M., Worrell, E., Crijns-Graus, W., 2013. Ammonia production: Energy efficiency technology, practices, organizations and programs. Institute for Industrial Productivity and Utrecht University, Utrecht (The Netherlands).

Kong, L., Hasanbeigi, A., Price, L., Liu, H., 2017. Energy conservation and $\mathrm{CO}_{2}$ mitigation potentials in the Chinese pulp and paper industry. Resources, Conservation \& Recycling, $117,74-84$.

Li, C., Zhu, L., Fleiter, T., 2014. Energy efficiency potentials in the chlor-alkali sector - A case study of Shandong province in China. Energy \& Environment, 25, 661-686. 
Li, L., 2018. China's manufacturing locus in 2025: With a comparison of "Made-in-China 2025 " and "Industry 4.0". Technological Forecasting and Social Change, 135, 66-74.

Lin, B., Long, H., 2016. Emissions reduction in China's chemical industry-Based on LMDI. Renewable and Sustainable Energy Reviews, 53, 1348-1355.

Liu, X., Yuan, Z., Xu, Y., Jiang, S., 2017. Greening cement in China: A cost-effective roadmap. Applied Energy, 189, 233-244.

Liu, X., Zhu, B., Zhou, W., Hu, S., Chen, D., Griffy-Brown, C., 2011. $\mathrm{CO}_{2}$ emissions in calcium carbide industry: An analysis of China's mitigation potential. International Journal of Greenhouse Gas Control, 5, 1240-1249.

Ma, C., Ge, Q., 2014. Method for calculating $\mathrm{CO}_{2}$ emissions from the power sector at the provincial level in China. Advances in Climate Change Research, 5, 92-99.

Ma, D., Chen, W., Yin, X., Wang, L., 2016. Quantifying the co-benefits of decarbonisation in China’s steel sector: an integrated assessment approach. Applied Energy, 162, 1225-1237.

Ma, D., Hasanbeigi, A., Chen, W., 2015. Energy-efficiency and air-pollutant emissions-reduction opportunities for the ammonia industry in China. Lawrence Berkeley National Laboratory, Berkeley (USA).

Ma, X., Wang, Y., Wang, C., 2017. Low-carbon development of China's thermal power industry based on an international comparison: review, analysis and forecast. Renewable and Sustainable Energy Reviews, 80, 942-970.

MEP (Ministry of Environmental Protection of China), AQSIQ (General Administration of Quality Supervision, Inspection and Quarantine of China), 2015. Emission standard of pollutants for petroleum chemistry industry (GB 31571-2015). URL: https://www.mee. gov.cn/ywgz/fgbz/bz/bzwb/dqhjbh/dqgdwrywrwpfbz/201505/t20150505_300663.shtml (accessed 06 February 2018).

Ministry of Agriculture of China, 2015. Zero growth programme in fertilizer use by 2020. URL: http://jiuban.moa.gov.cn/zwllm/tzgg/tz/201503/t20150318_4444765.htm (accessed 06 February 2018).

Ministry of Environmental Protection of China, 2009-2017. Annual statistic report on environment in China (2005-2015). URL: https://www.mee.gov.cn/hjzl/sthjzk/sthjtjnb/ (accessed 06 February 2018). 
Ministry of Environmental Protection of China, 2015. Emission standard of pollutants for calcium carbide industry. URL: https:/www.mee.gov.cn/gkml/hbb/bgth/201803/ W020180315548432279936.pdf (accessed 06 February 2018).

Ministry of Environmental Protection of China, 2011-2014. List of denitrification facilities for China's coal-fired power units (2010-2013). URL: http://www.mee.gov.cn/gkml/hbb/ bgg/201407/W020140711581927393439.pdf (accessed 06 February 2018).

Ministry of Environmental Protection of China, 2009-2014. List of desulfurization facilities for China's coal-fired power units (2008-2013). URL: https://www.mee.gov.cn/gkml/hbb/ bgg/201407/W020140711581927228220.pdf (accessed 06 February 2018).

Ministry of Environmental Protection of China, 2008. Cleaner production standard - Calcium carbide industry (HJ/T 430-2008). URL: https://www.mee.gov.cn/ywgz/fgbz/bz/bzwb/ other/qjscbz/200804/W020111121505991606184.pdf (accessed 06 February 2018).

Ministry of Environmental Protection of China, 2005-2015. Technical specifications of desulfurization and denitrification project for thermal power plant. URL: http://kjs.mep.gov. cn/hjbhbz/bzwb/other/hjbhgc/index.shtml (accessed 06 February 2018).

Ministry of Industry and Information Technology of China, 2016. The development plan of petrochemical and chemical industry 2016-2020. URL: http://www.miit.gov.cn/n1146285/ n1146352/n3054355/n3057267/n3057273/c5288529/content.html (accessed 06 February 2018).

Ministry of Industry and Information Technology of China, 2014a Implementation plan of energy consumption norm for China's calcium carbide industry. URL: http://miit.gov.cn/ newweb/n1146295/n1652858/n1652930/n3757016/c3762531/content.html (accessed 06 February 2018).

Ministry of Industry and Information Technology of China, 2014b. Guideline of national industrial energy efficiency. URL: http://www.miit.gov.cn/n1146285/n1146352/n3054355/ n3057542/n3057546/c3634672/content.html (accessed 06 February 2018).

Ministry of Industry and Information Technology of China, 2012. Advanced technologies guideline for energy conservation and emission reduction in China's petroleum and chemical industry. URL: http://www.miit.gov.cn/n1146285/n1146352/n3054355/n3057542/ n3057546/c3634361/content.html (accessed 06 February 2018).

Ministry of Industry and Information Technology of China, 2010. Implementation plan of cleaner production technologies in 17 key sectors. URL: http://miit.gov.cn/n1146290/ n1146402/n7039597/c7072456/content.html (accessed 06 February 2018). 


\section{Chapter 3}

Ministry of Industry and Information Technology of China, 2009-2011. Guidance catalogue of electronic information application technologies of energy conservation and emission reduction in industry (1-2). URL: http://miit.gov.cn/n1146295/n1652858/n1652930/ n3757016/c3759961/content.html (accessed 06 February 2018).

National Bureau of Statistics of China, 2015-2017. China energy statistical yearbook (20142016). China Statistics Press, Beijing (China).

National Bureau of Statistics of China, 2014-2017. China statistical yearbook (2014-2017). China Statistics Press, Beijing (China).

National Bureau of Statistics of China, 2006-2017. China industry (economy) statistical yearbook (2006-2017). China Statistics Press, Beijing (China).

National Development and Reform Commission of China, 2015-2017. National key energy conservation and low carbon technologies promotion catalogue (2014-2016). URL: http:// www.gov.cn/xinwen/2017-01/19/content_5161265.htm (accessed 06 February 2018).

National Development and Reform Commission of China, 2006-2017. Baseline emission factors in China's regional grids (2006-2015). URL: http://cdm.ccchina.org.cn/archiver/cdmcn/ UpFile/Files/Default/20160606120244478242.pdf (accessed 06 February 2018).

National Development and Reform Commission of China, 2011. Guideline for provincial greenhouse gas inventories. URL: http://www.cbcsd.org.cn/sjk/nengyuan/standard/ home/20140113/download/shengiwenshiqiti.pdf (accessed 06 February 2018).

National Development and Reform Commission of China, 2008. Implementation plan of energy efficiency report of key energy-consuming enterprises. URL: http://www.sdpc.gov.cn/ zcfb/zcfbtz/2008tongzhi/t20080618_218244.htm (accessed 06 February 2018).

National Development and Reform Commission of China, 2007. Measures for operation and management of desulfurization price and facilities of China's coal-fired units. URL: http:// www.gov.cn/jrzg/2007-06/11/content_644454.htm (accessed 06 February 2018).

National Government Offices Administration of China, 2011. Public institutional energy resource consumption statistics system. URL: http:/www.ggj.gov.cn/gzdt/ggjgzdt/ggjgjn/ ggjgjnzwgk/ggjgjntzgg/201207/t20120710_12087.htm (accessed 06 February 2018).

NBS (National Bureau of Statistics of China), MEP (Ministry of Environmental Protection of China), 2006-2016. China statistical yearbook on environment (2006-2016). China Statistics Press, Beijing (China). 
Ni, C., 2009. China energy primer. Lawrence Berkeley National Laboratory, Berkeley (USA).

OECD, 2017. OECD Satistics 2017. Organization for Economic Co-operation and Development (OECD), Pairs (France). URL: http://stats.oecd.org (accessed 06 February 2018).

Peng, W., Yang, J., Lu, X., Mauzerall, D.L., 2018. Potential co-benefits of electrification for air quality, health, and CO2 mitigation in 2030 China. Applied Energy, 218, 511-519.

Ren Y., 2015. Study on the potential of carbon reduction in China's synthetic ammonia industry. MS thesis, Beijing University of Chemical Technology, 67 pp., Beijing (China).

Saygin, D., Patel, M.K., Worrell, E., Tam, C., Gielen, D.J., 2011. Potential of best practice technology to improve energy efficiency in the global chemical and petrochemical sector. Energy, 36, 5779-5790.

Shi, Y., Xia, Y., Lu, B., Liu, N., Zhang, L., Li, S., Li, W., 2014. Emission inventory and trends of NOx for China, 2000-2020. Journal of Zhejiang University Science A, 15, 454-464.

Song, R., Zhu, J., Hou, P., Wang, H., 2013. Getting every ton of emissions right: An analysis of emission factors for purchased electricity in China. World Resources Institute, Washington (USA).

State Council of China, 2017. Comprehensive work plan for energy conservation and emission reduction in the 13th Five-Year Plan. URL: http://www.gov.cn/zhengce/content/2017-01/05/ content_5156789.htm (accessed 06 February 2018).

State Council of China, 2016. Work plan on controlling greenhouse gas emissions in 13th FiveYear Plan. URL: http:/www.gov.cn/zhengce/content/2016-11/04/content_5128619.htm (accessed 06 February 2018).

State Council of China, 2013a. Air pollution prevention and control action plan (English version). Beijing, China: Clean Air Alliance of China. URL: http://en.cleanairchina.org/ product/6346.html (accessed 06 February 2018).

State Council of China, 2013b. Development strategy of circular economy and recent action plan. URL: http://www.gov.cn/zhengce/content/2013-02/06/content_1631.htm (accessed 06 February 2018).

State Grid Corporation of China, 2015. Electricity pricing policy per province 2014. Beijing (China). 


\section{Chapter 3}

Summerbell, D.L., Khripko, D., Barlow, C., Hesselbach, J., 2017. Cost and carbon reductions from industrial demand-side management: Study of potential savings at a cement plant. Applied Energy, 197, 100-113.

Van Ruijven, B. J., Van Vuuren, D. P., Boskaljon, W., Neelis, M. L., Saygin, D., Patel, M. K., 2016. Long-term model-based projections of energy use and $\mathrm{CO}_{2}$ emissions from the global steel and cement industries. Resources, Conservation and Recycling, 112, 15-36.

Wang, K., Wang, S., Liu, L., Yue, H., Zhang, R., Tang, X., 2016. Environmental co-benefits of energy efficiency improvement in coal-fired power sector: A case study of Henan Province, China. Applied Energy, 184, 810-819.

Wen Q., 2012. Development analysis of China’s ammonia industry. Chemical Industry, 30,16-19.

Wen, Z., Xu, C., Zhang, X., 2015. Integrated control of emission reductions, energy-saving, and cost-benefit using a multi-objective optimization technique in the pulp and paper industry. Environmental Science \& Technology, 49, 3636-3643.

WHO, 2013. Health effects of particulate matter, Policy implications for countries in Eastern Europe, Caucasus and central Asia. Word Health Organization (WHO) Regional Office for Europe, Copenhagen (Denmark).

Worrell, E., Price, L., Martin, N., 2001. Energy efficiency and carbon dioxide emissions reduction opportunities in the US iron and steel sector. Energy, 26, 513-536.

Yang, X., Teng, F., Wang, G., 2013. Quantifying co-benefit potentials in the Chinese cement sector during 12th Five Year Plan: an analysis based on marginal abatement cost with monetized environmental effect. Journal of Cleaner Production, 58, 102-111.

Zhang, C., Chen, J., Wen, Z., 2012b. Assessment of policy alternatives and key technologies for energy conservation and water pollution reduction in China's synthetic ammonia industry. Journal of Cleaner Production, 25, 96-105.

Zhang C., 2008. Studies on present and future emissions of $\mathrm{PM}, \mathrm{SO}_{2}, \mathrm{NO}_{\mathrm{x}}$. MS thesis, Tsinghua University, 147 pp., Beijing (China).

Zhang P., 2018. Analysis of economic operation in 2017 of China chlor-alkali industry. China Chlor-Alkali, 2, 1-3.

Zhang, Q., Xu, J., Wang, Y., Hasanbeigi, A., Zhang, W., Lu, H., Arens, M., 2018a. Comprehensive assessment of energy conservation and $\mathrm{CO}_{2}$ emissions mitigation in China's iron and steel industry based on dynamic material flows. Applied Energy, 209, 251-265. 
Zhang, Q., Zhao, X., Lu, H., Ni, T., Li, Y., 2017. Waste energy recovery and energy efficiency improvement in China's iron and steel industry. Applied energy, 191, 502-520.

Zhang, Q., He, K., Huo, H., 2012a. Cleaning China’s air. Nature, 484, 161-162.

Zhang, S., Ren, H., Zhou, W., Yu, Y., Chen, C., 2018b. Assessing air pollution abatement cobenefits of energy efficiency improvement in cement industry: A city level analysis. Journal of Cleaner Production, 185, 761-771.

Zhang, S., Worrell, E., Crijns-Graus, W., Krol, M., de Bruine, M., Geng, G., Wagner, F., Cofala, J., 2016. Modeling energy efficiency to improve air quality and health effects of China's cement industry. Applied Energy, 184, 574-593.

Zhang, S., Worrell, E., \& Crijns-Graus, W., 2015. Evaluating co-benefits of energy efficiency and air pollution abatement in China’s cement industry. Applied Energy, 147, 192-213.

Zhang Y., 2017. Present situation analysis and prospect forecast of chlor-alkali industry of China. China Chlor-Alkali, 8, 1-6.

Zhang, W., Dou, Z., He, P., Ju, X., Powlson, D., Chadwick, D., Norse, D., Lu, Y., Zhang, Y., Wu, L., 2013. New technologies reduce greenhouse gas emissions from nitrogenous fertilizer in China. Proceedings of the National Academy of Sciences, 21, 8375-8380.

Zhao, Y., Wang, S., Nielsen, C. P., Li, X., Hao, J., 2010. Establishment of a database of emission factors for atmospheric pollutants from Chinese coal-fired power plants. Atmospheric Environment, 44, 1515-1523.

Zhao, Y., Wang, S., Duan, L., Lei, Y., Cao, P., Hao, J., 2008. Primary air pollutant emissions of coal-fired power plants in China: Current status and future prediction. Atmospheric Environment, 42, 8442-8452.

Zhou, N., Fridley, D., Khanna, N. Z., Ke, J., McNeil, M., Levine, M., 2013. China’s energy and emissions outlook to 2050: Perspectives from bottom-up energy end-use model. Energy Policy, 53, 51-62.

Zhou, W., Zhu, B., Li, Q., Ma, T., Hu, S., Griffy-Brown, C., 2010. $\mathrm{CO}_{2}$ emissions and mitigation potential in China's ammonia industry. Energy Policy, 38, 3701-3709.

Zhu, B., Chen, X., Zhang, W., Hu, S., Jin, Y., 2015. Potential assessment of cleaner production in China's ammonia industry. Journal of Tsinghua University (Science and Technology), 54, 309-313. 


\section{Chapter 3}

Zhu, B., Zhou, W., Hu, S., Li, Q., Griffy-Brown, C., Jin, Y., 2010. $\mathrm{CO}_{2}$ emissions and reduction potential in China's chemical industry. Energy, 35, 4663-4670.

Zuberi, M. J. S., Patel, M. K., 2017. Bottom-up analysis of energy efficiency improvement and $\mathrm{CO}_{2}$ emission reduction potentials in the Swiss cement industry. Journal of Cleaner Production, 142, 4294-4309. 


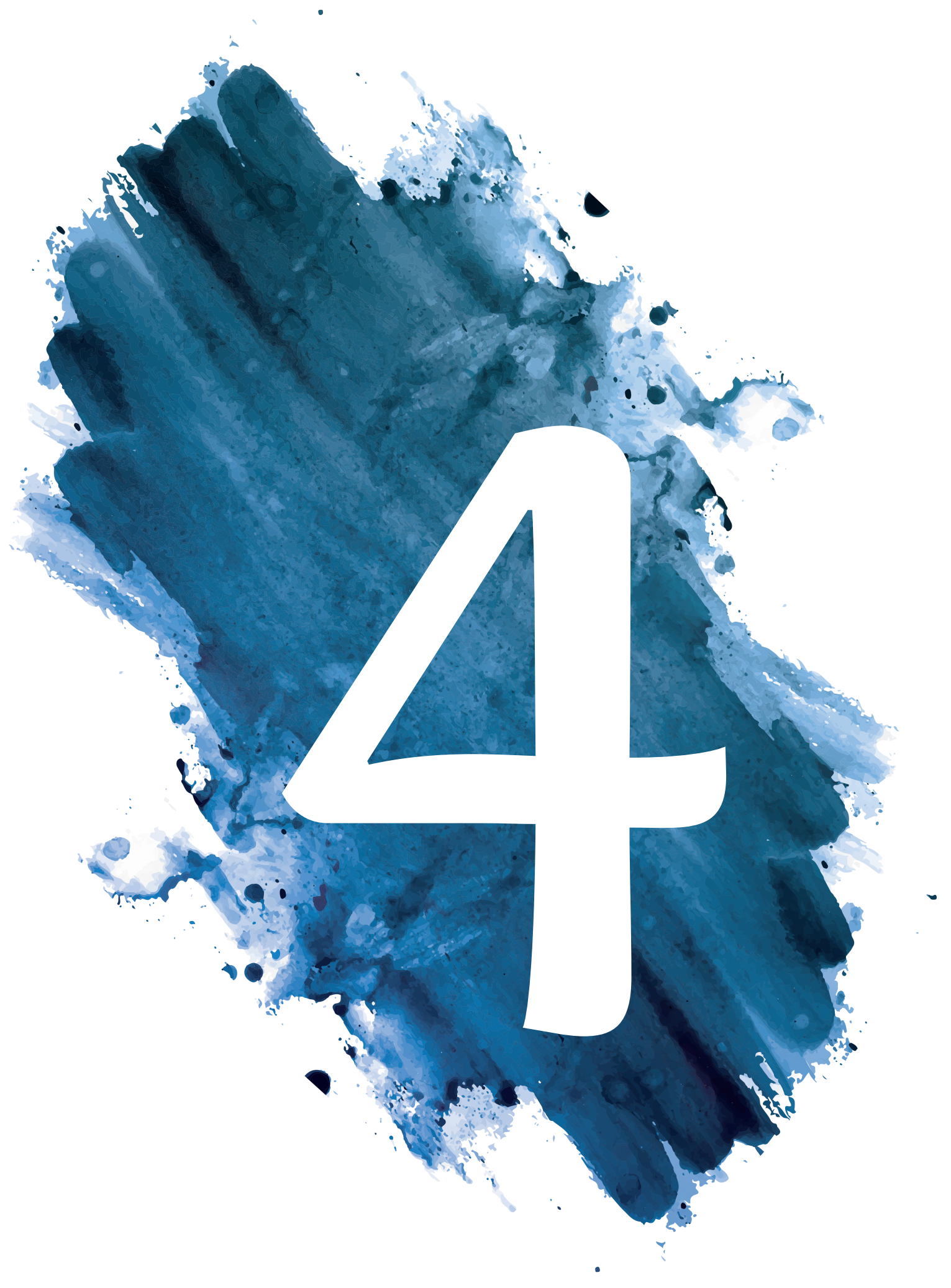




\section{Chapter 4}

\section{Air emissions and energy efficiency: realizing multiple benefits for power sector by saving industrial electricity use in China}

Hui Yue, Ernst Worrell, Wina Crijns-Graus, Shaohui Zhang 


\section{ABSTRACT}

Coal-intensive power supply systems, along with a fast-growing electricity demand driven by industry has caused serious air pollution and health concerns. These concerns are particularly prominent in countries where electricity use is likewise dominated by industry and heavily dependent on coal-based electricity. A more efficient industry and a coal-free electricity system are the core components of the United Nations 2030 Agenda for Sustainable Development. Previous studies rarely reflect on the impacts of the electricity savings of industrial consumers on the electricity supply sector with respect to future air emission changes, and also neglect the potential benefits of reducing investments in new generation capacity. Here, a comprehensive modeling framework is newly developed to quantify the connections of electricity savings, coal-based electricity systems, air pollutant emissions, control investments in China, a country exposed to poor air quality. The modeling framework includes 175 energy efficiency technologies (covering multiple industrial sectors) and detailed information of power generation units (thermal efficiency, environmental performance and lifespan), and allows for unit-by-unit assessment. We find that industrial efficiency improvements can significantly decrease the dependence on coal-fired power generation, particularly the most polluting power fleet. Efficient use of electricity in industry can drive all small high-polluting coal generation units (i.e. units below $300 \mathrm{MW}$, in total 753 units) to be phased out and effectively curb less efficient coal-fired plants to come online in China. The closed coal-fired power units substantially reduce the current air pollutant emission levels by $22.7 \%, 26.9 \%$ and $22.6 \%$ of $\mathrm{SO}_{2}, \mathrm{NO}_{\mathrm{x}}$ and PM, respectively. Developed cost portfolios demonstrate that improving industrial energy efficiency is more cost-effective than installing flue gas controls in coal-fired plants. We further reveal that a sustainable industry could contribute to climate change mitigation even if less remarkable than air quality improvement, while enabling the expansion of intermittent renewable power supply. 


\section{I. Introduction}

In light of transitioning to a sustainable energy system, more efficient use of electricity in industries is an effective way to displace emissions of air pollutants and greenhouse gas (GHG) from electricity production, and to limit investments in new power generation capacity (IEA, 2018a). The demand of electricity to support industrial development has surged in the world, particularly in developing economies, during the past five decades (IEA, 2018b). Fossil power plant fleets have expanded rapidly (with an annual growth rate of $-4 \%$ since 1997) to meet the surging demand, emitting vast amounts of air pollutants $\left(-36 \%,-15 \%\right.$ and $-6 \%$ of global anthropogenic emissions of $\mathrm{SO}_{2}, \mathrm{NO}_{\mathrm{x}}$ and fine particulate matter $\left(\mathrm{PM}_{2.5}\right)$, respectively, in 2016) (IEA, 2018c), thereby increasing human health risks (Gao et al., 2018; Oberschelp et al., 2019). Linking the supply-side (power sector) to the demand-side (industry) is therefore particularly relevant for several Sustainable Development Goals (SDGs): good health (SDG 3), energy access (SDG 7), sustainable industry (SDG 9), climate action (SDG 13) (Nerini et al., 2018; TWI2050, 2018). As emphasized by the United Nations, treating the complex linkages between the industry and power sectors from a cost performance perspective is critical to coordinate energy efficiency (EE) improvement and power plants deployment in an energy system that also benefits to achieve energy savings, air quality improvement, and climate change mitigation simultaneously.

As a rapidly developing country, China is currently facing the dual tasks of achieving industrialization while mitigating the costly burden of high energy use and environmental impacts ( Ministry of Industry and Information Technology of China, 2017; World Bank, 2016; Zhou et al., 2018a). Industry in China consumes $-40 \%$ of global industrial electricity demand $(-63 \%$ of China's total electricity demand), which is larger than the total power consumption of the European Union (IEA, 2018b). With an annual growth rate of $-10 \%$, electricity is the strongest growing energy carrier in China's industrial energy use between 2000 and 2016, constituting $-33 \%$ of the growth in end-use energy (IEA, 2018b). Electrification policies can lead to even stronger growth in industrial electricity use in China and potentially exacerbate the deployment of new power capacity (ERI and CNREC, 2018; National Development and Reform Commission of China, 2016; Wang et al., 2019a). Moreover, inefficient industrial processes, due to outdated technology and less efficient equipment, lead to large electrical energy losses, thereby increasing net electricity demand (ERI and CNREC, 2018; Ministry of Industry and Information Technology of China, 2014). At the same time, the supply of the rising electricity demand is heavily dependent on a coal-intensive power plant fleet in China $(-70 \%$ of total electricity generation), which in turn increases air pollutant emissions from power plants that significantly deteriorate local air quality (Abel et al., 2019; Khanna et al., 2019; Peng et al., 2018). China's poor air quality has posed a serious threat to public health. Annually 1.0-1.4 million people die prematurely in China as a result of exposure to high concentrations of total particulate matter (PM), while power 
generation is estimated to contribute to 5-39\% of mortality (Cohen et al., 2017; Gao et al., 2018; Lelieveld et al., 2015; Reddington et al., 2019). Therefore, it is urgent to seek a sustainable pathway for the globally largest manufacturer and emitter, China, while at the same time managing its existing power generation fleet and curbing future additions.

Various studies have indicated the adverse ambient air impacts of a coal-intensive power sector (Karplus et al., 2018; Oberschelp et al., 2019; Tong et al., 2018; Wang et al., 2019a). Installing end-of-pipe (EoP) controls can significantly decrease air pollutant emissions, but comes at the expense of high capital costs (Abel et al., 2019; Li and Patińo-Echeverri, 2017), a lower generation efficiency ( Crijns-Graus and Worrell, 2007) and consumption of additional resources (for example, catalyst and electricity) (Yang et al., 2018), leading to increased $\mathrm{CO}_{2}$ emissions (Abel et al., 2019). Besides flue gas control systems, minimizing electricity requirements to reduce coal generation unit deployment (for example, driving coal units into early retirement) is an important option, which has additional GHG mitigation benefits and is economically competitive (Cui et al., 2019; Fleischman et al., 2013).

The critical role of EE improvements has been emphasized by numerous narratives that can reduce new energy needs (which is the key to the transition to an efficient industry), but also generate non-energy benefits. Zhang et al. $(2015,2019)$ measured the air quality benefits of energy saving potentials in China's iron \& steel and cement industries, and suggested that the efficient production technologies play a win-win role in fulfilling both energy and air quality regulations. Zhou et al. (2018b) and Langevin et al. (2019) estimated the potential impact of EE improvements on $\mathrm{CO}_{2}$ emissions in the buildings sector of China and the United States, respectively. They revealed that boosting building efficiency can significantly reduce $\mathrm{CO}_{2}$ emissions by 2050. Most research looks at a specific sector and has a particular focus on co-benefits like carbon or air pollutant emission reductions. However, studies rarely reflect on the impacts of the savings of industrial users on the electricity supply sector with respect to future emission changes of air pollutants (Yue et al., 2018), and also neglect the potential benefits of reducing investments in new generation units (IEA, 2018a). The latter has been the focus of demand-side management (DSM) and integrated resource planning (IRP) in the 1990s in regulated power markets, but has achieved limited attention since, due to deregulation of most power markets around the world. Here, we comprehensively assess the potential for electricity savings in China's largest industries to reduce the deployment of specific coal generation units (those that are most polluting) in order to avoid air pollutant emissions, and compare this to the alternative of EoP flue gas control technologies in terms of emission abatement and costs.

In this study, we begin with developing an EE scenario that models electricity savings by implementing efficient technologies in China’s energy-intensive industries (including 
iron \& steel, cement, chemical, aluminum and paper) up to 2040 . In order to estimate the impact of these electricity savings on the electricity supply sector, this study compiles exhaustive unit-level information of the power plant fleet (e.g. commissioning year, fuel type used, generation efficiency, and flue gas concentrations), relying on various reliable sources. The future evolution of power supply, demand and capacity is simulated under a business-as-usual (BAU) scenario. Next, we integrate the electricity savings gained by industrial EE improvements into future alternative pathways for the development of the power plant fleet, in order to reduce air pollutant emissions (e.g. by retiring less efficient coal-fired power plants). Finally, cost-effective portfolios are determined to tackle air pollution from electricity generation by electricity savings and EoP controls pathway. These interesting results are both critical for successfully transiting to a sustainable industry, and shifting away from coal for electricity generation. Furthermore, we perform a comprehensive uncertainty analysis targeting research limitations and additional benefits.

\subsection{Methods}

A comprehensive modeling framework integrating four modules (power generation, industrial electricity demand, air emissions and economic assessment) is developed in this research to measure the pivotal role of targeting industry efficiency to strategically scale down the coal-fired power plant fleet (unit-by-unit) to curb air pollutant emissions from electricity systems. Essential energy consumption data by industrial sector at national level and macro-economic parameters (for example, fossil fuel price and capital cost per generation technology) in China are assumed, based on the Current Policies Scenario (World Energy Outlook, 2018 edition) developed by the International Energy Agency (IEA, 2018c). The cost parameters are processed to 2017 constant prices in US\$ (2017 \$). Other key parameters, such as industrial production projections, power plants lifespan and thermal efficiency, are provided in the Supplementary Tables.

\subsection{Modeling the deployment of power plant fleet}

We begin by using the Platts World Electric Power Plants (WEPP) database (September 2017 release) (S\&P Global Platts, 2018) to compile unit-level information of the power generation fleet in operation in 2016, in China. The WEPP database provides information on unit size, primary feedstock, commissioning year, physical location, and generation type (e.g. subcritical, ultra-supercritical, offshore and onshore wind power). The in total 31 types of primary energy included in the WEPP database are coded into 11 categories (e.g. coal, gas, oil, nuclear, and wind) based on IEA's definition (IEA, $2018 b)$. We combine this with data of installed capacity per category from IEA (2018c) and proceed with an appropriate adjustment to the WEPP data. 
Next, we design a retirement pathway for existing power capacity by considering both lifespan (Supplementary Table 4.S2) and commissioning year of individual units, following the convention of eliminating older facilities first (Ackerman and Fisher, 2013). For around $20 \mathrm{GW}$ (accounting for 1.5\% of total installed capacity) or 618 units in the WEPP database, commissioning year information is lacking. We fill this data gap by cross-checking various reliable power plant databases (for example, the Global Power Plant Database (Byers et al., 2019), the Global Energy Monitor (GEM, 2019), the Worldwide Industrial Information (IndustryAbout, 2019), the Clean Development Mechanism Database (United Nations Framework Convention on Climate Change, 2019), and the Almanac of China's Water Power). For 181 small hydropower units (in total $0.85 \mathrm{GW}$ ), the same assumptions on vintage year are used as Davis, S. J. and Socolow (2014).

Finally, we simulate the evolution of installed capacity per category over the 2016-2040 period by coupling the decommissioned capacity from WEPP with the future capacity projections from IEA (2018c). We further divide the 11 power plant categories into 25 subcategories (for example, coal capacity is divided into 4 technologies and 4 unit size levels; Supplementary Table 4.S1). The future installed capacity per subcategory is determined by the share of the generation technology in new capacity and the units still in existence after the decommissioning of existing units at the end of their lifetime. The newly constructed capacity is estimated by tracking newly proposed projects (power plants recorded in WEPP as planned and under construction), China's policy planning, and the renewable energy outlook (ERI and CNREC, 2018).

In addition, we collect the exact latitudes and longitudes information for the total of 10,159 units in China by either coupling WEPP with databases (Byers et al., 2019; Davis et al., 2015; GEM, 2019; IndustryAbout, 2019; Ummel, 2012; United Nations Framework Convention on Climate Change, 2019) that include geographical coordinates or using the Google Maps to infer geocoordinates on the basis of available physical address information provided by WEPP (for example, company, street, county, city and province information). Google Earth has been used to assist the maps to accurately determine the coordinates of individual power plants through capturing 3D satellite imagery with high resolution identifying power plant characteristics (for example, power houses, dam, photovoltaic array, and wind turbine). This coordinated information can greatly support researchers to map the distribution of fossil fuel and renewable power plants.

\subsubsection{Electricity saving technologies}

We construct an exhaustive database of EE measures for specific production processes in industries to determine bottom-up potentials for electricity savings (see Appendix 4.A). This database covers hundreds of commercially available technologies with detailed technical characterization, that reflects the current knowledge of performance in terms 
of energy savings and costs. The detailed parameters of each efficiency technology (e.g. electricity saving, fuel saving (if possible), capital investment and lifetime) are obtained from published research articles, technical books and government official documents while taking into account their reliability. Based on new to be installed capacity and the retirement of some of the existing capacity, implementation rates up to 2040 are determined for each technology, assuming linear deployment (Dai et al., 2013; Yue et al., 2018). The implementation rates follow four criteria: (1) the diffusion rate of each technology should be up to $100 \%$ by 2040 , except for certain technologies with limited application conditions (e.g. oxygen depolarized cathodes can only be applied to caustic soda from ionic membrane rather than diaphragm device); (2) if several technologies with similar roles (conflicting technologies) are used in a production line, the total implementation rate of these technologies should not be beyond $100 \%$ (e.g. a fully graphitized cathode and the competing TiB2/C composite cathode); (3) advanced technologies are given preference so that the diffusion rate of conflicting technology can be lower than its initial value in 2016; (4) the implementation rate of cost-effective technologies with great energy performance is higher than that of similar technologies by 2040 .

To estimate the economics of individual technologies, we use the following Equation for the cost of conserved energy (Yue et al., 2018).

$C C E_{t, i}=\frac{C C_{t, i} * A F_{t, i}+\Delta O \& M_{t, i}-\left(E S_{t, i} * P_{e l e}+F S_{t, i} * P_{f u e l}\right)}{T E S_{t, i}}$

Where $t$ and $i$ represent the technology type and industrial sector, respectively; CCE represents the cost of conserved energy for an efficient technology in US\$/GJ; CC represents the capital cost of the technology in US\$; $A P$ represents the annuity factor; $\triangle O \& M$ is the annual change in operation and maintenance cost in US\$; ES is the annual electricity saving for a technology in $\mathrm{kWh} ; P_{\text {ele }}$ is the electricity price in US\$/kWh; PS represents the annual fuel saving (GJ) in Equation (4.1); $P_{\text {fuel }}$ represents the fuel price in US\$/GJ; and TRS indicates the annual total energy saving of a technology in GJ.

\subsubsection{Estimation of emissions levels of air pollutants and $\mathrm{CO}_{2}$}

The emission levels of air pollutants and $\mathrm{CO}_{2}$ for the coal-fired power generation fleet, are estimated by the following Equation:

$E_{\text {coal }, e, y}=\sum_{n}^{e x i}\left(E F_{n, e, y} * C_{n, y} * 8760 * C F_{y}\right)+\sum_{m}^{\text {new }}\left(E F_{m, e, y} * C_{m, y} * 8760 * C F_{y}\right)$

Where coal, $e$ and $y$ indicate the coal-fired power fleet, emission type (that is, $\mathrm{SO}_{2}$, $\mathrm{NO}_{\mathrm{x}}, \mathrm{PM}$ and $\mathrm{CO}_{2}$ ) and year, respectively; and $E$ represents the emissions levels in $\mathrm{kg}$. $n$ and $m$ indicate the existing and new-built coal power unit, respectively; $E F$ represents 
the emission factors of air pollutants in $\mathrm{kg} / \mathrm{MWh} C$ is the capacity size in MW; the number 8760 is the full-load hours per year; and $C F$ represents the capacity factor in \%.

The emission factors of $\mathrm{SO}_{2}, \mathrm{NO}_{\mathrm{x}}$ and $\mathrm{PM}$ at unit-level are estimated using Equation (4.3) on the basis of operation and emission parameters (for example, stack gas concentration, control devices and removal efficiency). In total data from 2,500 units is obtained from the China Electricity Council (unit size ranging from 100 to $1050 \mathrm{MW}$ ) and from Tang et al. (2019) (unit size $<100 \mathrm{MW}$ ), matching $-65 \%$ of the existing coal capacity in service as of 2016 in the WEPP database.

$E F_{g, y}=\frac{A E C_{g, y} * \beta_{y} * A_{y}}{G_{y}}$

Where $g$ represents the air pollutant species (i.e. $\mathrm{SO}_{2}, \mathrm{NO}_{\mathrm{x}}$ and $\mathrm{PM}$ ); $A E C$ represents the abated emission concentration from power station stacks in $\mathrm{g} / \mathrm{Nm}^{3} ; \beta$ is the theoretical flue gas rate (Chinese Research Academy of Environmental Sciences, 2010) in $\mathrm{Nm}^{3} /$ ton-coal; $A$ is the amount of coal consumption in ton; and $G$ is the amount of electricity generation in $\mathrm{kWh}$. The emission factors for specific generation technologies at unitlevel (Karplus et al., 2018) are deduced based on the individual units, and the results are cross-checked with practical experience of coal power plants from the Energy Technology Systems Analysis Program (IEA-ETSAP). Furthermore, we use these unitbased emission factors to fill the missing data in the remaining $35 \%$ capacity.

The $\mathrm{CO}_{2}$ emission factors at unit-level are estimated based on coal generation efficiency and carbon content as follows (Crijns-Graus and Worrell, 2011).

$E F_{\mathrm{CO}_{2}, y}=\frac{\gamma * \mathrm{OR} * \mathrm{H} * \mathrm{Mol}_{\mathrm{CO}_{2}} / \mathrm{Mol}_{c}}{\eta_{y}}$

Where $\gamma$ represents the carbon content of coal in $\mathrm{g} / \mathrm{MJ}$; $O R$ is the oxidation rate of coal in \%; $H$ is the lower calorific value for electricity in $\mathrm{MJ} / \mathrm{kWh} ; \mathrm{Mol}_{C O 2}$ is the molar mass of $\mathrm{CO}_{2}(44.01 \mathrm{~g} / \mathrm{mol}) ; \mathrm{Mol}_{c}$ is the molar mass of carbon $(12.01 \mathrm{~g} / \mathrm{mol})$; and $\eta$ is the thermal efficiency of power unit in \% (see Supplementary Tables).

\subsubsection{Investment budgets for achieving air pollutants reductions}

Investments in efficiency improvements for the industrial sectors (iron \& steel, cement, chemical, aluminum and paper) are calculated based on individual efficiency technologies. The cost parameters for the specific technologies are shown in the Appendix 4.A. Unlike the efficiency measures, flue gas control devices do not bring additional benefits, but consume electricity and resources, emit solid waste and thereby increase the operation cost. Based on the ECLIPSE V5a database that includes 3,500 measures for reducing air pollutants (IIASA, 2015), the GAINS-China module is employed to measure the unit costs per ton air pollutant removed by EoP measures from China's coal power plants. 
The GAINS-China module, incorporating the specific characteristics of China, is a regional part of GAINS (Greenhouse gas - Air pollution Interactions and Synergies) model (Kanada et al., 2013). The GAINS model is an interdisciplinary \& integrated analytical tool, developed by the IIASA (International Institute for Applied Systems Analysis). This model includes detailed information regarding energy activity by sector, macro-economic drivers, emission control strategies by primary air pollutant (e.g. $\mathrm{SO}_{2}$, $\mathrm{NO}_{\mathrm{x}}, \mathrm{PM}, \mathrm{NH}_{3}$ and VOCs) and cost parameters of deployed pollution control measure on various spatial scales (e.g. global and national levels) (IIASA, 2018). The GAINS model allows user to customize emission reduction scenarios using exogenous parameters (e.g. energy use by fuel type, electricity supply and future assumptions) (Purohit et al., 2019; Qin et al., 2017) to examine the cost portfolios of control measures to tackle local air quality and mitigating climate change. Due to the rich information and flexibility, the GAINS model has been widely used to evaluate emission reduction potentials (Liu et al., 2013), health impacts (Tian et al., 2018) and control system costs (Pu et al., 2011) for air pollutants and GHGs. Moreover, the IEA and the European Union adopted the GAINS model to project air pollutant emission levels across countries and guide the policy design on addressing environmental concerns (European Commission, 2019; IEA, 2018c).

The calculation process of the unit abatement costs in the GAINS model is presented by Equation (4.5). The detailed description of the way GAINS models emission reduction and control costs can be found in the studies (Cofala and Syri, 1998a, 1998b; Klimont et al., 2002).

$U A C_{k, f, g}=\left.\left(\frac{A C C_{k, f}+O M_{k, f}^{f i x}}{F C_{f}}+O M_{k, f}^{v a r}\right)\right|_{\left(u e f_{f, g} * \lambda_{k, f, g} * o_{k, f, g}\right)}$

Where $k$ and $f$ represent the emission control technology and fuel type, respectively; $U A C$ is the unit costs per ton of air pollutant removed in US\$/ton; ACC is the annualized capital cost in US\$; $O M^{f i x}$ is the annual fixed expenditures of maintenance and operation in US\$; OM ${ }^{v a r}$ is the variable operating costs in US\$/PJ; FC is the annual fuel consumption in PJ; uef is the unabated emission factor for an air pollutant in ton/PJ; $\lambda$ is the removal efficiency of control technology for an air pollutant in $\%$; and $o$ is the capacities controlled factor in $\%$.

\subsubsection{Emission scenarios design}

Four emission scenarios are designed in this study, which are described in the following paragraphs, to explore the interconnections of a high-efficiency industry and electricity supply system to realize the synergies of addressing air pollution cost-effectively. 
A business-as-usual (BAU) scenario is constructed as a reference case based on currently implemented policies and standards, providing a benchmark against which the impact of alternative scenarios can be measured. The installed capacity, electricity supply and socio-economic assumptions at country level in this scenario are consistent with the Current Policies Scenario developed by IEA. The energy efficiency (EE) scenario describes the transition to an efficient and sustainable industry (which represents the efficient use of electricity towards to world's best practical levels) by implementing highefficiency technologies. This scenario measures the electricity savings and associated high-value multiple benefits via plausibly implementing 175 specific technologies in five energy-intensive industries (iron \& steel, cement, chemical, aluminum and paper industrial sectors). This scenario examines the role of industrial electricity savings on the (earlier) retirement of the existing power fleet (in total 3,102 coal power units) and curbing new proposed power projects, as well as the avoided air pollutants from the displaced power plants.

The end-of-pipe (EoP) scenario is developed in the GAINS model to explore the cost portfolios of retrofitting coal plants with flue gas control systems on cutting the same emissions that are avoided in EE scenario. The EoP scenario builds on the BAU scenario and considers the deployment of flue gas control systems that derives from the ECLIPSE V5a database. This scenario provides an alternative for air pollutant reductions to identify the most cost-effective scenario by comparing the costs of EoP controls to electricity savings (EE scenario). Finally, the joint energy efficiency and endof-pipe $(\mathrm{EE}+\mathrm{EoP})$ scenario includes both promoting efficient technologies in industry and installing extra EoP control systems in coal power plants, targeting to understand the combined impacts and costs on air pollutants reductions from power plants. This scenario is optional and uses the EoP installed as a starting point, but incorporates the same assumptions for electricity savings in China's industries as in the EE scenario (so the costs of the joint scenario are assumed to be the sum of the costs spending by EoP and EE scenarios).

\subsection{Results}

\subsection{Electricity savings in industry}

We estimate potential reductions in electricity demand (compared to a BAU scenario) of numerous commercially available electricity-saving technologies for five key electricityintensive industries during the period of 2016-2040. Figure 4.1 shows the results for the specific savings per industrial subsectors by year. 


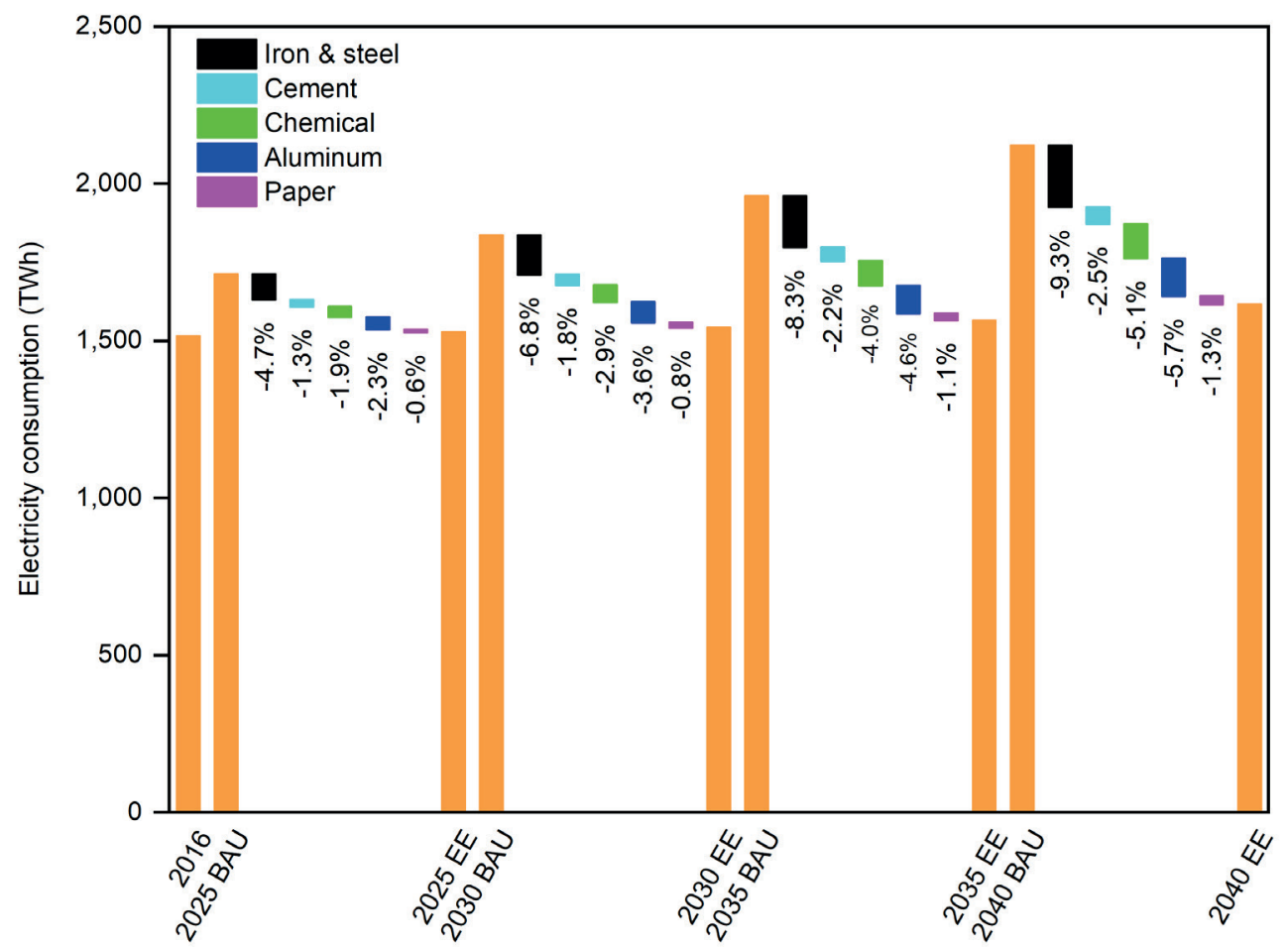

Figure 4.1. Total electricity consumption levels and electricity savings for key industries with EE improvements for the 2016-2040 period. The orange bars indicate the estimated annual electricity use under BAU and EE scenarios. The floated bars represent the electricity savings of the studied industrial sectors.

Total electricity demand for the included sectors is driven by increasing requirements of raw materials (for example, nitrogenous fertilizer, aluminum, and polyvinyl chloride) for downstream sectors (such as agriculture, construction and packaging sectors). Without EE improvements a substantial growth of $40 \%$ is observed in the period 2016 to 2040 (see Figure 4.1). In contrast, aggressive promotion of EE measures keeps the electricity use growth negligible and markedly reduces electricity demand compared to BAU levels by $185 \mathrm{TWh}$ in 2025 and $506 \mathrm{TWh}$ in 2040 (equal to $24 \%$ of electricity use in the BAU scenario). This indicates that significant room remains to save electricity in China's industry, in addition to savings already realized since 2000 (IEA, 2018a). The reason for these potentials might be that efficient technologies implemented to date are primarily aimed at reducing direct fossil fuel use, but ignored electricity so far.

From the industrial subsectors, the iron \& steel industry contributes to the largest share of the reduction (197 TWh) in 2040, followed by the aluminum (121 TWh), the chemicals (108 TWh), cement (53 TWh), and lastly the paper industry, which 
provides the smallest contribution (27 TWh). These correspond to great improvements of $47 \%, 13 \%, 19 \%, 38 \%$ and $27 \%$ in electric efficiency, respectively, compared to the BAU scenario. Progress on sectoral EE improvements drives the electricity use per unit production in China towards the world best practice level (Worrell et al., 2007). For instance, the electricity use per ton crude steel in the EE scenario, following an average annual decline of $2.6 \%$, effectively decreases electricity use to $344 \mathrm{kWh} / \mathrm{t}$ in 2040 , while the best level in the world (Worrell et al., 2007) is $227 \mathrm{kWh} / \mathrm{t}$. An important finding is that cost-effective opportunities represent more than $98 \%$ of the identified potentials in iron $\&$ steel, $87 \%$ in cement, $85 \%$ in chemicals, $96 \%$ in aluminum and $84 \%$ in paper (i.e. the annualized costs of these measures are lower than or equal to the annual benefits of the realized electricity savings; see Figure 4.2). This clearly suggests that, economically, investing in EE improvement, with its high share of cost-effective technologies, would be preferable to increasing electricity supply and expanding power generation and transport infrastructure with high investment costs to meet the surging demand.

a

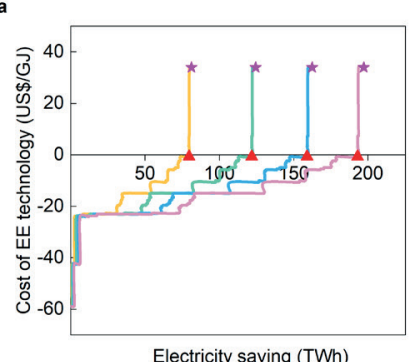

d

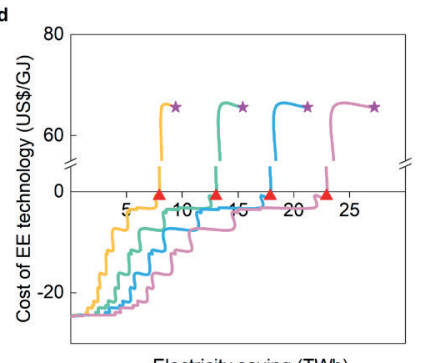

b
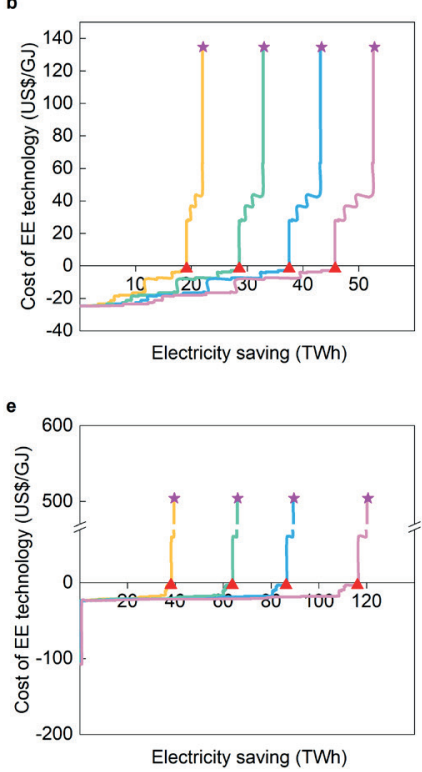

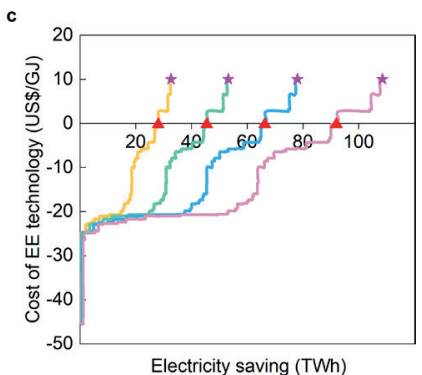

Electricity saving (TWh)

Figure 4.2. Cost of EE technology implemented in the energy-intensive industries and specific electricity savings at technology level. Panels a-e represent the iron \& steel, cement, chemicals, paper and aluminum sector, respectively. The bright colored curves represent the annual electricity savings cumulated by individual technologies. 
We decompose the annual reductions of electricity demand by production process for each sector, and critically compare the contribution of individual processes to highlight specific opportunities. As shown in Supplementary Figure 4.S2, the highest reduction potential in the iron $\&$ steel industry is found in the process of casting, rolling and finishing (representing $52 \%$ of the annual reductions from the steel sector). An important measure is the replacement of traditional casting in service for finishing mills with thin slab casting (see Supplementary Figure 4.S2). Similarly, a substantial reduction of 106 TWh in 2040 (greater than UK's total industrial electricity use in 2016) is found in the process of aluminum electrolysis, which is close to the potential savings in the chemical industry. Retrofitting or replacing outdated cell technology (for example, with lowtemperature and low-voltage cells) is the key to unleash the electricity saving potentials. Considering the process characteristics, the results reveal a rapid and deep improvement option to access significant reductions in the short run through supporting efforts to boost $\mathrm{EE}$ in the key areas within a sector, while a large part of the investments is highly cost effective (see Appendix 4.B).

\subsubsection{High-value benefits of industrial EE in the electricity supply sector}

Removing of coal-fired units plays a pivotal role in the deep reduction of air pollutant emissions (Zhai, 2019), largely because the emission intensities for generation units fueled by coal are significantly higher than those by natural gas (Tang et al., 2019; Tong et al., 2018; Zhai, 2019). Therefore, we prioritize that the electricity saved by industries is taken from the coal generation fleet. We do this by identifying the less efficient and most polluting power stations (see Table 4.1; Supplementary Tables 4.S1 and 4.S4). 


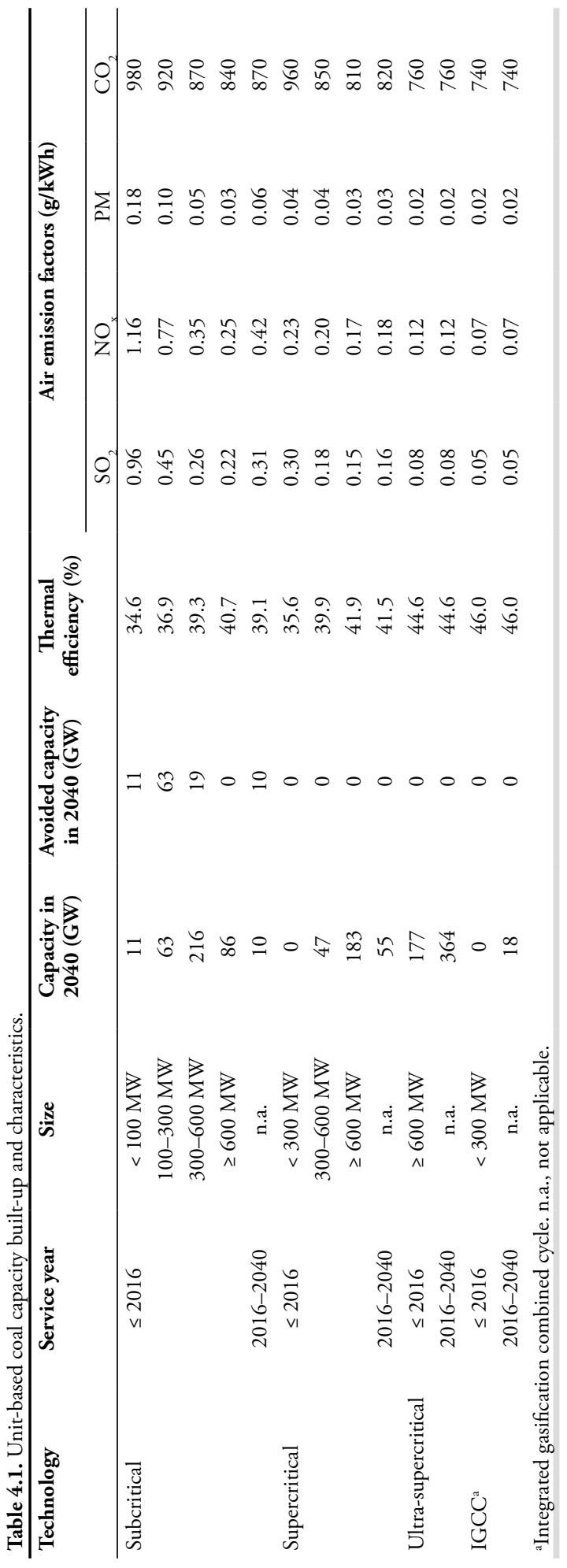


In the BAU scenario, coal-fired power plants continue to dominate the fleet in 2040 (accounting for $38 \%$ and $51 \%$ of the total installed capacity and electricity generation, respectively), even though 911 coal units (in total $162 \mathrm{GW}$ ) will be decommissioned after an average lifespan of 40 years. The capacity of coal-fired power plants that came online before 2016 is still $784 \mathrm{GW}$ in 2040, and the capacity of newly constructed coal power plants is $447 \mathrm{GW}$. Subcritical units, which operate under comparatively low pressures and temperatures, have a lower energy efficiency than supercritical units. This is especially the case for small units below $100 \mathrm{MW}$. Furthermore, these have typically less air pollution controls implemented and combined with the lower efficiencies have significantly higher specific air pollutant emissions (Tang et al., 2019; Tong et al., 2018). We find that subcritical power plants are still an important part of the coal capacity in $2040(31 \%)$, of which small units account for 3\%. These small units tend to be even less efficient and heavily polluting, and it is often unprofitable for them to comply with environmental regulations. Therefore, these small units are interesting candidates for early retirement, thereby maximizing emission reductions. We find that improving EE can deactivate a total capacity of $103 \mathrm{GW}$ coal, which enables the ambitious national plan aimed at a sustainable power fleet to go on wheels (i.e. annually cutting $\sim 2$ GW less efficient coal capacity) (NDRC et al., 2014).

This drives all the small subcritical units $(<100 \mathrm{MW}$ ), amounting to $11 \mathrm{GW}$ (which far exceeds the total capacity $(5 \mathrm{GW})$ of super-polluting units in China identified by Tong et al. (2018)), into early retirement (lifetime < average operational lifetime of 40 years). Besides the small units, we consider subcritical coal power units in the size range of 100-300 MW (63 GW in 2040) to be a priority in displacement, because of the poor environmental performance compared to the larger plants (unit $\geq 600 \mathrm{MW}$; see Table 4.1 and Figure 4.3). These two categories (subcritical units below $100 \mathrm{MW}$ and between $100-300 \mathrm{MW}$ ) are typically the most polluting units (contributing 18.8\%, 22.0\% and $20.0 \%$ of $\mathrm{SO}_{2}, \mathrm{NO}_{x}$ and $\mathrm{PM}$ emissions), but disproportionately account for a small share of capacity (representing $5.8 \%$ of total coal power capacity in 2040). Finally, the electricity savings in the EE scenario can curb all new to be constructed subcritical power plants $(10 \mathrm{GW})$, and allow early retiring part of larger size (range of 300-600 MW) subcritical units (19 GW).

By eliminating these four categories of coal-fired power plants, we estimate that in total 230, 353 and $46 \mathrm{kt}$ of $\mathrm{SO}_{2}, \mathrm{NO}_{\mathrm{x}}$ and $\mathrm{PM}$ emissions can be abated by 2040, respectively (see Figure 4.3). This contributes to $22.8 \%, 26.0 \%$ and $23.8 \%$ emission reductions relative to BAU levels. When comparing 2040 to 2016, the contributions effectively diminish the emission levels by $22.7 \%, 26.9 \%$ and $22.6 \%$ for $\mathrm{SO}_{2}, \mathrm{NO}_{\mathrm{x}}$ and $\mathrm{PM}$, respectively, in the EE scenario. The reductions in air pollutants can conform with the tough emissions standards (ultra-low emissions requirements) that aim for cleaning the air in China (MEE et al., 2015; Tang et al., 2019). This clearly demonstrates that as more efficient technologies are promoted for electricity consumers, substantial improvements 
in air quality can be made. Critical here is that shutting down the most polluting units is prioritized.

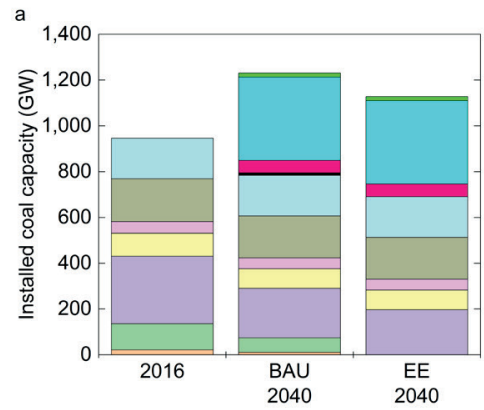

b
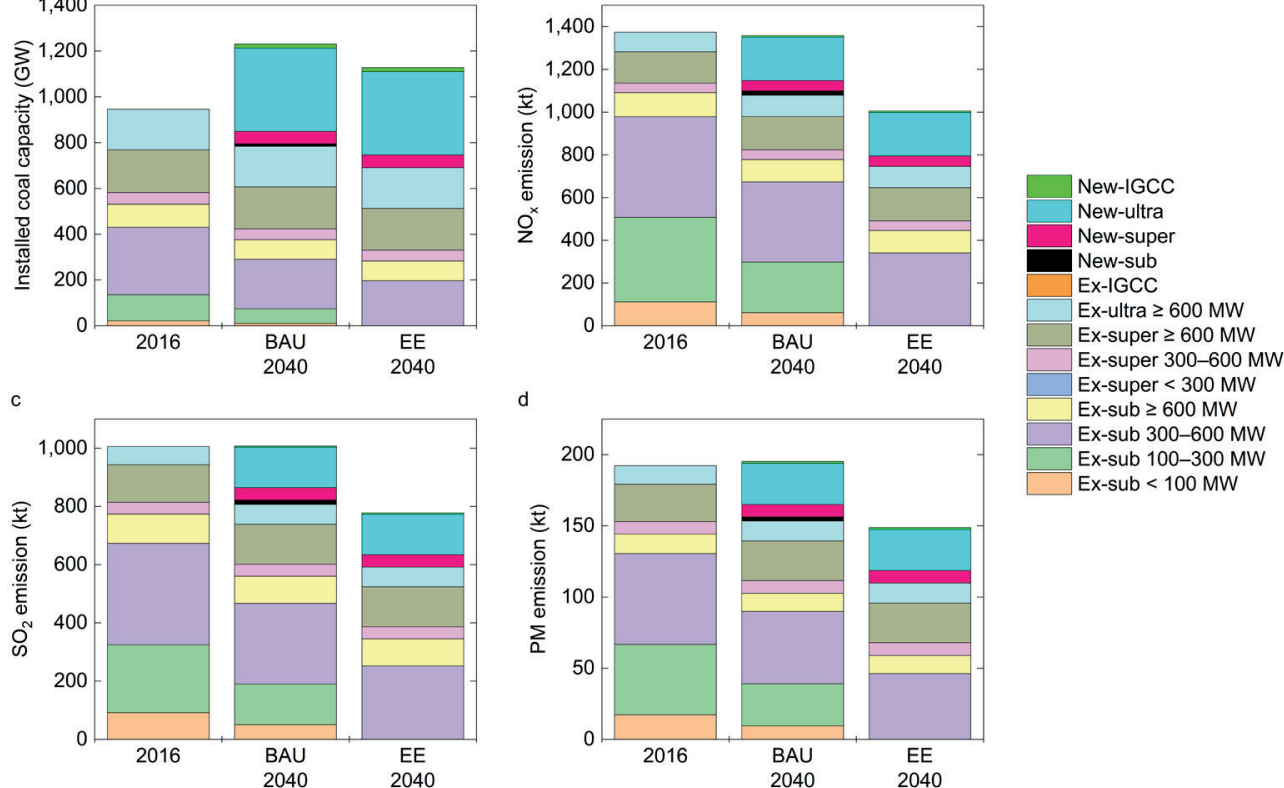

Figure 4.3. Evolution of coal-fired power fleet and emission levels of air pollutants between 2016 and 2040 under different scenarios. Panel a shows the installed capacity by coal generation technology at unit-level. Panels b-d represent the unit-based emission levels of $\mathrm{SO}_{2}, \mathrm{NO}_{\mathrm{x}}$ and PM by generation technology, respectively. In all panels, we use the light colours to mark existing coal units (ex-sub/super/ultra/IGCC) and bright colours to map newly proposed units (newsub/super/ultra/IGCC). Abbreviation: ex, existing; sub, subcritical; super, supercritical; and ultra, ultra-supercritical.

\subsubsection{Comparing the portfolio cost of EE and EoP}

Here, we compare the costs of various portfolios to tackle air pollutants by industrial EE improvements and EoP controls for coal power. Figure 4.4 plots the net mitigation costs of the different scenarios and the avoided investments in power generation capacity in the EE scenario. Although industrial efficient measures require a much higher initial investment (total US\$ 134 billion), the economic benefits, due to the cumulative energy savings and avoided new coal-fired power plants, significantly offsets the capital costs with US\$ 717 and US\$ 6 billion by 2040, respectively (see Appendix 4.B). These benefits are equivalent to $34 \%$ of the capital expenditures on all new proposed power projects by 2040 (see Figure 4.4). Our results indicate that almost all investments in EE measures will have paid back before 2040. Conversely, when the same level of emission reduction is achieved by installing EoP controls in the coal power fleet, it increases capital investments by US $\$ 3.8$ billion by 2040 in comparison to the BAU. Moreover, 
running the controls in the coal plants is more expensive (due to additional electricity consumption, sorbents, catalyst, and waste disposal), thus increasing additional economic burdens by US $\$ 4.0$ billion by 2040 . The economic results indicate that additional investments in installing flue gas controls, particularly for less efficient coal units, may generally be unnecessary and less cost-effective in comparison to demandside efficiency improvement. Through a combined portfolio analysis, we further note that harmonizing the gains of EE improvements and the deployment of flue gas controls into a unified strategy would potentially make deep cost-effective emissions reductions (Supplementary Discussion).
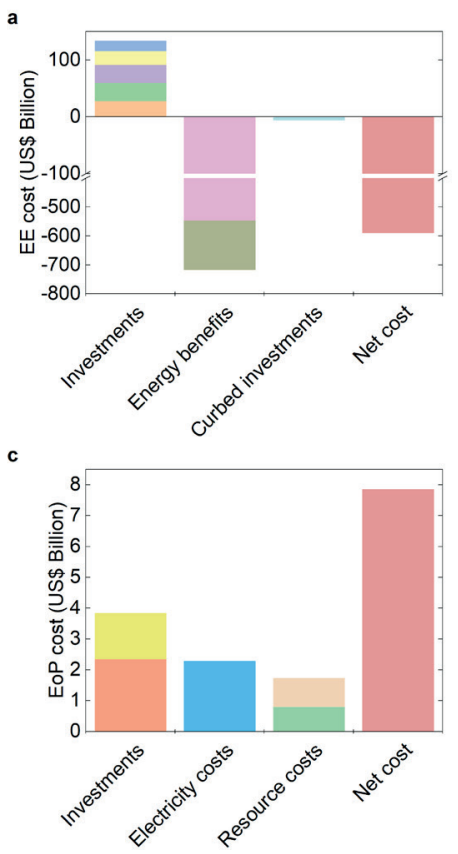

b

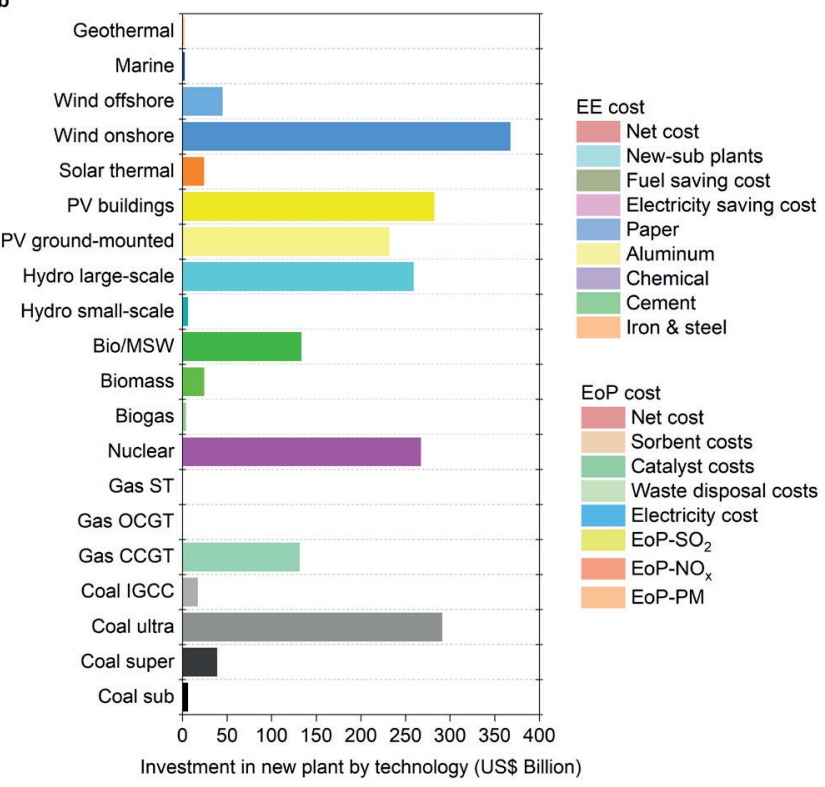

Figure 4.4. Cost portfolios for tackling air pollutants from electricity generation by EE improvements and by EoP control devices, and investments in newly proposed power plants in the BAU scenario up to 2040. a, Investment and benefits of efficiency measures. b, Capital budgets of newly constructed power plants by generation technology. c, Investment and operation costs of EoP control devices. Abbreviation: CCGT, combined cycle gas turbine; OCGT, open cycle gas turbine; ST, steam turbine; MSW, municipal solid waste; and PV, photovoltaic. 


\subsection{Discussion}

Our results show the potential for electricity savings in included industrial sectors and the impact of eliminating through these savings the most polluting power plants in the power generation fleet, including a financial assessment. In the analysis, we have included five energy-intensive industries, which together account for $46 \%$ of electricity use in China's industry. However, we do not have such detailed technology profiles for the other industries that consume the remaining $54 \%$ due to the limited data availability and diverse industry structures (for example, the manufacturing of textile consists of a large number of products per process and varying by plant (Hasanbeigi, 2010)). If we assume that the share of electricity savings in total consumption for the other industries is similar to the five studied industries (24\% in 2040), this would lead to $600 \mathrm{TWh}$ additional electricity savings in 2040 . The total reduced electricity demand would then be able to avoid $226 \mathrm{GW}(+123 \mathrm{GW})$ coal power capacity in China by 2040 . This means that more coal-fired units characterized by high air pollutant emissions can be phased out at an accelerated pace by 2040 . The reduced capacity could consist of early retirements of nearly $60 \%(+33 \%)$ of the subcritical generating capacity in operation in 2040, that was built before 2016. This additional coal phase-out would bring an additional $16 \%, 16 \%$ and $15 \%$ of $\mathrm{SO}_{2}, \mathrm{NO}_{\mathrm{x}}$ and PM reductions in 2040 , respectively, compared to the BAU scenario. These results further highlight the importance of targeting efficiency improvements in demand-side as a strategy to address air quality concerns. Meanwhile, specific information and research on the other industries can provide a more comprehensive evaluation of the co-benefits based on detailed technological data.

In addition to reducing air pollutants, the eliminated coal units can effectively mitigate climate change through reducing GHG emissions (Shindell and Smith, 2019; Zhai, 2019). Chinass $\mathrm{CO}_{2}$ emissions from power generation are expected to increase substantially by 2040, as new projects with large-size (for example, $1000 \mathrm{MW}$ ultra-supercritical units) come online. The EE scenario can deliver a total $\mathrm{CO}_{2}$ emissions reduction of 275 and $462 \mathrm{Mt}$ by 2030 and 2040, respectively, achieving 6.3\% and $9.5 \%$ reductions relative to BAU emission levels, caused by coal-burning electricity. The emissions reduction shares are smaller than the reduction of air pollutants (for example, $26.0 \%$ reductions of $\mathrm{NO}_{\mathrm{x}}$ in 2040), because the eliminated power plants have a low level of implementation of pollution controls, in comparison to the overall fleet. For $\mathrm{CO}_{2}$ emissions though the share of reduction follows the reduction in coal-fired power generation in an approximate linear correlation. In this study, the implementation of carbon capture and storage (CCS) in coal-fired power plants is not considered. Coal plants retrofitted with CCS suffer about 20\% parasitic loss of efficiency (ERI and CNREC, 2018; Supekar and Skerlos, 2015), potentially indirectly increasing the emission intensity of air pollutants. Moreover, the retrofitting costs of CCS systems in China's existing coal fleet are likely to be expensive for power managers without any cost incentives (Fan et al., 2018), hindering the promotion of CCS in mid-term (ERI and CNREC, 2018). Instead of 
installing CCS, China is aggressively promoting the deployment of renewable energy sources with policy incentives, aiming to increase installed renewable power capacity to $675 \mathrm{GW}$ by 2020, to defend the environmental degradation (climate change, air pollution and ecosystem damage). However, integrating high levels of intermittent renewable power will require increased demand-side flexibility to guarantee electricity grid stability, suggesting that the industrial sector, which is responsible for $-63 \%$ of China's electricity use (IEA, 2018b), has a critical role in enabling the expansion of the renewables fleet.

A total of nearly $450 \mathrm{GW}$ of new coal capacity is expected to come online by 2040 to meet increased electricity requirements due to the fast penetration of electrification. The deployed coal-fired power plants can operate for several decades ( -40 years in China), thereby have the potential to release emissions into the air throughout the century, with implications for local air quality. In this study, we present a scenario that includes early retirement. However, we can also assume that only new coal projects are avoided by the electricity savings (a total of 63 and 103 GW by 2030 and 2040, respectively). The estimated air pollution reductions would in that case amount to 72,90 and $15 \mathrm{kt}$ of $\mathrm{SO}_{2}, \mathrm{NO}_{\mathrm{x}}$ and PM in 2040, respectively, reducing emissions by $7.2 \%, 6.7 \%$ and $7.5 \%$ compared to BAU levels. We find that the contributions of curbing new coal projects to reduce air pollutants are substantially less than prioritizing existing small and poor performing coal retirements (see Table 4.2). This is particularly the case because high efficiency generating technologies with low emission intensities are widely adopted in the newly proposed coal projects, of which ultra-supercritical and IGCC technologies together account for $85 \%$ of total new coal capacity in 2040 (see Table 4.1).

Table 4.2. Comparison of air quality impacts for different coal displacement options in the EE scenario.

\begin{tabular}{lll}
\hline & $\begin{array}{l}\text { Initial option } \\
\text { (with early retirement) }\end{array}$ & $\begin{array}{l}\text { Alternative option } \\
\text { (without early retirement) }\end{array}$ \\
\hline Avoided capacity (GW) & 93 & 0 \\
Early retirement & 10 & 10 \\
New-built subcritical & 0 & 55 \\
New-built supercritical & 0 & 38 \\
New-built ultra-supercritical & & \\
Annually air pollutant reductions $(\mathbf{k t})$ & 230 & 72 \\
$\mathrm{SO}_{2}$ & 353 & 90 \\
$\mathrm{NO}_{\mathrm{x}}$ & 46 & 15 \\
$\mathrm{PM}$ & & \\
\hline
\end{tabular}




\subsection{Conclusions}

A sustainable industry and coal-free power generation are crucial to combat air pollution and climate change for the countries around the world, particularly for China, which is globally the largest manufacturer and depends heavily on coal-fired electricity supply. In this study, a technology-rich integrated framework is designed to capture the potentials of coal power capacity phaseout due to industrial electricity savings and quantify emission reductions at power plant unit-level in China. We also conducted a cost analysis of air pollutant reduction portfolios to identify a cost-effective air cleaning way.

We found that the electricity demand in China's industry is expected to increase by $40 \%$ from 1515 TWh from 2016 to $2022 \mathrm{TWh}$ in 2040. Energy efficiency technologies can effectively curb the ever-increasing electricity demand in China's industry during 2016 to 2040. We looked specifically at savings in energy-intensive industrial sectors, together covering $46 \%$ of total electricity use in industries. Of these the iron \& steel, aluminum and chemical sectors have the largest potential to improve electricity use efficiency, which together provides $84 \%$ of annual electricity savings in 2040 . The remaining $16 \%$ of electricity savings can be accessed in the cement and paper sectors. A decomposition analysis by the production process shows the largest potentials per process and sector, and can give guidance to policy-makers to determine priority sectors for the short-term. Considering the energy savings of energy efficiency measures, electricity conservation supply curves reveal that more than $90 \%$ of electricity savings can be achieved by costeffective opportunities.

The coal-fired power fleet continues to dominate China's electricity supply until 2040, which contributes to $51 \%$ of the total electricity generation in the BAU scenario. Moreover, the less-efficient coal-fired plants account for $31 \%$ of the total installed coal power capacity in 2040 . The reduced electricity load by industrial demand-side savings can significantly scale down China's coal power fleet, which can displace a total of 103 GW coal generation capacity. In this study, the high-polluting generation units are identified, i.e. subcritical unit size below $300 \mathrm{MW}$, to be offset as a priority. As a result, all the high-polluting units together with part of the larger size (range of 300-600 MW) subcritical units (total $93 \mathrm{GW}$ ) can be shut down early. Meanwhile, all newly proposed subcritical power plants, around $10 \mathrm{GW}$, can be canceled. The displaced coal power units bring a significant decrease of air pollutant emissions from the electricity generation sector. Compared to 2016, the emission levels of $\mathrm{SO}_{2}, \mathrm{NO}_{\mathrm{x}}$ and $\mathrm{PM}$ are reduced by 228, 369 and $43 \mathrm{kt}$ in 2040 under energy efficiency scenario, respectively. Compared to prioritizing the displacement of existing high-polluting units, canceling newly proposed coal power projects generates lower air pollutant reductions.

The costs of industrial efficiency improvements and retrofitting power plants with endof-pipe treatment measures to tackle air pollutants are also assessed. The result shows 
that the initial investments in energy efficiency technologies are much higher than those of end-of-pipe measures. However, installing the end-of-pipe measures will induce additional bills on electricity and resource consumption. In contrast, the energy benefits generated by the efficiency improvements can payback the initial investments.

Besides avoiding air pollutant emissions, the decommissioned coal power plants due to the reduced electricity load can bring $462 \mathrm{Mt} \mathrm{CO}_{2}$ emission reductions in 2040, which is equivalent to $9.5 \%$ of $\mathrm{CO}_{2}$ emissions in the BAU scenario. Expanding this study to include other industries at the technology level should be considered by future research for providing a comprehensive insight for the impacts of demand-side electricity savings on the evaluation of coal power systems and future air emission changes.

This study suggests that integrating industrial efficiency improvements to accelerate existing high-polluting coal retirements along with appropriately curbing new coal deployment (particularly, subcritical units) across a country can optimize parallel initiatives to deploy renewable energy, GHG emission reduction, and tackle air pollution and human health concerns. The newly proposed framework in this paper can be applied to different energy efficiency improvement strategies by demand-side sector and various spatial scales (e.g. global, national, and regional levels), particularly the high-polluting countries dominated by coal-intensive electricity (such as Mongolia, India, Poland and South Korea).

\section{CRediT authorship contribution statement}

Ernst Worrell, Wina Crijns-Graus and Hui Yue designed and performed the study. Shaohui Zhang contributed the original power plants data and the scenario construction in GAINS model. Hui Yue performed the model links between four modules (industrial demand, electricity supply, air emission and GAINS). Hui Yue, Ernst Worrell and Wina Crijns-Graus cross-checked the power plants data at unit-level and developed the energy efficiency technology dataset. Hui Yue, Ernst Worrell and Wina Crijns-Graus contributed to the scenario analysis and the writing of the initial manuscript.

\section{Declaration of Competing Interest}

The authors declare that they have no known competing financial interests or personal relationships that could have appeared to influence the work reported in this paper.

\section{Acknowledgements}

We acknowledge the funding support from the China Scholarship Council under Grant No. 201607040082 and are grateful to the National Natural Science Foundation (71904007). 
Appendix 4.A. Dataset of commercially available energy efficiency technologies

The compiled information for 175 energy efficiency technologies that implementing in iron \& steel, cement, chemicals, aluminum and paper sector is presented in Tables 4.A1-A5.

\section{Appendix 4.B. Electricity saving potentials and associated capital} expenditure for each industrial process

The annual electricity savings and required investments for individual production processes between 2030 and 2040 are shown in Table 4.B1. 
Realizing multiple benefits for power sector by saving industrial electricity use

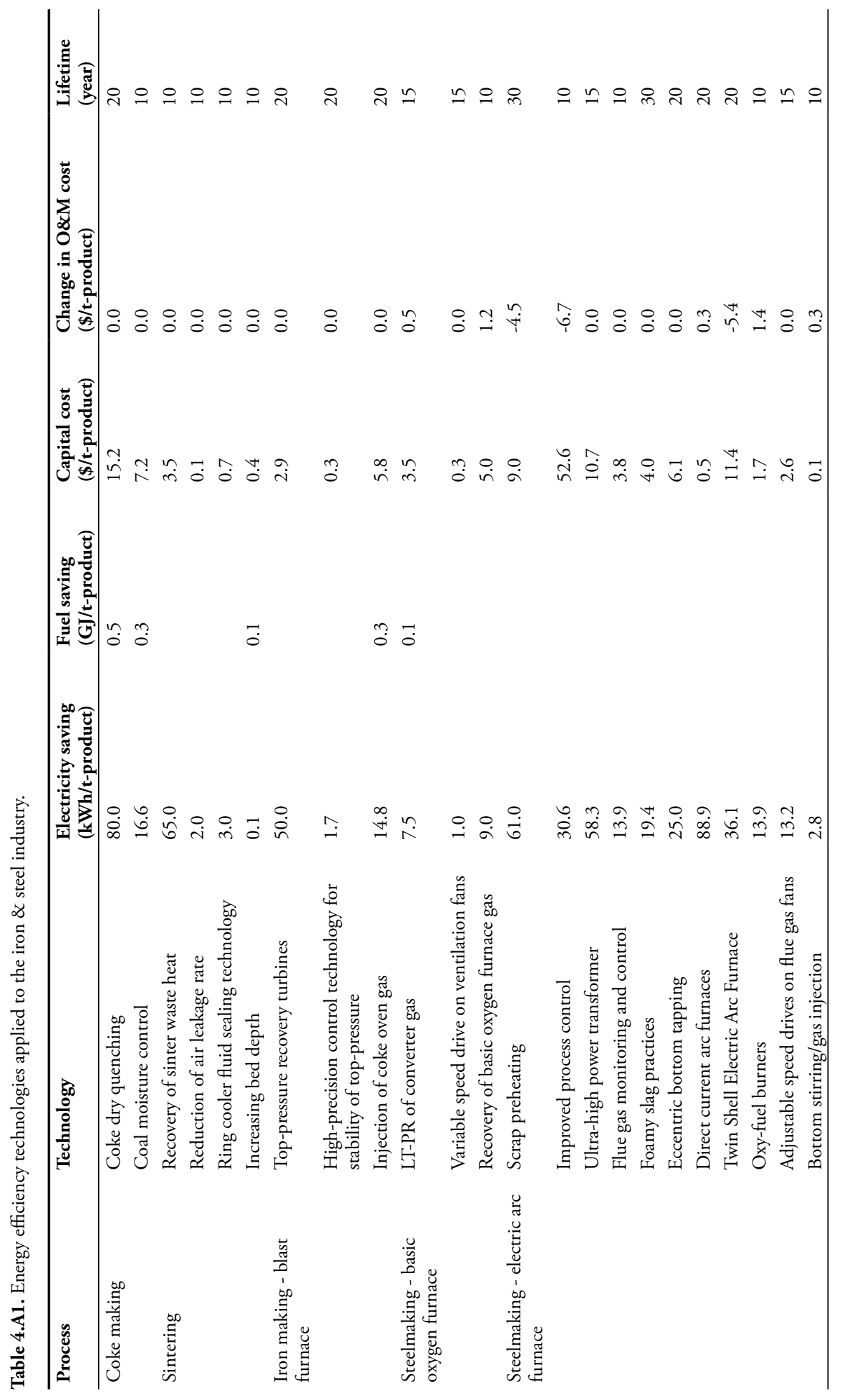




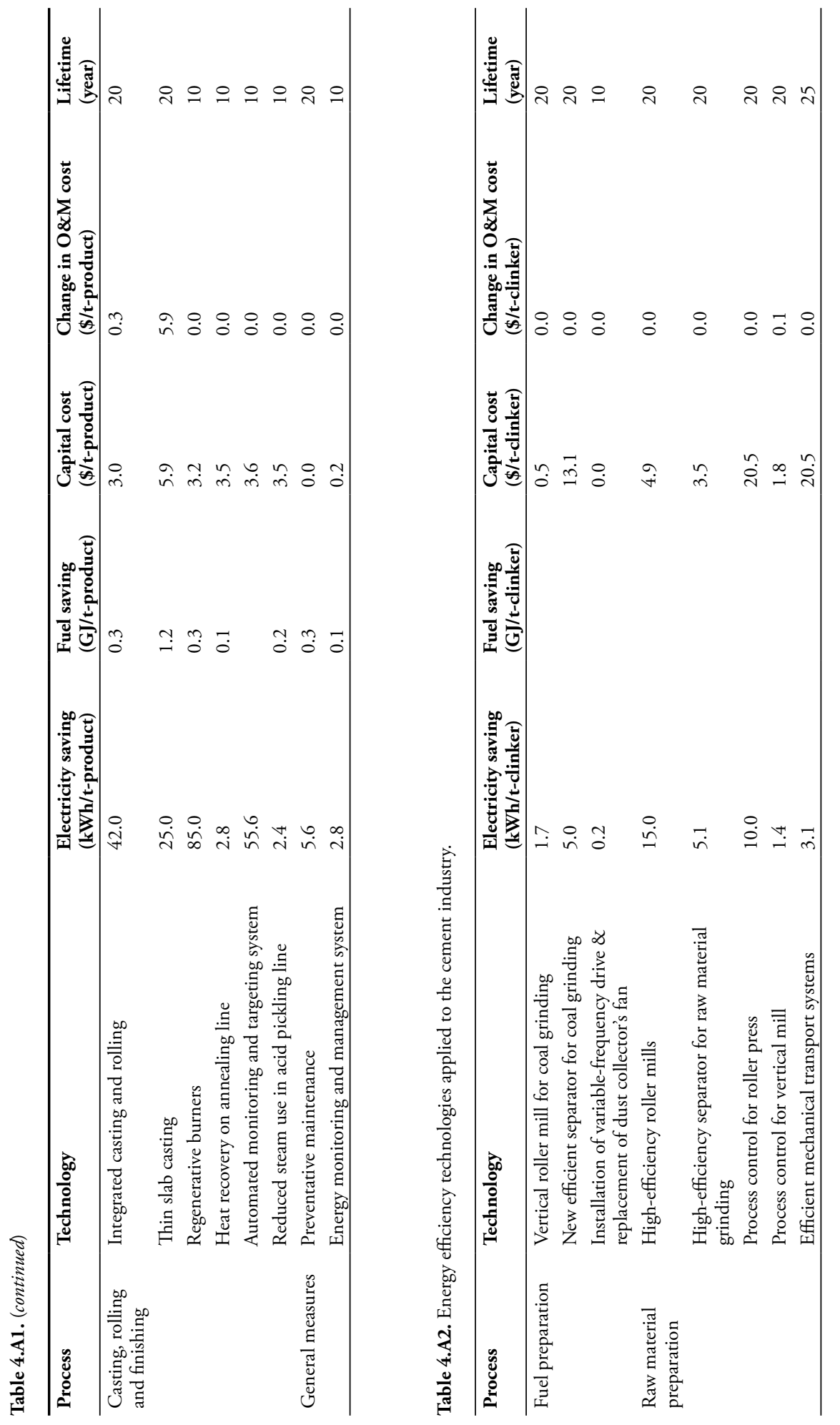


Realizing multiple benefits for power sector by saving industrial electricity use

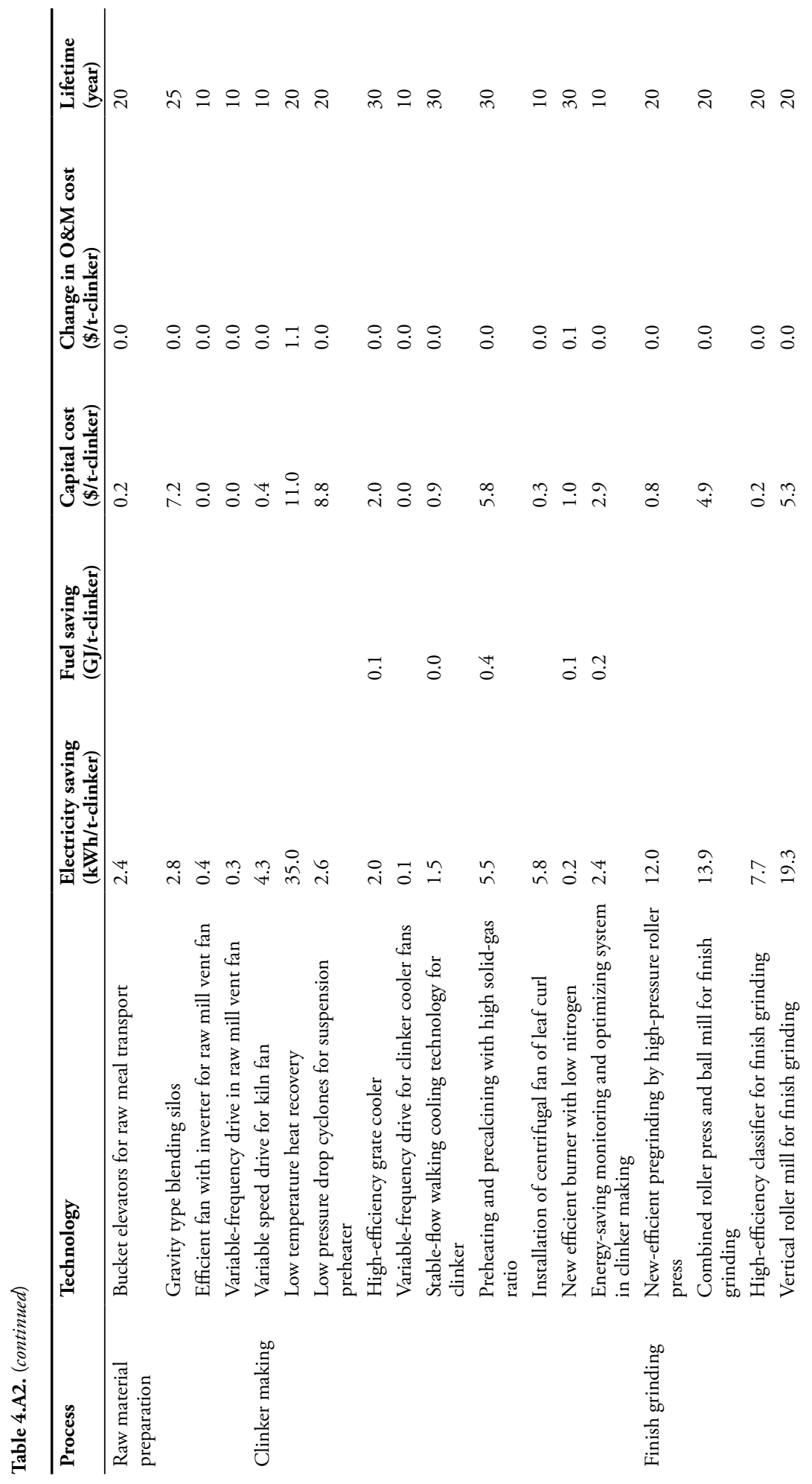




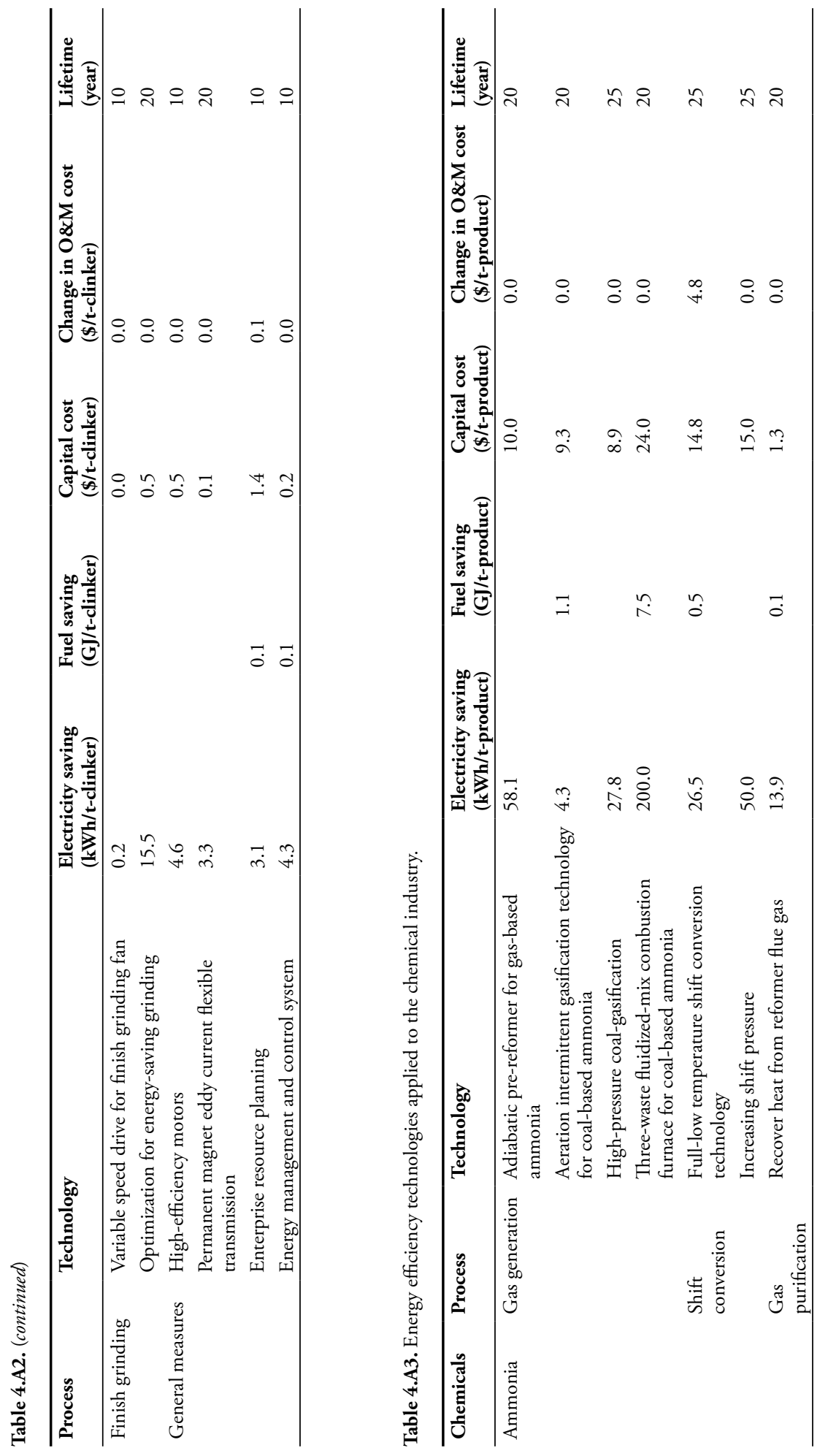


Realizing multiple benefits for power sector by saving industrial electricity use

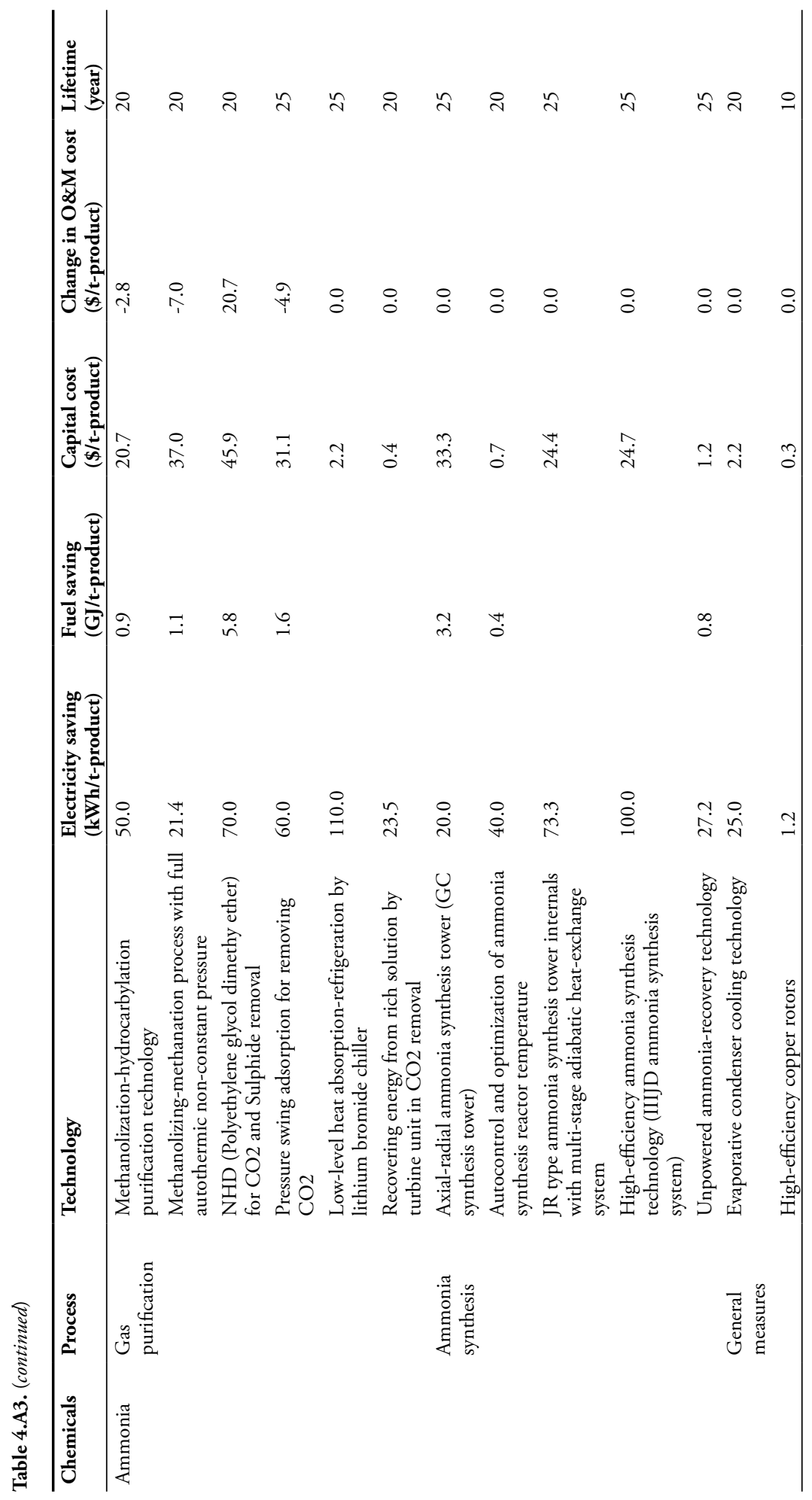




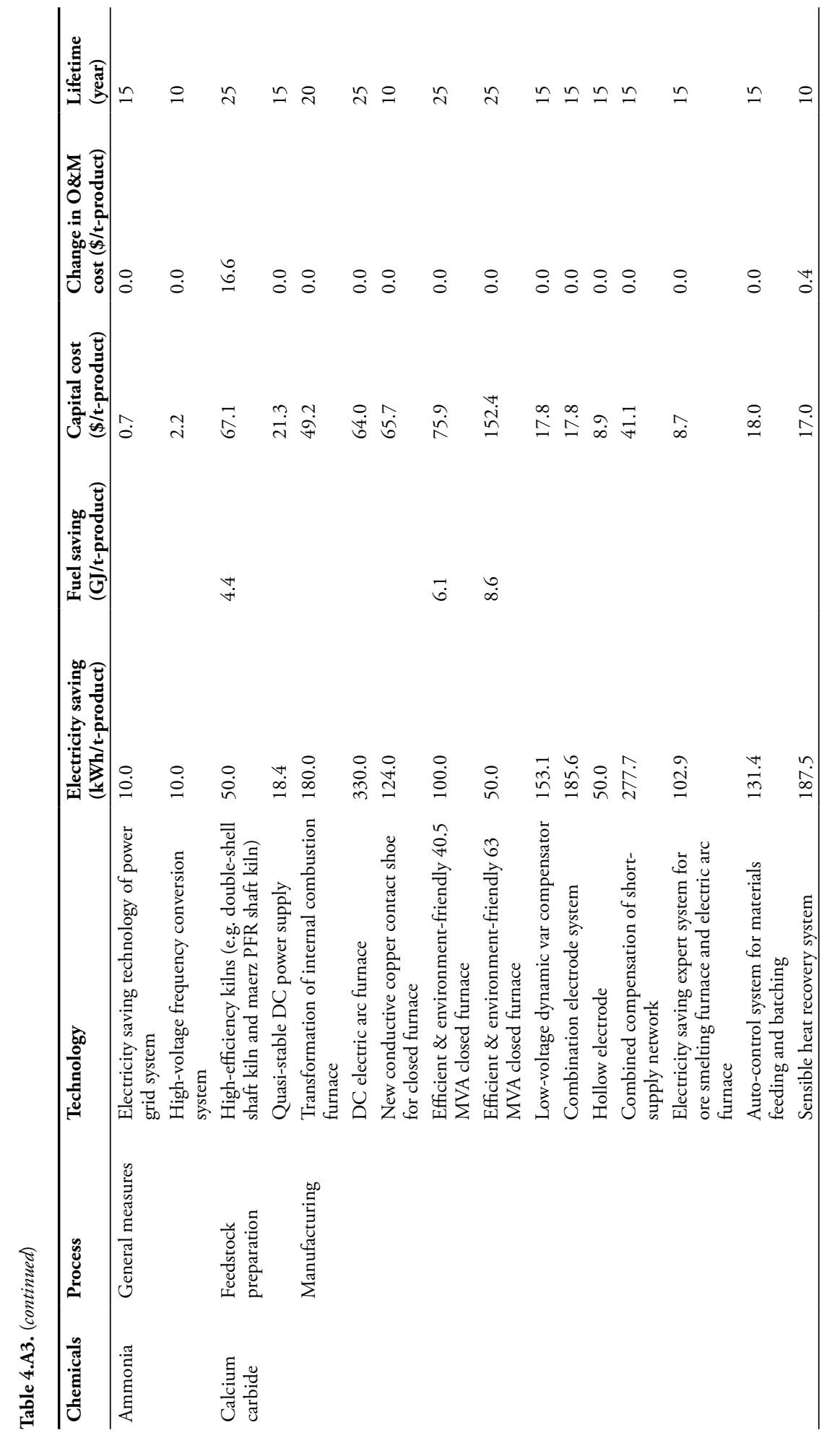


Realizing multiple benefits for power sector by saving industrial electricity use

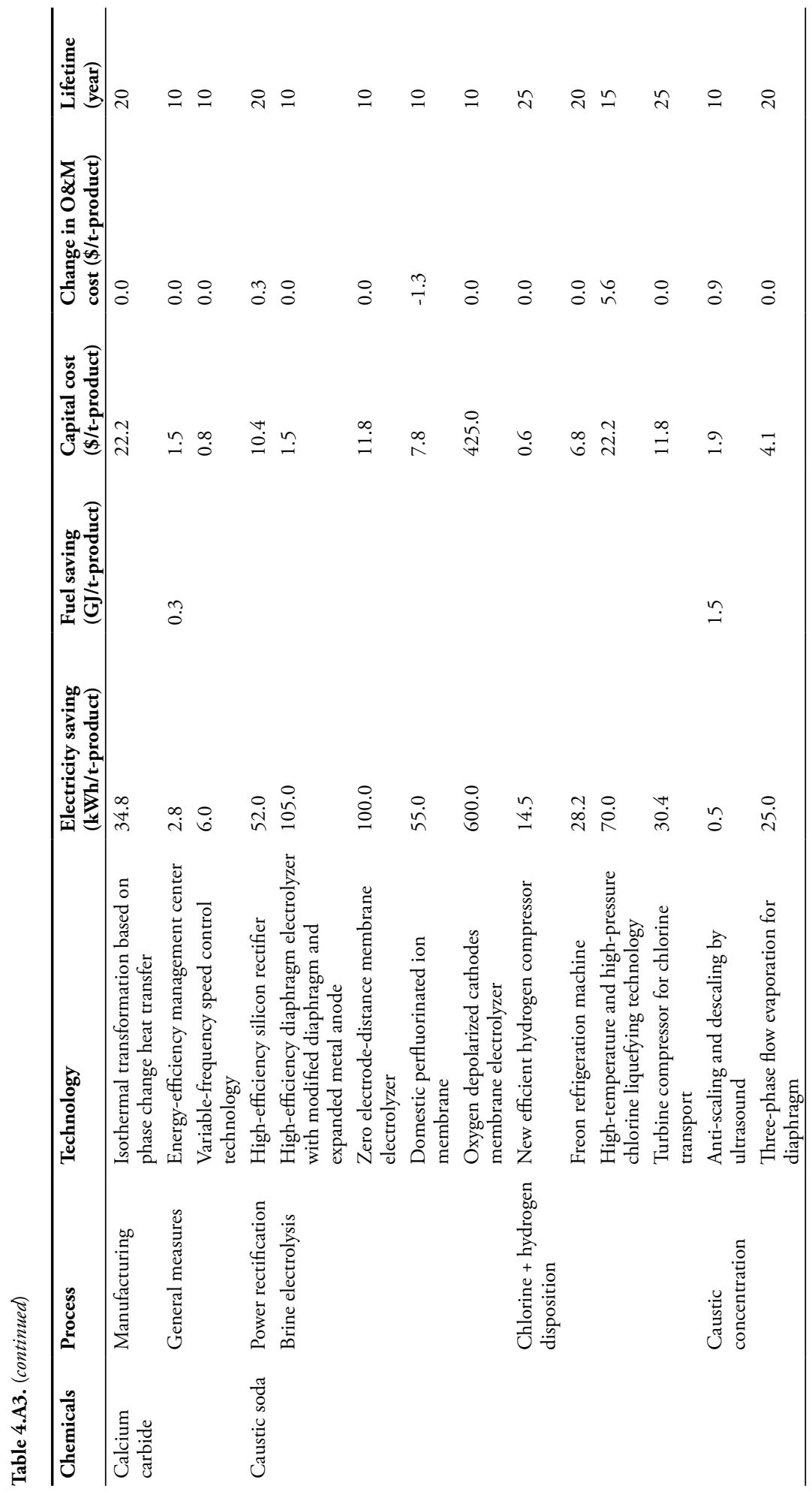




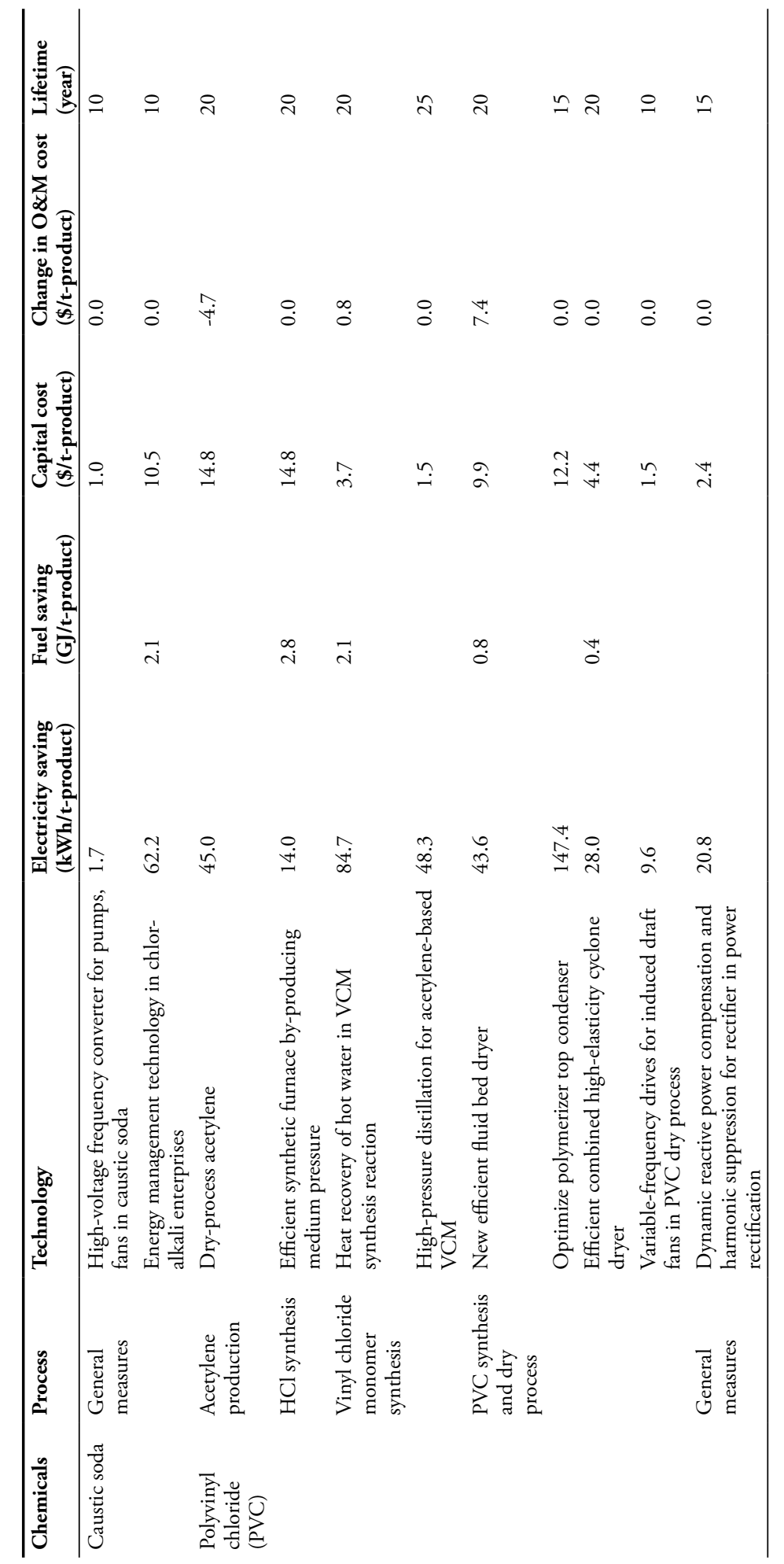


Realizing multiple benefits for power sector by saving industrial electricity use

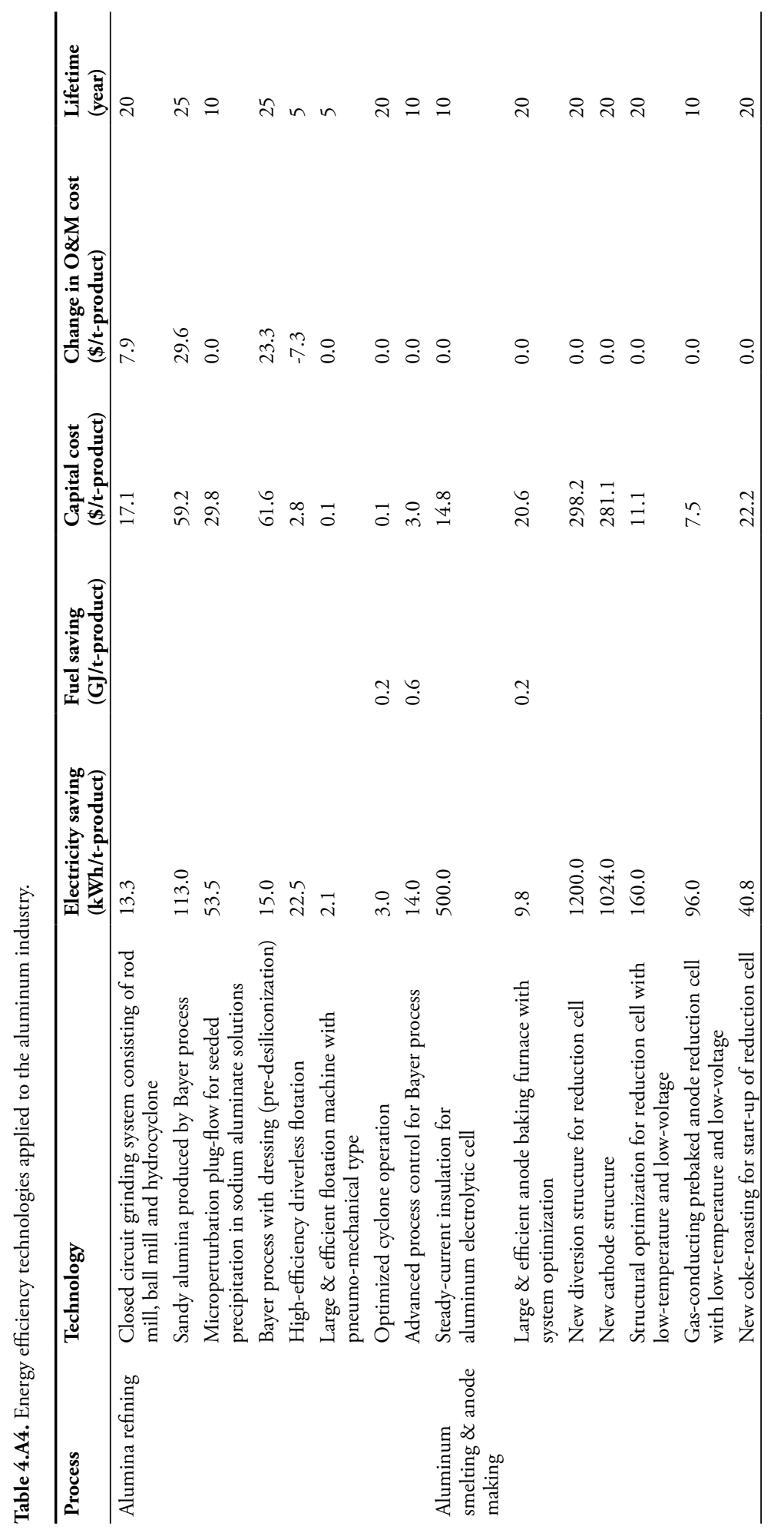




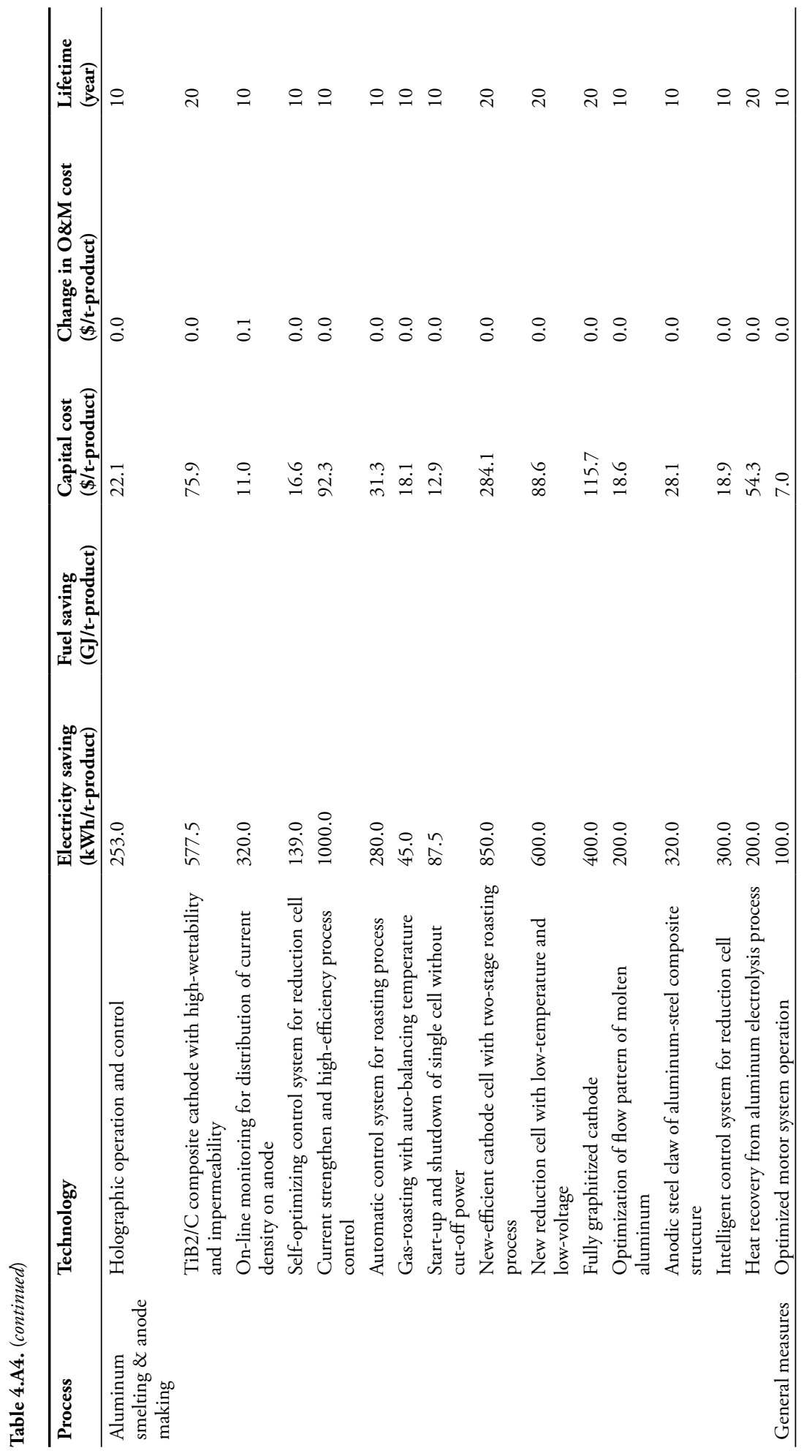


Realizing multiple benefits for power sector by saving industrial electricity use

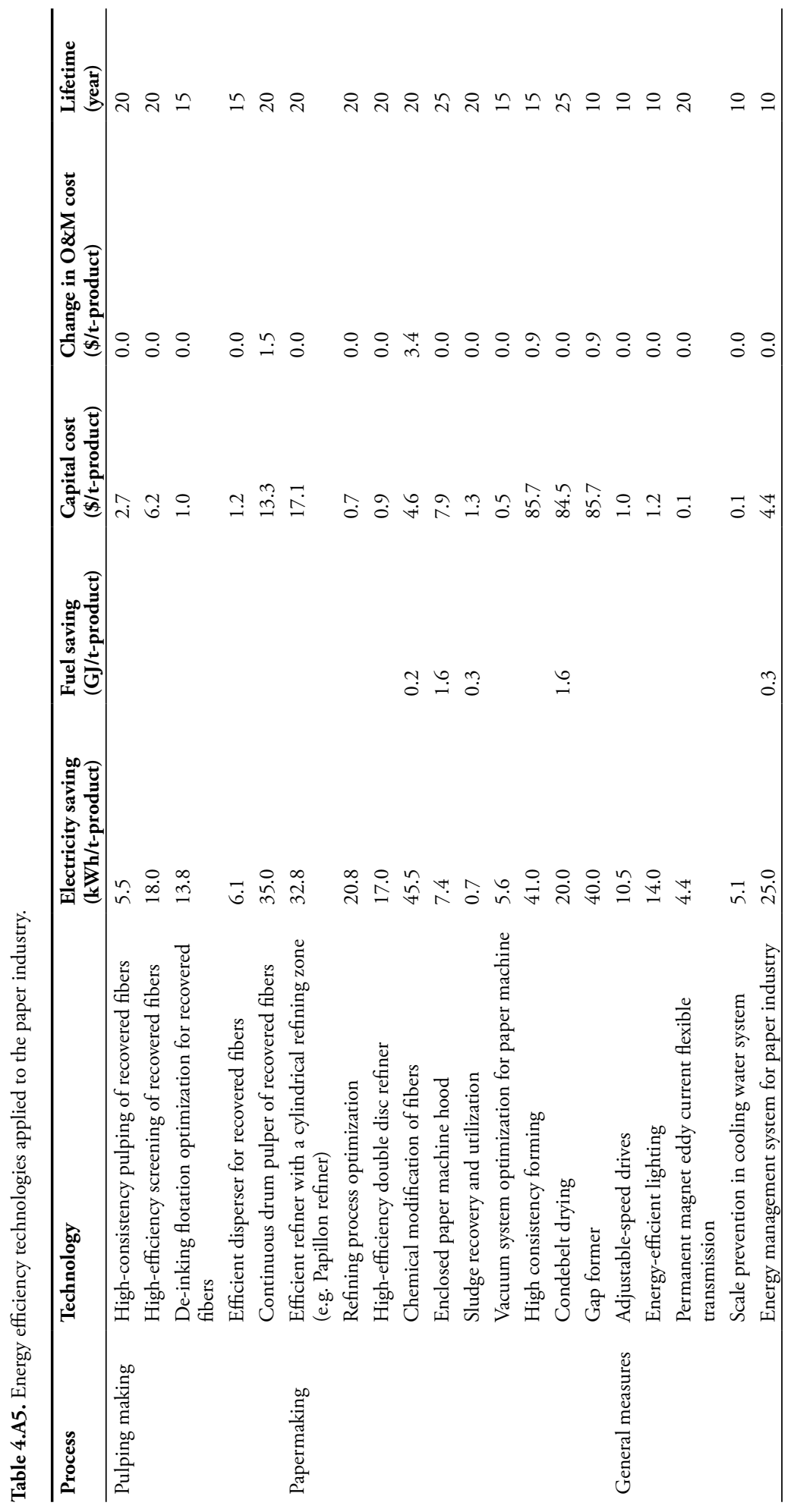




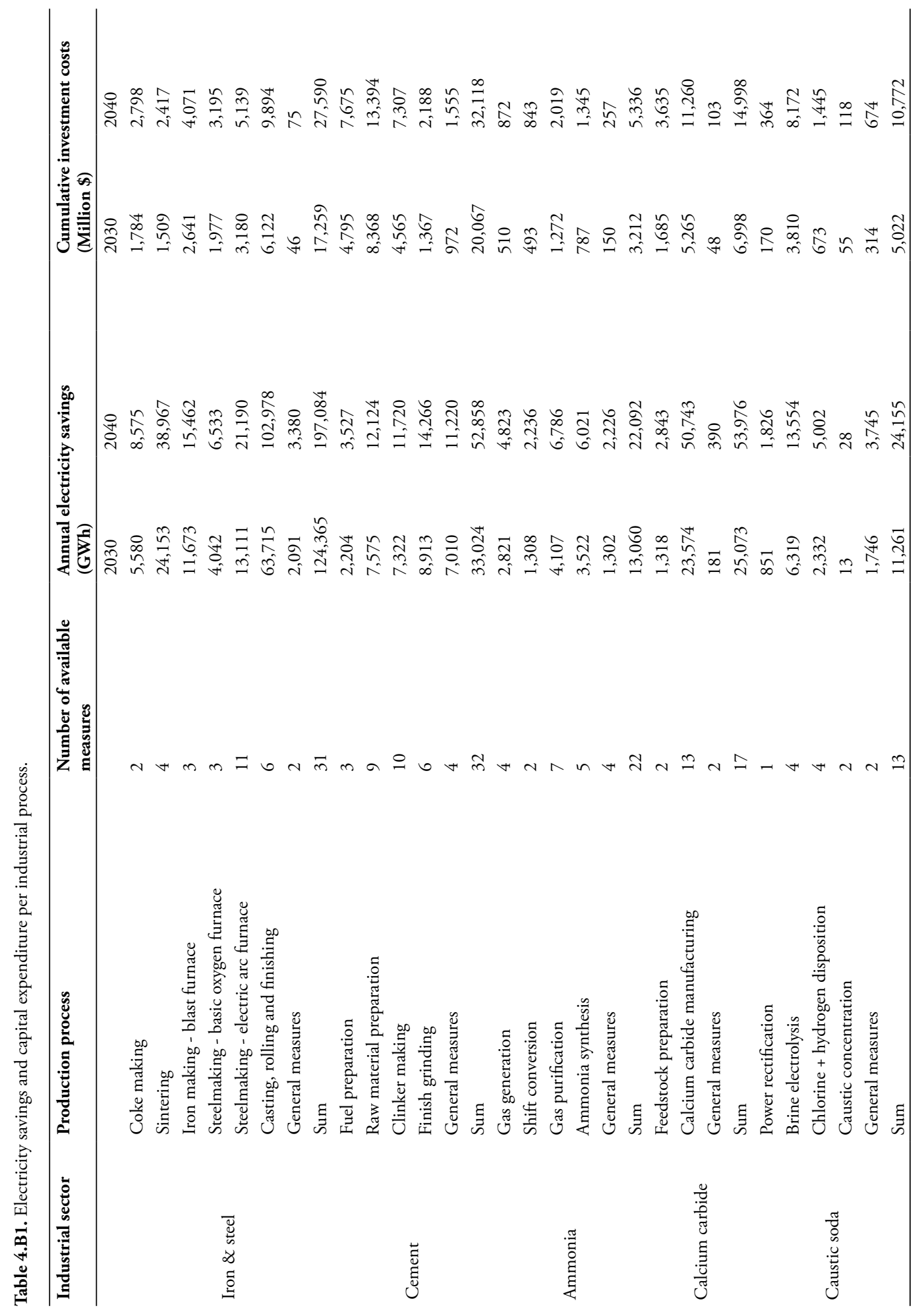


Realizing multiple benefits for power sector by saving industrial electricity use

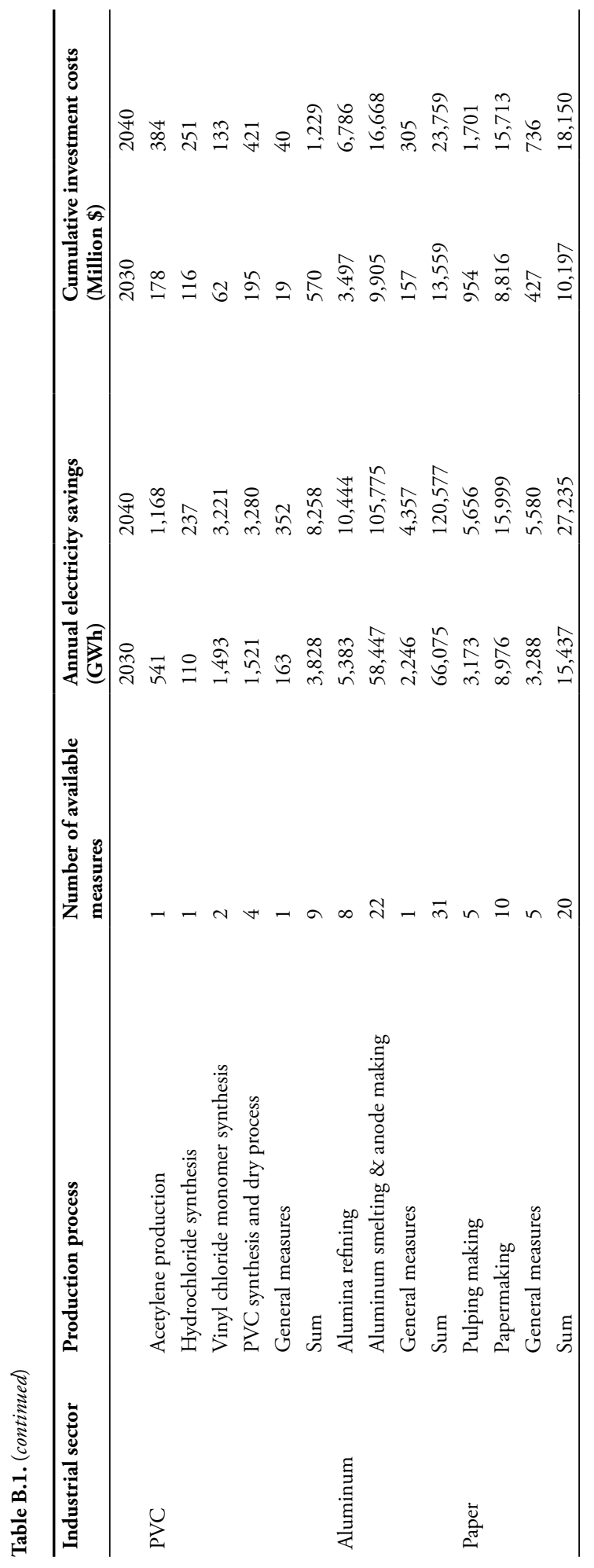




\section{Supplementary Discussion}

\section{SI. The impacts of joint measures on air pollutant emissions from coal fleet}

Here, we consider a deep emission reduction scenario by combining efficiency improvements with flue gas control systems to jointly reduce air pollution from coal. The emission levels of air pollutants by coal generation technology between 2016 and 2040 in different scenarios are plotted in Supplementary Figure 4.S1. The total annual avoided air pollutant emissions are clearly presented. A cost-benefit analysis is performed for this joint scenario.

Efficient use of electricity that occurs in conjunction with reductions in the air pollutants intensities of electricity generation (due to the installed end-of-pipe (EoP) control devices) can deliver substantially further emission decreases, 32.0\%, 34.8\% and 31.9\% of $\mathrm{SO}_{2}, \mathrm{NO}_{\mathrm{x}}$ and PM by 2040, respectively, in comparison to BAU emissions. Deep cuts of air pollutant emissions are obtained in the combined EE+EoP scenario, but we found improving industrial efficiency alone is more cost-effective (US\$ -64,461 per ton air pollutants; Figure 4.4) than combining it with EoP controls in the supply-side (US\$ $-46,428$ per ton air pollutants), considering the benefits from per unit multi-pollutant reductions. This can be explained by the fact that adding EoP controls will reduce the emission intensity, but will also add to the investment and operation costs and without entailing benefits such as electricity savings for the EE measures. This portfolio analysis demonstrates that coordinating the benefits from industrial EE improvements and coal power deployment on addressing air pollution is a cost-effective pathway while offsetting existing coal capacity also benefits climate change goals. 
a

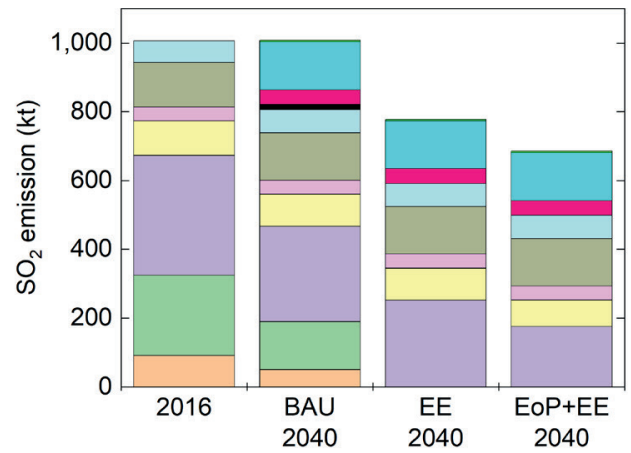

C

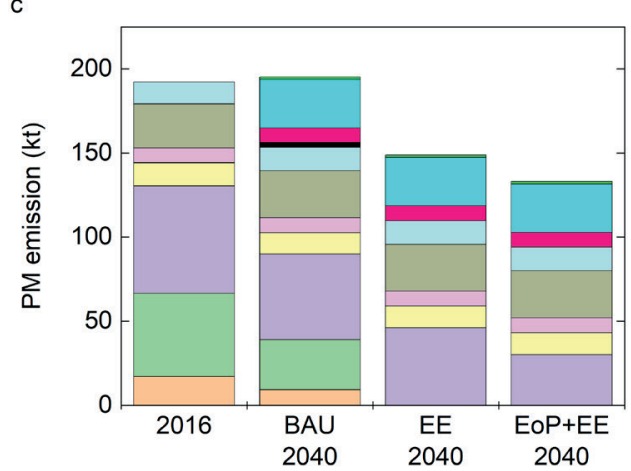

b

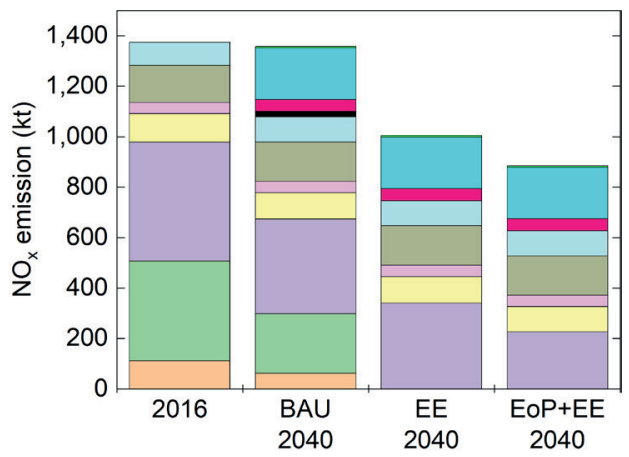

Supplementary Figure 4.S1. Emission levels of air pollutants between 2016 and 2040 under different scenarios. Panels a-c represent the unit-based emission levels of $\mathrm{SO}_{2}, \mathrm{NO}_{x}$ and PM by generation technology, respectively. In all panels, we use the light colours to mark existing coal units (ex-sub/super/ultra/IGCC) and bright colours to map newly proposed units (new-sub/super/ultra/IGCC). Abbreviation: ex, existing; sub, subcritical; super, supercritical; and ultra, ultrasupercritical. 


\section{Chapter 4}

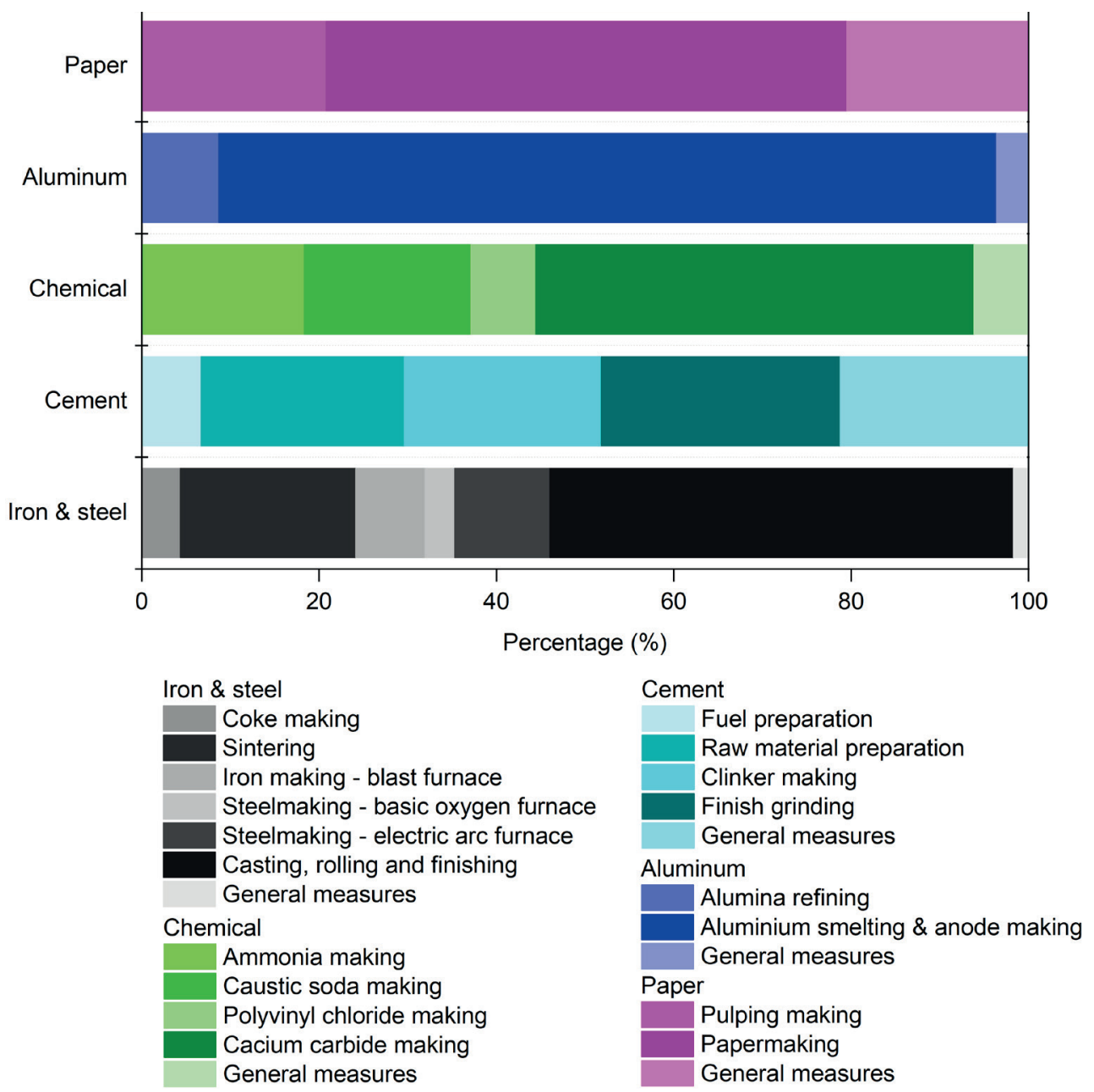

Supplementary Figure 4.S2. Specific opportunities of efficiency improvements in each industrial sector. Legends show the sequence of production process per industrial product. Bars show the potentials of electricity savings by each production process in individual industries. In each bar, the shade of colour indicates the amount of electricity savings for each process, and the deeper colour (for example, deeper blue) represents higher electricity saving benefits. 


\section{Supplementary Tables}

Supplementary Table 4.S1. Unit-based power generation efficiency (lower heating value).

\begin{tabular}{|c|c|c|c|c|}
\hline Fuel type & Technology & Unit size & Efficiency & Source \\
\hline \multirow[t]{9}{*}{ Coal } & Subcritical & $<100 \mathrm{MW}$ & $34.6 \%$ & ERI (2018); CEC (2015) \\
\hline & & 100-300 MW & $36.9 \%$ & CEC (2018) \\
\hline & & 300-600 MW & $39.3 \%$ & CEC (2018) \\
\hline & & $\geq 600 \mathrm{MW}$ & $40.7 \%$ & CEC (2018) \\
\hline & Supercritical & $<300 \mathrm{MW}$ & $35.6 \%$ & CEC (2018) \\
\hline & & 300-600 MW & $39.9 \%$ & CEC (2018) \\
\hline & & $\geq 600 \mathrm{MW}$ & $41.9 \%$ & CEC (2018) \\
\hline & Ultra-supercritical & $\geq 600 \mathrm{MW}$ & $44.6 \%$ & CEC (2018) \\
\hline & IGCC & & $46 \%$ & ETSAP (2010b) \\
\hline \multirow[t]{8}{*}{ Gas } & Combined cycle & $<100 \mathrm{MW}$ & $51.9 \%$ & EPA (2018) \\
\hline & & 100-300 MW & $54.8 \%$ & EPA (2018) \\
\hline & & $\geq 300 \mathrm{MW}$ & $57.3 \%$ & EPA (2018) \\
\hline & Open (simple) cycle & $<100 \mathrm{MW}$ & $35.2 \%$ & EPA (2018) \\
\hline & & $\geq 100 \mathrm{MW}$ & $35.6 \%$ & EPA (2018) \\
\hline & Steam turbine & $<100 \mathrm{MW}$ & $34.5 \%$ & EPA (2018) \\
\hline & & $\geq 100 \mathrm{MW}$ & $36.3 \%$ & EPA (2018) \\
\hline & Internal combustion & $<100 \mathrm{MW}$ & $35.3 \%$ & EIA (2018) \\
\hline \multirow[t]{7}{*}{ Oil } & Internal combustion & $<100 \mathrm{MW}$ & $35.2 \%$ & EIA (2018) \\
\hline & Combined cycle & $<100 \mathrm{MW}$ & $37.1 \%$ & EPA (2018) \\
\hline & & $\geq 100 \mathrm{MW}$ & $42.3 \%$ & EPA (2018) \\
\hline & Open (simple) cycle & $<100 \mathrm{MW}$ & $35.3 \%$ & EPA (2018) \\
\hline & & $\geq 100 \mathrm{MW}$ & $36.0 \%$ & EPA (2018) \\
\hline & Steam turbine & $<100 \mathrm{MW}$ & $32.1 \%$ & EPA (2018) \\
\hline & & $\geq 100 \mathrm{MW}$ & $34.1 \%$ & EPA (2018) \\
\hline \multirow[t]{3}{*}{ Bioenergy } & Biogas/internal combustion & $<100 \mathrm{MW}$ & $30.0 \%$ & EPA (2018); EIA (2018) \\
\hline & $\mathrm{LSB} /$ steam turbine & $<100 \mathrm{MW}$ & $23.3 \%$ & EPA (2018) \\
\hline & MSW/steam turbine & $<100 \mathrm{MW}$ & $22.0 \%$ & $\begin{array}{c}\text { EPA (2018); EIA (2018); } \\
\text { VGB (2003) }\end{array}$ \\
\hline Geothermal & & & $10.0 \%$ & IEA (2018c) \\
\hline Nuclear & & & $33.0 \%$ & IEA (2018c) \\
\hline Solar (CSP) & & & $40.0 \%$ & IEA (2018c) \\
\hline Solar (PV) & & & $100 \%$ & IEA (2018c) \\
\hline Hydro (small) & & & $100 \%$ & IEA (2018c) \\
\hline Hydro (large) & & & $100 \%$ & IEA (2018c) \\
\hline $\begin{array}{l}\text { Wind } \\
\text { (onshore) }\end{array}$ & & & $100 \%$ & IEA (2018c) \\
\hline $\begin{array}{l}\text { Wind } \\
\text { (offshore) }\end{array}$ & & & $100 \%$ & IEA (2018c) \\
\hline Marine & & & $100 \%$ & IEA (2018c) \\
\hline
\end{tabular}

Note: in China, small hydropower units are all those with a capacity less than or equal to 50 MW (IRENA, 2012; Ministry of Water Resources of China, 2017). Abbreviation: IGCC: integrated gasification combined cycle; LSB: liquid and solid biomass; MSW: Municipal solid waste; CSP: concentrating solar power; PV: photovoltaic (including ground-mounted and buildings in our study). The thermal efficiency by the fossil-fuel generation technology is the average value captured by the authors from annual operation data among power plants. 


\section{Chapter 4}

Supplementary Table 4.S2. Power plant lifespan (years) by fuel types.

\begin{tabular}{lcl}
\hline Fuel type & Average lifetime & Source \\
\hline Coal & 40 & IEA (2015) \\
Gas & 30 & IEA (2015) \\
Oil & 40 & Qin et al. (2019); Davis and Socolow (2014) \\
Bioenergy (biogas) & 25 & Qin et al. (2019); IRENA (2019); ETSAP (2010a) \\
Bioenergy (LSB) & 25 & Qin et al. (2019); IRENA (2019); ETSAP (2010a) \\
Bioenergy (MSW) & 20 & Qin et al. (2019); IRENA (2019); ETSAP (2010a) \\
Nuclear & 60 & IEA (2015) \\
Hydro & 80 & IEA (2015) \\
Marine & 20 & IEA (2010) \\
Solar (PV) & 25 & IEA (2010); IRENA (2019) \\
Solar (CSP) & 25 & IEA (2010); IRENA (2019) \\
Wind & 25 & IEA (2015) \\
Geothermal & 40 & IEA (2015) \\
\hline
\end{tabular}

Note: we compared the reported lifetime in these data sources with the actual average age of retired units by fuel types in the WEPP (S\&P Global Platts, 2018) and eGrid database EPA (2018) to determine the average lifetime in our study.

Supplementary Table 4.S3. Capacity factors by fuel types during the 2016-2040 period.

\begin{tabular}{lccccc}
\hline Fuel type & $\mathbf{2 0 1 6}$ & $\mathbf{2 0 2 5}$ & $\mathbf{2 0 3 0}$ & $\mathbf{2 0 3 5}$ & $\mathbf{2 0 4 0}$ \\
\hline Coal & $51 \%$ & $52 \%$ & $53 \%$ & $55 \%$ & $56 \%$ \\
Gas & $31 \%$ & $44 \%$ & $47 \%$ & $47 \%$ & $48 \%$ \\
Oil & $14 \%$ & $9 \%$ & $8 \%$ & $7 \%$ & $7 \%$ \\
Bioenergy & $72 \%$ & $74 \%$ & $73 \%$ & $73 \%$ & $74 \%$ \\
Nuclear & $72 \%$ & $73 \%$ & $36 \%$ & $80 \%$ & $84 \%$ \\
Hydro & $40 \%$ & $36 \%$ & $35 \%$ & $35 \%$ & $35 \%$ \\
Marine & $25 \%$ & $34 \%$ & $29 \%$ & $34 \%$ & $32 \%$ \\
Solar PV & $11 \%$ & $15 \%$ & $15 \%$ & $15 \%$ & $16 \%$ \\
Solar CSP & $14 \%$ & $39 \%$ & $33 \%$ & $38 \%$ & $41 \%$ \\
Wind & $18 \%$ & $23 \%$ & $24 \%$ & $25 \%$ & $27 \%$ \\
Geothermal & $50 \%$ & $63 \%$ & $70 \%$ & $73 \%$ & $77 \%$ \\
\hline
\end{tabular}

Note: the numbers are calculated by the authors based on the electricity generation and installed capacity data derived from IEA-WEO (IEA, 2018c). 
Supplementary Table 4.S4. Unit-based emission performance of China’s coal generation fleet (g/kWh).

\begin{tabular}{lccccccc}
\hline Technology & Unit size & \multicolumn{3}{c}{ Air pollutants with control } & \multicolumn{3}{c}{ Air pollutants without control } \\
\cline { 3 - 7 } & & $\mathbf{S O}_{2}$ & $\mathbf{N O}_{\mathbf{x}}$ & $\mathbf{P M}$ & $\mathbf{S O}_{2}$ & NO $_{\mathbf{x}}$ & PM \\
\hline Subcritical & $<100 \mathrm{MW}$ & 0.67 & 0.64 & 0.16 & 13.34 & 2.56 & 56.79 \\
& & & & & & & \\
& $100-300 \mathrm{MW}$ & 0.36 & 0.32 & 0.10 & 9.29 & 1.61 & 27.05 \\
& $300-600 \mathrm{MW}$ & 0.26 & 0.25 & 0.05 & 8.52 & 1.56 & 26.02 \\
& $\geq 600 \mathrm{MW}$ & 0.22 & 0.19 & 0.03 & 7.63 & 1.32 & 13.25 \\
Supercritical & $<300 \mathrm{MW}$ & 0.30 & 0.23 & 0.04 & n.a. & n.a. & n.a. \\
& 300-600 MW & 0.18 & 0.19 & 0.04 & 5.04 & 1.18 & 30.56 \\
& $\geq 600 \mathrm{MW}$ & 0.15 & 0.17 & 0.03 & 5.75 & 1.06 & 14.91 \\
Ultra-supercritical & $\geq 600 \mathrm{MW}$ & 0.08 & 0.12 & 0.02 & 3.58 & 0.68 & 9.74 \\
IGCC & & 0.05 & 0.07 & 0.02 & n.a. & n.a. & n.a. \\
\hline
\end{tabular}

Note: The emission factors are calculated based on the Equation (4.3) in Methods 4.2.3. n.a. not applicable.

Supplementary Table 4.S5. Production forecast of major industrial products (Million tons).

\begin{tabular}{lccccc}
\hline Production & $\mathbf{2 0 1 6}$ & $\mathbf{2 0 2 5}$ & $\mathbf{2 0 3 0}$ & $\mathbf{2 0 3 5}$ & $\mathbf{2 0 4 0}$ \\
\hline Crude steel & 808 & 778 & 724 & 673 & 636 \\
Cement & 2410 & 2000 & 1778 & 1683 & 1546 \\
Ammonia & 57 & 62 & 64 & 63 & 62 \\
Caustic soda & 32 & 47 & 58 & 73 & 91 \\
Polyvinyl chloride & 17 & 25 & 32 & 40 & 50 \\
Calcium carbide & 26 & 39 & 49 & 61 & 76 \\
Aluminum & 33 & 43 & 50 & 56 & 63 \\
Paper & 109 & 140 & 160 & 161 & 161 \\
\hline
\end{tabular}

Note: the data for 2016 are derived from World Steel Association (2018), U.S. Geological Survey (2019), China Statistical Yearbook (National Bureau of Statistics of China, 2018), China Chemical Industry Yearbook (China Petroleum and Chemical Industry Federation, 2017), International Aluminium Institute (2019), and FAO of the United Nations (2019).

For iron \& steel and cement industries, we use the mean value of the forecasts for crude steel and cement. Forecast data on crude steel are: An et al. (2018), Karali et al. (2016), Ma et al. (2016), Wen et al. (2018, 2019), Zhang et al. (2018); and for cement: Hasanbeigi et al. (2017), Li et al. (2017), Liu et al. (2017), Xu et al. (2016), Zhang et al. (2016), Zhou et al. (2016).

Studies from the Lawrence Berkeley National Laboratory (Zhou et al., 2013), Wen and $\mathrm{Li}$ (2014), Wen et al. (2015), and Yue et al. (2018) are used to estimate the production of chemical products, aluminum and paper. The raw material (for example, coke, pig iron and alumina) demand in production processes are calculated based on this information and the processing conversion ratio of per unit production (Supplementary Table 4.S6). 


\section{Chapter 4}

Supplementary Table 4.S6. Processing conversion ratio and structural parameter in China.

\begin{tabular}{|c|c|c|c|c|}
\hline Product & Process product & Conversion ratio & $\begin{array}{l}\text { Structural } \\
\text { parameter }\end{array}$ & Source \\
\hline \multirow[t]{6}{*}{ Crude steel } & Coke & 0.44 & & \multirow{6}{*}{$\begin{array}{l}\text { World Steel Association (2018); } \\
\text { Wang et al. (2019b); Wen et al. } \\
(2018,2019) ; \text { Zhang et al. (2018) }\end{array}$} \\
\hline & Sinter & 1.33 & & \\
\hline & Pig iron & 0.86 & & \\
\hline & Basic oxygen furnace & & 0.90 & \\
\hline & Electric arc furnace & & 0.10 & \\
\hline & Rolled steel & 0.98 & & \\
\hline Cement & Clinker & 0.60 & & $\begin{array}{l}\text { IEA (2019); Liu et al. (2017); } \\
\text { Zhang et al. (2016) }\end{array}$ \\
\hline \multirow[t]{2}{*}{ Ammonia } & Coal-based & & 0.83 & \multirow[t]{2}{*}{ CNFIA (2016); Yue et al., (2018) } \\
\hline & Gas-based & & 0.17 & \\
\hline \multirow[t]{2}{*}{ Caustic soda } & Diaphragm & & 0.0 & \multirow[t]{2}{*}{ MIIT (2016); Yue et al. (2018) } \\
\hline & Ionic membrane & & 1.0 & \\
\hline \multirow[t]{2}{*}{ Aluminum } & Alumina & 1.93 & & \multirow{2}{*}{$\begin{array}{l}\text { International Aluminium Institute } \\
\text { (2019); ETSAP (2012) }\end{array}$} \\
\hline & Anode & 0.43 & & \\
\hline \multirow[t]{3}{*}{ Paper } & Wood pulp ${ }^{a}$ & 0.92 & 0.30 & \multirow{3}{*}{$\begin{array}{l}\text { CTAPI (2018); FAO of the } \\
\text { United Nations (2019); Wen et } \\
\text { al. (2015) }\end{array}$} \\
\hline & Recovered pulp & 0.92 & 0.64 & \\
\hline & Non-wood pulp & 0.92 & 0.06 & \\
\hline
\end{tabular}

${ }^{a}$ Although wood pulp-based paper accounts for $30 \%$ of paper production, nearly $70 \%$ of required wood pulp is imported from other countries. Moreover, in the domestic made pulp, recovered pulp accounts for the largest share: $80 \%$ (CTAPI, 2018) (wood and non-wood total accounts for 20\%). Thus, recovered pulp-based paper in the papermaking process is our focus in this study. 


\section{References}

Abel, D.W., Holloway, T., Martínez-Santos, J., Harkey, M., Tao, M., Kubes, C., Hayes, S., 2019. Air quality-related health benefits of energy efficiency in the United States. Environmental science \& technology, 53, 3987-3998.

Ackerman, F., Fisher, J., 2013. Is there a water-energy nexus in electricity generation? Long-term scenarios for the western United States. Energy Policy, 59, 235-241.

An, R., Yu, B., Li, R., Wei, Y., 2018. Potential of energy savings and $\mathrm{CO}_{2}$ emission reduction in China's iron and steel industry. Applied Energy, 226, 862-880.

Byers, L., Friedrich, J., Hennig, R., Kressig, A., Li, X., McCormick, C., Malaguzzi Valeri, L., 2019. A Global Power Plant Database. World Resources Institute, Washington (USA).

CEC (China Electricity Council), 2015. Power industry statistical compilation 2014. Beijing (China).

CEC (China Electricity Council), 2018. Basic information of thermal power units (> $100 \mathrm{MW}$ ) in China v. 2017.

China Petroleum and Chemical Industry Federation, 2017. China chemical industry yearbook 2016. China National Chemical Information Center Press, Beijing (China).

Chinese Research Academy of Environmental Sciences, 2010. First Chinese pollution source census: Manual of industrial pollutants production and discharge coefficients. Beijing (China).

CNFIA (China Nitrogen Fertilizer Industry Association), 2016. China: 13th Five-Year Plan of nitrogenous fertilizer industry. Beijing (China).

Cofala, J., Syri, S., 1998a. Nitrogen oxides emissions, abatement technologies and related costs for Europe in the RAINS model database. International Institute for Applied Systems Analysis (IIASA), Laxenburg (Austria). URL: http://pure.iiasa.ac.at/id/eprint/5563/ (accessed 20 July 2020).

Cofala, J., Syri, S., 1998b. Sulfur emissions, abatement technologies and related costs for Europe in the RAINS model database. International Institute for Applied Systems Analysis (IIASA), Laxenburg (Austria). URL: http://pure.iiasa.ac.at/id/eprint/5613/ (accessed 20 July 2020). 


\section{Chapter 4}

Cohen, A.J., Brauer, M., Burnett, R., Anderson, H.R., Frostad, J., Estep, K., Balakrishnan, K., Brunekreef, B., Dandona, L., Dandona, R., et al., 2017. Estimates and 25-year trends of the global burden of disease attributable to ambient air pollution: an analysis of data from the Global Burden of Diseases Study 2015. The Lancet, 389, 1907-1918.

CTAPI (China Technical Association of Paper Industry), 2018. Almanac of China paper industry 2018. China Light Industry Press, Beijing (China).

Cui, R.Y., Hultman, N., Edwards, M.R., He, L., Sen, A., Surana, K., McJeon, H., Iyer, G., Patel, P., Yu, S., Nace, T., Shearer, C., 2019. Quantifying operational lifetimes for coal power plants under the Paris goals. Nature Communications. 10, 1-9.

Dai, Y., Xiong, H., Jiao, J., 2013. Roadmap study on achieving technical energy conservation potential in China's industrial sector by 2020. China Science and Technology Press, Beijing (China).

Davis, C.B., Chmieliauskas, A., Dijkema, G., Nikolic, I., 2015. Power plants (Enipedia) database. Energy \& Industry group, TU Delft, Delft (The Netherlands). URL: http://enipedia.tudelft. nl/wiki/Enipedia (accessed 20 July 2020).

Davis, S. J., Socolow, R. H., 2014. Commitment accounting of $\mathrm{CO}_{2}$ emissions. Environmental Research Letters, 9, 084018.

EIA (U.S. Energy Information Administration), 2018. Power plant operations report (EIA-923) v. 2016. URL: https://www.eia.gov/electricity/data/eia923/ (accessed 20 July 2020).

EPA (U.S. Environmental Protection Agency), 2018. Emissions \& generation resource integrated database (eGrid) v. 2016. URL: https://www.epa.gov/energy/emissions-generation-resourceintegrated-database-egrid (accessed 20 July 2020).

ERI (Energy Research Institute of Academy of Macroeconomic Research), CNREC (China National Renewable Energy Centre), 2018. China renewable energy outlook 2018. Beijing (China). URL: http://boostre.cnrec.org.cn/wp-content/uploads/2018/11/CREO2018-ENfinal-1.pdf (accessed 20 July 2020).

ETSAP (Energy Technology Systems Analysis Program), 2010a. Biomass for heat and power. International Energy Agency, Paris (France). URL: https://iea-etsap.org/E-TechDS/PDF/ E05-BiomassforHP-GS-AD-gct.pdf (accessed 20 July 2020).

ETSAP (Energy Technology Systems Analysis Program), 2010b. Coal-fired power. International Energy Agency, Paris (France). URL: https://iea-etsap.org/E-TechDS/PDF/E01-coal-firedpower-GS-AD-gct.pdf (accessed 20 July 2020). 
ETSAP (Energy Technology Systems Analysis Program), 2012. Aluminium production. International Energy Agency, Paris (France). URL: https://iea-etsap.org/E-TechDS/PDF/ I10_AlProduction_ER_March2012_Final\%20GSOK.pdf (accessed 20 July 2020).

European Commission, 2019. Modelling tools for EU analysis. URL: https:/ec.europa.eu/ clima/policies/strategies/analysis/models_en (accessed 20 July 2020).

Fan, J., Xu, M., Li, F., Yang, L., Zhang, X., 2018. Carbon capture and storage (CCS) retrofit potential of coal-fired power plants in China: The technology lock-in and cost optimization perspective. Applied Energy, 229, 326-334.

FAO (Food and Agriculture Organization) of the United Nations, 2019. Forestry production and trade 2019. Rome (Italy). URL: http://www.fao.org/faostat/en/\#data/FO/visualize (accessed 20 July 2020).

Fleischman, L., Cleetus, R., Deyette, J., Clemmer, S., Frenkel, S., 2013. Ripe for retirement: An economic analysis of the US coal fleet. The Electricity Journal, 26, 51-63.

Gao, M., Beig, G., Song, S., Zhang, H., Hu, J., Ying, Q., Liang, F., Liu, Y., Wang, H., Lu, X., Zhu, T., Carmichael, G.R., Nielsen, C.P., McElroy, M.B., 2018. The impact of power generation emissions on ambient $\mathrm{PM}_{2.5}$ pollution and human health in China and India. Environment International, 121, 250-259.

GEM (Global Energy Monitor), 2019. Database of worldwide coal-fired power stations. URL: https:/globalenergymonitor.org/coal/ (accessed 20 July 2020).

Graus, W., Worrell, E., 2007. Effects of $\mathrm{SO}_{2}$ and $\mathrm{NO}_{x}$ control on energy-efficiency power generation. Energy Policy, 35, 3898-3908.

Graus, W., Worrell, E., 2011. Methods for calculating $\mathrm{CO}_{2}$ intensity of power generation and consumption: A global perspective. Energy Policy, 39, 613-627.

Hasanbeigi, A., Khanna, N., Price, L., 2017. Air pollutant emissions projections for the cement and steel industry in China and the impact of emissions control technologies. Lawrence Berkeley National Laboratory, Berkeley (USA).

Hasanbeigi, A., 2010. Energy-efficiency improvement opportunities for the textile industry. Lawrence Berkeley National Laboratory, Berkeley (USA).

IEA, 2019. Tracking industry. International Energy Agency (IEA), Paris (France). URL: https:// www.iea.org/reports/tracking-industry-2019 (accessed 20 July 2020). 


\section{Chapter 4}

IEA, 2018a. Energy efficiency 2017. International Energy Agency (IEA), Paris (France).

IEA, 2018b. World energy balances (2018 edition). International Energy Agency (IEA), Paris (France).

IEA, 2018c. World energy outlook 2018. International Energy Agency (IEA), Paris (France).

IEA, 2015. Projected costs of generating electricity-2015. International Energy Agency (IEA) and Nuclear Energy Agency (NEA), Paris (France).

IEA, 2010. Projected costs of generating electricity-2010. International Energy Agency (IEA) and Nuclear Energy Agency (NEA), Paris (France).

International Aluminium Institute, 2019. Aluminum and alumina statistics. URL: http://www. world-aluminium.org/statistics/ (accessed 20 July 2020).

IIASA, 2018. Greenhouse gas - Air pollution Interactions and Synergies (GAINS) model description. International Institute for Applied Systems Analysis (IIASA), Laxenburg (Austria). URL: https://iiasa.ac.at/web/home/research/researchPrograms/air/GAINS.html (accessed 20 July 2020).

IIASA, 2015. ECLIPSE V5a global emission fields. International Institute for Applied Systems Analysis (IIASA), Laxenburg (Austria). URL: https://iiasa.ac.at/web/home/research/ researchPrograms/air/ECLIPSEv5a.html (accessed 20 July 2020).

IndustryAbout, 2019. Worldwide industrial information. URL: https://www.industryabout. com/country-territories-3/1705-china/fossil-fuels-energy (accessed 20 July 2020).

IRENA, 2019. Renewable power generation costs in 2018. International Renewable Energy Agency (IRENA), Abu Dhabi (UAE). URL: https:/www.irena.org/publications/2019/May/ Renewable-power-generation-costs-in-2018 (accessed 20 July 2020).

IRENA, 2012. Renewable energy cost analysis - hydropower. International Renewable Energy Agency (IRENA), Abu Dhabi (UAE). URL: https://www.irena.org/publications/2012/Jun/ Renewable-Energy-Cost-Analysis---Hydropower (accessed 20 July 2020).

Kanada, M., Dong, L., Fujita, T., Fujii, M., Inoue, T., Hirano, Y., Togawa, T., Geng, Y., 2013. Regional disparity and cost-effective $\mathrm{SO}_{2}$ pollution control in China: A case study in 5 megacities. Energy Policy, 61, 1322-1331. 
Karali, N., Xu, T., Sathaye, J., 2016. Developing long-term strategies to reduce energy use and $\mathrm{CO}_{2}$ emissions - analysis of three mitigation scenarios for iron and steel production in China. Mitigation and Adaptation Strategies for Global Change, 21, 699-719.

Karplus, V. J., Zhang, S., Almond, D., 2018. Quantifying coal power plant responses to tighter $\mathrm{SO}_{2}$ emissions standards in China. Proceedings of the National Academy of Sciences, 115, 7004-7009.

Khanna, N., Fridley, D., Zhou, N., Karali, N., Zhang, J., Feng, W., 2019. Energy and $\mathrm{CO}_{2}$ implications of decarbonization strategies for China beyond efficiency: Modeling 2050 maximum renewable resources and accelerated electrification impacts. Applied Energy, 242, $12-26$.

Klimont, Z., Cofala, J., Bertok, I., Amann, M., Heyes, C., Gyarfas, F., 2002. Modeling particulate emissions in Europe: A framework to estimate reduction potential and control costs. International Institute for Applied Systems Analysis (IIASA), Laxenburg (Austria). URL: http://pure.iiasa.ac.at/id/eprint/6712/ (accessed 20 July 2020).

Langevin, J., Harris, C.B., Reyna, J.L., 2019. Assessing the Potential to Reduce US Building $\mathrm{CO}_{2}$ Emissions $80 \%$ by 2050 . Joule, 3, 2403-2424.

Lelieveld, J., Evans, J.S., Fnais, M., Giannadaki, D., Pozzer, A., 2015. The contribution of outdoor air pollution sources to premature mortality on a global scale. Nature, 525, 367-371.

Li, M., Patiño-Echeverri, D., 2017. Estimating benefits and costs of policies proposed in the 13th FYP to improve energy efficiency and reduce air emissions of China's electric power sector. Energy Policy, 111, 222-234.

Li, N., Ma, D., Chen, W., 2017. Quantifying the impacts of decarbonisation in China's cement sector: a perspective from an integrated assessment approach. Applied Energy, 185, 18401848 .

Liu, F., Klimont, Z., Zhang, Q., Cofala, J., Zhao, L., Huo, H., Nguyen, B., Schöpp, W., Sander, R., Zheng, B., Hong, C., He, K., Amann, M., Heyes, C., 2013. Integrating mitigation of air pollutants and greenhouse gases in Chinese cities: development of GAINS-City model for Beijing. Journal of Cleaner Production, 58, 25-33.

Liu, X., Yuan, Z., Xu, Y., Jiang, S., 2017. Greening cement in China: A cost-effective roadmap. Applied Energy, 189, 233-244.

Ma, D., Chen, W., Yin, X., Wang, L., 2016. Quantifying the co-benefits of decarbonisation in China's steel sector: an integrated assessment approach. Applied Energy, 162, 1225-1237. 


\section{Chapter 4}

MEE (Ministry of Ecology and Environment of China), NDRC (National Development and Reform Commission of China), NEA (National Energy Administration), 2015. Full implementation of the ultra-low emission and energy-saving transformation for coal-fired power plants. URL: http://www.mee.gov.cn/gkml/hbb/bwj/201512/W020151215366215476108. pdf (accessed 20 July 2020).

Ministry of Industry and Information Technology of China, 2017. China's industry green development report 2017. Beijing Normal University Press, Beijing (China).

Ministry of Industry and Information Technology of China, 2014. Guideline of national industrial energy efficiency. URL: http://www.miit.gov.cn/n1146285/n1146352/n3054355/ n3057542/n3057546/c3634672/content.html (accessed 20 July 2020).

MIIT (Ministry of Industry and Information Technology of China), 2016. China: 13th FiveYear Plan of petrochemical and chemical industry. URL: http://www.miit.gov.cn/n1146295/ n1652858/n1652930/n3757017/c5285161/content.html (accessed 20 July 2020).

Ministry of Water Resources of China, 2017. Standard for evaluation of green small hydropower stations (SL752-2017). Beijing (China).

National Bureau of Statistics of China, 2018. China statistical yearbook 2018. China Statistics Press, Beijing (China).

National Development and Reform Commission of China, 2016. Guidelines on promoting the use of electricity to replace other energy sources. URL: http:/www.scio.gov.cn/xwfbh/ xwbfbh/wqfbh/39595/41802/xgzc41808/Document/1664893/1664893.htm(accessed 20 July 2020).

NDRC (National Development and Reform Commission of China), MEE (Ministry of Ecology and Environment of China), NEA (National Energy Administration), 2014. Action plan 2014-2020 for retrofitting and upgrading the coal-fired power plants aiming at energy conservation and emissions reduction. URL: http://www.mee.gov.cn/gkml/hbb/ gwy/201409/t20140925_289556.htm (accessed 20 July 2020).

Nerini, F.F., Tomei, J., To, L.S., Bisaga, I., Parikh, P., Black, M., Borrion, A., Spataru, C., Broto, V.C., Anandarajah, G., Milligan, B., Mulugetta, Y., 2018. Mapping synergies and trade-offs between energy and the Sustainable Development Goals. Nature Energy, 3, 10-15.

Oberschelp, C., Pfister, S., Raptis, C. E., Hellweg, S., 2019. Global emission hotspots of coal power generation. Nature Sustainability, 2, 113-121. 
Peng, W., Yang, J., Lu, X., Mauzerall, D.L., 2018. Potential co-benefits of electrification for air quality, health, and $\mathrm{CO}_{2}$ mitigation in 2030 China. Applied Energy, 218, 511-519.

Pu, Y., Song, J., Dong, L., Yang, W., Wang, S., Wang, X., 2019. Estimating mitigation potential and cost for air pollutants of China's thermal power generation: A GAINS-China modelbased spatial analysis. Journal of Cleaner Production, 211, 749-764.

Purohit, P., Amann, M., Kiesewetter, G., Rafaj, P., Chaturvedi, V., Dholakia, H.H., Koti, P.N., Klimont, Z., Borken-Kleefeld, J., Gomez-Sanabria, A., Schöpp, W., Sander, R., 2019. Mitigation pathways towards national ambient air quality standards in India. Environment International, 133, 105147.

Qin, Y., Mueller, N.D., Siebert, S., Jackson, R.B., AghaKouchak, A., Zimmerman, J.B., Tong, D., Hong, C., Davis, S. J., 2019. Flexibility and intensity of global water use. Nature Sustainability, 2, 515-523.

Qin, Y., Wagner, F., Scovronick, N., Peng, W., Yang, J., Zhu, T., Smith, K.R., Mauzerall, D.L., 2017. Air quality, health, and climate implications of China's synthetic natural gas development. Proceedings of the National Academy of Sciences, 114, 4887-4892.

Reddington, C.L., Conibear, L., Knote, C., Silver, B.J., Li, Y.J., Chan, C.K., Arnold, S.R., Spracklen, D.V., 2019. Exploring the impacts of anthropogenic emission sectors on $\mathrm{PM}_{2.5}$ and human health in South and East Asia. Atmospheric Chemistry and Physics, 19, 1188711910.

S\&P Global Platts, 2018. World electric power plants (WEPP) database v. September 2017. Washington (USA).

Shindell, D., Smith, C.J., 2019. Climate and air-quality benefits of a realistic phase-out of fossil fuels. Nature, 573, 408-411.

Supekar, S.D., Skerlos, S.J., 2015. Reassessing the efficiency penalty from carbon capture in coalfired power plants. Environmental science \& technology, 49, 12576-12584.

Tang, L., Qu, J., Mi, Z., Bo, X., Chang, X., Anadon, L.D., Wang, S., Xue, X., Li, S., Wang, X., Zhao, X., 2019. Substantial emission reductions from Chinese power plants after the introduction of ultra-low emissions standards. Nature Energy, 4, 929-938.

Tian, X., Dai, H., Geng, Y., Wilson, J., Wu, R., Xie, Y., Hao, H., 2018. Economic impacts from $\mathrm{PM}_{2.5}$ pollution-related health effects in China's road transport sector: A provincial-level analysis. Environment International, 115, 220-229. 


\section{Chapter 4}

Tong, D., Zhang, Q., Davis, S.J., Liu, F., Zheng, B., Geng, G., Xue, T., Li, M., Hong, C., Lu, Z., Streets, D.G., Guan, D., He, K., 2018. Targeted emission reductions from global superpolluting power plant units. Nature Sustainability, 1, 59-68.

TWI2050 (The World in 2050), 2018. Transformations to achieve the sustainable development goals. International Institute for Applied Systems Analysis (IIASA), Laxenburg (Austria).

Ummel, K., 2012. CARMA revisited: an updated database of carbon dioxide emissions from power plants worldwide. Center for Global Development Working Paper, (Personal contact 2019).

United Nations Framework Convention on Climate Change, 2019. Clean development mechanism (CDM) database. URL: https://cdm.unfccc.int/about/index.html (accessed 20 July 2020).

U.S. Geological Survey, 2019. Cement statistics and information 2019. Reston (USA). URL: https://www.usgs.gov/centers/nmic/cement-statistics-and-information (accessed 20 July 2020).

VGB, 2003. Efficiency in electricity generation. VGB PowerTech and Union of the Electricity Industry. URL: http://payesh.saba.org.ir/saba_content/media/image/2016/07/8412_orig. pdf (accessed 20 July 2020).

Wang, Y., Byers, E., Parkinson, S., Wanders, N., Wada, Y., Mao, J., Bielicki, J.M., 2019a. Vulnerability of existing and planned coal-fired power plants in Developing Asia to changes in climate and water resources. Energy \& Environmental Science, 12, 3164-3181.

Wang, Y., Chen, C., Tao, Y., Wen, Z., Chen, B., Zhang, H., 2019b. A many-objective optimization of industrial environmental management using NSGA-III: A case of China's iron and steel industry. Applied Energy, 242, 46-56.

Wen, Z., Li, H., 2014. Analysis of potential energy conservation and $\mathrm{CO}_{2}$ emissions reduction in China's non-ferrous metals industry from a technology perspective. International Journal of Greenhouse Gas Control, 28, 45-56.

Wen, Z., Wang, Y., Li, H., Tao, Y., De Clercq, D., 2019. Quantitative analysis of the precise energy conservation and emission reduction path in China's iron and steel industry. Journal of environmental management, 246, 717-729.

Wen, Z., Wang, Y., Zhang, C., Zhang, X., 2018. Uncertainty analysis of industrial energy conservation management in China's iron and steel industry. Journal of environmental management, 225, 205-214. 
Wen, Z., Xu, C., Zhang, X., 2015. Integrated control of emission reductions, energy-saving, and cost-benefit using a multi-objective optimization technique in the pulp and paper industry. Environmental Science \& Technology, 49, 3636-3643.

World Bank, 2016. The cost of air pollution: Strengthening the economic case for action. World Bank Group, Washington (USA). URL: https://openknowledge.worldbank.org/ handle/10986/25013 (accessed 20 July 2020).

World Steel Association, 2018. Steel statistical yearbook 2018. Brussels (Belgium). URL: https:// www.worldsteel.org/steel-by-topic/statistics/steel-statistical-yearbook.html (accessed 20 July 2020).

Worrell, E., Price, L., Neelis, M., Galitsky, C., Zhou, N., 2007. World best practice energy intensity values for selected industrial sectors. Lawrence Berkeley National Laboratory, Berkeley (USA).

Xu, J. H., Yi, B. W., Fan, Y., 2016. A bottom-up optimization model for long-term $\mathrm{CO}_{2}$ emissions reduction pathway in the cement industry: A case study of China. International Journal of Greenhouse Gas Control, 44, 199-216.

Yang, H., Zhang, Y., Zheng, C., Wu, X., Chen, L., Fu, J.S., Gao, X., 2018. Cost estimate of the multi-pollutant abatement in coal-fired power sector in China. Energy, 161, 523-535.

Yue, H., Worrell, E., Crijns-Graus, W., 2018. Modeling the multiple benefits of electricity savings for emissions reduction on power grid level: A case study of China's chemical industry. Applied Energy, 230, 1603-1632.

Zhai, H., 2019. Deep reductions of committed emissions from existing power Infrastructure: Potential Paths in the United States and China. Environmental Science \& Technology, 24, 14097-14098.

Zhang, Q., Xu, J., Wang, Y., Hasanbeigi, A., Zhang, W., Lu, H., Arens, M., 2018. Comprehensive assessment of energy conservation and $\mathrm{CO}_{2}$ emissions mitigation in China's iron and steel industry based on dynamic material flows. Applied Energy, 209, 251-265.

Zhang, S., Worrell, E., Crijns-Graus, W., 2015. Evaluating co-benefits of energy efficiency and air pollution abatement in China’s cement industry. Applied Energy, 147, 192-213.

Zhang, S., Worrell, E., Crijns-Graus, W., Krol, M., de Bruine, M., Geng, G., Wagner, F., Cofala, J., 2016. Modeling energy efficiency to improve air quality and health effects of China's cement industry. Applied Energy, 184, 574-593. 


\section{Chapter 4}

Zhang, S., Yi, B., Worrell, E., Wagner, F., Crijns-Graus, W., Purohit, P., Wada, Y., Varis, O., 2019. Integrated assessment of resource-energy-environment nexus in China's iron and steel industry. Journal of Cleaner Production, 232, 235-249.

Zhou, L., Gilbert, S., Wang, Y., Cabré, M.M., Gallagher, K.P., 2018a. Moving the green belt and road initiative: from words to actions. World Resources Institute, Washington (USA). URL: https://files.wri.org/s3fs-public/moving-green-belt-and-road-initiative-from-wordsto-actions.pdf (accessed 20 July 2020).

Zhou, N., Khanna, N., Feng, W., Ke, J., Levine, M., 2018. Scenarios of energy efficiency and $\mathrm{CO}_{2}$ emissions reduction potential in the buildings sector in China to year 2050. Nature Energy, 3, 978-984.

Zhou, N., Fridley, D., Khanna, N.Z., Ke, J., McNeil, M., Levine, M., 2013. China's energy and emissions outlook to 2050: Perspectives from bottom-up energy end-use model. Energy Policy, 53, 51-62.

Zhou, W., Jiang, D., Chen, D., Griffy-Brown, C., Jin, Y., Zhu, B., 2016. Capturing $\mathrm{CO}_{2}$ from cement plants: A priority for reducing $\mathrm{CO}_{2}$ emissions in China. Energy, 106, 464-474. 


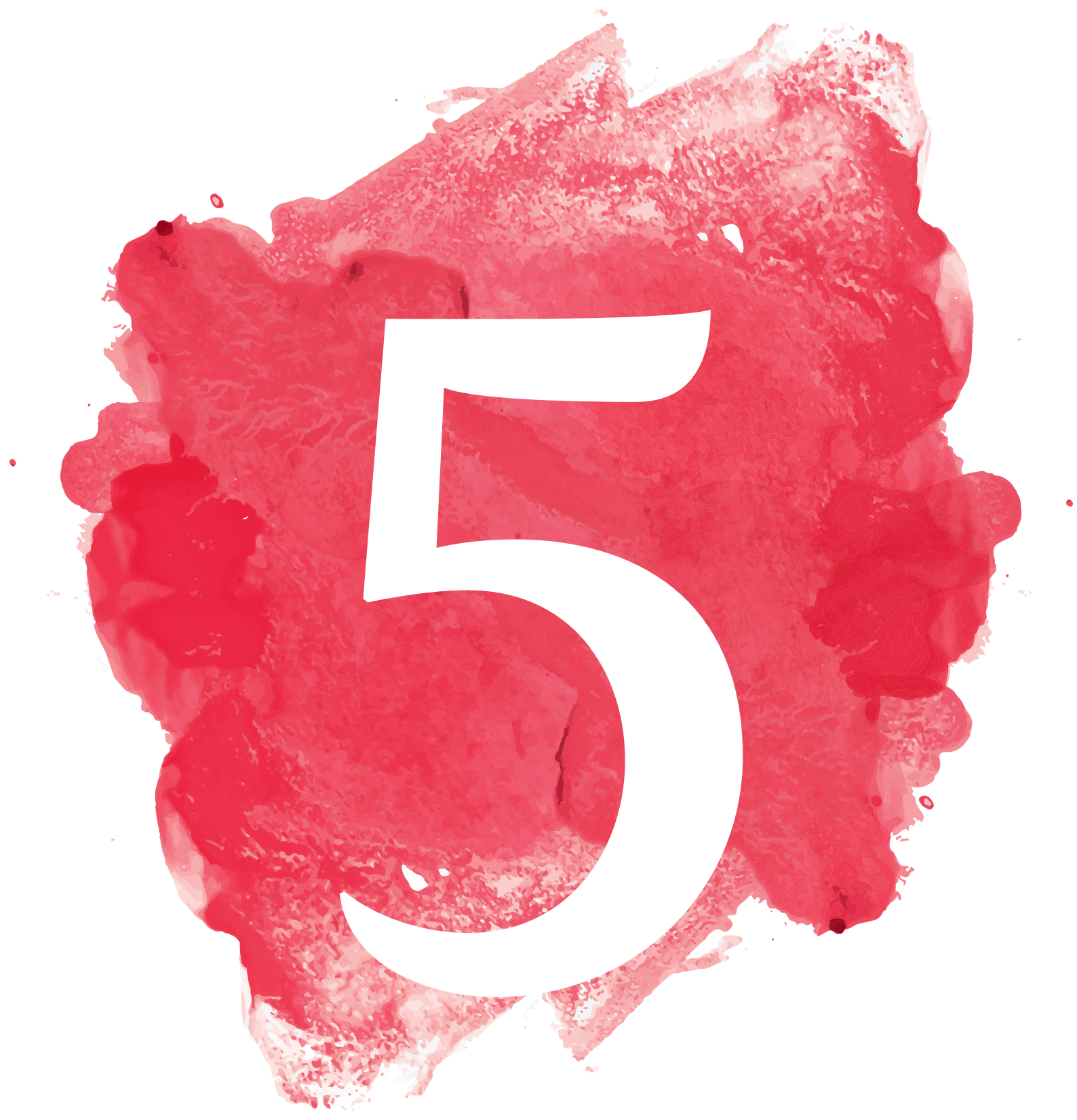




\section{Chapter 5}

\section{Impacts of regional industrial electricity savings on the development of future coal capacity per electricity grid and related air pollution emissions \\ - A case study for China}

Hui Yue, Ernst Worrell, Wina Crijns-Graus 


\section{ABSTRACT}

Moving to a sustainable industry and weaning electricity supply off coal are critical to mitigate ambient air pollution and climate change. This is particularly true in China which is globally the largest manufacturer and relies heavily on coal-fired electricity. Research that explores the linkages between industrial electricity use and the electricity supply sector to curb air pollution is limited. In this study, an integrated modeling framework is developed that quantifies the impact of industrial electricity savings on the evolution of the coal power plant fleet in China, and on air pollutants for the different power grids in the period 2016-2040. The framework includes a rich set of efficiency technologies and detailed unit-level information (geo-coordinates, thermal efficiency, environmental performance). We find that the reduced electricity load due to the industrial efficiency improvements can effectively scale down the coal power fleet, and most importantly allows closing the most polluting units. The potentials for electricity savings vary amongst the industrial sectors and provinces, resulting in significant heterogeneity of coal plant phaseout per power grid. Because energy-intensive industrial plants are mostly found in the North, Central and Northwest grids, these three grids provide $66 \%$ of the total displaced coal capacity. The closing of coal units leads to a variation in annual emission reductions per power grid of $13-85 \mathrm{kt}-\mathrm{SO}_{2}, 19-129 \mathrm{kt}-$ $\mathrm{NO}_{\mathrm{x}}, 3-17 \mathrm{kt}-\mathrm{PM}$ and 21-167 Mt- $\mathrm{CO}_{2}$, compared to business-as-usual emissions. The iron $\&$ steel, aluminium and chemical sectors, together contribute to $84 \%$ of the total electricity savings by 2040 , and are thereby most important to target. 


\section{I. Introduction}

Industry is responsible for $42 \%$ of global electricity consumption and even more than $60 \%$ of electricity consumption in China in 2018 (IEA, 2019b), making it undoubtedly the globally largest electricity consumer. With an annual growth rate of $9 \%$, electricity is the strongest driving force of China's growing industrial energy consumption from 2000 to 2018 , contributing to $38 \%$ of growth in industrial end-use energy (IEA, 2018c; IEA, 2019b). The share of electricity consumption in industrial final energy use has increased by 13 percentage points, from $19 \%$ in 2000 to $32 \%$ in 2018 . Industrial electricity use is expected to further grow due to electrification (China Electricity Council, 2020) and the unabated use of inefficient industrial equipment (Energy Research Institute and National Renewable Energy Centre of China, 2018). Hence, electricity will gradually displace fossil-fuels as the dominant energy source of industry (National Development and Reform Commission of China, 2016). This displacement can substantially reduce direct industrial air emissions (i.e. air pollutants and greenhouse gases (GHGs)) but lead to increased indirect emissions from electricity generation processes (Liang et al., 2019; Khanna et al., 2019). These concerns are particularly prominent in China, where electricity generation is heavily dependent on a coal-intensive power generation fleet (corresponding to $70 \%$ of total generation). This dependence on coal is more serious than that in the European Union (20\% from coal-fired plants) or the United States (30\% from coal-fired plants) (IEA, 2019b).

Coal-fired power plants have been massively deployed in China (more than 3,000 coal generation units in service in 2016), and are responsible for $-19 \%,-21 \%$ and $-11 \%$ of China's total $\mathrm{SO}_{2}, \mathrm{NO}_{\mathrm{x}}$ and PM emissions, respectively (Tang et al., 2019; IEA, 2018c), seriously impacting local air quality. At the same time, the deterioration of air quality has caused people to reflect on public health (Reddington et al., 2019; Hu et al., 2017). Gao et al. (2018) estimated that annually 520 thousand premature deaths in China are attributed to ambient air pollutants emitted from power generation. According to the World Electric Power Plants (WEPP) Database (S\&P Global Platts, 2018), China still has around $200 \mathrm{GW}$ new coal-fired power plants in the pipeline, which is more than the existing coal capacity in the European Union $(170 \mathrm{GW})$. Although many countries plan to phase out coal-fired power plants (Rentier et al., 2019; Climate Transparency, 2019; MEE et al., 2015) to help reduce emissions, China's growing appetite for new coal-fired power stations has outstripped plant closures (32 GW retirements) in the rest of the world in 2016 (Global Energy Monitor, 2019; S\&P Global Platts, 2018). This is particularly important because of the growing electricity demand driven by booming industrialization (Wang et al., 2019; IEA, 2017b). Transitioning to a sustainable industry and shifting away from coal for electricity generation is urgent for the world and China. Promoting efficient electricity use by end-users to reduce the deployment of coal power plants should play a significant role to reduce multiple air emissions from 
coal generation fleet in a cost-effective way (Energy Research Institute and National Renewable Energy Centre of China, 2018; IEA, 2018a; Buonocore et al., 2016).

Here, we comprehensively evaluate the impacts of industrial electricity savings via energy efficiency improvements on the deployment of coal-fired power plants by 2040 targeting to reduce air pollutant emissions in China. We do so at a regional grid level to correctly evaluate the impacts on air pollutant emissions. Air pollutants can also be removed by flue gas control devices. However, traditional pollution control systems reduce power generation efficiency (Graus and Worrell, 2007; EPA, 2018) and increase $\mathrm{CO}_{2}$ emissions due to the consumed additional energy and resources (e.g. sorbents and catalyst) (Peng et al., 2018; Abel et al., 2019). Economically, these technologies are usually expensive, with high capital costs plus considerable operation and maintenance costs. To identify the most economical way, a cost-performance analysis is carried out in this study to compare the investment and air quality benefits of electricity savings compared to end-of-pipe controls. Characterizing the complex relationship between the largest energy consumer (industry) and the largest energy infrastructure (power sector) is critical to cost-effectively pursue the four United Nations Sustainable Development Goals (SDGs): SDG 3 (good health), SDG 7 (energy access), SDG 9 (sustainable industry), and SDG 13 (climate action).

Various researchers have emphasized the pivotal role of energy efficiency improvements to offset additional energy supply (IEA, 2017a) and capturing air emission reduction benefits across different locations (Yue et al., 2018; Zhou et al., 2018; IEA, 2018a; Walls, 2017; Reyna and Chester, 2017; Zhang et al., 2015). Reyna and Chester (2017) projected the residential electricity use in Los Angeles County, U.S. during 2020-2060 under different scenarios, and found that energy efficiency can largely reduce net energy use, slowing the increase in electricity use by $13-59 \%$. Zhou et al. (2018) estimated the co-benefits of $\mathrm{CO}_{2}$ emission reductions by 2050 in China's buildings sector, and suggested that efficiency technologies can effectively limit the growth of energy use and peak $\mathrm{CO}_{2}$ emissions by 2030. Zhang et al. (2015) evaluated the impacts of energy savings on air pollutant emissions in China's cement industry, and revealed that many efficiency measures are cost-effective clean air strategies, and as such, are often preferable to alternatives. A large body of this research focuses on a specific energy user and pay attention to single benefits (e.g. carbon or air pollutant emission reductions) at a national or a local level. Few authors explore the regional heterogeneity of potential multiple benefits attributable to energy efficiency in economic activities across a country (Yue et al., 2018; Abel et al., 2019; Zhang et al., 2016). Yue et al. (2018) analyzed the multiple benefits of 60 energy efficiency technologies to reduce GHGs and air pollutant emissions in China's key chemical sectors across six power grids, up to 2035. Abel et al. (2019) assumed 15\% of annual energy efficiency improvements by states in the U.S. aiming to capture the health benefits of air pollutant abatement due to the reduced energy demands on a regional level. 
However, none have quantified the role of electricity savings of industrial consumers in the evolution of electricity supply systems, particularly in regards to displacing coal generation capacity and associated changes of multiple air emissions. Although demandside management (DSM) has stressed this impact (China Electricity Council, 2018; Energy Research Institute and National Renewable Energy Centre of China, 2018), these high-value benefits still receive less attention. This study is the first to build an integrated modeling framework considering regional characteristics to quantify displaced coal-fired power units (prioritizing high-polluting and less-efficient units) by load reduction, and assess the contributions to air emission reductions $\left(\mathrm{SO}_{2}, \mathrm{NO}_{\mathrm{x}}, \mathrm{PM}\right.$ and $\left.\mathrm{CO}_{2}\right)$ for six electricity grids (covering 31 provinces) across China. Our multi-sectoral and multiregional perspective allows national and provincial decision-makers to prioritize efforts across sectors and regions on building an efficient industry and decreasing dependence on coal power, given the regional differences in electricity demand and installation of coal power plants, as well as the level of local air pollution.

This research addresses the knowledge gap of what is the potential impact of efficient electricity use in the industrial demand-side on the evolution of the coal-based electricity supply system and associated air quality benefits, for different power grids. Three key subgoals, i.e. electricity savings by industries, displaced coal-fired power capacity, and air emission reductions from electricity generation, are established and measured in this study to meet the main purpose. Besides, cost portfolios of air pollutant abatement measures between industrial efficiency improvements and retrofitting coal power plants with flue gas controls are compared to determine the highest cost performance strategy. By assessing the interconnections of the industry and the electricity supply system, this study provides a comprehensive understanding of the pivotal role of industrial energy efficiency improvements, which is critical not only for China but for the world to achieve a more sustainable industry and move towards a coal-free electricity supply system in an economically feasible way. The structure of this paper is presented as follows. Section 2 provides information on the storylines of scenario design, an integrated modeling framework and data sources (e.g. unit-level information of power plants, characteristics of energy efficiency technologies and parameters of end-of-pipe control measures). The key research output in terms of electricity savings by industries, displaced coal power capacity, air pollutant emission levels and cost comparison of abatement portfolios in different scenarios for the six power girds, are presented in Section 3, while the important factors that affect the results are discussed in Section 4. Section 5 concludes the research and draws policy implications. 


\subsection{Methods and materials}

In this section, we develop an integrated analysis structure to model the impacts of reduced industrial electricity use on future power plant capacity developments, on a regional level in China. The resulting air pollutant emission abatement is compared to the alternative of installing flue gas control technologies in terms of costs for each region to achieve the same impact. The GAINS (Greenhouse Gas - Air Pollution Interactions and Synergies) model is used, in combination with two comprehensive databases, that are developed in this study. The first database consists of energy efficiency technologies in industry including energy savings potential and costs. The second database contains details about the current and future power generation fleet, on a power plant unit basis This database enables us to conduct a unit-by-unit assessment to identify which power plant units could be avoided because of electricity savings across the six electricity grids. The geographic location of coal-fired power units, emission levels, and potential electricity savings are mapped at a provincial and grid level using a geographic information system-ArcGIS. An overview of the research design for this study is briefly summarized below.

Section 5.2.1 describes the four scenarios that are modeled. Section 5.2.2 provides the method to quantify the electricity saving potential per energy efficiency technologies implemented in the industry. The GAINS model is introduced in Section 5.2.3, which is used to model the cost of per ton air pollutants removed by end-of-pipe controls. Section 5.2.4 proposes the methods to measure the emission inventory $\left(\mathrm{SO}_{2}, \mathrm{NO}_{\mathrm{x}}, \mathrm{PM}\right.$ and $\mathrm{CO}_{2}$ ) from the coal power fleet at unit level. Data sources are described in Section 5.2.5.

\subsection{Scenario design}

Four scenarios are designed to examine the impacts of industrial electricity savings on the power plant fleet and air emission changes. Our business-as-usual scenario (BAU) is constructed as a reference case based on the Current Policies (CPol) Scenario in the World Energy Outlook 2018 (IEA, 2018c) developed by the International Energy Agency (IEA). The BAU scenario respects the effects of currently implemented policies on electricity demand, power generation, and installed capacity over the period of 2016-2040, providing a baseline to compare with alternative scenarios. In this scenario, incremental growth of the electricity demand would lead to an expansion of the fossilfuel power fleet, particularly of coal power stations in China by 2040 (IEA, 2018c).

The efficient electricity use management (EUM) scenario describes the transition to an efficient and sustainable industry (which represents the efficient use of electricity in industrial processes) by implementing high-efficiency technologies. This scenario measures the electricity savings and associated benefits by implementing hundreds of specific technologies in five energy-intensive industries (iron \& steel, cement, chemicals, 
aluminium and pulp \& paper). These five industries are the largest electricity consumers, and together account for about $50 \%$ of total electricity consumption (IEA, 2018b) in China's industry, and are also emphasized by the IEA (2017b) and Chinese National Five-Year Plan (State Council of China, 2017). This scenario examines the role of industrial electricity savings on the (earlier) retirement of the existing power plant fleet and curbing new proposed power projects, as well as the avoided air pollutants from the displaced power plants.

The air pollution control (APC) scenario aims to explore the cost portfolios of retrofitting coal-fired power plants with end-of-pipe treatment measures to cut emissions to the same level as those avoided in the EUM scenario. The APC scenario is designed with the GAINS model and has the same energy related parameters (e.g. installed capacity and electricity generation) as the BAU scenario. The deployment of end-of-pipe treatment devices at provincial level in the APC scenario is based on the ECLIPSE V5a database (Klimont et al., 2017) developed by the International Institute for Applied Systems Analysis (IIASA). This scenario provides an alternative for air pollutant reductions to identify the most cost-effective scenario by comparing the costs of end-of-pipe to electricity savings.

Finally, the joint electricity savings and air pollution controls scenario (EUM+APC) includes both promoting energy efficiency technologies in industry and installing additional end-of-pipe controls in coal-fired power plants, to understand the combined impacts and costs on air pollutant reductions. This scenario uses the investments in endof-pipe measures in the APC scenario as a starting point, while incorporating the same assumptions for electricity savings in China's industries as in the EUM scenario (so the costs of the joint scenario are the sum of the costs spending of the APC and the EUM scenarios).

\subsubsection{Electricity conservation supply curve modeling}

Here, we construct electricity conservation supply curves (CSCs) at a regional level to quantify the electricity savings per province from both cost performance and technical perspectives, in the five energy-intensive industries. The concept of CSC, which is introduced by Lawrence Berkeley National Laboratory (Meier et al., 1983) to identify the cost-effective portfolios for meeting energy service demands (Worrell et al., 2003), is used to develop the electricity CSCs per province in this study. CSC is widely used as a quantitative analysis tool by energy researchers to model the potentials and costs of conserved energy in various demand-side energy systems (e.g. a group of plants and an independent economic activity). Zhang et al. (2018) modeled the performance of 35 available energy efficiency technologies applied to China's iron \& steel sector by CSC, and identified that $61 \%$ of energy savings can be achieved by 19 cost-effective technologies by 2050. Li et al. (2017) introduced carbon price in the CSC to evaluate the $\mathrm{CO}_{2}$ mitigation costs of 20 high-efficiency technologies in China's cement sector 
by 2050, and shown that improving energy efficiency is a cost-effective and powerful measure to decarbonize the cement industry. Prior CSCs typically focus on one sector (concentrating on iron \& steel (Hasanbeigi et al., 2013b; Zhang et al., 2018; Wu et al., 2016; Zhang et al., 2014) and cement (Zhang et al., 2015; Li et al., 2017; Hasanbeigi et al., 2013a)). However, rarely studies developed a regional CSC to explore the co-benefits of efficiency improvements, in particular electricity savings, for multi-sectors on a power grid level (Yue et al., 2018).

Based on the previous studies of co-authors (Yue et al., 2018; Zhang et al., 2016), the energy CSCs are modified and presented as Equation (5.1) to assess the electricity saving potentials and associated costs per available technology implemented in the studied industries. This formula reflects the electricity conservation potential as a function of the marginal cost of conserved final energy. The parameters related to fossil fuels are also considered in Equation (5.1). This is because some efficiency technologies do not only save electricity but also save fossil fuels, which should not be ignored when calculating the energy benefits. The electricity and fossil-fuel prices at provincial level (see Appendix) are introduced into the formula to represent the regional cost function heterogeneity.

$C C E_{i, k, p}=\frac{\frac{d}{\left(1-(1+d)^{\left.-l_{i, k, p}\right)}\right.} \times C C_{i, k, p}+\Delta O \& M_{i, k, p}-E S_{i, k, p} \times E P_{p}-F S_{i, k, p} \times F P_{p}}{T E S_{i, k, p}}$

Where $i, k$ and $p$ represent the technology type, industrial subsector and province, respectively; $C C E$ is the cost of conserved energy in $\$ / G \mathrm{~J} ; d$ is the discount rate in $\%$, i.e. $7 \% ; l$ is the lifetime in years; $C C$ is the capital cost per technology in $\$ ; \triangle O \& M$ is the change in annual operation and maintenance cost in $\$ ; E S$ is the annual electricity saving in $\mathrm{kWh} F P$ is the electricity price in $\$ / \mathrm{kWh} F S$ is annual fuel savings (if possible) per technology in GJ; $F P$ is the fuel price in $\$ / G J$; and TES is the annual total energy saving including all energy saving types in GJ.

\subsubsection{GAINS model}

The GAINS model is an integrated assessment tool, developed by IIASA, with detailed information regarding macroeconomic drivers, energy activity, cost parameters per installed emission control measure and emission control strategies by primary air pollutants (e.g. $\mathrm{SO}_{2}, \mathrm{NO}_{x}, \mathrm{PM}, \mathrm{NH}_{3}$ and VOCs) on various scales (e.g. global, national and subregional levels) (IIASA, 2016; Amann et al., 2014). The GAINS model allows user to customize emission reduction scenarios using exogenous parameters (Qin et al., 2017; Amann et al., 2011; Zhang et al., 2016) (e.g. energy use by fuel type, electricity supply and future assumptions) to examine the cost portfolios of control measures to tackle local air quality and mitigating climate change. Due to the rich information and flexibility, the GAINS model has been widely used to evaluate emission levels (Vandyck et al., 2018; Grubler et al., 2018), emission reduction potentials (Liu et al., 2013; Liu et al., 2019), and control system costs (Amann et al., 2011; Shindell et al., 
2012) for air pollutants and GHGs. Moreover, the IEA adopted the GAINS model to project air pollutant emission levels across countries (IEA, 2018c), and provides policy recommendations. Based on the ECLIPSE V5a database, we here use the GAINS-China module (Kanada et al., 2013) (a regional part of the GAINS model) to measure the unit costs per ton air pollutant removed by end-of-pipe measures from China's coal power plants, at provincial level.

The calculation process of the unit cost per ton air pollutant removed $U C$ in the GAINS model is presented by Equation (5.2) (Amann et al., 2011). The detailed description of the way GAINS models emission reduction and control costs can be found in the studies (Cofala and Syri, 1998b; Cofala and Syri, 1998a; Klimont et al., 2002).

$C_{m, t, p, j}=\left(\frac{A F_{m, t, p} \times C C_{m, t, p}+O M_{m, t, p}^{f i x}}{F C_{t, p}}+O M_{m, t, p}^{v a r}\right) /\left(e f_{t, p, j} \times \eta_{m, t, p, j} \times \gamma_{m, t, p, j}\right)$

Where $m, t$ and $j$ represent the emission control technology, fuel type and air pollutant (e.g. $\mathrm{SO}_{2}, \mathrm{NO}_{\mathrm{x}}$ and $\mathrm{PM}$ ), respectively; $A F$ is the annuity factor; $C C$ is the capital cost in $\$ ; O M^{f i x}$ is the annual fixed expenditures of maintenance and operation in $\$$; $O M^{v a r}$ is the variable operating costs in \$/PJ; FC is the annual fuel consumption in PJ; ef is the unabated emission factor for an air pollutant in ton/PJ; $\eta$ is the removal efficiency of a control technology for an air pollutant in $\%$; and $\gamma$ is the capacities controlled factor in $\%$.

\subsubsection{Emissions from coal generation fleet}

In the scenarios we assume that industrial electricity savings are used to offset coal-fired power plants. The coal plant power fleet in 2040 consists of currently operating coal power units (in service of 2016) and new coal power plants (constructed in the period 2017-2040). Based on unit-level information, we use Equation (5.3) to estimate air emission levels from coal-fired power plants at power grid level in the future.

$E_{c o a l, a, g, y}=\sum_{p \in g}\left(\sum_{e \in p}^{e x i}\left(E F_{e, a, y} \times S_{e, y} \times \beta \times C F_{p, y}\right)+\sum_{n \in p}^{n e w}\left(E F_{m, a, y} \times S_{m, y} \times \beta \times C F_{p, y}\right)\right)$

Where coal, $a, g, e, n$ and $y$ indicate the coal generation fleet, air emission species, power grid, existing unit, newly installed unit and year, respectively; $E$ is the air emission level in $\mathrm{kg}$; $E F$ is the emission factor for a unit in $\mathrm{kg} / \mathrm{MWh}$; $S$ is the installed capacity size in MW; $\beta$ is the full-load period per year, i.e. 8760 hours; and $C F$ is the capacity factor in $\%$.

The emission factors of air pollutants (i.e. $\mathrm{SO}_{2}, \mathrm{NO}_{\mathrm{x}}$ and $\mathrm{PM}$ ) for a generation unit are estimated using the following Equation (Tang et al., 2019; Karplus et al., 2018). 
$E F_{j, y}=\frac{\theta_{j, y} \times v_{y} \times A_{y}}{E G_{y}}$

Where $\theta$ represents the abated emission concentration from power station stacks in $\mathrm{g} / \mathrm{Nm}^{3} ; v$ is the theoretical flue gas rate in $\mathrm{Nm}^{3} /$ ton-coal; $A$ is the amount of coal consumption in ton; and $E G$ is the electricity generation by a unit in $\mathrm{kWh}$.

The $\mathrm{CO}_{2}$ emission factors at unit-level are estimated based on coal generation efficiency and carbon content as follows.

$$
E F_{\mathrm{CO}_{2}, y}=\frac{\omega \times C O F \times L H V}{\lambda_{y}} \times \frac{M_{\mathrm{CO}_{2}}}{M_{c}}
$$

Where $\omega$ is the carbon content of coal in $\mathrm{g} / \mathrm{MJ}$; $C O F$ is the carbon oxidation factor of coal in \%; $L H V$ is the lower calorific value for electricity in $\mathrm{MJ} / \mathrm{kWh} ; \lambda$ is the unit generation efficiency in \%; $M_{\mathrm{CO} 2}$ is the molar mass of $\mathrm{CO}_{2}$, i.e. $44 \mathrm{~g} / \mathrm{mol}$; and $M_{c}$ is the molar mass of carbon, i.e. $12 \mathrm{~g} / \mathrm{mol}$.

\subsubsection{Data sources}

\subsubsection{Power plant fleet}

Our data are based on unit-level assessments of existing and new coal power plants in China. Operational coal-fired power units in 2016 are taken from the Platts World Electric Power Plants (WEPP) database (September 2017 release) (S\&P Global Platts, 2018) (in total 3102 operational units). The information per unit includes capacity, commissioning year, fuel type, location and generation technology (i.e. subcritical, supercritical, USC and IGCC). Around 14 GW or 167 coal power units lack commissioning year in the database. Through cross-checking various global power plant databases (Byers et al., 2019; IndustryAbout, 2019; Global Energy Monitor, 2019), power company websites and environmental impact assessment report from reliable sources, the commissioning year information of 153 coal power units is found. For the remaining 14 units (a total installed capacity of $1.5 \mathrm{GW}$ ), we fill the data gap by adopting the mean commissioning year of the units who (1) are located in the same province, (2) use the same feedstock, (3) generate electricity by the same technology, and (4) have a similar capacity size (within three standard deviations) (Davis and Socolow, 2014). A retirement pathway is designed for the installed power plants by assuming a lifetime of 40 years. This lifetime of coal power plant is an average value, which is calculated from globally retired units before 2016 (in total 2968 retired units). The average lifetime matches with values found in literature sources (Farfan and Breyer, 2017; Qin et al., 2019).

Although the WEPP database includes the administrative-level information, the exact latitudes and longitudes per unit are missing. Thus, we collect the geocoordinates for each power plant unit, of which $85 \%$ of the units' coordinates (accounting for $97 \%$ 
of existing installed capacity) is obtained from the Global Energy Monitor (2019), the Global Power Plant Database (Byers et al., 2019), the Global Energy Observatory (Los Alamos National Laboratory, 2018), the Worldwide Industrial Information (IndustryAbout, 2019) and Enipedia Database (Davis et al., 2015). The remaining $15 \%$ of units are generally small, with an average capacity of $70 \mathrm{MW}$. The geographical information of these small coal units is captured using the Google Maps on the basis of physical address information recorded in the WEPP (e.g. company, street, county and city). Google Earth is also used to accurately determine the coordinates of individual power plants through identifying power plant characteristics (e.g. on-site fuel storage, power houses and flue stacks) from the captured high-resolution satellite imagery.

The WEPP database does not provide unit operation and emission parameters, such as pollutant stack concentration, removal efficiency of end-of-pipe measures and thermal efficiency. We cross-checked unit-based parameters with CEC-China Electricity Council (unit > $100 \mathrm{MW}$ ), Tang et al. (2019) (unit < 100MW) and China Renewable Energy Outlook (unit $<100 \mathrm{MW}$ ), and collected the information of around 2,500 units in WEPP, equivalent to $65 \%$ of the operational coal capacity in 2016 . From the collected emission factors and thermal efficiencies, general values are derived for technology categories (see Table 5.1). The results are cross-checked with data on coal-fired power plants in the Energy Technology Systems Analysis Program (IEA-ETSAP). The unitbased emission factors and thermal efficiencies are applied to fill the missing data for the remaining $35 \%$ of the capacity.

Table 5.1. Energy and emission characteristics of China's coal-fired power units.

\begin{tabular}{lcccccccc}
\hline Technology & $\begin{array}{c}\text { Unit size } \\
(\mathbf{M W})\end{array}$ & $\begin{array}{c}\text { Thermal } \\
\text { efficiency }(\%)\end{array}$ & \multicolumn{3}{c}{$\begin{array}{c}\text { Emission factors with controls } \\
(\mathbf{g} / \mathbf{k W h})\end{array}$} & $\begin{array}{c}\text { Emission factors w/o controls } \\
(\mathbf{g} / \mathbf{k W h})\end{array}$ \\
\hline Subcritical & $<100$ & 35 & $\mathbf{S O}_{\mathbf{2}}$ & $\mathbf{N O}_{\mathbf{x}}$ & $\mathbf{P M}$ & $\mathbf{S O}_{\mathbf{2}}$ & $\mathbf{N O}_{\mathbf{x}}$ & $\mathbf{P M}$ \\
& $100-299$ & 0.67 & 0.64 & 0.16 & 13.34 & 2.56 & 56.79 \\
& $300-599$ & 39 & 0.36 & 0.32 & 0.10 & 9.29 & 1.61 & 27.05 \\
& $\geq 600$ & 41 & 0.26 & 0.25 & 0.05 & 8.52 & 1.56 & 26.02 \\
& & & 0.22 & 0.19 & 0.03 & 7.63 & 1.32 & 13.25 \\
Supercritical & $<300$ & 36 & 0.30 & 0.23 & 0.04 & N/A & N/A & N/A \\
& $300-599$ & 40 & 0.18 & 0.19 & 0.04 & 5.04 & 1.18 & 30.56 \\
& $\geq 600$ & 42 & 0.15 & 0.17 & 0.03 & 5.75 & 1.06 & 14.91 \\
USC & $\geq 600$ & 45 & 0.08 & 0.12 & 0.02 & 3.58 & 0.68 & 9.74 \\
IGCC & 46 & 0.05 & 0.07 & 0.02 & N/A & N/A & N/A \\
\hline N/A, not applicable. & & & & & & & &
\end{tabular}

\subsubsection{Energy efficiency technologies}

A total of 175 commercially available electricity-saving measures is included in this study to pursue a sustainable industry in China. Specifically, 31 technologies for the 
iron \& steel sector, 32 technologies for cement, 61 technologies for the chemical sector, 31 technologies for the aluminium sector and 20 technologies for the pulp \& paper sector are compiled in the technology database. The technologies are applied to different production processes per sector (e.g. alumina refining, aluminium smelting, anode making and general measures in aluminium sector). The detailed characteristics of each energy efficiency technology (e.g. electricity saving, installed cost, lifetime and market share) are derived from published research articles (e.g. Yue et al., 2018; Zhang et al., 2016; Liu et al., 2017; Zhang et al., 2018)), technical books (e.g. Dai et al., 2013; China Chemical Energy Efficiency Technology Association, 2006)) and government official documents (e.g. National Development and Reform Commission of China, 2018; Ministry of Industry and Information Technology of China, 2013)), while taking into account their reliability. In this study, process structure changes are reflected by production yield adjustments. For example, caustic soda can be produced by both the diaphragm and ion-exchange membrane processes. As the diaphragm process is being phased out, the yields of diaphragm-based caustic soda production is assumed to be 0 after 2020 (Yue et al., 2018; Crijns-Graus et al., 2020).

\subsubsection{Cost parameters of end-of-pipe measures}

The ECLIPSE V5a global emission fields (IIASA, 2015), included in the GAINS model, is used to simulate the installation cost and operation cost of flue gas control measures for China's coal power plants at a provincial level. The ECLIPSE database considers 3,500 pollutant control measures, and provides detailed information (e.g. capital cost, catalyst cost, sorbent cost and capacity control rate) for air pollution control in power and industrial plants, at a regional level. The Electricity and fuel (coal, gas and oil) prices at provincial level are obtained from NDRC of China (National Development and Reform Commission of China, 2014-2019; National Development and Reform Commission of China, 2013-2019), NEA of China (National Energy Administration of China, 2018) and IEA-WEO (IEA, 2018c) (see Appendix). Although the base year in our study is 2016, our data are all derived at the end of 2016. The technology cost and energy prices are converted to 2017 constant prices in \$ (2017\$).

\subsection{Results}

The research results are presented progressively in four ways, which address the proposed subgoals that answer the main purpose of assessing the multiple benefits of actions to reduce industrial electricity demand for removing coal-fired power capacity and thus improving air quality. The results begin with a unit-based overview of China's coalfired power plant fleet in terms of geolocation, generation technology, installed capacity, electricity generation and air emission levels, across China's provinces. Subsequently, the technology-driven electricity savings by industries at regional level are presented in subchapter 3.2. The quantified impacts of industrial electricity savings on displacing coal- 
fired power capacity and reducing air pollutant emissions from electricity generation are given in subchapter 3.3; and finally, the cost analysis results of different emission control strategies are drawn in subchapter 3.4 .

\subsection{Commissioning coal power fleet in 2016}

Figure 5.1 shows the location of installed coal-fired power plants in 2010 and 2016 including capacity size categories, generation technology, and sum of electricity generation. With surged electricity requirements, the total installed coal-fired power capacity in China increased by 41\%, from $671 \mathrm{GW}$ in 2010 to $946 \mathrm{GW}$ in 2016. Around 640 coal-fired units, with a total capacity 295 GW, came online after 2010, of which $40 \%$ consisted of ultra-supercritical capacity. Meanwhile, only 200 subcritical coal units, with a combined capacity of $20 \mathrm{GW}$, retired during 2010-2016, which is far less than the newly commissioned capacity. The subcritical steam generator operates at low pressure, resulting in a comparatively low thermal efficiency, particularly for unit sizes of less than $300 \mathrm{MW}$. Although the retired units are all subcritical coal units, the less-efficient coal fleet with a total installed capacity of $524 \mathrm{GW}$ still is the backbone of the electricity supply in 2016. As shown in Figure 5.1, China's electricity generation from the subcritical coal fleet accounts for $57 \%$ of total power generation in 2016, following by the supercritical fleet (25\%). While the high efficiency low emissions (HELE) fleet consisting of ultra-supercritical (USC) and integrated gasification combined cycle (IGCC) units contribute to only $18 \%$ of the country's electricity.

Most of the coal-fired power plants were deployed in coal-rich inland provinces (e.g. Shanxi, Inner Mongolia and Shaanxi) and power-hungry coastal regions (e.g. Shanghai, Jiangsu, Zhenjiang and Guangdong). The uneven distribution of coal power plants shows resource and demand oriented deployment patterns. This means that the North and East grids are the two largest coal power bases, which together account for $50 \%$ of the total installed capacity in 2016 (see Figure 5.1). It is worth noting that the Northwest grid has seen a rapid expansion of its coal power fleet. The new capacity in service after 2010 is equal to the total installed capacity in 2010, of which $76 \%$ of the new capacity installed in Xinjiang and Shaanxi Provinces. The main driving forces are coal-electricity vertical integration strategies and energy-intensive industry development plan proposed by the policy of the Development of China's Western Region in 12th FiveYear Period (2011-2016) (National Development and Reform Commission of China, 2012). The Central and Southern grids have both expanded their coal fleet with around $50 \%$ in the period 2010-2016. This is in line with the overall expansion, meaning that their share in total installed capacity remains at around $30 \%$. This is below the share of the biggest grids North and East, which together account for $50 \%$ of capacity in 2016, coming down from 53\% in 2010. The Northeast gird covers only three provinces; Liaoning, Jilin and Heilongjiang, and has the smallest coal power fleet (covering 8\% of the installed coal power capacity in 2016). The regions in the Northeast grid are surrounded by traditional manufacturing industry, thus the demand for electricity is far 


\section{Chapter 5}

less than that in the eastern coastal and central regions. Only $5 \%$ of the new coal power capacity (that came online in the period 2010 to 2016) is installed in the Northeast grid, meanwhile, without the newly commissioned HELE units. Most of the new HELE plants are built in the East, Central and Southern grids (accounting for $81 \%$ of the total newly-built HELE capacity), which directly improves the coal generation performance in these three power grids.
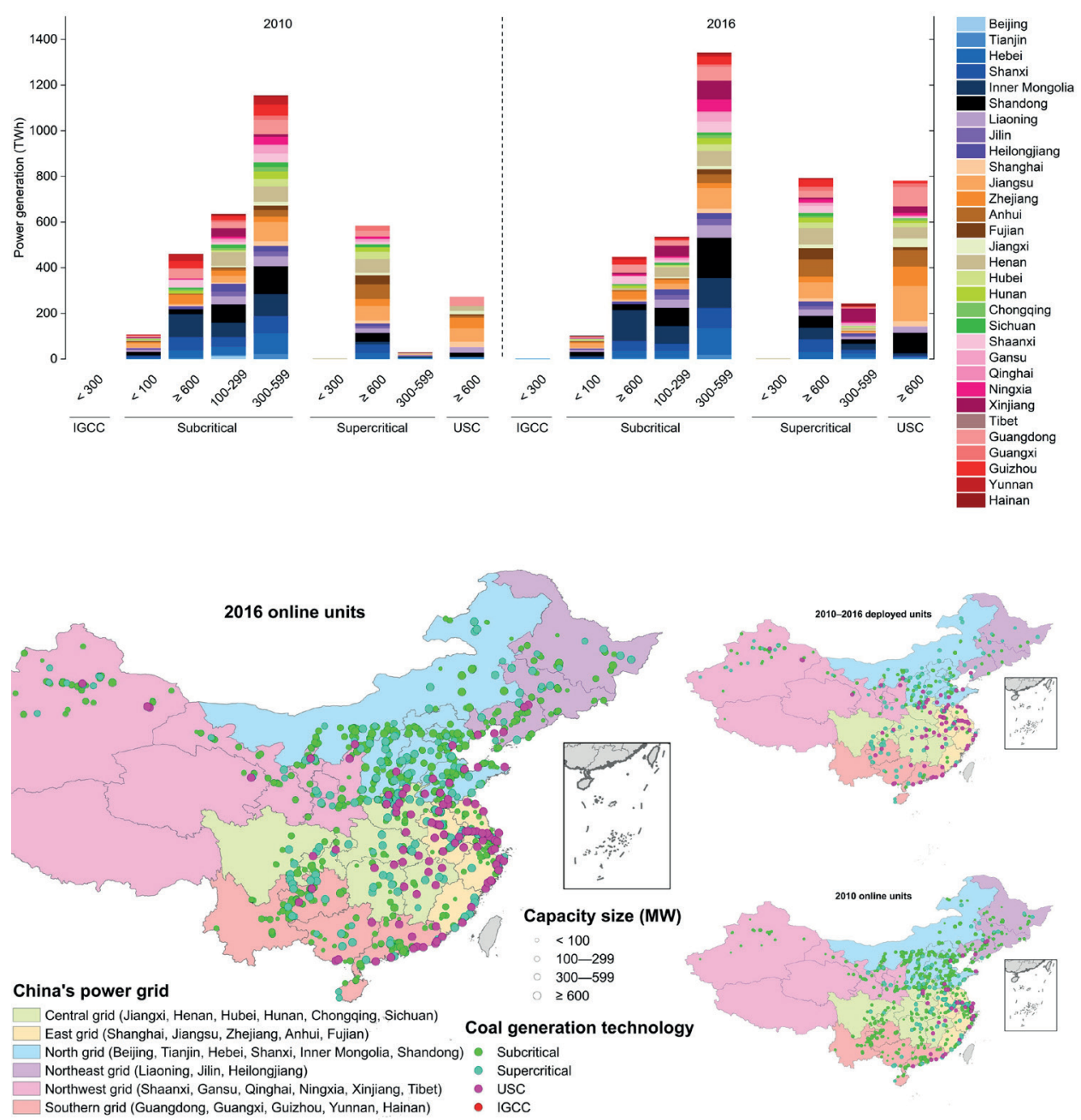

Figure 5.1. (Top) Electricity generation from coal power fleet by technology and capacity size at provincial level in 2010 and 2016. (Bottom) the distribution of coal power units in China's six power grids during 2010-2016. 
Figure 5.2 shows the air pollutants and $\mathrm{CO}_{2}$ emissions in 2016 for each province at technology level. The subcritical coal fleet generates the largest amount of electricity and emits the highest shares of power emissions $\left(78 \%, 80 \%, 76 \%\right.$ and $59 \%$ of $\mathrm{SO}_{2}, \mathrm{NO}_{\mathrm{x}}$, $\mathrm{PM}$ and $\mathrm{CO}_{2}$, respectively). Nevertheless, the small less-efficient units tend to be most polluting. The subcritical units with capacities below $300 \mathrm{MW}$ account for only $14 \%$ of total installed capacity, but contribute disproportionately to air pollution (representing $33 \%, 38 \%$ and $36 \%$ of total $\mathrm{SO}_{2}, \mathrm{NO}_{\mathrm{x}}$ and PM emissions, respectively). Conversely, the HELE units, with large capacity size ( $\geq 600 \mathrm{MW})$, with a share of $19 \%$ of total installed capacity, emits relatively few air pollutants (representing 6.0\%, 6.4\% and 6.5\% of total $\mathrm{SO}_{2}, \mathrm{NO}_{\mathrm{x}}$ and PM emissions). These characteristics are reflected in the six power grids (see Figure 5.2). The Northwest grid has a lower installed coal-fired capacity compared to the Central grid, but the air pollutant emissions in the Northwest gird (139 kt- $\mathrm{SO}_{2}$, $191-\mathrm{kt} \mathrm{NO}_{\mathrm{x}}$ and $\left.27 \mathrm{kt}-\mathrm{PM}\right)$ are larger than in the Central grid (125 kt-SO, $172 \mathrm{kt}-\mathrm{NO}_{\mathrm{x}}$ and $24 \mathrm{kt}-\mathrm{PM})$. This is particularly the case because the deployment share of HELE units in the Central grid (representing 21\% of the installed capacity in the Central grid) is much higher than that in the Northwest grid ( $9 \%$ of installed capacity in the Northwest capacity). A similar situation also appeared in the Northeast grid vs. the Southern grid. The higher share of HELE in the Central and Southern grids is a result of the increased new capacity installed after 2010, which accounts for $76 \%$ and $73 \%$ of total HELE installed capacity of the Central and Southern grids in 2016, respectively. Furthermore, the deployed coal capacity in the North grid is only $30 \%$ more than the East grid, while the North grid emits twice as much air pollutants as the East grid. The main reason is that around $25 \mathrm{GW}$ of subcritical coal capacity came online between 2010-2016 in the North grid, while only 5 GW of subcritical capacity are installed in the East grid in the same period. Therefore, an accelerated phaseout of these lessefficient and high-polluting units in each grid is critical for China to achieve the ultralow emission target (MEE et al., 2015) faster. Here, we identify the super-polluting power units that urgently need to be phased out (see Table 5.1). 

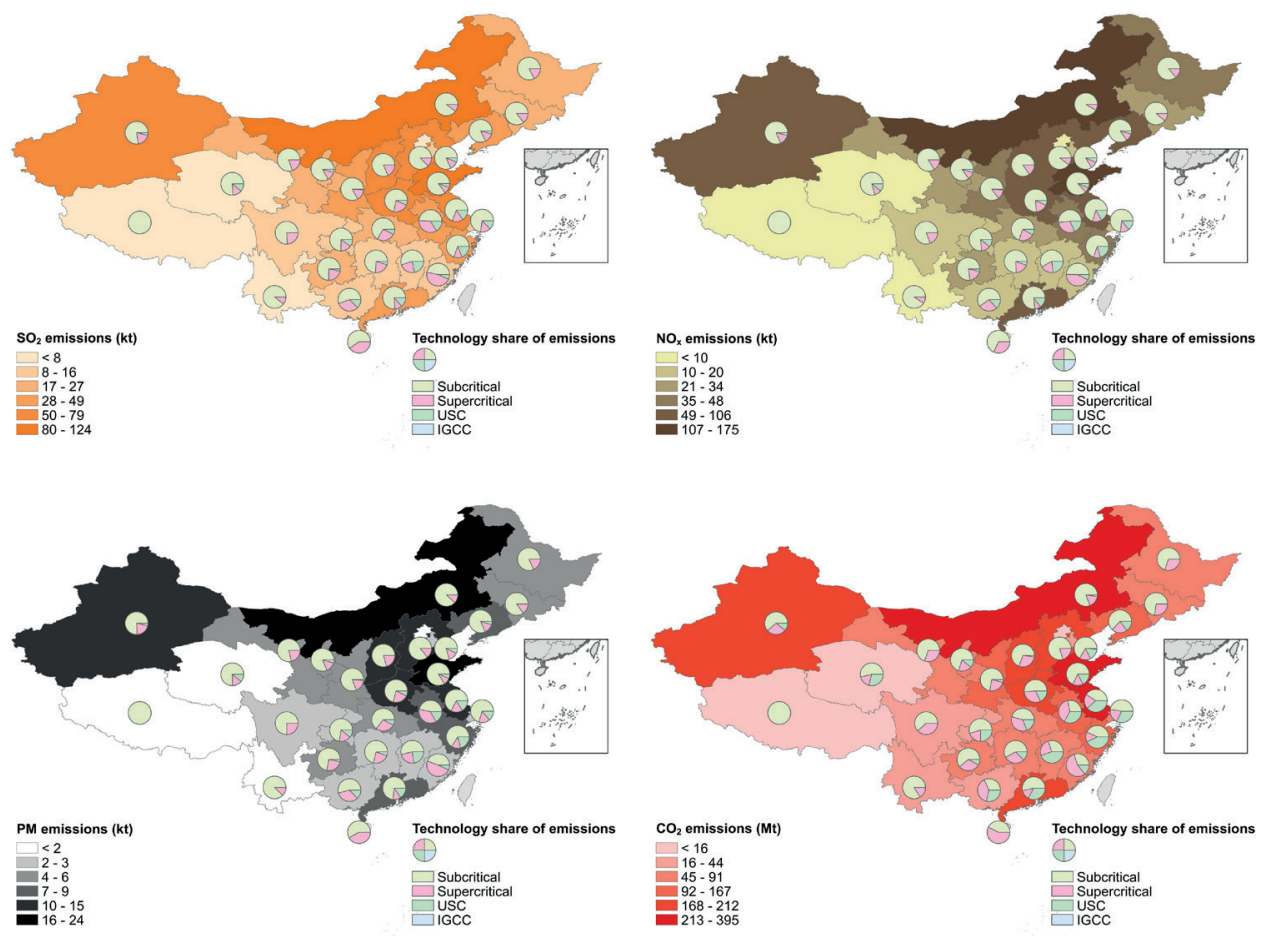

Figure 5.2. The emissions of air pollutants and $\mathrm{CO}_{2}$ in 2016 by generation technology at province level.

\subsubsection{Electricity savings by industrial sectors at power grid level}

The electricity consumption per energy-intensive industrial sector in 2040 is depicted in Figure 5.3, per power grid, under the BAU and EUM scenarios. The electricity demand at the national level undergoes a significant increase in the BAU scenario, with an annual growth rate of $1.4 \%$ during the period 2016-2040. Only the iron \& steel and cement sectors show a decreasing trend, by $21 \%$ and $36 \%$ in 2040, respectively, relative to 2016 . This is mainly because the production demand of crude steel (An et al., 2018; Wen et al., 2018; Ma et al., 2016; Zhang et al., 2018) and cement (Liu et al., 2017; Hasanbeigi et al., 2017; Zhang et al., 2016; Li et al., 2017) is expected to peak around 2020, and decrease by 2040 . Driven by the demand for primary aluminium and a vast array of chemicals (IEA, 2019a), China's aluminium and chemical sectors are key drivers for the growing electricity requirements. These energy-intensive industrial plants are mostly distributed in the North and Northwest regions (e.g. Hebei, Shandong and Xinjiang) and bring a heavy electricity supply burden to the local power grid. The ever-growing electricity demand in these industries can be effectively curbed by implementing energy efficiency measures (see Figure 5.3). In the EUM scenario, the total electricity demand in the industries drops by $16 \%$ and $24 \%$ in 2030 and 2040 , respectively, compared to the BAU scenario. The annual curbed electricity demand by 2040 (506 TWh) is equivalent to the total electricity consumption by the industrial users in Northeast, 
Northwest and Southern grids in 2016. The iron \& steel and aluminium sectors are the two largest contributors to the total electricity savings, which together provide $63 \%$ of the reduction by 2040 , followed by the chemical (21\%) and cement sector (11\%). Although the pulp \& paper sector has the smallest contribution $(5 \%)$ to the electricity reduction, it holds a substantial potential to improve its own end-use efficiency (27\% of unreleased potentials). The electricity saving potentials of each industrial subsector vary among the six power grids.

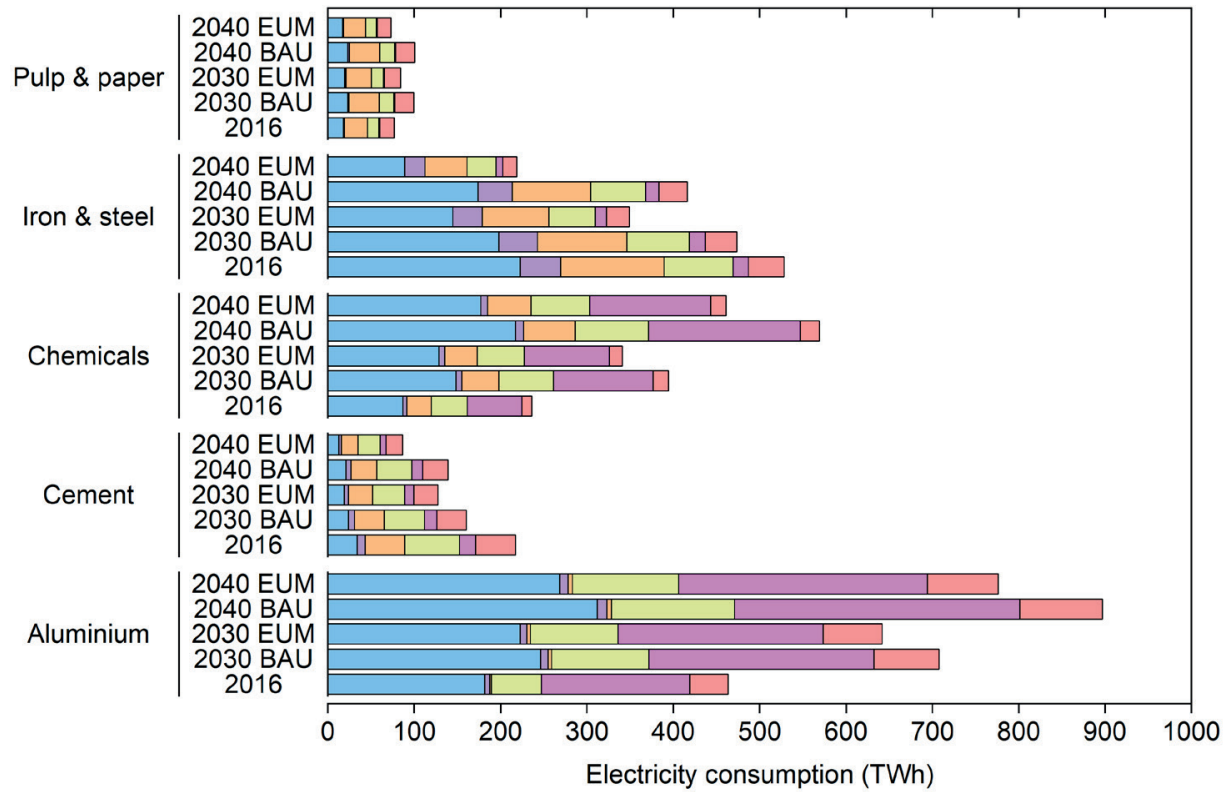

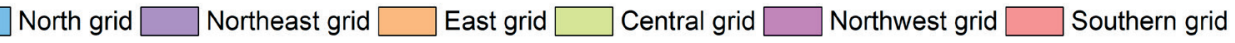

Figure 5.3. Electricity demand per industrial sector for each power grid in 2030 and 2040 under the BAU and EUM scenario. 

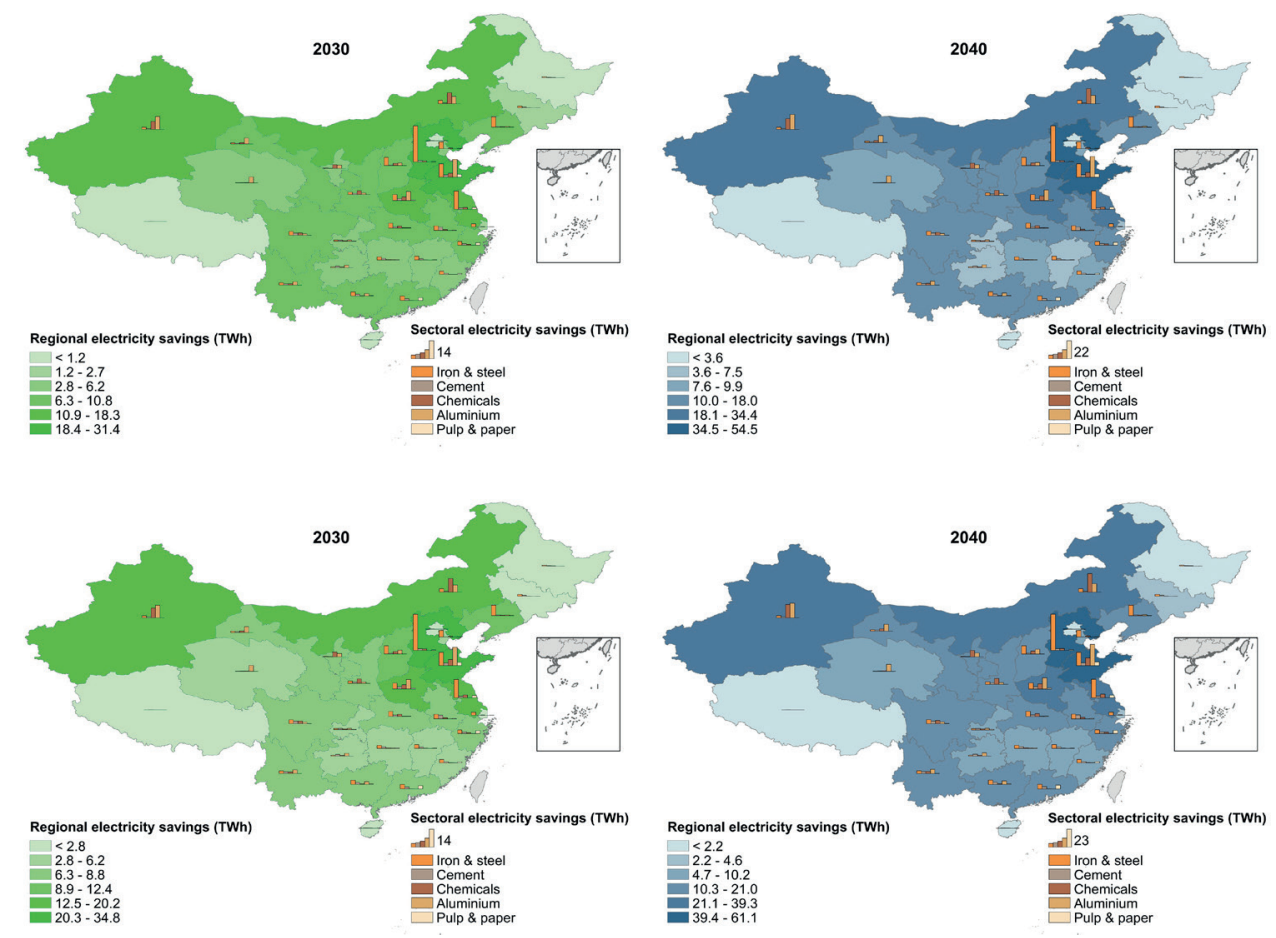

Figure 5.4. Electricity savings by industrial sectors at a regional level in 2030 and 2040 . The top two figures represent the cost-effective electricity savings, and the bottom two figures show the technical electricity savings in 2030 and 2040.

To compare the regional variations, as shown in Figure 5.4, we explored the sectoral electricity savings from an economic perspective at a regional level in 2030 and 2040. Around 182 TWh of electricity use in 2040 can be reduced in the North grid, contributing to the largest share of national electricity savings (36\%). While the iron $\&$ steel sector provides $47 \%$ of the electricity reductions in the North grid. As most of the emerging industries are based in Gansu, Ningxia and Xinjiang, the Northwest grid also provides considerable electricity reductions by 2040 , accounting to $18 \%$ of total electricity savings. The chemical and aluminium sectors are the two largest contributors in the Northwest grid, which together represent $85 \%$ of electricity savings. Provinces (e.g. Henan, Hubei and Sichuan) in the Central grid, with dominant cement and chemicals production, show a significant reduction of electricity use (86 TWh), representing 17\% of national electricity reductions. Developed coastal regions (e.g. Guangdong, Zhejiang and Shanghai) are located in the East and Southern grids, which have small scale energyintensive industries. Therefore, the contributions of electricity savings provided by the East grid and Southern grids are relatively small, which together can decrease $123 \mathrm{TWh}$ of electricity use. The Northeast grid contributes to only 5\% of electricity demand reductions. Although the smallest reductions are obtained from the Northeast grid, this 
grid has more opportunities to improve energy efficiency than the other power grids, in a relative sense. This is because the regions (Liaoning, Heilongjiang and Jilin) in the Northeast grid are old industrial bases that operate with substantially less-efficient equipment, leading to large electrical energy losses. The maps also demonstrate the many energy efficiency measures are cost-effective and as such are often preferable to alternatives. In totally, more than $90 \%$ of electricity savings between 2030 and 2040 can be accessed by cost-effective measures. Specifically, cost-effective opportunities can provide around $91 \%, 94 \%, 91 \%, 92 \%, 91 \%$ and $89 \%$ of electricity savings in the North, Northeast, East, Central, Northwest and Southern grid by 2040, respectively.

\subsubsection{Displaced coal power capacity and synergies of emission reductions} Electricity savings in China's energy-intensive industries can displace a total of $108 \mathrm{GW}$ coal-fired power capacity by 2040 , which can help to achieve the target of annually phasing out $4 \mathrm{GW}$ less-efficient units (National Development and Reform Commission of China, 2017). Retiring coal-fired power plants, coupled with improving demandside energy efficiency can not only meet future electricity demand, but is particularly important for the transition to a sustainable industry and coal-free power generation. Here, a unit-by-unit phaseout strategy for the coal-fired power plant fleet at grid level is presented in Table 5.2, which considers less-efficient and high-polluting units to be a priority in substitution. Considering the regional heterogeneity, we find that the industrial efficiency improvements can drive around $84 \%$ of the most polluting units (existing subcritical units with size $<300 \mathrm{MW}$ ) into early retirement and allow an accelerated $38 \mathrm{GW}$ of older power plants phaseout (consisting of $37 \mathrm{GW}$ subcritical and $1 \mathrm{GW}$ supercritical coal power capacity). Besides displaced existing units, around 6 GW of newly proposed coal power projects, particularly subcritical coal plants, can be cancelled under the EUM scenario.

The North grid undoubtedly has the most potential for removing coal power plants (accounting for $28 \%$ of the total offset coal capacity), because of the largest electricity savings. An interesting finding is that the Northwest grid has a larger electricity saving than the Central grid, but the displaced coal capacity in the grid (18 GW) is lower than the Central grid $(24 \mathrm{GW})$. This is because the utilization level (capacity factor) of coal generation capacity in the Central grid is much lower than the Northwest grid. The electricity supply by regions located in the Central grid, like Sichuan and Hubei, depends on the renewables power fleet, especially on hydropower. Although the Northwest grid has deployed $29 \%$ and $40 \%$ of national installed capacity of wind and solar, respectively, the serious wind and solar curtailment issues causes the heavy dependence of the Northwest grid on coal power. Similarly, the Southern grid has deployed a large share of hydropower capacity in power supply system, thus the potential for early retiring coal units in the Southern gird (17 GW) is higher than the East grid (15 GW). Liaoning and Heilongjiang located in the Northeast grid have rich coal resource but poor hydro energy. Compared to the (still) low generation cost of coal, the intermittent generation 
from wind and solar has a negative market competitiveness in the Northeast grid (China Electricity Council, 2018; Energy Research Institute and National Renewable Energy Centre of China, 2018). Only $4 \mathrm{GW}$ of coal power capacity can be taken offline in the Northeast grid because of the low electricity savings.

Figure 5.5 depicts the emission levels of air pollutants from coal-fired power plant fleet, distinguished by the vintage year of units, are plotted for the year 2040 under BAU and EUM scenarios. Although the coal power fleet is expanded by 2040, the emissions levels of air pollutants from the coal power fleet in the BAU in $2040\left(1021 \mathrm{kt}-\mathrm{SO}_{2}, 1381 \mathrm{kt}-\right.$ NOx and $198 \mathrm{kt}-\mathrm{PM}$ ) are close to the 2016 values. The reason is that around $85 \%$ of the new capacity are HELE units with low emissions, while some old, less-efficient units are decommissioned in the period up to 2040, at the end of their lifetime (see Figure 5.5). The ambient air quality has a significant potential to be improved by the early retirement of super-polluting units (age < 40 years in 2040). The current emission levels of $\mathrm{SO}_{2}$, $\mathrm{NO}_{\mathrm{x}}$ and PM would be decreased by $217 \mathrm{kt}, 346 \mathrm{kt}$ and $41 \mathrm{kt}$, with a reduction of $21 \%$, $25 \%$ and $21 \%$ by 2040 , respectively. Comparing the BAU with the EUM scenarios, air pollutant emissions in the EUM scenario are reduced by $224 \mathrm{kt}-\mathrm{SO}_{2}, 336 \mathrm{kt}-\mathrm{NO}_{\mathrm{x}}$ and $45 \mathrm{kt}-\mathrm{PM}$ in 2040. Around $78 \%, 81 \%$ and $80 \%$ of the reduced $\mathrm{SO}_{2}, \mathrm{NO}_{\mathrm{x}}$ and $\mathrm{PM}$, respectively, are provided by the early retirement of the most polluting units. Curbed construction of new plants also plays a key role in avoiding air pollutant emissions, which totally contribute to $4 \%, 3 \%$ and $3 \%$ of the $\mathrm{SO}_{2}, \mathrm{NO}_{x}$ and $\mathrm{PM}$ reductions, respectively.

Due to the different electricity saving potentials and installed share of coal generation technology, the emission reductions of air pollutants vary among the six power grids. The North grid emits $38 \%$ of total air pollutants in 2040 in the BAU scenario, including $391 \mathrm{kt}-\mathrm{SO}_{2}, 530 \mathrm{kt}-\mathrm{NO}_{\mathrm{x}}$ and $74 \mathrm{kt}-\mathrm{PM}$. This is because the regions (e.g. Shanxi, Inner Mongolia and Shandong) located in the North grid have deployed a large number of super-polluting generation units (around $30 \mathrm{GW}$ installed capacity in 2040). Displacing these units due to the reduced electricity load leads the North grid to the largest contributor to the air pollutant emission reductions (avoiding $85 \mathrm{kt}, 129 \mathrm{kt}$ and $17 \mathrm{kt}$ of $\mathrm{SO}_{2}, \mathrm{NO}_{\mathrm{x}}$ and PM emissions, respectively). Driven by the electricity demand in coastal regions (i.e. Zhejiang, Jiangsu and Fujian), the coal power fleet in the East grid shows a rapid expansion during the period 2016 to 2040, resulting from a share of $23 \%$ in newly installed coal-fired power generation capacity, and emits $17 \%$ of total air pollutants in 2040. However, the potential of removing coal capacity in the East grid are lower than the Northwest grid (see Table 5.2), which results in a lower contribution by the East grid to the emission reductions (representing $16 \%, 15 \%$ and $15 \%$ of total $\mathrm{SO}_{2}$, $\mathrm{NO}_{\mathrm{x}}$ and $\mathrm{PM}$ emission reductions, respectively). Around $38 \mathrm{kt}, 59 \mathrm{kt}$ and $8 \mathrm{kt}$ of $\mathrm{SO}_{2}$, $\mathrm{NO}_{\mathrm{x}}$ and PM emissions, respectively, can be avoided in the Northwest grid. It is worth noting that the Central grid can deactivate more coal capacity than the East gird, but decreases air pollutant emissions slightly lower than the East grid. This is because the East 
grid has more potential on decommissioning the units with the poorest performance, compared to the Central grid. This is also reflected in the Southern and Northeast gird that together contribute to $14 \%$ of the total avoided air pollutant emissions (reducing $32 \mathrm{kt}-\mathrm{SO}_{2}, 48 \mathrm{kt}-\mathrm{NO}_{\mathrm{x}}$ and $\left.6 \mathrm{kt}-\mathrm{PM}\right)$. The displaced coal capacity in the Southern grid is four times as high as in the Northeast grid, while the emission reductions of $\mathrm{SO}_{2}, \mathrm{NO}_{\mathrm{x}}$ and PM are only 45\%, 48\% and 43\% higher than the Northeast grid. $\mathrm{CO}_{2}$ emission reductions are discussed in Section 5.4 .
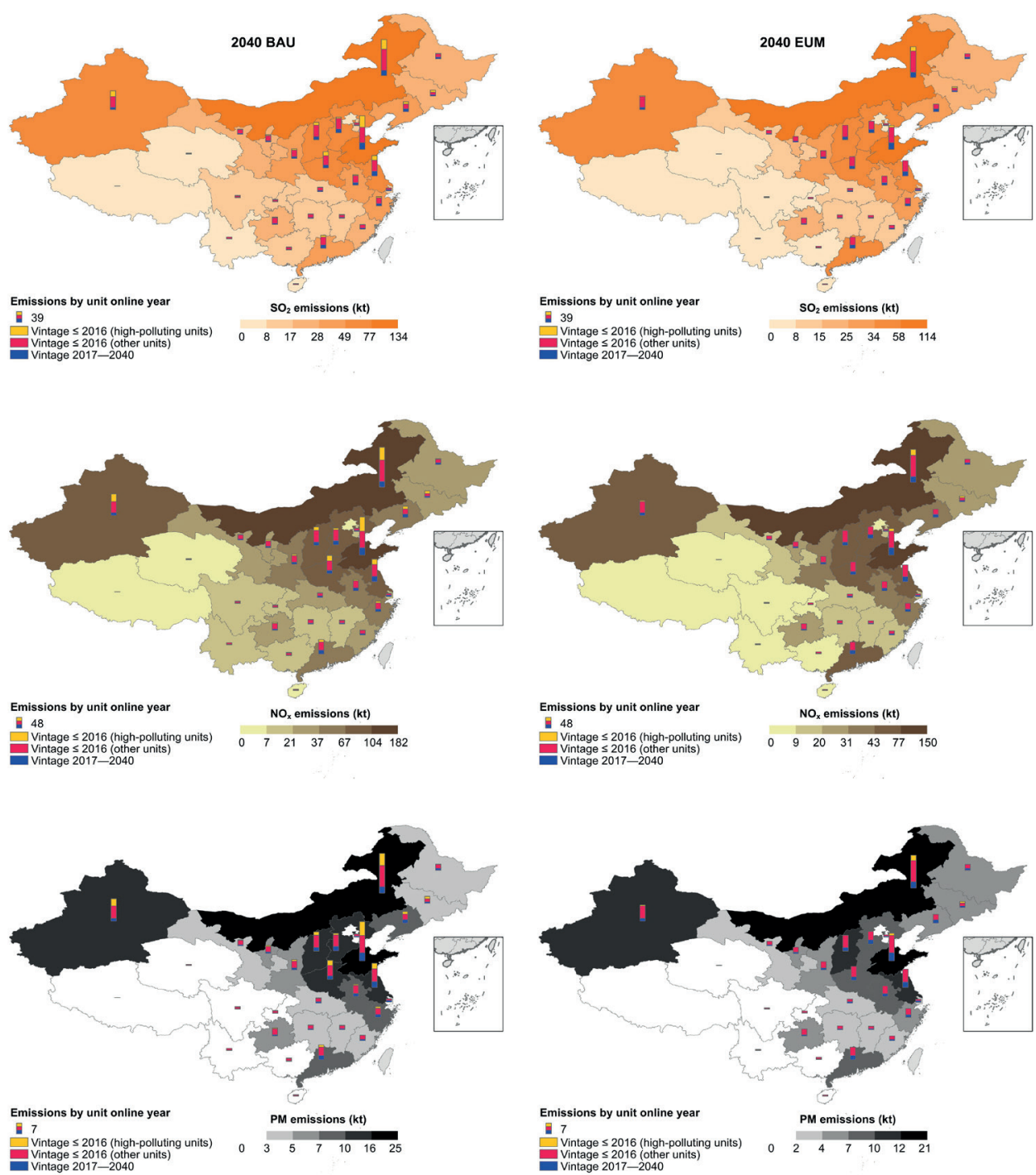

Figure 5.5. $\mathrm{SO}_{2}, \mathrm{NO}_{\mathrm{x}}$ and $\mathrm{PM}$ emissions from coal power units by the vintage year for each province in 2040 under the $\mathrm{BAU}$ and EUM scenarios. 


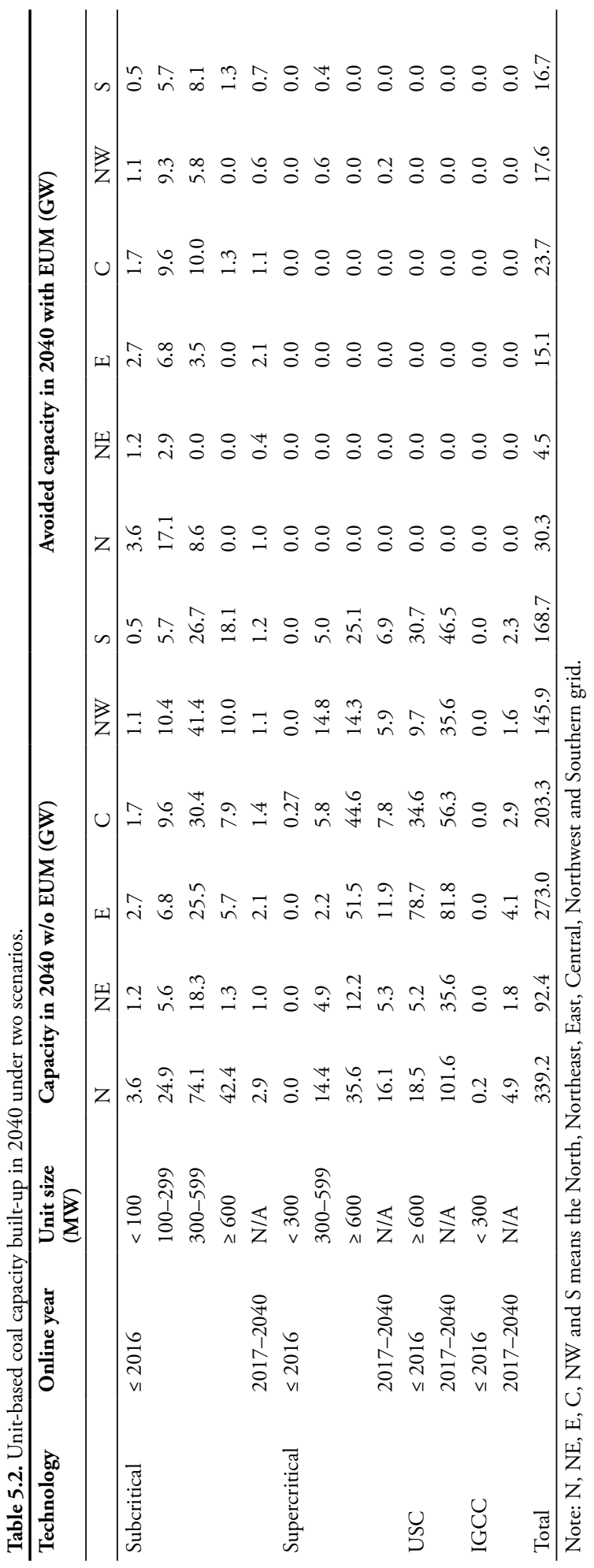


a

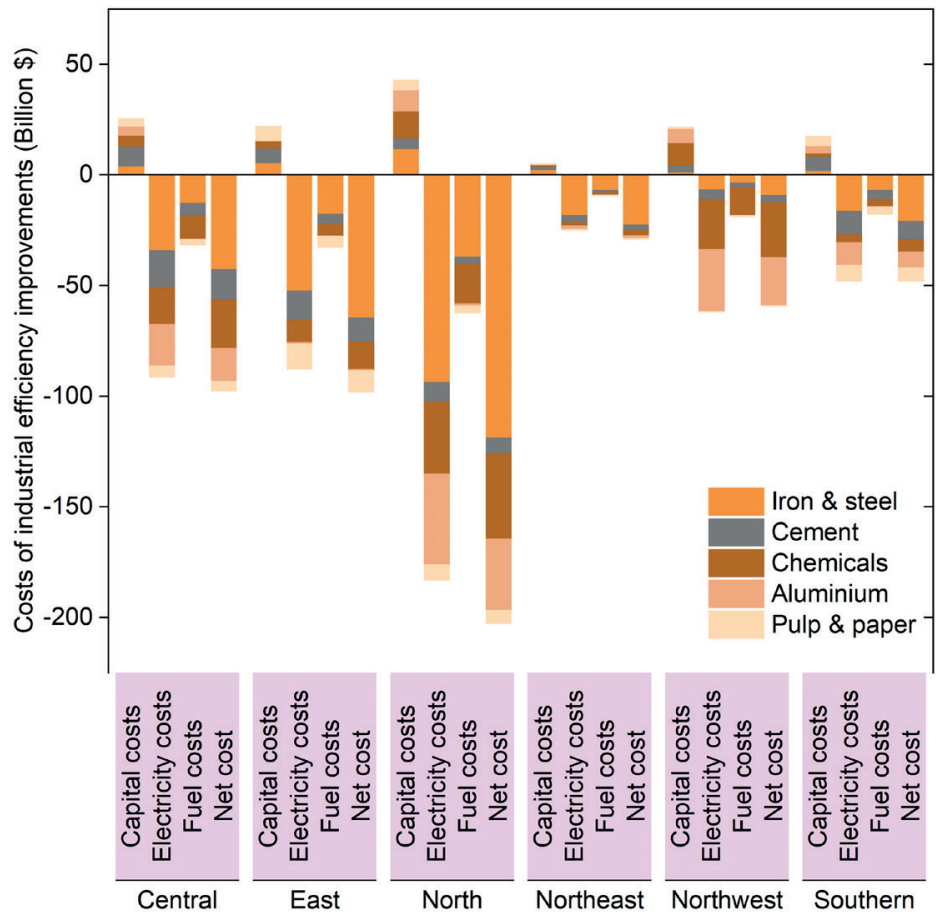

b

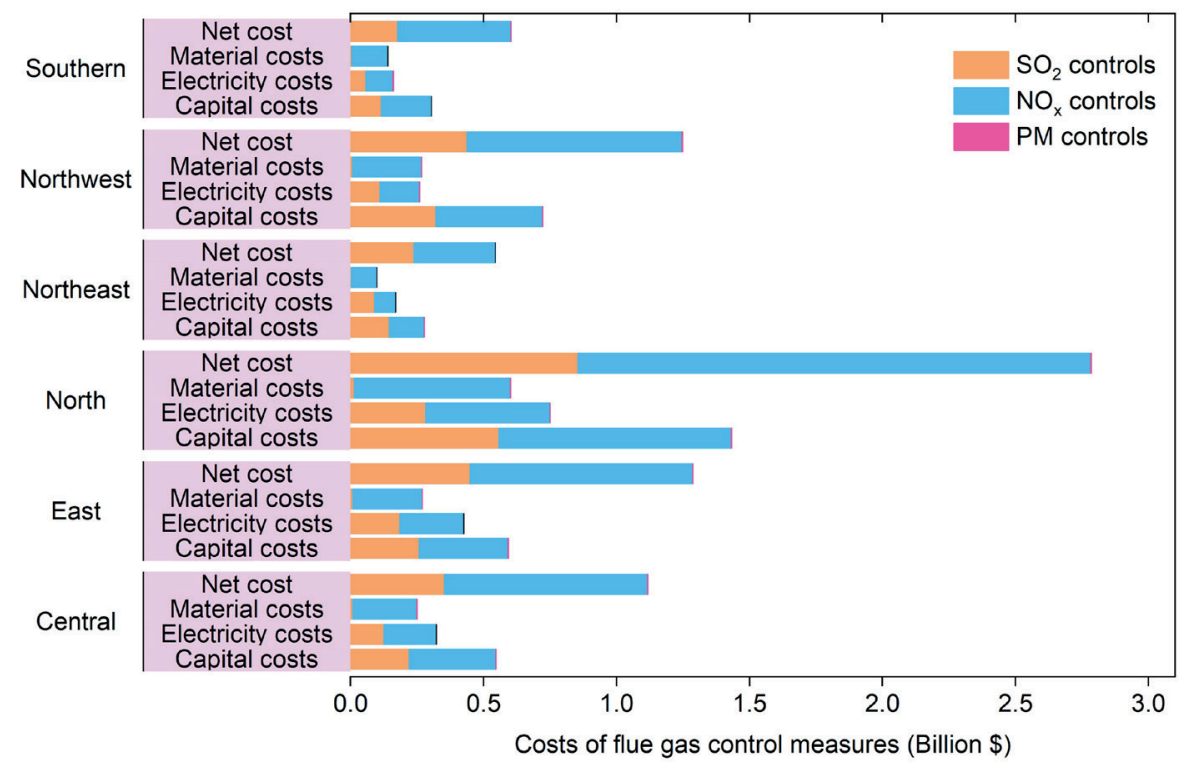

Figure 5.6. Cost portfolios of air pollutant reductions by 2040 under EUM (a) and APC (b) scenarios. 


\subsubsection{Portfolio costs of air pollutant reductions}

Figure 5.6 compares the costs of air pollutant abatement for six power grids between EUM and APC scenarios. The capital expenditures on energy efficiency improvements in industries are much higher than those of the flue gas control technologies, when avoiding the same levels of air pollutant emissions in both scenarios (see Figure 5.5). However, energy efficiency technologies can significantly cut the energy bills because of conserved electricity. Investors can expect to recover all of their initial investment within 2-15 years, whereas costs of pollution abatement equipment are not recovered (without a price for air pollutant emissions). Besides the energy benefits, the curbed coal-fired power plants avoids investing $\$ 4$ Billion by 2040 . However, the installed end-of-pipe treatment measures, in particular the $\mathrm{SO}_{2}$ and $\mathrm{NO}_{x}$ treatment measures, would further induce additional bills of energy and material (e.g. sorbent and catalyst) consumption (see Figure 5.6b). The cost comparison reveals that reducing coal-fired power generation by electricity savings in consumer is a more cost-effective way to clean the air than endof-pipe control.

The capital expenditures to conserve electricity, and the energy profits show a large variation per industrial sector (see Figure 5.6a). The biggest savings potential in absolute sense is found in the iron \& steel industry, followed by the chemical, the aluminium, the cement and the pulp \& paper sector. The payback time is shortest for the iron $\&$ steel sector, followed by the aluminium and chemical sectors. The cement and pulp \& paper sectors have a relatively longer investment return periods, around 10 years. From an economic perspective, these results suggest that policy should prioritize investing in energy efficiency improvements in the iron \& steel sector.

The results per grid level show that a massive investment should be allocated to industry in the North grid in both scenarios, due to the large potential to mitigate air pollutants. The investment in end-of-pipe treatment measures is directly related to the air pollutant reductions in the coal-fired power fleet. The net abatement costs for the six grids under the EUM scenario are all negative, which means the energy returns from industrial efficiency improvements offset the initial investments during their lifetime. The largest energy return is gained in the North grid, which reduced $\$ 245$ Billion energy costs (representing 37\% of total economic returns). This is because the iron \& steel plants are mostly located in this grid (e.g. in Hebei and Shandong), which provide substantial potentials of electricity and fossil fuel savings. Interestingly, the Northwest grid requires a lower capital investment ( $\$ 21$ Billion) to improve energy efficiency but displaces relatively more air pollutant emissions from coal power plants under the EUM scenario, compared to the East and Central grids. However, the energy returns in the Northwest grid ( $\$ 81$ Billion) are lower than the East and Central grids ( $\$ 120$ and 123 Billion, respectively). This is particularly because the electricity prices in the Northwest grid (average $0.06 \$ / \mathrm{kWh}$, excl. Tibet) are much lower than that in the East (average 0.10 $\$ / \mathrm{kWh}$ ) and Central grids (average $0.09 \$ / \mathrm{kWh}$ ). The lowest amount of investment 
in the EUM scenario is spent in the Northeast grid, providing \$34 Billion of energy conservation income, which is also lower than in the other grids. It is worth noting that the reduction potential of air pollutants in the Northeast grid are considerable, which are similar to the Southern grid as we discussed in Section 5.3.3. Although electricity prices will affect electricity saving benefits to a certain extent, the expenditures on the efficiency projects would be gained back. The central government should give attention to the North, Northwest and Northeast grids, which provide strong value-for-money emission reductions.

\subsection{Discussion}

This study linked demand-side and supply-side, on technology level, to co-manage electricity savings, air pollution and climate change mitigation. An integrated framework was developed to quantify the pivotal role of industrial electricity savings to cut coal-fired power generation on the level of the individual unit to maximize benefits of mitigating air pollutant emissions for China's regional power grids. Furthermore, the costs of industrial efficiency improvements and retrofitting coal power plants with end-of-pipe controls are compared from multi-sectoral and multi-regional levels to understand the economic feasibility and optimize the investments of air pollutant reductions. There are still uncertainties that could impact the results. Therefore, we conduct a sensitivity analyses for three major factors. First, we design a joint scenario (see Methods and Materials) that simultaneously considers electricity load reductions and flue gas controls to model the emission changes of air pollutants. Secondly, the electricity savings measured from five energy-intensive sectors are extrapolated to the whole industry. Thirdly, $\mathrm{CO}_{2}$ emission reductions are discussed.

Figure 5.7 plots air pollutant emissions at power grid level in 2016 and 2040 for different scenarios. The efficient use of electricity that occurs in conjunction with flue gas controls of power plants can deliver deep emission reductions of air pollutants, compared to 2016. Comparing the EUM+APC and EUM scenarios, the total air pollutant emissions in the EUM are further reduced-10.5\%, $10.6 \%$ and $9.6 \%$ of $\mathrm{SO}_{2}, \mathrm{NO}_{\mathrm{x}}$ and $\mathrm{PM}$ by 2040 , respectively, because of decreased emission intensities of electricity generation. However, the additional emission reductions yielded by retrofitting coal-fired power plants with end-of-pipe measures are less important, compared to the phaseout of coalfired generation units. For example, only $7.4 \%$ and $7.7 \%$ of emission reductions of total air pollutants in the Northeast and Southern grids, respectively, are attributable to additional flue gas cleaning beyond the EUM scenario. This is because the most polluting units (displaced by electricity savings) still have high emission rates (see Table 5.1). Furthermore, installing the end-of-pipe control systems would substantially increase initial investments, plus considerable increased operation and maintenance costs. The added costs of the installed controls are particularly significant in the North 
grid, which has the largest coal-fired power plant fleet of the six power grids (see Figure 5.6). Meanwhile, the pollution abatement measures would result in an efficiency penalty of power generation by around 2\% for coal-fired units (EPA, 2018; Graus and Worrell, 2007), and drive the increase of GHG emissions (Peng et al., 2018). The results suggest that massive spending on pollution control measures, especially for small high-polluting units, may generally less economically attractive (Zhang et al., 2017; EPA, 2018) to tackle air pollutants compared to improving demand-side efficiency.

a

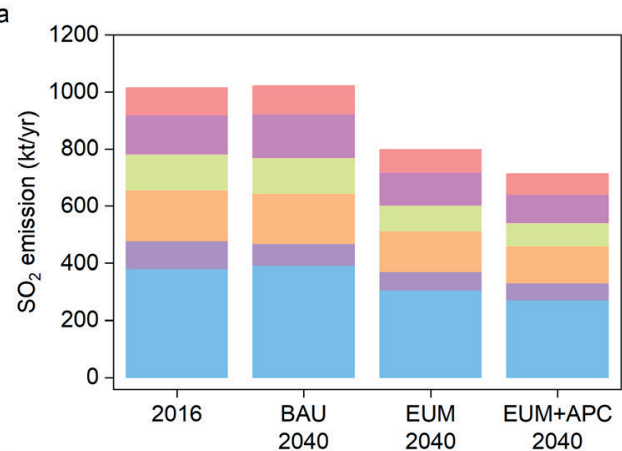

C

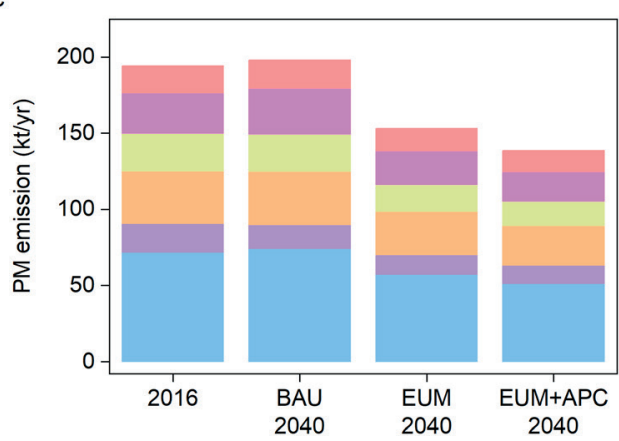

b

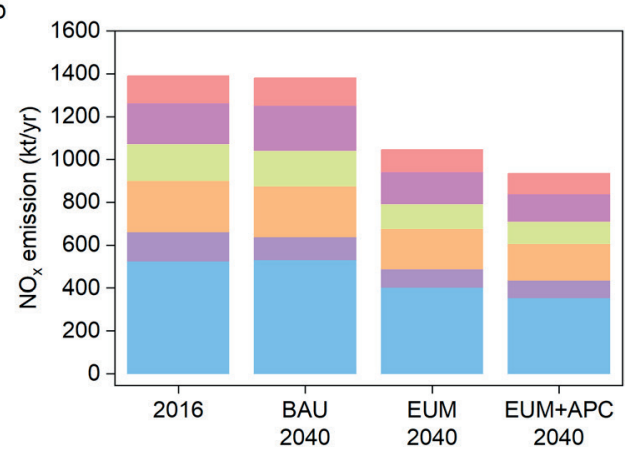

Figure 5.7. Air pollutant emissions at power grid level in 2016 and 2040 between different scenarios. Note, the air pollutant emissions in the APC scenario are not shown in this graph. Because we assumed the emissions levels are same as in the EUM scenario (see Methods and Materials).

This study estimates the technology-driven potentials of electricity savings in five energy-intensive industrial sectors, which represent around $50 \%$ of industrial electricity consumption in China. Quantifying technology-level impacts in the entire industry is difficult due to a lack of data. Here, we assume that the electricity savings potential (relative to the BAU scenario) in other industrial sectors is assumed to be the same as the five studied sectors to better understand the role of industrial electricity savings played in removing coal and improving air quality. A total of $595 \mathrm{TWh}$ additional electricity savings is expected to be obtained from other sectors in 2040, of which nearly $60 \%$ of the electricity savings are found in the East and Southern grids. The 
additional reduced electricity load can further displace $133 \mathrm{GW}$ of coal generation capacity by 2040 , as a result, which means that nearly all of the most polluting units can be closed. Considering the impacts for the entire industry, the largest potential of coal generation capacity phaseout is provided by the East grid (representing $25 \%$ of the total displaced coal capacity), followed by the Southern, Central, North, Northwest, and finally the Northeast grid, which contributes to the smallest reductions in coal-fired capacity (4\%). The offset coal-fired capacity provided by the other industrial sectors can significantly decrease the annual emissions of air pollutants in the EUM scenario, i.e. avoiding around $18.2 \%, 18.8 \%$ and $17.8 \%$ of $\mathrm{SO}_{2}, \mathrm{NO}_{\mathrm{x}}$ and $\mathrm{PM}$ emissions by 2040 , respectively. The main contributors to the additional emission reductions are the East and North grids, which together account for 54.8\%, 56.0\% and 55.6\% of the additional reductions of $\mathrm{SO}_{2}, \mathrm{NO}_{\mathrm{x}}$ and $\mathrm{PM}$, respectively. The sensitivity analysis reveals that the efforts of reducing electricity demand in the other industrial sectors would accelerate the achievement of a coal-free power generation and addressing air quality concerns. Therefore, we suggest that future research considers expanding the analysis to the other industrial sectors (e.g. plastic and textile sectors) at explicit technology level for a more comprehensive assessment.
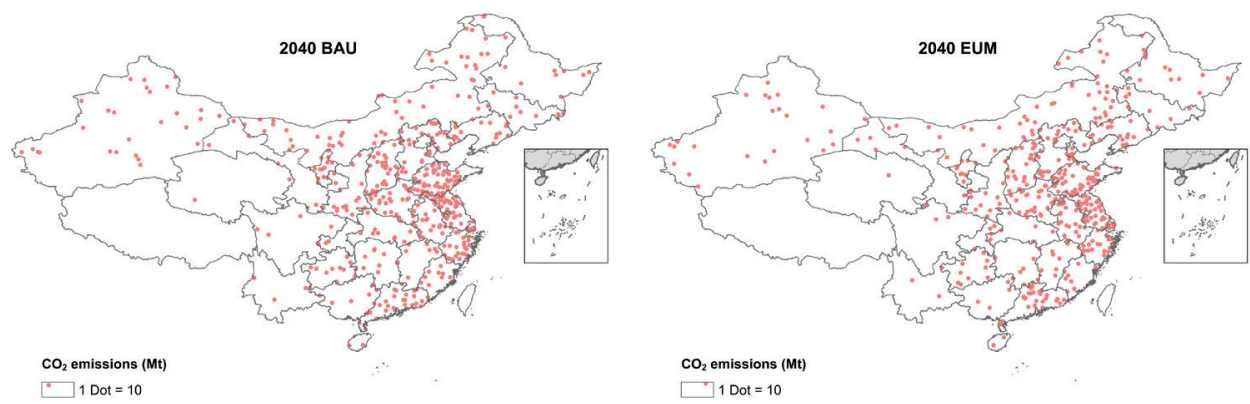

Figure 5.8. Provincial $\mathrm{CO}_{2}$ emissions in 2040 under the $\mathrm{BAU}$ and EUM scenarios.

Besides contributing to air quality, a rapid transition away from coal-generated electricity use is essential to mitigate climate change. Figure 5.8 shows the $\mathrm{CO}_{2}$ emission levels for each region in the BAU and EUM scenario. The $\mathrm{CO}_{2}$ emissions increase by $36 \%$ from 2016 to 2040 , with an average annual growth rate of $1.3 \%$, in the BAU scenario. This is because of the continuous expansion of the coal-fired power plant fleet, without the assumption of implementing carbon capture and storage (CCS) systems. Promoting the decommissioning of the least efficient coal-fired power plants in the EUM scenario can effectively slow the annual growth rate of $\mathrm{CO}_{2}$ emissions to $0.9 \%$, resulting in a total of $460 \mathrm{Mt}-\mathrm{CO}_{2}$ emission reductions in 2040, compared to the BAU scenario. The largest potential of $\mathrm{CO}_{2}$ emission reductions is discovered in the North grid, which represents 
$36 \%$ of the total avoided $\mathrm{CO}_{2}$ emissions. The Northwest (18\%), Central (17\%), East $(14 \%)$ and Southern (10\%) girds are close behind, and the lowest contribution is provided by the Northeast grid (5\%) due to the small electricity savings in this grid. Unlike the avoided air pollutant emissions, the contribution to carbon reductions among the six power grids follows the decline of coal-burning electricity. The thermal efficiency of coal-fired power plants has a small effect on the changes in $\mathrm{CO}_{2}$ emissions. This indicates that only shutting down the less-efficient coal power units by 2040 is not enough to limit the growing concentration of $\mathrm{CO}_{2}$ in the atmosphere, threatening the achievement of the Paris temperature goals. An ambitious coal-fired power generation reduction pathway, integrating demand-side savings should be designed to accelerate early decommissioning of existing coal plants and cancel as many newly proposed coalfired power plants as possible. Although deploying renewable energy to substitute coal in a power grid system can access zero emissions in the power sector (Millstein et al., 2017; Yang et al., 2018), the intermittent character (e.g. solar and wind) is highly susceptible to the ambient environment (Zhang et al., 2013; Habib et al., 2018); challenging the reliability of electricity supply (Energy Research Institute and National Renewable Energy Centre of China, 2018; IRENA, 2017; Mitchell, 2016). End-use efficiency improvements offer a cost-effective way to reduce the electricity load, thus help ensure grid stability and support high renewables penetration.

\subsection{Conclusions and policy implications}

\subsection{Conclusions}

Coal-intensive power supply systems, along with a fast-growing electricity demand driven by industry has caused serious air pollution and health concerns. This study develops a multi-sectoral and multi-regional framework to model the linkages between the industry and power sector to co-manage electricity savings and air pollution on various spatial scales. Cost analyses for different mitigation portfolios are conducted to identify the most cost-effective way to tackle air pollution. The results are processed in ArcGIS to capture the characteristics on provincial, grid and national administrative levels.

China's coal-fired power capacity has increased by $41 \%$ from 2010 to 2016, which drives the global expansion of the coal power fleet. The North and East grids include the two largest coal power fleets, holding steady at around $50 \%$ of the total installed coal power capacity. The Northwest grid is the fastest-growing region in terms of coal-fired power plants. China's power grids are dominated by subcritical generation technology, which provides $57 \%$ of electricity supply in 2016 . Subcritical power units, particularly of the size below $300 \mathrm{MW}$, are often the most polluting. The small subcritical units represent only $14 \%$ of total installed capacity, but contribute disproportionately to air pollution 
(accounting for 36\% of total air pollutant emissions). These units should therefore be a priority to shut down in all power grids (due to increasing electricity savings).

Energy efficiency improvements can decrease the industrial electricity demand by $24 \%$ in 2040. The iron \& steel sector contributes to the largest electricity savings, followed by the aluminium, chemical, cement and pulp \& paper sectors. Considering the regional characteristics, the electricity savings per sector differ for the six grids. The biggest electricity savings potential is found in the North and Northwest grids (representing $54 \%$ of the total electricity savings). This is because of the high concentration level of iron \& steel, aluminium and chemical plants in the included provinces. Furthermore, we find that around $90 \%$ of the electricity savings can be achieved cost-effectively.

The reduced electricity load, due to the industrial efficiency improvements, can scale down China's coal power fleet by $108 \mathrm{GW}$, which is equal to $62 \%$ of the existing coal capacity in the European Union. The regional utilization rate of coal-fired power capacity and the electricity saving potentials jointly determine the cut down levels of each power grid. The greatest potential to deactivate coal power plants lies in the North grid $(28.1 \%)$, followed by the Central (22.0\%), Northwest (16.3\%), Southern $(15.4 \%)$, East (14.1\%) and Northeast grid (4.1\%).

The emission levels of air pollutants in 2040 is expected to reduce by $21.9 \%, 24.4 \%$ and $22.6 \%$ of $\mathrm{SO}_{2}, \mathrm{NO}_{\mathrm{x}}$ and PM, respectively, due to the closed coal power plants. For the grid level, the largest contribution to air pollutant emission reductions is provided by the North grid. While the avoided emissions in both the Northwest and East grid are higher than the Central grid. The Northeast has the smallest potential in reducing air pollutant emissions. The result shows that the energy and environmental performance of closed coal units are key factors impacting the avoided air pollutant emissions for the six power girds, besides the amount of displaced capacity.

An integrated assessment framework including four modules (industrial electricity demand, coal power generation, air emissions and economic assessment) is newly constructed in this research to measure the pivotal role of targeting industry efficiency to strategically scale down the coal-fired power plant fleet to curb air pollutant emissions from electricity systems. The results imply that a sustainable industry is key to the transition to a coal-free electricity supply system, not only in China but for the countries where electricity use is likewise dominated by industry and heavily dependent on coalbased electricity, such as India, Germany, Poland, The Netherlands, Australia, and South Africa. 


\subsubsection{Policy implications}

Although the required investments in energy efficiency are higher than when achieving the same emission reduction with implementing flue gas controls, the energy returns delivered by the conserved electricity offset the initial expenditures for energy efficiency. The economic analysis suggests that national policymakers that purpose to cocontrol coal-intensive electricity use and air pollution need to facilitate the potential contributions of industrial efficiency improvements for optimizing electricity supply systems. The power grid managers need to not only clearly understand the co-benefits of integrating energy efficiency strategies in the regional energy system, but also accurately coordinate the reduced electricity load and power generation to decrease the dependency on (poor performing) coal-fired power plants. Meanwhile, the provincial government and investors are suggested to prioritize actions in the iron $\&$ steel because of the fastest payback period (within on average three years), followed by the aluminium, chemical, and finally the cement and pulp \& paper sectors.

\section{CRediT authorship contribution statement}

Ernst Worrell, Wina Crijns-Graus and Hui Yue designed and performed the study. Hui Yue performed the model links between ECSC, GAINS, emission module and ArcGIS. Hui Yue, Ernst Worrell and Wina Crijns-Graus developed the energy efficiency technology dataset and improved the power plants data at unit level. Hui Yue, Ernst Worrell and Wina Crijns-Graus contributed to the scenario analysis and the writing of the initial manuscript.

\section{Declaration of Competing Interest}

The authors declare that they have no known competing financial interests or personal relationships that could have appeared to influence the work reported in this paper.

\section{Acknowledgements}

We acknowledge the funding support from the China Scholarship Council under Grant No. 201607040082. The authors would like to thank Shaohui Zhang (Beihang University \& IIASA) for technical support for the GAINS modeling, and Yuanqian Xu (Institute for Environment and Climate Research, Jinan University) for improving the map graphics. 
Impacts of regional industrial electricity savings on coal capacity and related air emissions

\section{Appendix 5.A}

Table 5.A1. Energy prices for each province.

\begin{tabular}{|c|c|c|c|c|c|c|c|}
\hline Region & $\begin{array}{l}\text { Electricity } \\
(\$ / \mathbf{k W h})\end{array}$ & $\begin{array}{l}\text { Coal } \\
(\$ / G J)\end{array}$ & $\begin{array}{l}\text { Gas } \\
\text { (\$/Mbtu) }\end{array}$ & $\begin{array}{l}\text { Oil } \\
(\$ / G J)\end{array}$ & $\begin{array}{l}\text { Biogas } \\
(\$ / G J)\end{array}$ & $\begin{array}{l}\text { Wood } \\
(\$ / G J)\end{array}$ & $\begin{array}{l}\text { Straw } \\
(\$ / G J)\end{array}$ \\
\hline Beijing & 0.11 & 3.4 & 7.6 & 9.1 & 8.1 & 4.8 & 3.5 \\
\hline Tianjin & 0.10 & 3.8 & 7.6 & 9.1 & 8.1 & 4.8 & 3.5 \\
\hline Hebei & 0.09 & 3.4 & 7.5 & 9.1 & 8.1 & 4.8 & 3.5 \\
\hline Shanxi & 0.07 & 2.6 & 7.3 & 9.1 & 8.1 & 4.8 & 3.5 \\
\hline Inner Mongolia & 0.07 & 1.9 & 5.0 & 9.1 & 8.1 & 4.8 & 3.5 \\
\hline Shandong & 0.09 & 4.3 & 7.5 & 9.1 & 8.1 & 4.8 & 3.5 \\
\hline Liaoning & 0.09 & 3.8 & 7.5 & 9.1 & 8.1 & 4.8 & 3.5 \\
\hline Jilin & 0.09 & 3.6 & 6.7 & 9.1 & 8.1 & 4.8 & 3.5 \\
\hline Heilongjiang & 0.08 & 3.3 & 6.7 & 9.1 & 8.1 & 4.8 & 3.5 \\
\hline Shanghai & 0.11 & 4.1 & 8.3 & 9.1 & 8.1 & 4.8 & 3.5 \\
\hline Jiangsu & 0.10 & 4.1 & 8.3 & 9.1 & 8.1 & 4.8 & 3.5 \\
\hline Zhejiang & 0.10 & 4.0 & 8.3 & 9.1 & 8.1 & 4.8 & 3.5 \\
\hline Anhui & 0.09 & 4.3 & 8.0 & 9.1 & 8.1 & 4.8 & 3.5 \\
\hline Fujian & 0.09 & 4.2 & 8.2 & 9.1 & 8.1 & 4.8 & 3.5 \\
\hline Jiangxi & 0.10 & 4.9 & 7.5 & 9.1 & 8.1 & 4.8 & 3.5 \\
\hline Henan & 0.09 & 4.1 & 7.7 & 9.1 & 8.1 & 4.8 & 3.5 \\
\hline Hubei & 0.09 & 4.4 & 7.5 & 9.1 & 8.1 & 4.8 & 3.5 \\
\hline Hunan & 0.10 & 4.7 & 7.5 & 9.1 & 8.1 & 4.8 & 3.5 \\
\hline Chongqing & 0.09 & 4.2 & 6.2 & 9.1 & 8.1 & 4.8 & 3.5 \\
\hline Sichuan & 0.08 & 4.4 & 6.2 & 9.1 & 8.1 & 4.8 & 3.5 \\
\hline Shaanxi & 0.07 & 3.2 & 5.0 & 9.1 & 8.1 & 4.8 & 3.5 \\
\hline Gansu & 0.06 & 3.3 & 5.3 & 9.1 & 8.1 & 4.8 & 3.5 \\
\hline Qinghai & 0.05 & 3.7 & 4.7 & 9.1 & 8.1 & 4.8 & 3.5 \\
\hline Ningxia & 0.05 & 2.7 & 5.7 & 9.1 & 8.1 & 4.8 & 3.5 \\
\hline Xinjiang & 0.06 & 1.4 & 4.2 & 9.1 & 8.1 & 4.8 & 3.5 \\
\hline Tibet & 0.10 & 3.6 & 6.8 & 9.1 & 8.1 & 4.8 & 3.5 \\
\hline Guangdong & 0.10 & 4.4 & 8.3 & 9.1 & 8.1 & 4.8 & 3.5 \\
\hline Guangxi & 0.08 & 5.0 & 7.7 & 9.1 & 8.1 & 4.8 & 3.5 \\
\hline Guizhou & 0.07 & 3.5 & 6.5 & 9.1 & 8.1 & 4.8 & 3.5 \\
\hline Yunnan & 0.06 & 3.5 & 6.5 & 9.1 & 8.1 & 4.8 & 3.5 \\
\hline Hainan & 0.11 & 4.1 & 6.2 & 9.1 & 8.1 & 4.8 & 3.5 \\
\hline
\end{tabular}

Note: the prices of oil and bioenergy are the national level. 


\section{References}

Abel, D.W., Holloway, T., Martínez-Santos, J., Harkey, M., Tao, M., Kubes, C., Hayes, S., 2019. Air quality-related health benefits of energy efficiency in the United States. Environmental science $\&$ technology, 53, 3987-3998.

Amann, M., Bertok, I., Borken-Kleefeld, J., Cofala, J., Heyes, C., Höglund-Isaksson, L., Klimont, Z., Nguyen, B., Posch, M., Rafaj, P., Sandler, R., Schöpp, W., Wagner, F., Winiwarter, W., 2011. Cost-effective control of air quality and greenhouse gases in Europe: Modeling and policy applications. Environmental Modelling \& Software, 26, 1489-1501.

Amann, M., Borken-Kleefeld, J., Cofala, J., Hoeglund-Isaksson, L., Kiesewetter, G., Klimont, Z., Rafaj, P., Schöpp, W., Winiwarter, W., 2014. Updates to the GAINS model databases after the bilateral consultations with national experts in 2014. International Institute for Applied Systems Analysis (IIASA), Laxenburg (Austria). URL: https://ec.europa.eu/environment/air/ pdf/TSAP-14.pdf (accessed 21 July 2020).

An, R., Yu, B., Li, R., Wei, Y., 2018. Potential of energy savings and $\mathrm{CO}_{2}$ emission reduction in China's iron and steel industry. Applied Energy, 226, 862-880.

Buonocore, J.J., Luckow, P., Norris, G., Spengler, J.D., Biewald, B., Fisher, J., Levy, J.I., 2016. Health and climate benefits of different energy-efficiency and renewable energy choices. Nature Climate Change, 6, 100-105.

Byers, L., Friedrich, J., Hennig, R., Kressig, A., Li, X., McCormick, C., Malaguzzi Valeri, L., 2019. A Global Power Plant Database. World Resources Institute, Washington (USA).

China Chemical Energy Efficiency Technology Association, 2006. Handbook of energy saving technology in chemical industry. Chemical Industry Press, Beijing (China).

China Electricity Council, 2020. China electrification development report 2019. Beijing (China).

China Electricity Council, 2018. Annual development report for China's power industry 2018. China Market Press, Beijing (China).

Climate Transparency, 2019. Managing the phase-out of coal: a comparison of actions in G20 countries. Berlin (Germany). URL: https:/www.climate-transparency.org/wp-content/ uploads/2019/05/Managing-the-phase-out-of-coal-DIGITAL.pdf (accessed 21 July 2020). 
Cofala, J., Syri, S., 1998a. Nitrogen oxides emissions, abatement technologies and related costs for Europe in the RAINS model database. International Institute for Applied Systems Analysis (IIASA), Laxenburg (Austria). URL: http://pure.iiasa.ac.at/id/eprint/5563/ (accessed 21 July 2020).

Cofala, J., Syri, S., 1998b. Sulfur emissions, abatement technologies and related costs for Europe in the RAINS model database. International Institute for Applied Systems Analysis (IIASA), Laxenburg (Austria). http://pure.iiasa.ac.at/id/eprint/5613/ (accessed 21 July 2020).

Crijns-Graus, W., Yue, H., Zhang, S., Kermeli, K., Worrell, E., 2020. Energy Efficiency Improvement Opportunities in the Global Industrial Sector. Encyclopedia of Renewable and Sustainable Materials, 5, 377-388.

Dai, Y., Xiong, H., Jiao, J., 2013. Roadmap study on achieving technical energy conservation potential in China's industrial sector by 2020. China Science and Technology Press, Beijing (China).

Davis, C.B., Chmieliauskas, A., Dijkema, G., Nikolic, I., 2015. Power plants (Enipedia) database. Energy \& Industry group, TU Delft, Delft (The Netherlands). URL: http://enipedia.tudelft. nl/wiki/Enipedia (accessed 21 July 2020).

Davis, S.J., Socolow, R.H., 2014. Commitment accounting of $\mathrm{CO}_{2}$ emissions. Environmental Research Letters, 9, 084018.

Energy Research Institute, National Renewable Energy Centre of China, 2018. China renewable energy outlook 2018. Beijing (China). URL: http://boostre.cnrec.org.cn/wp-content/ uploads/2018/11/CREO2018-EN-final-1.pdf (accessed 21 July 2020).

EPA (U.S. Environmental Protection Agency), 2018. Documentation for EPA Platform v6 - Chapter 5: Emission Control Technologies. URL: https:/www.epa.gov/airmarkets/ documentation-epa-platform-v6-chapter-5-emission-control-technologies (accessed 21 July 2020).

Farfan, J., Breyer, C., 2017. Structural changes of global power generation capacity towards sustainability and the risk of stranded investments supported by a sustainability indicator. Journal of Cleaner Production, 141, 370-384.

Gao, M., Beig, G., Song, S., Zhang, H., Hu, J., Ying, Q., Liang, F., Liu, Y., Wang, H., Lu, X., Zhu, T., Carmichael, G.R., Nielsen, C.P., McElroy, M.B., 2018. The impact of power generation emissions on ambient $\mathrm{PM}_{2.5}$ pollution and human health in China and India. Environment International, 121, 250-259. 


\section{Chapter 5}

Global Energy Monitor, 2019. Database of worldwide coal-fired power stations. URL: https:// globalenergymonitor.org/coal/ (accessed 21 July 2020).

Graus, W., Worrell, E., 2007. Effects of $\mathrm{SO}_{2}$ and $\mathrm{NO}_{x}$ control on energy-efficiency power generation. Energy Policy, 35, 3898-3908.

Grubler, A., Wilson, C., Bento, N., Boza-Kiss, B., Krey, V., McCollum, D.L., Rao, N.D., Riahi, K., Rogelj, J., De Stercke, S., Cullen, J., Frank, S., Fricko, O., Guo, F., Gidden, M., Havlík, P., Huppmann, D., Kiesewetter, G., Rafaj, P., Schoepp, W., Valin, H., 2018. A low energy demand scenario for meeting the $1.5^{\circ} \mathrm{C}$ target and sustainable development goals without negative emission technologies. Nature Energy, 3, 515-527.

Habib, A., Sou, C., Hafeez, H.M., Arshad, A., 2018. Evaluation of the effect of high penetration of renewable energy sources (RES) on system frequency regulation using stochastic risk assessment technique (an approach based on improved cumulant). Renewable Energy, 127, 204-212.

Hasanbeigi, A., Khanna, N., Price, L., 2017. Air pollutant emissions projections for the cement and steel industry in China and the impact of emissions control technologies. Lawrence Berkeley National Laboratory, Berkeley (USA).

Hasanbeigi, A., Morrow, W., Masanet, E., Sathaye, J., Xu, T., 2013a. Energy efficiency improvement and $\mathrm{CO}_{2}$ emission reduction opportunities in the cement industry in China. Energy Policy, 57, 287-297.

Hasanbeigi, A., Morrow, W., Sathaye, J., Masanet, E., Xu, T., 2013b. A bottom-up model to estimate the energy efficiency improvement and $\mathrm{CO}_{2}$ emission reduction potentials in the Chinese iron and steel industry. Energy, 50, 315-325.

Hu, J., Huang, L., Chen, M., Liao, H., Zhang, H., Wang, S., Zhang, Q., Ying, Q., 2017. Premature mortality attributable to particulate matter in China: source contributions and responses to reductions. Environmental science \& technology, 51, 9950-9959.

IEA, 2019a. Tracking industry. International Energy Agency (IEA), Paris (France). URL: https:// www.iea.org/reports/tracking-industry-2019 (accessed 21 July 2020).

IEA, 2019b. World energy outlook 2019, International Energy Agency (IEA), Paris (France).

IEA, 2018a. Energy efficiency 2017, International Energy Agency (IEA), Paris (France).

IEA, 2018b. World energy balances (2018 edition), International Energy Agency (IEA), Paris (France). 
IEA, 2018c. World energy outlook 2018, International Energy Agency (IEA), Paris (France).

IEA, 2017a. Energy access outlook 2017, International Energy Agency (IEA), Paris (France).

IEA, 2017b. Energy technology perspectives 2017: Catalysing energy technology transformation, International Energy Agency (IEA), Paris (France).

IIASA, 2016. Greenhouse gas - Air pollution Interactions and Synergies (GAINS) model description. International Institute for Applied Systems Analysis (IIASA), Laxenburg (Austria). URL: https://ec.europa.eu/clima/sites/clima/files/strategies/analysis/models/docs/ gains_en.pdf (accessed 21 July 2020).

IIASA, 2015. ECLIPSE V5a global emission fields. International Institute for Applied Systems Analysis (IIASA), Laxenburg (Austria). URL: https://iiasa.ac.at/web/home/research/ researchPrograms/air/ECLIPSEv5a.html (accessed 21 July 2020).

IndustryAbout, 2019. Worldwide industrial information. URL: https://www.industryabout. com/energy/5575-fossil-fuels-energy (accessed 21 July 2020).

IRENA, 2017. Synergies between renewable energy and energy efficiency, a working paper based on REmap, International Renewable Energy Agency (IRENA), Abu Dhabi (UAE). URL: https://www.irena.org/publications/2017/Aug/Synergies-between-renewable-energy-andenergy-efficiency (accessed 21 July 2020).

Kanada, M., Dong, L., Fujita, T., Fujii, M., Inoue, T., Hirano, Y., Togawa, T., Geng, Y., 2013. Regional disparity and cost-effective $\mathrm{SO}_{2}$ pollution control in China: A case study in 5 megacities. Energy Policy, 61, 1322-1331.

Karplus, V.J., Zhang, S., Almond, D., 2018. Quantifying coal power plant responses to tighter $\mathrm{SO}_{2}$ emissions standards in China. Proceedings of the National Academy of Sciences, 115, 7004-7009.

Khanna, N., Fridley, D., Zhou, N., Karali, N., Zhang, J., Feng, W., 2019. Energy and $\mathrm{CO}_{2}$ implications of decarbonization strategies for China beyond efficiency: Modeling 2050 maximum renewable resources and accelerated electrification impacts. Applied Energy, 242, $12-26$.

Klimont, Z., Cofala, J., Bertok, I., Amann, M., Heyes, C., Gyarfas, F., 2002. Modeling particulate emissions in Europe: A framework to estimate reduction potential and control costs. International Institute for Applied Systems Analysis (IIASA), Laxenburg (Austria). URL: http://pure.iiasa.ac.at/id/eprint/6712/ (accessed 21 July 2020). 
Klimont, Z., Kupiainen, K., Heyes, C., Purohit, P., Cofala, J., Rafaj, P., Borken-Kleefeld, J., Schöpp, W., 2017. Global anthropogenic emissions of particulate matter including black carbon. Atmospheric Chemistry and Physics Discussions, 17, 8681-8723.

Li, N., Ma, D., Chen, W., 2017. Quantifying the impacts of decarbonisation in China's cement sector: A perspective from an integrated assessment approach. Applied Energy, 185, 18401848.

Liang, X., Zhang, S., Wu, Y., Xing, J., He, X., Zhang, K.M., Wang, S., Hao, J., 2019. Air quality and health benefits from fleet electrification in China. Nature Sustainability, 2, 962-971.

Liu, F., Klimont, Z., Zhang, Q., Cofala, J., Zhao, L., Huo, H., Nguyen, B., Schöpp, W., Sander, R., Zheng, B., Hong, C., He, K., Amann, M., Heyes, C., 2013. Integrating mitigation of air pollutants and greenhouse gases in Chinese cities: development of GAINS-City model for Beijing. Journal of Cleaner Production, 58, 25-33.

Liu, J., Kiesewetter, G., Klimont, Z., Cofala, J., Heyes, C., Schöpp, W., Zhu, T., Cao, G., GómezSanabria, A., Sander, R., Guo, F., Zhang, Q., Nguyen, B., Bertok, I., Rafaj, P., Amann, M., 2019. Mitigation pathways of air pollution from residential emissions in the Beijing-TianjinHebei region in China. Environment international, 125, 236-244.

Liu, X., Yuan, Z., Xu, Y., Jiang, S., 2017. Greening cement in China: A cost-effective roadmap. Applied Energy, 189, 233-244.

Los Alamos National Laboratory, 2018. Global Energy Observatory. URL: http:// globalenergyobservatory.org/ (accessed 21 July 2020).

Ma, D., Chen, W., Yin, X., Wang, L., 2016. Quantifying the co-benefits of decarbonisation in China's steel sector: an integrated assessment approach. Applied Energy, 162, 1225-1237.

MEE (Ministry of Ecology and Environment of China), NDRC (National Development and Reform Commission of China), NEA (National Energy Administration), 2015. Full implementation of the ultra-low emission and energy-saving transformation for coal-fired power plants. URL: http://www.mee.gov.cn/gkml/hbb/bwj/201512/W020151215366215476108. pdf (accessed 21 July 2020).

Meier, A., Wright, J., Rosenfeld, A.H., 1983. Supplying energy through greater efficiency: the potential for conservation in California's residential sector. University of California Press, Berkeley (USA).

Millstein, D., Wiser, R., Bolinger, M., Barbose, G., 2017. The climate and air-quality benefits of wind and solar power in the United States. Nature Energy, 2, 17134. 
Ministry of Industry and Information Technology of China, 2013. Advanced technologies guideline for energy conservation and emission reduction in China's petroleum and chemical industry. URL: http://www.miit.gov.cn/n1146295/n1652858/n1652930/n3757017/ c3759238/content.html (accessed 21 July 2020).

Mitchell, C., 2016. Momentum is increasing towards a flexible electricity system based on renewables. Nature Energy, 1, 1-6.

National Development and Reform Commission of China, 2016. Guidelines on promoting the use of electricity to replace other energy sources. URL: http:/www.scio.gov.cn/xwfbh/ xwbfbh/wqfbh/39595/41802/xgzc41808/Document/1664893/1664893.htm (accessed 21 July 2020).

National Development and Reform Commission of China, 2018. National key energy conservation and low carbon technologies promotion catalogue. URL: https:/www.ndrc. gov.cn/fggz/hjyzy/jnhnx/201803/t20180302_1134163.html (accessed 21 July 2020).

National Development and Reform Commission of China, 2017. China: 13th FiveYear Plan for power sector. URL: http://www.gov.cn/xinwen/2016-12/22/5151549/ files/696e98c57ecd49c289968ae2d77ed583.pdf (accessed 21 July 2020).

National Development and Reform Commission of China, 2012. China: 12th Five-Year Plan of China Western Development. http://www.gov.cn/zwgk/2012-02/21/content_2072227. htm (accessed 21 July 2020).

National Development and Reform Commission of China, 2013-2019. Benchmark price of natural gas. URL: http://www.gov.cn/xinwen/2019 03/29/content_5378081.htm (accessed 21 July 2020).

National Development and Reform Commission of China, 2014-2019. China coal price index for electricity generation. URL: http://jgjc.ndrc.gov.cn/zgdmjgzs.aspx?clmId=syjgzs6 (accessed 21 July 2020).

National Energy Administration of China, 2018. Annual report of national electricity price 2017. URL: http://www.belle-mure.com/138530255_15729388881531n.pdf (accessed 21 July 2020).

Peng, W., Wagner, F., Ramana, M.V., Zhai, H., Small, M.J., Dalin, C., Zhang, X., Mauzerall, D.L., 2018. Managing China's coal power plants to address multiple environmental objectives. Nature Sustainability, 1, 693-701. 


\section{Chapter 5}

Qin, Y., Mueller, N.D., Siebert, S., Jackson, R.B., AghaKouchak, A., Zimmerman, J.B., Tong, D., Hong, C., Davis, S. J., 2019. Flexibility and intensity of global water use. Nature Sustainability, 2, 515-523.

Qin, Y., Wagner, F., Scovronick, N., Peng, W., Yang, J., Zhu, T., Smith, K.R., Mauzerall, D.L., 2017. Air quality, health, and climate implications of China's synthetic natural gas development. Proceedings of the National Academy of Sciences, 114, 4887-4892.

Reddington, C.L., Conibear, L., Knote, C., Silver, B.J., Li, Y.J., Chan, C.K., Arnold, S.R., Spracklen, D.V., 2019. Exploring the impacts of anthropogenic emission sectors on $\mathrm{PM}_{2.5}$ and human health in South and East Asia. Atmospheric Chemistry and Physics, 19, 1188711910.

Rentier, G., Lelieveldt, H., Kramer, G.J., 2019. Varieties of coal-fired power phase-out across Europe. Energy Policy, 132, 620-632.

Reyna, J.L., Chester, M.V., 2017. Energy efficiency to reduce residential electricity and natural gas use under climate change. Nature Communications, 8, 1-12.

S\&P Global Platts, 2018. World electric power plants (WEPP) database v. September 2017. Washington (USA).

Shindell, D., Kuylenstierna, J.C., Vignati, E., van Dingenen, R., Amann, M., Klimont, Z., Anenberg, S.C., Muller, N., Janssens-Maenhout, G., Raes, F., Schwartz, J., Faluvegi, G., Pozzoli, L., Kupiainen, K., Höglund-Isaksson, L., Emberson, L., Streets, D., Ramanathan, V., Hicks, K., Oanh, N.T.K., Milly, G., Williams, M., Demkine, V., Fowler, D., 2012. Simultaneously mitigating near-term climate change and improving human health and food security. Science, 335, 183-189.

State Council of China, 2017. China: 13th Five-Year Plan for energy conservation and emission reduction programme. http://www.gov.cn/zhengce/content/2017-01/05/content_5156789. htm (accessed 21 July 2020).

Tang, L., Qu, J., Mi, Z., Bo, X., Chang, X., Anadon, L.D., Wang, S., Xue, X., Li, S., Wang, X., Zhao, X., 2019. Substantial emission reductions from Chinese power plants after the introduction of ultra-low emissions standards. Nature Energy, 4, 929-938.

Vandyck, T., Keramidas, K., Kitous, A., Spadaro, J.V., Van Dingenen, R., Holland, M., Saveyn, B., 2018. Air quality co-benefits for human health and agriculture counterbalance costs to meet Paris Agreement pledges. Nature Communications, 9, 1-11.

Walls, M., 2017. Energy efficiency: Building labels lead to savings. Nature Energy, 2, 1-2. 
Wang, Y., Byers, E., Parkinson, S., Wanders, N., Wada, Y., Mao, J., Bielicki, J.M., 2019. Vulnerability of existing and planned coal-fired power plants in Developing Asia to changes in climate and water resources. Energy \& Environmental Science, 12, 3164-3181.

Wen, Z., Wang, Y., Zhang, C., Zhang, X., 2018. Uncertainty analysis of industrial energy conservation management in China's iron and steel industry. Journal of environmental management, 225, 205-214.

Worrell, E., Laitner, J.A., Ruth, M., Finman, H., 2003. Productivity benefits of industrial energy efficiency measures. Energy, 28, 1081-1098.

Wu, X., Zhao, L., Zhang, Y., Zhao, L., Zheng, C., Gao, X., Cen, K., 2016. Cost and potential of energy conservation and collaborative pollutant reduction in the iron and steel industry in China. Applied Energy, 184, 171-183.

Yang, J., Li, X., Peng, W., Wagner, F., Mauzerall, D.L., 2018. Climate, air quality and human health benefits of various solar photovoltaic deployment scenarios in China in 2030. Environmental Research Letters, 13, 064002.

Yue, H., Worrell, E., Crijns-Graus, W., 2018. Modeling the multiple benefits of electricity savings for emissions reduction on power grid level: A case study of China's chemical industry. Applied Energy, 230, 1603-1632.

Zhang, J., Zhang, Y., Yang, H., Zheng, C., Jin, K., Wu, X., Gao, X., Cen, K., 2017. Costeffectiveness optimization for $\mathrm{SO}_{2}$ emissions control from coal-fired power plants on a national scale: a case study in China. Journal of Cleaner Production, 165, 1005-1012.

Zhang, P., Li, W., Li, S., Wang, Y., Xiao, W., 2013. Reliability assessment of photovoltaic power systems: Review of current status and future perspectives. Applied Energy, 104, 822-833.

Zhang, Q., Xu, J., Wang, Y., Hasanbeigi, A., Zhang, W., Lu, H., Arens, M., 2018. Comprehensive assessment of energy conservation and $\mathrm{CO}_{2}$ emissions mitigation in China's iron and steel industry based on dynamic material flows. Applied Energy, 209, 251-265.

Zhang, S., Worrell, E., Crijns-Graus, W., 2015. Evaluating co-benefits of energy efficiency and air pollution abatement in China’s cement industry. Applied Energy, 147, 192-213.

Zhang, S., Worrell, E., Crijns-Graus, W., Krol, M., de Bruine, M., Geng, G., Wagner, F., Cofala, J., 2016. Modeling energy efficiency to improve air quality and health effects of China's cement industry. Applied Energy, 184, 574-593. 


\section{Chapter 5}

Zhang, S., Worrell, E., Crijns-Graus, W., Wagner, F., Cofala, J., 2014. Co-benefits of energy efficiency improvement and air pollution abatement in the Chinese iron and steel industry. Energy, 78, 333-345.

Zhou, N., Khanna, N., Feng, W., Ke, J., Levine, M., 2018. Scenarios of energy efficiency and $\mathrm{CO}_{2}$ emissions reduction potential in the buildings sector in China to year 2050. Nature Energy, 3, 978-984. 


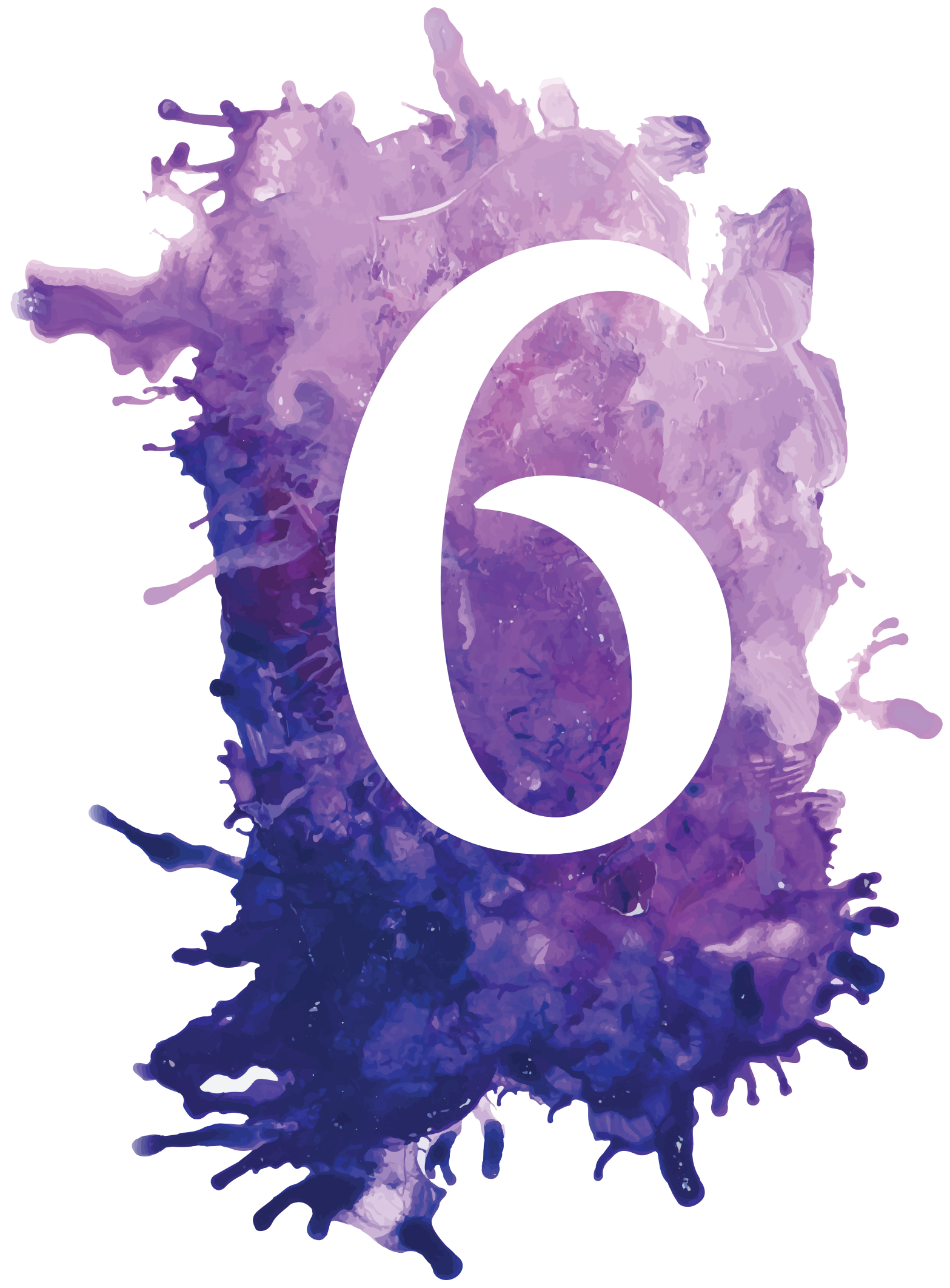




\section{Chapter 6}

\section{Summary and conclusions}




\section{I. Research context}

Access to electricity is the core element for poverty alleviation, economic growth and improved living standards (Nerini et al., 2018). Several countries worldwide, particularly the developing economies, have made great efforts in recent years to expand electricity access. Correspondingly, the share of people living without electricity fell to $11 \%$ in 2017 from 27\% in 2000 (IEA et al., 2019). Meanwhile, the urbanization level increased by around $10 \%$ over the past two decades, while Asia contributes to $65 \%$ of the increase in urban population (United Nations, 2019). Driven by fast-growing electrification and urbanization, electricity demand increased dramatically from 12,700 TWh in 2000 to 21,400 TWh in 2017 (IEA, 2018; IEA, 2019c). This strong desire for electricity is expected to continue for another twenty years because rapid economic development is shifting from developed regions to developing economies (Panos et al., 2016). The primary source of electricity is burning coal, which has long supplied around $40 \%$ of the global power generation (IEA, 2018). However, coal-intensive electricity systems make the global power sector to be the biggest emitter of anthropogenic global greenhouse gases (GHG) (IEA, 2019a) and a key producer of air pollutants (IEA, 2019c), thus posing a fatal threat to the pursuit of sustainable human development (IPCC, 2018; WHO, 2020).

Although a number of countries promote the transition to a coal-free electricity system (Climate Transparency, 2019), the newly constructed coal-fired power plants in China drive the expansion of the coal-fired power fleet worldwide (S\&P Global Platts, 2018). Nearly $50 \%$ of the global coal power capacity is deployed in China, while providing $70 \%$ of the total electricity generation to meet its surging economic development. Industry, particularly the energy-intensive sectors (e.g. iron \& steel, cement, aluminium and chemicals), dominates China's economy, contributing to $46 \%$ of the country's gross domestic product (World Bank, 2020). Undoubtedly, industry is the largest consumer of coal-intensive electricity (accounting for $62 \%$ of China's total electricity demand) and also is the major factor increasing China's hunger for new coal-fired power generation. Coal-based electricity supply systems, along with an ever-increasing industrial electricity demand placed China into a dilemma between accelerating industrialization and reducing environmental impacts. Thus, managing electricity use in industry to scale down the coal-fired power fleet has a pivotal role to play in combating climate change and air quality while minimizing the impacts on the economy.

Energy efficiency has proven to be a win-win strategy for reducing energy demand while creating high-value benefits, such as increasing energy security (IEA, 2019b), limiting global warming (Grubler et al., 2018), avoiding air pollutant emissions (Abel et al., 2019), decreasing premature mortality (Zhang et al., 2020) and improving industrial productivity (Worrell et al., 2003). However, the improvement rate of energy efficiency seems to be slowing down around the world in recent years, which potentially weakens 
future efficiency gains (IEA, 2019b). One of the main reasons is that China and the United States substantially increased their outputs of energy-intensive industrial products (IEA, 2019b). To date, China hasn't practically integrated the multiple benefits of energy efficiency improvements into air pollution control and energy system strategies. This is because a comprehensive understanding of the co-benefits, in terms of energy savings and multiple air emission reductions, is still lacking. It is worth noting that the electricity intensity in 2017 remains at almost the same level as in 1990s not only for the world, but especially China (IEA, 2019c). The country's electricity intensity is twice the global average level. Previous studies only concerned energy savings for a specific demand-side sector (e.g. for the iron \& steel (Wen et al., 2019) and cement sectors (Zhang et al., 2016)). Analyses rarely quantify the technology-driven electricity savings and also ignore the impacts of electricity savings on the power generation sector. These knowledge gaps inspire the thesis to explore the complex connections of electricity savings, evolution of the power plant fleet and air emission changes. What's more, revealing the relationship would be helpful towards a high-efficiency industry and clean electricity system, thus mitigating climate change and improving air quality. This is becoming more urgent, not only for China, but also for other countries where electricity generated by a coal-intensive power plant fleet.

\subsection{Research goals}

The objective of this thesis is to conduct an in-depth analysis of electricity saving potentials and cost-benefits of emission mitigation due to scaling up energy efficiency. Our research targets the industrial electric efficiency improvements in China, where electricity supply heavily depends on coal-fired power plants and faces multiple challenges to a sustainable future. To achieve the objective, a research framework consisting of five sub-goals is formulated:

1. Comparing electricity use projections and electricity saving potentials for China's industry in different studies to provide an overview of efficiency improvement opportunities and identify sectors with the highest potential for electricity savings.

2. Understanding the modeling parameters and approaches that affect the studied results across different scenarios.

3. Measuring the multiple benefits of electricity savings in industrial sub sectors, in terms of GHG and air pollution emission reductions at a power grid level.

4. Quantifying the potential impacts of reduced electricity load from industry on the phaseout of high-polluting coal power units, air emission changes from the power sector, and air pollutant control costs. 
5. A comprehensive assessment of the mutual benefits of industrial electricity savings, coal power removal, emission reductions and related investment optimization across provincial and grid level.

These research goals are addressed in Chapter 2 through Chapter 5. Table 6.1 provides an overview of the thesis chapters and which goals they cover. Chapter 2 conducts a review and analysis of studies modeling industrial electricity savings and exploring air emission reduction opportunities. Further, this chapter critically evaluates the scenario-modeled characteristics in available studies, which affect modeling results to varying degrees. The systematic review presented in Chapter 2 provides a guideline in the area of building an integrated modeming framework (which consists of electricity consumption, power generation, air emissions and cost modules) and managing the industrial electricity use to reduce detrimental air emissions from the power sector. Electricity conservation supply curves are developed per grid in Chapter 3 to quantify the synergies of actions to conserve electricity in terms of avoiding air pollutants and GHG emissions from a cost and technical perspective for a complex industrial system; China's chemical sector. A more complete database of industrial energy efficiency technology is developed in the following chapters, that incorporate the electricity saving technologies applied to the chemical industry. Besides the detailed technology database, a comprehensive power plant database is newly created, which greatly supports to perform a quantitative assessment. Chapter 4 quantifies the multiple benefits of industrial electricity savings on deactivating super-polluting generation units in order to reduce air emissions $\left(\mathrm{CO}_{2}\right.$, $\mathrm{SO}_{2}, \mathrm{NO}_{\mathrm{x}}$ and $\mathrm{PM}$ ) from China's electricity systems. Chapter 5 develops an integrated modeling framework considering regional heterogeneities to quantify the vital role of targeting industrial efficiency on decreasing dependence on coal-fired power plants to maximize benefits of mitigating air pollutant emissions on various scales. The costs of air pollutant abatement by improving industrial energy efficiency and retrofitting power plants with end-of-pipe controls are also estimated.

Table 6.1. Overview of the thesis chapters and their corresponding research sub-goals.

\begin{tabular}{|c|c|c|c|c|c|c|}
\hline \multirow[t]{2}{*}{ Chapter } & \multirow[t]{2}{*}{ Topic } & \multicolumn{5}{|c|}{ Research sub-goal } \\
\hline & & 1 & 2 & 3 & 4 & 5 \\
\hline 2 & $\begin{array}{l}\text { Saving electricity in China's industry: A review of opportunities, } \\
\text { potentials, and environmental benefits }\end{array}$ & $\mathrm{X}$ & $\mathrm{X}$ & & & \\
\hline 3 & $\begin{array}{l}\text { Modeling the multiple benefits of electricity savings for } \\
\text { emissions reduction on power grid level: A case study of China's } \\
\text { chemical industry }\end{array}$ & & & $\mathrm{X}$ & & \\
\hline 4 & $\begin{array}{l}\text { Air emissions and energy efficiency: realizing multiple benefits } \\
\text { for power sector by saving industrial electricity use in China }\end{array}$ & & & & $\mathrm{X}$ & \\
\hline 5 & $\begin{array}{l}\text { Modeling linkages between the industry and power sector to } \\
\text { co-manage regional electricity savings and air pollution - A case } \\
\text { study of China }\end{array}$ & & & & $\mathrm{X}$ & $\mathrm{X}$ \\
\hline
\end{tabular}




\subsection{Main findings of the thesis}

This section provides a summary of the main findings drawn from the previous chapters by research goal of this thesis:

1. Comparing electricity use projections and electricity saving potentials for China's industry in different studies to provide an overview of efficiency improvement opportunities and identify sectors with the highest potential for electricity savings.

Research goal 1 is addressed in Chapter 2 by performing a comparative evaluation of available literature on electricity use performance in China's industry with an in-depth focus on the largest consuming subsectors and key energy efficiency technologies. Based on the modeling results of the selected studies, the emission reductions of GHGs and air pollutants attributed to industrial electricity savings are estimated.

Chapter 2 aims to evaluate energy saving potentials in China's industry, while especially quantifying the electricity savings in the five largest end-use sectors, i.e. iron \& steel, cement, non-ferrous metals, pulp \& paper and chemical sector. Additionally, for the textile sector which has a large electricity consumption, a qualitative analysis of the opportunities for improving electricity use efficiency is conducted. The results show that electricity is the fast-growing energy carrier in China's industrial energy system, which is shifting to higher power and lower fossil fuels. The electricity consumption in China's industry is expected to account for more than one-third of the industrial final energy consumption by 2040 , optimistically estimated to reach around $40 \%$. At the same time, a large potential of electricity savings, equaling $14 \%$ of industrial electricity use in 2040, lies in the industry. Electricity-derived emissions of $660 \mathrm{Mt}-\mathrm{CO}_{2 \mathrm{eq}}, 1300$ $\mathrm{kt}-\mathrm{SO}_{2}, 1400 \mathrm{kt}-\mathrm{NO}_{\mathrm{x}}$ and $300 \mathrm{kt}-\mathrm{PM}_{2.5}$ are expected to be avoided by improving energy efficiency in China's industry. The iron \& steel sector is the largest contributor to the total electricity savings. Considerable electricity savings are also found in the non-ferrous metals and chemical sectors. While the cement and pulp \& paper sectors have a smaller contribution to the total electricity reductions. Targeting to release their potentials, most opportunities exist in the non-ferrous metals and chemical sectors, followed by the iron $\&$ steel, cement and pulp \& paper sector. In the textile industry, motor-driven systems have a substantial potential for saving electricity.

2. Understanding the modeling parameters and approaches that affect the studied results across different scenarios.

Chapter 2 also addresses research goal 2 by exploring factors affecting modeling results per subsector for the selected studies. A total of 27 key drivers, classified into five aspects (i.e. system boundaries, modeling method, social and economic indicator, technology representation and data source), are discussed in this chapter. System boundary means 
the coverage of the studied sector, which is usually identified based on the classification of national economic activities. This factor greatly influences the projections of electricity consumption in the industrial sectors in multiple ways. The modeling method indirectly impacts the choice of scenario parameters and research scope, thus resulting in significant divergencies between modeling results. For example, a top-down model using aggregated production functions allows researchers to evaluate the performance of electricity use in the short-term, while the electricity savings modeled by the top-down approach are generally higher than the bottom-up modeling. Integrated and bottomup approaches with explicit technology representation focus more on technologydriven pathways in the medium- and long-term. Besides the modeling structure, the parameter settings of scenario storyline strongly impacts the modeling results. Social \& economic indicators (e.g. industrial value-added and urbanization level) strongly impact production functions, which in turn influence the modeled output for electricity demand, in particular for top-down models. Technology representation (e.g. technology selection, costs and diffusion rates) especially have a great influence on the sectoral electricity saving potentials modeled by bottom-up approaches. Reliable data is an essential element for any model and reduces uncertainties. This chapter indicates that the different data sources used have a limited influence on the long-term simulation of electricity demand and intensity.

3. Measuring the multiple benefits of electricity savings in industrial sub sectors, in terms of GHG and air pollution emission reductions at a power grid level.

Chapter 3 responds to research goal 3 by developing a bottom-up model to quantify the technology-driven electricity savings for the chemical industry and estimate avoided indirect air emissions. The chapter fills the knowledge gap by analyzing the energy efficiency and emission reduction opportunities in the chemical industry, which is composed of a complicated set of chemical reaction processes. The chemical industry is the world's largest industrial electricity consumer, accounting for $14 \%$ of global industrial electricity consumption.

Chapter 3 targets to capture co-benefits of energy efficiency improvements of electricity savings and multiple air emission reductions in the chemical industry for China's six regional grids during 2012-2035. China has been the world's top producer and consumer in key chemical products such as ammonia, caustic soda, polyvinyl chloride and calcium carbide, which are primarily driven by the demand of downstream industries (e.g. construction, agriculture and packaging sectors). At the same time, China's chemical industry consumes a vast amount of coal-intensive electricity, reaching 475 TWh in 2015. It has thus been a key contributor to either GHGs or air pollutant emissions. Electricity-related emissions account for around 39\%, 40\%, 58\% and 19\% of $\mathrm{CO}_{2}, \mathrm{SO}_{2}, \mathrm{NO}_{\mathrm{x}}$ and PM emissions in 2015, respectively, in China's chemical industry. Electricity conservation supply curves are established to analyze the cost associated with 
each energy efficiency measure (a total of 60 technologies). In order to assess emission reductions attributable to electricity savings, emission factors of purchased electricity per grid are calculated and installed flue gas control measures are included.

The results show that the implementation of all 60 efficiency technologies is expected to save $185 \mathrm{TWh}$ of electricity consumption in 2035 , of which $79 \%$ can be realized by cost-effective measures. Compared to the baseline, about $121 \mathrm{Mt}, 233 \mathrm{kt}, 254 \mathrm{kt}$ and $51 \mathrm{kt}$ of $\mathrm{CO}_{2 \mathrm{eq}}, \mathrm{SO}_{2}, \mathrm{NO}_{\mathrm{x}}$ and $\mathrm{PM}_{2.5}$ emissions, respectively, can be avoided costeffectively in 2035 . The emissions can be further dropped by $8 \%$ on average, under the technical scenario. Among the power grids, the North grid has the largest electricity saving potentials, accounting for $34 \%$ of total electricity savings, thus contributing to the biggest emission reduction of GHGs and air pollutants. The chemical plants are mainly distributed in regions with abundant resources and huge demand (e.g. Shaanxi, Sichuan, Henan and Xinjiang), showing reflecting resource- and demand-oriented development patterns. Therefore, the Northwest and Central grids have considerable potentials for electricity savings and associated emission reductions, followed by the East and Southern grids. The Northeast grid (covering three provinces, Liaoning, Jilin and Heilongjiang) with low shares of chemicals output only accounts for around $2 \%$ of total electricity savings, and has the lowest contributions to curbing GHGs (3\%), $\mathrm{SO}_{2}(2 \%)$, $\mathrm{NO}_{\mathrm{x}}(3 \%)$ and $\mathrm{PM}_{2.5}(4 \%)$ emissions.

Three chemical sectors, i.e. ammonia, chlor-alkali and calcium carbide, represent 54\% of total electricity consumption in the chemical industry, and have the highest potential for reducing electricity demand. Calcium carbide production in China, is mainly manufactured in an electric arc furnace and has the largest electricity consumption among the three sectors. The electricity consumption in the calcium carbide sector can be reduced by $39 \%$ in 2035 by implementing 17 energy efficiency technologies. The reduced electricity demand can result in around $71 \mathrm{Mt}, 129 \mathrm{kt}, 151 \mathrm{kt}$ and $28 \mathrm{kt}$ of $\mathrm{CO}_{2 \mathrm{eq}}, \mathrm{SO}_{2}, \mathrm{NO}_{\mathrm{x}}$ and $\mathrm{PM}_{2.5}$ emission reductions. The ammonia sector leaves much room for improving current electricity use efficiency by $65 \%$, while the potential is $28 \%$ in the chlor-alkali sector. Around $54 \%$ and $55 \%$ of total GHGs and air pollutant emission reduction benefits, respectively, can be obtained by efficient use of electricity in these two chemical sectors.

4. Quantifying the potential impacts of reduced electricity load from industry on the phaseout of high-polluting coal power units, air emission changes from the power sector, and air pollutant control costs.

Research goal 4 is addressed in Chapters $4-5$ by characterizing the complex relationship between the industry and power sector in terms of electricity savings, climate change and air pollution. Huge electricity demand by industry drives the expansion of coalintensive power generation systems, thus resulting in climate change, air pollution and 
health concerns. Although research has highlighted the vital role of energy efficiency, studies that explore the linkages between industrial electricity use and electricity supply to avoid multiple air emissions are limited.

A comprehensive analysis structure (coupling the electricity conservation supply curves with the GAINS (Greenhouse Gas - Air Pollution Interactions and Synergies) model) is developed in Chapter 4. This model is applied to quantify the potential for electricity savings in China's largest industries to close high-polluting units in order to reduce air pollutant emissions, and compare this to the alternative of flue gas control technologies in terms of emission abatement and costs. The share of electricity consumption in China's industrial final energy mix has increased to $32 \%$ in 2018 from $19 \%$ in 2000 . The coalfired power plant fleet, providing $70 \%$ of total electricity generation, is the backbone to meet the surged electricity demand in China. Electrifying industry can effectively reduce direct emissions, but in turn, can cause high indirect emissions from the electricity generation processes. Coal-fired power plants are responsible for about 50\%, 19\%, 21\% and $11 \%$ of China's total $\mathrm{CO}_{2}, \mathrm{SO}_{2}, \mathrm{NO}_{\mathrm{x}}$ and $\mathrm{PM}$ emissions, respectively. Transitioning to a more efficient industry and shifting away from coal for electricity supply is urgent not only for China but for countries which have similar energy structures.

The results of Chapter 4 show that a total of 506 TWh of electricity demand can be reduced in 2040 by industrial efficiency improvements. The iron \& steel and aluminium sectors are the two largest contributors to the total electricity savings, which together provide $63 \%$ of the reduction by 2040 , followed by chemicals, cement, and lastly the pulp \& paper sector. An average of $90 \%$ of the identified potentials in the industrial sectors can be released by cost-effective technologies. The reduced electricity demand in China's energy-intensive industries can offset a total of $103 \mathrm{GW}$ coal-fired power capacity by 2040. Nationally, this drives all the identified super-polluting units (existing subcritical coal generation units with size $<300 \mathrm{MW}$ ) into early retirement and allows an accelerated $19 \mathrm{GW}$ of older power plants phaseout. Besides closing existing units, around $10 \mathrm{GW}$ of newly proposed coal power projects, particularly subcritical coal plants, can be cancelled in the energy efficiency scenario. Compared with the business-as-usual scenario, removing these coal-fired power plants can significantly decrease air pollutant emission levels of $\mathrm{SO}_{2}, \mathrm{NO}_{\mathrm{x}}$ and PM by 23\%, 26\% and 24\%, respectively, in 2040, while avoiding $9 \%$ of $\mathrm{CO}_{2}$ emissions. The economic analysis of air pollution mitigation strategies demonstrates that industrial efficiency improvements require a much higher initial investment than end-of-pipe treatments, but the capital expenditures on energy efficiency are expected to recover within average in 5 years due to the reduced energy bills. 
5. A comprehensive assessment of the mutual benefits of industrial electricity savings, coal power removal, emission reductions and related investment optimization across provincial and grid level.

Chapter 5 addresses research goal 5 through exploring the industrial plant distribution, the evolution of coal-intensive electricity systems, electricity demand, the utilization rate of coal power plants and emission levels for the six power grids (covering 31 provinces) in China. This chapter fills the knowledge gap in fully quantifying the pivotal role efficiency improvements played in reducing coal use, mitigating climate change and improving air quality at provincial and grid level. Understanding the regional heterogeneity is critical for national and provincial decision-makers to prioritize efforts across sectors and regions in building an efficient industry and decreasing dependence on coal power.

An integrated modeling framework, which links four models, is developed to assess the mutual benefits for both China's industry and power sector on various scales under four scenarios with the main purpose of reducing air pollutant emissions during the period 2016-2040. First, electricity conservation supply curves are built per province to determine bottom-up potentials for electricity savings and associated investment costs by calling a comprehensive database consisting of 175 energy efficiency technologies (Chapter 4). Secondly, an emission assessment model, based on China's power plant database, is used to quantify emission reductions from displaced coal power plants, due to the reduced electricity load, at provincial and grid level. Thirdly, the GAINS model is used to measure the investments per province for retrofitting coal power plants with end-of-pipe treatment devices for achieving the same air pollutant reductions as with industrial efficiency improvements. Finally, ArcGIS (a geographic information system) is applied to capture the characteristics on provincial, grid and national administrative levels.

Chapter 5 shows that the deployment pattern of coal-fired power plants is heavily affected by local coal resources and electricity demand. Around $50 \%$ of the total coal capacity is installed in the North (covering coal-rich provinces, e.g. Shandong, Shanxi and Inner Mongolia) and East grids (including power-hungry coastal regions, e.g. Zhejiang and Jiangsu), which have been the two biggest coal power bases. The installed coal capacity of the North grid is slightly higher than that in the East grid, while the air pollutant emissions from the North grid are double those of the East grid. The main reason is that the North gird deploys twice as much high-polluting coal power capacity as the East grid in 2016. Closing the most polluting units by reducing electricity demand in each grid is critical for China to improve air quality. The electricity saving potentials differs per province and shows a range of $4 \mathrm{GW}$ to $30 \mathrm{GW}$ offset capacity per power grid. The North grid has the greatest potential for displacing coal-fired generation capacity, followed by the Central, Northwest, Southern, East and Northeast grid. Due to the different potentials for removing coal-fired power plants and the varying 
environmental performance of coal generation units, the avoided air emissions by 2040 show a significant heterogeneity among the six power grids, ranging from $13-85 \mathrm{kt}$, 19-129 kt, 3-17 kt and 21-167 Mt for $\mathrm{SO}_{2}, \mathrm{NO}_{\mathrm{x}}, \mathrm{PM}$ and $\mathrm{CO}_{2}$ emission reductions, respectively. The investments in energy efficiency should be focused mainly on the iron $\&$ steel sector and be concentrated in the North grid, which is expected to generate high energy returns in the short-term. For the other grids, the specific investment per ton air pollutant removed in the Northeast and Northwest grid is lower than the East, Central and Southern grids.

\subsection{General conclusions and policy implications}

Energy efficiency plays an indispensable role in realizing a highly efficient industry and a coal-free electricity supply system to combat air pollution and climate change. This thesis investigates the connections between industrial demand-side and power supply-side to achieve electricity savings, air quality improvement, and climate change mitigation simultaneously in a cost-effective way, using China as a study case. It primarily focuses on the multiple benefits of action to improve industrial efficiency and reducing the use of coal-fired power plants and related air emissions. The conclusions and policy recommendations are drawn from the earlier chapters:

The fast-growing electricity demand in Chinese industry results in huge GHG and air pollutant emissions from electricity generation processes. China's industrial electricity intensity remains at almost the same level in the 2000s. It is urgent for China to promote the progress of electricity use efficiency. The Chinese industry is responsible for around $20 \%$ of the global total electricity consumption in 2017, being the largest electricity user worldwide. The surging electricity demand is primarily driven by the ever-increasing output of energy-intensive products (i.e. crude steel, cement, primary aluminium, chemicals and paper), which represents $50 \%$ of total electricity consumption in China's industry (Chapters 2, 4 and 5). China is a coal-dependent country, where $70 \%$ of electricity generation is derived from coal-combustion. Although substituting electricity for fossil-fuel can effectively reduce the direct emissions from industrial demand-side, it drives a significant increase in indirect emissions due to electricity generation. Newly planned coal-fired power plants show that around 200 GW of new capacity is scheduled to come online by 2030 (Chapters 4 and 5). This expansion would threaten the Paris climate goals and local air quality. Compared to developed countries (e.g. Germany and Japan), China still has enormous opportunities for electricity savings in industry. Around 24\% of electricity demand by 2040 can be reduced by scaling up energy efficiency technologies (Chapters 2, 4 and 5). The highest potential for improving electricity use efficiency lies in the three largest industrial consumers, i.e. iron \& steel, aluminium and chemical sectors (Chapters 2, 4 and 5). Besides these three industries, considerable electricity savings are found in the cement 
and pulp \& paper sectors (Chapters 2, 4 and 5). Therefore, policies promoting energy efficiency improvements should prioritize these five energy-intensive industries.

Actions to improve industrial energy efficiency can help reshape electricity systems across China to combat global warming and air pollution cost-effectively. The synergies due to demand-side electricity savings have rarely been integrated into the assessment of Chinese sustainable development policies. The pivotal role of energy efficiency has been emphasized by a large number of studies, but the potential mutual benefits for both industrial consumers and electricity generators have not been fully quantified. Due to the lack of understanding of the full benefits, energy efficiency strategies fail to be included in either power system planning or air pollutant emissions management in China. Electricity savings in the Chinese industry can potentially replace a total of $108 \mathrm{GW}$ coal-fired power capacity, which pushes nearly all most polluting units into early retired (Chapters 4 and 5). Displacing these coal power capacities drastically reduces air pollutant emissions in 2040 to below 2016 emission levels, thus delivering significant air quality improvements (Chapters 4 and 5). Massive spending on pollution control measures, especially for small subcritical generation units, is generally economically less attractive to tackle air pollutants compared to demand-side efficiency improvements (Chapters 3, 4 and 5). Besides the reduced air pollutant emissions, substantial $\mathrm{CO}_{2}$ emissions are avoided by improving industrial efficiency. These results suggest that national policymakers who aim to co-control air pollutants and carbon emissions through decreasing the dependency on coal-intensive electricity need to recognize the importance of concurrent efforts to improve demand-side electricity use efficiency.

Regional heterogeneity in terms of electricity saving potentials and coal plant phaseout in the different power grids should be included in policy design for tackling air quality and climate concerns. Synergies between electricity savings and emission reductions vary per region due to the different levels of industrial plant concentration and environmental performance of electricity supply systems (Chapters 3 and 5). The North grid, covering many coal-dependent and industrial provinces (e.g. Hebei, Inner Mongolia, Shanxi and Shandong), has the highest potential to phase out coal power plants, thus contributing to the largest emission reductions. The Central grid can deactivate more coal capacity than the East gird but has a lower contribution to air pollutant reductions, compared to the East grid. This is because most of the displaced coal power capacity in the East grid consists of poor performing units. These results suggest that the regional grid managers need to understand not only the grid-specific synergies of a more efficient industry and electricity generation systems, but also the different scales of coal power plant fleet and emission-reduction benefits. Furthermore, the provincial decision-makers are recommended to prioritize investments in the sector with short payback times and high potentials for electricity savings (e.g. the iron \& steel industry). 
It is necessary to further improve the modeling framework, upgrading key drivers (e.g. structural index, energy price and urbanization) and improving technical characterization (e.g. aggregated functions or specific technology). Model-based scenario analysis has a key role to play in informing decision-makers about future trends in the energy system and air emissions. Five key modeling factors have a significant impact on simulation results: 1) system boundaries; 2) modeling approaches; 3) social and economic indicators; 4) technology representation; and 5) data sources (Chapter 2). The modeling approach is the core element to evaluate the evolution, investments and emission levels of energy systems linking demand-side and supply-side under different future pathways (Chapters 4 and 5). Besides the model structure, technology representation, for example rich-technology bottom-up modeling versus top-down modeling, determines the projections of energy savings and emission mitigation over the medium- or long-term. Once high-quality data becomes available, a comprehensive modeling framework plays a guiding role in developing more feasible and effective policies, thus helping the country to realize sustainable development.

\subsection{Future research direction}

Based on the research a number of recommendations for future research directions are determined:

This thesis fully characterizes the multiple benefits of electricity savings on air emission reductions (GHGs, $\mathrm{SO}_{2}, \mathrm{NO}_{\mathrm{x}}$ and $\mathrm{PM}$ ) by connecting the Chinese industry and the power sector. Nevertheless, it fails to capture other derived benefits (e.g. air qualityrelated health benefits) and to consider the trade-offs between multiple environmental objectives. Quantifying the avoided premature deaths due to the reduced air pollutant concentration can provide a strong motivation for promoting the progress of energy efficiency. Scaling up demand-side energy efficiency to reducing the trade-offs between air quality, $\mathrm{CO}_{2}$ and water is critical for planning electricity supply systems, for example, deploying new power generation capacity. Additional work is needed to further understand the synergies and trade-offs, thus providing powerful evidence for design-makers to integrate energy efficiency into the policies of air quality or low-carbon electricity system design.

Despite the inclusion of five energy-intensive industries in this study, other end-use sectors with considerable electricity consumption, such as textile, building industries, as well as residential and commercial sectors, are not included. This is partly because of unavailable data (e.g. specific technology and unmeasured production) and unclear boundaries for these economic activities. Studies suggest that huge potentials for electricity savings would exist in these electricity consuming sectors. Challenges remain present to assess and understand the electricity saving potentials across multiple sectors 
in a whole country or region. The unidentified demand side electricity savings would result in an underestimation of coal-fired power capacity phaseout in the current studies, thereby failing to understand the full potential to reduce emissions. Thus, further research is suggested to also study and include those electricity consumers in the analysis, and, furthermore, improve data quality and transparency for these sectors.

Although this research presents a cost-effective emission reduction pathway, most of its attention is focused on demand-side electricity savings. Accelerating electrification in demand-side and promoting renewable energy penetration in electricity supply systems are two recent strategies that are considered to deeply reduce global air emissions. Incorporated energy efficiency with renewables and electrification strategies would more effectively improve air quality and peak GHG emissions within the expected time or in the short term. Further research on the assessment of the impacts of these strategies is required to provide a more comprehensive understanding of the connections in terms of low-carbon measures, efficiency improvements and air emissions.

Investigating the regional heterogeneity across a country needs to be continued. Although a variety of studies have explored the multiple benefits, most of these researches are concentrated on a national level and fail to characterize the energy systems on a regional level. The multi-regional perspective provided in this thesis allows allocating the national climate or air quality targets to the regional level. This will help local governments formulate energy-saving and emission-reduction measures that suit their conditions. Thus, a multi-sectoral and multi-regional modeling framework is highly recommended in further research to explore the spatial patterns of coal-free energy systems with low emissions of air pollutants and greenhouse gases. 


\section{References}

Abel, D.W., Holloway, T., Martínez-Santos, J., Harkey, M., Tao, M., Kubes, C., Hayes, S., 2019. Air quality-related health benefits of energy efficiency in the United States. Environmental science \& technology, 53, 3987-3998.

Climate Transparency, 2019. Managing the phase-out of coal: a comparison of actions in G20 countries. Berlin (Germany). URL: https://www.climate-transparency.org/wp-content/ uploads/2019/05/Managing-the-phase-out-of-coal-DIGITAL.pdf (accessed 01 August 2020).

Grubler, A., Wilson, C., Bento, N., Boza-Kiss, B., Krey, V., McCollum, D.L., Rao, N.D., Riahi, K., Rogelj, J., De Stercke, S., Cullen, J., Frank, S., Fricko, O., Guo, F., Gidden, M., Havlík, P., Huppmann, D., Kiesewetter, G., Rafaj, P., Schoepp, W., Valin, H., 2018. A low energy demand scenario for meeting the $1.5^{\circ} \mathrm{C}$ target and sustainable development goals without negative emission technologies. Nature Energy, 3, 515-527.

IEA, 2019a. $\mathrm{CO}_{2}$ emissions from fuel combustion 2019. International Energy Agency (IEA), Paris (France).

IEA, 2019b. Energy efficiency 2019. International Energy Agency (IEA), Paris (France). URL: https://webstore.iea.org/download/direct/2891 (accessed 01 August 2020).

IEA, 2019c. World energy outlook 2019. International Energy Agency (IEA), Paris (France).

IEA, 2018. World energy balances (2018 edition), International Energy Agency (IEA), Paris (France).

IEA (International Energy Agency), IRENA (International Renewable Energy Agency), UNSD (United Nations Statistics Division), WB (World Bank), WHO (World Health Organization), 2019. Tracking SDG 7: The energy progress report 2019. Washington (USA). URL: https:// www.irena.org/publications/2019/May/Tracking-SDG7-The-Energy-Progress-Report-2019 (accessed 01 August 2020).

IPCC, 2018. Global warming of $1.5^{\circ} \mathrm{C}$ : An IPCC Special Report on the impacts of global warming of $1.5^{\circ} \mathrm{C}$ above pre-industrial levels and related global greenhouse gas emission pathways, in the context of strengthening the global response to the threat of climate change, sustainable development, and efforts to eradicate poverty. Intergovernmental Panel on Climate Change (IPCC), Geneva. URL: https://www.ipcc.ch/sr15/ (accessed 01 August 2020). 


\section{Chapter 6}

Nerini, F.F., Tomei, J., To, L.S., Bisaga, I., Parikh, P., Black, M., Borrion, A., Spataru, C., Broto, V.C., Anandarajah, G., Milligan, B., Mulugetta, Y., 2018. Mapping synergies and trade-offs between energy and the Sustainable Development Goals. Nature Energy, 3, 10-15.

Panos, E., Densing, M., Volkart, K., 2016. Access to electricity in the World Energy Council's global energy scenarios: An outlook for developing regions until 2030. Energy Strategy Reviews, 9, 28-49.

S\&P Global Platts, 2018. World electric power plants (WEPP) database v. September 2017. Washington (USA).

United Nations, 2019. World urbanization prospects: The 2018 revision. New York. URL: https://population.un.org/wup/ (accessed 01 August 2020).

Wen, Z., Wang, Y., Li, H., Tao, Y., De Clercq, D., 2019. Quantitative analysis of the precise energy conservation and emission reduction path in China's iron and steel industry. Journal of environmental management, 246, 717-729.

WHO, 2020. World health statistics 2020: monitoring health for the SDGs, sustainable development goals. World Health Organization (WHO), Geneva. URL: https://apps.who. int/iris/bitstream/handle/10665/332070/9789240005105-eng.pdf (accessed 01 August 2020).

World Bank, 2020. Industry value added (constant 2010 US\$). URL: https://data.worldbank. org/indicator/NV.IND.TOTL.KD (accessed 01 August 2020).

Worrell, E., Laitner, J.A., Ruth, M., Finman, H., 2003. Productivity benefits of industrial energy efficiency measures. Energy, 28, 1081-1098.

Zhang, S., Worrell, E., Crijns-Graus, W., Krol, M., de Bruine, M., Geng, G., Wagner, F., Cofala, J., 2016. Modeling energy efficiency to improve air quality and health effects of China's cement industry. Applied Energy, 184, 574-593.

Zhang, S., Xie, Y., Sander, R., Yue, H., Shu, Y., 2020. Potentials of energy efficiency improvement and energy-emission-health nexus in Jing-Jin-Ji's cement industry. Journal of Cleaner Production, 278, 123335. 


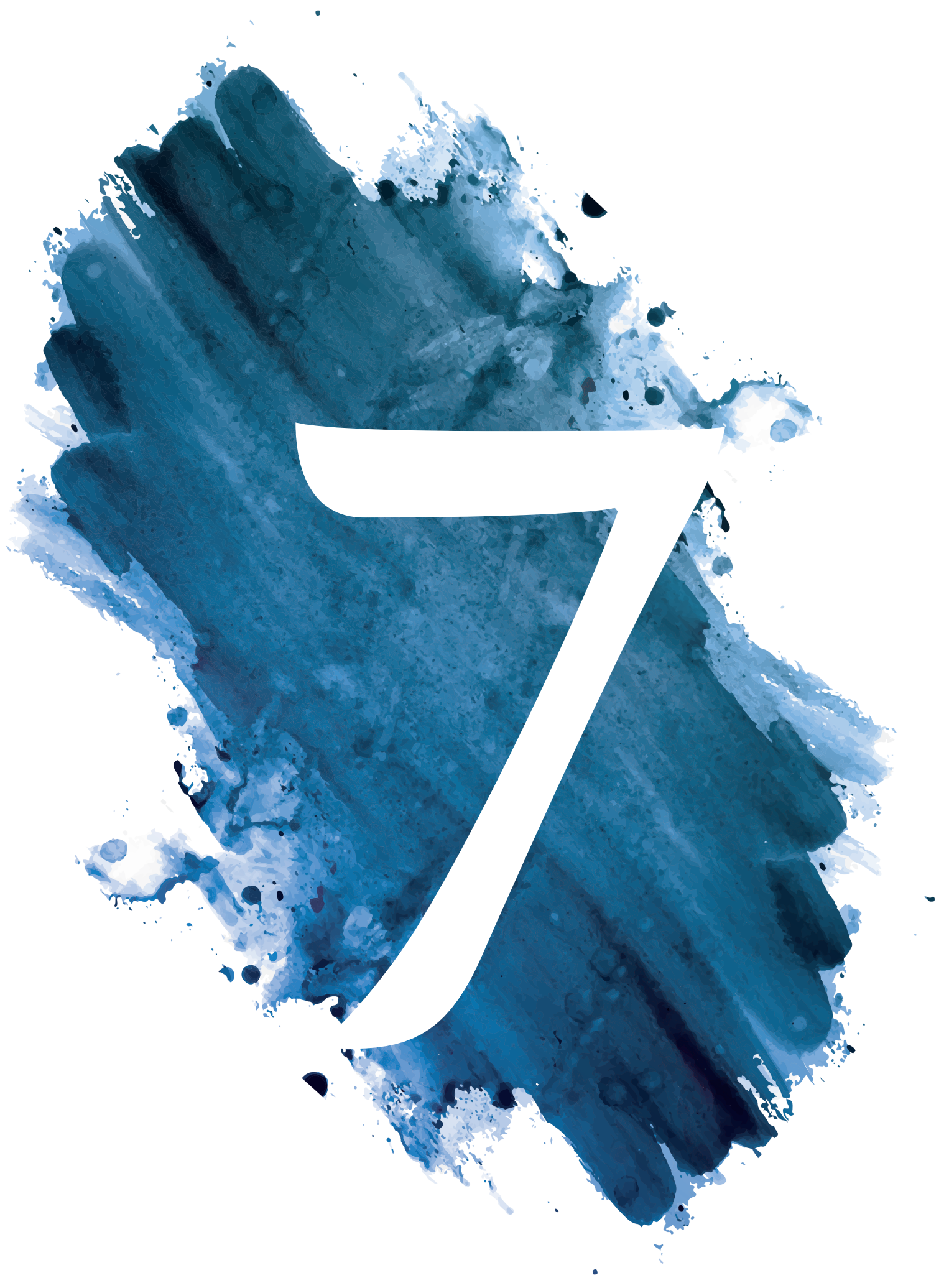




\section{Chapter 7}

\section{Samenvatting en conclusies}




\section{I. Onderzoekscontext}

Toegang tot elektriciteit is het kernelement voor armoedebestrijding, economische groei en een betere levensstandaard (Nerini et al., 2018). Verschillende landen over de hele wereld, met name de opkomende economieën, hebben de afgelopen jaren grote inspanningen geleverd om de toegang tot elektriciteit uit te breiden. Dienovereenkomstig is het aandeel mensen dat zonder elektriciteit leeft gedaald naar $11 \%$ in 2017 van $27 \%$ in 2000 (IEA et al., 2019). Ondertussen is het verstedelijkingsniveau de afgelopen twee decennia met ongeveer 10\% gestegen, terwijl Azië bijdraagt aan 65\% van de toename van de stedelijke bevolking (United Nations, 2019). Gedreven door snelgroeiende elektrificatie en verstedelijking, steeg de elektriciteitsvraag dramatisch van $12.700 \mathrm{TWh}$ in 2000 tot $21.400 \mathrm{TWh}$ in 2017 (IEA, 2018; IEA, 2019c). Dit sterke verlangen naar elektriciteitzal naarverwachting nog twintig jaar aanhouden, omdat de snelle economische ontwikkeling verschuift van ontwikkelde regio's naar opkomende economieën (Panos et al., 2016). De belangrijkste bron van elektriciteit is het verbranden van steenkool, die al lang voor ongeveer $40 \%$ van de wereldwijde stroomopwekking zorgt (IEA, 2018). Door steenkoolintensieve elektriciteitssystemen is de mondiale elektriciteitssector echter de grootste uitstoter van antropogene mondiale broeikasgassen (GHG) (IEA, 2019a) en een belangrijke producent van luchtverontreinigende stoffen (IEA, 2019c), wat een fatale bedreiging vormt voor de streven naar duurzame menselijke ontwikkeling (IPCC, 2018; WHO, 2020).

Hoewel een aantal landen de overgang naar een kolenvrij elektriciteitssysteem bevorderen (Climate Transparency, 2019), zorgen de nieuw gebouwde kolencentrales in China voor de wereldwijde uitbreiding van de kolengestookte elektriciteitsvloot (S\&P Global Platts, 2018) . Bijna 50\% van de wereldwijde capaciteit voor steenkool wordt ingezet in China, terwijl het $70 \%$ van de totale elektriciteitsopwekking levert om an de stijgende economische ontwikkeling te voldoen. De industrie, met name de energieintensieve sectoren (bijv. IJzer \& staal, cement, aluminium en chemicaliën), domineert de Chinese economie en draagt bij tot $46 \%$ van het bruto binnenlands product van het land (World Bank, 2020). De industrie is ongetwijfeld de grootste verbruiker van steenkool-intensieve elektriciteit (goed voor 62\% van de totale elektriciteitsvraag in China) en is ook de belangrijkste factor die de Chinese honger naar nieuwe kolengestookte elektriciteitsopwekking doet toenemen. Op steenkool gebaseerde elektriciteitsvoorzieningssystemen, samen met een steeds toenemende industriële elektriciteitsvraag, plaatsten China voor een dilemma tussen versnelde industrialisatie en het verminderen van de impact op het milieu. Het beheer van het elektriciteitsverbruik in de industrie om de kolengestookte vloot te verkleinen, speelt dus een cruciale rol bij het bestrijden van klimaatverandering en luchtkwaliteit en het minimaliseren van de gevolgen voor de economie. 
Energie-efficiëntie is een win-win-strategie gebleken om de energievraag te verminderen en tegelijkertijd hoogwaardige voordelen te creëren, zoals het vergroten van de energiezekerheid (IEA, 2019b), het beperken van de opwarming van de aarde (Grubler et al., 2018) en het vermijden van luchtverontreinigende emissies ( Abel et al., 2019), waardoor vroegtijdige sterfte afneemt (Zhang et al., 2020) en de industriële productiviteit verbetert (Worrell et al., 2003). De verbetering van de energie-efficiëntie lijkt de afgelopen jaren echter overal ter wereld te vertragen, wat de toekomstige efficiëntiewinst mogelijk verzwakt (IEA, 2019b). Een van de belangrijkste redenen is dat China en de Verenigde Staten hun productie van energie-intensieve industriële producten aanzienlijk hebben verhoogd (IEA, 2019b). Tot op heden heeft China de vele voordelen van verbeteringen op het gebied van energie-efficiëntie praktisch niet geïntegreerd in de strategieën voor luchtverontreiniging en energiesystemen. Dit komt doordat een alomvattend begrip van de nevenvoordelen, in termen van energiebesparing en meervoudige luchtemissiereducties, nog steeds ontbreekt. Het is vermeldenswaard dat de elektriciteitsintensiteit in 2017 vrijwel hetzelfde niveau blijft als in de jaren negentig, niet alleen voor de wereld, maar vooral voor China (IEA, 2019c). De elektriciteitsintensiteit van het land is tweemaal het mondiale gemiddelde. Eerdere studies hadden alleen betrekking op energiebesparingen voor een specifieke sector aan de vraagzijde (bijv. Voor de sectoren ijzer \& staal (Wen et al., 2019) en cement (Zhang et al., 2016)). Analyses kwantificeren zelden de technologiegedreven elektriciteitsbesparingen en negeren ook de effecten van elektriciteitsbesparingen op de energieopwekkingssector. Deze hiaten in de kennis inspireren het proefschrift om de complexe verbanden van elektriciteitsbesparing, evolutie van de vloot van energiecentrales en veranderingen in luchtemissies te onderzoeken. Bovendien zou het onthullen van de relatie nuttig zijn voor een hoogrenderende industrie en een schoon elektriciteitssysteem, waardoor de klimaatverandering wordt beperkt en de luchtkwaliteit wordt verbeterd. Dit wordt urgenter, niet alleen voor China, maar ook voor andere landen waar elektriciteit wordt opgewekt door een kolenintensieve vloot van elektriciteitscentrales.

\subsection{Onderzoeksdoelen}

Het doel van dit proefschrift is om een diepgaande analyse uit te voeren van het potentieel voor elektriciteitsbesparing en de kosten-baten van emissiereductie door het opschalen van energie-efficiëntie. Ons onderzoek richt zich op de verbeteringen van de industriële elektrische efficiëntie in China, waar de elektriciteitsvoorziening sterk afhankelijk is van kolengestookte elektriciteitscentrales en voor meerdere uitdagingen staat voor een duurzame toekomst. Om de doelstelling te bereiken wordt een onderzoekskader geformuleerd dat bestaat uit vijf subdoelen:

1. Het vergelijken van prognoses voor het elektriciteitsverbruik en het elektriciteitsbesparingspotentieel voor de Chinese industrie in verschillende onderzoeken 
om een overzicht te geven van de mogelijkheden voor efficiëntieverbeteringen en om sectoren te identificeren met het grootste potentieel voor elektriciteitsbesparing.

2. Inzicht in de modelparameters en benaderingen die de bestudeerde resultaten in verschillende scenario's beïnloeden.

3. Het meten van de vele voordelen van elektriciteitsbesparingen in industriële subsectoren, in termen van vermindering van broeikasgassen en luchtverontreiniging op het niveau van het elektriciteitsnet.

4. Kwantificering van de mogelijke effecten van een verminderde elektriciteitsbelasting door de industrie op de geleidelijke stopzetting van sterk vervuilende kolencentrales, veranderingen in de luchtemissie door de elektriciteitssector en de beheersingskosten van luchtverontreinigende stoffen.

5. Een alomvattende beoordeling van de wederzijdse voordelen van industriële elektriciteitsbesparing, verwijdering van kolencentrales, emissiereducties en gerelateerde investeringsoptimalisatie op provinciaal en netniveau.

Deze onderzoeksdoelen komen aan bod in hoofdstuk 2 tot en met hoofdstuk 5. Tabel 7.1 geeft een overzicht van de scriptiehoofdstukken en de doelen die ze behandelen. Hoofdstuk 2 bevat een overzicht en analyse van studies die industriële elektriciteitsbesparingen modelleren en mogelijkheden voor reductie van luchtemissies onderzoeken. Verder evalueert dit hoofdstuk kritisch de scenario-gemodelleerde kenmerken in beschikbare studies, die de modelresultaten in verschillende mate beïnvloeden. De systematische review gepresenteerd in hoofdstuk 2 biedt een richtlijn op het gebied van het bouwen van een geïntegreerd modemkader (dat bestaat uit elektriciteitsverbruik, stroomopwekking, luchtemissies en kostenmodules) en het beheren van het industriële elektriciteitsverbruik om schadelijke luchtemissies van de energiesector te verminderen. In hoofdstuk 3 worden voorzieningscurves voor elektriciteitsbesparing per net ontwikkeld om de synergieën van maatregelen om elektriciteit te besparen te kwantificeren in termen van het vermijden van luchtverontreinigende stoffen en broeikasgasemissies vanuit een kosten- en technisch perspectief voor een complex industrieel systeem; China's chemische sector. In de volgende hoofdstukken wordt een completere database van industriële energie-efficiëntietechnologieën ontwikkeld, waarin de elektriciteitsbesparende technologieën worden opgenomen die in de chemische industrie worden toegepast. Naast de gedetailleerde technologiedatabase is er onlangs een uitgebreide database met energiecentrales gemaakt, die het uitvoeren van een kwantitatieve beoordeling enorm ondersteunt. Hoofdstuk 4 kwantificeert de vele voordelen van industriële elektriciteitsbesparingen bij het deactiveren van supervervuilende opwekkingseenheden om de luchtemissies $\left(\mathrm{CO}_{2}, \mathrm{SO}_{2}, \mathrm{NO}_{\mathrm{x}}\right.$ en $\left.\mathrm{PM}\right)$ van de Chinese elektriciteitssystemen te verminderen. Hoofdstuk 5 ontwikkelt een geïntegreerd modelleerraamwerk dat rekening 
houdt met regionale heterogeniteiten om de vitale rol te kwantificeren van industriële efficiëntie bij het verminderen van de afhankelijkheid van kolencentrales om de voordelen van het verminderen van luchtverontreinigende emissies op verschillende schaalniveaus te maximaliseren. De kosten van het terugdringen van luchtverontreinigende stoffen door het verbeteren van de industriële energie-efficiëntie en het achteraf uitrusten van energiecentrales met end-of-pipe controles, worden ook geraamd.

Table 7.1. Overzicht van het proefschrift hoofdstukken en de bijbehorende onderzoek subdoelen.

\begin{tabular}{|c|c|c|c|c|c|c|}
\hline \multirow[t]{2}{*}{ Hoofdstuk } & \multirow[t]{2}{*}{ Onderwerp } & \multicolumn{5}{|c|}{ Subdoel onderzoek } \\
\hline & & 1 & 2 & 3 & 4 & 5 \\
\hline 2 & $\begin{array}{l}\text { Elektriciteit besparen in de Chinese industrie: een overzicht van } \\
\text { kansen, mogelijkheden en milieuvoordelen }\end{array}$ & $\mathrm{X}$ & $\mathrm{X}$ & & & \\
\hline 3 & $\begin{array}{l}\text { Modellering van de vele voordelen van elektriciteitsbesparing voor } \\
\text { emissiereductie op elektriciteitsnetniveau: een casestudy van de } \\
\text { Chinese chemische industrie }\end{array}$ & & & $\mathrm{X}$ & & \\
\hline 4 & $\begin{array}{l}\text { Luchtemissies en energie-efficiëntie: het realiseren van } \\
\text { meerdere voordelen voor de energiesector door het industriële } \\
\text { elektriciteitsverbruik in China te besparen }\end{array}$ & & & & $\mathrm{X}$ & \\
\hline 5 & $\begin{array}{l}\text { Modellering van verbanden tussen de industrie en de energiesector } \\
\text { om regionale elektriciteitsbesparingen en luchtvervuiling } \\
\text { gezamenlijk te beheren - Een casestudy van China }\end{array}$ & & & & $\mathrm{X}$ & $\mathrm{X}$ \\
\hline
\end{tabular}

\subsection{Belangrijkste bevindingen van het proefschrift}

Deze sectie geeft een samenvatting van de belangrijkste bevindingen uit de voorgaande hoofdstukken per onderzoeksdoel van dit proefschrift:

1. Het vergelijken van prognoses voor het elektriciteitsverbruik en het elektriciteitsbesparingspotentieel voor de Chinese industrie in verschillende onderzoeken om een overzicht te geven van de mogelijkheden voor efficiëntieverbeteringen en om sectoren te identificeren met het grootste potentieel voor elektriciteitsbesparing.

Onderzoeksdoel 1 wordt behandeld in hoofdstuk 2 door een vergelijkende evaluatie uit te voeren van beschikbare literatuur over de prestaties van het elektriciteitsverbruik in de Chinese industrie met een diepgaande focus op de grootste verbruikende subsectoren en de belangrijkste technologieën voor energie-efficiëntie. Op basis van de modelresultaten van de geselecteerde studies, worden de emissiereducties van broeikasgassen en luchtverontreinigende stoffen die worden toegeschreven aan industriële elektriciteitsbesparingen geschat.

Hoofdstuk 2 heeft tot doel het energiebesparingspotentieel in de Chinese industrie te evalueren, terwijl vooral de elektriciteitsbesparingen in de vijf grootste eindgebruiksectoren worden gekwantificeerd, namelijk ijzer \& staal, cement, non-ferro 
metalen, pulp \& papier en de chemische sector. Daarnaast wordt voor de textielsector met een groot elektriciteitsverbruik een kwalitatieve analyse gemaakt van de mogelijkheden om de efficiëntie van het elektriciteitsgebruik te verbeteren. De resultaten laten zien dat elektriciteit de snelgroeiende energiedrager is in het industriële energiesysteem van China, dat verschuift naar meer vermogen en minder fossiele brandstoffen. Het elektriciteitsverbruik in de Chinese industrie zal naar verwachting in 2040 meer dan een derde van het industriële eindverbruik van energie uitmaken, optimistisch geschat op ongeveer $40 \%$. Tegelijkertijd ligt er een groot potentieel aan elektriciteitsbesparing, gelijk aan $14 \%$ van het industriële elektriciteitsverbruik in 2040, in de industrie. Uit elektriciteit afkomstige emissies van $660 \mathrm{Mt}^{-\mathrm{CO}_{2 \mathrm{eq}}}, 1300 \mathrm{kt}-\mathrm{SO}_{2}, 1400 \mathrm{kt}-\mathrm{NO}_{\mathrm{x}}$ en 300 kt-PM ${ }_{2,5}$ zullen naar verwachting worden vermeden door de energie-efficiëntie in de Chinese industrie te verbeteren. De ijzer- en staalsector levert de grootste bijdrage aan de totale elektriciteitsbesparing. Ook in de non-ferrometalen en de chemie worden forse elektriciteitsbesparingen gerealiseerd. Terwijl de cement- en pulp- \& papiersector een kleinere bijdrage leveren aan de totale elektriciteitsvermindering. Om hun potentieel te benutten, liggen de meeste kansen in de sectoren non-ferrometalen en chemie, gevolgd door de sector ijzer \& staal, cement en pulp \& papier. In de textielindustrie hebben motoraangedreven systemen een aanzienlijk potentieel om elektriciteit te besparen.

\section{Inzicht in de modelparameters en benaderingen die de bestudeerde resultaten in verschillende scenario's beïvloeden.}

Hoofdstuk 2 behandelt ook onderzoeksdoel 2 door factoren te onderzoeken die de modelresultaten per subsector voor de geselecteerde studies beïnvloeden. In dit hoofdstuk worden in totaal 27 belangrijke drijfveren, ingedeeld in vijf aspecten (d.w.z. systeemgrenzen, modelleringsmethode, sociale en economische indicator, technologierepresentatie en gegevensbron) besproken. Systeemgrens betekent de dekking van de bestudeerde sector, die meestal wordt geïdentificeerd op basis van de classificatie van nationale economische activiteiten. Deze factor heeft op meerdere manieren een grote invloed op de projecties van het elektriciteitsverbruik in de industriële sectoren. De modelleringsmethode heeft indirect invloed op de keuze van scenarioparameters en onderzoeksbereik, wat resulteert in aanzienlijke verschillen tussen de modelresultaten. Een top-downmodel dat gebruikmaakt van geaggregeerde productiefuncties stelt onderzoekers bijvoorbeeld in staat om de prestaties van elektriciteitsverbruik op korte termijn te evalueren, terwijl de elektriciteitsbesparingen gemodelleerd door de topdownbenadering doorgaans hoger zijn dan de bottom-upmodellering. Geïntegreerde en bottom-up benaderingen met expliciete technologische representatie richten zich meer op technologiegedreven trajecten op middellange en lange termijn. Naast de modelleerstructuur hebben de parameterinstellingen van de scenario-verhaallijn een grote invloed op de modelleerresultaten. Sociale en economische indicatoren (bv. Industriële toegevoegde waarde en verstedelijkingsniveau) hebben een sterke invloed op productiefuncties, die op hun beurt de gemodelleerde output voor elektriciteitsvraag 
beïnvloeden, in het bijzonder voor top-down modellen. Technologische representatie (bijv. Technologieselectie, kosten en diffusiesnelheden) hebben vooral een grote invloed op het sectorale elektriciteitsbesparingspotentieel dat gemodelleerd is door bottom-upbenaderingen. Betrouwbare gegevens zijn een essentieel element voor elk model en verminderen onzekerheden. Dit hoofdstuk geeft aan dat de verschillende gebruikte databronnen een beperkte invloed hebben op de langetermijnsimulatie van elektriciteitsvraag en intensiteit.

3. Het meten van de vele voordelen van elektriciteitsbesparingen in industriële subsectoren, in termen van vermindering van broeikasgassen en luchtverontreiniging op het niveau van het elektriciteitsnet.

Hoofdstuk 3 beantwoordt aan onderzoeksdoel 3 door een bottom-up model te ontwikkelen om de technologiegedreven elektriciteitsbesparingen voor de chemische industrie te kwantificeren en de vermeden indirecte luchtemissies te schatten. Dit hoofdstuk vult de kenniskloof door de mogelijkheden voor energie-efficiëntie en emissiereductie te analyseren in de chemische industrie, die is samengesteld uit een gecompliceerde reeks chemische reactieprocessen. De chemische industrie is 's werelds grootste industriële elektriciteitsverbruiker, goed voor $14 \%$ van het wereldwijde industriële elektriciteitsverbruik.

Hoofdstuk 3 heeft tot doel de nevenvoordelen van verbeteringen in de energieefficiëntie van elektriciteitsbesparingen en meervoudige luchtemissiereducties in de chemische industrie te benutten voor de zes regionale netwerken van China in de periode 2012-2035. China is 's werelds grootste producent en consument van belangrijke chemische producten zoals ammoniak, natronloog, polyvinylchloride en calciumcarbide, die voornamelijk worden aangedreven door de vraag van downstreamindustrieën (bijv. Bouw-, landbouw- en verpakkingssectoren). Tegelijkertijd verbruikt de Chinese chemische industrie een enorme hoeveelheid steenkoolintensieve elektriciteit, tot $475 \mathrm{TWh}$ in 2015. Het leverde dus een belangrijke bijdrage aan de uitstoot van broeikasgassen of luchtverontreinigende stoffen. Elektriciteitsgerelateerde emissies zijn goed voor respectievelijk ongeveer $39 \%, 40 \%, 58 \%$ en $19 \%$ van de $\mathrm{CO}_{2^{-}}, \mathrm{SO}_{2^{-}}, \mathrm{NO}_{\mathbf{x}}$ en PM-emissies in 2015 in de Chinese chemische industrie. Er worden leveringscurves voor elektriciteitsbesparing opgesteld om de kosten van elke energie-efficiëntiemaatregel te analyseren (in totaal 60 technologieën). Om emissiereducties toe te schrijven aan elektriciteitsbesparing worden emissiefactoren van ingekochte elektriciteit per net berekend en geïnstalleerde rookgasbeheersmaatregelen meegenomen.

De resultaten laten zien dat de implementatie van alle 60 efficiëntietechnologieën naar verwachting 185 TWh aan elektriciteitsverbruik in 2035 zal besparen, waarvan $79 \%$ kan worden gerealiseerd door kosteneffectieve maatregelen. Ten opzichte van de nulmeting kan in 2035 ongeveer $121 \mathrm{Mt}, 233 \mathrm{kt}, 254 \mathrm{kt}$ en $51 \mathrm{kt}$ aan $\mathrm{CO}_{2 \text { eq }}$, $\mathrm{SO}_{2}^{-}$, $\mathrm{NO}_{\mathrm{x}}$ - en PM2,5- 
emissies kosteneffectief worden vermeden. De emissies kunnen op gemiddeld, in het technische scenario. Van de elektriciteitsnetten heeft het Noord-net het grootste potentieel voor elektriciteitsbesparing, goed voor 34\% van de totale elektriciteitsbesparing, en draagt zo bij tot de grootste emissiereductie van broeikasgassen en luchtverontreinigende stoffen. De chemische fabrieken zijn voornamelijk verspreid in regio's met overvloedige hulpbronnen en een enorme vraag (bijvoorbeeld Shaanxi, Sichuan, Henan en Xinjiang), wat een weerspiegeling is van op hulpbronnen en vraag gerichte ontwikkelingspatronen. Daarom hebben de noordwestelijke en centrale netten een aanzienlijk potentieel voor elektriciteitsbesparing en bijbehorende emissiereducties, gevolgd door de oostelijke en zuidelijke netten. Het noordoostelijke net (dat drie provincies beslaat, Liaoning, Jilin en Heilongjiang) met een laag aandeel in de productie van chemicaliën, vertegenwoordigt slechts ongeveer $2 \%$ van de totale elektriciteitsbesparing en levert de laagste bijdragen aan het terugdringen van broeikasgassen $(3 \%), \mathrm{SO}_{2}(2 \%), \mathrm{NO}_{\mathrm{x}}(3 \%)$ en $\mathrm{PM}_{2,5}(4 \%)$ emissies.

Drie chemische sectoren, namelijk ammoniak, chlooralkali en calciumcarbide, vertegenwoordigen $54 \%$ van het totale elektriciteitsverbruik in de chemische industrie en hebben het grootste potentieel om de vraag naar elektriciteit te verminderen. De productie van calciumcarbide in China wordt voornamelijk geproduceerd in een vlamboogoven en heeft het grootste elektriciteitsverbruik van de drie sectoren. Het elektriciteitsverbruik in de calciumcarbide-sector kan in 2035 met 39\% worden verminderd door 17 energie-efficiëntietechnologieën te implementeren. De verminderde elektriciteitsvraag kan resulteren in ongeveer $71 \mathrm{Mt}, 129 \mathrm{kt}, 151 \mathrm{kt}$ en $28 \mathrm{kt}$ emissiereducties van $\mathrm{CO}_{2 \mathrm{eq}}, \mathrm{SO}_{2}, \mathrm{NO}_{\mathrm{x}}$ en $\mathrm{PM}_{2,5^{\circ}}$. De ammoniaksector biedt veel ruimte om het huidige elektriciteitsverbruik met $65 \%$ te verbeteren, terwijl het potentieel $28 \%$ is in de chlooralkali-sector. Ongeveer $54 \%$ en $55 \%$ van de totale uitstoot van broeikasgassen en emissies van luchtverontreinigende stoffen kunnen respectievelijk worden behaald door efficiënt gebruik van elektriciteit in deze twee chemische sectoren.

\section{Kwantificering van de potentiële effecten van een verminderde elektriciteitsbelasting door de industrie op de geleidelijke stopzetting van hoogvervuilende kolencentrales, veranderingen in de luchtemissie door de elektriciteitssector en de beheersingskosten van luchtverontreinigende stoffen.}

Onderzoeksdoel 4 komt aan de orde in de hoofdstukken 4-5 door de complexe relatie tussen de industrie en de energiesector te karakteriseren in termen van elektriciteitsbesparing, klimaatverandering en luchtvervuiling. De enorme vraag naar elektriciteit door de industrie stimuleert de uitbreiding van kolenintensieve stroomopwekkingssystemen, wat resulteert in klimaatverandering, luchtvervuiling en gezondheidsproblemen. Hoewel onderzoek de vitale rol van energie-efficiëntie heeft aangetoond, zijn studies die de verbanden tussen industrieel elektriciteitsverbruik en elektriciteitsvoorziening onderzoeken om meerdere luchtemissies te vermijden, beperkt. 
Een uitgebreide analysestructuur (koppeling van de anbodcurves voor elektriciteitsbehoud met het GAINS-model (Greenhouse Gas - Air Pollution Interactions and Synergies)) wordt ontwikkeld in hoofdstuk 4. Dit model wordt toegepast om het potentieel voor elektriciteitsbesparingen in de grootste industrieën van China te kwantificeren. -verontreinigende eenheden om de uitstoot van luchtverontreinigende stoffen te verminderen, en dit te vergelijken met het alternatief van rookgasbeheersingstechnologieën in termen van emissiereductie en kosten. Het aandeel van het elektriciteitsverbruik in de industriële finale energiemix van China is in 2018 gestegen van $19 \%$ in 2000 naar 32\% in 2018. De vloot van kolencentrales, die $70 \%$ van de totale elektriciteitsopwekking levert, vormt de ruggengraat om te voldoen aan de stijgende vraag naar elektriciteit in China. De elektrificerende industrie kan de directe emissies effectief verminderen, maar kan op zijn beurt hoge indirecte emissies van de elektriciteitsproductieprocessen veroorzaken. Kolencentrales zijn verantwoordelijk voor respectievelijk ongeveer 50\%, 19\%, 21\% en $11 \%$ van de totale uitstoot van $\mathrm{CO}_{2}, \mathrm{SO}_{2}$, $\mathrm{NO}_{x}$ en PM in China. De overgang naar een efficiëntere industrie en het overschakelen van steenkool voor elektriciteitsvoorziening is urgent, niet alleen voor China, maar ook voor landen met vergelijkbare energiestructuren.

De resultaten van hoofdstuk 4 laten zien dat in 2040 in totaal 506 TWh aan elektriciteitsvraag kan worden verminderd door industriële efficiëntieverbeteringen. De sectoren ijzer \& staal en aluminium leveren de twee grootste bijdragen aan de totale elektriciteitsbesparing, die samen goed zijn voor $63 \%$ van de reductie tegen 2040, gevolgd door chemicaliën, cement en tenslotte de pulp- en papiersector. Gemiddeld $90 \%$ van het geïdentificeerde potentieel in de industriële sectoren kan worden vrijgemaakt door kosteneffectieve technologieën. De verminderde elektriciteitsvraag in de energieintensieve industrieën van China kan tegen 2040 een totaal van $103 \mathrm{GW}$ kolengestookte stroomcapaciteit compenseren. pensionering en staat een versnelde uitfasering van 19 GW van oudere energiecentrales toe. Naast het sluiten van bestaande eenheden, kan in het energie-efficiëntiescenario ongeveer $10 \mathrm{GW}$ aan nieuw voorgestelde kolencentrales, met name subkritische kolencentrales, worden geannuleerd. In vergelijking met het businessas-usual-scenario kan het verwijderen van deze kolengestookte elektriciteitscentrales de uitstoot van $\mathrm{SO}_{2}, \mathrm{NO}_{\mathrm{x}}$ en $\mathrm{PM}$ in de lucht aanzienlijk verminderen met respectievelijk $23 \%, 26 \%$ en $24 \%$ in 2040 , terwijl $9 \%$ van $\mathrm{CO}_{2}$ uitstoot. De economische analyse van strategieën om de luchtverontreiniging te verminderen, toont aan dat verbeteringen van de industriële efficiëntie een veel hogere initiële investering vereisen dan behandelingen aan het einde van de pijp, maar de investeringsuitgaven voor energie-efficiëntie zullen naar verwachting binnen gemiddeld 5 jaar herstellen als gevolg van de lagere energierekeningen. 
5. Een alomvattende beoordeling van de wederzijdse voordelen van industriële elektriciteitsbesparingen, verwijdering van kolencentrales, emissiereducties en gerelateerde investeringsoptimalisatie op provinciaal en netniveau.

Hoofdstuk 5 behandelt onderzoeksdoel 5 door de distributie van industriële centrales, de evolutie van kolenintensieve elektriciteitssystemen, de elektriciteitsvraag, de bezettingsgraad van steenkoolcentrales en emissieniveaus voor de zes elektriciteitsnetten (die 31 provincies beslaan) in China te onderzoeken. Dit hoofdstuk vult de kenniskloof in het volledig kwantificeren van de cruciale rol die efficiëntieverbeteringen spelen bij het verminderen van het gebruik van steenkool, het verminderen van klimaatverandering en het verbeteren van de luchtkwaliteit op provinciaal en netniveau. Inzicht in de regionale heterogeniteit is van cruciaal belang voor nationale en provinciale besluitvormers om prioriteit te geven aan inspanningen in sectoren en regio's om een efficiënte industrie op te bouwen en de afhankelijkheid van steenkool te verminderen.

Een geïntegreerd modelleringskader, dat vier modellen met elkaar verbindt, is ontwikkeld om de wederzijdse voordelen voor zowel de Chinese industrie als de energiesector op verschillende schaalniveaus te beoordelen onder vier scenario's met als hoofddoel de uitstoot van luchtverontreinigende stoffen in de periode 2016-2040 te verminderen. Ten eerste worden per provincie voorzieningscurves voor elektriciteitsbesparing opgesteld om het bottom-uppotentieel voor elektriciteitsbesparing en bijbehorende investeringskosten te bepalen door een uitgebreide database op te roepen die bestaat uit 175 energieefficiëntietechnologieën (hoofdstuk 4). Ten tweede wordt een emissiebeoordelingsmodel, gebaseerd op de Chinese elektriciteitscentraledatabase, gebruikt om emissiereducties van verplaatste kolencentrales, als gevolg van de verminderde elektriciteitsbelasting, op provinciaal en netniveau te kwantificeren. Ten derde wordt het GAINS-model gebruikt om de investeringen per provincie te meten voor het ombouwen van kolencentrales met end-of-pipe-behandelingsapparatuur om dezelfde reducties van luchtverontreiniging te bereiken als met industriële efficiëntieverbeteringen. Ten slotte wordt ArcGIS (een geografisch informatiesysteem) toegepast om de kenmerken op provinciaal, net- en landelijk bestuursniveau vast te leggen.

Hoofdstuk 5 laat zien dat het inzetpatroon van kolencentrales sterk wordt beïnvloed door lokale kolenbronnen en elektriciteitsvraag. Ongeveer $50 \%$ van de totale steenkoolcapaciteit is geïnstalleerd in het noorden (in de kolenrijke provincies, bijv. Shandong, Shanxi en Binnen-Mongolië) en in de oostelijke netten (inclusief naar stroom hongerige kustgebieden, zoals Zhejiang en Jiangsu), die de twee waren. grootste kolencentrales. De geïnstalleerde kolencapaciteit van het Noord-net is iets hoger dan die van het Oost-net, terwijl de luchtverontreinigende emissies van het Noord-net het dubbele zijn van die van het Oost-net. De belangrijkste reden is dat de Noordgordel in 2016 twee keer zoveel hoogvervuilende kolenstroomcapaciteit inzet als het oostelijke net. Het sluiten van de meest vervuilende eenheden door de vraag naar elektriciteit in elk net 
te verminderen, is van cruciaal belang voor China om de luchtkwaliteit te verbeteren. Het elektriciteitsbesparingspotentieel verschilt per provincie en vertoont een bereik van $4 \mathrm{GW}$ tot $30 \mathrm{GW}$ gecompenseerd vermogen per elektriciteitsnet. Het Noord-net heeft het grootste potentieel voor het verdringen van kolengestookte opwekkingscapaciteit, gevolgd door het Midden-, Noordwest-, Zuid-, Oost- en Noordoostnet. Vanwege de verschillende mogelijkheden voor het verwijderen van kolencentrales en de variërende milieuprestaties van steenkoolproductie-eenheden, vertonen de vermeden luchtemissies tegen 2040 een aanzienlijke heterogeniteit tussen de zes elektriciteitsnetten, variërend van 13-85 kt, 19-129 kt, 3-17 kt en 21-167 Mt voor respectievelijk $\mathrm{SO}_{2-}$, NO -, PMen $\mathrm{CO}_{2}$-emissiereducties. De investeringen in energie-efficiëntie moeten vooral gericht zijn op de ijzer- en staalsector en geconcentreerd worden in het Noord-net, dat naar verwachting op korte termijn hoge energierendementen zal genereren. Voor de overige netten is de specifieke investering per ton verwijderde luchtverontreinigende stof in het Noordoost- en Noordwestnet lager dan in de Oost-, Centraal- en Zuidelijke netten.

\subsection{Algemene conclusies en beleidsimplicaties}

Energie-efficiëntie speelt een onmisbare rol bij het realiseren van een zeer efficiënte industrie en een kolenvrij elektriciteitsvoorzieningssysteem om luchtvervuiling en klimaatverandering tegen te gaan. Dit proefschrift onderzoekt de verbanden tussen industriële vraagzijde en stroomtoevoerzijde om tegelijkertijd op een kosteneffectieve manier elektriciteitsbesparing, verbetering van de luchtkwaliteit en beperking van de klimaatverandering te realiseren, met China als studiecase. Het richt zich voornamelijk op de vele voordelen van maatregelen om de industriële efficiëntie te verbeteren en het gebruik van kolencentrales en de daarmee verband houdende luchtemissies te verminderen. De conclusies en beleidsaanbevelingen zijn ontleend aan de eerdere hoofdstukken:

De snelgroeiende vraag naar elektriciteit in de Chinese industrie resulteert in enorme uitstoot van broeikasgassen en luchtverontreinigende stoffen door elektriciteitsproductieprocessen. De industriële elektriciteitsintensiteit in China bleef in de jaren 2000 op bijna hetzelfde niveau. China moet dringend de vooruitgang op het gebied van efficiënt elektriciteitsgebruik bevorderen. De Chinese industrie is verantwoordelijk voor ongeveer $20 \%$ van het wereldwijde totale elektriciteitsverbruik in 2017 en is daarmee de grootste elektriciteitsverbruiker ter wereld. De stijgende vraag naar elektriciteit wordt voornamelijk aangedreven door de steeds toenemende productie van energie-intensieve producten (zoals ruw staal, cement, primair aluminium, chemicaliën en papier), die 50\% van het totale elektriciteitsverbruik in de Chinese industrie vertegenwoordigt (hoofdstukken 2, 4 en 5). China is een land dat afhankelijk is van steenkool, waar $70 \%$ van de elektriciteitsopwekking afkomstig is van de verbranding van steenkool. Hoewel het vervangen van elektriciteit door 
fossiele brandstoffen de directe emissies van de industriële vraagzijde effectief kan verminderen, zorgt het voor een aanzienlijke toename van de indirecte emissies als gevolg van elektriciteitsopwekking. Uit nieuw geplande kolencentrales blijkt dat tegen 2030 ongeveer $200 \mathrm{GW}$ aan nieuwe capaciteit online zal komen (hoofdstukken 4 en 5). Deze uitbreiding zou een bedreiging vormen voor de klimaatdoelen van Parijs en de lokale luchtkwaliteit. In vergelijking met ontwikkelde landen (bijv.Duitsland en Japan) heeft China nog steeds enorme mogelijkheden om elektriciteit te besparen in de industrie. Ongeveer 24\% van de elektriciteitsvraag tegen 2040 kan worden verminderd door technologieën voor energie-efficiëntie op te schalen (hoofdstukken 2, 4 en 5). Het grootste potentieel voor het verbeteren van de efficiëntie van het elektriciteitsgebruik ligt in de drie grootste industriële verbruikers, namelijk ijzer \& staal, aluminium en chemische sectoren (hoofdstukken 2, 4 en 5). Naast deze drie industrieën worden aanzienlijke elektriciteitsbesparingen gevonden in de sectoren cement en pulp \& papier (hoofdstukken 2, 4 en 5). Daarom moet beleid ter bevordering van energie-efficiëntie verbeteringen prioriteit geven aan deze vijf energie-intensieve industrieën.

Maatregelen om de industriële energie-efficiëntie te verbeteren, kunnen helpen bij het hervormen van elektriciteitssystemen in heel China om de opwarming van de aarde en luchtverontreiniging kosteneffectief te bestrijden. De synergieën als gevolg van elektriciteitsbesparingen aan de vraagzijde zijn zelden meegenomen in de beoordeling van het Chinese beleid voor duurzame ontwikkeling. De cruciale rol van energie-efficiëntie isbenadrukt door eengrootaantal studies, maardepotentiëlewederzijdse voordelen voor zowel industriële verbruikers als elektriciteitsopwekkers zijn niet volledig gekwantificeerd. Vanwege het gebrek aan kennis van de volledige voordelen, worden energie-efficiëntiestrategieën niet opgenomen in de planning van het energiesysteem of het beheer van luchtverontreinigende emissies in China. Elektriciteitsbesparingen in de Chinese industrie kunnen mogelijk in totaal $108 \mathrm{GW}$ kolengestookte stroomcapaciteit vervangen, waardoor bijna alle meest vervuilende eenheden vervroegd met pensioen gaan (hoofdstukken 4 en 5). Door deze energiecapaciteit voor steenkool te verplaatsen, wordt de uitstoot van luchtverontreinigende stoffen in 2040 drastisch verminderd tot onder de emissieniveaus van 2016, waardoor de luchtkwaliteit aanzienlijk verbetert (hoofdstukken 4 en 5). Massale uitgaven voor maatregelen ter beheersing van de verontreiniging, met name voor kleine subkritische productie-eenheden, zijn over het algemeen economisch minder aantrekkelijk om luchtverontreinigende stoffen aan te pakken in vergelijking met efficiëntieverbeteringen aan de vraagzijde (hoofdstukken 3, 4 en 5). Naast de verminderde uitstoot van luchtverontreinigende stoffen, wordt aanzienlijke $\mathrm{CO}_{2}$-uitstoot vermeden door de industriële efficiëntie te verbeteren. Deze resultaten suggereren dat nationale beleidsmakers die ernaar streven luchtverontreinigende stoffen en koolstofemissies mede te beheersen door de afhankelijkheid van steenkoolintensieve elektriciteit te verminderen, het belang moeten erkennen van gelijktijdige inspanningen om de efficiëntie van het elektriciteitsgebruik aan de vraagzijde te verbeteren. 
Regionale heterogeniteit in termen van potentieel voor elektriciteitsbesparing en uitfasering van kolencentrales in de verschillende elektriciteitsnetten moet worden meegenomen in het beleidsontwerp voor het aanpakken van luchtkwaliteit en klimaatproblemen. Synergieën tussen elektriciteitsbesparingen en emissiereducties verschillen per regio vanwege de verschillende concentratieniveaus van industriële installaties en de milieuprestaties van elektriciteitsvoorzieningssystemen (hoofdstukken 3 en 5). Het noordelijke net, dat veel van kolen afhankelijke en industriële provincies bestrijkt (bijv.Hebei, Binnen-Mongolië, Shanxi en Shandong), heeft het hoogste potentieel om kolencentrales geleidelijk uit te faseren, en draagt zo bij tot de grootste emissiereducties. Het centrale net kan meer kolencapaciteit deactiveren dan de oostelijke gordel, maar levert een lagere bijdrage aan de vermindering van luchtverontreiniging in vergelijking met het oostelijke net. Dit komt doordat het grootste deel van de verplaatste kolenstroomcapaciteit in het oostelijke net bestaat uit slecht presterende eenheden. Deze resultaten suggereren dat de regionale netbeheerders niet alleen de netspecifieke synergieën van een efficiëntere industrie en elektriciteitsopwekkingssystemen moeten begrijpen, maar ook de verschillende schalen van de vloot van kolencentrales en de voordelen voor emissiereductie. Bovendien wordt de provinciale besluitvormers aanbevolen om prioriteit te geven aan investeringen in de sector met korte terugverdientijden en een hoog potentieel voor elektriciteitsbesparing (bijv. De ijzer- en staalindustrie).

Het modelleerraamwerk moet verder worden verbeterd door de belangrijkste drijfveren (bv. Structurele index, energieprijs en verstedelijking) te upgraden en de technische karakterisering te verbeteren (bv. Geaggregeerde functies of specifieke technologie). Modelgebaseerde scenarioanalyse speelt een sleutelrol bij het informeren van besluitvormers over toekomstige trends in het energiesysteem en luchtemissies. Vijf belangrijke modelleringsfactoren hebben een significante invloed op de simulatieresultaten: 1) systeemgrenzen; 2) modelbenaderingen; 3) sociale en economische indicatoren; 4) representatie van technologie; en 5) databronnen (Hoofdstuk 2). De modelbenadering is het kernelement om de evolutie, investeringen en emissieniveaus van energiesystemen die vraag- en aanbodzijde via verschillende toekomstige trajecten met elkaar verbinden, te evalueren (hoofdstukken 4 en 5). Naast de modelstructuur bepaalt technologierepresentatie, bijvoorbeeld bottom-upmodellering met rijke technologie versus top-downmodellering, de projecties van energiebesparingen en emissiereductie op middellange of lange termijn. Zodra hoogwaardige gegevens beschikbaar komen, speelt een alomvattend modelkader een leidende rol bij het ontwikkelen van meer haalbare en effectieve beleidsmaatregelen, waardoor het land wordt geholpen om duurzame ontwikkeling te realiseren. 


\subsection{Toekomstige onderzoeksrichting}

Op basis van het onderzoek worden een aantal aanbevelingen voor toekomstige onderzoeksrichtingen bepaald:

Dit proefschrift beschrijft volledig de vele voordelen van elektriciteitsbesparing op luchtemissiereducties (broeikasgassen, $\mathrm{SO}_{2}, \mathrm{NO}_{\mathrm{x}}$ en $\mathrm{PM}$ ) door de Chinese industrie en de energiesector met elkaar te verbinden. Desalniettemin slaagt het er niet in om andere afgeleidevoordelen (bijv. Gezondheidsvoordeleninverband metluchtkwaliteit) tebenutten en de afwegingen tussen meerdere milieudoelstellingen te overwegen. Het kwantificeren van de vermeden vroegtijdige sterfgevallen als gevolg van de verminderde concentratie van luchtverontreinigende stoffen kan een sterke motivatie zijn om de vooruitgang op het gebied van energie-efficiëntie te bevorderen. Het opschalen van de energie-efficiëntie aan de vraagzijde om de afweging tussen luchtkwaliteit, $\mathrm{CO}_{2}$ en water te verminderen, is van cruciaal belang voor het plannen van elektriciteitsvoorzieningssystemen, bijvoorbeeld voor het inzetten van nieuwe energieopwekkingscapaciteit. Er is meer werk nodig om de synergieën en afwegingen beter te begrijpen en zo krachtig bewijs te leveren voor ontwerpmakers om energie-efficiëntie te integreren in het beleid inzake luchtkwaliteit of het ontwerp van koolstofarme elektriciteitssystemen.

Ondanks de opname van vijf energie-intensieve industrieën in deze studie, zijn andere eindgebruikerssectoren met een aanzienlijk elektriciteitsverbruik, zoals textiel, bouwnijverheid, maar ook residentiële en commerciële sectoren, niet meegerekend. Dit komt deels door onbeschikbare gegevens (bv. Specifieke technologie en nietgemeten productie) en onduidelijke grenzen voor deze economische activiteiten. Studies suggereren dat er in deze elektriciteitsverbruikende sectoren enorme mogelijkheden voor elektriciteitsbesparing bestaan. Er blijven uitdagingen bestaan om het elektriciteitsbesparingspotentieel in meerdere sectoren in een heel land of hele regio te beoordelen en te begrijpen. De niet-geïdentificeerde elektriciteitsbesparingen aan de vraagzijde zouden leiden tot een onderschatting van de uitfasering van de capaciteit van kolengestookte elektriciteit in de huidige studies, waardoor het volledige potentieel om de emissies te verminderen niet wordt begrepen. Daarom wordt voorgesteld verder onderzoek te doen om ook die elektriciteitsverbruikers te bestuderen en mee te nemen in de analyse, en bovendien de datakwaliteit en transparantie voor deze sectoren te verbeteren.

Hoewel dit onderzoek een kosteneffectief traject biedt voor emissiereductie, gaat de meeste aandacht uit naar elektriciteitsbesparing aan de vraagzijde. Het versnellen van de elektrificatie aan de vraagzijde en het bevorderen van de penetratie van hernieuwbare energie in elektriciteitsvoorzieningssystemen zijn twee recente strategieën die worden overwogen om de wereldwijde luchtemissies sterk te verminderen. Door energieefficiëntie te integreren in hernieuwbare energiebronnen en elektrificatiestrategieën 
zouden de luchtkwaliteit en de piekemissies van broeikasgassen binnen de verwachte tijd of op korte termijn effectiever worden verbeterd. Verder onderzoek naar de beoordeling van de effecten van deze strategieën is nodig om een beter begrip te krijgen van de verbanden in termen van koolstofarme maatregelen, efficiëntieverbeteringen en luchtemissies.

Het onderzoek naar de regionale heterogeniteit in een land moet worden voortgezet. Hoewel een verscheidenheid aan onderzoeken de vele voordelen heeft onderzocht, zijn de meeste van deze onderzoeken geconcentreerd op nationaal niveau en slagen ze er niet in de energiesystemen op regionaal niveau te karakteriseren. Het multiregionale perspectief dat in dit proefschrift wordt geboden, maakt het mogelijk om de nationale klimaat- of luchtkwaliteitsdoelstellingen toe te wijzen aan het regionale niveau. Dit helpt lokale overheden bij het formuleren van energiebesparende en emissiereducerende maatregelen die passen bij hun omstandigheden. Daarom wordt een multisectoraal en multiregionaal modelleringskader ten zeerste anbevolen bij verder onderzoek om de ruimtelijke patronen van kolenvrije energiesystemen met lage emissies van luchtverontreinigende stoffen en broeikasgassen te verkennen. 


\section{Referenties}

Abel, D.W., Holloway, T., Martínez-Santos, J., Harkey, M., Tao, M., Kubes, C., Hayes, S., 2019. Air quality-related health benefits of energy efficiency in the United States. Environmental science \& technology, 53, 3987-3998.

Climate Transparency, 2019. Managing the phase-out of coal: a comparison of actions in G20 countries. Berlin (Germany). URL: https://www.climate-transparency.org/wp-content/ uploads/2019/05/Managing-the-phase-out-of-coal-DIGITAL.pdf (accessed 01 August 2020).

Grubler, A., Wilson, C., Bento, N., Boza-Kiss, B., Krey, V., McCollum, D.L., Rao, N.D., Riahi, K., Rogelj, J., De Stercke, S., Cullen, J., Frank, S., Fricko, O., Guo, F., Gidden, M., Havlík, P., Huppmann, D., Kiesewetter, G., Rafaj, P., Schoepp, W., Valin, H., 2018. A low energy demand scenario for meeting the $1.5^{\circ} \mathrm{C}$ target and sustainable development goals without negative emission technologies. Nature Energy, 3, 515-527.

IEA, 2019a. $\mathrm{CO}_{2}$ emissions from fuel combustion 2019. International Energy Agency (IEA), Paris (France).

IEA, 2019b. Energy efficiency 2019. International Energy Agency (IEA), Paris (France). URL: https://webstore.iea.org/download/direct/2891 (accessed 01 August 2020).

IEA, 2019c. World energy outlook 2019. International Energy Agency (IEA), Paris (France).

IEA, 2018. World energy balances (2018 edition), International Energy Agency (IEA), Paris (France).

IEA (International Energy Agency), IRENA (International Renewable Energy Agency), UNSD (United Nations Statistics Division), WB (World Bank), WHO (World Health Organization), 2019. Tracking SDG 7: The energy progress report 2019. Washington (USA). URL: https:// www.irena.org/publications/2019/May/Tracking-SDG7-The-Energy-Progress-Report-2019 (accessed 01 August 2020).

IPCC, 2018. Global warming of $1.5^{\circ} \mathrm{C}$ : An IPCC Special Report on the impacts of global warming of $1.5^{\circ} \mathrm{C}$ above pre-industrial levels and related global greenhouse gas emission pathways, in the context of strengthening the global response to the threat of climate change, sustainable development, and efforts to eradicate poverty. Intergovernmental Panel on Climate Change (IPCC), Geneva. URL: https://www.ipcc.ch/sr15/ (accessed 01 August 2020). 


\section{Chapter 7}

Nerini, F.F., Tomei, J., To, L.S., Bisaga, I., Parikh, P., Black, M., Borrion, A., Spataru, C., Broto, V.C., Anandarajah, G., Milligan, B., Mulugetta, Y., 2018. Mapping synergies and trade-offs between energy and the Sustainable Development Goals. Nature Energy, 3, 10-15.

Panos, E., Densing, M., Volkart, K., 2016. Access to electricity in the World Energy Council's global energy scenarios: An outlook for developing regions until 2030. Energy Strategy Reviews, 9, 28-49.

S\&P Global Platts, 2018. World electric power plants (WEPP) database v. September 2017. Washington (USA).

United Nations, 2019. World urbanization prospects: The 2018 revision. New York. URL: https://population.un.org/wup/ (accessed 01 August 2020).

Wen, Z., Wang, Y., Li, H., Tao, Y., De Clercq, D., 2019. Quantitative analysis of the precise energy conservation and emission reduction path in China's iron and steel industry. Journal of environmental management, 246, 717-729.

WHO, 2020. World health statistics 2020: monitoring health for the SDGs, sustainable development goals. World Health Organization (WHO), Geneva. URL: https://apps.who. int/iris/bitstream/handle/10665/332070/9789240005105-eng.pdf (accessed 01 August 2020).

World Bank, 2020. Industry value added (constant 2010 US\$). URL: https://data.worldbank. org/indicator/NV.IND.TOTL.KD (accessed 01 August 2020).

Worrell, E., Laitner, J.A., Ruth, M., Finman, H., 2003. Productivity benefits of industrial energy efficiency measures. Energy, 28, 1081-1098.

Zhang, S., Worrell, E., Crijns-Graus, W., Krol, M., de Bruine, M., Geng, G., Wagner, F., Cofala, J., 2016. Modeling energy efficiency to improve air quality and health effects of China's cement industry. Applied Energy, 184, 574-593.

Zhang, S., Xie, Y., Sander, R., Yue, H., Shu, Y., 2020. Potentials of energy efficiency improvement and energy-emission-health nexus in Jing-Jin-Ji's cement industry. Journal of Cleaner Production, 278, 123335. 
Acknowledgements 
Four years seems to be a long journey, but it is amazing how fast time goes. Pursing the $\mathrm{PhD}$ in the Netherlands gave me an unprecedented experience in both research career and private life. This journey was exciting and challenging. During the past four years, I have met interesting friends, witnessed different cultures, and faced difficult academic problems. Without the encouragement and support of all kinds of people involved in my PhD journey, I could not have finished the dissertation successfully. I would like to express my warm thanks to those sweet people, and the China Scholarship Council which funds my research project.

I am especially grateful to my supervisors Ernst Worrell and Wina Crijns-Graus for their guidance, support and patience throughout the $\mathrm{PhD}$ journey. It was great to work with both of you over the past 4 years. You are the best supervisors in my heart, and have given me opportunities to freely develop my abilities in scientific research. Ernst, I am proud to be guided by you and thank you so much for helping me to build the blueprint of my research. Your optimistic and humorous personality always motivated me, even during difficult moments. Your positive qualities have deeply affected my ability in solving scientific problems, which also boosted my confidence. Wina, I truly appreciate your continuous support in research and trivial issues during my $\mathrm{PhD}$ journey. I feel so lucky to have you as my co-supervisor. I especially enjoyed the discussions in our weekly meetings. The critical discussion per week was very important for the completion of my $\mathrm{PhD}$ thesis and the exploration of my future research career. Not only did the open discussions enable to discover my own weaknesses in the research, it also helped to capture valuable insights of myself. Again, I am deeply grateful to both of you for joining this $\mathrm{PhD}$ journey as my supervisors.

I would also like to express gratitude to my co-authors. Shaohui Zhang from Beihang University: thank you so much for your contributions to my $\mathrm{PhD}$ thesis, especially in Chapters 4 and 5. Your shared databases and technical support for the GAINS modeling are important for me to smooth my $\mathrm{PhD}$ path. I would like to specially thank Wen Liu for your feedback and valuable comments on Chapter 2. Besides academic discussions, I particularly enjoyed our chats about life and career in leisure time. They really helped me to reduce stress. Besides the co-authors, I would like to thank Zongguo Wen (Tsinghua University), Sheng Zhou (Tsinghua University) and Qi Zhang (Northeastern University) for providing the required data and concrete suggestions on Chapter 2, Yuanqian Xu (Jinan University) for support with improving the map graphics on Chapter 5.

I am also thankful for my great colleagues from the Energy \& Resource group within the Copernicus Institute of Sustainable Development at Utrecht University. I enjoyed the nice moments of academic discussions and casual chats. Jing $\mathrm{Hu}$, I wish to specially thank you for sharing interesting things and research experience with me. I have learned a lot from you, and I am happy to be a colleague with you during the past four years. I am so grateful to my wonderful officemates. Thank you: Christian "amazing" Moretti, 
Lukas Weimann, Thuy Mai-Moulin, and Ivan Vera. I really enjoyed the excellent working environment and the lovely time in the shared office. My thanks are extended to my Chinese colleagues: Li Shen and Tianrun Yang. I would also like to thank those I always encountered over the past: Robert Harmsen, Tarek Alskaif, Ana Poças Ribeiro, "party animal" Odysseas Tsafarakis, Steven Mandley, Subramani Krishnan, Ivan aan den Toorn, Jesus Rosales Carreon, Katerina Kermeli, and all the others. I love the Energy \& Resource group, which provides a great atmosphere for doing a doctorate and an open space for touching different cultures.

I would like to thank the reading committee, which includes Detlef Van Vuuren, Wolfgang Eichhammer, Fabian Wagner, Ying Fan, and Eric Masanet. Thank you very much for taking the time to review my $\mathrm{PhD}$ thesis and providing valuable comments for my research.

Beyond the research world, there are many friends who supported me and enriched my life in the Netherlands. I would like to express gratitude to my two housemates: Yang $\mathrm{Xu}$ and Ruiwen He. I already miss the fantastic moments of hanging out, traveling and riding together. I especially enjoyed our table chitchat at dinner, which is a relaxing time for exchanging views on interesting research, European art and architecture, the next travel destination, and football. Although we were under different pressures, we spent the happiest time together in Europe. Jin Gan, Xiaoqing Xu, Luhuan Huang, Zhongfang Fu, Wenjin Xu, Wenyang Wu, Yu Yang, and Xianke Meng, I am glad we had memorable moments and kept in touch over the past years. I also miss the moment of playing games with Dushen Chen. While my special thanks go out to one of my old friends: Weiwei Wu.

Last but most importantly, I would like to thank and dedicate this work to my beloved fiancée: Xueke Huang. Although she stayed in China during my $\mathrm{PhD}$ journey, her love always leads the way for me, like a guiding star. Thank you for supporting me in all moments of stress, for dealing with all my feelings and emotions about my research, and for helping me everyday to be a better man. Without all your patience and comprehension, this long journey would have not been possible. Thanks a lot for waiting and behind me. Living without an aim is like sailing without a compass, and you are my goal. The world may change my whole life through, but nothing's gonna change my love for you. Also, I must express my deepest appreciation to my beloved family for their devotion and care.

It's a pity that I was not able to say goodbye in a more personal way to all of you due to the special circumstance. Thanks to all of you! Wherever you go, no matter what the weather, always bring your own sunshine. 
Curriculum vitae 
Hui Yue was born on December 6th, 1992. From 2009 to 2013, he studied Computer Science and Technology at Zhengzhou University in China. In June 2013, he graduated with a Bachelor of Engineering. Driven by a strong interest in Environmental Science, Hui then enrolled in the Master of Science in Engineering at the same university. During this period, Hui's research especially focused on energy conservation and emission reduction. He was involved in five research projects (2013-2016), which are funded by the Energy Foundation (USA) and the Ministry of Environmental Protection of China. These projects are mostly on the energy system transition and environmental assessments.

After completing his MSc program in June 2016, Hui moved to the Netherlands and began to pursue his doctorate at the Copernicus Institute of Sustainable Development, Utrecht University, under the supervision of Prof. dr. E. Worrell and Dr. W.H.J. CrijnsGraus. The results are described in this thesis entitled "Saving Electricity for a Green Energy System in China: The pivotal role of industrial energy efficiency to phase out coal, improve air quality and mitigate climate change", which he will defend on the 4th of December 2020. 


\section{Research output}




\section{Publications during the PhD journey}

Yue, H., Worrell, E., Crijns-Graus, W., 2018. Modeling the multiple benefits of electricity savings for emissions reduction on power grid level: A case study of China's chemical industry. Applied Energy, 230, 1603-1632.

Lv, Q., Yue, H*., Xu, Q., Zhang, C., Zhang, R., 2018. Quantifying the exergetic performance of bio-fuel production process including fast pyrolysis and bio-oil hydrodeoxygenation. Journal of Renewable and Sustainable Energy, 10(4), 043107.

Crijns-Graus, W., Yue, H., Zhang, S., Kermeli, K., Worrell, E., 2020. Energy Efficiency Improvement Opportunities in the Global Industrial Sector. in: Encyclopedia of Renewable and Sustainable Materials, Hashmi, S. and Choudhury, I.A. (Eds.), Elsevier, Oxford, pp. 377-388.

Yue, H., Worrell, E., Crijns-Graus, W., 2020. Impacts of regional industrial electricity savings on the development of future coal capacity per electricity grid and related air pollution emissions - A case study for China. Applied Energy.

Yue, H., Worrell, E., Crijns-Graus, W., Liu, W., Zhang, S., 2020. Saving energy in China's industry with a focus on electricity: A review of opportunities, potentials, and environmental benefits. Energy Efficiency.

Yue, H., Worrell, E., Crijns-Graus, W., Zhang, S., 2021. Air emissions and energy efficiency: realizing multiple benefits for power sector by saving industrial electricity use in China. Journal of Cleaner Production.

Zhang, S., Xie, Y., Sander, R., Yue, H., Shu, Y., 2021. Potentials of energy efficiency improvement and energy-emission-health nexus in Jing-Jin-Ji's cement industry. Journal of Cleaner Production, 278, 123335.

${ }^{*}$ contributed equally 
